\title{
Adolescents and Youth in Pakistan 2001-2002: A Nationally Representative Survey
}

\author{
Zeba Sathar \\ Population Council \\ Minhaj ul Haque \\ Population Council \\ Azeema Faizunnissa \\ Population Council \\ Munawar Sultana \\ Population Council \\ Cynthia B. Lloyd \\ Population Council
}

See next page for additional authors

Follow this and additional works at: https://knowledgecommons.popcouncil.org/departments_sbsr-pgy

Part of the Demography, Population, and Ecology Commons, Family, Life Course, and Society Commons, Gender Equity in Education Commons, International Public Health Commons, and the Migration Studies Commons

How does access to this work benefit you? Let us know!

\section{Recommended Citation}

Sathar, Zeba, Minhaj ul Haque, Azeema Faizunnissa, Munawar Sultana, Cynthia B. Lloyd, Judith A. Diers, and Monica J. Grant. 2003. "Adolescents and Youth in Pakistan 2001-2002: A Nationally Representative Survey." Islamabad: Population Council. 


\section{Authors}

Zeba Sathar, Minhaj ul Haque, Azeema Faizunnissa, Munawar Sultana, Cynthia B. Lloyd, Judith A. Diers, and Monica J. Grant 


\section{Adolescents and Youth}

\section{in Pa.kistan 2001-02}

A Nationally Representative Survey

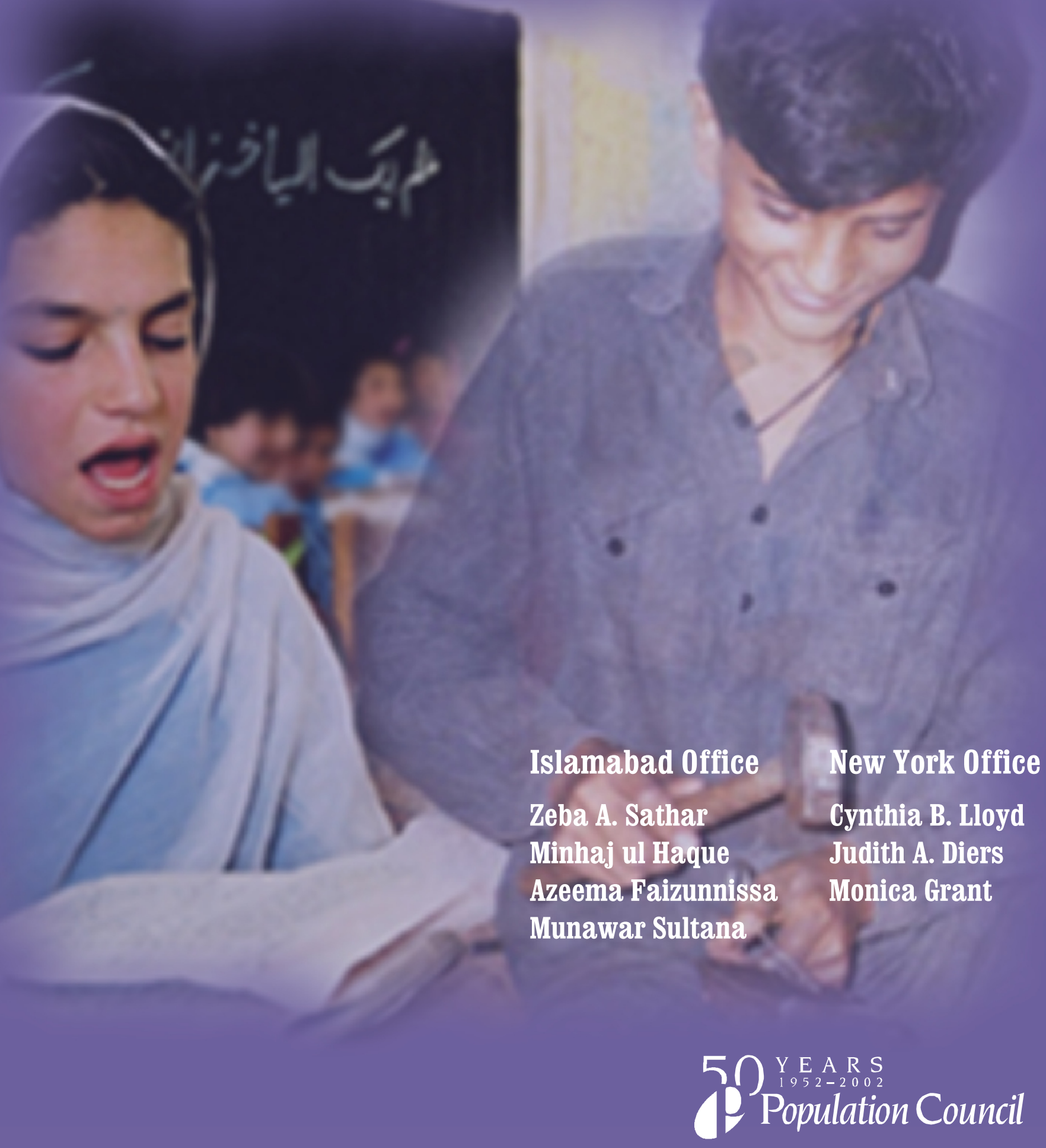




\section{Adolescents and Youth in Pakistan 2001-2002 A Nationally Representative Survey}

Islamabad Office

Zeba A. Sathar

Minhaj ul Haque

Azeema Faizunnissa

Munawar Sultana
New York Office

Cynthia B. Lloyd Judith A. Diers Monica Grant

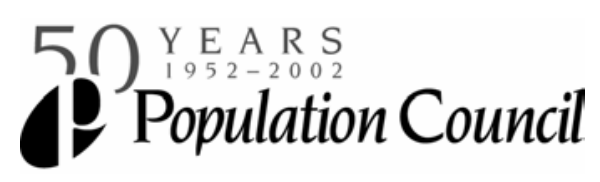




\section{For further inquiries:}

\section{Population Council}

\#7, St. 62, F-6/3, Islamabad, Pakistan. Ph: 9251-2277439 Fax: 9251-2821401 Email: ayp@pcpak.org Web: www.popcouncil.org

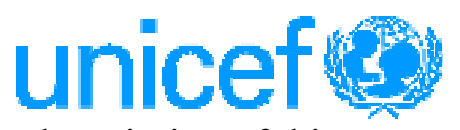

The printing of this report was executed and funded by UNICEF, Pakistan. 


\section{CONTENTS}

ACKNOWLEDGEMENTS $\quad$ XI

PREFACE XIV

GLOSSARY OF TERMS XIV

EXECUTIVE SUMMARY XVII

$\begin{array}{ll}\text { INTRODUCTION } & \mathbf{1}\end{array}$

Background $\quad 1$

Sampling Design $\quad 2$

The Survey and its Instruments $\quad 4$

Implementation of Design and Data Collection $\quad 6$

Unique Features of the AYP 13

Architecture of the Report $\quad 14$

$\begin{array}{ll}\text { References } & 19\end{array}$

SOCIAL Dimensions OF Young PeOPle's LiVes 21

Introduction $\quad 21$

Living Arrangements of Young People $\quad 21$

Household Characteristics $\quad 23$

$\begin{array}{ll}\text { Mobility and Migration } & 27\end{array}$

Time Use and Recreation 33

Communication and Social Networks 36

Agency in DecisionMaking and Gender Roles 37

$\begin{array}{ll}\text { Conclusion } & 40\end{array}$

$\begin{array}{ll}\text { EDUCATION } & 43\end{array}$

Introduction $\quad 43$

Ever Attendance in School $\quad 45$

Levels of School Attainment 48

Dropping Out of School $\quad 53$

Aspirations for Education 56

Conclusion $\quad 57$

$\begin{array}{ll}\text { References } & 59\end{array}$ 
$\begin{array}{lr}\text { WORK } & 61\end{array}$

Introduction $\quad 61$

Young People's Participation in Work 62

Decisions Regarding Work $\quad 69$

Attributes of Work $\quad 70$

Work Opportunities in the Community $\quad 77$

$\begin{array}{ll}\text { Conclusion } & 79\end{array}$

References $\quad 80$

PUberty, MaRriage, AND CHILDbEARING $\quad 81$

Introduction $\quad 81$

The Transition to Puberty $\quad 83$

The Transition to Marriage $\quad 87$

Transition to Pregnancy and Childbearing 96

$\begin{array}{ll}\text { Conclusion } & 104\end{array}$

The Communities IN Which Young PeOple Live 107

$\begin{array}{ll}\text { Introduction } & 107\end{array}$

Topography and Irrigation $\quad 108$

Access to Roads and Transport 109

Access to Other Infrastructure 111

Health Services $\quad 113$

$\begin{array}{ll}\text { School Availability } & 115\end{array}$

$\begin{array}{ll}\text { NGO Activities } & 118\end{array}$

$\begin{array}{ll}\text { Conclusion } & 118\end{array}$

$\begin{array}{ll}\text { References } & 120\end{array}$

$\begin{array}{ll}\text { CONCLUSION } & 121\end{array}$ 


\section{TABLES}

Table 2.1 Percent living with both biological parents in the same household, of all young people, by age and sex

Table 2.2 Percent of all households that are nuclear, of all households interviewed and all households containing young people

Table 2.3 Mean size of all households, and those households where young people were interviewed

Table 2.4 Mean number of rooms in households and mean number of persons per living rooms, of all households containing young people

Table 2.5 Percent of household with the following facilities, of all households containing young people

Table 2.6 Percent of households with the following facilities, of all households where young people were interviewed

Table 2.7 Percent of households owning specific items by province and SES, of all households containing young people

Table 2.8 Percent who must ask for permission in order to visit various locations and percent who are allowed to visit various locations alone, of all young people

Table 2.9 Percent of adults who reported places in the community where young people are not allowed to go, by type of such places

Table 2.10 Percent of young people reporting places in their area where they are not allowed to go, by type of place, of all young people who reported such places

Table 2.11 Percent of young people and responsible adults citing specific reasons for not being allowed to go to "unsafe" places, of all who reported such places

Table 2.12 Percent distribution of reasons for visit in the last six months, by marital status and sex, of those young people who have visited a place outside their own city or village

Table 2.13 Percent who have ever migrated, of all young people

Table 2.14 Mean number of hours per day that young people spent in various activities, by working, marriage, schooling, and "other" status

Table 2.15 Percent of young people reporting their recreational activities, by residence and sex, of all young people

Table 2.16 Percent of all young people reporting their source of consultation for various issues, by age, marital status, and sex 
Table 2.17 Percent of all household survey respondents who think young people can make their own decisions on education, work, marriage, and mobility, by residence

Table 2.18 Percent of all household survey respondents who think young people have a right to make their own decisions regarding education, work, marriage, and life, by residence

Table 3.1 Percent ever attended school, of all young people

Table 3.2 Mean age of entry to class one, of young people who ever attended school

Table 3.3 Percent who completed primary school, of all young people

Table 3.4 Percent of young people (aged 20-24) who completed middle school

Table 3.5 Percent of young people (aged 20-24) who completed secondary school

Table 3.6 Mean highest class completed, of young people aged 20-24 who ever attended school

Table 3.7 Percent currently in school, of all young people

Table 3.8 Percent whose last school attended was a mixed school, of young people who ever attended school

Table 3.9 Percent whose last school attended was a government school, of young people who ever attended school

Table 3.10 Percent reporting a role in the decision to leave school, of young people who ever attended and dropped out

Table 3.11 Percent of household survey respondents who believe that young person should have a role in deciding their level of education

Table 3.12 Percent distribution of aspired level of education, of all young people by residence and sex

Table 3.13 Percent interested in receiving further training, of all young people

Table 3.14 Distribution of desired vocational training, of all young people who wanted additional training

Table 4.1 Age-specific labor force participation rates

Table 4.2 Percent ever worked, of all young people

Table 4.3 Percent ever worked before age 15, of all young people

Table 4.4 Percent who would work if given the opportunity, of all young people not currently working

Table 4.5 Percent of young people who report family discussions on work, of all young people 
Table 4.6 Percent of young people who felt "listened to" in discussions on work, of all young people who were involved in household discussions and were able to express an opinion

Table 4.7 Percent of household survey respondents who think young males and females can have a role in deciding about work, by sex of household respondent

Table 4.8 Percent who have worked in agriculture, by sex and age, of young people who have ever worked

Table 4.9 Percent who work at own family house or farm, of young people who ever worked

Table 4.10 Source of information leading to employment by sex and age cohort, of young people who ever worked

Table 4.11 Percent who worked throughout the year, of young people who ever worked

Table 4.12 Mean number of hours worked per week, of young people who have ever worked by age and sex

Table 4.13 Number of hours worked per week, of young people who have ever worked

Table 4.14 Percent of young people who receive salary/profit themselves (or along with their parents), of those who work for an income

Table 4.15 Distribution of type of opportunity for work and vocational training in the community, of all young people

Table 4.16 Distribution of average daily wages for unskilled adults/youth and adolescents in the community, of all communities

Table 5.1 Mean age of puberty among those currently 20-24 years old

Table 5.2 Percent who were informed about puberty before it began, among those who had undergone puberty

Table 5.3 Percent of young people who think information about puberty should be provided in advance

Table 5.4 Person who should provide information about puberty, according to those who think information should be provided

Table 5.5 Percent of all females enrolled in a school at the time of puberty

Table 5.6 Percent ever married, of all respondents

Table 5.7 Percent married before age 20, of those currently aged 20-24

Table 5.8 Percent with some say in choosing spouse, of those who are married

Table 5.9 Distribution of dowry items exchanged, of those who are married, by age and sex.

Table 5.10 Percent of marriages that included transfers to bride and/or her parents, of those ever married, by age and sex 
Table 5.11 Average value of transfer to bride and/or her parents (in Pakistan Rupees) for marriages that included such transfers, by age and sex

Table 5.12 Average value of transfer to bride and/or her parents (in Pakistan Rupees) for marriages that included such transfers, by rural/urban residence

Table 5.13 Median value of Haq Mehar (in Pakistani Rupees) for marriages in which the respondent could recall the amount by age, sex, and residence

Table 5.14 Mean age difference between spouses, of those ever married by residence and sex

Table 5.15 Percent of all marriages that are to relatives by age and sex

Table 5.16 Appropriate age of marriage for males, as reported by young people and household respondents (hhr)

Table 5.17 Appropriate age of marriage for females, as reported by young people and household respondents (hhr)

Table 5.18 Minimum appropriate age of marriage for males, as reported by young people, by age and sex and marital status

Table 5.19 Minimum appropriate age of marriage for females, as reported by young people, by age, sex and marital status

Table 5.20 Mean children ever born, of those ever married by age and sex

Table 5.21 Of those ever married, percent who have ever been pregnant (or whose spouse has ever been pregnant)

Table 5.22 Percent pregnant before age 20, of those aged 20-24 who were ever married

Table 5.23 Percent who received any antenatal care for their first birth, of those ever married who had a child

Table 5.24 Percent of first births at home, among those ever married who had a child

Table 5.25 Mean desired number of children, among ever-married (who expressed gender preference)

Table 5.26 Percent currently using family planning, of those currently married

Table 5.27 Percent who plan to use family planning in the future, of those currently married

Table 5.28 Method to be used, of currently married young people who intend to use family planning in the future

Table 6.1 Number of communities by topography and irrigation, by province and residence

Table 6.2 Community access to road and public transportation, by province and residence 
Table 6.3 Number of communities with access to various facilities and amenities, by province and residence

Table 6.4 Number of communities by access to health facilities, by province and residence

Table 6.5 Number of communities that seek medical treatment primarily from various health service providers, by province and residence

Table 6.6 Number of communities with single sex and mixed schools inside/ within two kilometers by province and residence

Table 6.7 Number of communities with government, private and NGO schools inside/ within two kilometers by province and residence

Table 6.8 Distribution of communities by affiliation with other NGOs, by province and residence

Table 6.9 Distribution of communities by who benefits from the work of NGOs, by province and residence

Table 6.10 NGO activities in communities, by province and residence

\section{FIGURES}

Figure 1.1 Location of rural and urban primary sampling units

Figure 1.2 Distribution of households by province and residence

Figure 1.3 Number of households identified at each stage

Figure 1.4 Distribution of households by number of young people (15-24 years old), of all households where rosters were completed

Figure 1.5 Distribution of households by number of young persons interviewed, of all households that contained eligible young people

Figure 1.6 Reasons that young persons could not be interviewed, by sex

Figure 1.7 Percent distribution of the characteristics of household respondents (in households where a young person was interviewed), by sex

Figure 1.8 Relationship of household respondents to young people interviewed

Figure 1.9 Distribution of sample by residence, age, and sex

Figure 1.11 Distribution of sample by socioeconomic status, age, and sex

Figure 1.12 Distribution of sample by marital status, age, and sex

Figure 1.13 Distribution of sample by province, age, and sex

Figure 2.1 Living arrangements of females up to age 24, by age 
Figure 2.3 Percent of young people whose parents were literate by province and sex of parent

Figure 2.4 Percent who need permission to visit various places alone by sex, all young people

Figure 2.5 Percent who can go to various places alone by sex, all young people

Figure 2.6 Percent reporting presence of "unsafe" places for young people in their community by sex, of all household survey respondents and young people

Figure 2.7 Percent reporting having ever visited other city or district, of all young people

Figure 2.8 Percent who have ever migrated in their life, all young people

Figure 2.9 Reasons for migration, by sex of those who migrated

Figure 2.10 Proportion of time young people spent on various activities, by nature of activity, sex and age

Figure 2.11 Mean number of times respondent visited a friend for more than one hour, in the past week, of all young people

Figure 2.12 Percent distribution of persons who young people think should be responsible for various household chores, of all young people

Figure 2.13 Percent distribution of those whom young people think should make various household decisions, of all young people

Figure 3.1 Trends in ever enrollment rates for males aged 15-19 (PIHS and AYP)

Figure 3.2 Trends in ever enrollment rates for females aged 15-19 (PIHS and AYP)

Figure 3.3 Percent ever attended school, by sex, residence, and province

Figure 3.4 Percent ever attended school, by sex and age, all respondents

Figure 3.5 Past trends in school enrollment, using life event calendar, 5-9 year olds

Figure 3.6 Past trends in school enrollment, using life event calendar, 10-14 year olds

Figure 3.7 Mean age of entry to class one, of those who have ever enrolled

Figure 3.9 Class at dropout, for those who ever attended school, by sex

Figure 3.10 Class at dropout, by socioeconomic status, for all males who ever attended school

Figure 3.11 Class at dropout, by socioeconomic status, for all females who ever attended school

Figure 3.12 Reasons for school dropout by sex 
Figure 4.1 Percent ever worked by sex, age, and socioeconomic status, of all respondents

Figure 4.2 Proportion of males who have ever worked by age, by age cohort

Figure 4.3 Proportion of females who have ever worked, by age cohort

Figure 4.4 Percent of young people who worked before age 15, by residence, sex, and current age cohort

Figure 4.5

Work and school status of males, by age

Figure 4.6 Work and school status of females, by age

Figure 4.7 Percent of young people who have migrated out of the household for work, of those who have left their natal home

Figure 4.8 Percent of all young people currently working or willing to work if it were available, by residence, sex, and age

Figure 4.9 Distribution of whether or not young people were able to express an opinion and whether or not this opinion was listened to, of all young people

Figure 4.10 Distribution of those who have ever worked by type of employment, age, and sex

Figure 4.11 Distribution of those who have ever worked by nature of employment, age, and sex

Figure 4.12 Percent who worked throughout the year by province, of those who ever worked, by sex

Figure 4.13 Hours worked per week, of those who ever worked by age and sex

Figure 4.15 Distribution of the control of earnings, based on the income of those young people who have been the direct recipients of earned income, by sex

Figure 4.16 Percent of all young people who reside in communities where vocational training is available, by sex, residence, and age cohort

Figure 5.1 Proportion reaching puberty and marriage, by age and sex

Figure 5.2 Percent of young people who were informed about puberty and those who think young people should be informed, by age and sex

Figure 5.3 Persons from whom young people heard about puberty, by age and sex

Figure 5.4 Proportion of young people enrolled and reaching puberty, by age and sex

Figure 5.5 Percent of males entering puberty, work, or marriage, by age 
Figure 5.8 Life-table analysis: proportion of young people married, by age and sex

Figure 5.9 Percent of 20-24 year olds who were married before age 20

Figure 5.10 Percent of 20-24 year olds who were married before the age of 20, by education and sex

Figure 5.11 Age difference between spouses, by sex and age at marriage

Figure 5.12 Living arrangements for young married people, by age and sex

Figure 5.13 Reasons that young people should be married at a given age, according to all young people and household survey respondents, by sex

Figure 5.14 Reasons for later marriage for males and females, as reported by household survey respondents

Figure 5.15 Percent married and percent first pregnant, by age

Figure 5.16 Mean number of children ever born (CEB) to ever-married women

Figure 5.17

Percent of adolescent females (aged 15-19) who are mothers or pregnant with their first child, by various categories

Figure 5.18 Percent of 20-24 year old females who were pregnant before age 20, by current residence

Figure 5.19 Person who attended at first birth, for all ever married who have had a child

Figure 5.20 Mean desired number of male and female children, by sex and marital status, among 20-24 year olds

Figure 5.21 Trends in current use of any family planning method (married females)

Figure 5.22 Percent of currently married young people who are current, ever, or future users of contraception, by age and sex

\section{APPENDICES}

Appendix I Sampling Design $\quad 212$

Appendix II Construction of the Socioeconomic Status Index 214

Appendix III Response Rates 216

Appendix IV List of Staff Involved in the Survey 217

$\begin{array}{lll}\text { Appendix V Standard Errors of Estimates } & 221\end{array}$ 


\section{ACKNOWLEDGEMENTS}

This survey is the result of over four years of work. The leading light behind the project

is Cynthia B. Lloyd who conceived the idea, sought the funding, and proposed the research be undertaken in Pakistan. Dr. Lloyd provided excellent leadership from New York and was the binding force behind this survey. She was assisted by Wesley Clark, in the initial period of the survey and by Monica Grant and Judith A. Diers in its final stages.

Judith Bruce, Director, Gender, Family and Development, has been a great supporter of the importance of initiating work on adolescents in developing countries. She has whole-heartedly and continuously supported adolescent research activities in Pakistan.

The survey was a huge operation and mainly funded by the Rockefeller Foundation-USA, Department for International Development-UK, and UNICEFPakistan. Their gracious support has made this undertaking possible. In particular, UNICEF Pakistan also made significant contributions to the technical content of the survey. UNFPA also donated some funds for the completion of the project.

Peter Miller, who was Country Director, Population Council, Pakistan, at the time the work began, gave inspirational support for work on adolescents and for the survey at the initial stages. Zeba A. Sathar, who was Deputy Country Director at the start of the project, took over during the later part of the survey planning; as Country Director, Dr. Sathar then provided the guidance that brought the work to completion.

This long journey took root in January 1999 when a core team (involved from the questionnaire design to the final report) included Minhaj ul Haque, Munawar Sultana, Mumraiz Khan, Tahira Parveen, and Wajahat Raza. Their perseverance in conducting unstructured focus group discussions, primarily to develop a need-based research agenda for Pakistani young people, resulted in the final questionnaire.

We appreciate in particular the efforts of Mumraiz Khan in designing and later training for the community profile. This questionnaire and methodology enabled us to collect rich and invaluable information from the communities. During the earlier phase of need assessment we had the help of Rashid Memon, Rukhsana Halepota, Rukhsana Kausar, Saira Memon, Sajeda Naheed, and Sara Javed. 
Minhaj ul Haque was the principal investigator for the survey in Pakistan. The survey was a huge undertaking especially due to its vast size and the unusual circumstances at the time of its inception after September 11, 2001. Minhaj ul Haque managed the field operations assisted by Munawar Sultana, Mumraiz Khan, Wajahat Raza and Tahira Perveen, with admirable competency and professionalism.

We have to thank Shagufta Naheed, Ashfa Hashmi, Nayyar Farooq, Asad ullah Bhatti, and Mohammad Khalil for their support during the training. Ambreen Gul, Nilofar Ali Khan, Khurram Shehzad, and Nadia Mumtaz helped in the development of a training manual and later provided support in checking of questionnaires.

Data entry and editing has been handled by Irfan Masood who worked long hours to find and eliminate processing errors. His help, along with Rehan Niazi, who assisted him during the entire task of data entry and cleaning, is highly acknowledged.

The survey would not have been possible without those who render logistic services. Imran Ahmad (Sr.) ensured financial support for the survey. Kiramat Shah provided unparallel, round-the-clock administrative support. Abrar Ahmad took effective control of finances and Imran Ahmed (Jr.) assisted him throughout the fieldwork. Tayyaba Gul provided excellent logistic support during the training. Bakht Munir, Samar Akram, Nisar Ali assisted us throughout.

The sampling and PSU listing are the most essential parts of a national representative survey. Dr. Noor Mohammad Larik, formerly DG, Federal Bureau of Statistics, and Khalid Mehmood, Director, took a special interest in the timely provision of listings for the survey sample. Muhammad Ramzan Khan, Chief Statistical Officer, produced the sample design and weights. We greatly acknowledge the support we received from the field staff of FBS in locating the selected PSUs.

The survey teams and the outstanding efforts made by the 111 field staff including 15 female supervisors, 15 logistic supervisors and 3 provincial coordinators were the backbone of the field research on which the findings of this report are based. We thank them profusely and acknowledge their contributions greatly. They are named in appendix IV of the report. Our sincere appreciation goes to these individuals who carried out the task of interviewing young people and adults in the study households. The timing of the survey and the demands of fieldwork were difficult to meet, but they did not allow the quality of work to suffer. Their efforts are reflective of their commitment to this important work. 
The preparation of this report was greatly assisted by Juliette Von Seibold, an independent consultant, who was critical in putting the first and second drafts of the report together. The report was finally copy edited by Pamela Ledbetter. Their contributions in finalizing the report are invaluable.

Mehmood Asghar, IT officer at the Population Council, Pakistan, has entirely and single-handedly formatted and produced the graphics of this report. He has changed the whole face of the report from a draft to a final document in the shape you see it today, with skill and an enthusiasm for which we are very grateful.

Shireen Jejeebhoy, Senior Associate, at the Population Council, New Delhi, was the outside reviewer for the report. Recognizing the urgency in getting the results out in order for them to be useful for policy and programs, Dr. Jejeebhoy provided invaluable comments in record time. She did this by putting aside other urgent work and we are extremely appreciative of her comments on the report.

Finally, but most importantly, we are grateful to all of the survey respondents who took the burden of our detailed enquiry and remained involved during the interview process. On many occasions they provided support in their communities, offered us shade from the beating sun or when it was raining, and encouraged us to go on with our work. We had nothing to give them in return, but we take pride in dedicating this effort to them and to the future young people of our country whose lives we want to change through the findings of the report. 


\section{PREFACE}

Policy makers rely on credible data for the establishment of effective social infrastructure and to provide cost effective education and health facilities at the community level. Data to serve this purpose must be comprehensive and accurate and as far as possible should reflect ground realities. They should also encompass social and economic diversities of target groups.

The Rockefeller Foundation, DFID, UNICEF, UNFPA has funded the Population Council for a national survey on Adolescents and Youth in Pakistan. This report authored by Dr. Zeba Sathar, Country Director and Dr. Cynthia Lloyd and colleagues is a useful source of data. It provides insights into the social, educational, marital and community lives of young people who according to this report are more than 30 million in Pakistan. The survey conducted in coordination with the Statistical Division will facilitate the Government, civil society, and the private sector in formulation of their programmes on youth for education and for their careers. It will also augment the Government's efforts to evolve a coordinated approach envisaged under the Poverty Reduction Strategy to holistically address the issue of social imbalances, create hope and expand opportunities with the support of Pakistan's development partners, international stakeholders, private sector, civil society and academia.

Of special significance are the chapters on social dimensions of young peoples' lives, education, and marriage trends. The survey reflects the social and economic attitudes and behaviour patterns of male and female youth and their parents both in urban and rural areas. The survey also attempts to identity the social conflicts and cultural constraints that youth face in their respective environment. These acquired social trends reflect on whether they can create social groups cohesively or whether they face conflict, whether they can contribute successfully to the economy and become useful citizens of Pakistan.

Indeed, the survey bears testimony to the Government's resolve to work in tandem with civil society in a coordinated effort at the national and international level to arrive at remedial measures for the problems faced by youth of this country. This report is the first step in the right direction. It contains useful information for an in depth study on a variety of topics. This survey's finding should be translated into a social plan aimed at resolving health, education and other problems that youth face at the community level. 
The Government on its own part is well aware of the importance of adolescents, their problems and social needs. The demographic window provides an opportunity to focus on accelerating social services with firm commitment to harness the youth of Pakistan to become a useful resource for the country's development.

In the end I would like to commend the Population Council for doing a thorough and professional job of gathering the evidence, which will go a long way in guiding programs and policies for young persons and will benefit Pakistan immensely.

\section{Mr. Shaukat Aziz}

Federal Minister for Finance and Revenue, Government of Pakistan 


\section{GLOSSARY OF TERMS}

\begin{tabular}{ll} 
AYP & The Adolescent and Youth in Pakistan \\
AHHR & Adult Household Respondent \\
BHU & Basic Health Unit \\
CEB & Children Ever Born \\
EB & Enumeration Block \\
FBS & Federal Bureau of Statistics \\
HHR & Household Respondent \\
LEC & Life Event Calendar \\
LFS & Labor Force Survey \\
NGO & Nongovernmental Organization \\
NWFP & North West Frontier Province \\
PCPS & Pakistan Contraceptive Prevalence Survey \\
PCO & Public Call Office \\
PDHS & Pakistan Demographic and Health Survey \\
PFFPS & Pakistan Fertility and Family Planning Survey \\
PIHS & Pakistan Integrated Household Survey \\
PRHFPS & Pakistan Reproductive Health and Family Planning Survey \\
PSU & Primary Sampling Unit \\
SES & Socioeconomic Status \\
SSU & Secondary Sampling Unit \\
TUP & Time Use Profile \\
YP & Young People \\
xvi & \\
\hline
\end{tabular}




\section{EXECUTIVE SUMMARY}

Pakistan currently has the largest cohort of young people in its history ( 25 million aged 15-24), and subsequent cohorts are projected to be even larger. As in most countries, there is the awareness that the health and well-being of the current and subsequent young cohorts is profoundly important for the social, political, and economic development and stability of the country. However, national programs aimed at addressing adolescents and youth need to be addressed in a holistic, multidisciplinary way to reflect the varied nature of their lives. The various programs based on the polices of the Ministry of Population Welfare, Health, Education, Women's Affairs and the Ministry of Education and Youth Affairs Division have to be integrated and synergies between them crystallized. It is hoped that this report will provide insights into this process. But above all, the report has the potential to inform the emerging national Youth Policy.

Recognizing the dearth of information on the situation of young people in Pakistan, the Population Council undertook a nationally representative survey from October 2001 to March 2002. The Adolescent and Youth in Pakistan (AYP) is the largest nationally representative survey focusing on this particular cohort of Pakistanis. The survey sought information from young people (aged 15-24), responsible adults (parents, where possible) in the household where young interviewees lived, and key informants in each of the 254 communities where the survey took place.

Young people face a number of critical life decisions between the ages of 15 and 24 that relate to a series of transitions to adulthood: school-leaving, employment, greater responsibility for oneself and family, choosing a spouse, and beginning a family. However, little is known about how time is spent and how decisions are made at these ages. The questionnaire for adolescents and youth included topics such as education, livelihoods, puberty, marriage and childbearing, gender roles, mobility, aspirations and decision-making, and migration. Two tools within the questionnaire gathered detailed information, based on a young person's recall: a life event calendar recording activities in major domains of life going back to age five and a time use profile recording activities in the previous 24-hours or the last school day.

The Federal Bureau of Statistics (FBS) in Pakistan and the Population Council jointly determined the sample design for this survey, based on the sampling frame of the 1998 Census in Pakistan. In the end, a total of 6,585 households and 8,074 young people were interviewed. 
Social Context of Young People's Lives: Young males and young females in Pakistan spend their time very differently, particularly those who are not in school. Males are more likely to work outside the household in paid work or outside chores while females are more likely to work inside the home on domestic chores. These patterns reveal very different mobility patterns, with males being much freer than females to leave the home unaccompanied. While neither males nor females have much say in the marriage decision, there are sharp gender divisions in the proportions having some say over education and work decisions. Young people's attitudes about gender roles remain traditional with well-defined lines between the worlds of males and females.

Education: Fewer than half of all females aged 15-24 have ever enrolled in school. Furthermore, those that do attend are more likely to drop out at an earlier class than their male counterparts. This pattern of low enrollment for females is magnified at the lowest socioeconomic stratum. While there is evidence that school enrollment is increasing for females in the last five years, the gains are small and the gender gap remains huge. Enrollment levels for males are over 80 percent, but there has been minimal improvement in recent years. Almost all males and females hold higher educational aspirations than their parents, feeling that they should be educated either to secondary or university level.

Work: The transition to work plays out very differently for young men and women. A minority of both males and females appear to begin their work life as child laborers. However, child labor involves at least a third of all girls and half of all boys in the poorest quartile of the population. While most young men eventually transition into the paid labor force, less than 40 percent of young women have entered the workforce by the age of 24. A particularly notable recent change has been the rise in paid work among the younger cohort of females (aged 15-19) after the age of 15 in comparison to the cohort born five year earlier; there has been no equivalent trend for young men. Among young people who work, the most common type of employment is in the agricultural sector. Other employment domains are segregated by gender, with many young women engaged in stitching, embroidery, and knitting (largely based at home) while young men work in the factories, are self-employed, or are engaged in skilled labor. Young women who work for pay are more likely to work part-time than young men.

Puberty, Marriage, and Childbearing: Although the onset of puberty occurs earlier for girls than boys, girls are less likely to be informed about the event in advance and are less likely to be among peers in school when it occurs. Of particular interest is the gap between the onset of puberty and the time of marriage for females which is 
growing due to the increased age of marriage but there is little substantive, skillsenhancing activity to fill this increasing gap.

While age at marriage has increased for both males and females over the past fifty years, females continue to marry at a significantly younger age than their male counterparts, and rural residents tend to marry much earlier than those in urban areas. A rural adolescent female is more than twice as likely to be married before age 20 as her urban peer (58 versus 27 percent, respectively). The birth of a child tends to follow fairly immediately upon marriage; young married females are not likely to use contraception, although a substantial number indicate an interest in future use.

Community Context and Opportunity Structure: Young people in rural areas of Pakistan are less advantaged in terms of access to essential facilities than their urban counterparts. Lack of facilities exposes young people in rural areas to more health risks and impedes the delivery of quality schooling. Most communities appear to have some schooling facilities available. Indeed, private sector primary schools, which are largely mixed, are now a significant part of the urban landscape. However, the number of schools that are accessible to females at each level still falls far short of the number of schools that are accessible to males. This gender gap in the delivery of schooling is most pronounced in rural areas. Finally, the survey found that NGOs currently play a limited role as service providers or facilitators of development in the communities visited. It appears that when NGOs are available they are largely located in urban areas where their focus is on community development rather than education or health

Conclusion: The report findings confirm the large differences in the current situation of adolescents and youth, males versus females, from different strata of residence and economic status. There is also a huge gap between aspirations of young persons in terms of education and work and the opportunities that they can avail. This demands interventions which are well planned and sharply targeted but which meet the approval of parents and families. Most of these require the effort of the Government, and the private sector calling for creation of schools, institutions of higher education, and jobs in nontraditional sectors. However, there is also a need to change attitudes and behaviors, particularly around some of the ingrained gender restrictions to work, school attendance, and female mobility. These will require inputs from the media, active women and youth groups, and members of civil society. 



\section{Introduction}

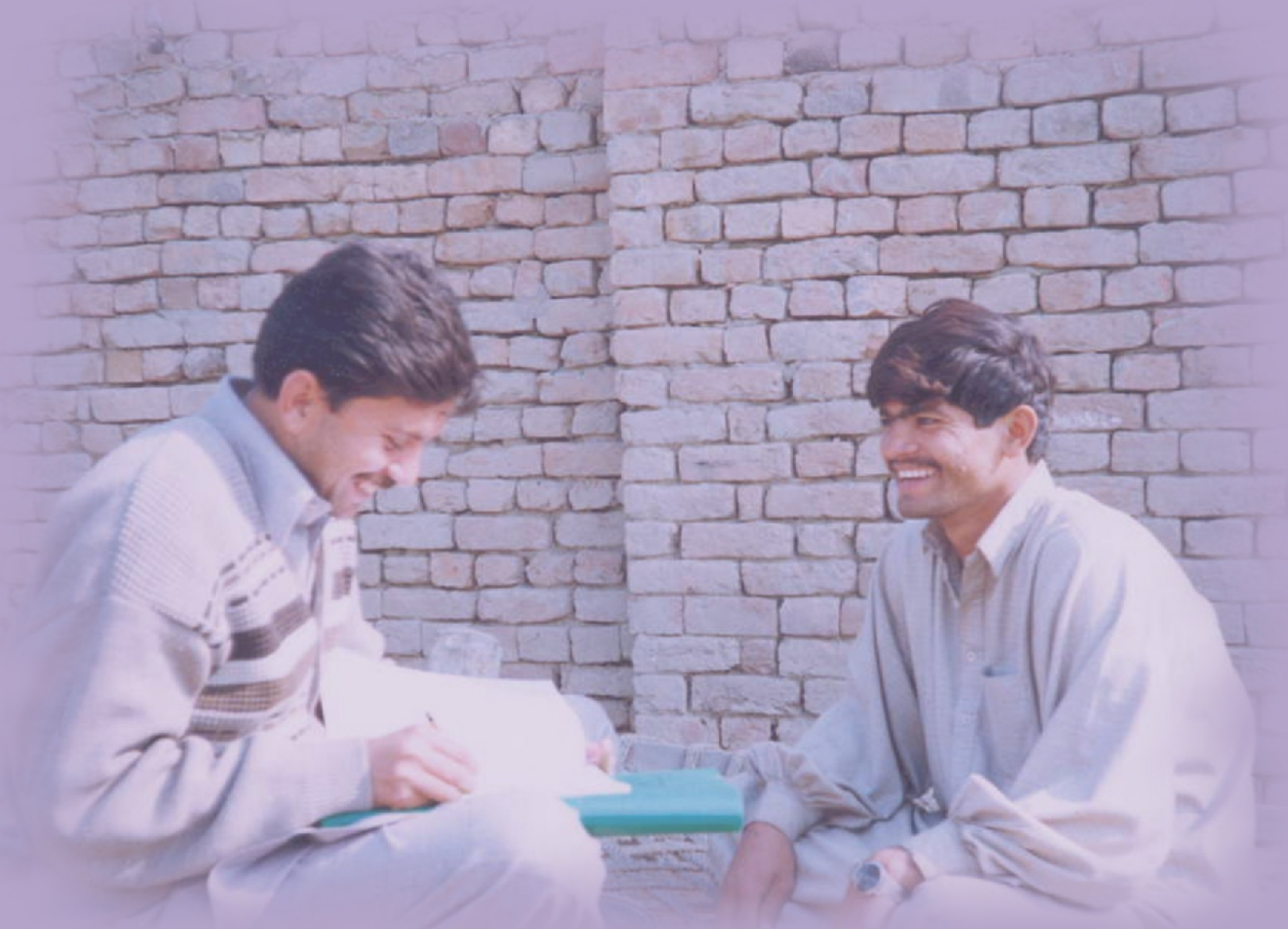

\section{In this chapter:}

- Background

- Sampling Design

- The Survey and its Instruments

- Implementation of Design and Data Collection

- Unique Features of the AYSP

- Architecture of the Report

- References 


\section{INTRODUCTION}

\section{BACKGROUND}

Pakistan currently has one of the largest cohorts of young people in its history, with approximately 25 million adolescents and youth between the ages of 15 and 24 (Government of Pakistan 2001). As in most countries, there is awareness in Pakistan that this cohort is profoundly important for the social, political, and economic development and stability of the country. However, national programs aimed at addressing adolescents and youth tend to be narrowly defined and based either on policies developed by the Ministry of Women's Affairs or on programs implemented by the Ministry of Education and Youth Affairs Division. These programs have largely been formulated as a reaction to "problems" related to young people, such as child labor, low levels of education, and underage marriage. Based in a single sector, few of these programs addressed the holistic, multi-disciplinary nature of the lives of young people.

Young people face a number of critical life decisions between the ages of 15 and 24 that relate to a series of transitions to adulthood: school-leaving, employment, greater responsibility for oneself and family, choosing a spouse, and beginning a family. The links between these decisions, their sequencing, and young people's agency in each sphere varies widely across and within countries. These transitions are also not static across time. For instance, as the age of marriage increases in Pakistan, the time between puberty and marriage also increases, perhaps providing additional time for a young person to develop socially and economically. However, little is known about how time is spent and how decisions are made at this age.

Recognizing the dearth of information on the situation of young people in Pakistan, and thus little evidence on which to build policies and programs, the Population Council embarked on a nationwide representative survey, detailing the lives of Pakistan's adolescents and youth. The Adolescent and Youth in Pakistan 2001-2002 (AYP) is the largest nationally representative survey of its kind undertaken in Pakistan and the first one to gather information from young people themselves. The purpose of the survey is to explore the context and experience of the transition to adulthood, including education, employment, marriage, and family initiation, thereby providing the government, donors, nongovernmental organizations, and other partners and 
stakeholders with the evidence needed to develop appropriate policies and programs that address the unique and diverse needs of Pakistan's young people.

The potential benefits of the survey results are to:

- prioritize areas of importance in the lives of adolescents and youth;

- provide baseline information on regional and gender-role variations in opportunities available to adolescents and youth;

- initiate an informed dialogue between stakeholders (such as the government) and young people about thoughtful and relevant policy formulation and programming for adolescents and youth; and

- provide valid data on current and relevant issues for informing policy concerning adolescents and youth.

\section{SAMPLING DESIGN}

The Federal Bureau of Statistics (FBS) in Pakistan and the Population Council jointly determined the sample design for this survey, based on the sampling frame of the 1998 Census in Pakistan. Applying a two-step stratified sampling technique, the FBS recommended 254 Primary Sampling Units (PSUs). The sampled PSUs are represented in the map found in Figure 1.1.

Once a full listing of all households in each PSU was established, the survey teams selected approximately 25 households within each rural and urban PSU, using a random start. In the end, a total of 6,812 households were contacted. Figure 1.2 provides a breakdown of the number of households contacted in each province to achieve the target. ${ }^{1}$ Further details on survey design can be found in Appendix I.

${ }^{1}$ All tables presented in this chapter are based on unweighted data. Weights have been ascribed in later chapters to arrive at estimates that are representative at the provincial and urban/rural levels. 
Figure 1.1 Location of rural and urban primary sampling units

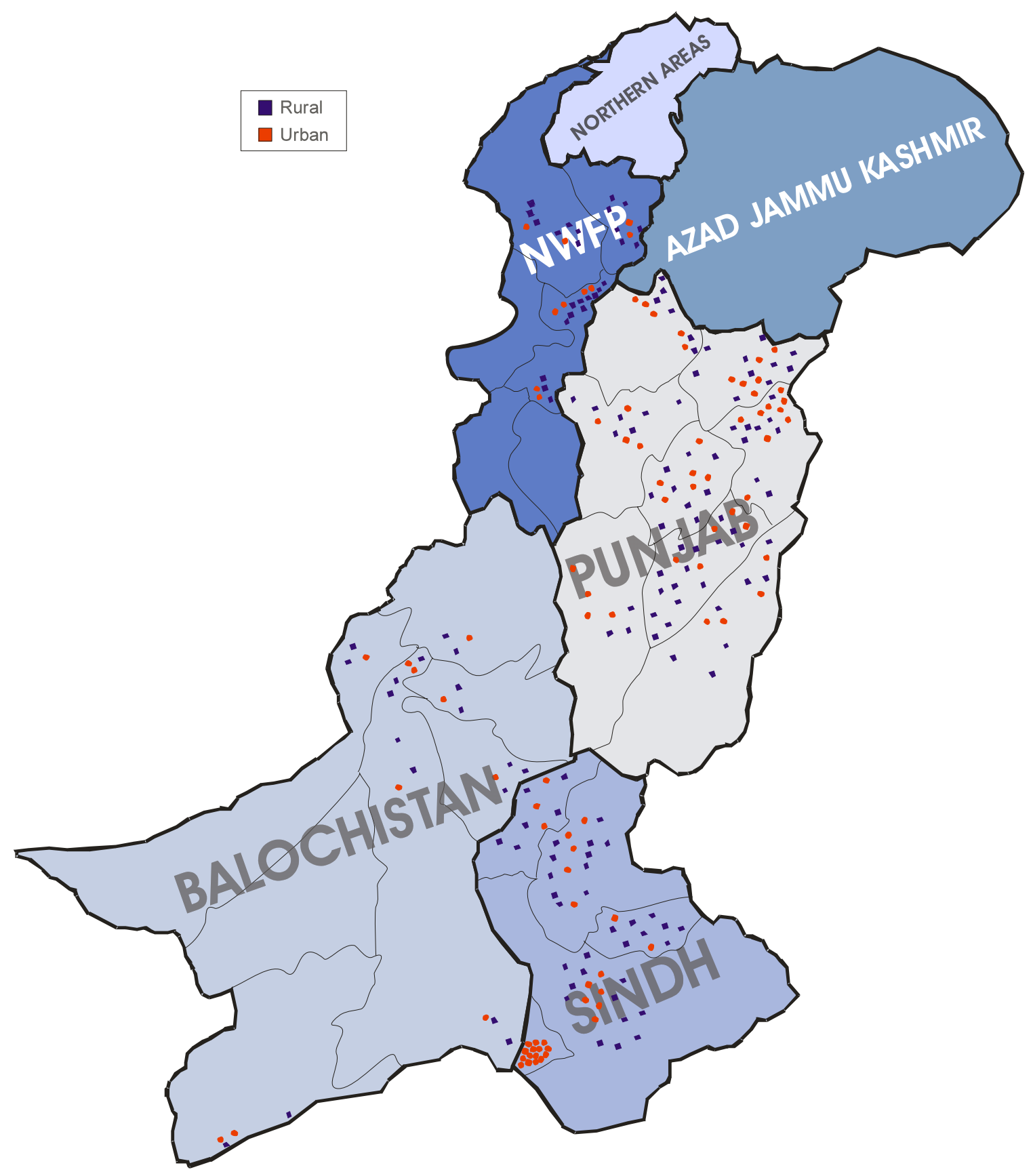


ADOLESCENTS AND YOUTH IN PAKISTAN 2001-2002: A NATIONALLY REPRESENTATIVE SURVEY

Figure 1.2 Distribution of households by province and residence

\begin{tabular}{lrrr}
\hline & \multicolumn{3}{c}{ By residence } \\
Province & Rural & Urban & Total \\
\hline Punjab & 2,003 & 1,349 & 3,352 \\
Sindh & 874 & 829 & 1,703 \\
NWFP & 720 & 398 & 1,118 \\
Balochistan & 400 & 239 & 639 \\
Total & 3,997 & 2,815 & 6,812 \\
\hline
\end{tabular}

\section{THE SURVEY AND ITS INSTRUMENTS}

The Population Council conducted the AYP from October 2001 to February 2002 in all four provinces to provide information at the national and provincial levels about the lives of young people aged 15-24..$^{2}$ The survey targeted four main groups:

- adolescents (15-19 years);

- youth (20-24 years);

- responsible adults (parents, spouses of young persons, and other relatives) in the household where young interviewees lived; and

- key informants in the community.

Described in more detail below is the range of instruments used by the survey: the household questionnaire, the adolescent and youth questionnaire, and the community profile.

\section{Household questionnaire}

A household questionnaire was administered to an adult in each household, with every attempt made to speak to a parent of a resident adolescent. The adult was interviewed first and permission was subsequently sought for interviews with the adolescents and youth in the household. The household profile included a listing of all household members in the roster, their education, work, and marital status. Information was also gathered on the timing and reason for those not currently living at home. A separate section covered the attitude of the responsible adult toward the education, work, and marriage of young people. Socioeconomic information was collected using proxy indicators to establish a socioeconomic status (SES) variable. Households were then

${ }^{2}$ The Federally Administered and Northern Areas and Azad Jammu Kashmir were excluded because these are not under the direct administration of the Government of Pakistan and as such have their own rules and regulations. 
classified as belonging to one of four quartiles: low, medium-low, medium-high, and high. Appendix II provides more information on the construction of the SES variable.

\section{Adolescent and youth questionnaire}

Once permission was obtained from the household head, young people aged 15-24 years were administered a standard questionnaire, with questions differing for males and females as appropriate. The questionnaire covered:

- Education: type, level, and access;

- Livelihood: type of employment, hours, remuneration, and education-work tradeoffs;

- Puberty, marriage, and childbearing: knowledge about puberty, arrangements and preparation for marriage, fertility, desired family size, and knowledge of family planning and safe motherhood;

- Social context: gender roles, access to public places, mobility, relationship to peers/others, aspirations, and decisionmaking concerning education, work, and marriage; and

- Migration: timing and reason for migration from natal home.

Two tools within the questionnaire gathered detailed information, based on a young person's recall:

- A Life Event Calendar (LEC) was integrated in the main module for adolescents and youth to collect comprehensive data on various aspects of young people's lives, pertinent to the age when certain events occurred. The tool was designed to capture these events in reverse chronological order starting from the calendar year 2001 and ending in 1981. Each column placed against individual calendar years recorded the occurrence of major life events such as: schooling, work, migration, living arrangements, marriage, fertility, and family planning use. Each year was split across two cells to represent events in the first and latter half of each year. The preferred way of collecting this information was to start with the current year and then go backward in the life history to age five. However, at times it was easier for respondents to recall events by starting at age five and progressing toward current ages. The LEC information not only provided a cross-check for data collected elsewhere in the interview, but comprises a density of information that enables the experience of the two age cohorts to be tracked at least ten years back in time. 
ADOLESCENTS AND YOUTH IN PAKISTAN 2001-2002: A NATIONALLY REPRESENTATIVE SURVEY

- A Time Use Profile (TUP) complimented the information in the LEC by providing details about a "typical" day using a 19-hour recall of daily activities from 6 a.m. to midnight. This mechanism captures activities such as domestic work and use of leisure time that are not otherwise captured in the interview.

\section{Community profile}

A community profile was developed in the communities where the survey was undertaken, using a structured group discussion with key informants. Group members, such as teachers, village leaders, elders, shopkeepers, moulvi (religious leaders), social workers, and chawkidars (guards), provided information on contextual variables about the community, including infrastructure, schools, and other facilities. The aim was to assess the different opportunity structures and facilities available to adolescents and youth across the country. Survey teams stayed in each community for three days and in most cases the male team supervisor collected this information. In the first two days, reliable informants were identified and efforts were made to select a neutral place for discussions with informants in order to avoid bias or conflict. On the third day, structured group discussions focused on reaching a consensus on the precise availability in the community of: basic infrastructure (e.g., roads, electricity, etc.), schools, clinics, training institutions, employment opportunities, and nongovernmental organizations. These data can now then be linked with household data and individual data for crosschecking and further analysis.

\section{IMPLEMENTATION OF DESIGN AND DATA COLLECTION}

\section{Qualitative research and pretesting of instruments}

The preliminary work on the survey began in September 1998, with a process of qualitative research to inform the design of the survey instruments. More than 40 focus group discussions with young people and their parents were initially carried out in six districts of Pakistan. These discussions were aimed at exploring the issues faced by young people in Pakistan and building an understanding and vocabulary of distinct issues to be addressed in the research instruments.

Structured questionnaires were then developed and pretested in the districts of Abottabad and Sialkot (NWFP and Punjab provinces, respectively). The objectives of this pretest were to experiment with the methodology of identifying and accessing young people aged 15-24, to explore the best possible sources of age reporting, and to scrutinize the viability of the LEC. Age verification was attempted using a variety of sources, 
including parents, birth records, and young people. The pretest determined that young people themselves reported their own age most accurately.

The entire set of research instruments was pretested in Islamabad and Rawalpindi during which time a number of issues were identified for integration into the final survey. First, based on the estimated number of young residents in each household, it was decided to interview all resident young people (aged 15-24 years) in sampled households. Second, the parent's questionnaire was merged with the household roster to create one household instrument. Third, the LEC appeared to work best at the beginning of the questionnaire, to enable the interviewer to reconcile the pretest, the research instruments were further refined for the final survey.

\section{Training and fieldwork}

A total of 15 survey teams, each comprised of four women and three men proficient in local languages, were hired to carry out the survey. In early to mid-October 2001, six teams were trained to administer the survey in Punjab as the first phase of the study. Manuals were developed to provide a reference for important concepts and definitions as well as to provide instructions on how to deal with various fieldwork situations that could arise. The first day of training coincided with Allied action in Afghanistan, which had an impact on all development work in Pakistan, including this survey. However, despite the volatile situation and security alerts, training continued and fieldwork began in late October 2001 as scheduled. Survey teams began their work on PSUs around the capital, Islamabad, and the twin city of Rawalpindi. Trainers remained with the teams to monitor and mentor during the first two weeks. This not only enhanced the data quality but also led to the refinement of training during the second and third phases. In November 2001, the second phase began and three teams from NWFP were trained to conduct fieldwork. In December 2001, the four teams for Sindh and the two teams for Balochistan were trained jointly in Karachi for 10 days and then began fieldwork. The project teams were closely monitored during the fieldwork period in all four provinces, which was completed by mid-February 2003.

\section{Field coordination}

A total of 111 field staff worked simultaneously in the four provinces in very diverse field situations (Appendix IV). Teams were in regular communication with their respective provincial co-coordinators (in NWFP, Sindh, and Balochistan), and the team leaders had direct contact with the main trainers to seek solutions if problems arose. Close coordination with the central office in Islamabad made it possible to maintain data quality and to manage problems related to logistics and field conditions. The fieldwork in Punjab was completed in mid-January 2002, in NWFP in early February 2002, in 
Sindh and Balochistan by mid-February 2002. The core team also conducted the training of the drivers, and the other support staff. A four-person team at the head office was responsible for coding, editing and checking the questionnaires as they were received from the field in order to provide immediate feedback. As soon as the fieldwork was complete, a ten-member team entered the data in Islamabad.

\section{Challenges in the field}

The national survey team contended with the linguistic, geographic, seasonal, cultural, and economic diversity that prevails in Pakistan. In some parts of the country, access during the winter months was variable and tremendous efforts were made by the field team to reach respondents. In the north and northwest of the country many homes were caught in the midst of cold weather and in the south the survey team had to track respondents who had migrated due to an eight-year drought and subsequent loss of livestock.

The volatile political situation also contributed to field challenges, in both serious and trivial ways. Many respondents near the Afghani border insisted that the survey teams relay information on civilian casualties of the war rather than gathering information on "useless things." Other respondents were suspicious that the survey was somehow connected to the Allied action and the interviewers were frequently asked their opinions about the war. Teams were trained to respond as neutrally as possible, and, in the end, the survey was completed with minimal disruption. More trivial inconveniences involved price increases (the price of a cup of tea in Peshawar rose from 2 rupees to 20 rupees) which had an impact on field expenses.

\section{Administration of surveys for young people and household respondents}

Once the 6,812 randomly selected households were identified, survey teams attempted to contact and complete a roster for each. Although the objective was to identify households with resident individuals aged 15-24, even those households without young people were interviewed. Many of these households listed non-resident young people who had migrated for work, marriage, or school, and these rosters helped to provide an unbiased picture of the situation of young people.

Assessing age in Pakistan is difficult, since families do not necessarily record ages. Survey teams made all possible efforts to determine the ages of young people within each household as accurately as possible. Within each household all members were listed by age, sex, and residence status. If no young person within the age group was resident, then the next household in the sampling list was contacted in order to ensure an adequate sample of young people. Several attempts were made to verify ages 
from young people themselves as well as to preclude the possibility of missing eligible adolescents and youth in any household. Over 5,000 households were short-listed as containing residents aged between 13 and 26. These were then screened more carefully yielding 4,884 households that were finally targeted for interviews with young persons aged 15-24 years. As noted in Figure 1.3, young people in 4,530 households were finally interviewed.

Figure 1.3 Number of households identified at each stage

\begin{tabular}{lccc}
\hline & \multicolumn{3}{c}{ By residence } \\
\cline { 2 - 4 } Household status & Rural & Urban & Total \\
\hline Contacted/visited & 3,997 & 2,815 & 6,812 \\
Roster completed & 3,927 & 2,658 & 6,585 \\
Contain 13-26 year olds & 3,232 & 2,158 & 5,390 \\
Contain 15-24 year olds & 2,956 & 1,928 & 4,884 \\
Contain young people successfully interviewed & 2,744 & 1,786 & 4,530 \\
\hline
\end{tabular}

Among the 6,585 households where a household roster was completed, there were a sizeable number that had no resident young persons, but there were also households that had more than two young residents. As noted in Figure 1.4, 26 percent of these households had no residents aged 15-24, 30 percent of households had just one resident young person, and 44 percent had two or more young persons residing in them. There was considerable variation by sex, as 41 percent of households had no resident young male as compared to 51 percent with no resident young female.

Figure 1.4 Distribution of households by number of young people (15-24 years old), of all households where rosters were completed

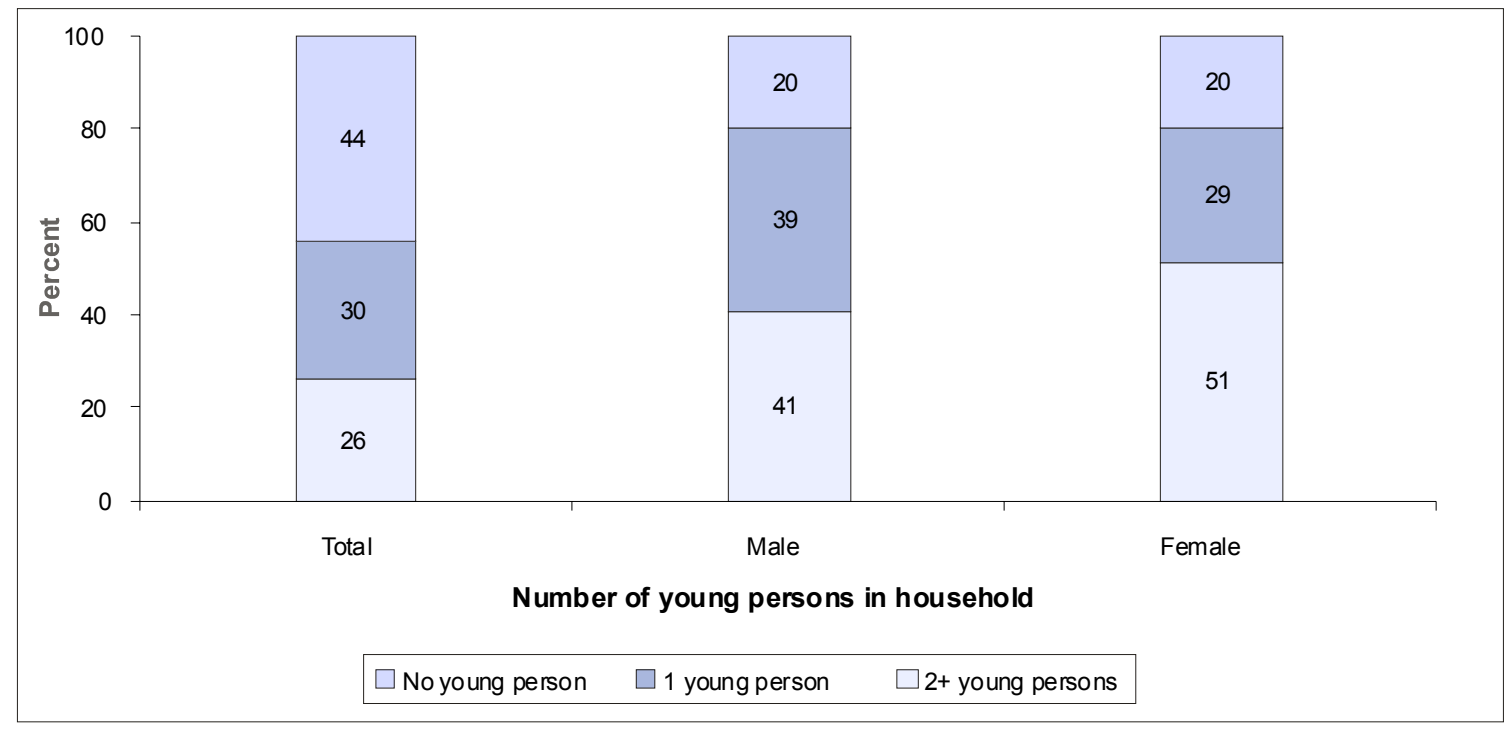




\section{Response rate and reasons for not holding interviews}

In the 4,884 households that contained eligible young people aged 15-24, a total of 10,760 young people were identified. Out of this number, 8,074 (3,333 males and 4,741 females) were interviewed, resulting in a 75 percent response rate. The data reflect a consistent gendered pattern of response across Pakistan where females responded at a higher rate than males. Although field teams made multiple visits to a home, finding young males at home was particularly difficult, as they were often outside the home (e.g., in the field, in shops, street corners, playgrounds, etc.). Those young persons who were not found at home or elsewhere in the community during the three days the team was in the vicinity remained un-interviewed.

The problems of locating and interviewing young people in Pakistan did lead to some important differences in characteristics of those persons the survey was unable to capture. Details on the response rate can be found in Appendix III. It is important to point out, not surprisingly, that older males were more likely to have been missed and this was also true but to a lesser extent among females. Provincial distribution differences were very negligible but socioeconomic status and education were important as those not interviewed were more likely to be from poorer households and to be less educated. This is more striking among males: 26 percent of those not interviewed had never attended school compared to 18 percent among those interviewed. Among females the difference in characteristics of those missed in the interviews is strikingly associated with marital status: those not interviewed were more likely to be currently married mainly because they are likely not to be at home.

Figure 1.5 shows the distribution of households where an eligible young person was in residence by the number of young persons interviewed in each. In seven percent of these households, no young person was interviewed. In 49 percent of households, one young person was interviewed, and in 44 percent of households, two young persons were interviewed. In 48 percent of households, no male could be interviewed, as opposed to only 27 percent where no females were interviewed.

Figure 1.5 Distribution of households by number of young persons interviewed, of all households that contained eligible young people

\begin{tabular}{lrrrrrr}
\hline \multirow{2}{*}{$\begin{array}{l}\text { Number of young persons } \\
\text { interviewed }\end{array}$} & \multicolumn{2}{c}{ Male } & \multicolumn{2}{c}{ Female } & \multicolumn{2}{c}{ Total } \\
\cline { 2 - 7 } & $\%$ & $\mathbf{N}$ & $\%$ & $\mathbf{N}$ & $\%$ & $\mathbf{N}$ \\
\hline None & 48.3 & 2,360 & 27.4 & 1,338 & 7.2 & 354 \\
One & 38.4 & 1,875 & 53.3 & 2,604 & 48.9 & 2,388 \\
Two or more & 13.3 & 649 & 19.3 & 942 & 43.9 & 2,142 \\
$N$ & 100.0 & 4,884 & 100.0 & 4,884 & 100.0 & 4,884 \\
\hline
\end{tabular}


The reason that the 2,676 young people could not be interviewed varied significantly by sex. As Figure 1.6 shows, the primary reason is that no contact could be made with the young person, in spite of multiple visits to the household. This was truer for males than for females (75 percent and 54 percent, respectively). Thus not only was it less likely that a male young person was in residence in any one household, but even those who were resident were less likely than resident females to be present for contact with an interviewer. This issue is closely tied to the differentials in mobility and migration among the sexes and will be discussed in detail in Chapter 2. Another difference that emerges in Figure 1.6 is that females were more likely to refuse or not be given permission than males (30 percent versus 14 percent).

\section{Figure 1.6 Reasons that young persons could not be interviewed, by sex}

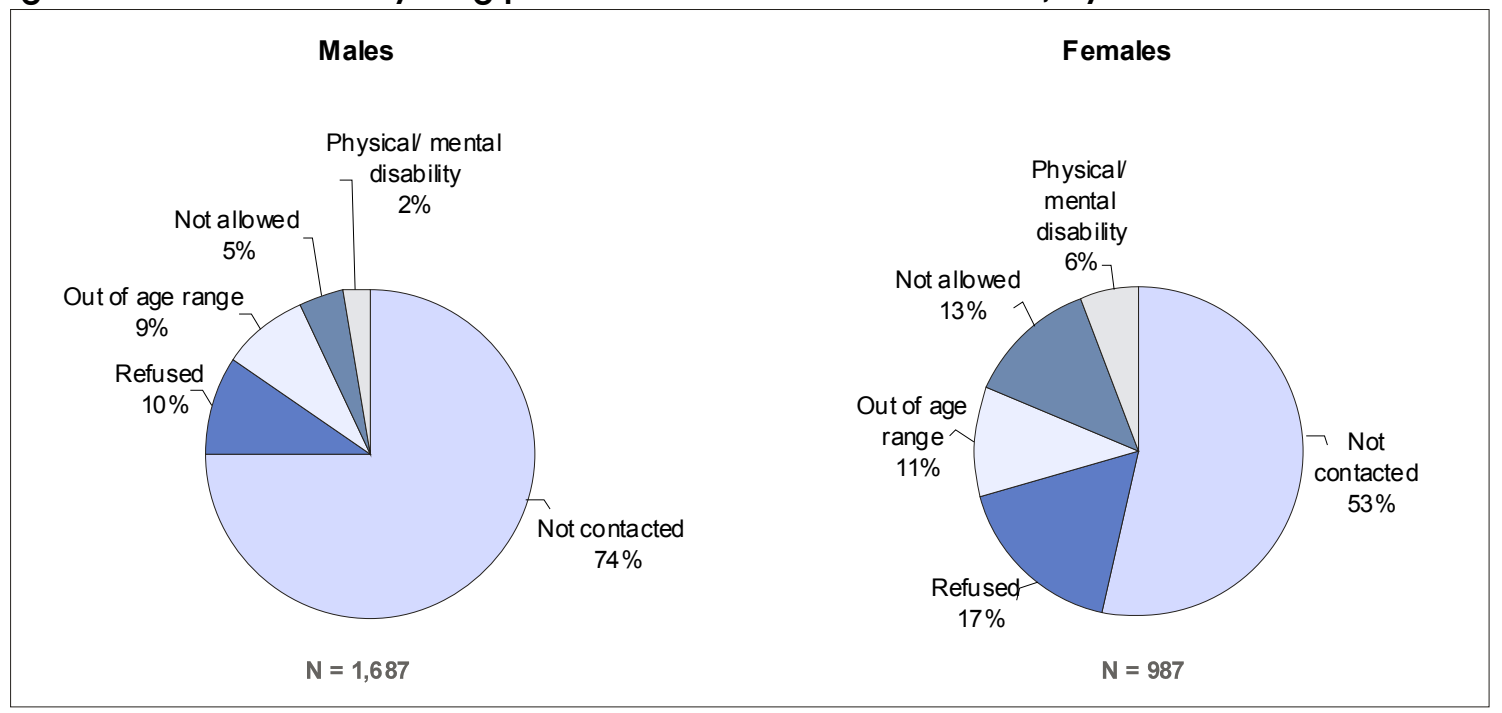

Another important part of the survey is the information collected from household respondents in those households where at least one resident young person was successfully interviewed. Figure 1.7 provides a breakdown by gender, of the characteristics of household respondents by province and residence. Overall, more females were household respondents than were males (62 and 38 percent, respectively). A closer examination across provinces shows that NWFP has the largest percentage of households where females were the respondents for the household profile (74 percent), whereas greater proportions of males were interviewed in Punjab and Sindh relative to other provinces. These figures reflect the greater availability of females at home especially in NWFP and Balochistan where large proportions of males live away from home for work-related reasons. A similar pattern can be viewed across residence for which, in both rural and urban areas, the proportion of female respondents is considerably higher compared with their male counterparts (Figure 1.7). 
ADOLESCENTS AND YOUTH IN PAKISTAN 2001-2002: A NATIONALLY REPRESENTATIVE SURVEY

Figure 1.7 Percent distribution of the characteristics of household respondents (in households where a young person was interviewed), by sex

\begin{tabular}{crrrrrr}
\hline & \multicolumn{2}{c}{ Male } & \multicolumn{2}{c}{ Female } & Total \\
\cline { 2 - 6 } Characteristic & $\%$ & $\mathbf{N}$ & & $\%$ & $\mathbf{N}$ & $\mathbf{N}$ \\
\hline Province & & & & & \\
Punjab & 42.2 & 864 & 57.8 & 1,182 & 2,046 \\
Sindh & 41.8 & 507 & 58.1 & 704 & 1,211 \\
NWFP & 25.7 & 192 & 74.3 & 556 & 748 \\
Balochistan & 31.0 & 161 & 69.0 & 358 & 519 \\
Total & 38.1 & 1,724 & 61.9 & 2,800 & 4,524 \\
Residence & & & & & \\
Rural & 38.4 & 1,051 & 61.6 & 1,687 & 2,738 \\
Urban & 37.7 & 673 & 62.3 & 1,113 & 1,786 \\
Total & 38.1 & 1,724 & 61.9 & 2,800 & 4,524 \\
\hline
\end{tabular}

The household questionnaire was designed to gain insight into the attitudes and perspectives of parents, pertinent to issues surrounding young people's lives (i.e., education, work, mobility, and marriage). Survey teams attempted to interview either parent, but in situations where parents were absent and not expected back during the team's stay in the community, another adult member of the household was interviewed. Figure 1.8 presents the distribution of the relationship of household respondents to young persons interviewed. In almost 60 percent of the total households, the respondents were parents of the young people interviewed with mothers more likely to be interviewed than fathers (65 and 52 percent, respectively). However, in as many as 28 percent of the households, another adult family member (mostly close relatives: grandparent, uncle, aunt, or parent-in-law) responded to the household questionnaire (Figure 1.8). Thus, we cannot utilize information from the household questionnaire to represent the responses of parents of young persons alone. Furthermore, in seven percent of cases, the household respondent was the young person him/herself; this was true for a larger proportion of female respondents (10 percent of households where a female was interviewed) than for male respondents ( 2 percent of households where a male was interviewed). In other situations, 13 percent of male household respondents were the husband of a young female, less then 1 percent of female household respondents were wives of young males interviewed. 
Figure 1.8 Relationship of household respondents to young people interviewed

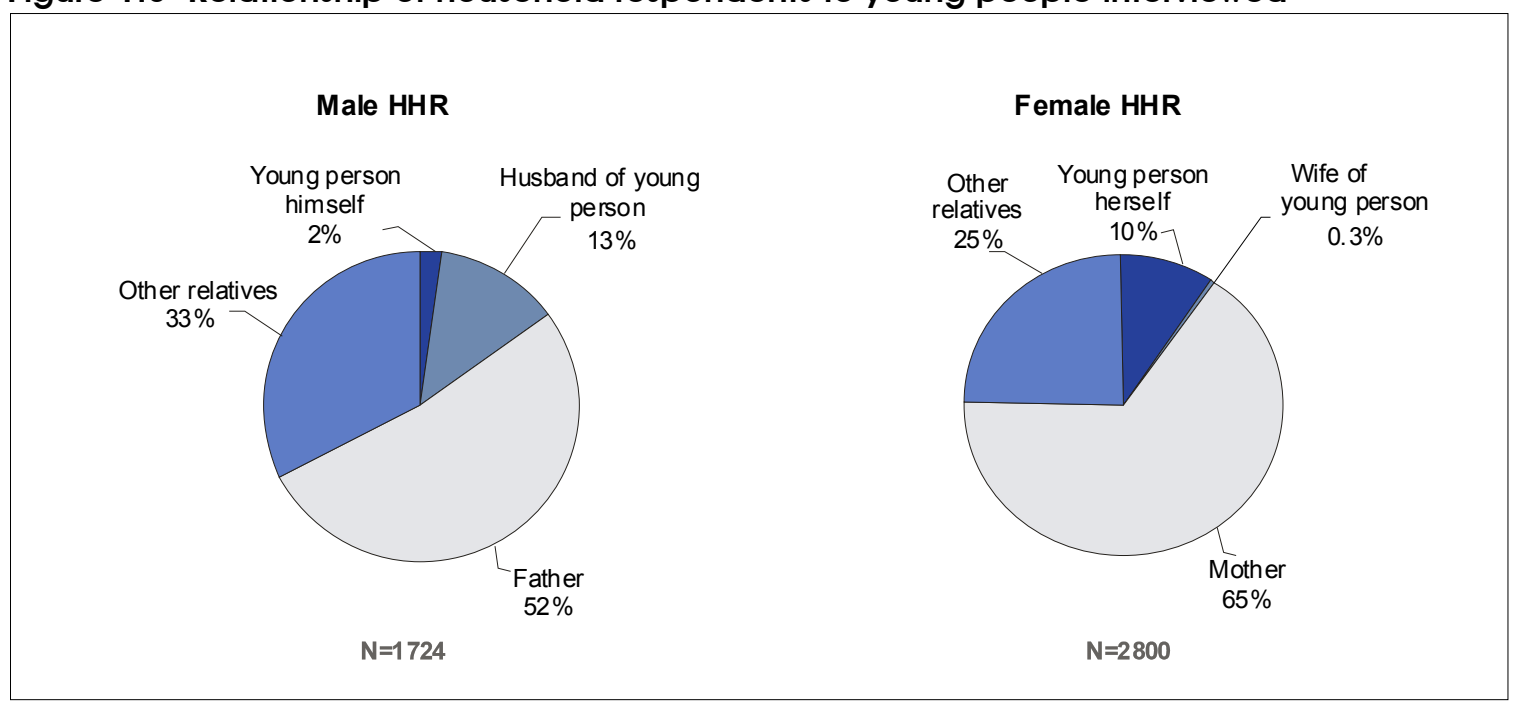

\section{Context of the interview}

The reliability of the data also depends on the degree to which a young person was free to answer the questions posed. The majority of interviews were conducted with at least one other person present throughout the interview. In general, more females than males were interviewed in the presence of at least one other person (often a parent, sibling, or other relative), but there were not significant differences between the two age cohorts. The most sensitive parts of the interview dealt with the issues of gender and empowerment, puberty, marriage, and reproductive history. While field teams were somewhat successful in reducing the number of additional persons present during these sensitive periods, the majority of interviews were still conducted in a less than ideal setting for honest and confidential reporting. Data are consistent with the observations and reports by field staff that it was difficult to find a young female alone, that the majority of females were interviewed at home, and that most were surrounded by other household members. In contrast, males were usually found outside the home, more likely to be interviewed away from parental observation, but often were accompanied by friends and peers.

\section{UNIQUE FEATURES OF THE AYP}

The AYP is the first nationally representative survey of young people in Pakistan. The information gathered provides the first opportunity for a detailed exploration into the transitions to adulthood for Pakistani young people, as well as the social and economic contexts that shape those transitions. 
The survey also marks the first time that young people were directly asked questions concerning their lives, rather than an adult reporting on their behalf. The AYP has captured the experience and attitudes surrounding their world--school, work, and marriage--and offers the opportunity to compare and contrast these perspectives with those of responsible adult members of their households. In this way, generational differences and similarities can be identified.

Another unique aspect of the AYP is that both married and unmarried men and women were asked their opinions about the process and timing of marriage and childbearing. This breaks with the usual strategy of only asking such questions of married women.

Finally, the LEC and the TUP that were incorporated into the adolescent and youth surveys provide a level of detail never before recorded at a national level. The Calendar recorded critical life events in the past years.

The TUP noted the minutiae of events in a 19-hour recall of daily activities from 6 am to midnight. Together, they paint a very detailed and complex mosaic of the lives of young people.

\section{ARCHITECTURE OF THE REPORT}

This report is organized into thematic chapters that provide detailed information on young people's experience with each transition. What quickly emerges is the heterogeneity of the lives of young people, thus suggesting that policies and programs for young people cannot be generic. Policymakers and program planners need to respond to the diversity of this population, as defined by sex, rural/urban residence, age, and educational and socioeconomic status. Therefore each theme is examined using a common set of variables throughout the report. These variables, as they relate to the transition discussed, are found in comprehensive tables at the end of the report. Where particularly interesting findings need to be highlighted, a portion of that table is illustrated by a figure within the text of the chapter.

\section{Background variables}

The variables that are examined throughout the report are gender, age, urban/rural residence, educational attainment, socioeconomic status, marital status, and provincial residence. Each is described in detail below. 


\section{Gender}

The gendered nature of these transitions is perhaps the most striking element of distinction. To a large degree, a young person's life is scripted by his or her sex. When puberty arrives, opportunities and mobility are constricted for females, as they are protected from the outside public world. For males, puberty may mark the time at which his world expands, opportunities present themselves, and he presents himself to the community at large. Because gender defines such unique experiences, the tables and figures in this report show males and females separately to allow for comparison and to acknowledge the diversity.

\section{Age cohort}

Making general policies or programs for young people aged 15-24 does not take into account the distinctive needs, experience, and attitudes defined by the younger cohort (adolescents aged 15-19) compared to the older cohort (youth aged 20-24). Therefore, to reflect the distinctiveness, most tables and figures in the report, are disaggregated by age cohorts. In some instances, in order to describe the "adolescent experience," the analysis is restricted to the older cohort and their experience, retrospectively, of a particular transition prior to the age of 20. For instance, in order to figure the percent of young people who complete secondary school, one needs to examine the older cohort, youth who are old enough to have completed that level. Similarly for marriage, one looks at how many of those who are currently married before age 20 among those who are 20 or older to get a precise statistic for adolescent marriage.

\section{Residence (urban or rural setting)}

Whether a young person resides in an urban or a rural setting has a great impact on all aspects of his or her transitions to adulthood. Access to infrastructure and opportunities, levels and timing of marriage, schooling, and work, are all informed to a large degree by urban or rural residence. Thus most tables and figures differentiate a young person's situation by residence. As noted in Figure 1.9, the majority of the sample resides in the rural areas.

Figure 1.9 Distribution of sample by residence, age, and sex

\begin{tabular}{lrrrr}
\hline \multirow{2}{*}{ Residence } & \multicolumn{2}{c}{$\mathbf{1 5 - 1 9}$ year olds } & \multicolumn{2}{c}{$\mathbf{2 0 - 2 4}$ year olds } \\
\cline { 2 - 5 } & Male & Female & Male & Female \\
\hline Rural & 56.9 & 60.0 & 56.2 & 60.6 \\
Urban & 43.1 & 40.0 & 43.8 & 39.4 \\
$N$ & 2,055 & 2,748 & 1,278 & 1,993 \\
\hline
\end{tabular}




\section{Educational attainment}

The educational attainment of a young person is found to be intimately linked to other transitions to adulthood. Thus a common education variable is used throughout the chapters to examine the relationship of any given transition to an individual's educational attainment. Respondents were classified into four groups according to the highest class passed (Figure 1.10). The groups were divided according to key accomplishments in the Pakistan government school system, where primary school consists of class 0 (Katchi) through class 5. Middle school stretches from class 6 through class 8, and secondary school includes classes 9 and 10. The AYP scale, based on the highest class completed is constructed as follows:

1) those who never attended school,

2) those who attended school but did not complete primary (classes 0 to 4 ),

3) those who completed primary but did not complete secondary (classes 5 to 9), and

4) those who completed secondary and beyond (class 10 and higher).

Figure 1.10 Distribution of sample by educational attainment, age, and sex

\begin{tabular}{lcrrr}
\hline \multirow{2}{*}{ Education } & \multicolumn{1}{c}{$\mathbf{1 5 - 1 9}$ year olds } & \multicolumn{2}{c}{$\mathbf{2 0 - 2 4}$ year olds } \\
\cline { 2 - 5 } Never attended & Male & Female & Male & Female \\
Completed less than primary & 14.2 & 41.9 & 16.5 & 50.2 \\
Completed primary & 13.5 & 14.2 & 11.3 & 9.7 \\
Completed secondary & 52.9 & 31.9 & 35.0 & 19.7 \\
$N$ & 19.4 & 12.0 & 37.2 & 20.4 \\
\hline
\end{tabular}

\section{Socioeconomic status}

Socioeconomic information was collected using 29 proxy indicators to establish a socioeconomic status (SES) variable (see Appendix II for details). Households were classified as belonging to one of four quartiles: low, medium-low, medium-high, and high. Individuals were then assigned the socioeconomic status of the household in which he or she was residing (Figure 1.11). It is important to note that the status reflects current residence and not necessarily that of one's natal home or the place in which a decision was made concerning school leaving, work, or marriage. As will be noted in the marriage chapter, for those young married women who are now residing in the home of her spouse, the socioeconomic indicator associated with her does not necessarily reflect the context in which decisions surrounding her marriage took place (unless one assumes that a young woman has married into a similar socioeconomic status).

Since more than one young person could be interviewed from each household, the distribution of individuals across the socioeconomic quartiles is not even. 
Figure 1.11 Distribution of sample by socioeconomic status, age, and sex

\begin{tabular}{lrrrr}
\hline \multirow{2}{*}{ Socioeconomic status } & \multicolumn{2}{c}{$\mathbf{1 5 - 1 9}$ year olds } & \multicolumn{2}{c}{$\mathbf{2 0 - 2 4}$ year olds } \\
\cline { 2 - 5 } & Male & Female & Male & Female \\
\hline Low & 18.6 & 20.3 & 18.8 & 20.0 \\
Low-mid & 20.1 & 22.6 & 18.7 & 20.0 \\
High-mid & 27.9 & 26.7 & 24.1 & 25.7 \\
High & 33.4 & 30.4 & 38.4 & 34.3 \\
$N$ & 1,974 & 2,629 & 1,207 & 1,913 \\
\hline
\end{tabular}

\section{Marital status}

Marital status is another variable by which a young person's access, attitudes, and needs are differentiated. Questions related to one's childbearing experience were only asked of respondents who were ever married (in the case of males, the question was asked as it relates to his spouse). However, questions related to appropriate age at marriage or ideal number of children were asked of both married and unmarried respondents and the differentials are important. (See Figure 1.12)

Figure 1.12 Distribution of sample by marital status, age, and sex

\begin{tabular}{|c|c|c|c|c|}
\hline \multirow[b]{2}{*}{ Marital status } & \multicolumn{2}{|c|}{$15-19$ year olds } & \multicolumn{2}{|c|}{ 20-24 year olds } \\
\hline & Male & Female & Male & Female \\
\hline Never married & 95.3 & 78.6 & 73.6 & 39.0 \\
\hline Ever married & 4.7 & 21.4 & 26.4 & 61.0 \\
\hline$N$ & 2,055 & 2,748 & 1,278 & 1,993 \\
\hline
\end{tabular}

\section{Province}

All statistics are presented at the provincial level, to allow for comparison and contrasts across provinces with regards to the transitions discussed. (Figure 1.13)

Figure 1.13 Distribution of sample by province, age, and sex

\begin{tabular}{|c|c|c|c|c|}
\hline \multirow[b]{2}{*}{ Province } & \multicolumn{2}{|c|}{$15-19$ year olds } & \multicolumn{2}{|c|}{$20-24$ year olds } \\
\hline & Male & Female & Male & Female \\
\hline Punjab & 42.8 & 42.5 & 43.6 & 45.3 \\
\hline Sindh & 28.7 & 27.5 & 30.6 & 26.7 \\
\hline NWFP & 16.8 & 16.9 & 14.4 & 17.3 \\
\hline Balochistan & 11.7 & 13.0 & 11.4 & 10.7 \\
\hline$N$ & 2,055 & 2,748 & 1,278 & 1,993 \\
\hline
\end{tabular}




\section{Thematic chapters}

The remaining chapters provide a detailed examination of the lives of young people in Pakistan. Chapter two describes the social context in which the transitions to adult hood take place. It provides insight into their living arrangements, how they use their time, their mobility and the social structures that underpin their lives. It argues that social norms, particularly in the arena of gender relations, strongly influence the roles young people play and the responsibilities they hold during their teen years and later in life.

The third chapter analyses levels and trends of educational attainment as well as access to schools. It profiles the key characteristics of those who attended school and those who did not. It looks at trends in primary enrollment and levels of educational attainment. It examines issues relating to school dropouts highlighting the major role of poverty and socio-cultural attitudes particularly regarding females in the decision to drop out. It also looks at the types of schools available in Pakistan and who is most likely to frequent them. The chapter ends by assessing the difference between reality and the aspirations of young people and their parents for education.

The fourth chapter deals with the economic activity of young people. It considers work prevalence, the transition to work, types of work, and levels and trends including those of child labor. It explores young people's desire to work and their participation in family decisions regarding their work. The chapter also considers the availability of work for young people, particularly near their home environment. The chapter concludes that the transition of young people to the labor force plays out very differently for young men and women in Pakistan.

The fifth chapter addresses puberty, a physical marker of maturity for adolescents and precursor to marriage for many females. It places emphasis on who equips young people with information about physical changes prior to the onset of puberty and their preferences for persons from whom they would like such information. The chapter also examines trends and levels of marriage, childbearing and contraception amongst adolescents and youth. In addition, married and unmarried young people and household heads report their attitudes and perceptions regarding marriage and child bearing.

The sixth chapter presents detailed information on the communities in which young people reside. The data depict the 254 communities where young people were interviewed and provide information regarding access to roads, communication and other services particularly education and health. The chapter reveals that many young 
people in Pakistan are still growing up in isolated underdeveloped areas without essential facilities.

The last chapter of the report comprises conclusions and selected recommendations for policy and programming regarding young people in Pakistan. The aim of this chapter is to highlight the gaps between the actual situation of young people and their aspirations and to suggest some directions for programs and policies. Its main message is to reinforce the heterogeneity in the lives of young people and the necessity for tackling their needs on the basis of gender, age, region of residence, and economic status.

\section{REFERENCES}

Survey of Pakistan, 1997. Atlas of Pakistan. Surveyor General of Pakistan.

Government of Pakistan, 2001. 1998 Census Report of Pakistan. Population Census Organization Statistics Division, Islamabad. 



\section{Social Dimensions of Young People's Lives}

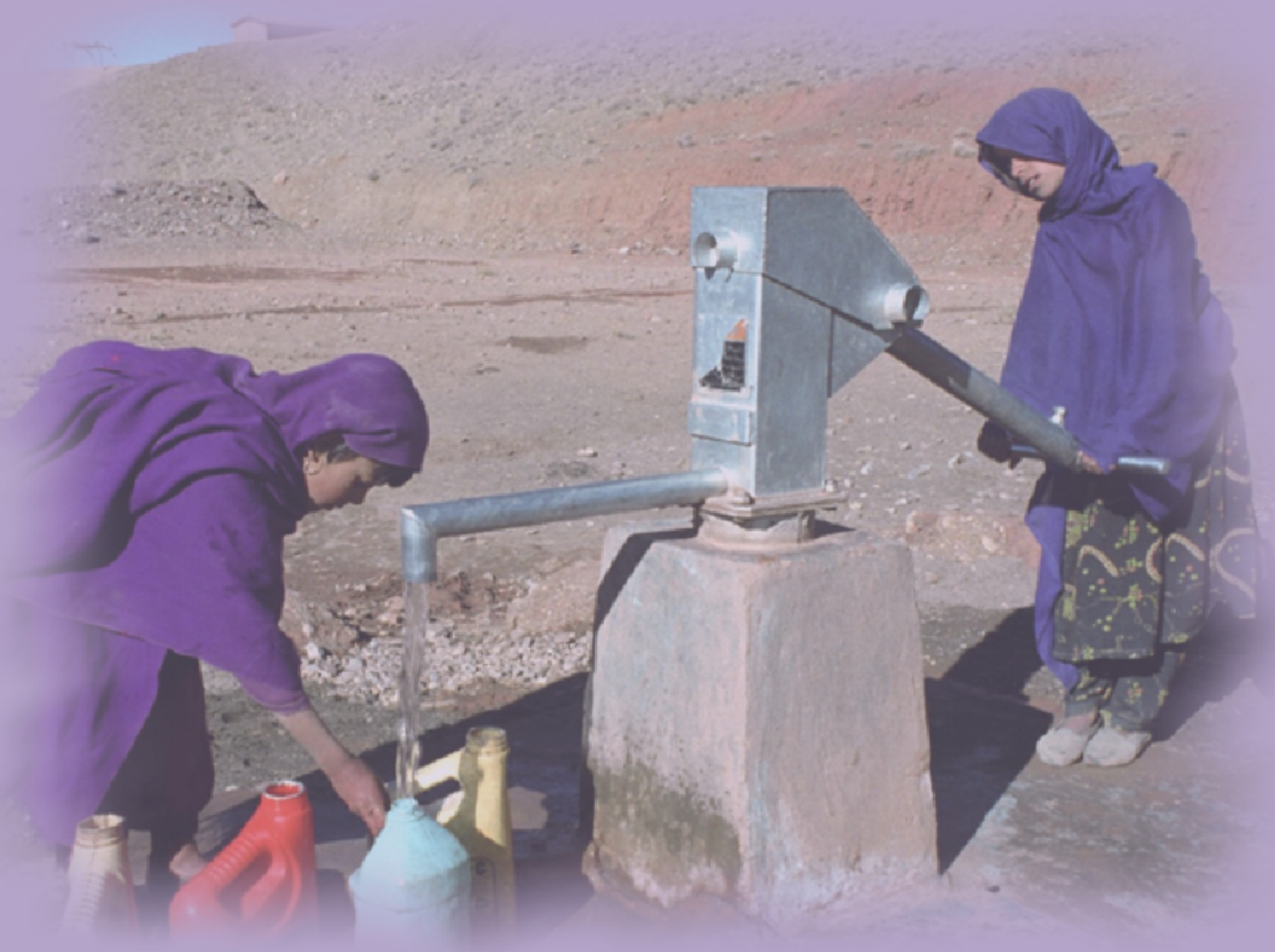

In this chapter:

- Introduction

- Living Arrangements of Young People

- Household Characteristics

- Mobility and Migration

- Time Use and Recreation

- Communication and Social Networks

- Agency in DecisionMaking and Gender Roles

- Conclusion 


\section{Social Dimensions of Young People's Lives}

\section{INTRODUCTION}

This chapter addresses the social and cultural context of young people's lives at the individual and household levels and will set the stage for better understanding the individual transitions that are presented in forthcoming chapters. Clearly the transitions young people make do not take place in neutral settings but are in fact supported by social structures that shape the outlook, experience, and opportunities that young people have as they mature into adults. Therefore, this chapter provides an in-depth look at the cultural and socioeconomic environments in which these transitions take place before examining each major transition, for example, education, work, puberty, and marriage, in subsequent chapters.

The AYP is the first nationally representative study to gather information from young people on the social dimensions of their lives, including living arrangements, time use, and mobility. It also examines the circumstances that prompt young people to leave their households for simple daily errands and outings, as well as more significant journeys, such as migration for work or marriage. The chapter also highlights young people's access to social networks and other channels of communication. It ends by exploring the autonomy and attitudes of young people regarding the gender division of roles and responsibilities in the family.

\section{LIVING ARRANGEMENTS OF YOUNG PEOPLE}

The LEC reveals that 77 percent of all males and 49 percent of all females aged 15-24 are living with both of their parents in the same household (Table 2.1). Disaggregating the data by urban and rural residence reveals considerable differences. Young females in urban areas are more likely to be living with both of their parents than females in rural areas, while no such differential exists for males. The difference for females is driven almost entirely by the higher rate of early marriage in the rural areas, a transition that is accompanied by a move to the groom's family for most females.

Figures 2.1 and 2.2 illustrate the differences in living arrangements. The transition out of the natal home begins soon after puberty (around age 14) for females 
and by the age of 20 the majority of females are no longer living with their biological parents. Instead, they are either with their spouse in a nuclear family or, more likely, in the household of their in-laws. Figure 2.2 shows the contrasting situation of males where the marriage transition begins approximately three years after females. Note also that males, unlike females, continue to reside in their natal home after marriage.

Figure 2.1 Living arrangements of females up to age 24 , by age

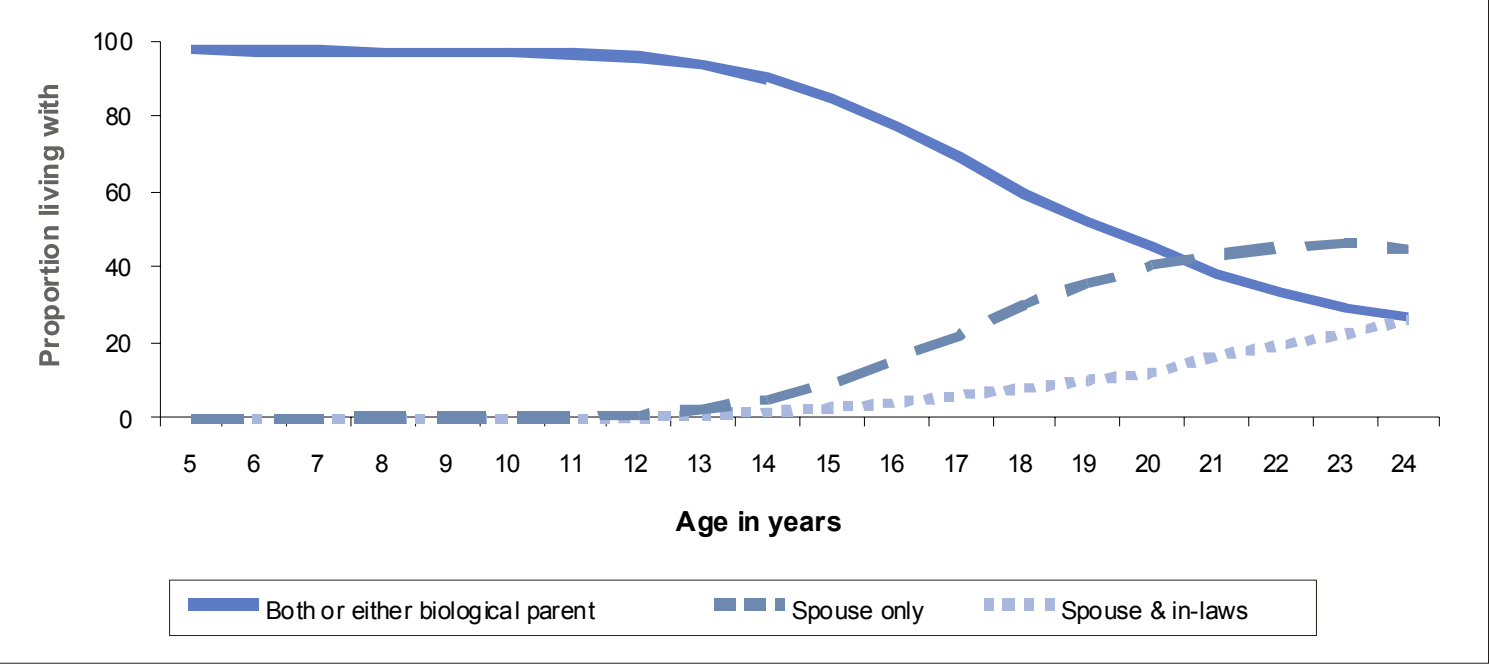

Figure 2.2 Living arrangements of males up to age 24 , by age

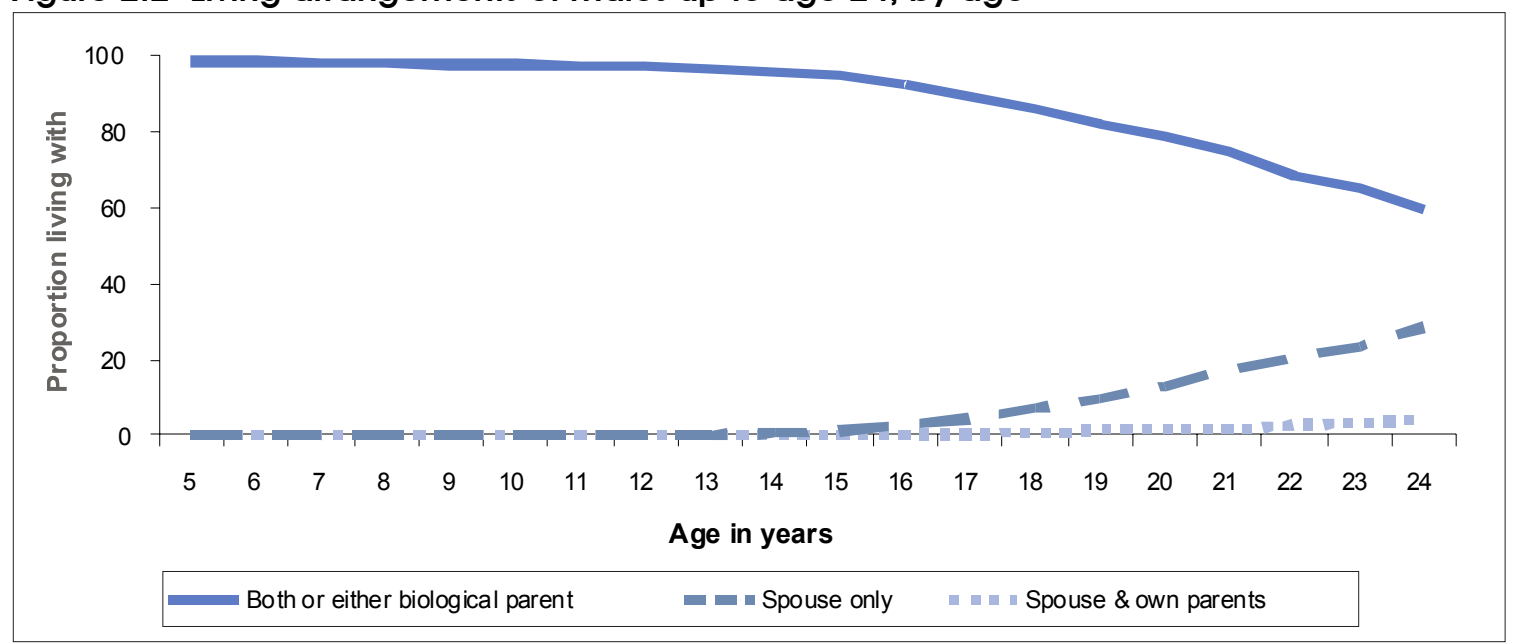




\section{HOUSEHOLD CHARACTERISTICS}

The characteristics of the households of young people were exhaustively examined in the survey. This section looks at the living arrangements, parental literacy, and conditions of the household as contextual factors that might influence the lives of young people.

\section{Family type}

Approximately half of all households included in the sample are comprised of nuclear families (Table 2.2). The non-nuclear households include young married couples who live in the husband's natal home, as well as multi-generational families, while nuclear households are limited to those households containing only the household head, spouse of the household head, and their unmarried children. A smaller percent of rural households than urban are nuclear, and this is true for all provinces. Nuclear households are least common in Balochistan, representing less than 35 percent of all households contacted. Furthermore, households where a young person was interviewed were also less likely to be nuclear; however, these differences are most likely attributable to the phase of the life cycle that these households are currently in, relative to households without young people.

An analysis of all households surveyed, including those with no resident young people, reveals that the mean size of households is 7.6, with a slightly larger size in rural areas (7.7) compared to urban areas (7.4). When looking at only those households with at least one resident young person, the mean rises to 8.4 persons per household, with 8.5 in the rural area and 8.1 in the urban area. As noted in Table 2.3, there are clear interprovincial differences within each sample. Among households where young people reside, Balochistan has the largest household size (10.3 persons per household), followed by Sindh, NWFP, and Punjab (7.9). These figures are slightly lower when sampling all households (Balochistan at 9.7 and Punjab at 7.2).

\section{Parental literacy}

Parents play a critical role in socializing their young and passing on essential information and life skills. A parent's ability to read and write facilitates his or her ability to use resources and take advantage of opportunities that will benefit the family. AYP's sample of young people reveals that only one-third of fathers and less than 10 percent of mothers are literate (Figure 2.3). ${ }^{3}$ In Balochistan these figures are starker: less than a quarter of the fathers and only three percent of mothers are literate. This means

3 This survey defined literacy as someone who can read and write in any language, as reported by the survey respondent. 
that the majority of young people are growing up in households where neither parent is able to read or write.

Figure 2.3 Percent of young people whose parents were literate by province and sex of parent

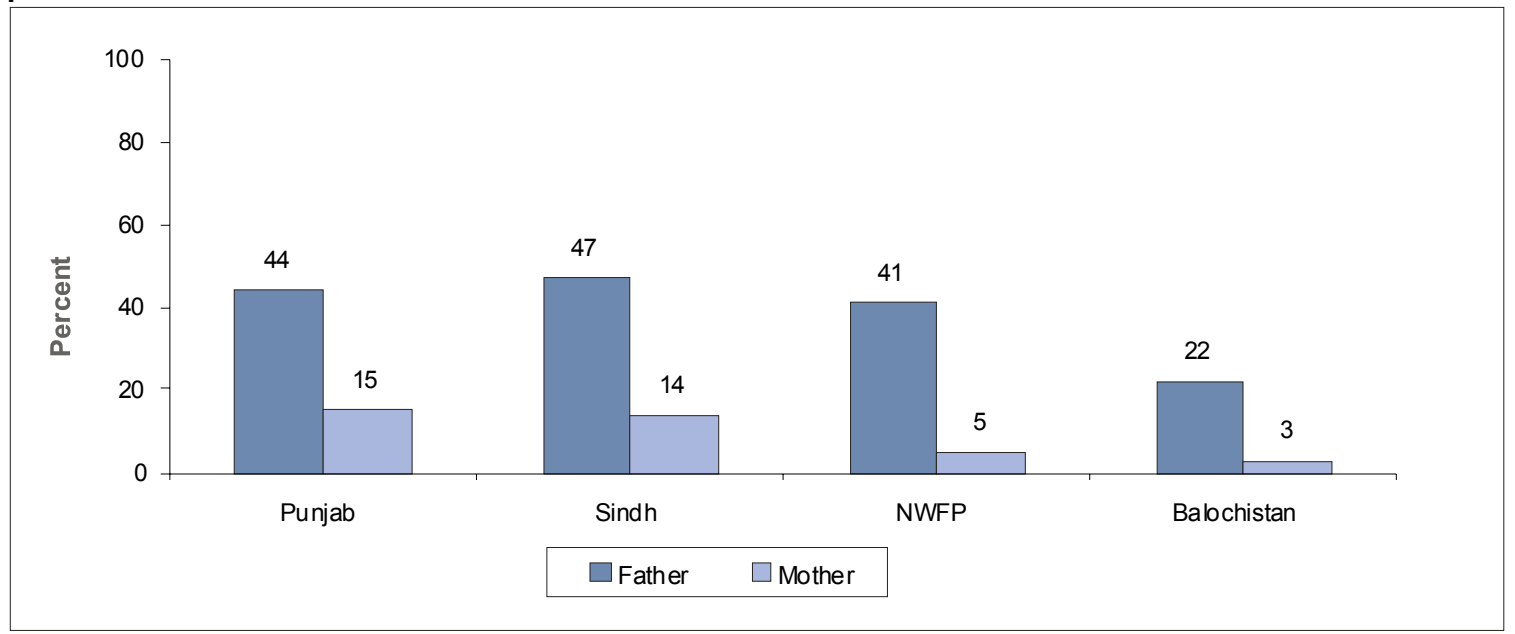

\section{Housing conditions and socioeconomic status (SES)}

Young people in Pakistan tend to live in houses with an average of 2.5 rooms (Table 2.4). ${ }^{4}$ Interestingly, urban residences have slightly more rooms than those in the rural area. Thus higher household size combined with smaller spaces generally results in more crowding in the rural areas. Table 2.4 also looks at the number of people per room in a dwelling. The data show an average of 4.0 people per room. The most crowded conditions exist in rural Sindh with 5.1 people per room, compared to 3.8 in urban Sindh.

While there may be one or more rooms in a house, it is important for health reasons to have a separate cooking space. Half of the households where young people were surveyed report a separate room for cooking in their household (Table 2.5). However, there are notable differences across residence: households in urban areas are much more likely to have a separate kitchen than their rural counterparts, particularly in urban households in Sindh and NWFP (73 and 75 percent, respectively). Although there is a practice of outside cooking in Pakistan (especially in Punjab), considerable numbers of families cook inside their households, particularly in the mountainous areas during the winter. This practice is known to lead to higher incidences of upper respiratory infections in these areas.

4 The term "rooms" includes living, drawing, and dining rooms. 
The survey also considered the presence of a pour or flush latrine as an important indicator of a safe home environment. Notable differences between rural and urban areas are found in the availability of sanitation: almost three times as many households in urban areas have these facilities than households in rural areas (Table 2.5).

An equally important indicator of health outcomes is access to a safe water supply. This survey focused on the availability of government-supplied piped water as a safe source of water. Although not necessarily safe, piped water does offer more protection than other sources of water in Pakistan, such as open ponds, rivers, and unprotected wells. Overall, only 18 percent of households report access to a government piped water supply. Although provincial variations are negligible, there are huge differences between urban and rural areas. Half of all urban households across the provinces report piped water availability at home. In contrast, only seven percent of rural households report such services. Rural NWFP has the highest percentage of households reporting government supplied piped water to the house (20 percent), while in other provinces, less than 10 percent have this facility (Table 2.5).

Only 21 percent of households were found to have a concrete rather than a mud roof, a strong indicator of income and living conditions in Pakistan. There are important differences by residence in terms of roofing, which further suggest better living conditions in urban areas than rural areas. Fifty-one percent of households report concrete roofs in urban areas, while only 10 percent report the same in rural areas (Table 2.5).

Access to major utilities also shapes living conditions within a household; the presence of electricity and piped natural gas significantly reduces the time that household members must spend collecting other sources of energy, such as firewood. Furthermore, these utilities may replace sources of energy that lower the air quality within households. The data indicate that most households in urban areas have electricity, as well as rural households in Punjab and NWFP. Natural gas is not as common as electricity, but is still found in 63 percent of urban households. However, it is rarely found in rural areas where families rely mainly on wood and dung for cooking (Table 2.6).

Table 2.7 provides information on the ownership of a home and major household items. Home ownership appears to be very common: the survey found 86 percent of households owned their dwelling. Unlike the other indicators mentioned above, 
differences by locality and province are minor, although home ownership is slightly higher for those who live in Punjab. It is worth noting that construction costs and the price of real estate are lower in rural areas of Pakistan than in urban areas and that more accommodation in urban areas is rented or government owned.

Motor vehicle ownership appears to be very low in Pakistan, with only five percent of households owning a car or a van. Ownership was highest in urban Sindh (14 percent) and lowest in rural Punjab (2 percent). In the absence of widespread private vehicle ownership, access to public transportation may improve the potential mobility of community residents. As discussed in the community chapter, over four-fifths of communities in all four provinces have access to at least one mode of transport.

This survey also looked at the ownership of other consumer items, such as television and radio (Table 2.7). Not only are these items indicators of income, but, more importantly, they represent young people's access to information and general knowledge relating to their immediate circumstances and the wider world. An accurate assessment of young people's access to media is very important for policymakers and program planners interested in reaching young people with information or education. Home ownership of a television is quite high in Pakistan at 35 percent. TV home ownership differs significantly by urban and rural residence, but ownership levels are quite similar across the provinces. Almost two-thirds of households in urban areas have a television, whereas only a quarter of rural households report the same. Radio, which is more affordable than television, appears to be less popular. Only 27 percent of households own a radio. Unlike other household utilities, there are only minor variations by residence. It is important to point out that home ownership of a television or radio is likely to underestimate young people's access to the media because it does not capture joint listening in public places, such as teahouses or with neighbors. Policymakers and programmers aiming to reach young people through the media are advised to take joint listening into consideration and to view these channels of media as having the potential to reach significant numbers of young people in Pakistan.

Computers are a fairly new phenomenon in Pakistan and private ownership has only just begun. Just three percent of households own computers. However, quite apart from home ownership of computers, there has been a rise in commercial "internet cafes," especially in urban areas; these facilities are found in a third of the communities sampled. ${ }^{5}$ Therefore, it can be assumed that access to computers and the internet is in

${ }^{5}$ Internet cafe is a place that has a computer and internet usage facility and operates on a commercial basis. 
fact wider for young people (particularly males) than ownership reflects. Nevertheless, the internet, which relies on an educated audience, may not be an appropriate or costeffective channel for reaching young people across all income groups.

The assets and amenities described above are included in the 29 items used to construct an index of the relative wealth status of each household. The households were ranked and then divided into four equal socioeconomic quartiles. Young people within the household were then assigned the SES of his or her household (see Appendix II for further details).

\section{MOBILITY AND MIGRATION}

\section{Mobility}

Contrary to expectations, this survey found that cultural restrictions on mobility are not limited to females alone; young males also face controls on their movements in Pakistan. The majority of the young females and more than half of all young males say they need permission to visit any of the places mentioned in the survey questionnaire (Figure 2.4). ${ }^{6}$ However, while most young males say they need permission from parents, the data also indicate they could visit these places alone (Figure 2.5). This is not the case for females, who not only have to gain permission from parents or an adult, but also have to be accompanied for such visits outside the home. Going to visit neighbors emerged as the only outing that more than half of the females could take unaccompanied. For all other places, including school, shops, friends, and relatives, less than 40 percent of females could visit alone. Overall, young females say they are most restricted in visits to other nearby communities or going to a nearby health centre alone. Age appears to be an important determinant of mobility. As age increases, the restrictions on the free movement of both males and females gradually decrease. In the older cohort, both males and females are less likely to need to ask for permission to visit most locations (Table 2.8). Furthermore, more female youth than female adolescents are allowed to visit these locations alone; differences for males are less significant since most young males are already allowed to visit these places alone.

${ }^{6}$ Including: neighbor, shop, school, sporting grounds, friend's place, relative's house, fields inside/outside the village, nearby community, and nearby health outlet. Note: in urban areas the "fields" category was omitted. 
Figure 2.4 Percent who need permission to visit various places alone by sex, all young people

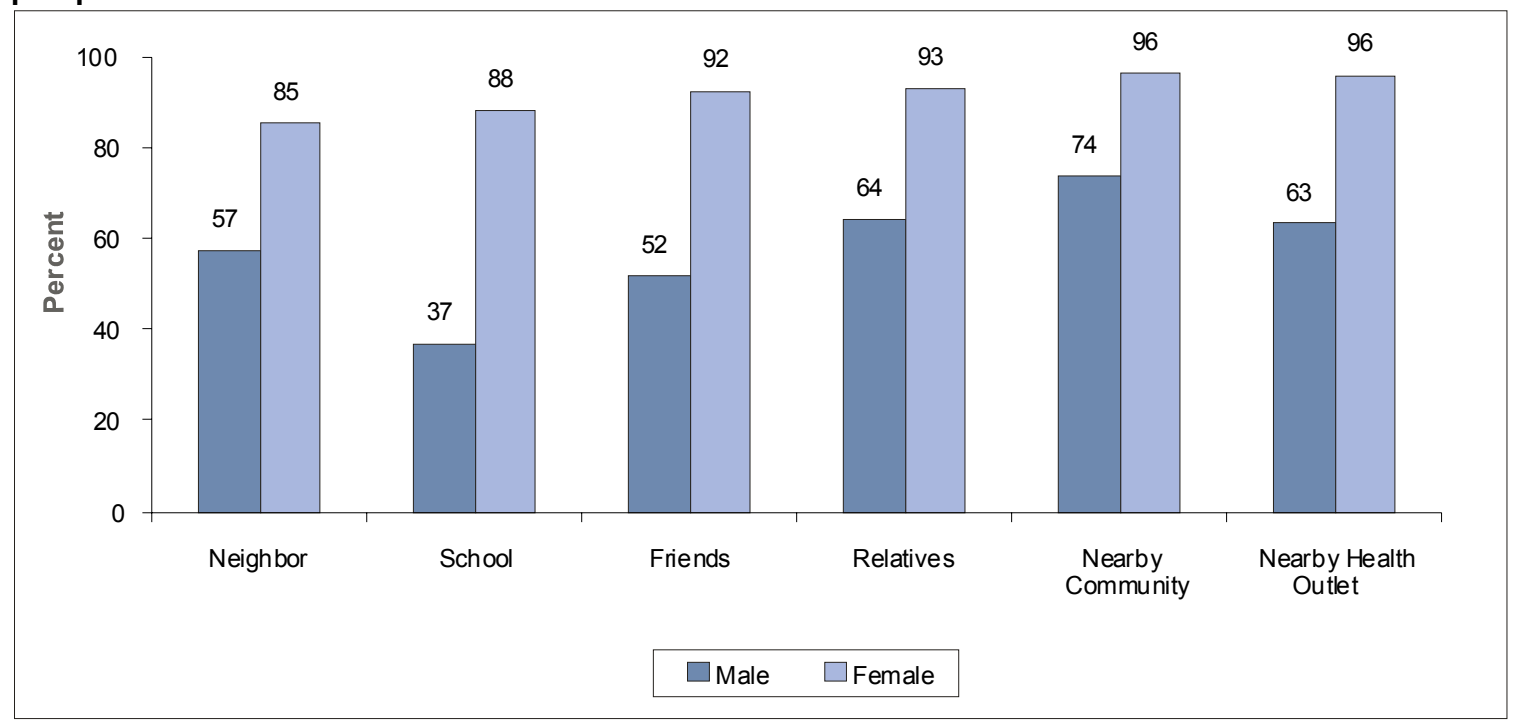

Figure 2.5 Percent who can go to various places alone by sex, all young people

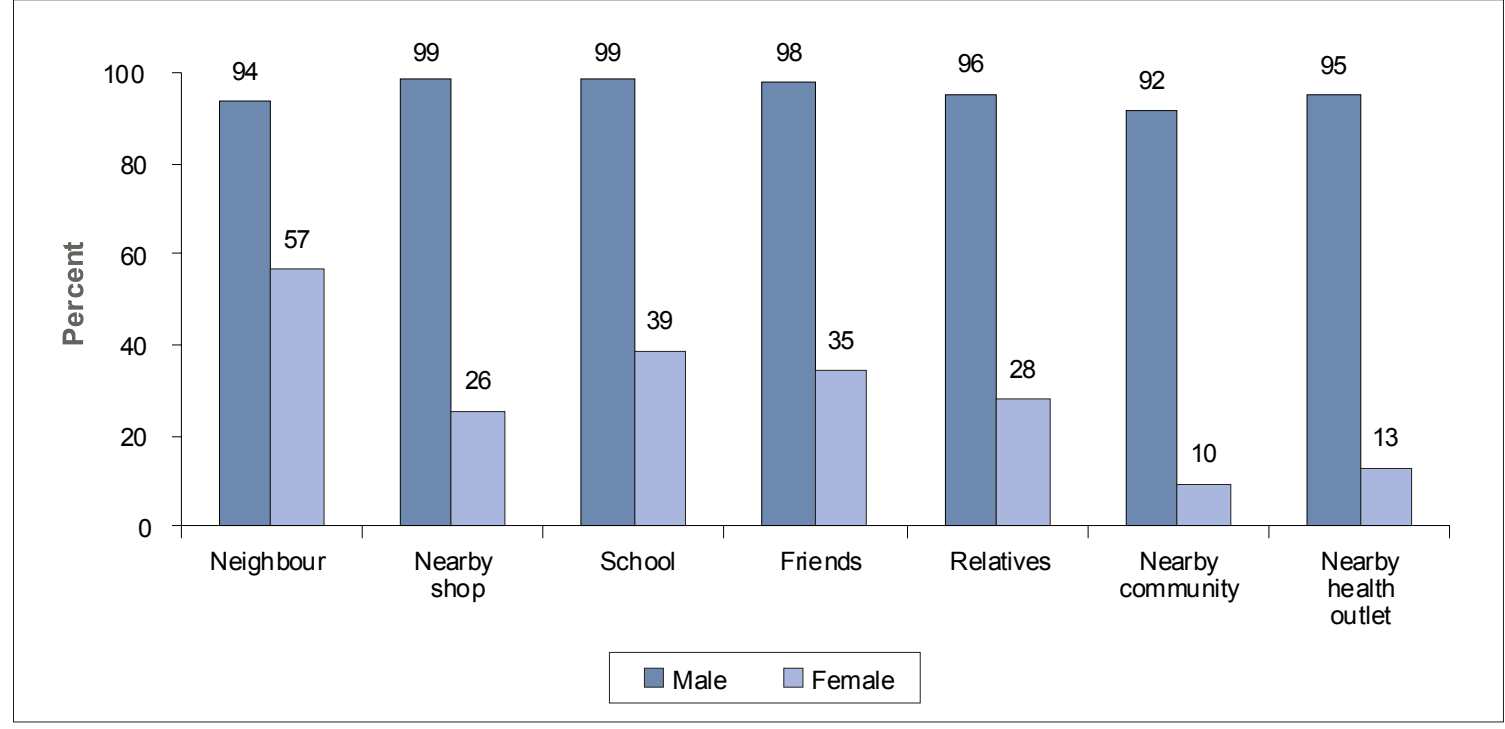

\section{Unsafe places ${ }^{7}$}

There are various places in any culture that are deemed "unsafe" and where young people are discouraged or forbidden to visit. This survey asked young people and responsible adults whether there are such places in their communities that are

7 Places where young people are not allowed to go at all and are considered harmful for young people, by themselves or their adults, are referred to in this chapter as unsafe places. 
considered inappropriate for young people aged 15 years. Nature of such places, as well as the reason the respondent considers them inappropriate was also asked. ${ }^{8}$

Analysis shows that urban areas have comparatively more unsafe places than rural areas for both males and females (Figure 2.6). Among rural respondents, a quarter of young persons mention the presence of such places in their area both for males and females. However, their adults seem more concerned for young females (33 percent) than young males (21 percent). Among urban males about one-half mention the presence of such places in their communities in contrast to only one-third of their female counterparts. It is important to recall the fact that females in general are restricted in mobility and exposure and their responses are shaped and influenced by their experience of reality. Adult household respondents (possibly due to their greater exposure) not only list more unsafe places for females than for males, but also report more places to be unsafe for females than do young people themselves. Thus parents and other household respondents are, in general, more protective of young females than young males and perceive a higher relative risk for the former than do young people.

Figure 2.6 Percent reporting presence of "unsafe" places for young people in their community by sex, of all household survey respondents and young people

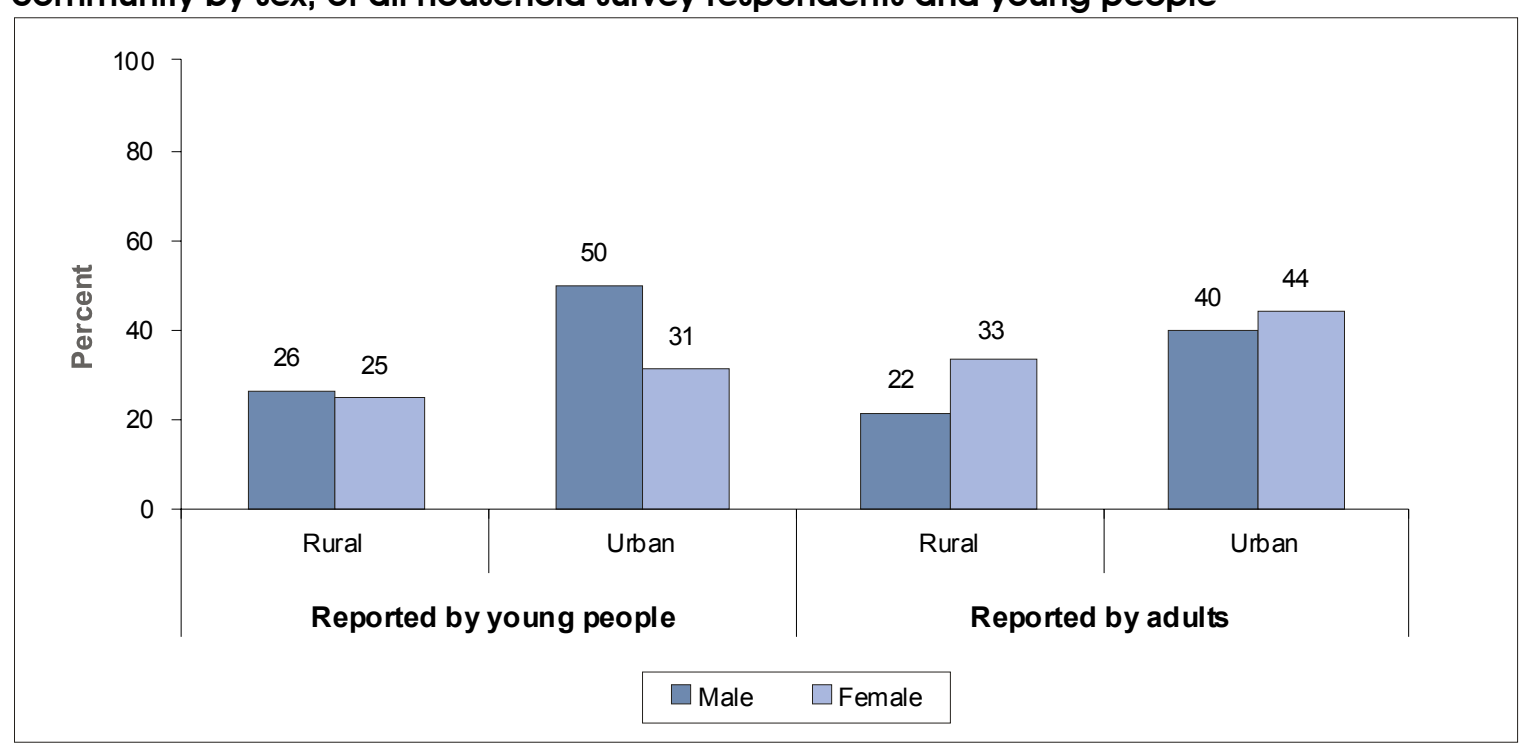

Parents, responsible adults, and young people also elaborated on the nature of such unsafe places and the reasons why young people should not venture there (Table

8 Responsible adults were asked to respond to these questions in relation to 15 -year-old unmarried males and females. 
2.9, Table 2.10, and Table 2.11). Among places that young people and their responsible adults report as inappropriate are hotels, restaurants, cinemas, video game shops, and remote isolated areas. There are notable differences in type and location of such places by residence. Eighteen percent of rural adults, when speaking about males, say they consider cinemas unsafe, 14 percent say markets and shops, and the same number say hotels or restaurants. A further 10 percent say videogame shops and nine percent cite snooker clubs and graveyards as being unsafe for males (Table 2.9). When speaking about females, one-third of the rural adults say that markets and shops are not safe, and less than one-tenth say snooker clubs, hotels and restaurants are inappropriate. In urban areas the picture is different. Videogame shops emerge as adults' greatest concern for young males followed by cinema and snooker clubs, whereas for females, 46 percent of adults were concerned about markets and shops. Less than one-fifth mention cinemas and snooker clubs.

Responses from young people (Table 2.10) are very similar to those of adults. In rural areas, 19 percent of young males said cinemas are unsafe and a slightly lower percentage said hotels and restaurants and other villages or mohallahs (neighborhood). Many rural young females cite markets and shops as unsafe (36 percent). In urban areas, 41 percent of young males mention the cinema and video game shops as unsafe, while 42 percent of females said shops or markets were unsafe. Finally, it is important to keep in mind that these urban and rural and gender differences in unsafe places may also indicate differential access to such places. For example, females do not normally go frequently to snooker clubs and video game shops in Pakistan.

Young people and responsible adults cite a variety of different reasons for restrictions to certain places considered unsafe (Table 2.11). For rural males, around a quarter of respondents cite the prospect of falling into physical harm, bad company, drug addiction, and immoral activities as reasons. In contrast, for young rural females there is greater concern about damage to the family reputation, family tradition, or opposition by family, both as expressed by young females and their adults. Females and their adults also mention damage to reputation and "eve teasing" (i.e., sexual and physical harassment by men). In urban areas, around 40 percent of males cite immoral activities and bad company. A quarter also mentions drug addiction and damage to reputation. For urban young females reasons are similar to those given by their rural counterparts, but with more emphasis on "eve teasing" (about 50 percent). Around a quarter of young urban females mention family and personal reputation, whereas their adults seem to be more apprehensive in this regard and more than a third link this to damage to reputation. Family traditions or opposition emerged as another important reason for these restrictions. These responses highlight important gender and residential 
differences in the perceptions and practices among young people concerning the safety of their environment.

Clearly both adults and young people agree that some places are not safe for young people. However, views differ on which places are unsafe for males and females. Views also differ by location between rural and urban areas, but the most striking differences lie in the reasons for concern. Young male respondents and their adults link the concerns to the physical harm they might experience if they visited unsafe places; when young females respondents and their adults speak about unsafe places, they link their reasons not to the physical harm they could do to themselves, but to the harm they could do to their reputations, or more importantly, the family reputation and honor.

\section{Mobility beyond the community}

Despite restrictions on free movement and the concern expressed about visiting certain places alone, the survey shows considerable mobility among young people in Pakistan. It is important therefore to consider mobility and whether it is likely to enhance young people's prospects in gaining positive exposure outside their own community of residence. Figure 2.7 highlights those young people who have ever visited a place outside their community by residence. ${ }^{9}$ While there are no major differences between the two age cohorts, there are differences between males and females and between rural and urban residents. In both rural and urban areas young males are more likely to make a visit outside their community than females. In rural areas this difference is greater than in urban areas. Young rural males are also more likely to have made a visit outside their community than their urban counterparts (72 percent and 65 percent, respectively). For females there is almost no difference.

\footnotetext{
${ }^{9}$ Young people residing in rural areas were asked if they have ever been to a city. Urban young people were asked if they have ever been to another city. They were also asked about visiting another district, province, or country.
} 
Figure 2.7 Percent reporting having ever visited other city or district, of all young people

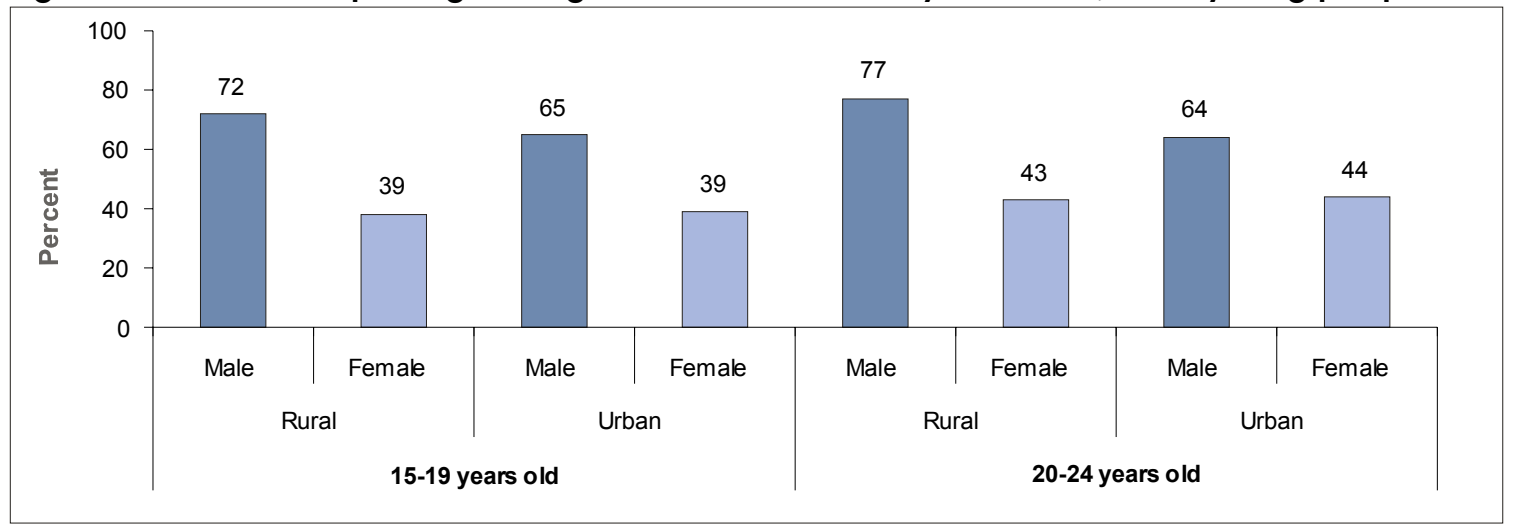

The survey found that reasons for leaving the community to make such visits within a period of six months varied between young men and women (Table 2.12). Most young females say they left to visit relatives, to attend marriages or funerals, or for medical care. Visiting relatives was the primary reason for both married and unmarried females, while reasons for males depended on marital status. For unmarried males, the most common reason was to visit relatives; for married males, the reason was for work.

Figure 2.8 Percent who have ever migrated in their life, all young people

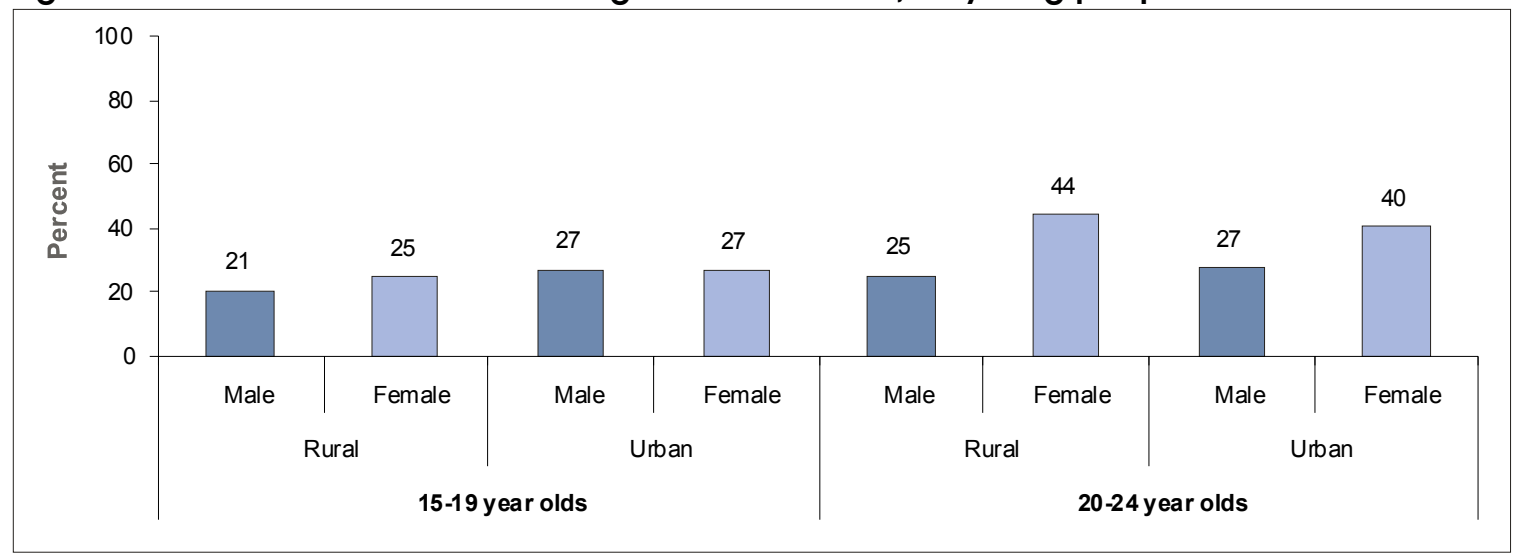

\section{Migration}

A closer look at migration data show that at least a quarter of young people in Pakistan have ever migrated (Table 2.13). ${ }^{10}$ Females are more likely than males to have ever migrated in most categories. Furthermore, migration appears to be affected by socioeconomic status and level of educational attainment, although this is not as true of

${ }^{10}$ Leaving one's place of residence to shift to another community for any reason (other than recreation or vacation) is considered migration in this survey. 
the younger cohort. Older females residing in rural areas are also more likely to have ever migrated than their urban counterparts, while slightly more young men in urban areas than in rural areas have ever migrated (Figure 2.8). Young men from the lowest socioeconomic group are also slightly more likely to have ever migrated. Analysis of the reasons given for such movement clarify the gender differences observed above (Figure 2.9). While this measure of migration includes both young people who moved on their own or with their family, the largest proportion of females who have ever migrated left their natal homes to marry (nearly 60 percent). As discussed earlier, males usually do not leave their natal home for marriage, but migrate for different reasons, such as employment (32 percent) or to join family members (27 percent). The proportion of males migrating for schooling is also higher than it is for females (nine percent and three percent, respectively).

Figure 2.9 Reasons for migration, by sex of those who migrated

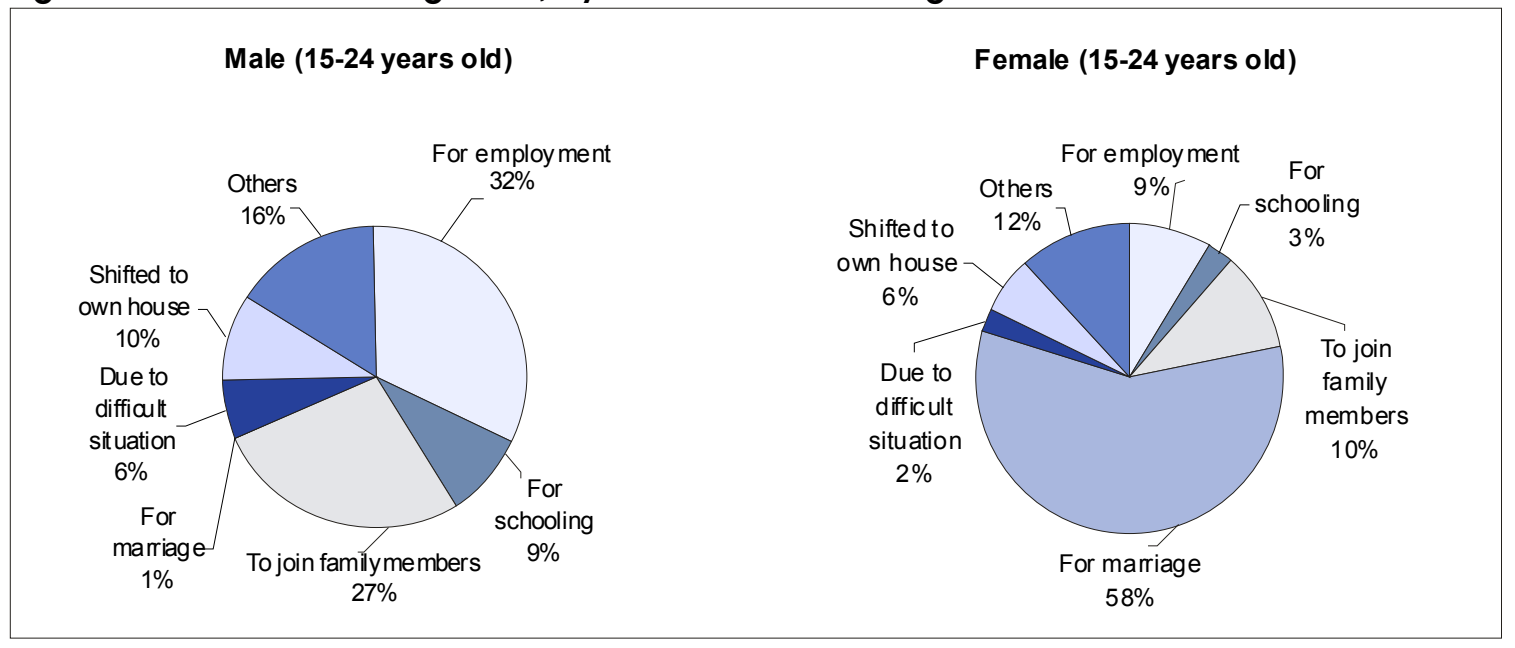

\section{TIME USE AND RECREATION}

\section{Time use}

One of the unique features of this inquiry is the collection and compilation of time-use data documenting the hours spent by young people on various activities in what they considered a "usual day." These data were collected for both age cohorts and provide insight into the daily routines of adolescents and youth. While the questionnaire gathered information on 20 different activities measured from 6 a.m. to 12 a.m. (19 
hours), this analysis is shown in seven composite categories developed by merging the activities. ${ }^{11}$

There are dramatic differences in the way young people spend their time in Pakistan, particularly between males and females. When the time spent on personal care is excluded, it is clear that young females spend most of their time on household chores, while males tend to be working (Figure 2.10). There is a notable increase in the burden of household chores for females between the two age cohorts. There is also an increase in the work responsibilities for males between the two age cohorts but it does not match the levels of domestic responsibilities for females in the higher age cohort.

Figure 2.10 Proportion of time young people spent on various activities, by nature of activity, sex and age

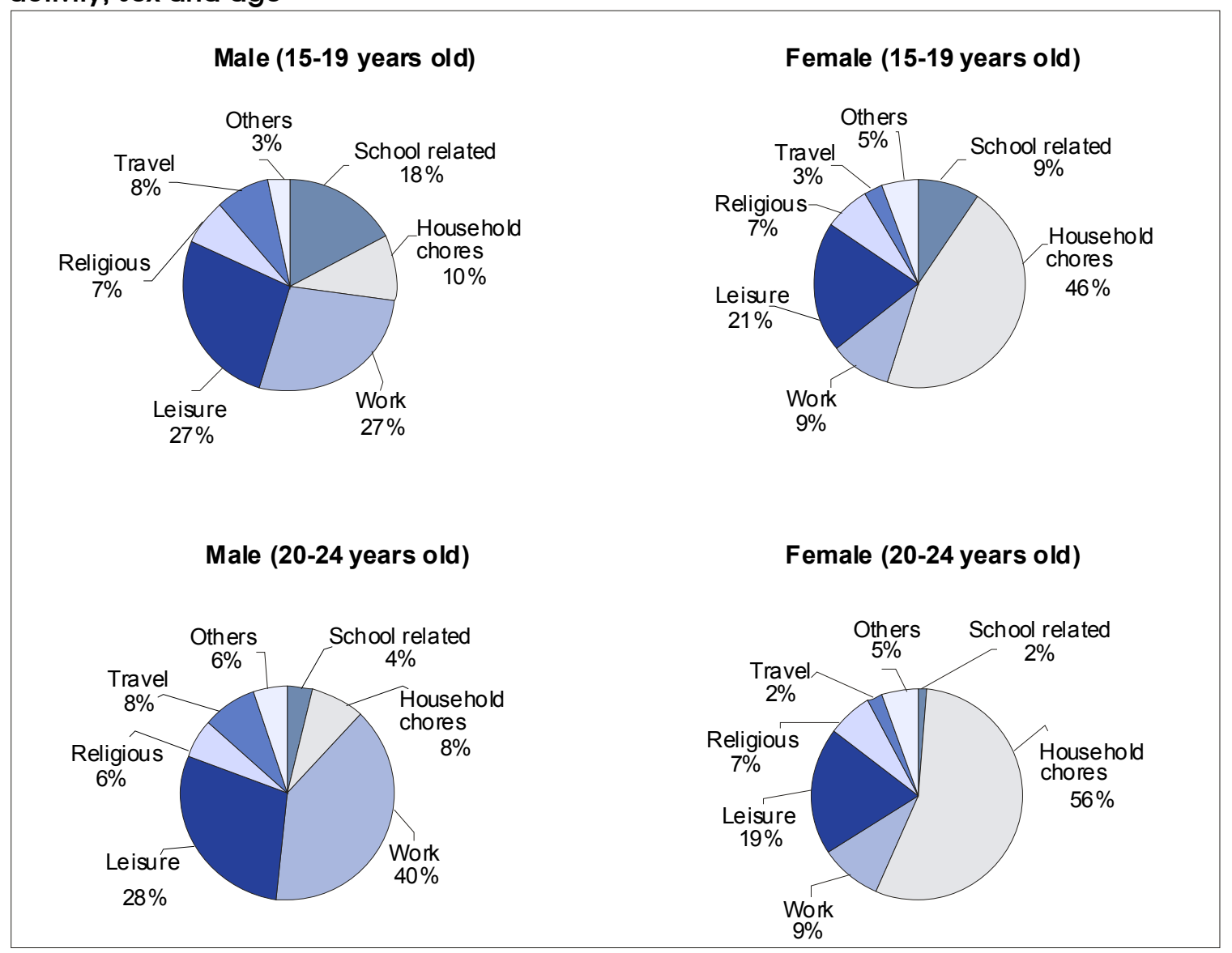

11 The seven categories considered here include: 1) school-related activities--time in school, homework/tuition/studies; 2) household chores--chores inside house, chores outside house, care of children, sick and elderly; 3) work (paid/unpaid) and learning a skill; 4) leisure--rest, visiting friends/relatives, watching $\mathrm{TV} /$ movies, reading/listening to music, games/sports; 5) religious activities; 6) travel; and 7) other activities. 
Table 2.14 shows how young people use their time by activity. As expected, there are considerable differences related to status. Young men working for pay spend almost seven hours a day working, while those in school spend a little less than seven hours on schoolwork. However, young women who are working for pay spend less time working than their male counterparts, but they spend more time working if household chores are considered. The females in school spend a little more time than males in school-related activities. Gender differences in time use are small among those still enrolled in school.

Young married males spend a major portion of their time working for wages whereas young married females spend more time on household chores (almost 8 hours). This reflects the traditional gender division of labor in Pakistan where home maintenance and motherhood are primarily the responsibility of females, while working for wages is considered the duty of males. While male labor is almost exclusively remunerated in cash and kind, female labor on home maintenance is of course unpaid.

The survey shows that young males spend very little time working on household chores and instead spend considerable time on leisure activities. In contrast, young females shoulder the burden of domestic chores and have less time for leisure. Thus young people are socialized into quite different gender roles from an early stage in life. Young females are directed toward domestic duties, even when they are working, while young males, whether they are involved in any profitable activity or not, have very few domestic responsibilities.

\section{Recreation}

Recreation is an important dimension in young people's lives and has the potential to provide inspiration and intellectual and physical stimulation. Therefore, the survey asked young people what activities they did in their free time (Table 2.15). Again, the picture for males and females is very different. Outdoor games and sports emerge as the favorite recreational activity for young males in both rural and urban areas. A significant proportion of rural males also mention visiting friends (28 percent), watching television (15 percent), roaming around (15 percent), and listening to music (14 percent). In contrast, females in both rural and urban areas hardly report any leisure activities. Thirty percent of rural females report doing nothing. Of those who do mention an activity, they tended to cite one undertaken in the home: watching television, knitting, and embroidery.

Young people were also asked about the number of times they visited a friend for more than an hour in the week prior to the survey. The mean number of such visits is 
presented in Figure 2.11. On average young males report seeing their friends three times more than females. The average number of visits for males is highest for those who are not working (4.0) and lowest (2.9) for those who were ever married. For females however, visiting friends is almost nonexistent, with less than one such visit per week for all categories. This suggests that young females of any status are relatively isolated compared to males and have few social networks to draw upon for inspiration and support.

Figure 2.11 Mean number of times respondent visited a friend for more than one hour, in the past week, of all young people

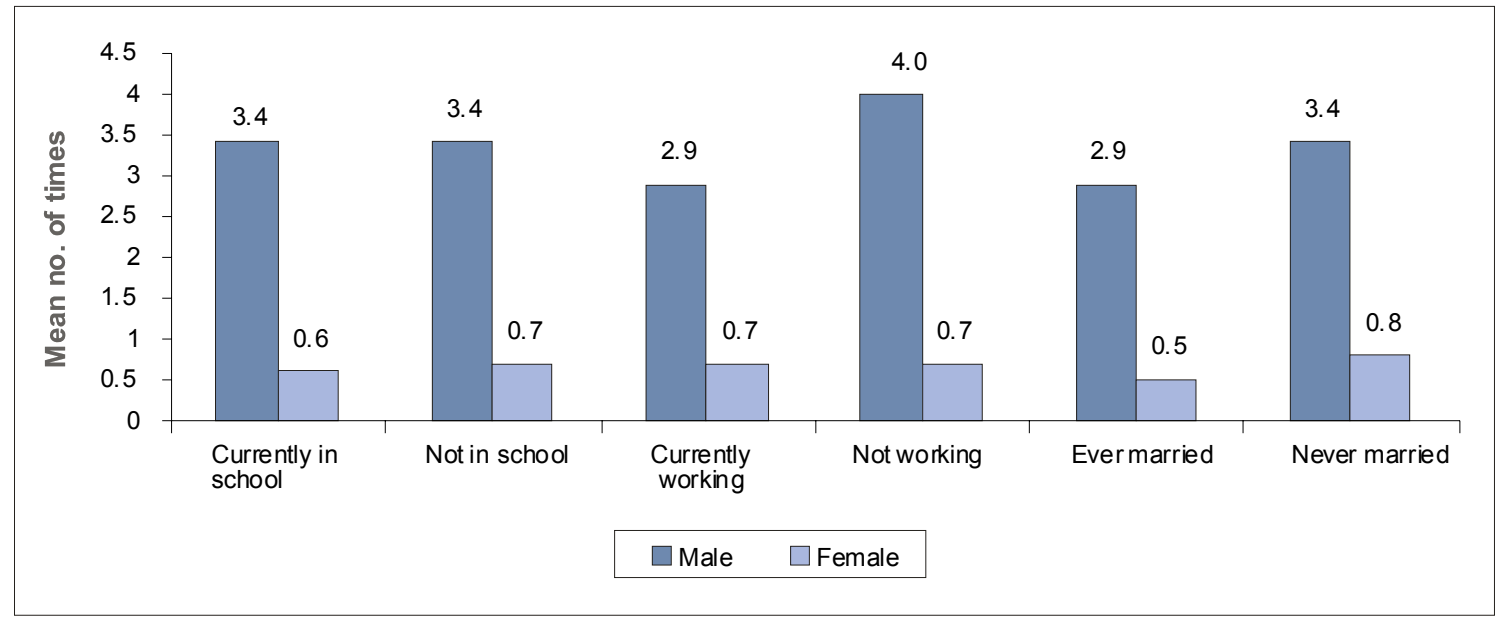

\section{COMMUNICATION AND SOCIAL NETWORKS}

In the socio-cultural context of Pakistan where universal access to a range of facilities such as schooling, health facilities, formal work, and structured channels of information has not yet materialized, young people often rely on other household members, particularly parents, to discuss any issues pertaining to their lives.

This survey tried to capture the behavioral patterns of young people as well as their sources of information on issues relating to health, employment, education, and marital matters. Results show nearly all respondents will discuss such issues with at least one person (Table 2.16). Young males often choose to talk to their fathers, single females choose their mothers, and married females choose their spouse.

If a sensitive health problem arose, 42 percent of adolescent married males say they would approach a doctor, 38 percent mention their father, and 22 percent choose their brother. In contrast, 46 percent of married adolescent females say they would approach their spouse, another 40 percent say a female relative, and 27 percent choose 
their mothers. Few differences were observed between the two age cohorts except that married female youth tend to confide more in their spouses than their mothers and sisters, compared to adolescent females.

For issues relating to education and work, fathers are the most common choice for the majority of males regardless of their marital status, but a considerable proportion of males also mention their mothers. Fewer males mention their brothers or a friend as a source of information (19 percent and nine percent, respectively). In contrast, unmarried females say they would talk to their parents or brothers about work related issues whereas married females opt for their spouse.

On issues relating to engagement and marriage, most young people say they would talk to their parents. ${ }^{12}$ In this case, young males report talking to both fathers and mothers. Unmarried young males are more likely to talk to their mothers than their fathers. Among young females, mothers are the primary source of discussions, followed by sisters. It is important to note that a significant proportion of young females in both age cohorts say they would not discuss these issues with anyone and this is particularly true of married females (21-27 percent). The asymmetry in decisionmaking between young married males and young married females on all issues indicates a greater degree of trust and reliance among females on the views of their spouses than the other way around.

\section{AGENCY IN DECISIONMAKING AND GENDER ROLES}

\section{Decisionmaking}

The survey asked adult household respondents what authority young people might have in decisionmaking on issues relating to their own lives, specifically education, work, and marriage (Table 2.17). The majority of adults interviewed believe parents or the family as a whole should make such decisions rather than the individual concerned.

On the issue of education, only 15 percent of adults think that young males should participate in decisions on their schooling. But for decisions regarding the selection of a spouse, even fewer adults expect young males to participate in such decisions. Ten percent of the adults believe that females can participate in decisions about work, while seven percent think females can participate in decisions regarding

12 If the respondent was married, the question was asked in retrospect: whom would they have approached to discuss any issue pertaining to their engagement or marriage. 
education and six percent on the selection of a spouse. Almost all adults feel female mobility is a parental issue and not for young women to decide at all. ${ }^{13}$

Parents and adults were also asked if young people had the right to enter into or participate in decisions about work, education, and marriage. Interestingly, in contrast to the findings above, a large proportion of adults respond in the affirmative: young people have rights to enter into decisions that affect their lives (Table 2.18). Almost all adults interviewed believe young males have the right to participate on issues relating to work and education, and slightly fewer say they also have the right to make general decisions about life (88, 87, and 72 percent, respectively). In addition, about half think they should have the right to participate in the selection of a spouse. Although 51 percent of adults say females should have the right to decide about work, 60 percent think they have a right regarding schooling. However, adults hold less progressive attitudes on the issue of marital choice. Only 17 percent believe young females have the right to participate in decisions regarding the choice of a husband. There is, therefore, a disconnect between the decisionmaking ability accorded to young people by parents and their perceptions regarding the scope of young people's rights. While the majority of adults demonstrate a lack of trust in their children's ability to make decisions on important issues, more parents are prepared to acknowledge their children's rights in such matters. For young females, however, adults display even less belief in their ability to take decisions than young males and they are also less inclined to accord them the same rights as males.

\section{Gender roles and responsibilities}

The survey explored a range of issues relating to gender norms and attitudes with young males and females from both age cohorts. The responses provide useful insights into how gender roles and responsibilities are constructed and perpetuated.

The data show that most young people consider domestic duties, such as cleaning, washing, and cooking, to be exclusively female responsibilities (Figure 2.12). Indeed, a large proportion of young people say adult women (90 percent) and girls (75 percent) should be responsible for these activities. Other tasks which take place outside of the household are strongly associated with males, young and old. Almost all young people feel adult males should be responsible for earning money for the family and taking sick children to the doctor and almost three-quarters believe they should also buy household goods.

13 The question of mobility was with reference to 15 year old males and females. 
Figure 2.12 Percent distribution of persons who young people think should be responsible for various household chores, of all young people

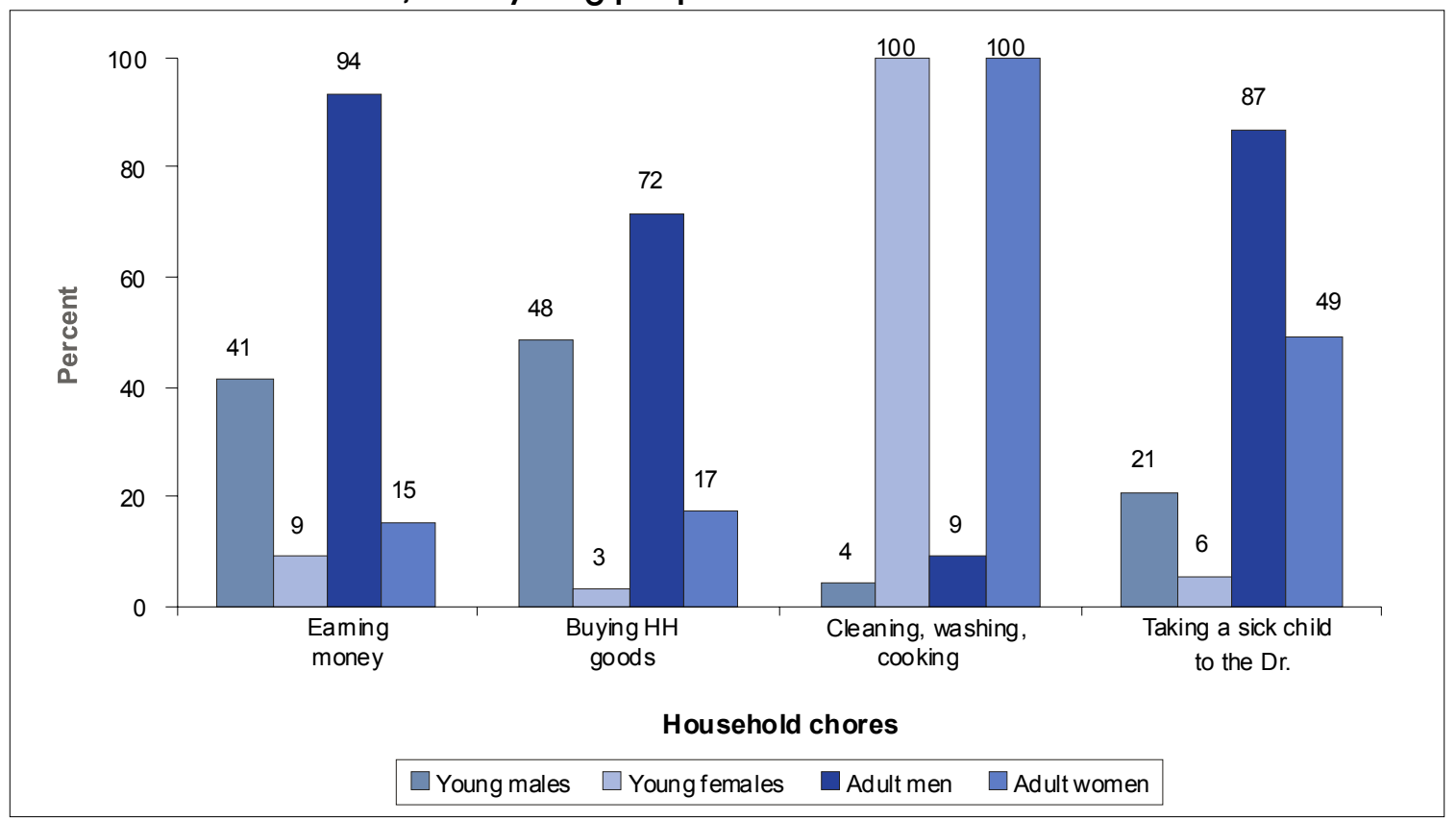

Note: Multiple responses possible.

Figure 2.13 Percent distribution of those whom young people think should make various household decisions, of all young people

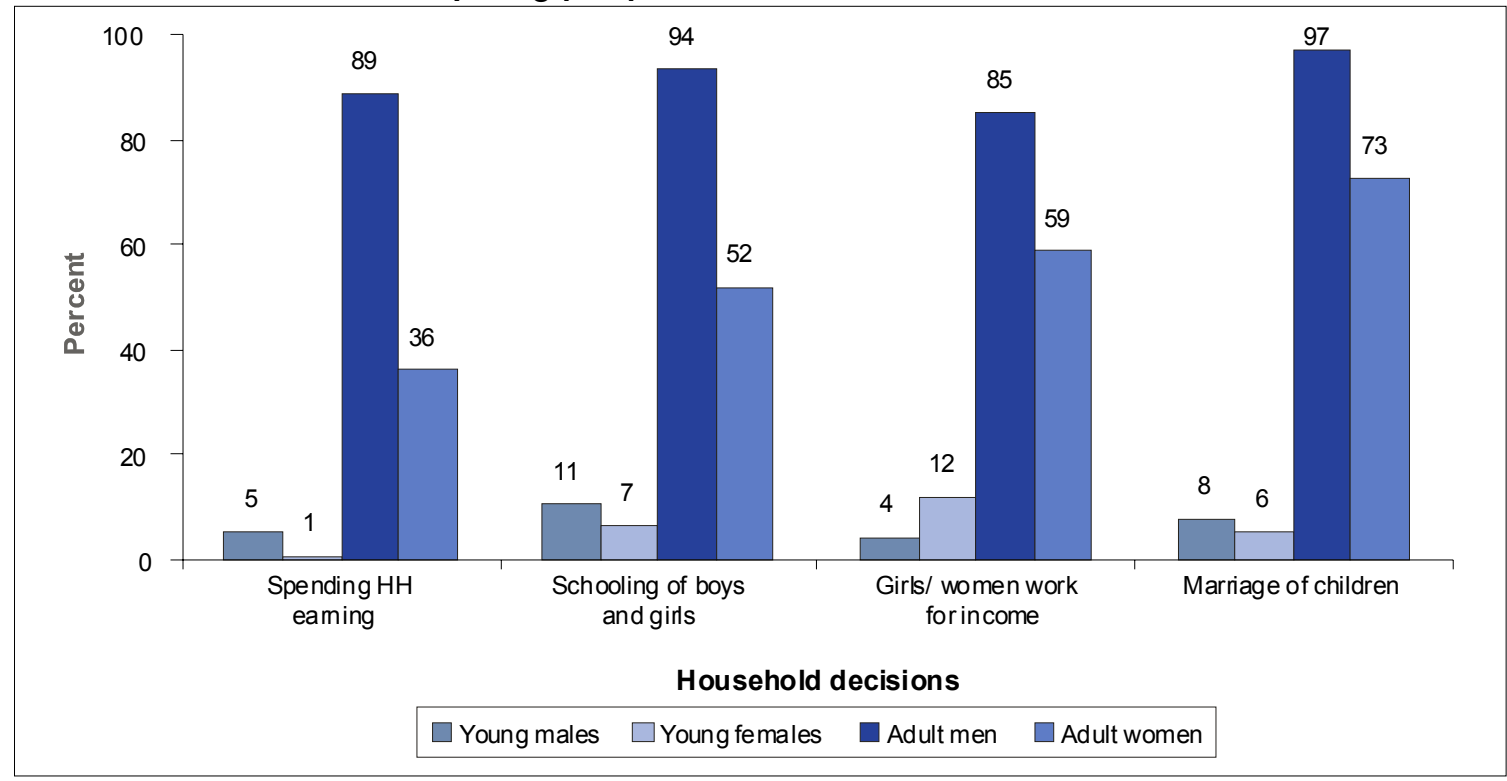

Note: Multiple responses possible.

Figure 2.13 shows how young people perceive decisionmaking roles within the family. An overwhelming majority of males and females in both age groups hold the 
view that adult males should make decisions about spending household income, schooling, marriage of children, and income generating activities of females in the family. Though not equal, a significant majority also recognize the role of adult females in these decisions. For example, in terms of decisions relating to marriage of children, three-quarters of young people think a woman should be involved, but when it comes to spending household income only a third support the idea. For decisions on schooling or "female work," half of the young people think women should play a role, and a third believe women should be involved in decisions regarding the spending of household income.

\section{CONCLUSION}

This chapter has highlighted the social asymmetry between the experiences of young women and young men growing up in Pakistan. While young females of all socioeconomic status are restricted to a life that largely centers on home and chores, young males have much greater exposure to the outside world. Younger males are quite likely to spend all their lives in their natal homes whereas many females leave for marriage shortly after puberty to join another household. This pattern leaves young females more likely to rely on their spouses and parents as sources of information and advice. Young males, on the other hand, rely on their parents as an important point of reference, but their networks are much wider and are more likely to include relatives and friends. This factor has important implications for how policies and programs reach young people in terms of messages and programs and who may be important to co-opt as partners in the process.

Mobility is severely constrained for females, but it is not entirely unconstrained for males either. There are important gender dimensions in the execution of constraint on young people. Once young males gain permission from parents they are able to move outside the home unaccompanied, whereas females need to be accompanied almost anywhere outside the home, apart from the neighbors. This has direct implications for the attainment of education, access to health facilities, opportunities for work, and recreation and social networks for young females. The manifestation of these gendered restrictions will be seen in subsequent chapters. Indeed as evidence from this survey shows, social restrictions implemented by the family on females clearly affect access to differentials in resources and services (physical, social, and psychological) between young men and women.

Those places considered unsafe by parents differ for young females and males, as do the reasons justifying restrictions on mobility. In the case of males, parents fear is 
related to their personal safety (i.e., whether they might have an accident that results in physical harm). However, for females there appears to be more at stake than personal physical safety and concerns tend to center on family honor and reputation.

The other dramatic difference in the lives of young people is in how they spend their time. For adolescent males, school, waged work, and recreation are likely to take up most of the day, while females are most likely to be involved in household chores with less time for going to school and little potential for recreation. Clearly, young females in Pakistan lack the opportunities of schooling, work, and recreation afforded to males. While males in urban and rural areas across all four socioeconomic groups have uneven opportunities as well, it is the gender differences that are most striking. In terms of broad programs for young people, priority must be given to all young females and males from poorer homes and underserved areas.

Agency in decisionmaking varies between males and females and by the topic under discussion. Overall young persons in Pakistan have limited agency to shape important decisions affecting their lives. Females are particularly restricted in this regard and especially so in the case of marriage decisions. While parents may report deferring some authority to young persons, there is a notable gap between their perceptions and reality. Given this gap, there may be an opportunity for communication campaigns that endorse basic rights for young people and reinforce the critical role played by adults in enabling young people to exercise these rights.

Social values and norms regarding responsibilities of males and females are divided along gender lines for both adult and youth respondents in this survey. There is only very little evidence of digression from stereotyped divisions of responsibilities within the home for females. Rarely are equal domestic responsibilities ascribed to males. One approach to change is to present alternative role models via television and other forms of media networks that allow young women greater autonomy and scope for development.

Finally, there are some factors that directly affect the lives of young persons of both sexes. These include overcrowded households, lack of kitchen space, and adequate safe water and sanitation, which vary significantly by economic class and by residence. In some cases, lack of these facilities impacts on males and females differentially, as is the case with water and sanitation where younger females bear the burden and inconvenience of collection. In the case of home versus community access to telephones, television and internet, more young males with their expanded mobility are likely to benefit from community-level facilities than young females. 



\section{Education}

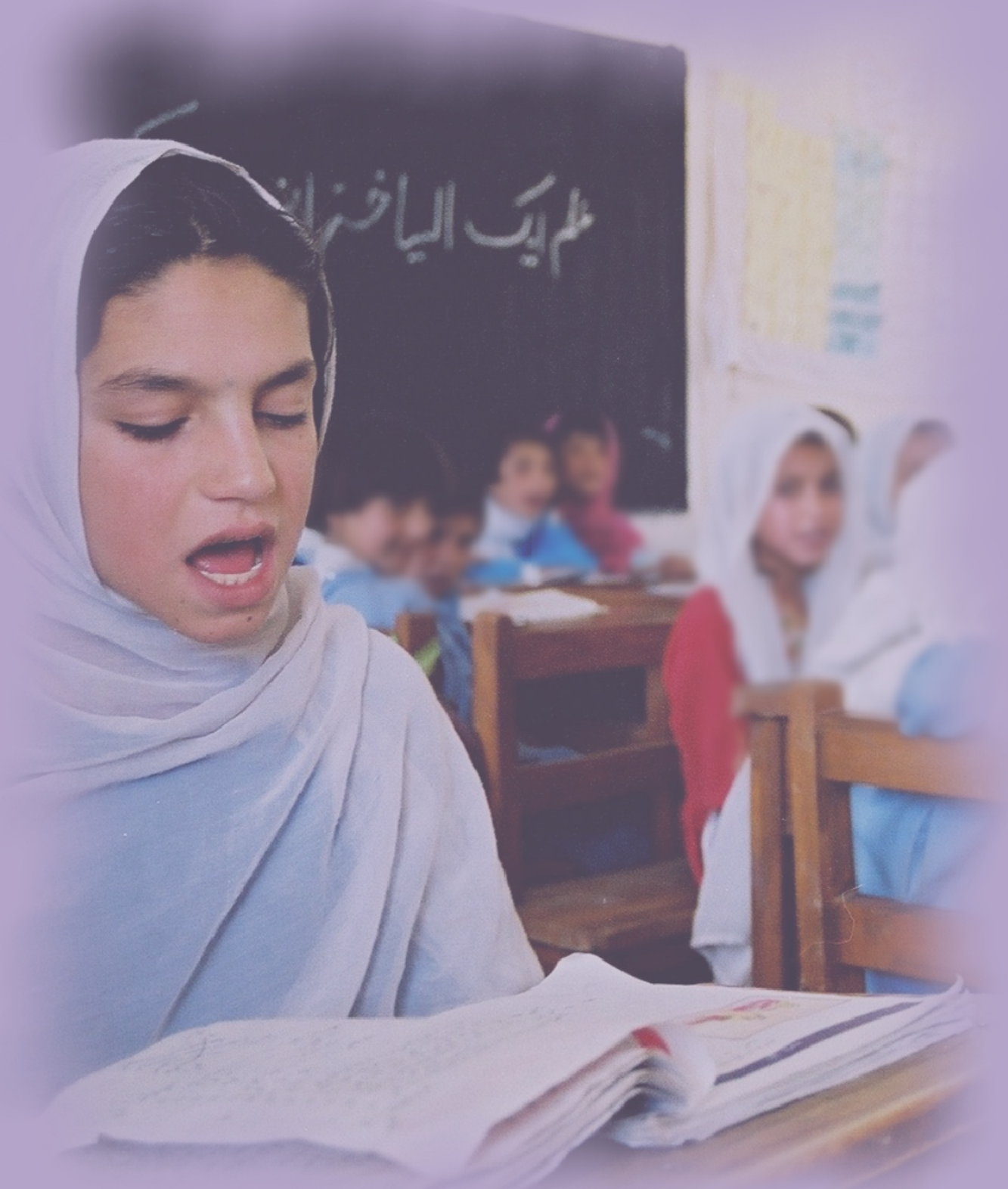

\section{In this chapter:}

- Introduction

- Ever Attendance in School

- Levels of School Attainment

- Dropping Out of School

- Aspirations for Education

- Conclusion

- References

- Conclusion 


\section{EDUCATION}

\section{INTRODUCTION}

The transition to school is probably the most important transition shaping the lives of young people. As this report will show, the very fact of having attended school or not is likely to have a major impact on all other transitions young people make in their lives, namely: beginning work, getting married, and bearing children. It will determine not only when young people, male and female, begin work, but also what type of work they do and how much they are paid. It also determines when they get married and how much control they have in family decisionmaking. Being able to read and write in today's modern world is probably the most important set of skills young people can learn. These skills not only affect the lives of young people themselves, but also that of their children. Furthermore, the education status among young people has and will have a major bearing on the development and future of Pakistan.

This chapter examines ever attendance in school among young people and highlights the stark differences by gender, residence, and socioeconomic status. It also explores: past trends in primary school enrollment; mean age of entry; primary, middle and, secondary school completion; and mean highest class completed. The chapter assesses the issue of dropping out, including the reasons young people give for dropping out and decisionmaking processes in the family on this issue. The chapter ends by revealing young people's aspirations for education in the light of what they actually achieve. The chapter opens with a broad comparison between this survey and the Pakistan Integrated Household Survey (PIHS).

It is possible to compare the enrollment estimates derived from our data with trends implied by the data from the PIHS surveys fielded four earlier years (1991, 1995/96, 1996/97, and 1998/99). Figures 3.1 and 3.2 compare trends implied by our data with trends implied by the PIHS. Figure 3.1 shows that the trends implied by PIHS and by AYP are consistent for young males. Basically, enrollment rates for males have stayed relatively flat since the mid-1990s with a slight rise to 85 percent. However, estimated levels of enrollment for females differ substantially between the 1996/97 PIHS and the AYP (Figure 3.2). The AYP shows much lower enrollment for females in 1996 (47 percent versus 54 percent, as estimated by PIHS) and depict a significant rise in 2001. In contrast, 
the PIHS data show stagnancy in the period 1996-98. The AYP data are based on interviews with young females directly interviewed by female interviewers and may be a closer reflection of actual trends. It is reasonable to conclude from these comparisons that prior surveys may have overestimated enrollment for females and enrollment rates probably have risen in the period from 1996 to 2001.

Figure 3.1 Trends in ever enrollment rates for males aged 15-19 (PIHS and AYP)

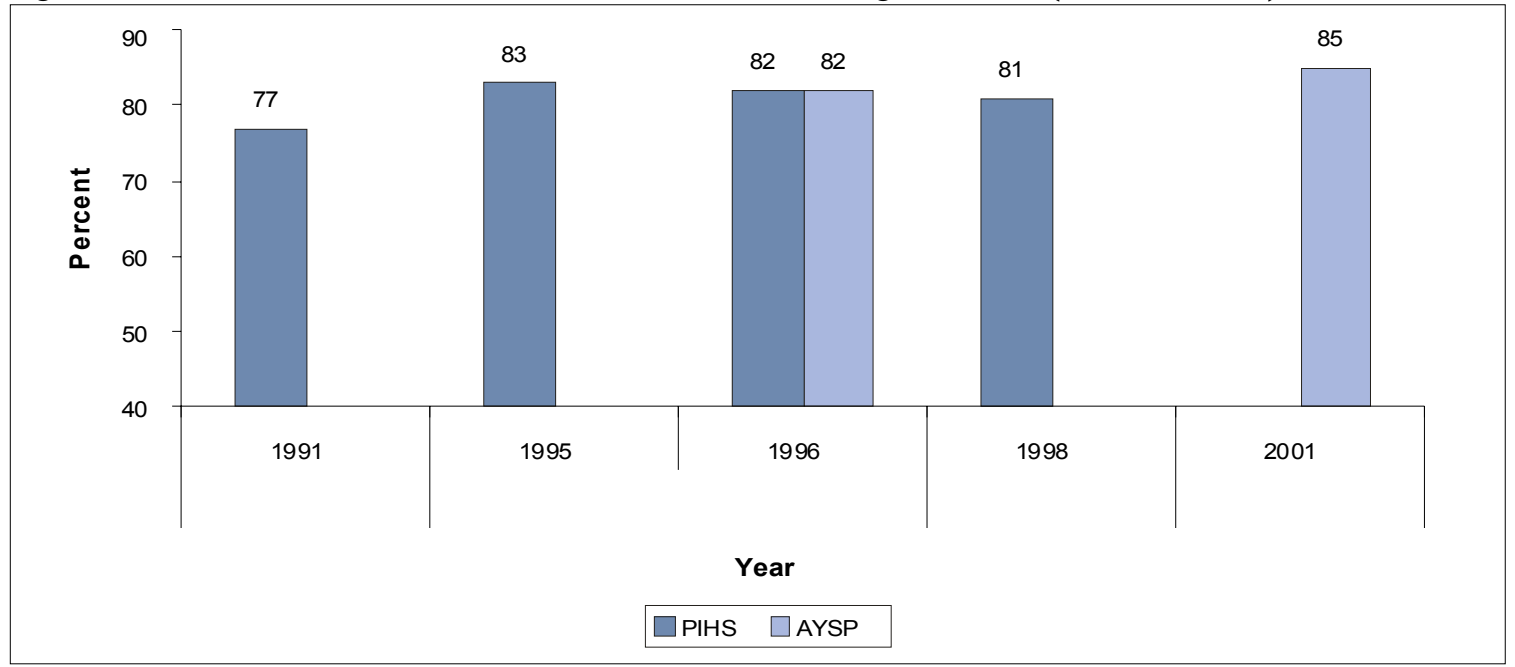

Sources: 1991 PIHS, 1995-96 PIHS, 1996-97 PIHS, 1998-99 PIHS, 2001-02 AYP (representing two cohorts).

Figure 3.2 Trends in ever enrollment rates for females aged 15-19 (PIHS and AYP)

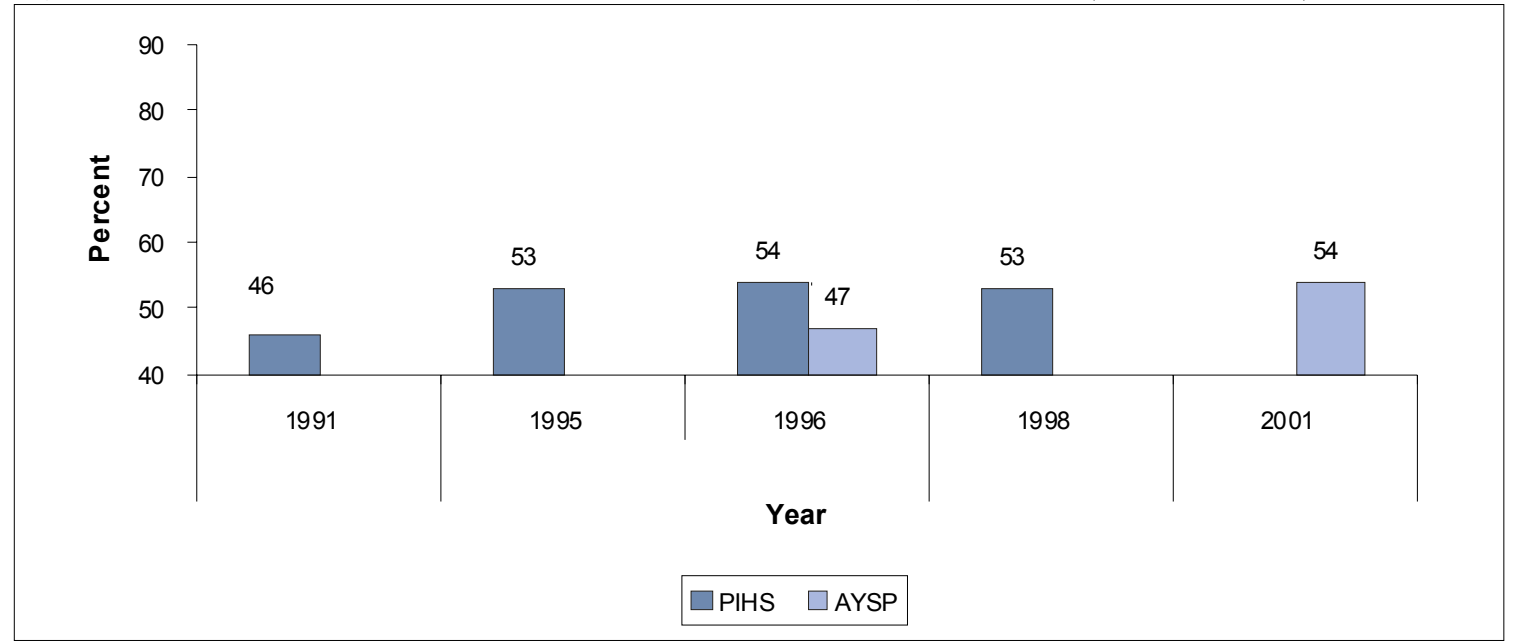

Sources: 1991 PIHS, 1995-96 PIHS, 1996-97 PIHS, 1998-99 PIHS, 2001-02 AYP (representing two cohorts) 


\section{EVER ATTENDANCE IN SCHOOL}

\section{Never attended and ever attended}

The survey asked the two age cohorts of adolescents and youth whether they had ever attended school. By implication their responses indicate whether they had at the very least attended primary school, even for a short while. ${ }^{14}$ This survey shows that 36 percent of young people across the four provinces have never attended school and are therefore unlikely to be able to read or write. Gender differences are striking. Three times as many young females say they never attended school as compared to males (46 and 16 percent, respectively).

Ever attendance at school therefore stands at 84 percent for male and 54 percent for female adolescents in 2001. These gender differences in school attendance exist in all provinces and in urban and rural areas (Table 3.1). As expected, the percentage of respondents who ever attended school increases with higher levels of socioeconomic status. For the two higher income groups, the gap between male and female school attendance is relatively small, particularly in urban areas. However, the gap between those in the two highest and the two lowest income groups illustrates the underlying importance of poverty on school attendance: While 88 percent of female adolescents from the highest income group report ever attending school, only 23 percent of female adolescents from the lowest income group report the same. It is encouraging to note that more female adolescents than female youth have ever attended school, among the lowest income group (23 versus 13 percent, respectively). This suggests an increase in school attendance among the poorest females over the last five years, but one insufficient to close the gender gap significantly.

While ever attendance among male adolescents and youth is high in all provinces (and slightly higher in urban areas than in rural areas), there is greater variation in levels of ever attendance across the provinces for females. As Figure 3.3 shows, females in Punjab have higher levels of ever attendance than females in other provinces, and in urban areas their levels of attendance are comparable to those of males. However, in all provinces except Punjab, females in rural areas have very low levels of ever attendance (less than 35 percent). In NWFP, while ever-attendance levels for adolescent males are 90 percent, they are much lower for adolescent females: indeed, at 42 percent they are less than half of the high rates achieved by males.

14 Primary school in Pakistan is defined as Classes $0-5$ and for the purposes of this report it includes katchi, a class that prepares children for the primary curriculum. 
Figure 3.3 Percent ever attended school, by sex, residence, and province

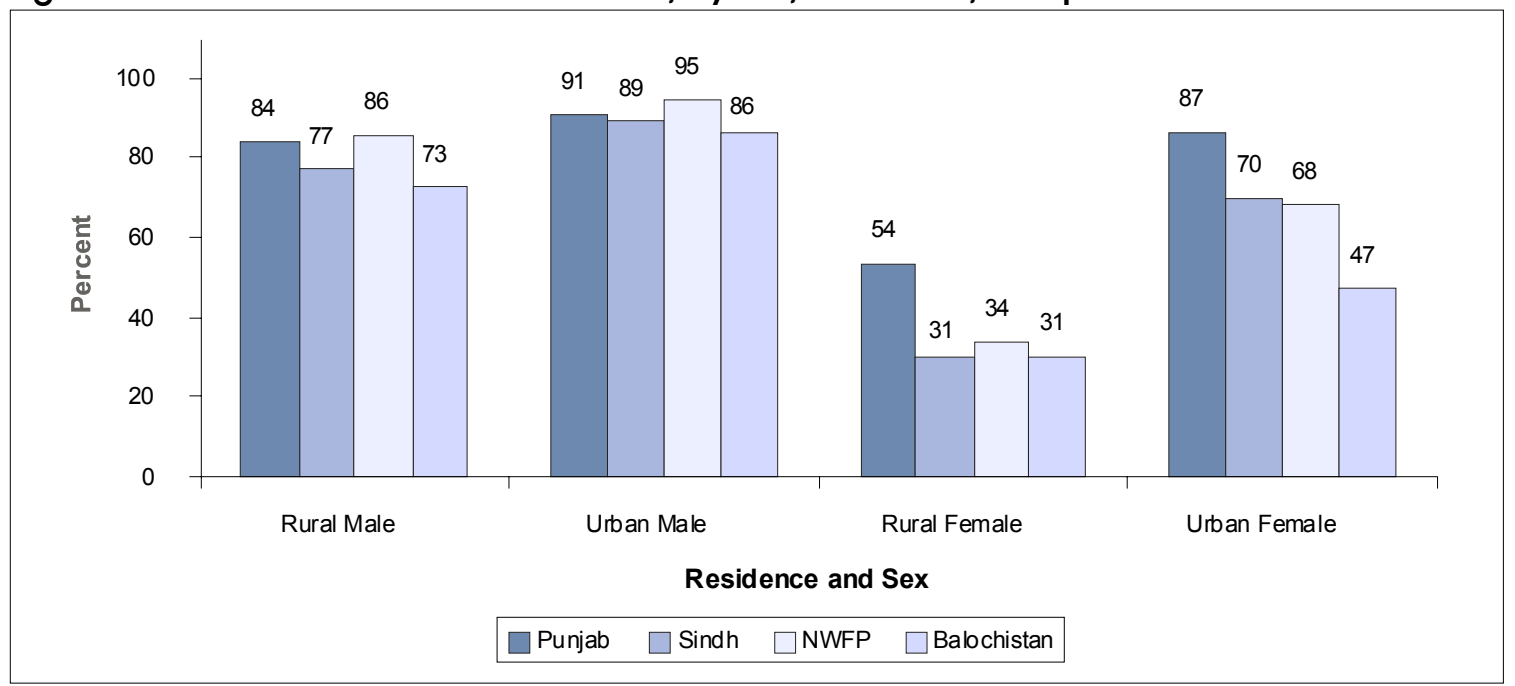

Because it is expected that all respondents who have ever attended school will have done so before the age of 15, the difference between the two age cohorts can be interpreted as a change in ever-enrollment levels over time. Figure 3.4 reveals that the percentage of females ever enrolled has risen from 46 percent to 54 percent. The corresponding rise for males is smaller, from 82 to 84 percent. As a result, the very large gender gap in ever enrollment appears to have narrowed slightly.

Figure 3.4 Percent ever attended school, by sex and age, all respondents

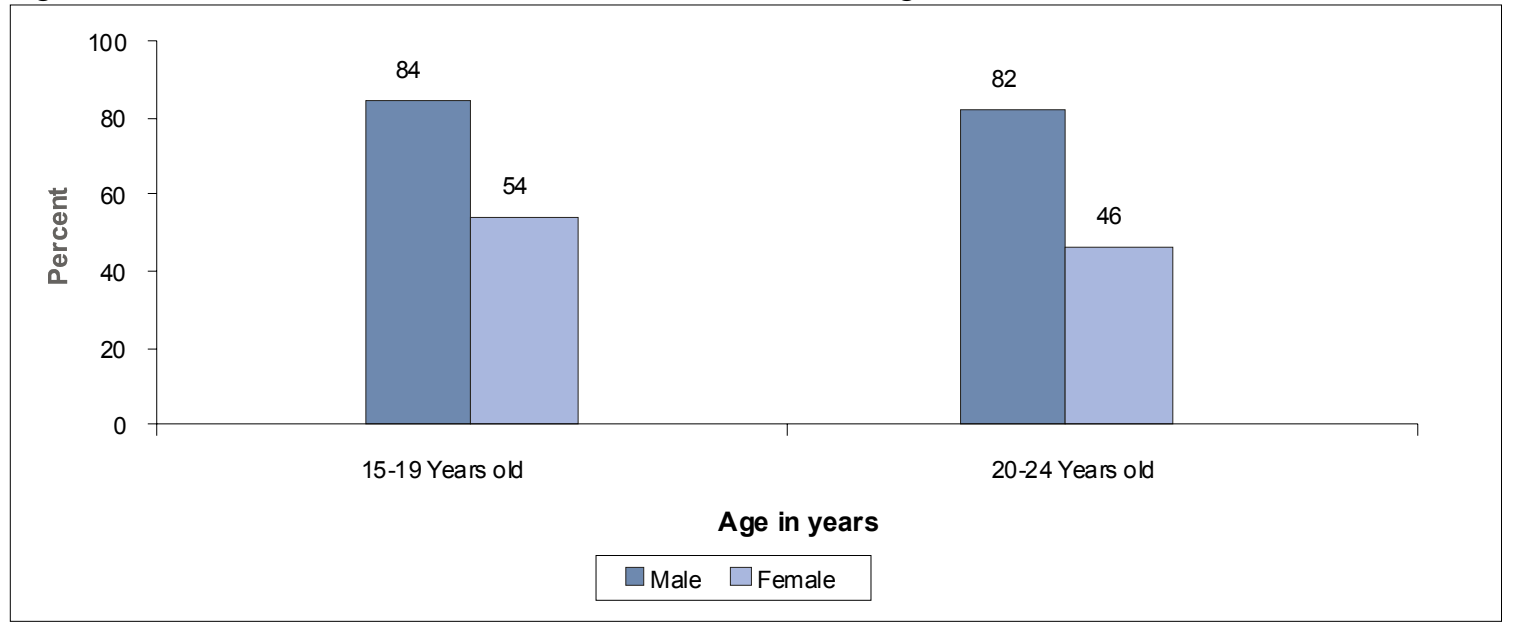

\section{Past trends in primary school enrollment}

The LEC shows the percentage of respondents enrolled in school in specific calendar years and therefore allows an examination of past trends in school enrollment. However, 
this analysis of enrollment is limited by the age span of respondents, which restricts calculations to those years in which the entire cohort aged 5-9 or 10-14 could be represented in the calculation.

Figure 3.5 presents past enrollment trends for the years 1987 to 1992, when adolescent respondents were between 5 and 9 years old. It shows that there was a slight increase in enrollments during this period, which is more pronounced for males than for females. Further investigation is required to assess whether this increase is attributable to an actual increase in enrollment or to other factors, such as a decline in the mean age of entry to school.

\section{Figure 3.5 Past trends in school enrollment, using life event calendar, 5-9 year olds}

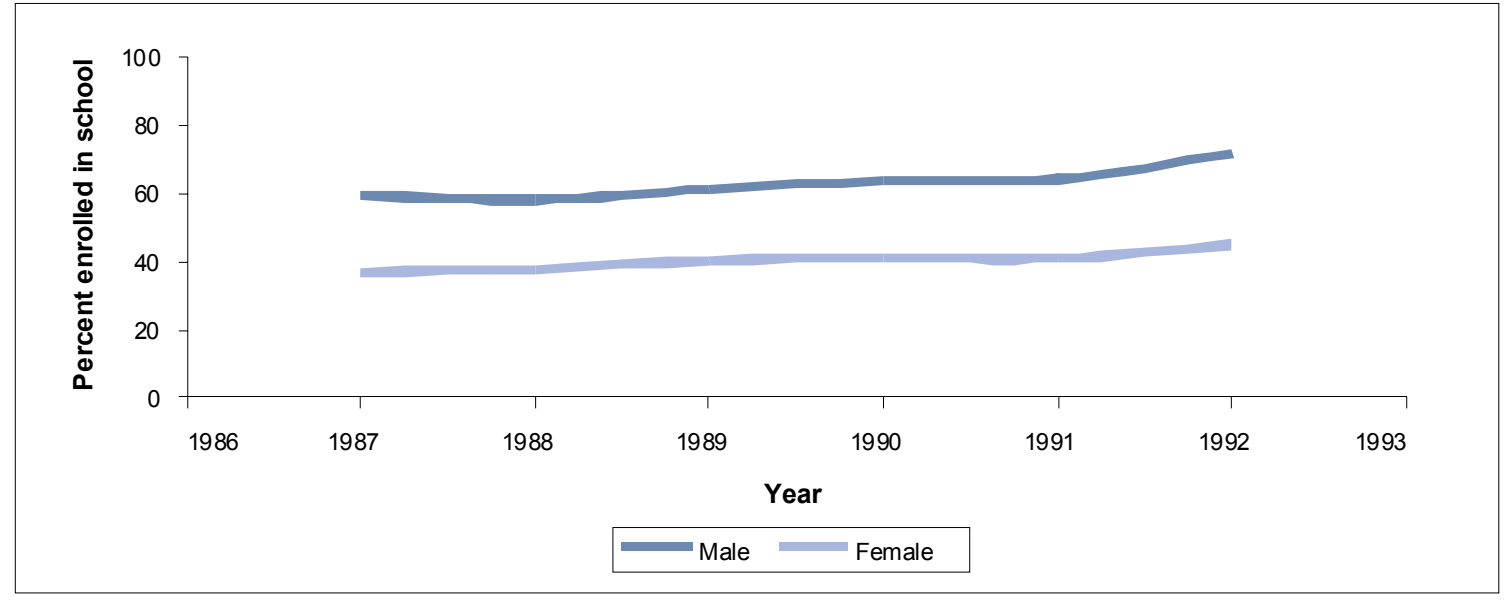

Figure 3.6 shows past enrollment trends from 1992 to 1997 when respondents from the older age cohort were between 10 and 14 years of age. During this period, there appears to have been little change in enrollment levels for male and female adolescents. It is interesting to note that in 1992 a higher percentage of males aged 10-14 were enrolled in school than the cohort of males aged 5-9 in 1987. Since these data points are for the same cohort at two points in time, this implies that a number of respondents entered school during the five-year time interval of 1987 to 1992. As enrollment levels for 10-14 year olds do not change over time, while the levels of 5-9 years old enrolled in school increase, this suggests that the mean age of entry to school was in fact declining over this period. 
Figure 3.6 Past trends in school enrollment, using life event calendar, 10-14 year olds

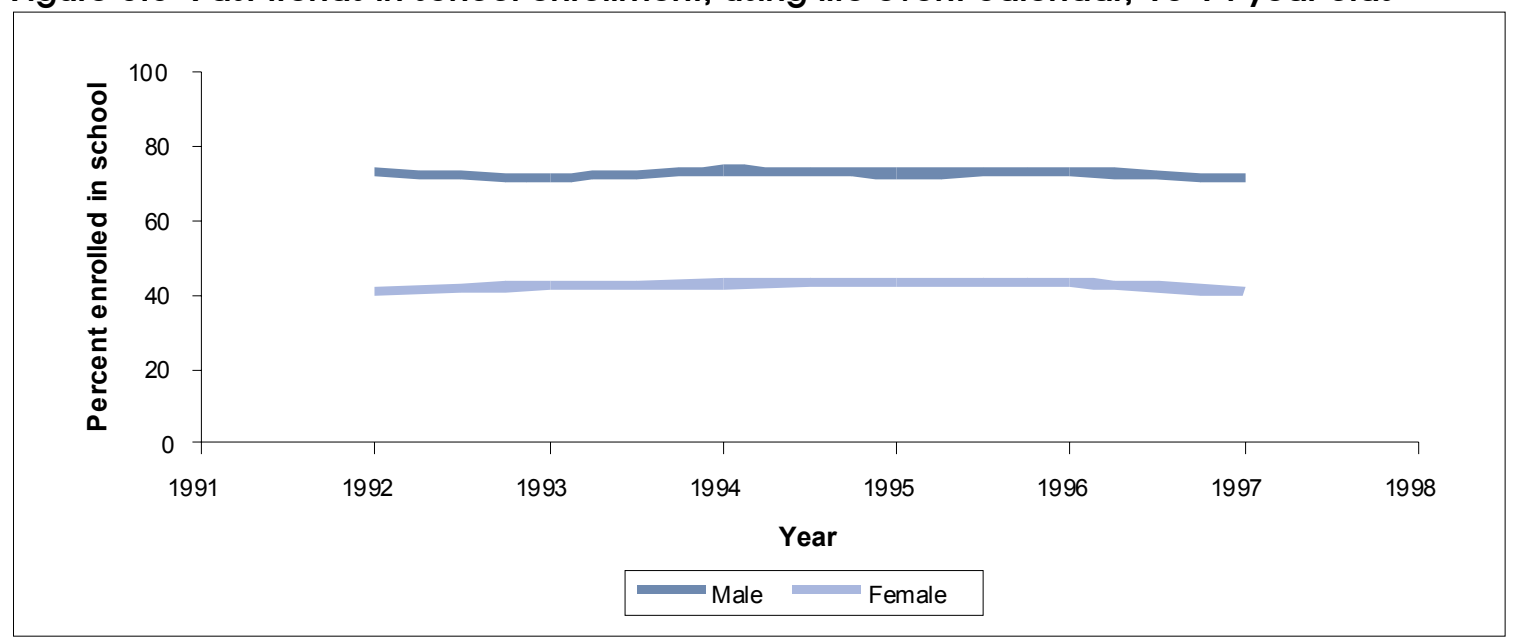

\section{LEVELS OF SCHOOL ATTAINMENT}

This section explores important variables in relation to school attainment level, namely, the mean age of entry to school for those who ever attended school; the proportions completing primary, middle, and secondary; and the class completed at the time of exit.

\section{Mean age of entry among those ever enrolled}

The survey shows that for all variables examined, the mean age of entry to class one is lower for the younger cohort than it was for the older, supporting the notion that past increases in enrollment for the group aged 5-9 may be explained by declines in the mean age at entry (Table 3.2). Figure 3.7 displays the mean age of entry for each age group by province. The greatest decline occurred in NWFP, while the mean age of entry is high for both age groups in Balochistan. This could be related to the longer distance that children in this province have to travel to reach school.

For male and female adolescents and youth the mean age of entry declines with higher socioeconomic status, with males aged 15-19 and females in the highest income group entering class one at less than age six. The mean age of entry is also lower in urban areas than it is in rural areas for both groups. Among youth, mean age at entry is higher for males than females, while among adolescents, the mean age of entry is slightly lower for males than for females. This implies that males have experienced the greatest benefit of declines in the mean age of entry to primary school. Furthermore, the mean age of entry has not changed significantly for females; in fact, it is higher for adolescents than it is for youth in some categories (Table 3.2). This means that Figure 3.5 actually shows a slight increase in enrollment over time for females. 
Figure 3.7 Mean age of entry to class one, of those who have ever enrolled

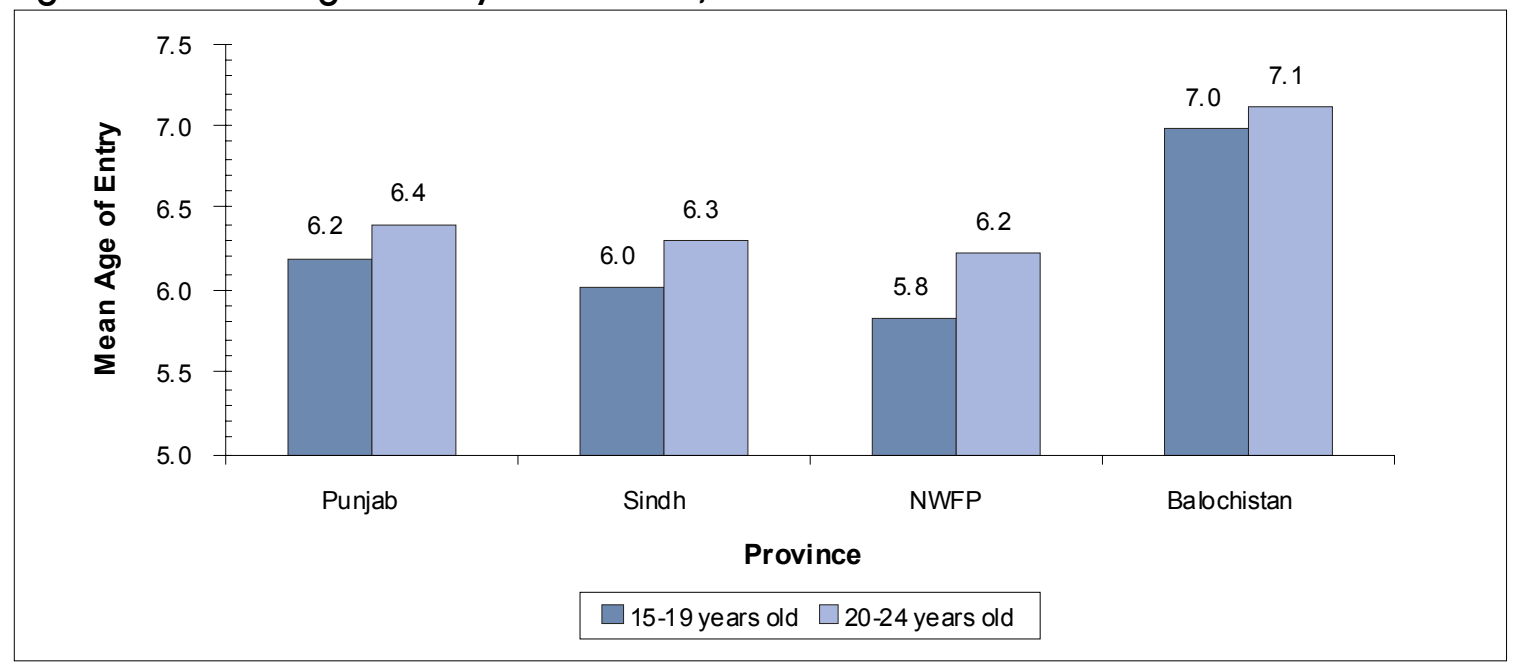

\section{Completion of primary school}

The completion of primary school is an important marker for both males and females in Pakistan. A comparison of the older and younger age cohorts shows scant improvement in primary school completion rates for females in the last five years, which have risen very slightly from 36 to 40 percent (Table 3.3). They have also risen in all income categories and in all provinces. Completion rates for males, on the other hand, have remained roughly the same between the two age cohorts.

Most parents, even in rural areas, express a desire to have their daughters complete primary school at the very minimum (Sathar, Lloyd, Ul Haque 2000). Yet, the results for primary school completion are low. Almost 70 percent of adolescent males and only 40 percent of adolescent females report completing primary school. Completion rates for adolescent females in rural areas are even lower (29 percent) whereas for adolescent males they are 66 percent. Completion rates for females are lowest in rural Balochistan (16 percent) and rural Sindh (21 percent) and highest in urban Punjab (74 percent). For males they are lowest in rural Balochistan (48 percent) and highest in urban Sindh (85 percent).

The gender gap in primary school completion rates is narrower in urban areas: 81 percent for males versus 69 percent for females. It is also relatively narrow in the highest income group (91 percent for males versus 81 percent for females) whereas the gap between males and females is at least 30 percentage points or more in all of the other income categories. 


\section{Completion of middle and secondary school}

It is also important to look at the levels of schooling beyond primary school as most young people can only reach their full potential once they have completed a secondary education. In particular, access to technical training and skilled jobs is highly dependent on education beyond the primary level. Middle and secondary school completion levels are shown only for the older cohort, since those in the younger cohort were still in the midst of such training. Table 3.4 shows vast differences by gender and residence in proportions of youth completing middle-level education (through class eight). More than twice the proportion of males complete middle schooling compared to females and gender differentials are more pronounced in rural areas. Not surprisingly, only 13 percent of young female respondents in rural areas complete middle level compared to more than four times that proportion in urban areas. Urban attainment rates are higher for males also, but this difference is not as striking as in the case of females. As expected, income levels have a strong influence on middle school completion, and this is most apparent in urban areas where presumably availability of schools is much less of a constraint. Only 33 percent of males in the lowest income level complete middle school compared to more than twice as many in the highest income group. Once more, differentials by income are starker for females. Two percent of females in the poorest households complete middle school, compared to 59 percent in the richest households. Poorer families, when faced with economic constraints, are less likely to see females through middle school and above.

Completion of matric (secondary school certificate) is a major marker of educational attainment for Pakistanis. The completion of ten years of schooling and the passing of matriculation is a requisite for many jobs and for college and university entrance. It is discouraging to find that only about 33 percent of young men and 18 percent of young women complete this class (Table 3.5). The differentials by residence and economic class are along the same lines as middle schooling, but even starker. Only one percent of young women complete class ten in the lowest income group compared to about 48 percent in the highest income group.

\section{Mean highest class completed}

Most male and female youth report having completed their education. Therefore, it is appropriate to look at the mean highest class completed for survey respondents in the older age group, counting those who never attended school as having attained zero classes. Among the youth surveyed, males had completed a mean of 6.2 classes (just above primary), while females had completed a mean of 3.5 classes (well below primary completion). The smallest gap between male and female youth occurred in Punjab, where there is a difference of 2.3 years; however, across provinces, male Punjabi youth 
have among the lowest mean number of completed classes. The largest gender gap occurred in NWFP where males completed almost five classes more than females (Table 3.6).

As expected, male and female youth in the highest income group completed the greatest number of classes. Mean classes attained ranges from 4.2 for males from low income households to 9.3 for those from high income households. For females, the range is even greater: from 0.6 to 7.6 classes (Figure 3.8). The gender gap is similar in all income groups (3.6 to 3.8 classes), but the highest where the gap narrows to 1.7 years. On average, females from the poorest families have barely a year of schooling.

Figure 3.8 Mean highest class completed of all 20-24 year olds

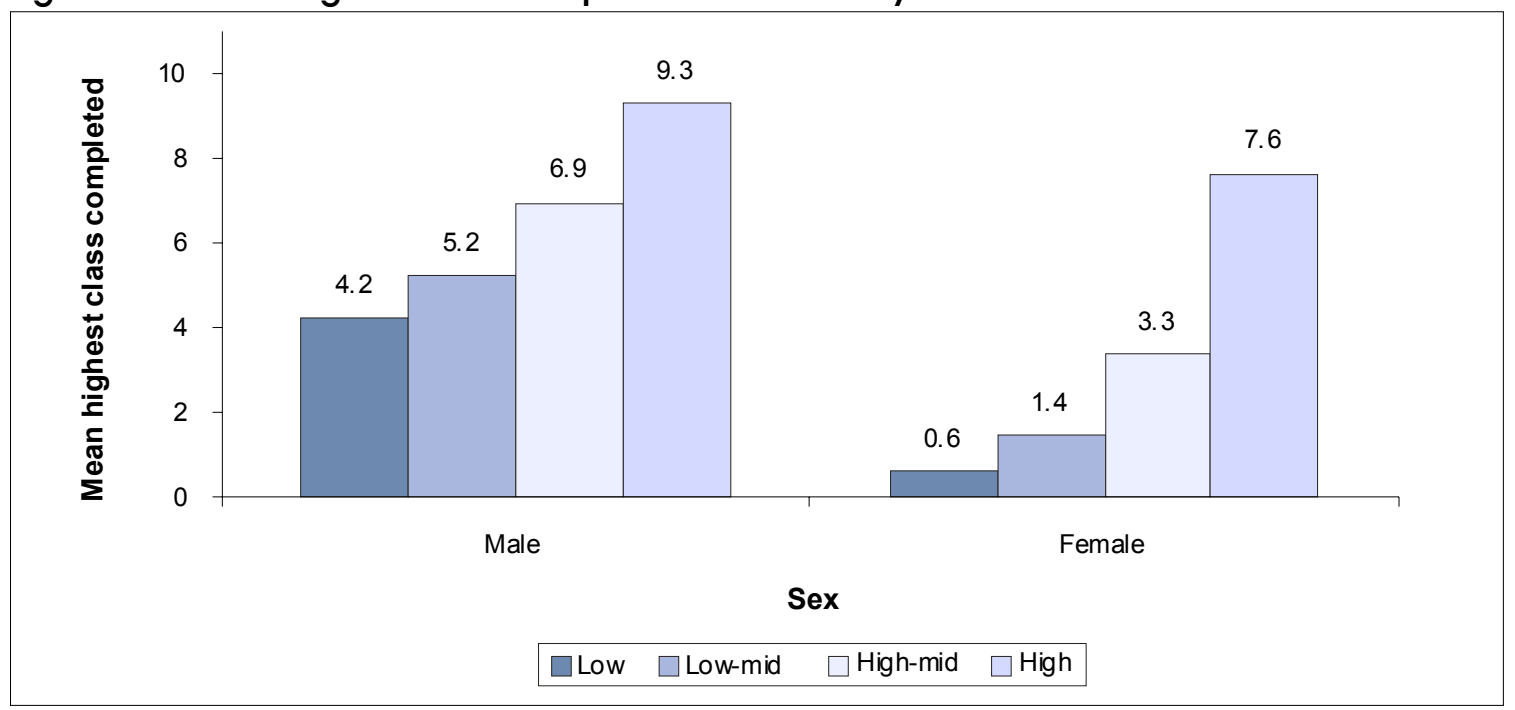

\section{Current enrollment levels and types of school attended}

At the time of the survey only a few respondents from the older cohort were currently in school (Table 3.7), with the exception of male youth in urban areas and in the highest income group (13 and 15 percent, respectively).

Current enrollment rates are also low for adolescents and strikingly low for females. While 33 percent of male adolescents report being in school, less than half as many adolescent females report the same (15 percent). Current enrollment for all adolescents is lowest among rural females and females in the two lowest income groups $(9,2$, and 7 percent, respectively). As expected, current enrollment rates are highest for adolescent males, particularly in NWFP and urban Balochistan, and among males in the highest income group (46, 50, and 50 percent, respectively). 
In Pakistan, all government schools are officially single sex. Nonetheless, for practical reasons of proximity or availability of teaching staff, some government schools enroll students of both sexes. ${ }^{15}$ Most private schools are mixed ${ }^{16}$. Not surprisingly, the majority of young people report that they attend single sex schools in Pakistan. However, there is a significant proportion of young people who describe the last school they attended as mixed. The mixed schools they report attending can be either government or private schools. For example, in Balochistan 99 percent of adolescent females report that they attended government schools, but at the same time 17 percent report that the school they attended was a mixed school. For both age groups and in all but the highest income group for adolescents, females are more likely to attend mixed schools than males (Table 3.8). Younger respondents are also more likely to attend a mixed school, as are respondents in urban areas, where private schools are more prevalent. Attendance of mixed schools is varied between the provinces, with females in Sindh the highest and in Punjab the lowest. However, as noted in the community chapter, single-sex schools for either sex are found in more communities than are mixed schools, although schools exclusively for females are found in fewer communities than are schools exclusively for males. The combination of lower availability of schools for females and greater attendance of females in mixed schools suggests an unmet need for all schools for females.

Most young people indicate that their last school attended was a government school (Table 3.9). Slightly fewer females than males in both cohorts report attending a government school. Furthermore, fewer adolescents report attending a government school than do members of the older cohort. Fewer young people in Punjab and Sindh last attended government schools, whereas almost all young people in Balochistan attended government schools. Young people in urban areas are also less likely than those in rural areas to have attended a government school, as are those of higher socioeconomic status. Although the changes between cohorts are small, they can be found across almost all of the characteristics examined here, indicating that private schools are beginning to play a more important role in education.

15 The de facto mixing of government schools has been reported elsewhere (Sathar, ul Haque and Lloyd 2000).

16 The province of Sindh has a considerable number of mixed schools. (Pakistan School Education Statistics, 1999-2000, Academy of Educational Planning and Management. Islamabad) 


\section{DROPPING OUT OF SCHOOL}

\section{Levels of school dropout}

Using individual school histories from the LEC, patterns of school dropout, particularly at the primary level, reveal a distinct asymmetry between females and males. In short, females drop out at a far greater rate and much earlier than males. Furthermore, dropout levels are strongly influenced by residence and by income group.

Among respondents who ever attended school, females were more likely to drop out of school at a lower class than their male counterparts (Figure 3.9). From the moment that males and females begin school, females have higher attrition rates than males so that at each class level fewer females remain in school than males. This is primarily due to higher dropout rates for rural females. Urban females, on the other hand, have similar dropout patterns to males, which converge near class nine, a point at which over 50 percent of the respondents who ever enrolled in school actually remain in school.

Rural females drop out of school at much lower classes than their urban female and rural male counterparts. The sharpest period of dropout for rural females occurs between classes four and five, such that more than 50 percent of rural females who ever attended school dropout without completing class five. Of those who remain in school until class ten, similar proportions of males and females are found in school at each of the following classes.

Figure 3.9 Class at dropout, for those who ever attended school, by sex

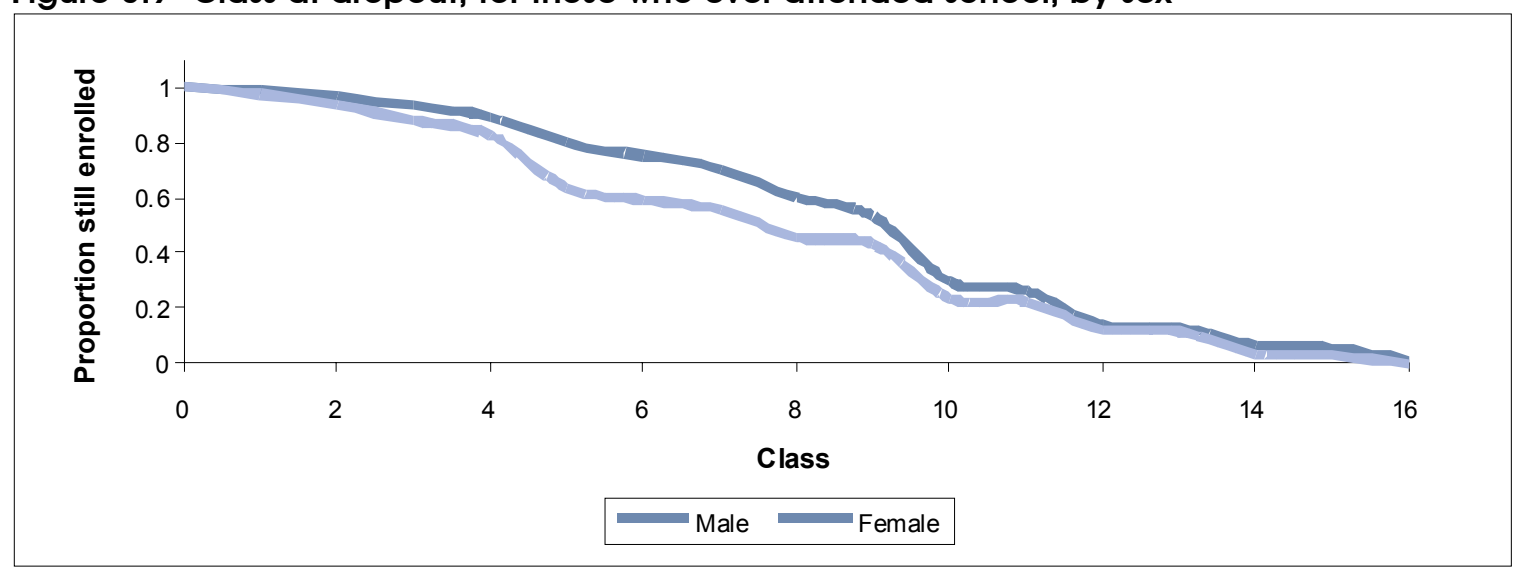

This survey shows that socioeconomic status plays a very strong role in determining the class of school dropout for both males and females with poverty clearly associated with earlier dropout. This is especially true for females (Figures 3.10 and 
3.11). By the end of class five, the last year of primary school, 80 percent of females in the highest income group remain in school, whereas only about 20 percent of females from the lowest income group remain in primary school. Among males, 60 percent of the lowest and 80 percent of the highest group are remaining in school by the end of class five.

Figure 3.10 Class at dropout, by socioeconomic status, for all males who ever attended school

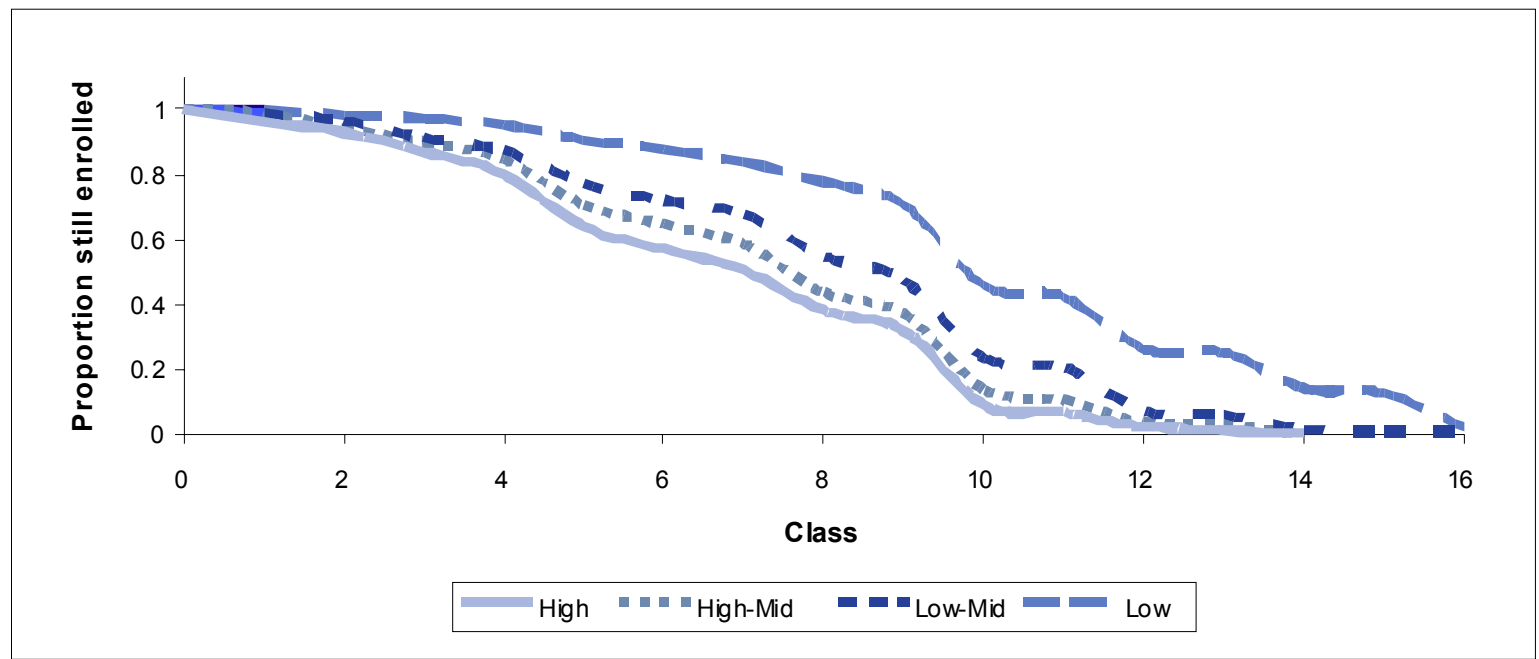

Figure 3.11 Class at dropout, by socioeconomic status, for all females who ever attended school

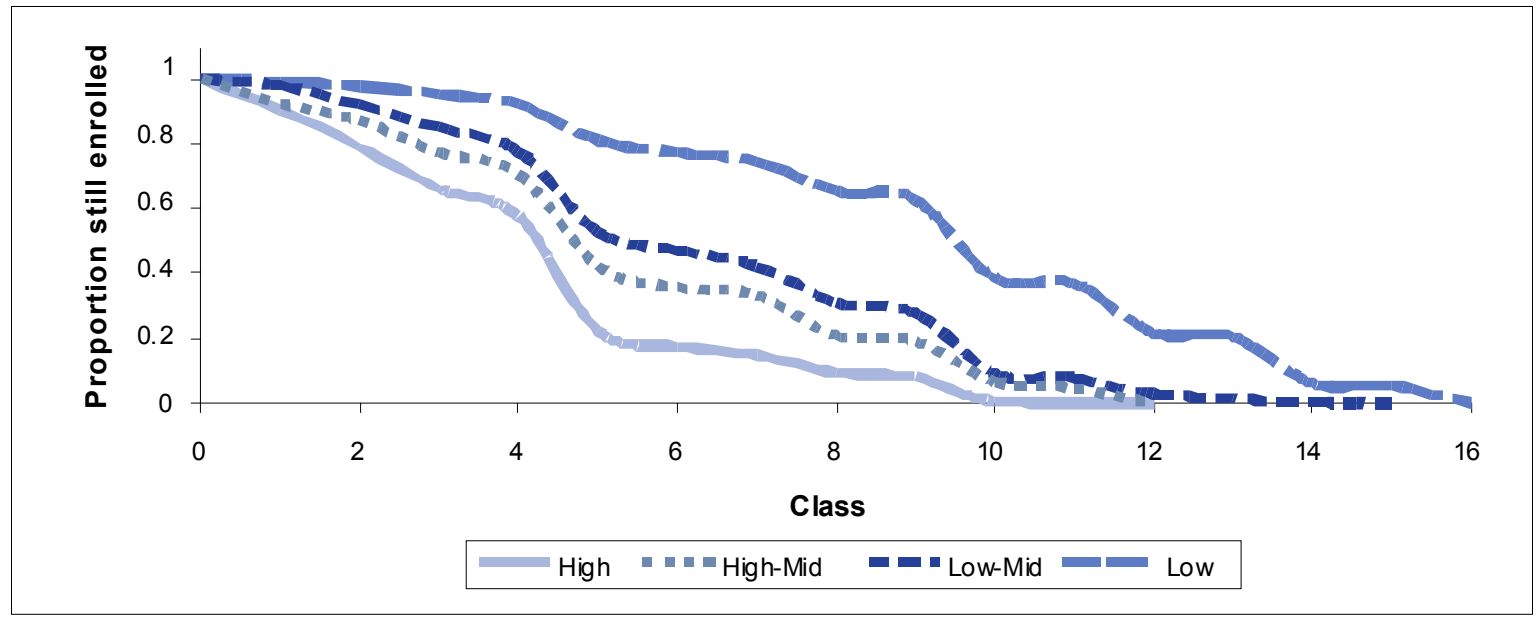

\section{Reasons for dropping out of school}

There are important differences in the reasons why males and females drop out of school (Figure 3.12). For males, multiple responses include: school costs (39 percent); 
lack of interest (33 percent); domestic chores or economic responsibility (24 percent); and poor performance (13 percent). For females, however, multiple responses include: school costs (23 percent); family opposition (23 percent); domestic chores or economic responsibility (21 percent); lack of interest (19 percent); and, distance to school (22 percent).

\section{Figure 3.12 Reasons for school dropout by sex}

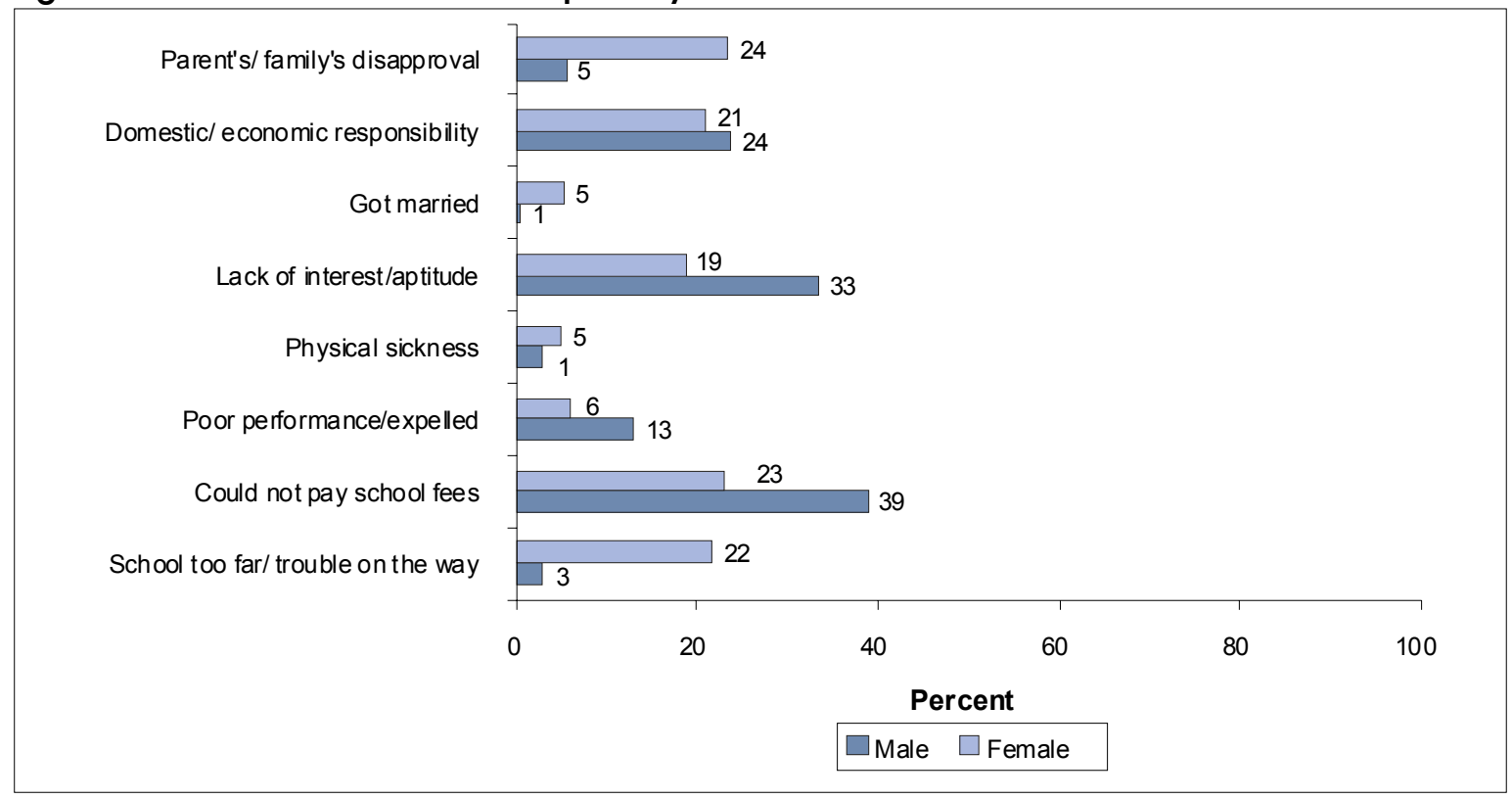

Note: Multiple responses were possible.

Domestic responsibility applies to females; economic responsibility applies to males.

Other important factors influencing dropout by residence may include better infrastructure and transportation in urban areas, and the reduced mobility of young females as compared to young males in rural areas. Another explanation for higher drop-out rates among females could be related to their security on the way to school. As Chapter 2 points out, parents and young people often perceive it unsafe for females to go to school alone. Although safety issues and inconvenience are not cited by females as a direct reason for dropping out, these factors may have a bearing on parental opposition.

\section{Decisionmakers involved in decision to drop out of school}

Who participates in the decision to drop out? The survey examined the responses of young people and adults and found important differences between the percent of the youth aged 20-24 years who claimed a role in the decision to drop out of school and the percent of household survey respondents who felt young people should play a role in 
this decision (Tables 3.10 and 3.11). In both cases, this includes either a decision by the young person alone or in combination with his or her parents or family. Over threequarters of male youth report playing a role in the decision to leave school, whereas less than a quarter of the responsible adults who responded to the household survey felt that young males should be involved. Likewise, nearly 50 percent of the female youth report a role in this decision, while only 11 percent of responsible adult respondents felt that young females should play a role.

Elsewhere in the survey, respondents aged 15-24 years were also queried about whether or not they were able to express an opinion in a household discussion of how much education they should receive, and then whether or not their opinion was listened to (Table 3.11). A full third of the respondents who report a role in the decision to drop out of school also report that they were not able to express an opinion during household discussions on this issue. It is not possible to discern the reality of perceived versus actual agency from these data. While these contrasting percentages may only represent the difference between a desired norm and actual practice, they call into question both the actual agency exercised by adolescents and youth and the reliability and veracity of adult responses.

\section{ASPIRATIONS FOR EDUCATION}

The survey found that young people have positive aspirations for education for primary school and beyond (Table 3.12). Almost all young people in rural and urban areas feel primary school alone is insufficient. Indeed, 80 percent of young people feel males should be educated to secondary or university levels and 70 percent say females should be educated similarly. Data show that more young people feel that males should be educated for as long as they want, as compared to females (15 percent and 9 percent, respectively).

There are some differences in aspirations for education by residence that relate to the levels of schooling. For example, in rural areas most youth felt that a secondary education was appropriate for females whereas in urban areas youth were keener for females to also experience university.

If a comparison is made between the aspirations of parents/adults and those of young people, some differences can be found that indicate an important and positive generational change of attitude toward education, particularly for females in rural areas. Almost half of the rural adult respondents felt that females should attain a secondary level of education whereas less than a quarter continue to feel that primary is sufficient. 
Two major sample surveys in Pakistan, this survey and the PIHS, both looked at the issue of young people's aspirations for education. While PIHS usually questioned male heads of households, this survey questioned both young people themselves and their parents or responsible adults. Both surveys show young people's aspirations for education are not being translated into reality for the majority of those growing up in Pakistan. The greatest gap between aspirations and reality lie between females and males, between rural areas and urban areas, and between those from low and high income families.

However, this survey also shows that lack of interest in continuing studies was a significant reason for dropping out of school. Further qualitative research could usefully explore factors that contribute to lack of interest if, as this survey shows, aspirations for education are so high.

\section{Desire for post-school training}

The majority of adolescent and youth respondents in the survey expressed an interest in receiving vocational training (Table 3.13). Overall more females than males, and more adolescents than youth, wanted additional training. The preference of adolescents for training over youth may reflect the possibility that some youth have already completed training or have begun vocational work. Generally more urban respondents are interested in receiving training than rural respondents, although this is not always true at the provincial level.

There are important gender differences regarding the type of training young people desire (Table 3.14). Among females who desire additional training, most want to learn about embroidery, stitching, and knitting, and slightly less than 30 percent want to learn dress making, all skills that could be used at home or in cottage industry projects. In contrast, males are interested in gaining skills that can be applied outside the home, such as learning how to be an electrician, an auto mechanic, or training in computers.

\section{CONCLUSION}

To summarize: an exploration into education as a major transition in young people's lives provides a picture of stark gender differences above all else. Young women in Pakistan continue to be at a disadvantage in the pursuit of education when compared to young men. The survey demonstrates that fewer than half of all young females aged 1524 years have ever enrolled in school. Of those who are fortunate enough to gain some education, more are likely to drop out of school at an earlier class than their male 
counterparts. This pattern of low enrollment for females is magnified at the lowest socioeconomic stratum. Only 20 percent of females from the lowest income group remain in school by the end of class five, as compared to 80 percent of females in the highest income group among those who ever enrolled.

While there is evidence that school enrollment is increasing for females in the last five years, the gains are small and the gender gap remains huge. Nonetheless it is now true that for the first time in Pakistan, a majority of adolescent females have been enrolled (54 percent).

There is enormous variation in educational attainment across provinces, between income groups, and by rural and urban residence. Female ever enrollment is highest in Punjab, while, of all adolescents who were able to attend school, those in NWFP have the greatest mean number of completed classes. Socioeconomic status played a very important role in all aspects of educational attainment examined in this chapter. Adolescents from the lowest group, especially females, are the least likely to ever attend school. Those females who did enroll are more likely to drop out of school at an earlier class, begin school at a later age, and complete fewer classes.

While there is evidence that cultural barriers to the education of females persist, the survey also highlights from the community sample that there are fewer schools open to females indicating a gender bias in public expenditure on education. Rising private school enrollment also suggests that many parents perceive the quality of government schools to be inadequate. As enrollment of males in private schooling is rising faster than for females, it appears that parents are willing to incur greater educational costs for their sons than for their daughters. As a result, females from the poorest families are particularly disadvantaged.

All young people express aspirations for education well beyond the primary school level. Indeed almost all males and females feel they should be educated either to secondary or university level. There is a slight difference between rural and urban areas where young people in rural areas feel secondary education to be sufficient for females whereas in urban areas there is more of a tendency to opt for females going to university. There appears to be a positive generation change in the attitude toward education. Young people have higher aspirations for their education than their parents. This parental lag may be holding young people back. Certainly young people's aspirations for education at present are not being translated into reality. 


\section{REFERENCES}

Academy of Educational Planning and Management. 2000. Pakistan School Education Statistics, 1999-2000. Islamabad. Ministry of Education.

Zeba A. Sathar, Cynthia B. Lloyd and Minhaj ul Haque. 2000. Investments in Children's Education and Family-building Behavior in Pakistan: Findings from Rural NWFP and Punjab. Islamabad: Population Council. 



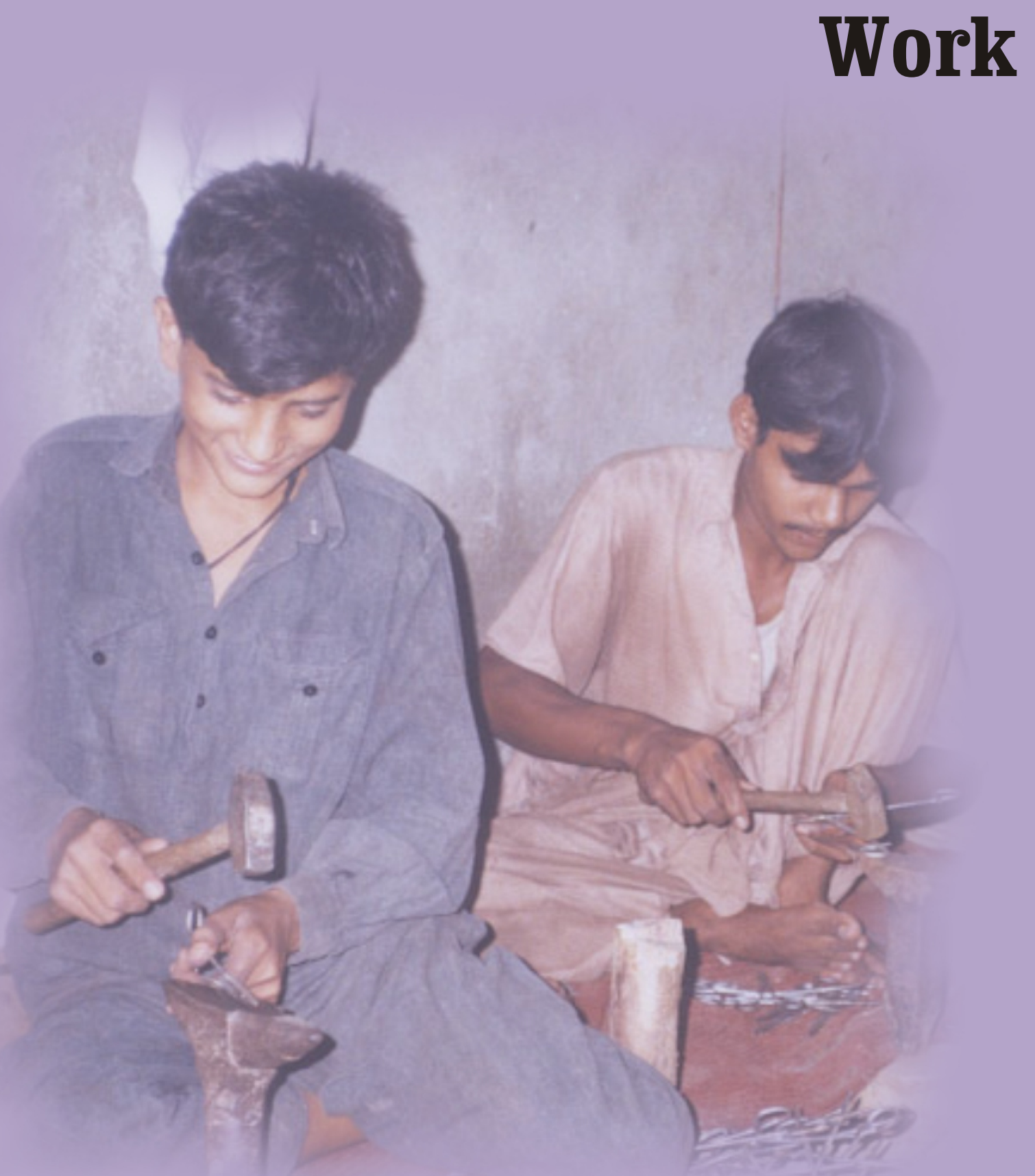

\section{In this chapter:}

- Introduction

- Young People's Participation in Work

- Decisions Regarding Work

- Attributes of Work

- Work Opportunities in the Community

- Conclusion

- References 


\section{WORK}

\section{INTRODUCTION}

Work is a key transition in the lives of young people. In some cases it is an important signifier of responsibility and adulthood. In other cases it is an economic imperative undertaken well before or in advance of adulthood. Work has the potential to provide young people with a livelihood, contribute toward building life skills, and to signify an important marker of adulthood. Work is defined in this chapter as any activity undertaken for pay, profit, or family gain. The question to respondents was phrased as follows: "As you know, some people are involved in sowing, harvesting or picking crops, raising and selling livestock, selling dairy products, stitching/embroidery, or piece rate work to help their family (for livelihood). Some time this work is paid in cash or in kind or not paid at all. ${ }^{17}$ Have you ever done or currently doing any such activity for pay, profit, or family gain?"

This chapter explores young people's work experience in depth, first examining work prevalence, the transition to work, the relationship between schooling and work, young people's desire to work, and their participation in family decisionmaking regarding work. The second part of the chapter focuses on those young people who have had experience with work. In this section, various features of work are examined, including type and location of work, intensity of work and remuneration, and how the characteristics of work vary according to background characteristics. The final section draws on the community survey to examine the availability of work.

A comparison between Pakistan's Federal Bureau of Statistics Labor Force Survey (LFS) and the AYP reveals a number of differences in terms of results for labor force participation rates (Table 4.1). According to the government surveys, labor force participation rates among adolescent males have risen from 52 to 53 percent throughout the decade of the 1990s and 58 percent in 2002. This is 10 percentage points higher than the labor force participation rates for the same age cohort calculated by this survey. In addition, the government surveys show labor participation rates for adolescent females to have declined from 12 percent to seven percent at the end of the decade, which is 19 percentage points lower than those calculated in this survey. In contrast to these differences, the government survey and this survey show similar labor force

17 The preamble was used to capture and distinguish the kind of work that is otherwise regarded as housework. Work which falls more obviously in the category of formal work such as factory labor was not specified. 
participation rates for both male and female youth, which rise with age. However, the gap between this survey and the government surveys in overall levels of labor force participation for youth is similar to the gap observed for adolescents.

There are a variety of possible reasons for the discrepancies between the LFS and the AYP. The first relates to the time frame of the surveys and the second relates to the different time spans of the surveys in question. The AYP survey included a question on work that is similar to questions in the standard annual LFS. The LFS question, asked to the head of household, mostly the males, was: "Did (name) do any work for pay, profit, or family gain during last week, at least for one hour on any day?" The AYP survey however asked two questions in place of the one: "Have you ever done or currently doing any such activity for pay, profit, or family gain?" and "How long ago did you last work?" So while the AYP questions on work are comparable with the government surveys, the figures for work may not exactly match. Differences in work rates are therefore more likely to be related to who was questioned. While this survey questioned young people, the other surveys questioned primarily male household heads.

Regarding the time span of the surveys in question, the LFS fieldwork stretched over a year and encompassed all seasons whereas this survey took place during the winter season and would have captured more readily the labor of that particular season, for example, cotton picking, which is largely carried out by females. This one-season focus in the AYP may account for differences in the rates between this survey and the government surveys.

\section{YOUNG PEOPLE'S PARTICIPATION IN WORK}

\section{Prevalence of work}

Work prevalence is greater among males than females in both age cohorts. In the younger age group, 54 percent of males and 32 percent of females have ever worked, whereas for the older age group, these figures are 83 percent and 39 percent, respectively (Table 4.2). The experience of work does not rise much with age for females, except in the highest income group and in urban areas. For males, as might be expected, rates rise strongly over these five years in all subgroups as more and more young men make the transition into the workforce as they exit from school.

Work prevalence varies by residence. In rural areas the prevalence of work is slightly higher than in urban areas for both males and females, because of the laborintensive agricultural sector (Table 4.2). The percent of females who have ever worked is lowest for both age groups in NWFP, reflecting both cultural restrictions for females as well as fewer avenues for both agricultural and nonagricultural work. In contrast, work 
rates are highest for females and males in Sindh. Two-thirds of males and more than one-third of females in the younger age group and even higher proportions in the older age group in Sindh have worked at some time. It is also interesting to note that ages 20-24, many fewer young men have ever worked in NWFP (62 percent) relative to other provinces. On the other hand, work rates for young men are as high as 86 percent in Punjab and Sindh.

The survey found that socioeconomic status is negatively associated with work prevalence for both males and females. This finding is largely a reflection of the positive association between SES and schooling (Table 3.1). Young people in higher income groups have the opportunity to stay in school longer and are more likely to be in school than at work. About three-fourths of the adolescent males in the poorest households have ever worked whereas in the richest households, a little more than one-third of their counterparts have ever worked (Figure 4.1). The same contrast is true for females as well, with 16 percent working in the highest income group and 47 percent in the lowest income group.

Figure 4.1 Percent ever worked by sex, age, and socioeconomic status, of all respondents

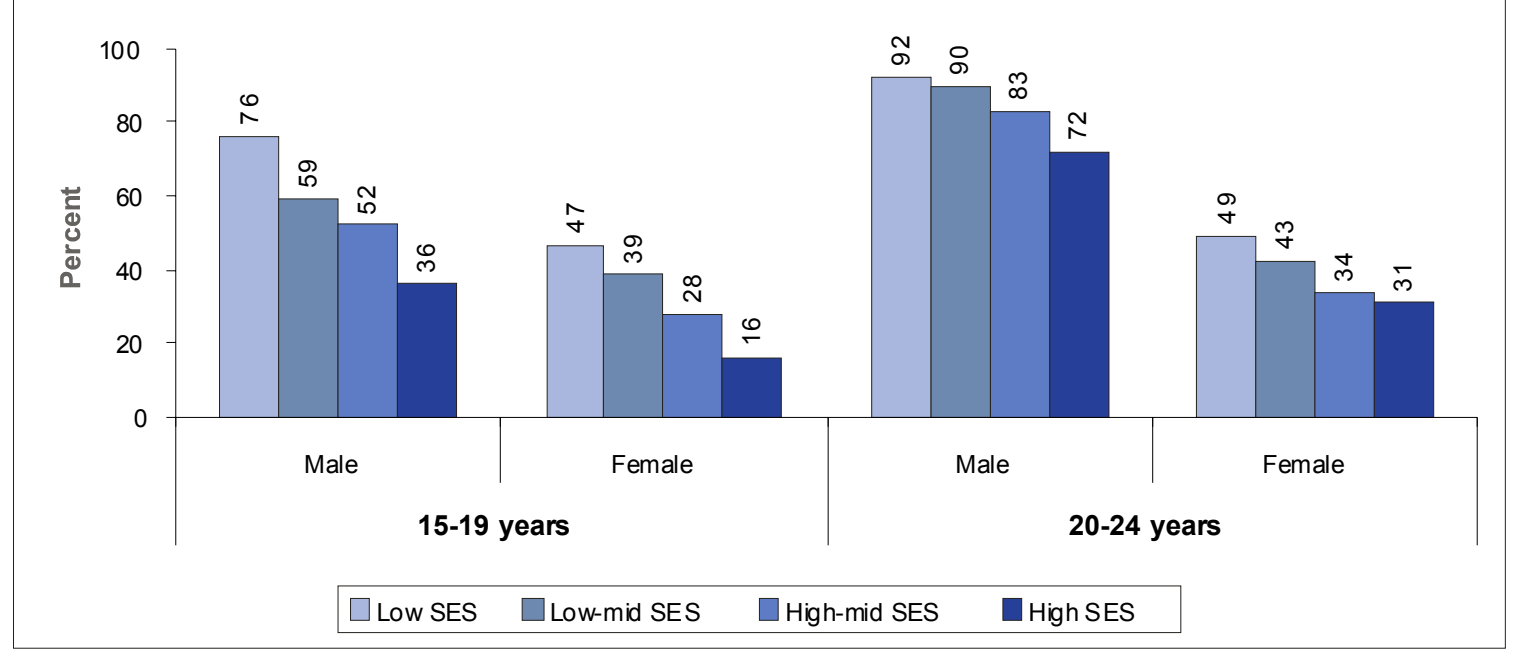

\section{Transition to work}

The LEC offers the opportunity to analyze the transition to work back to the age of five. Figures 4.2 and 4.3 use life-table techniques to show the timing of first work over the transition. Graphing the experience of each cohort separately, it is possible to contrast the experience of the two and draw conclusions about change over the past five years. Results show that less than 10 percent of children have started work before the age of ten. During the next five years, another 20 percent of males begin work for the first time, along with another 12 percent of females. It is during this period that the gap between 
males and females begins to grow, diverging more dramatically after the age of 15 . Transitions to work for young men do not seem to be changing, but among young women there is a rising propensity to work with age among the younger cohort.

Figure 4.2 Proportion of males who have ever worked by age, by age cohort

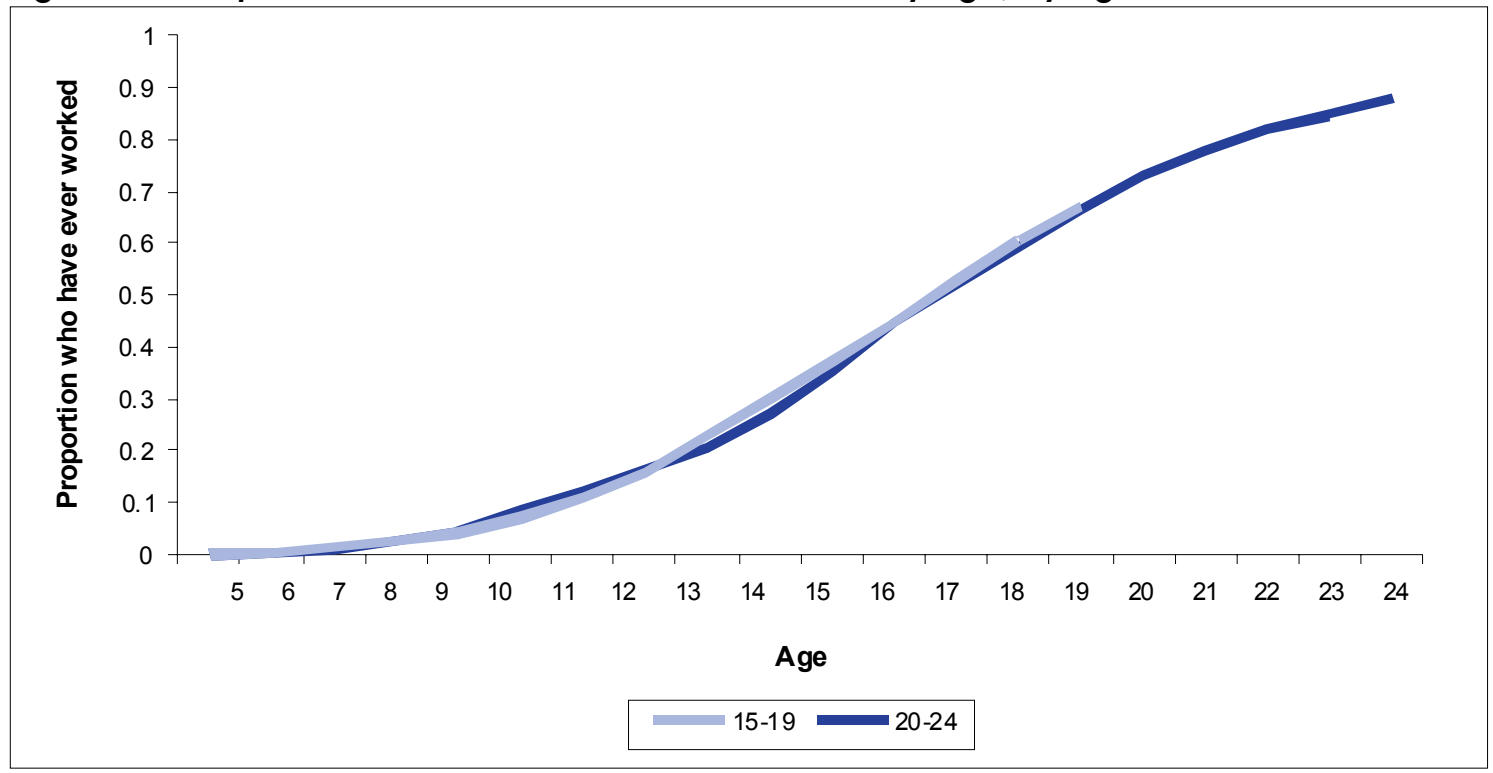

Figure 4.3 Proportion of females who have ever worked, by age cohort

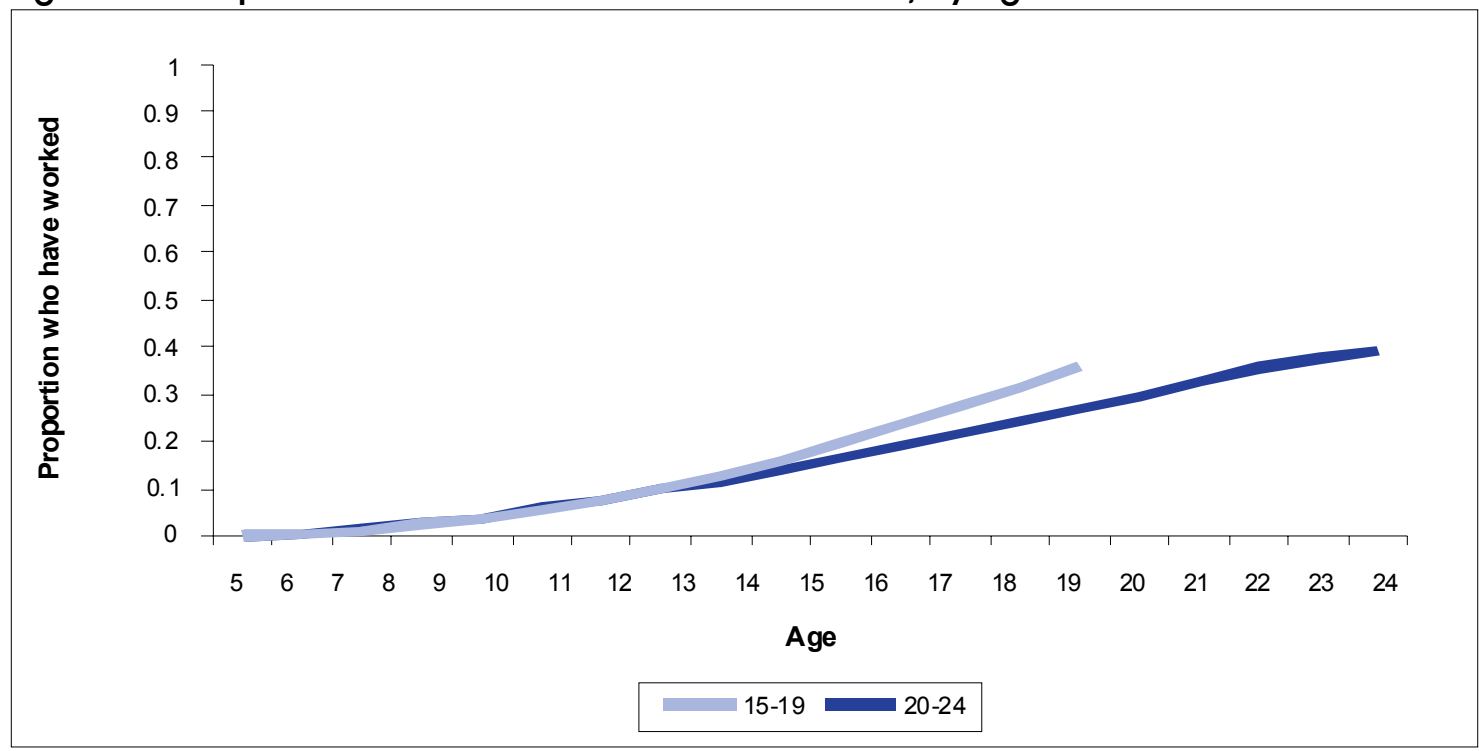

\section{Child labor}

Of particular interest are those adolescents who report having engaged in work prior to their fifteenth birthday, as this is considered child labor and is specifically sanctioned 
against in numerous international conventions, including the Convention on the Rights of the Child. Table 4.3 shows the percent of young men and women who started work before the age of 15. The overall rates are higher for males than females; among adolescents, 32 percent of males and 20 percent of females had worked before the age of 15. Child labor rates are higher in rural than urban areas and are highest for both males and females in rural Sindh. Rates of child labor are inversely correlated with household income status ranging from 16 percent to 51 percent (from the highest to the lowest SES group) for adolescent males and from six percent to 36 percent for females. Child labor rates are also inversely correlated with educational attainment.

A comparison between the two age cohorts provides the opportunity to detect recent trends in child labor rates. These data show that there is a two percent increase in the number of males and females working before the age of 15 (Figure 4.4). This rise for females is most notable in rural Punjab whereas for males it is most notable in rural Sindh, NWFP, and Balochistan (Table 4.3). While male child labor rates in Punjab have decreased slightly in rural areas, they have also increased slightly in urban areas. Other provinces show increases in the range of five to ten percent in both urban and rural areas. This survey shows, therefore, that there is no evidence to suggest that child labor rates have declined in Pakistan during the last five years; in fact, they appear to be increasing slightly.

Figure 4.4 Percent of young people who worked before age 15, by residence, sex, and current age cohort

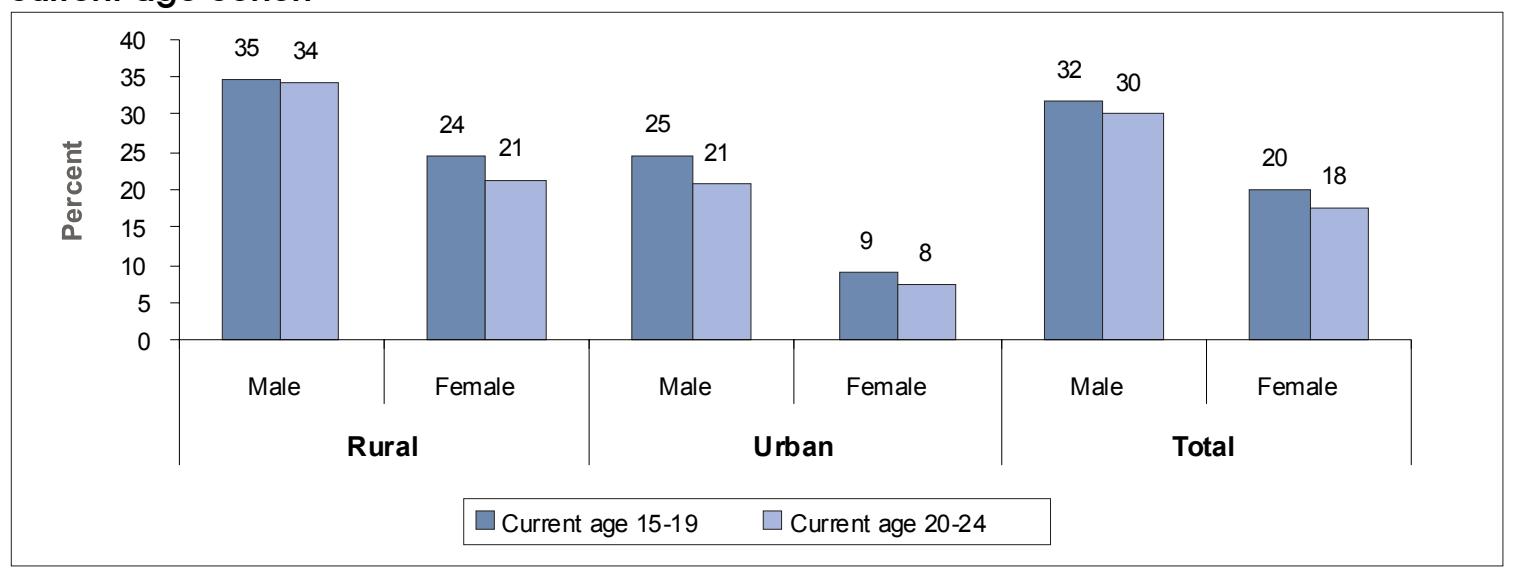

\section{Relationship between work and school}

Not surprisingly, schooling and work are negatively associated (Table 4.2). The data show that those who have never been to school have a greater chance of having worked in the past than those who have some schooling. Eighty-three percent of rural adolescent males who have never been to school have ever worked, whereas only 47 percent of 
those with five to nine years of schooling have ever worked. Similar differences are found for rural females, but at much lower levels. (Table 4.2)

The LEC provides an opportunity to explore major events in young people's lives by providing a snapshot of their history since the age of five. Figures 4.5 and 4.6 present these histories by sex as a tableau of four colored categories: school, work, both school and work, and neither in school nor working. Variations in work and education status for females and males are represented separately by age. Throughout these years, the overwhelming majority of females remain invisible. They are neither working nor in school. This invisibility grows with age. There is only a slight rise in work rates for females as they transition from adolescence to young adulthood. Further, the combination of work and schooling is very rare. For males, the exit from school is accompanied by a rise in work rates. However, the percent neither in school nor working also rises after the age of 16 , suggesting some difficulties with entry into the labor force. The combination of work and school for males is also very rare.

\section{Figure 4.5 Work and school status of males, by age}

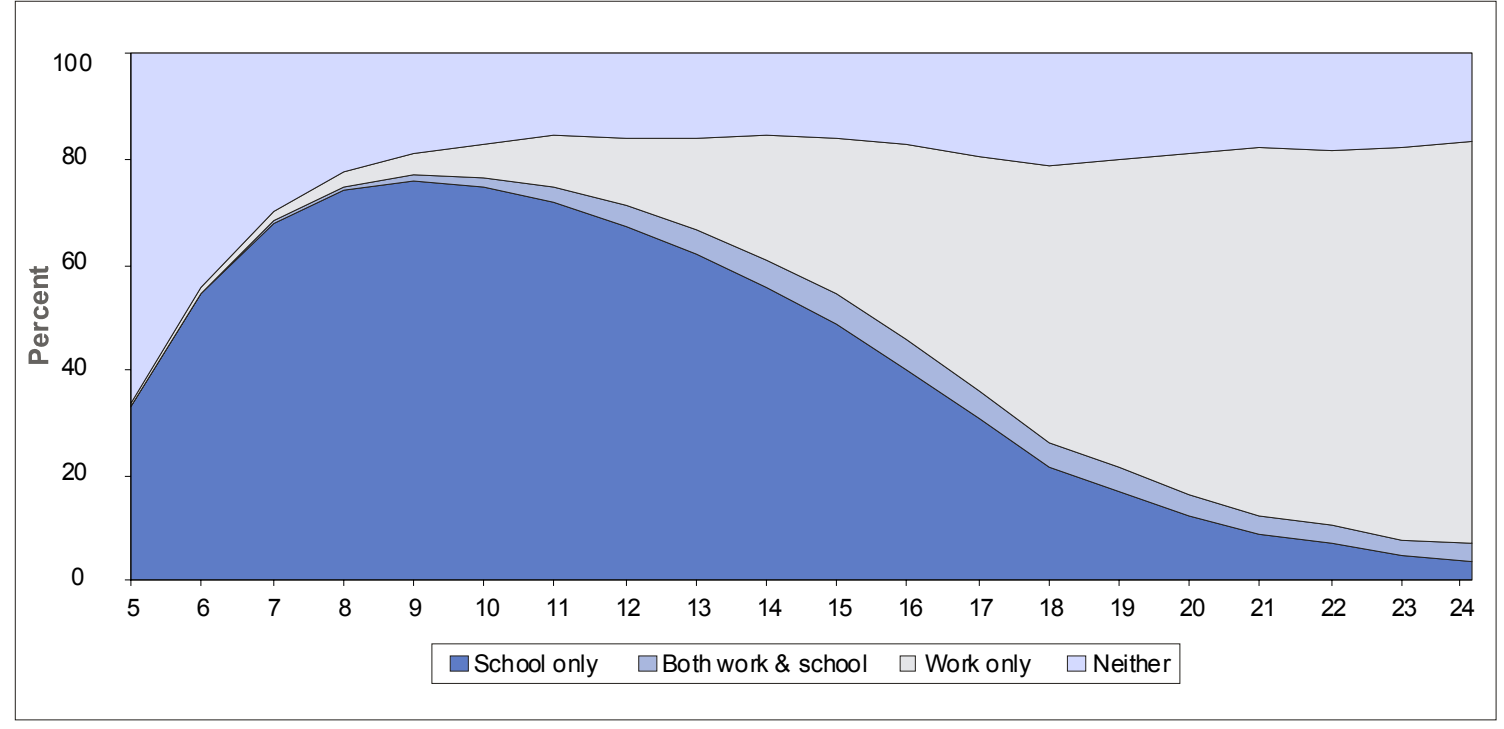


Figure 4.6 Work and school status of females, by age

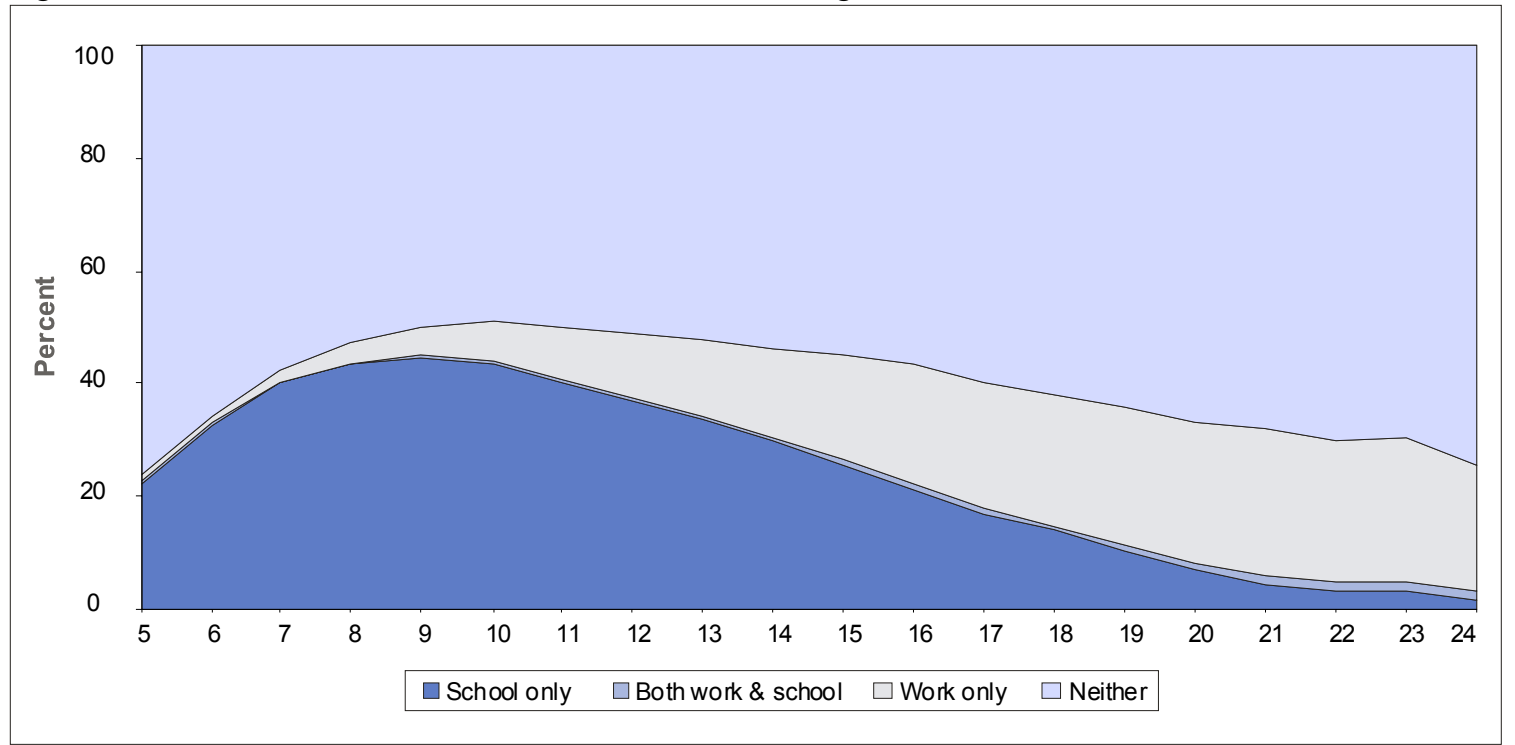

\section{Migration and work}

During the household survey, enumerators listed all young people resident in the household as well as those young people who were not resident but had at least one parent resident in the household. This subset provided information about those young people who no longer reside with their biological parents. Thus a sample of young people was created, consisting of all those who are the biological children of resident members of the sample households. Using this sample, estimates can be derived of the proportion having migrated out of the household for work. Figure 4.7 shows that 71 percent of adolescent males who have left their natal home did so to work or to seek work, and 65 percent of male youth did the same. Only a small percent of females leave home for work.

Figure 4.7 Percent of young people who have migrated out of the household for work, of those who have left their natal home

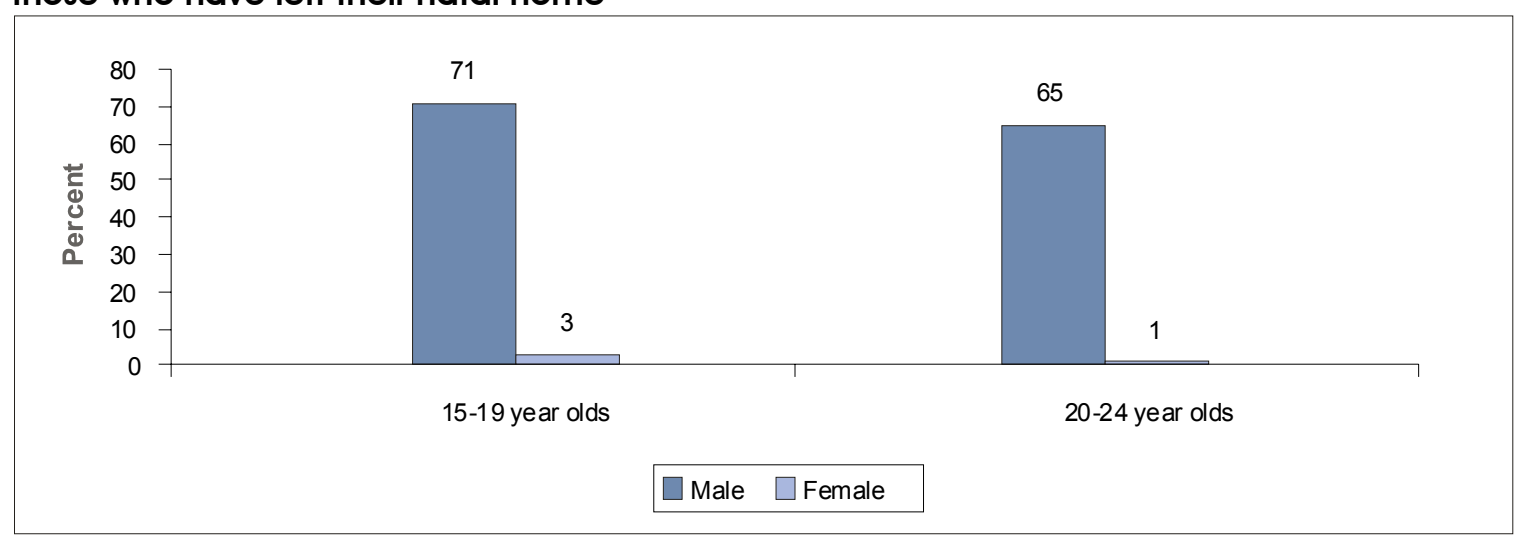




\section{Desire to work}

Respondents who were not currently working were asked: "If work opportunities were available, would you like to work in the near future?" Almost all (98 percent) nonworking males in the older cohort and 93 percent in the younger cohort said they would work if given the opportunity (Table 4.4). Among nonworking females, the intention to work if given the opportunity was slightly lower than that among males, but much higher than expected (77 and 70 percent for the younger and older age groups, respectively). Regardless of socioeconomic background, educational attainment, province, or marital status, the desire to work among young people was high: 90 percent or higher among males and 70 percent or higher among females.

Figure 4.8 combines the percent currently working with the percent that expressed a desire to work. Not surprisingly, by the ages of 20 to 24, all males would like to work. Remarkably, 79 percent of rural women and 74 percent of urban women are working or would like to work. This strongly suggests that the majority of young people see the value of work and aspire to work, regardless of their sex. However, the gap between aspiration and reality is much higher for females than it is for males. For male youth, 27 percent are not working, but would like to work; whereas for female youth, 50 percent are not working, but would like to work, representing considerable untapped productivity in Pakistan .

Figure 4.8 Percent of all young people currently working or willing to work if it were available, by residence, sex, and age

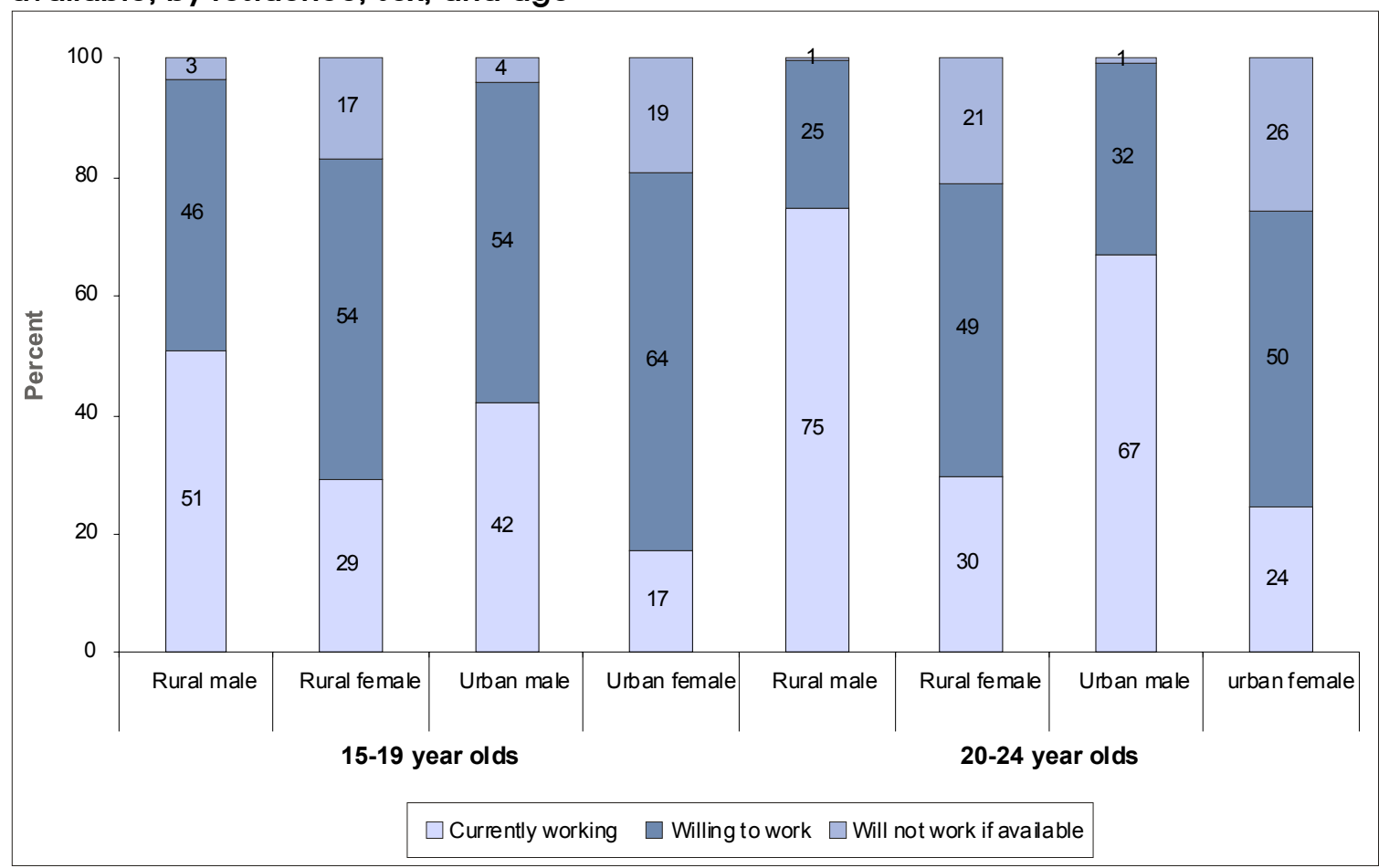




\section{DECISIONS REGARDING WORK}

The survey included a series of questions for the young people and the household survey respondents about decisionmaking processes concerning work. The first question was whether there had ever been discussions within the household about whether or not the young person should work. About two-thirds of the adolescent males and 81 percent of the male youth report that there was a discussion in the household about their work (Table 4.5). In contrast, approximately 53 and 55 percent of female adolescents and youth report the same. This is not surprising, since fewer females are engaged in paid work.

In another part of the survey, young people who responded that a discussion had taken place were asked two additional questions: (1) whether they were able to express an opinion to family members about whether or not they should work and, if so, (2) if their opinion was listened to. Figure 4.9 shows that males in both age cohorts were more likely than females to express an opinion and their ability to do so increased with age. Females were not only less likely to be able to express an opinion, but given that they had, a smaller percent were listened to. There was not much improvement as they got older.

Figure 4.9 Distribution of whether or not young people were able to express an opinion and whether or not this opinion was listened to, of all young people

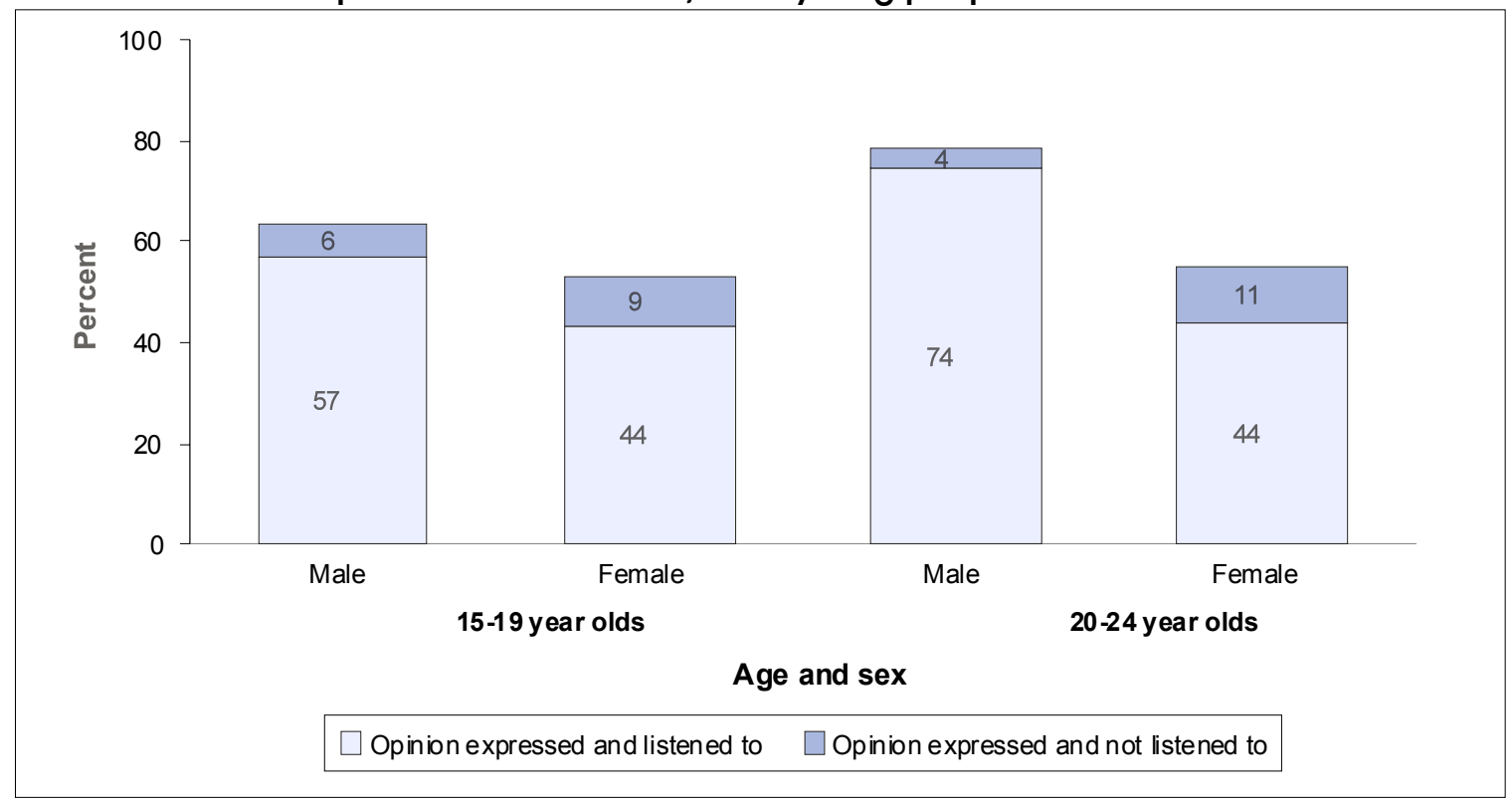


A more detailed examination is found in Table 4.6 which presents the percent of young people who felt listened to, given that they were able to express an opinion. The survey found that more male adolescents felt their views were considered, compared to female adolescents (91 percent and 83 percent, respectively). Interestingly, the views of rural females appear to be listened to more than their urban counterparts.

Among the 20-24 year olds, the pattern is similar. Once again males feel listened to more than females (95 percent and 80 percent, respectively). Interestingly, the survey shows that adolescent males and females are more likely to feel listened to if they come from the lower income groups. Adolescent males with no schooling and adolescent females from Balochistan, Sindh, and Punjab were most likely to be listened to on the issue of work. For female youth, educational attainment has a positive influence on whether they feel a responsible adult would take their views about work into consideration.

It is also of interest to look at the views of responsible adults in the households where young people reside. Adults were asked who in the household should decide whether or not a young person should work--the young person themselves or other family members. Male and female adults shared similar views about the relative decisionmaking role of young people (Table 4.7). About 87 percent of adult males and females think that it is acceptable for young males to have a role in decisions concerning their employment. However, only half of the adults think that young females should participate in such decisions. Adults share the view outlined above for males regardless of socioeconomic status or provincial residence. However, for young females, adults are more likely to endorse their role in decisionmaking in the two provinces of Punjab and Sindh, and less likely if they live in poor households. Therefore, while 13 percent of adults are not prepared to listen to young males, 49 percent are not prepared to listen to young females. This confirms a much lower status in decisionmaking for young females in most households on an issue that directly concerns them, whether or not they should work for wages.

\section{ATTRIBUTES OF WORK}

The analysis presented below is restricted to those young people who have ever worked, including those who are currently working and those who have worked in the past. The reason for choosing this definition is in order to include seasonal and occasional work

that only occurs at certain times of the year. Themes explored include the type of work undertaken, the workload, and the distribution and control of earnings. The status of 
young people's work is also explored (i.e., whether they are self-employed, working in a private business, or working in household production).

\section{Type of work}

Figure 4.10 shows the distribution of the most common economic activities undertaken by young people in Pakistan. As expected, a different picture emerges for males than for females. For adolescent males, a significant proportion report working in agriculture (32 percent) and unskilled/factory labor (29 percent), followed by skilled labor (18 percent), and self-employment/business activities (16 percent). The pattern is similar for the older age cohort. Although female employment is also concentrated in agriculture (42 and 37 percent in the two cohorts), additional work opportunities are limited. The next major work category was "stitching, embroidery, and knitting" (35 percent of adolescents and 31 percent of youth). Compared to males, female participation in factory work (7 percent), skilled labor (9 percent), and business activities ( 3 percent) is small and much less frequent.

Figure 4.10 Distribution of those who have ever worked by type of employment, age, and sex

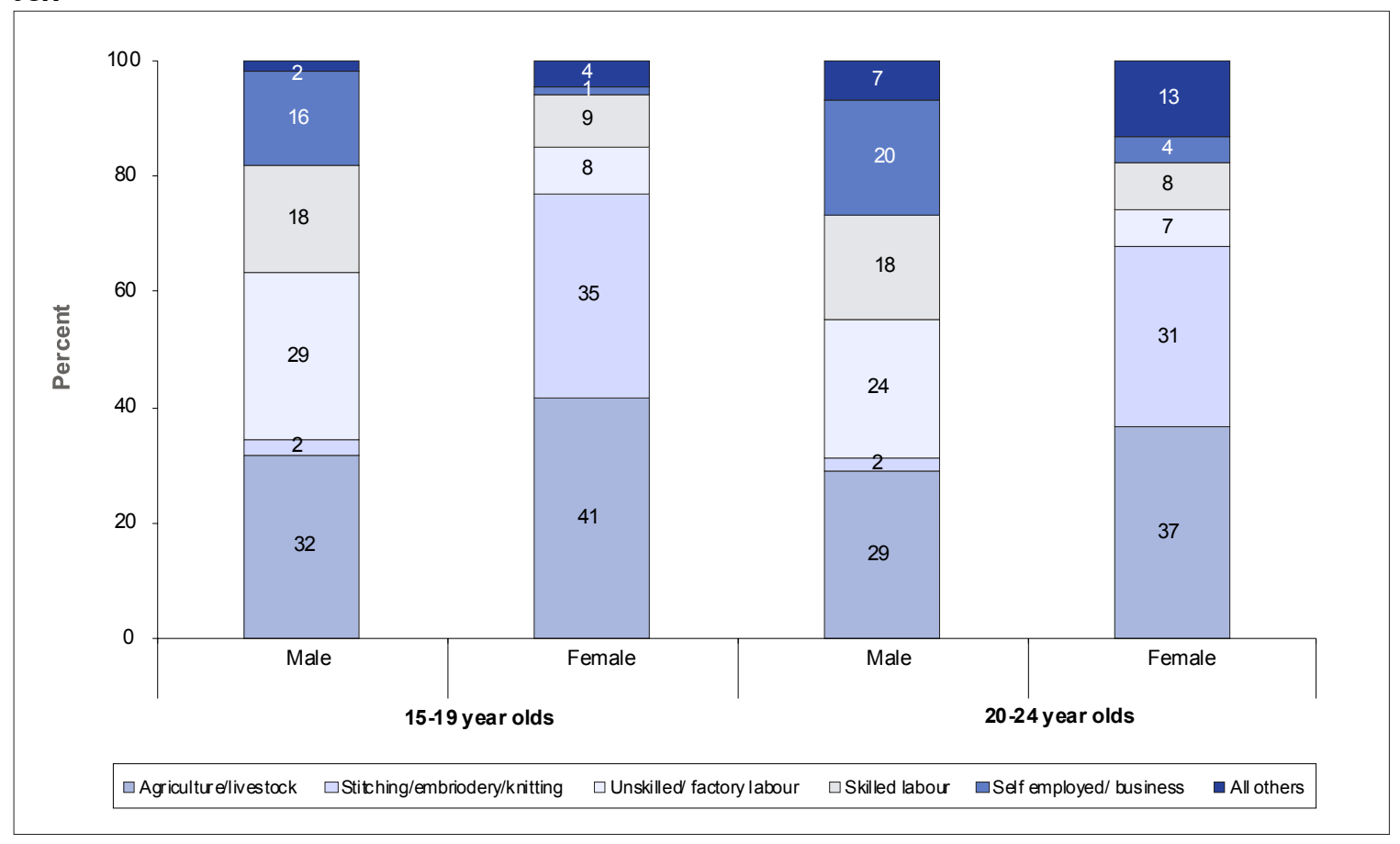

Given the dominance of the agricultural sector in Pakistan, it is worth examining the characteristics of young people involved in this sector in more detail. According to Table 4.8, of those young people who have ever worked, a higher proportion of females than males are involved in agriculture (39 and 30 percent, respectively). Furthermore, 
agrarian work is closely correlated with lower socioeconomic status, particularly in the case of females. Only four percent of the females from the wealthiest households work in agriculture, compared to 62 percent in the poorest. The spread is slightly smaller for males, with 8 and 52 percent of the wealthiest and poorest households, respectively, working in agriculture. Such extreme differences may point to the limited employment opportunities for young people in poor, rural households. The survey also shows striking provincial differences. The highest proportion of male agrarian workers is found in Sindh, where 39 percent of those who ever worked did so in agriculture. Balochistan was the next highest for males (34 percent) and was the highest for females (51 percent). For both males and females, NWFP had the lowest proportion in agrarian work (13 and 4 percent, respectively).

The survey also asked young people who had ever worked about the nature of their employment. Figure 4.11 shows the distribution of work across the two age cohorts using four categories to indicate status: self-employed, working with own household or family, employee, and others. Overall, adolescent males tend to be employees (54 percent) whereas most adolescent female respondents report working for their own households or family. The pattern is similar for the older age cohort. Self-employment is also higher among females in both age cohorts ( 30 percent of adolescents and 32 percent of youth) than it is among males (15 and 20 percent, respectively).

Figure 4.11 Distribution of those who have ever worked by nature of employment, age, and sex

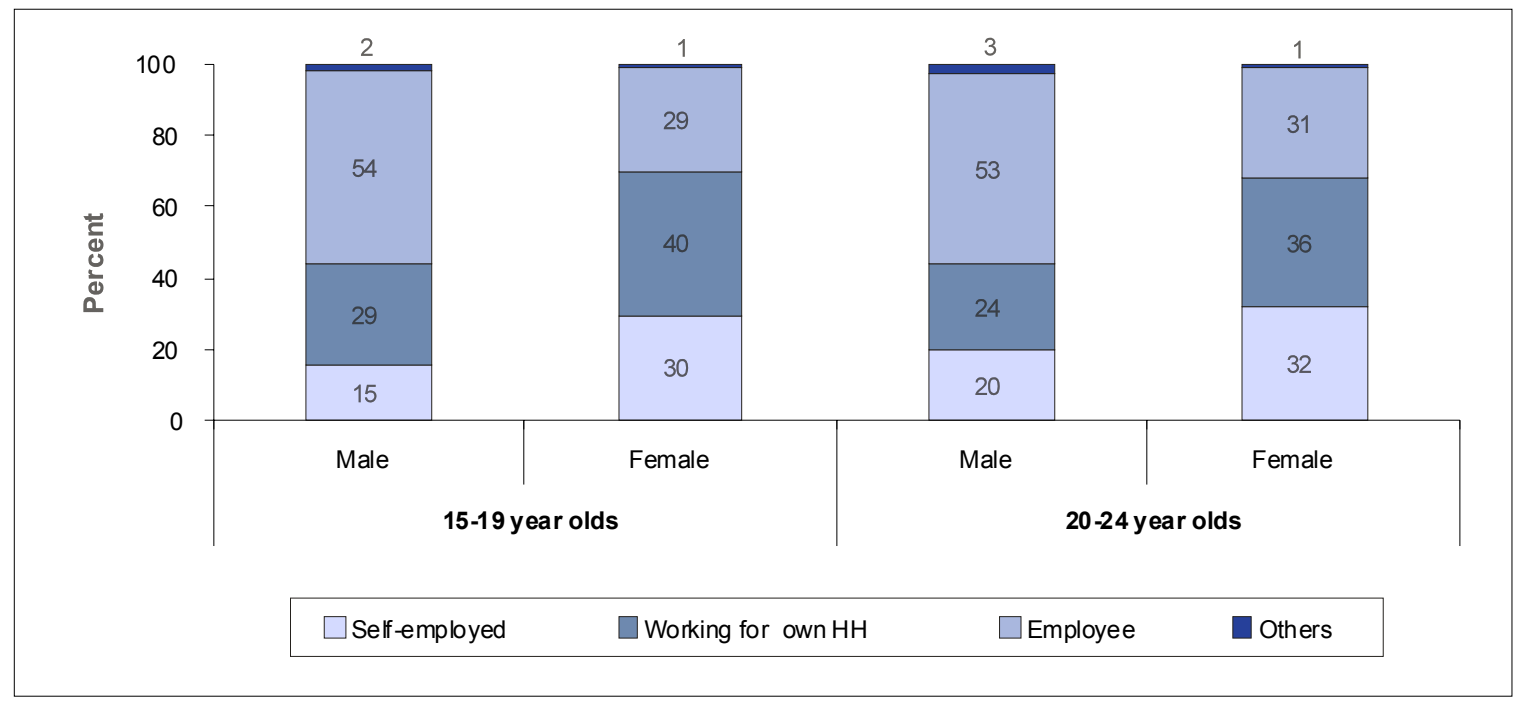

A closer look at young people who work at home or on their own farm shows that home-based work predominately relates to female. Approximately 65 percent of 
young females who work do so at home, compared to only 22 percent of young males (Table 4.9). Across the provinces, NWFP claims the highest proportion of young females working at home (mirroring the low proportion in agriculture, noted earlier). The lowest proportion of home-based work is found in Balochistan for females and in Sindh for males. Residence, urban or rural, does not significantly affect a female's participation in home-based work, but rural males are four times more likely than their urban counterparts to do home-based work. Interestingly, home-based work neither appears to be associated with socioeconomic status, nor with educational attainment for females. Meanwhile, there is a slight decrease for males in home-based work as socioeconomic status increases.

When asked about sources of knowledge about employment opportunities, more than three-fourths of young people report family members or relatives as the ideal source (Table 4.10). A distant second were friends, followed by "looking/asking around," person in the community, and former employer. Formal advertisements for jobs are consulted by almost no respondents. Thus employment opportunities across all sectors of work seem to spread by word of mouth, largely through networks of family and friends, rather than formal means, such as advertisements.

\section{Seasonality and intensity of work}

Table 4.11 highlights the duration of employment for young people over the past year and highlights the temporary nature of employment for females in particular. A large percentage of males who have ever worked are employed throughout the year (approximately 82 percent), compared to only 55 percent of female adolescents and 58 percent of female youth). At the provincial level, more than 80 percent of young males and 49-59 percent of young females are employed throughout the year in Punjab, Sindh, and Balochistan (Figure 4.12). In NWFP, however, far fewer males and females report stable work (59 percent for males and 38 percent for females). Females who are most likely to work full time come from the highest income groups and have higher levels of education. For young males, there is no variation across income groups or levels of educational attainment. 
Figure 4.12 Percent who worked throughout the year by province, of those who ever worked, by sex

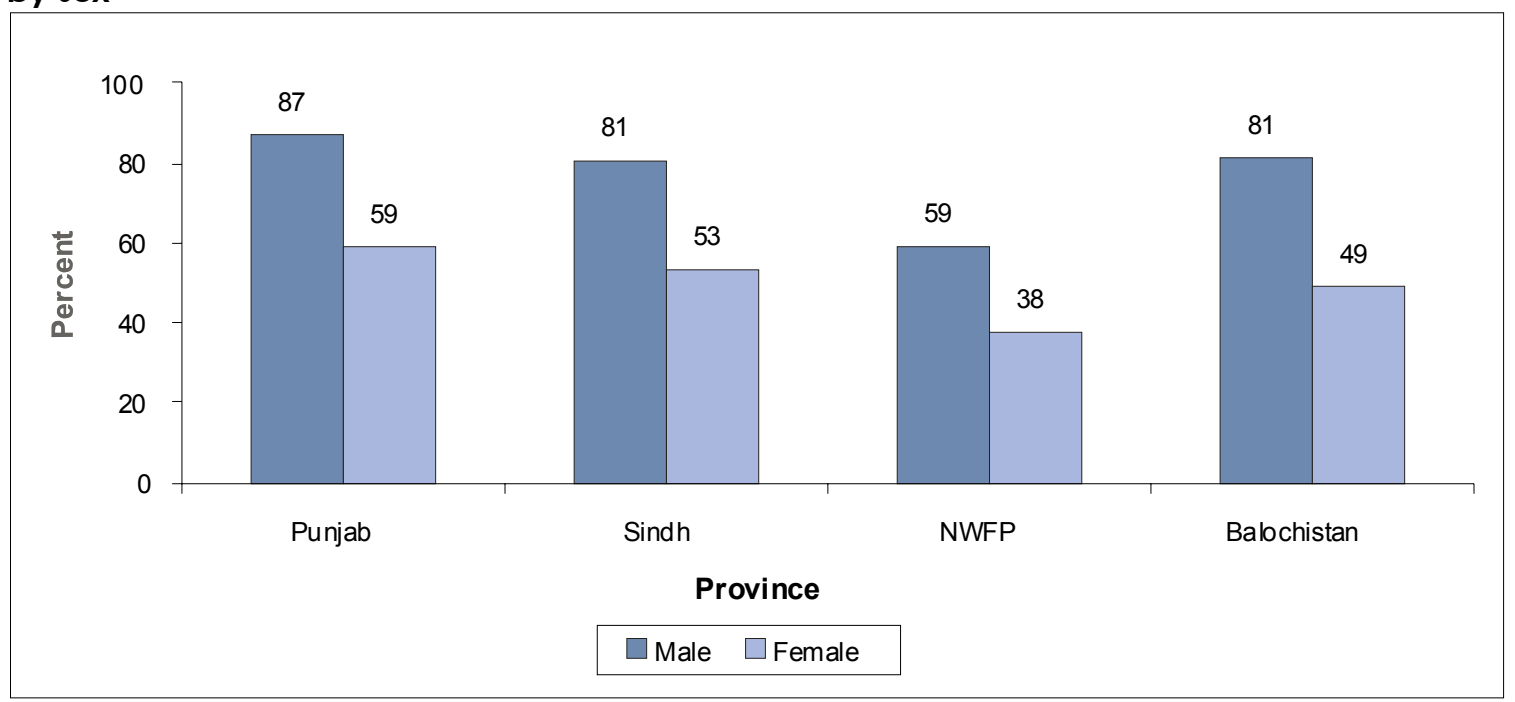

The number of hours worked per day and the duration of employment provide a useful insight into the workload of young people. This analysis will focus on adolescents, as there is minimal variation between the two age cohorts. Table 4.12 shows that on average adolescent males work 53 hours per week compared to 40 hours for adolescent females. In urban areas, work hours are slightly longer for males and slightly shorter for females, but they do not appear to vary significantly with other background characteristics. For young females, mean hours of work are, as expected, higher among low-income groups and those who are least educated. However, these statistics on mean hours of work considerably underestimate the workload for some females, because of the additional burden of household chores (reported in the analysis of time-use data in Chapter 2).

Agricultural work is very demanding in terms of time for both young males and females, and the majority of both sexes work 40 hours or more a week (Table 4.13). Other occupations are more flexible for women and allow them to pursue them on a part-time basis. In the agricultural sector more adolescent females work 40 hours per week than males (75 percent and 60 percent, respectively); however, in all other work categories males are more likely to work longer hours than females which suggests that females opt for part-time work in the face of their domestic workload. Nevertheless, regardless of occupation, the overwhelming majority of young males employed in the labor force in Pakistan are working 40 hours or more (Figure 4.13). 
Figure 4.13 Hours worked per week, of those who ever worked by age and sex

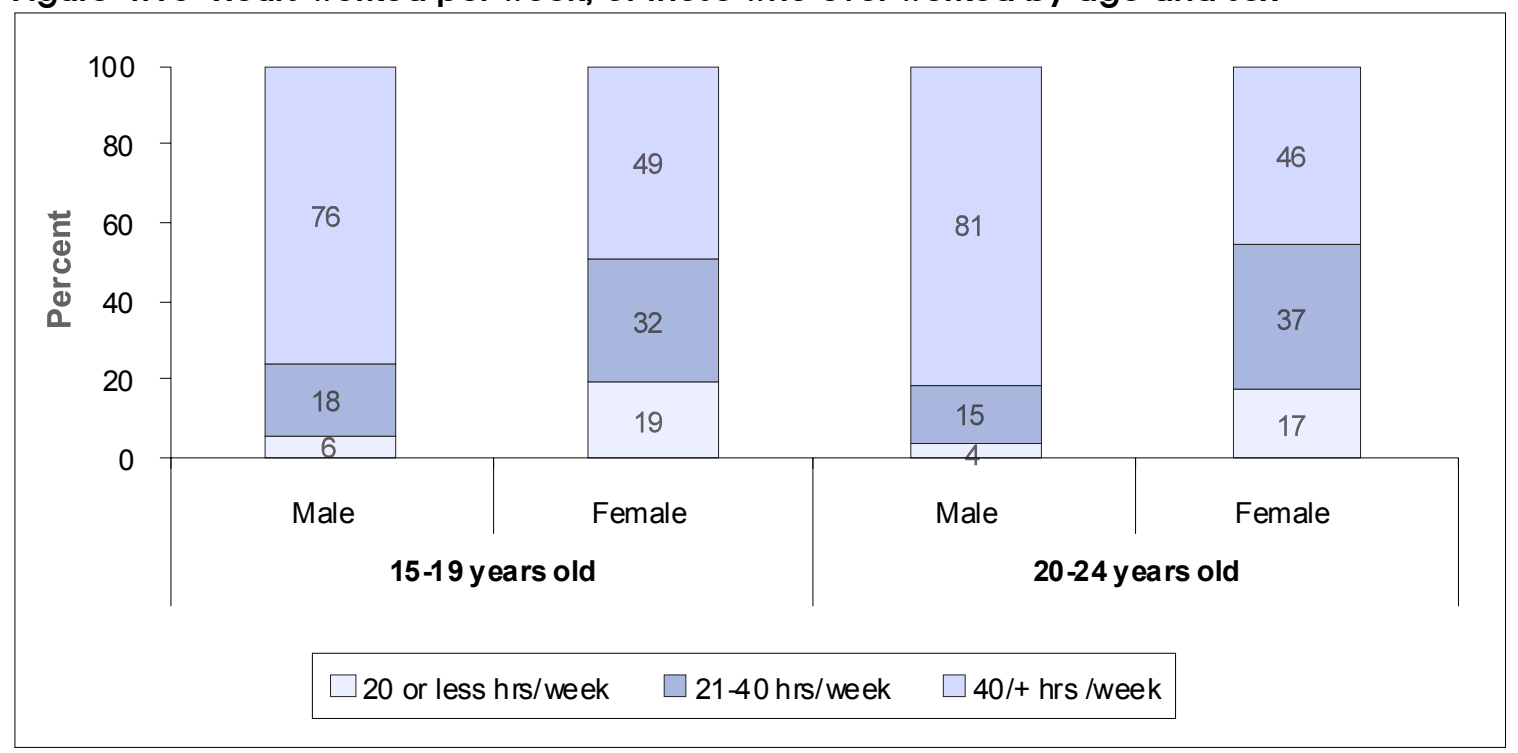

\section{Remuneration and control of earnings}

Almost all young people in the labor force report receiving remuneration either in cash or in kind. The survey collected information on who received the earnings as well as who controlled that income in the household. A larger percentage of working young males appear to receive their pay directly compared to young females (68 and 56 percent, respectively). In cases where young people did not receive their salary directly, an older family member took receipt. The percent of respondents who receive their own pay appears to rise with age for both sexes, but particularly for females. 
Figure 4.14 Distribution of recipients of young people's earnings, by sex and age

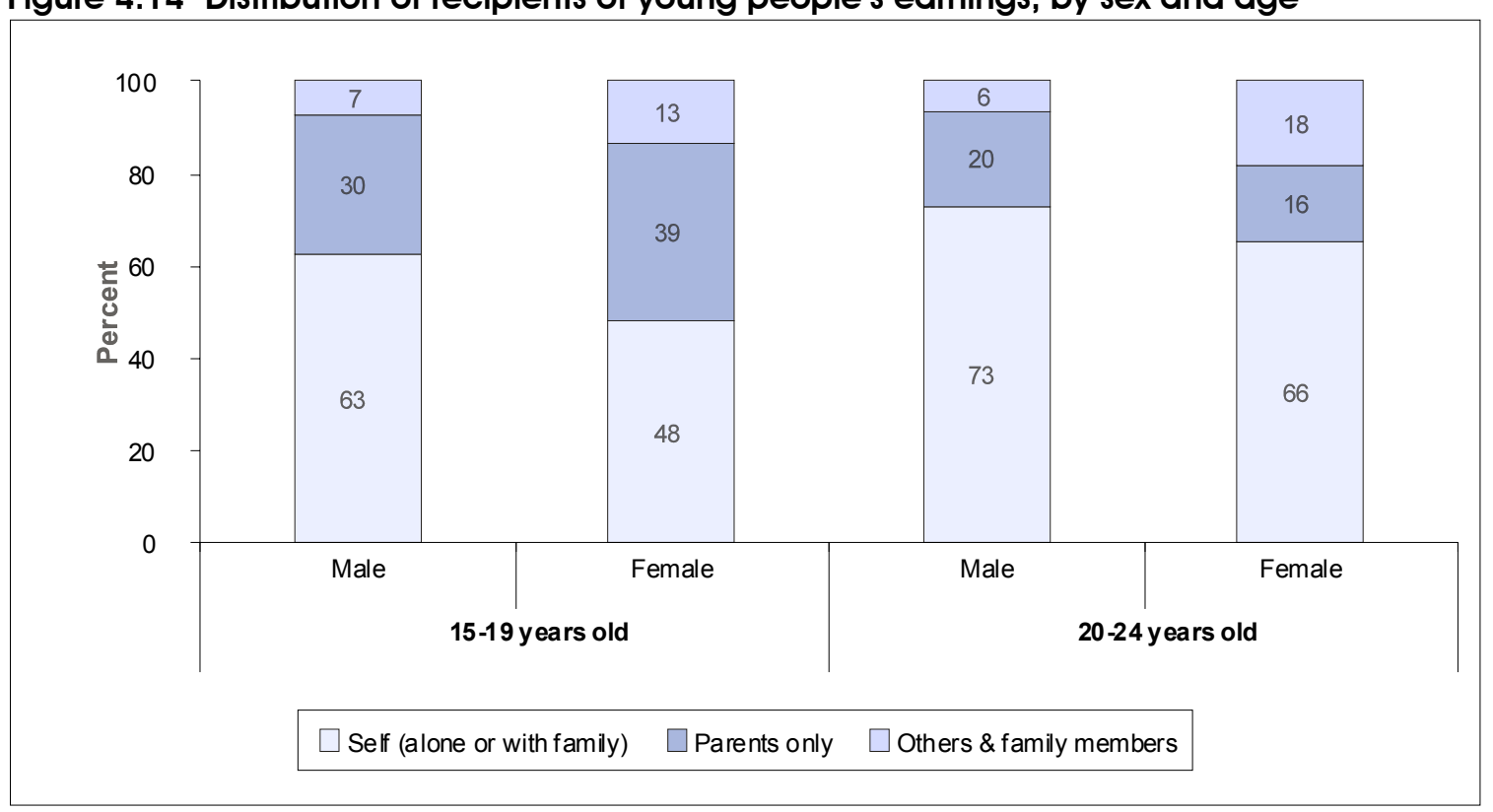

A closer look at this sub-set also shows that young urban females and males are more likely to receive their own payments than their rural counterparts. Those who were least likely to receive direct payment for their labor were young females in Balochistan and Punjab where the majority of working females are engaged in homebased work, come from poor households, or have less education (Table 4.14).

The survey also asked about control of income in the household, among those who were the direct recipients of the income. Interestingly, while only about 10 percent of young males in both age groups are able to keep all of their income for themselves, this proportion is much higher for females (Figure 4.15). Over one-third of adolescent females and almost half of female youth report that they keep all of their earnings for themselves. The majority of young males (approximately 60 percent) appear to share their income with their family, while about one-third of them hand over the entire wage. In contrast, only 20 percent of female adolescents and 16 percent of female youth give their entire salaries to their household and a much higher proportion of females share only a part of their income (43 percent for adolescents and 37 percent for youth). There are several possible explanations for the greater control over earnings exercised by females. First, female earnings are likely to be lower than male earnings and may be considered too insignificant a contribution to household maintenance. Second, it could be a matter of male pride not to take female earnings so as to maintain the status quo of intra-family power relations related to earning power. Another reason could relate to the irregularity and instability of female work, which would make it a less reliable regular source of income. Alternatively females may be encouraged to direct their own incomes 
toward their dowries. There is also the possibility that these findings actually relate to the selectivity of the females who receive their own pay to begin with.

Figure 4.15 Distribution of the control of earnings, based on the income of those young people who have been the direct recipients of earned income, by sex

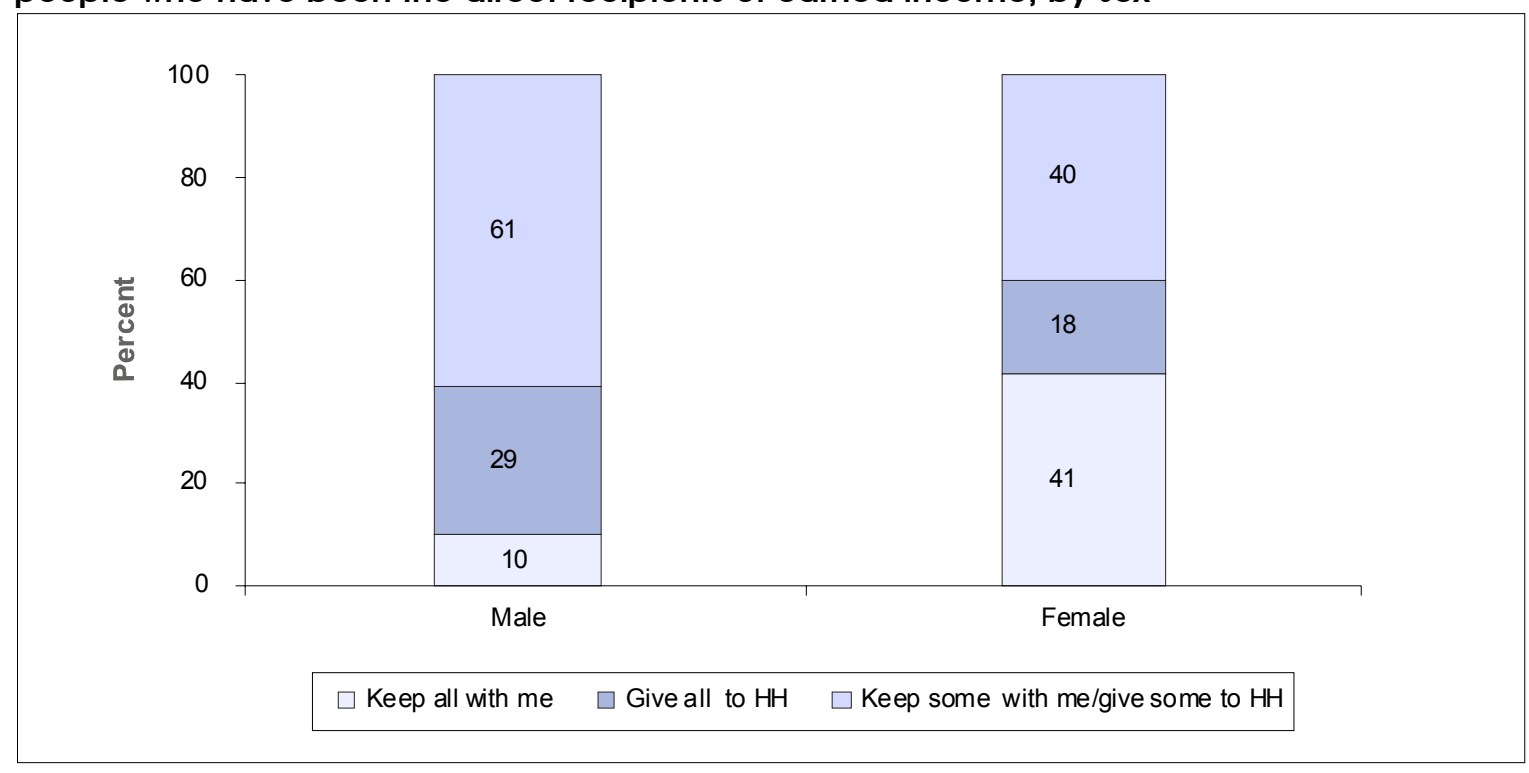

\section{WORK OPPORTUNITIES IN THE COMMUNITY}

The community survey provides insight into training opportunities for young people in the vicinity of their own communities. Such training opportunities include vocational training where young persons can improve and build their skills for work. Informants in the communities report very few formal opportunities for such training. Overall, only five percent of males and nearly 10 percent of females appear to reside in communities where training opportunities exist. The situation is slightly better in the urban areas, as noted in Figure 4.16. 
Figure 4.16 Percent of all young people who reside in communities where vocational training is available, by sex, residence, and age cohort

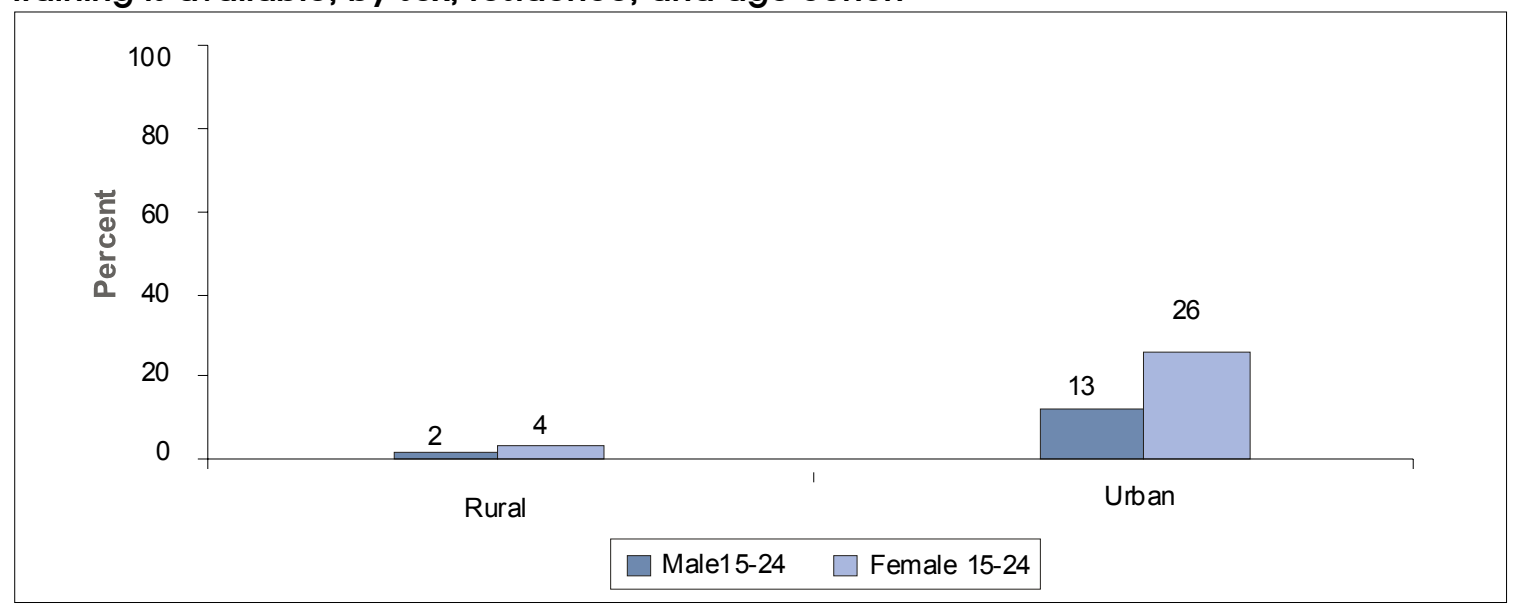

Where vocational training exists, access is restricted along residential and gender lines. Urban communities offer the most training possibilities although, surprisingly, there seem to be slightly more opportunities available for females than for males (Figure 4.16). However, when access to vocational training opportunities are disaggregated by the type of training available, it appears that access for males is actually better than for females (Table 4.15). Almost one-third of urban males live in communities with computer centers, around 16 percent live near mechanical workshops, 19 percent live near electrical workshops, and almost 10 percent live near carpentry workshops, the last three of which presumably offer apprenticeships. For young urban females, the only training opportunities are for handicrafts and computers, and even these opportunities are only available to less than a fifth of females in the sample. In rural areas the picture is different, with less than five percent of young males and females having access to any type of training opportunity.

Employment options for young people appear also to be limited. However, work opportunities appear to be equally available for both males and females. In urban areas, waged labor appears to be the most likely option followed by industry and private service. In rural areas, the agricultural sector offers the most opportunity for work for both males and females, followed by waged labor, again for both sexes.

Looking at the unskilled daily wages earned by adults as reported by community informants, females appear to earn less than their male counterparts across all age groups (Table 4.16). Nearly all communities report that males earn between 50-200 rupees whereas two-thirds of communities report the same for female adults. While 40 percent of communities report that female adults were earning less than 50 rupees a day, only eight percent of communities report the same for male adults. Among rural 
communities, 13 percent say male adults earn less than 50 rupees a day whereas the majority of urban communities report higher wages for men. For working adolescents, the gender differential persists.

\section{CONCLUSION}

The transition to work plays out very differently for young men and women in Pakistan. A minority of both males and females appear to begin their work life as child laborers. However, child labor involves at least a third of all females and half of all males in the poorest quartile of the population. Child labor rates are higher in rural areas than urban areas, particularly for females. The highest rates for both males and females are to be found in Sindh. Across the provinces there appears to be a slight increase in child labor rates for males in rural Balochistan and NWFP. Although rates have decreased slightly in rural Punjab, they have increased slightly in urban areas. It is likely that an increase in the number of children who complete primary school would lead to a decline in child labor as this survey shows very few young people combining work with schooling.

Children from the poorest households and with the least education are the most likely to work before their $15^{\text {th }}$ birthday. Although most young men eventually transition into the paid labor force, less than 40 percent of women have entered the workforce by the age of 24 . Indeed, throughout their childhood and adolescent years, the majority of young women remain invisible in that they are neither attending school nor engaging in economic work. Although female domestic work was not discussed in this chapter, Chapter 2 uses time-use data to demonstrate the heavy domestic burden carried by females who do not attend school. Most young people who have never worked express a desire to work in the future.

Among young people who work, the most common type of employment is in the agriculture sector. Other employment domains are segregated by gender, with many young women engaged in stitching, embroidery, and knitting, while young men work in factories, are self-employed, or are engaged in skilled labor. Young women are also much more likely to work at home. Young males work on average longer hours than young females; however, young females are more likely to engage in seasonal work than males. Young females are slightly less likely to receive their pay directly, but if they do, there are more likely to be able to keep it.

For young people growing up in Pakistan there are limited opportunities for vocational training and work. In urban areas most vocational training opportunities for males are in computer centers or apprenticeships in mechanical or electrical workshops. 
Fewer avenues open to females and are often limited to handicrafts, or for the literate, computer centers. In rural areas, opportunities are very narrow for both sexes, primarily consisting of mechanical workshops for males and handicrafts for females. Work opportunities are also limited, particularly in rural areas. Waged labor, industry, and some private service work are available for males, while industry, private service, and some government jobs are available for females. Agricultural work and waged labor are almost the only options in rural areas.

\section{REFERENCES}

Durrant, Valerie. 2000. Adolescent Girls and Boys in Pakistan: Opportunities and Constraints in the Transition to Adulthood. Islamabad: Population Council.

Khan, Aliya and Lubna Shahnaz. 2001. Trade-Off Patterns between Work and Education of Adolescents: Evidence from PIHS 1998-1999.

Shahnaz, Lubna and Abid Burki. 2001. An Empirical Analysis of Child Labour and Child Schooling in Rural and Urban Areas of Pakistan. Islamabad: Conference Proceedings. Population Association of Pakistan.

Fedral Bureau of Statistics 1999-2000. Labour Force Survey 1999-2000. Islamabad: Government of Pakistan.

United Nations Convention on the Rights of the Child. 1989. UN General Assembly Document A/RES/44/25. 


\section{Puberty, Marriage, and Childbearing}

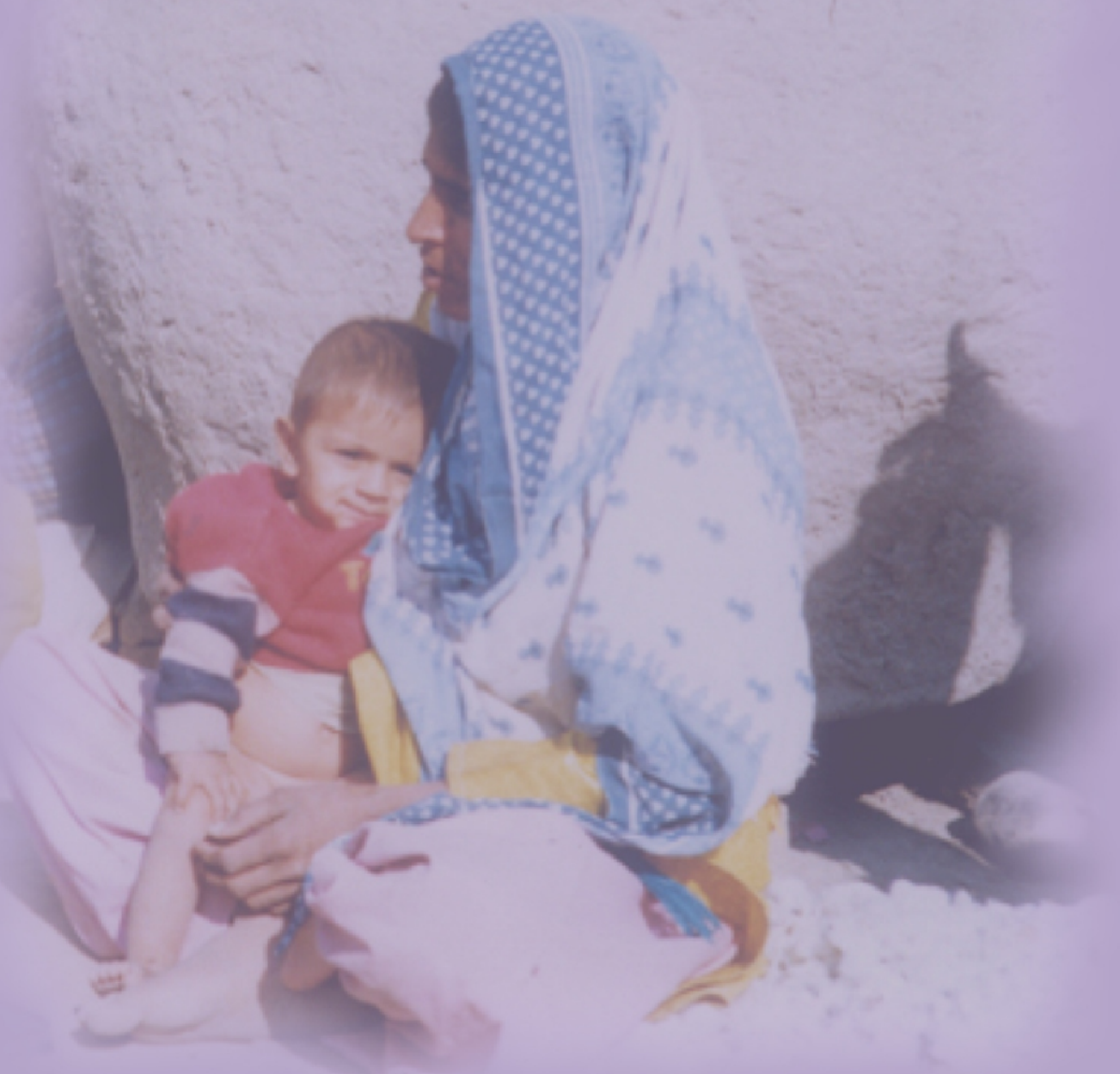

In this chapter:

- Introduction

- The Transition to Puberty

- The Transition to Marriage

- Transition to Pregnancy and Childbearing

- Conclusion 


\section{Puberty, MARRIAGe, AND ChildBeaRING}

\section{INTRODUCTION}

Puberty, marriage, and childbearing have long been of interest to demographers, largely due to the link of fertility levels with the timing of these transitions. However, little attention has been paid to the social, economic, and cultural context or consequences of these transitions. Likewise, the focus has been almost exclusively on the experience of females and has ignored the diversity of experience arising from the social relations of gender.

The AYP provides a rich source of information on puberty, marriage, and childbearing from a cross-section of adolescents and youth in Pakistan. Both married and unmarried young people, male and female, were asked about their experiences with puberty, as well as attitudes and expectations about marriage and childbearing. Perspectives from both male and unmarried young people on these matters provide new insight into these transitions. Formerly, most data on these topics only covered married women.

The first section explores experiences relating to puberty, a physical marker of maturity for adolescents and a precursor to marriage for many females. The onset of puberty ushers in distinctive gender-defined social trajectories for adolescents, with opportunities increasing for males coming of age and the world of possibility narrowing for females.

In the marriage section, trends and levels are examined by education, socioeconomic status, ${ }^{18}$ rural-urban differentials, and provincial residence at the time of the interview. The second section addresses the process of marriage, including how spouses are selected and the economic exchanges involved in the union. Finally,

18 The socioeconomic variable is difficult to interpret in the context of marriage, particularly for females, because it refers to the status of the respondent's current household and not necessarily the natal household from which the decision to marry was made. Whereas the variable has more meaning for males who often stay in their natal home immediately after marriage, the variable only has meaning for females if the assumption is made that a female marries into a similar socioeconomic status as her natal home. Therefore, while the results for the socioeconomic status will be reported in the tables at the end of the chapter, there will be little discussion of its relevance in the text. 
attitudes and perceptions surrounding marriage are presented as reported by married and unmarried young people and household respondents.

The other set of issues addressed in this chapter relate to pregnancy, childbearing, and contraceptive use. While this analysis focuses on ever-married women, questions on attitudes and expectations were asked of the entire sample and are reported. The data are also rich in the sense that information was collected from both females and males (on pregnancy and childbearing of the male's spouse) using direct questions as well as employing a birth history. Particular attention is given to pregnancy and childbearing among adolescents.

The life table in Figure 5.1 provides an overall view of the two transitions and suggests that while the patterns by sex for puberty are quite similar, the level and timing are clearly distinctive. From the ages of 11 through 21, a Pakistani female is likely to experience both of two events: puberty and marriage. For a male, these transitions are delayed and are stretched out over a longer period of time, beginning around age 13 and extending well into his late 20s. This chapter will also explore transitions to childbearing and contraceptive usage in further depth, looking at the timing, decisionmaking, and attitudes surrounding each.

Figure 5.1 Proportion reaching puberty and marriage, by age and sex

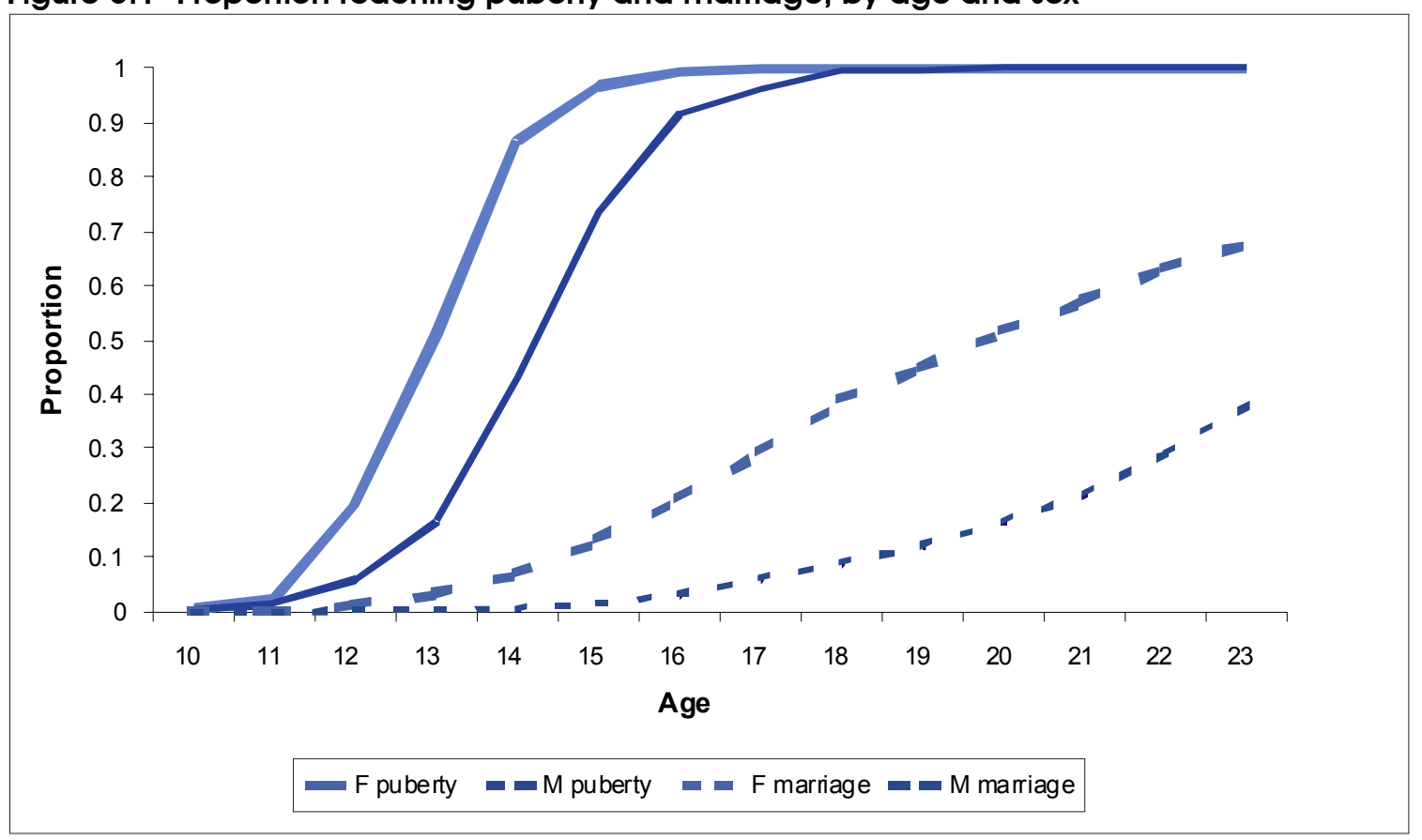

Note: Age represents end of full year at that age; for example, "under 20" is read at age 19. 


\section{THE TRANSITION TO PUBERTY}

\section{Timing and information}

Questions regarding puberty were asked of the entire sample of young people. For females, the question pertained to the onset of menstruation, while for males it concerned bodily changes associated with puberty. ${ }^{19}$ According to the respondents, puberty occurs on average at the age of 13.5 for females and 15.0 for males. Table 5.1 provides details on reported age at puberty for those who were aged 20-24 at the time of the survey. The cohort of adolescents was omitted in this table because they had not all reached puberty and results would be biased towards the younger ones who had. However, the life table in Figure 5.1 illustrates the experience of puberty across the ages using the information from all respondents.

Those young people who had reached puberty were asked whether they had been informed about the event beforehand. According to Figure 5.2, more males than females reported such knowledge in both age groups, while a slightly higher proportion of females in the younger group had been informed, compared to the older group (33 percent versus 29 percent). Surprisingly, those currently residing in the rural areas and from poorer households were more likely to have been informed than those in the urban areas, with the difference being greatest among females (Table 5.2). Asked whether they thought they should be informed in advance, three-quarters of females and two-thirds of males answered in the affirmative (Table 5.3), suggesting a particularly significant gap between females who are informed and those who wish they were informed.

19 The interviewer began the discussion with: "As males begin to mature into men, certain changes occur in their bodies - for example, their voices become deeper, their genitals get bigger and they develop pubic hair, they begin to get hair on their faces, and perhaps they begin to get acne on their skin or to have wet dreams." The first question to the male respondent is: "Have any of these changes begun to happen to you?" It should be noted here, that due to the sensitive nature of this question, the interviewer had the flexibility to modify this statement according to the respondent and field circumstances. 
Figure 5.2 Percent of young people who were informed about puberty and those who think young people should be informed, by age and sex

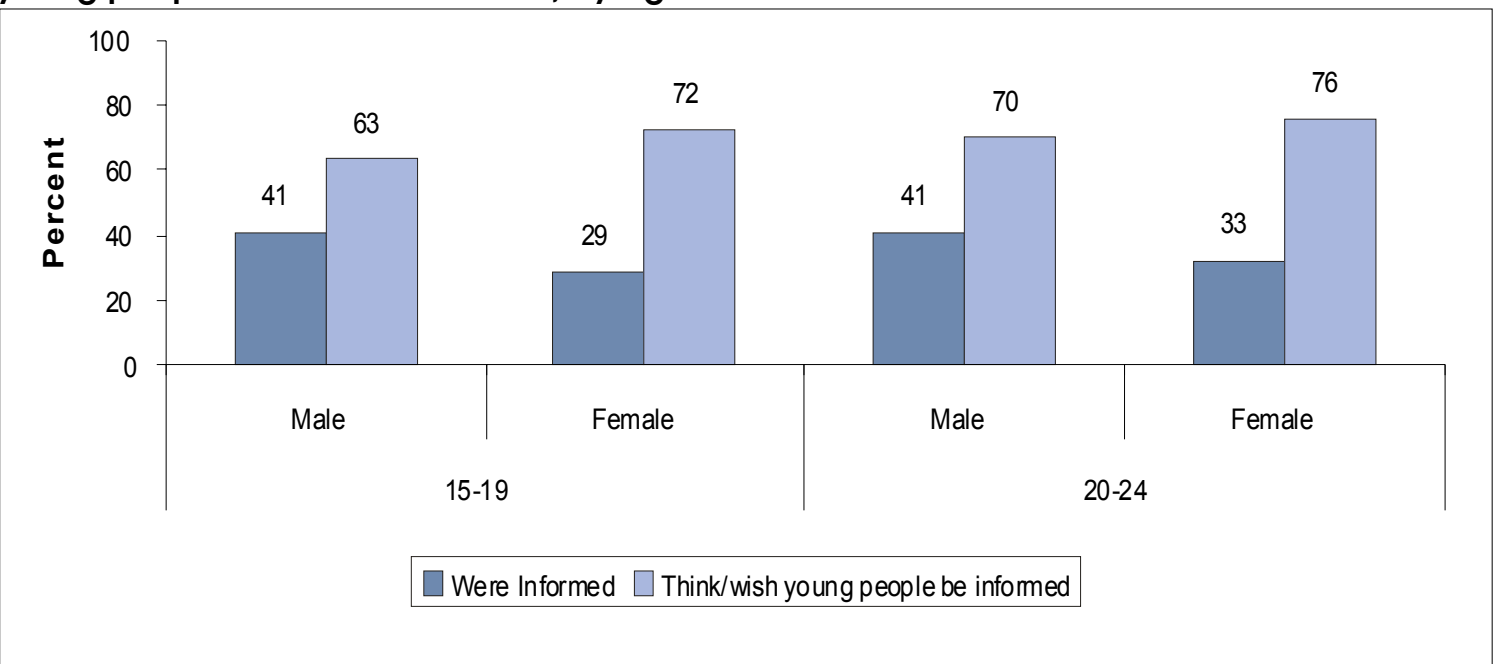

Note: Multiple responses were possible; male respondents were offered choice of male relatives and friends and females were offered choice of female relatives and friends.

Of those informed, females were most likely to hear about this transition from their mothers, but with a number also learning from a sister or friend (Figure 5.3). Among males, a vast majority heard from a friend. When asked who they would like to inform them about puberty, females said they would like to hear from their mothers, followed by a sister. In contrast, males wished to hear from friends, followed by fathers. Across age and sex, more young people wanted to hear from their parents about the experience of puberty than were currently being informed (Table 5.4 and Figure 5.3).

Figure 5.3 Persons from whom young people heard about puberty, by age and sex

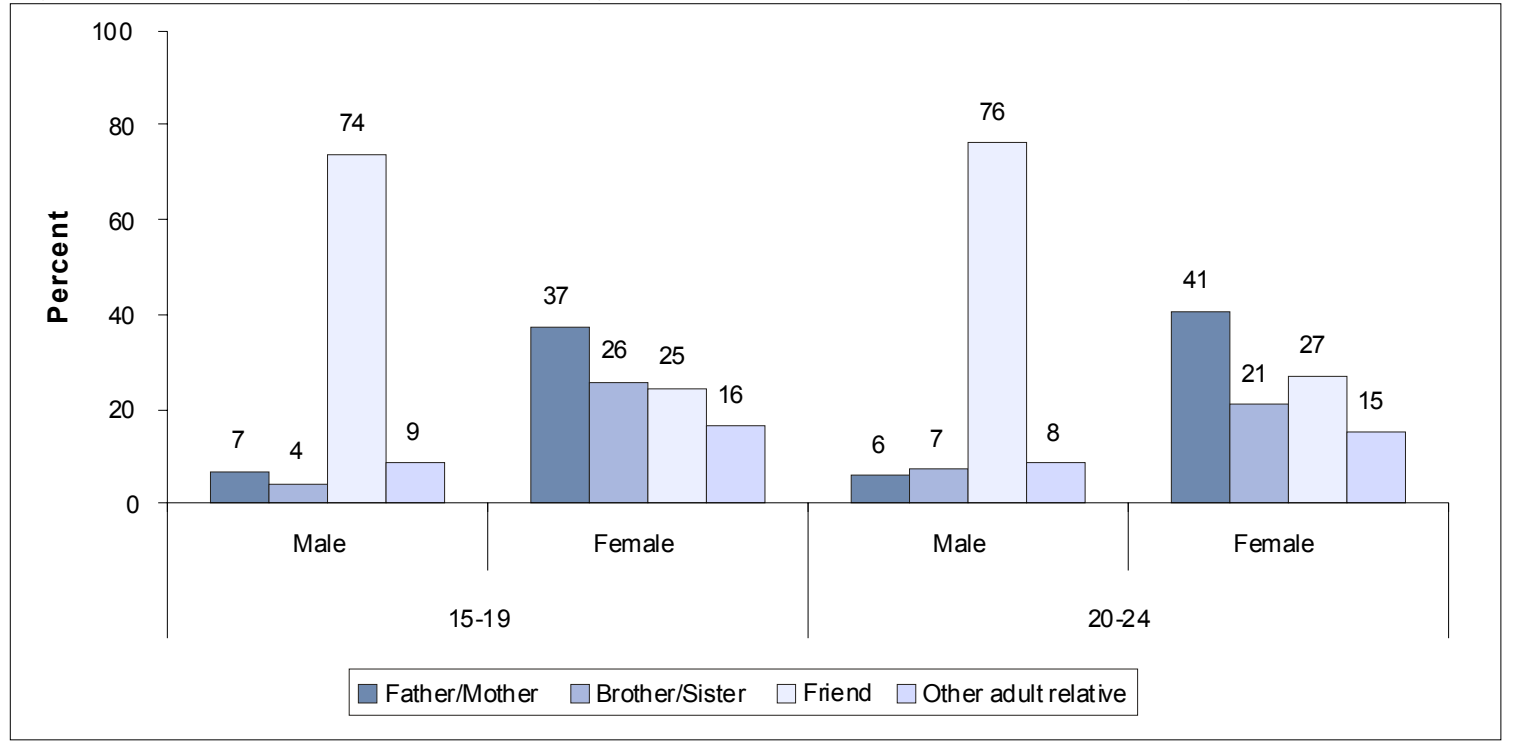

Note: Multiple responses were possible. Response choices: see note Table 5.2. 


\section{Interaction of puberty with other transitions}

\section{School enrollment and the onset of puberty}

The lack of information transferred to females prior to puberty suggests that her social network and access to information is quite limited at the onset of menarche. This hypothesis is further confirmed when looking at school enrollment by puberty status. The combination of low ever enrollment and high dropout rates for females means that only a third of all females were enrolled in school at the onset of puberty (Table 5.5).20 These results show that more adolescents were enrolled in school at the time of puberty than youth; however, the picture remains discouraging.

The greatest difference between the two age groups is in Balochistan, where only 17.3 percent of all adolescent females were in school at the time of puberty, indicating that despite apparently large gains in the province, overall enrollment for females remains low. Even in Punjab, where enrollment at puberty was the highest, only 38 percent of adolescent females were in school at menarche. Even more dramatic is the variation across socioeconomic quartiles, such that only six percent of all adolescent females in the lowest SES quartile were in school at the time of puberty.

When the curves of school enrollment and the onset of puberty are plotted against each other for both males and females (Figure 5.4), it is clear that a much higher proportion of males than females are in school at the onset of puberty, even though puberty occurs at a later age for males.

Figure 5.4 Proportion of young people enrolled and reaching puberty, by age and sex
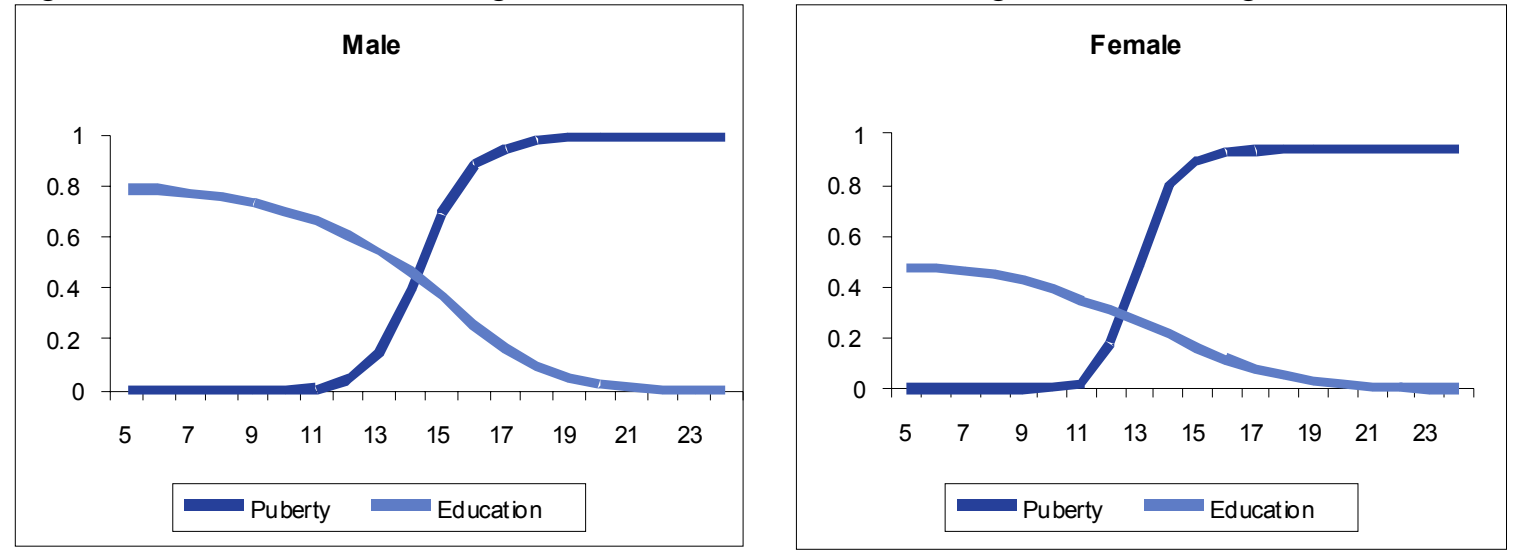

20 These results were calculated by taking the age at which a respondent reported that menarche occurred, identifying the data related to that age in the LEC, and then checking the respondent's school status at that time. 


\section{Marriage, work, and the onset of puberty}

A dramatic picture is revealed when examining the onset of puberty in light of transitions to work and marriage. With the age of marriage increasing for females in Pakistan, the gap between puberty and marriage is becoming wider. Figures 5.5 and 5.6 illustrate the pattern of these three transitions for both males and females. For males, more than 20 percent have already entered the work force at the onset of puberty and there is a steady increase in work afterwards. Marriage is a much less common phenomenon for younger men.

For females, the onset of puberty is coupled with significant restrictions on their mobility. During this period, females are more likely to be "protected" from exposure outside the home, which can include access to education and work. These restrictions often stem from parental fears of harassment outside the home and the potential of bringing disrespect to the family. Therefore, taking into account the difficult access to school, especially in rural areas, the family may decide to take their pubescent daughters out of school. The same is likely for labor force participation, although a considerable proportion of rural females participate in agricultural labor. However, there is little opportunity for any skills development or enhancement as pubescent females wait for marriage.

Figure 5.5 Percent of males entering puberty, work, or marriage, by age

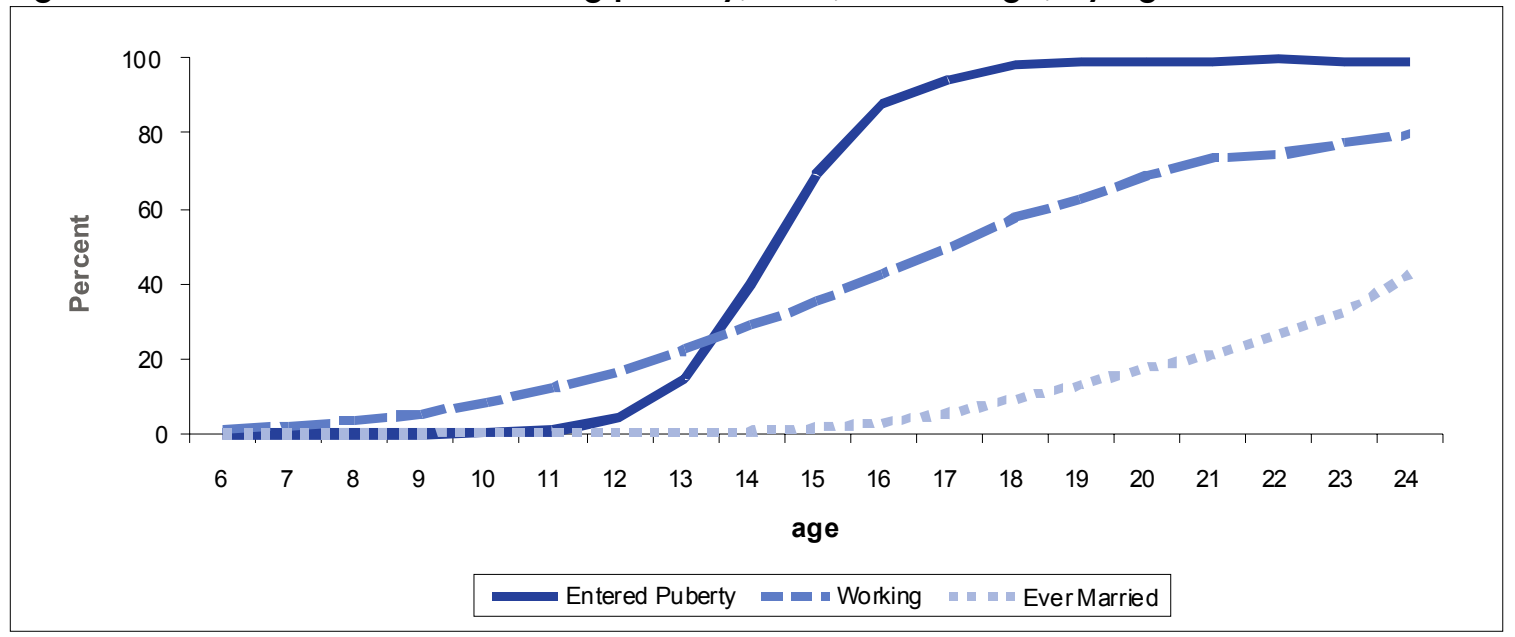


Figure 5.6 Percent of females entering puberty, work, or marriage, by age

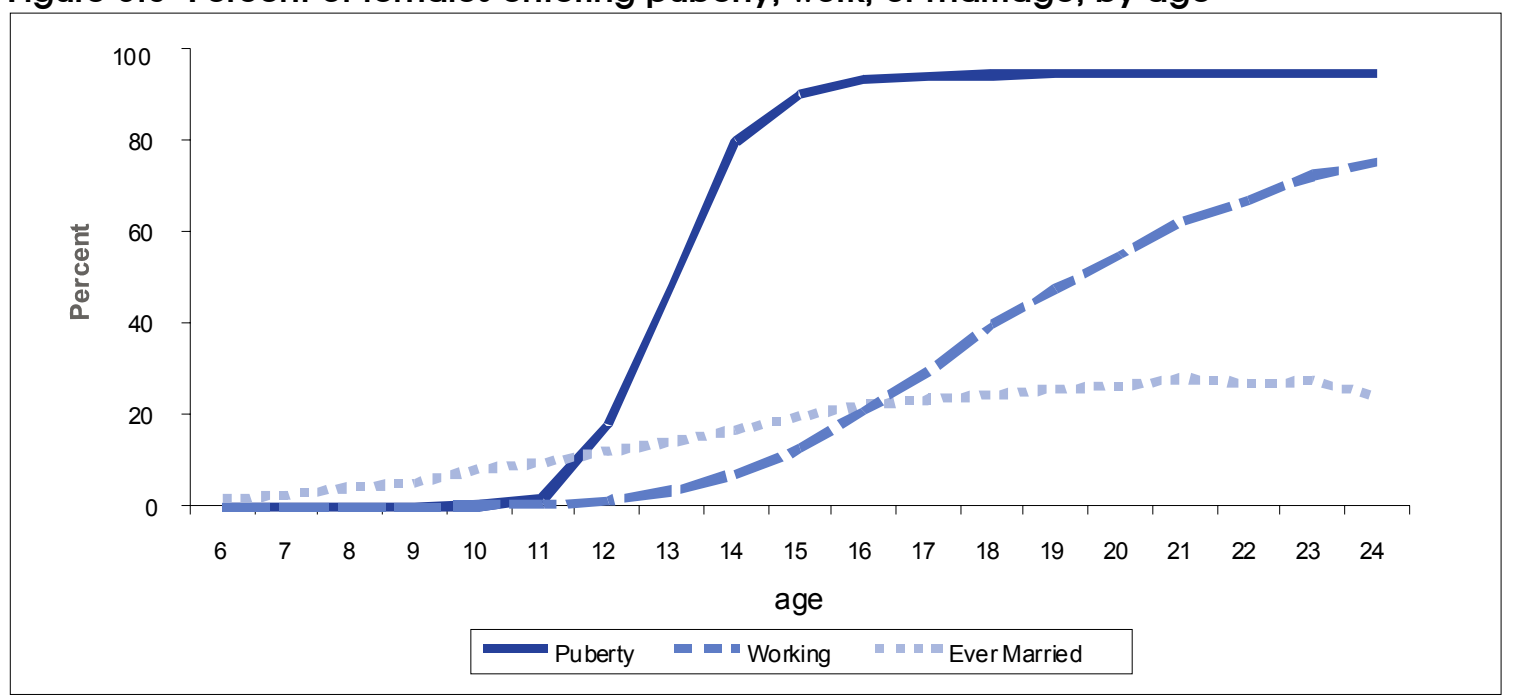

\section{THE TRANSITION TO MARRIAGE}

The AYP provides a fresh perspective of the phenomenon of marriage in Pakistan. For the first time in a nationally representative survey, young people themselves are reporting on questions regarding marriage, including the process of spouse selection.

\section{Levels and trends}

Over the past 50 years, the percent of young men and women aged 20-24 who are married has declined steadily (Figure 5.7). Whereas in 1951, 52 percent of males, and 82 percent of female youth were married, the AYP data reveal a drop to 27 percent of males and 63 percent of females in 2001, figures that fall on the trend line depicted below. 
Figure 5.7 Trends in percent married for males and females aged 20-24

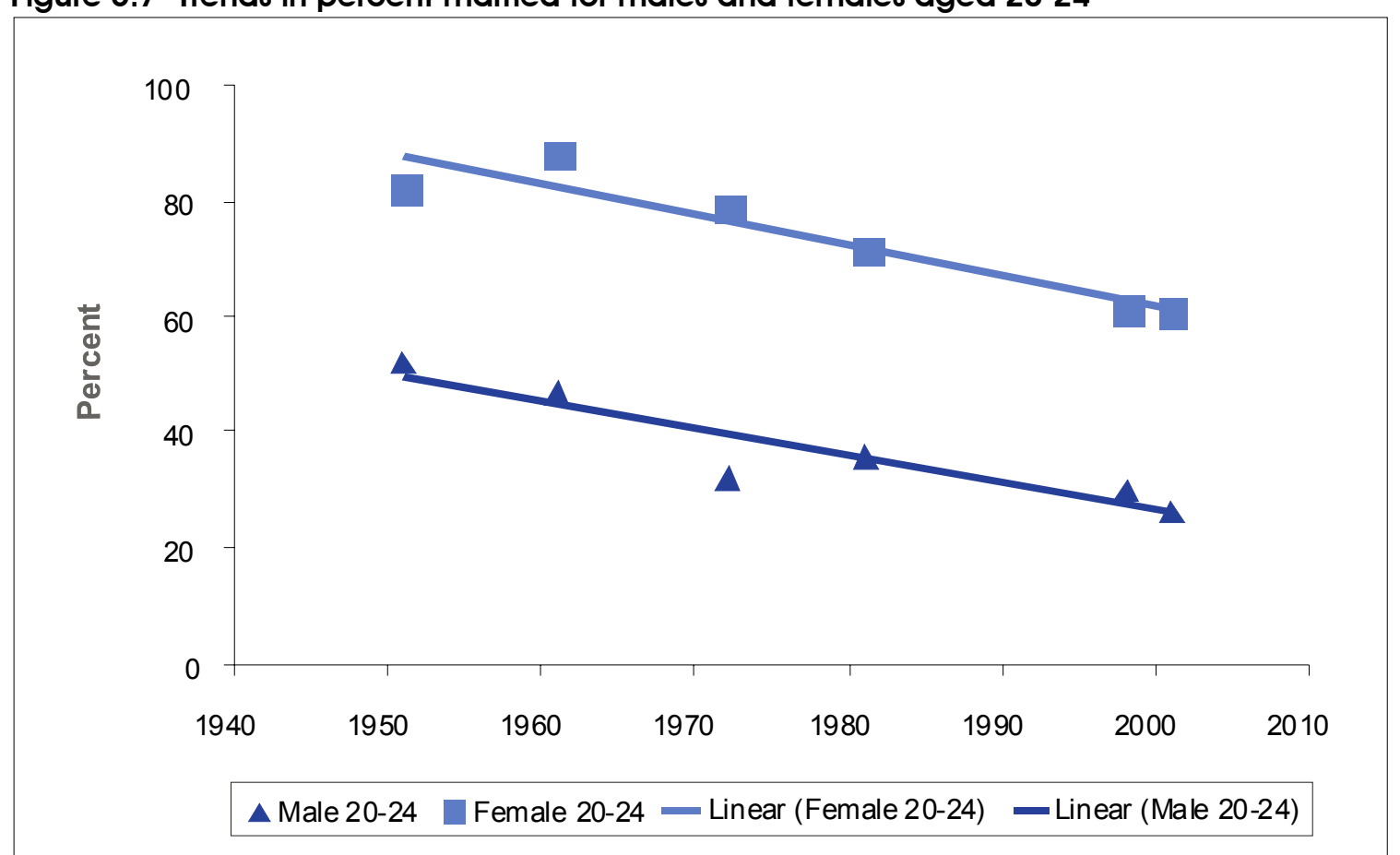

Source: Government of Pakistan Census, as reported in Valerie L. Durrant, Adolescent Girls and Boys in Pakistan: Opportunities and Constraints in the Transition to Adulthood, Islamabad: Population Council, 2000.

Note: Trend lines derived from linear regressions

A life-table analysis can provide the richest summary of age at marriage, ${ }^{21}$ accounting for all information collected and predicting the number who will be married by any given age. The underlying assumption of this analysis is that there has not been dramatic change in behavior for the ten years represented. The predicted "survival to marriage" analysis for females and males in Figure 5.8 shows that 47 percent of females and 14 percent of males are married before the age of 20. The minimum legal age at marriage in Pakistan is 16 for females and 18 for males. The life table suggests that 14 percent of females and seven percent of males marry before the legal age. The steepness of the curve for females is greatest from age 15 to 18. After age 21, males begin a steeper climb towards marriage, slightly narrowing the gap with females.

21 Although interviewers were trained to obtain the most accurate responses possible, those regarding age are among the most difficult to collect, since many respondents are unaware of their current chronological age. When asked about age at marriage, a respondent may therefore refer to the age at which they think it is appropriate to marry. Unlike much data on such life events, there was not significant "heaping" on major ages such as 16,18 , and 20, suggesting that care was taken by interviewers to extract the most precise age possible. 
Figure 5.8 Life-table analysis: proportion of young people married, by age and sex

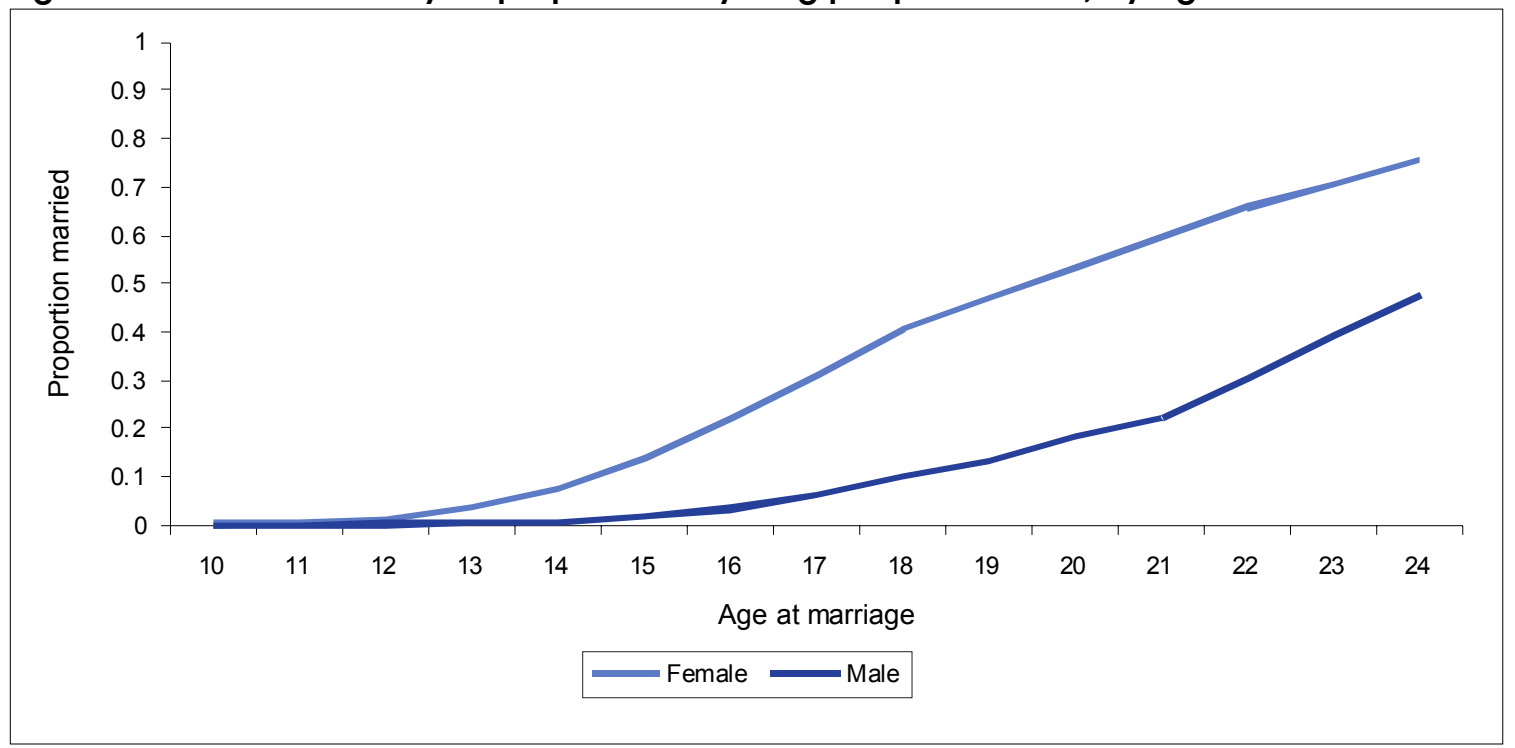

Note: "Age" represents end of full year at that age.

For both males and females, rural residence accounts for the majority of early marriages. For adolescents in the younger cohort, five percent of males and 23 percent of females reported being ever married (Table 5.6). At the time of the survey, 27 percent of rural females and seven percent of rural adolescent males were ever married, compared with 11 and 2 percent of urban females and males, respectively. At the later ages of 2024, the pattern continues, with 70 and 34 percent of rural females and males ever married, compared to 44 and 15 percent of urban females and males.

While this analysis reflects the percentage of adolescents who were ever married at the time of the survey, the statistic underestimates the number who will eventually marry at their current age and significantly underestimates the number who will marry before the age of 20. A more precise snapshot of the number of adolescents who marry before the age of 20 can therefore be obtained by analyzing those who were aged 20-24 at the time of the survey. In this sample, 14 percent of men and 50 percent of women married before the age of 20. Among those who are currently aged 20-24, 58 percent of rural females and 27 percent of urban females were married before the age of 20 . Among males in this group, 18 percent in rural areas and five percent in urban areas were married before age 20 (Table 5.7).

In addition to rural/urban differences, there is also significant variation in age at marriage across and within provinces. Using the sample of those who are currently 2024 and were married by age 20, rural Sindh emerges with the highest percentage of both females and males marrying before the age of 20 , with 72 percent of females marrying 
by age 20 (see Figure 5.9). Balochistan is not far behind in rural marriages and has the highest urban marriage level of any province. As noted earlier, the rural/urban distinction is dramatic, with more than twice as many rural females married before age 20 than urban females (58 percent rural versus 27 percent of urban residents) and more than three times as many rural males married compared to their urban counterparts (18 versus 5 percent).

Punjab stands out as the province where females marry at a later age in both urban and rural settings (50 percent rural and 20 percent urban marry before age 20). Among males, urban Punjab reports the lowest proportion married before age 20 (4 percent), while NWFP holds the distinction for rural males (8 percent).

Figure 5.9 Percent of $\mathbf{2 0 - 2 4}$ year olds who were married before age 20

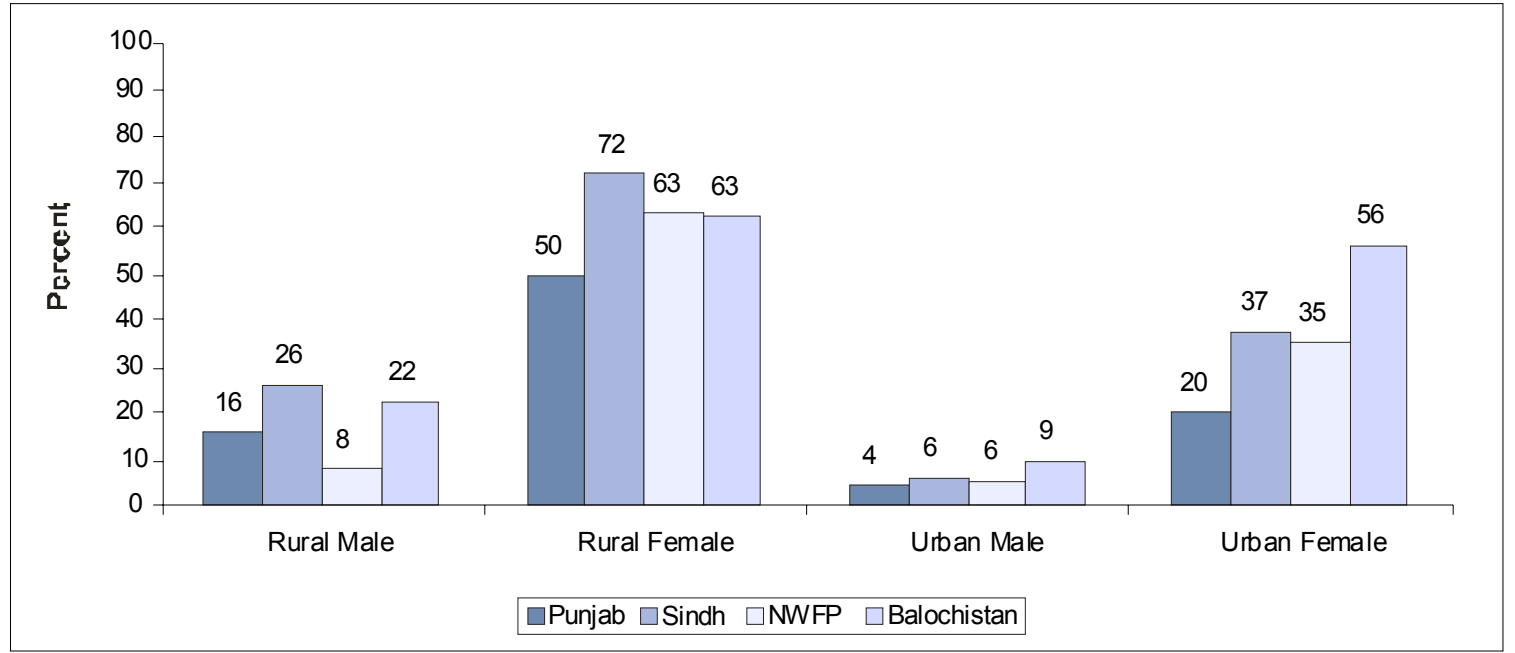

\section{Marriage and education}

Later age at marriage is strongly correlated with educational attainment, particularly for females. Figure 5.10 depicts the percent of those currently aged 20-24 who were married before age 20 by their educational status. Over 60 percent of rural and urban females who never attended school were married before the age of 20. There is a sharp decline in marriage that accompanies every level of educational attainment. At least some attendance of primary school reduces the level of marriage from 68 to 49 percent for females. The pattern is similar for males, although not nearly as dramatic. 
Figure 5.10 Percent of 20-24 year olds who were married before the age of 20 , by education and sex

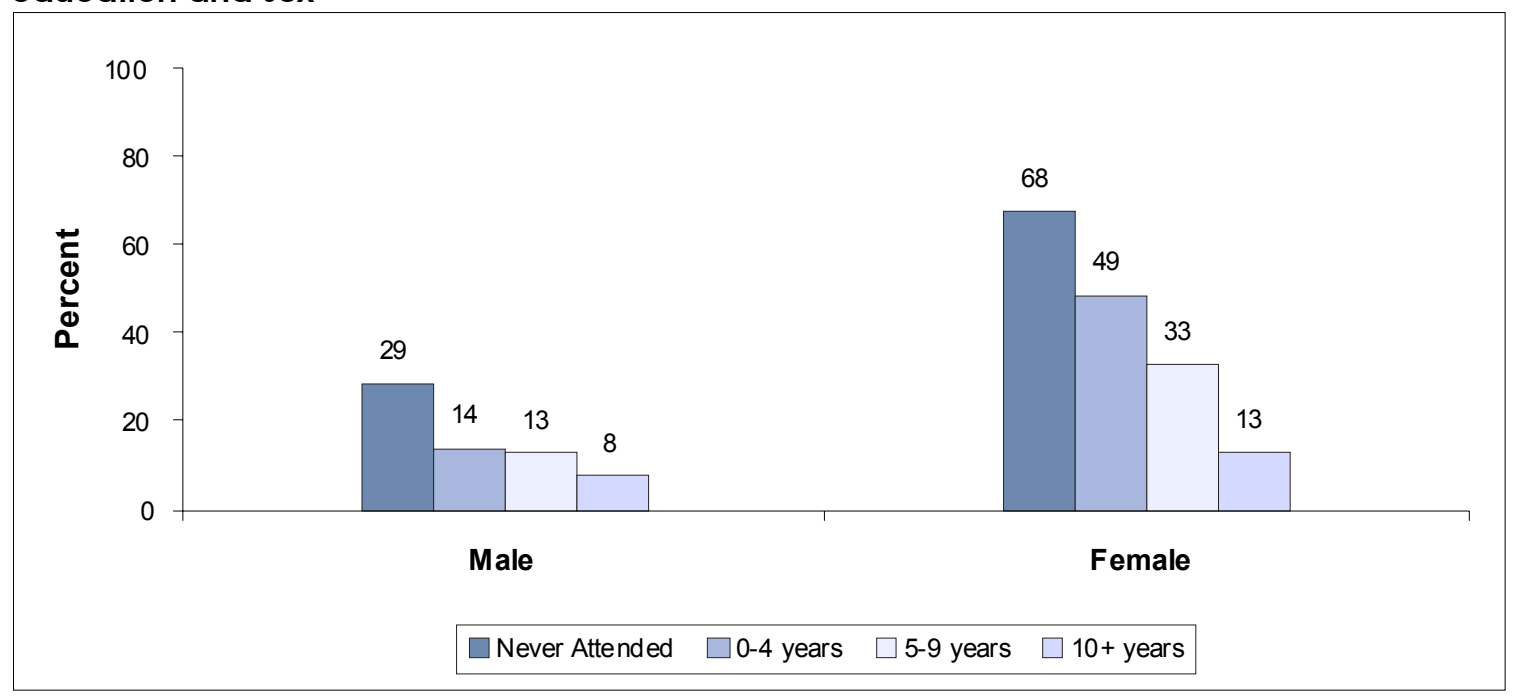

\section{Marriage process}

Using the subset of ever-married young people, the marriage process is closely examined with regard to selection of spouse and the economic exchanges involved. Because so few males aged 15-19 in the sample were married, this commentary will focus on the females of that age group, along with the older cohort of males and females. Totals by sex will include both age groups.

The majority of marriages in Pakistan are arranged by parents and other adults, and young people, and females in particular, have little to no voice in the selection of whom they marry. In the AYP, the youth were asked who selected their husband or wife. The results shown in Table 5.8 are dichotomized into having some say versus having no say. "Have some say" includes three responses: parents and self, others and self, and self only. The final category was a very small sample, and therefore was included under the heading of having some say. "Having no say" includes two responses: parents only and others only. Among the younger age cohort, three percent of females report having had some role in choosing their spouse. At the older ages, 11 percent of males and four percent of females take part in the decisionmaking process. Overall, Balochistan emerges with the most unequal level of inputs between the sexes, with males enjoying the highest level of input (24 percent) and females granted the least of any province (less than 1 percent). Males have the least say in Punjab ( 9 percent), where females marginally have the most input (4 percent). Although socioeconomic status does not present a strong association at all levels, the role of a young man or woman increases with high socioeconomic status. Overall, urban residence appears to be highly correlated with increased input. 


\section{Marriage and economic exchange}

As will be noted in a forthcoming section on characteristics of a match and household respondents' explanations for delayed marriage, the economic element of marriage is central to the union. A dowry, involving the transfer of money and goods from the family of the bride to the family of the groom, is the most commonly noted and practiced economic exchange at the time of marriage. In the AYP sample, over 95 percent of marriages included a dowry, with very little variation across province, socioeconomic status, education, or urban/rural residence. The dowry is primarily gifts, such a furniture, clothing, jewelry, crockery, and cash (Table 5.9). Only a few dowries (about 1 percent) include large in-kind gifts, such as land, homes, car, or motorcycle.

In addition to a dowry, some unions include a transfer of money and goods in the other direction: from the groom's family to the bride and her family. These transfers include the bride price (paid to the bride's family) and bride's gifts (given directly to the bride). Even when combined together as "transfers to the bride and her family" these transfers are much less common than a dowry, occurring in only 15 percent of those marriages sampled (Table 5.10). It is most common in Balochistan among married adolescent females (37 percent) and married male youth (28 percent) (Table 5.10). The average value of such transfers is slightly higher among adolescent males and females (Table 5.11). The average value of such transfers is Rs. 26,885 (Table 5.12).

A third type of financial agreement at marriage is referred to as Haq Mehar. Rather than an exchange at the time of marriage, Haq Mehar takes the form of a notional amount due from the groom to the bride. The amount is fixed at the time of marriage and is a mandatory part of a "nikkah namah." However, it is to be paid to the wife only in the event of a divorce or upon demand by her. Among respondents who could recall and report the amount of Haq Mehar (about 75 percent), its median value is Rs. 500. For both sexes and age groups, higher Haq Mehar is associated with urban residence (Table $5.13)$.

\section{Age difference of spouse}

Although this survey provides information on the behavior of married young men, the information collected on marriage is based on a very selected group that marries quite young. Not only can they not be generalized to marriage patterns of males as a whole, but they are also not comparable to their female counterparts at this age.

In the survey sample, on average, females in the sample married a man 5.3 years older, while males reported marrying a woman 1.9 years younger (Table 5.14). For females, the widest age gap occurred in rural and urban NWFP (6.0 and 5.9 years), while 
the largest gap for males was found in rural Balochistan and urban NWFP (3.1 and 3.3 years). The smallest age gap for females occurred in rural Punjab and urban Balochistan (4.6 and 5.0 years); for males in rural and urban Punjab with a gap of 1.3 years and 1.4 years.

Figure 5.11 Age difference between spouses, ${ }^{22}$ by sex and age at marriage

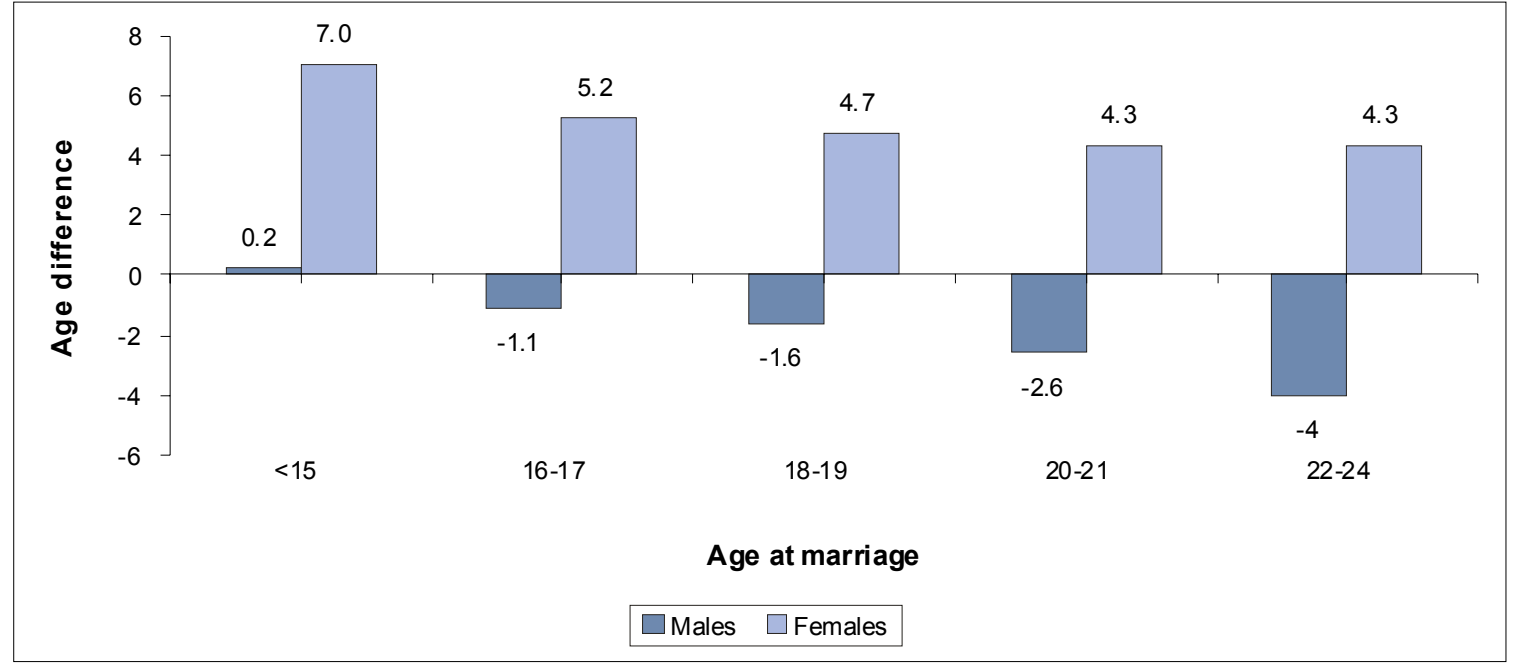

The age difference appears to narrow as age at marriage increases for females and widen as age at marriage increases for males. Figure 5.11 shows that a female who is married prior to the age of 15 will have a husband who is, on average, seven years her senior. However, if she marries after 18, the spousal age difference is likely to be less than five.

\section{Marriage among relatives}

The largest proportion of marriages in Pakistan is among relatives. In the AYP, 80 percent of females and 85 percent of males reported that their marriage was to a relative (Table 5.15). The highest percentage of such marriages occurred in Balochistan (89 percent of females and 94 percent of males) and the lowest percentage was in NWFP (72 percent of females and 82 percent of males).

Receiving an education appears to reduce the probability that a woman will marry a relative, while the trend for males is more difficult to interpret, with the highest level of education coinciding with the highest level of marriage among relatives. For both males and females, rural residence was associated with higher levels of marriages

22 Age difference is measured as age of spouse minus age of respondent. 
ADOLESCENTS AND YOUTH IN PAKISTAN 2001-2002: A NATIONALLY REPRESENTATIVE SURVEY

to relatives. The AYP found little difference in the economic exchanges of marriages to relatives, compared to non-related unions.

\section{Social dimensions of marriage}

While marriage is seen as the initiation to sexual relations and childbearing, it also signals other changes in an adolescent's life, including new responsibilities, living arrangements, and mobility. This section contrasts the situations, attitudes, and expectations of married and unmarried young persons, in an attempt to uncover the diversity of experience for the two groups.

\section{Living arrangements}

Once married, the large majority of females move to their husband's house and live with their spouse and in-laws (81 percent of the younger cohort and 70 percent of the older). Meanwhile, the majority of married males stays in their own home and is joined by their spouse (Figure 5.12). Thus, marriage requires significant adjustments for a young woman, as she forges a relationship with not only her husband, but also the social structure of her in-laws and others in this new household.

While not very common, some married young people reside on their own. Over one-fifth of married women aged 20-24 report living with their spouse, and 10 percent did so among the women aged 15-19. The figure for males was lower: seven percent of the older cohort and five percent of the younger cohort live with their spouse only.

Figure 5.12 Living arrangements for young married people, by age and sex

\begin{tabular}{lrrrrrr}
\hline & \multicolumn{2}{c}{$\mathbf{1 5 - 1 9}$ year olds } & \multicolumn{2}{c}{$\mathbf{2 0 - 2 4}$ year olds } & \multicolumn{2}{c}{ Total } \\
\cline { 2 - 7 } Living with: & Male & Female & Male & Female & Male & Female \\
\hline Parents & 8.3 & 4.5 & 11.7 & 4.1 & 11.0 & 4.2 \\
Spouse & 5.2 & 9.9 & 7.2 & 21.1 & 6.8 & 17.4 \\
Spouse and parents/in-laws & 83.3 & 80.6 & 76.5 & 69.7 & 78.0 & 73.2 \\
In-laws & 0.0 & 3.3 & 0.0 & 3.7 & 0.0 & 3.6 \\
Other & 3.1 & 1.7 & 4.5 & 1.5 & 4.2 & 1.6 \\
$N$ & 96 & 578 & 332 & 1,196 & 428 & 1,173 \\
\hline
\end{tabular}

\section{Age at marriage}

The young people and household respondents were asked about the appropriate age at marriage for each sex. The response was given as a range between two numbers. In order to determine the minimal appropriate age at marriage, the lowest number in the range was used. In general, respondents indicated the minimal age of marriage for females was lower than for males, with age increasing by education and household socioeconomic status of the respondent. Yet female respondents consistently advocated 
for a later age at marriage for both males and females than did their male counterparts and the household respondents. Males who desired a higher age at marriage were from rural NWFP and urban Punjab, while the lowest ages were expressed among those in rural Sindh and urban Balochistan. Age at marriage for females was highest among respondents in rural and urban Punjab and lowest among those in rural Sindh and urban Balochistan (Tables 5.16 and 5.17).

When broken down by age and marital status, most patterns remain constant: 1) females continue to cite a higher minimum age at marriage for both males and females than do their male counterparts, and 2) both males and females, regardless of marital status and age, cite a lower minimum age of marriage for females than for males (Tables 5.18 and 5.19). However, as one would expect, those who are married tend to cite a lower age of marriage than those who are unmarried, closely reflecting the age of their own experience or expectation.

Once the minimum appropriate age for marriage was established, young people and household respondents were asked to articulate the reasons that marriage would be appropriate at that age. The majority of respondents, both male and female young people and adults, stated that males were ready for marriage when they had the financial means or a job, while the financial means of a young woman had very little bearing on her marriagability (Figure 5.13). Females and household respondents cited mental maturity and ability/readiness to manage a household as the most important traits for a female, while the young men cited physical maturity as the most important trait for a female.

Figure 5.13 Reasons that young people should be married at a given age, according to all young people and household survey respondents, by sex

\begin{tabular}{lrrrrrr}
\hline \multirow{2}{*}{ Reason } & \multicolumn{3}{c}{ Reasons for young females } & \multicolumn{3}{c}{ Reasons for young males } \\
\cline { 2 - 7 } & Male & Female & Adult & Male & Female & Adult \\
\hline Mental maturity & 27.5 & 44.5 & 25.0 & 26.4 & 31.2 & 24.2 \\
Physical maturity & 65.1 & 38.0 & 34.6 & 42.7 & 22.2 & 22.2 \\
Able/ready to manage a HH & 29.6 & 45.3 & 28.7 & 24.8 & 32.4 & 23.4 \\
Financial means/job & 4.6 & 5.3 & 3.6 & 65.0 & 67.6 & 43.9 \\
N & 3,327 & 4,735 & 6,812 & 3,327 & 4,735 & 6,812 \\
\hline
\end{tabular}

\section{Reasons for later age at marriage}

Given that age at marriage has continued to rise in Pakistan over the past fifty years, the AYP sought to gain insight into the perceived reasons for this shift. Household survey respondents were asked to provide reasons for why males as well as females were marrying later. The responses were overwhelmingly related to economic factors, but in a 
gendered way. As noted in Figure 5.14, the lack of economic resources ${ }^{23}$ was the primary reason cited for the delay for both males and females. This was supplemented by trouble in arranging the dowry for females and employment search for males. Financial means and having a job are fundamental for a marrying male, while financial means in the form of a dowry are the fundamentals for a marrying female. Rising dowry expectations and unemployment most probably have bearings on this trend of later marriage.

Figure 5.14 Reasons for later marriage for males and females, as reported by household survey respondents

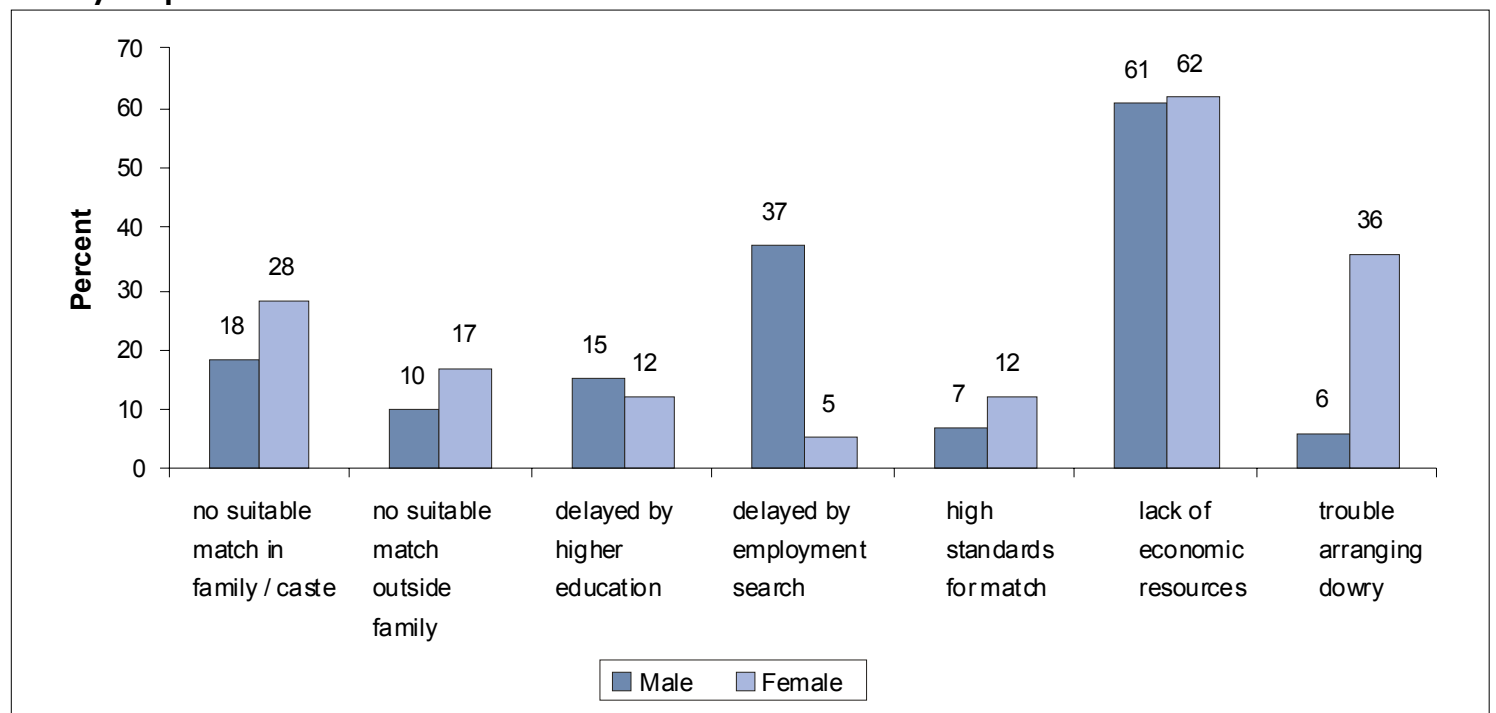

Note: Multiple responses were possible.

\section{TRANSITION TO PREGNANCY AND CHILDBEARING}

Questions concerning pregnancy and childbirth were asked only of ever-married females and males, since childbearing occurs almost entirely within the context of marriage in Pakistan. Sexual activity outside of marriage is not captured in this survey or any other national survey undertaken in the country. One advantage of the AYP is the inclusion of married males in the sample. Throughout this section, tables will include the experience of males, with reference to the pregnancies of their spouses. This information is available for the first time from a nationally representative survey. Whereas major information will be reported as a percent of ever-married individuals, the full sample is employed to demonstrate the level of childbearing at the population level and to examine attitudinal questions that were asked of all respondents.

${ }^{23}$ Lack of economic resources, denote not having enough resources to bear the expenses of marriage ceremony that requires plenty of money. It also refers to, having insufficient resources to transfer the bride price or other gifts to bride/ her parents. (in areas where such customs are practiced). 


\section{Level and timing of pregnancy and childbearing}

Even as age of marriage continues to increase in Pakistan, the close relationship of marriage and childbearing persists. As illustrated in the life table in Figure 5.15, marriages are almost immediately followed with a pregnancy. For females younger than 20 , the time to childbirth is slightly longer than for older females.

Figure 5.15 Percent married and percent first pregnant, by age

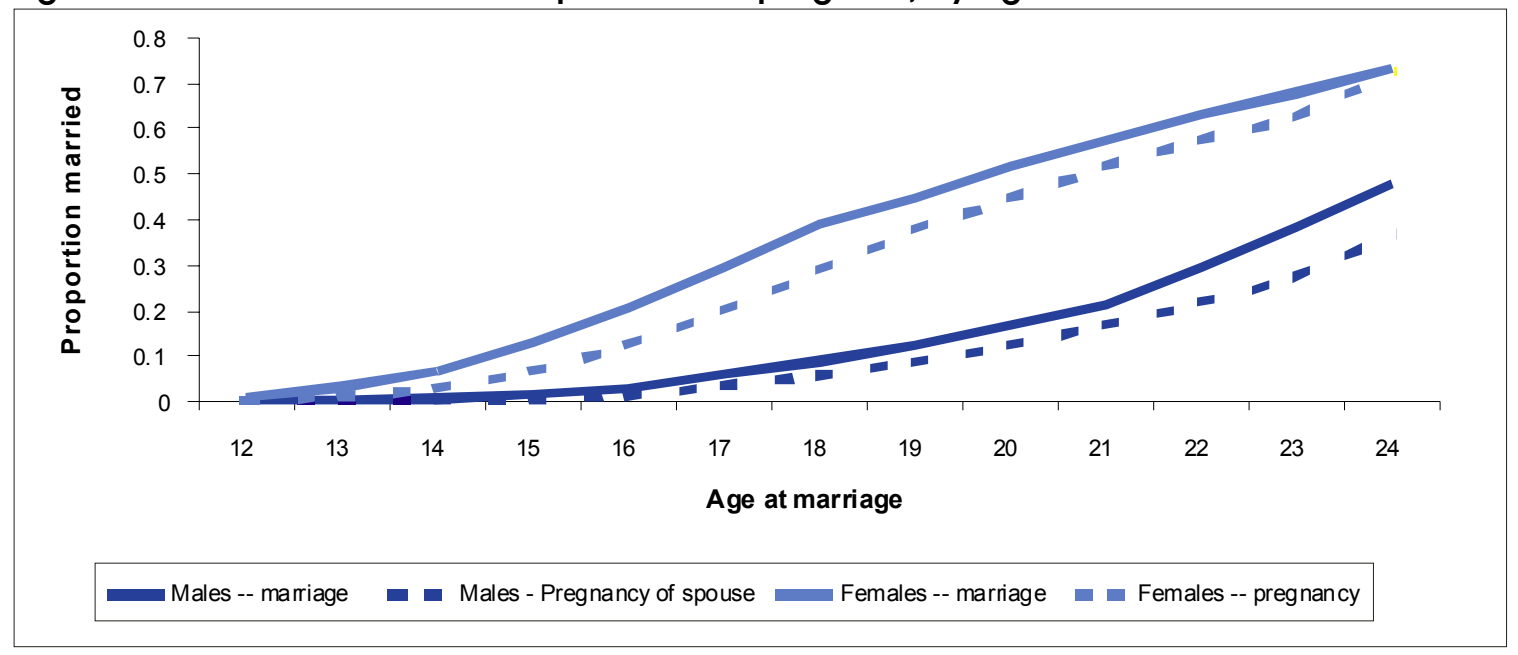

Among ever-married females, 68 percent aged 15-19 have been pregnant and had an average 0.69 children ever born (CEB) and 0.61 mean living children. Among those aged 20-24, 89 percent have experienced a pregnancy, an average of 1.89 CEB and 1.42 mean living children (Figure 5.16 and Table 5.20). Because of the pattern illustrated in Figure 5.16, there is little systematic variation in pregnancy rates in percent ever pregnant, among ever-married females (Table 5.21).

Figure 5.16 Mean number of children ever born (CEB) to ever-married women

\begin{tabular}{|c|c|c|c|c|c|c|c|c|c|}
\hline \multirow[b]{2}{*}{ Age } & \multirow{2}{*}{$\begin{array}{r}\% \text { ever } \\
\text { pregnant }\end{array}$} & \multicolumn{5}{|c|}{ Number of children ever born } & \multirow[b]{2}{*}{$\boldsymbol{N}$} & \multirow[b]{2}{*}{ Mean CEB } & \multirow{2}{*}{$\begin{array}{r}\text { Mean living } \\
\text { children }\end{array}$} \\
\hline & & $\mathbf{0}$ & 1 & 2 & 3 & 4+ & & & \\
\hline $15-19$ & 67.7 & 48.4 & 36.8 & 12.1 & 2.7 & 0 & 575 & 0.69 & 0.61 \\
\hline $20-24$ & 89.4 & 17.4 & 24.5 & 28.4 & 18.0 & 7.4 & 1196 & 1.89 & 1.42 \\
\hline Total & 82.7 & 27.4 & 28.5 & 23.1 & 13.1 & 5.0 & 1771 & 1.50 & 1.14 \\
\hline
\end{tabular}

The greatest variation is among ever-married males aged 20-24. Only 74 percent report that a spouse has ever been pregnant. The lowest is in Balochistan, where 64 percent of males report pregnancies, and highest in Sindh with 76 percent. Males also 
report more pregnancies among their spouses in the rural areas (76 percent) compared to urban areas (67 percent).

\section{Adolescent childbearing}

An examination of factors associated with adolescent childbearing is provided in Figure 5.17. The percent who are mothers or pregnant with a first child increases with every year between ages 15 and 19. It is encouraging to note that very few of the youngest adolescents are bearing children; only five percent aged 15 and eight percent aged 16 report being pregnant or already mothers. By the age of 19, 30 percent of females report being pregnant or already mothers. In general, adolescent motherhood is associated with rural residence, little or no schooling, and low socioeconomic status. The highest level of adolescent pregnancy and motherhood was found in Balochistan and the lowest was in NWFP. Rural adolescents were more than twice as likely to be pregnant than those in urban areas. Household socioeconomic status was closely linked to adolescent childbearing, with the poorest households having the greatest proportion of pregnancies: 25 percent in the lowest quartile and six percent in the highest income quartile. Similarly, among those who never attended school, 24 percent were pregnant or mothers, compared to four percent among those who had more than four years of schooling.

While the figures in Figure 5.17 provide a glimpse of those who are currently aged 15-19, a more accurate picture on adolescent pregnancy is achieved by examining those respondents currently aged 20-24 to determine what percent were pregnant before the age of 20. According to Table 5.22, 42 percent of females gave birth before age 20 and 10 percent of males report their wives becoming pregnant before they were 20 . As with early marriage, the high levels in the rural areas, where 49 percent of females experienced a pregnancy before their 20th birthday, drive these figures (Figure 5.18). For rural females, Sindh residents report the highest level of pregnancies among this age group, followed by rural and urban Balochistan. The lowest levels are found in Punjab. 
Figure 5.17 Percent of adolescent females (aged 15-19) who are mothers or pregnant with their first child, by various categories

\begin{tabular}{|c|c|c|c|c|}
\hline Category & Mother & $\begin{array}{r}\text { Pregnant } w / \\
\text { first child }\end{array}$ & Total & $\mathbf{N}^{\mathrm{a}}$ \\
\hline \multicolumn{5}{|l|}{ Current age in years } \\
\hline 15 & 3.0 & 1.6 & 4.6 & 754 \\
\hline 16 & 5.7 & 2.4 & 8.1 & 489 \\
\hline 17 & 10.8 & 2.2 & 13.0 & 489 \\
\hline 18 & 17.0 & 3.2 & 20.2 & 591 \\
\hline 19 & 25.3 & 4.2 & 29.5 & 424 \\
\hline$N$ & 2,750 & 2,739 & 2,750 & 2,750 \\
\hline \multicolumn{5}{|l|}{ Province } \\
\hline Punjab & 10.7 & 2.7 & 13.4 & 1,169 \\
\hline Sindh & 13.7 & 2.7 & 16.4 & 754 \\
\hline NWFP & 9.6 & 1.2 & 10.8 & 463 \\
\hline Balochistan & 13.7 & 4.9 & 18.6 & 358 \\
\hline$N$ & 2,744 & 2,739 & 2,744 & 2,744 \\
\hline \multicolumn{5}{|l|}{ Residence } \\
\hline Rural & 13.9 & 3.2 & 17.1 & 1,646 \\
\hline Urban & 5.4 & 1.1 & 6.5 & 1,098 \\
\hline$N$ & 2,744 & 2,739 & 2,744 & 2,744 \\
\hline \multicolumn{5}{|l|}{ SES } \\
\hline Low & 20.7 & 3.8 & 24.5 & 532 \\
\hline Low-mid & 13.4 & 3.5 & 16.9 & 593 \\
\hline High-mid & 8.2 & 1.8 & 10.0 & 698 \\
\hline High & 5.1 & 1.0 & 6.1 & 799 \\
\hline$N$ & 2,625 & 2,621 & 2,625 & 2,625 \\
\hline \multicolumn{5}{|l|}{ Educational attainment } \\
\hline Never attended & 19.0 & 4.6 & 23.6 & 1,152 \\
\hline Less than primary & 10.4 & 1.6 & 12.0 & 390 \\
\hline Completed primary & 3.3 & 0.9 & 4.2 & 877 \\
\hline Completed secondary & 3.5 & 0.4 & 3.9 & 327 \\
\hline$N$ & 2,747 & 2,742 & 2,747 & 2,750 \\
\hline
\end{tabular}

${ }^{a}$ Marginal $\mathrm{N}$ for "percent mothers." 
Figure 5.18 Percent of 20-24 year old females who were pregnant before age 20 , by current residence

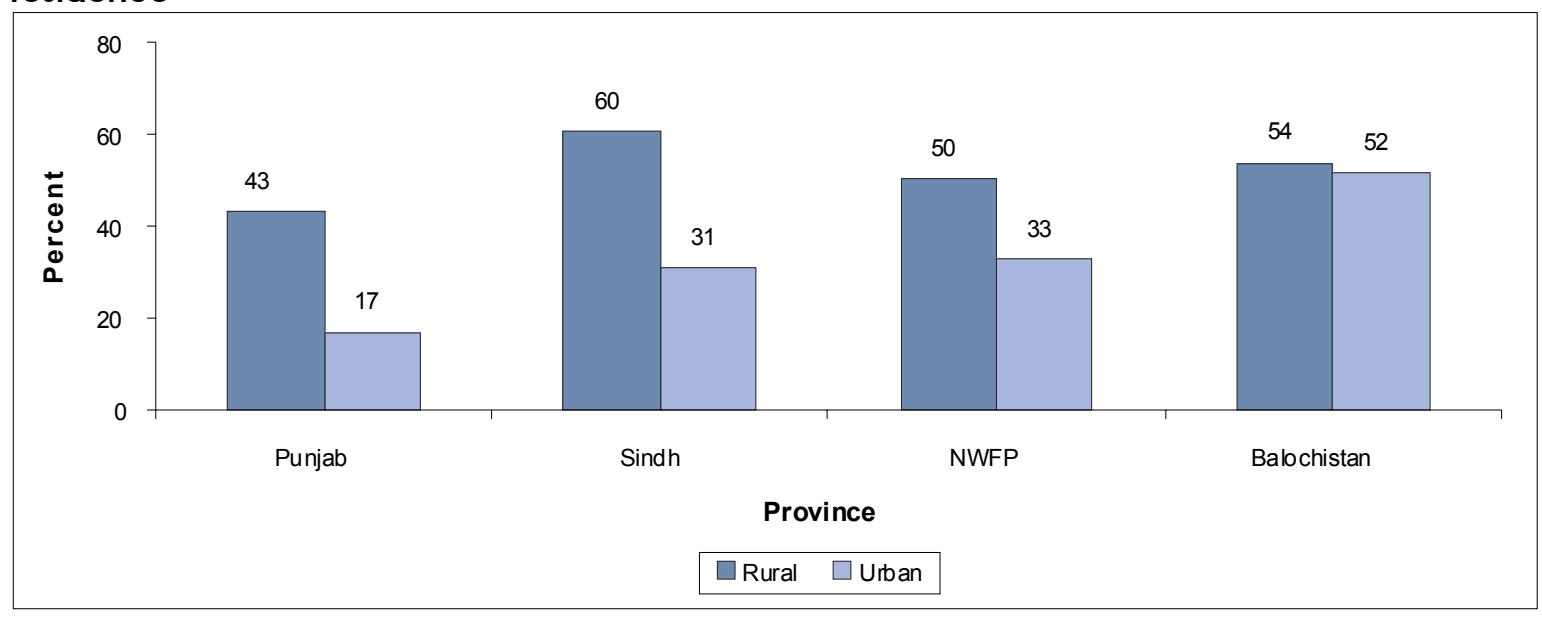

\section{Access to antenatal care ${ }^{24}$ and patterns of delivery}

Use of antenatal services by married young people is not even across Pakistan. Using the experience of the first birth for comparison purposes, it appears that the younger cohort of women has less access than the older cohort did at first birth. Only in Sindh did more than half of females aged 15-19 make a visit for antenatal care, where as over half in Sindh, NWFP, and Balochistan accessed such care in the older cohort aged 20-24. (Table 5.23). The percent that used antenatal services increased with socioeconomic status for both cohorts, but was strongest in the older cohort; 31 percent of the poorest women received any antenatal care, compared to 87 percent of the women from the richest households. Likewise, educational attainment was closely associated with the probability of having received such care, with the largest incremental gap occurring between those who never attended school and those who received some education, but did not complete primary. Finally, the most dramatic result is that over 70 percent of urban females of both cohorts reported receiving antenatal care for their first child, compared to $40-45$ percent of those in the rural areas (Table 5.23).

A second measurement of service use is the percentage of first children who were born at home, compared to a health facility. More of the younger female cohort report a birth at home (78 percent) compared to 70 percent of the older cohort. Home births are most widespread in Balochistan (87 and 86 percent of the younger and older cohorts, respectively), followed by Punjab (82 and 73 percent). There is a clear association of home births with low socioeconomic status, less education, and rural residence (Table 5.24).

24 For this survey, any consultation or checkup through a medical doctor, nurse, lady health visitor, lady health worker, village based family planning worker, or a trained birth attendant was considered as antenatal checkup, including dispensing of TT shots. 
The majority of all first births included the services of a traditional attendant, as noted in Figure 5.19. At their first birth, the younger cohort of females were more likely to have a traditional attendant (63 percent compared to 56 percent of the older females) and less likely to have a medical person ( 24 percent compared to 32 percent).

\section{Figure 5.19 Person who attended at first birth, for all ever married who have had a child}

\begin{tabular}{lcccc}
\hline & \multicolumn{2}{c}{$\mathbf{1 5 - 1 9}$ year olds } & \multicolumn{2}{c}{$\mathbf{2 0 - 2 4}$ year olds } \\
\cline { 2 - 5 } Birth attendant & Male & Female & Male & Female \\
\hline Relative/friend & 10.2 & 37.7 & 18.7 & 27.0 \\
Traditional attendant & 81.2 & 63.2 & 56.1 & 56.2 \\
Medical person & 19.4 & 23.8 & 29.6 & 31.9 \\
$N$ & 35 & 292 & 194 & 985 \\
\hline
\end{tabular}

Note: The three most cited answers included. Multiple responses possible.

\section{Desire for children}

All young people, married and unmarried, were asked about their desire for children, as well as preferences by gender. Figure 5.20 presents the mean desired number of children reported by married respondents. The males had a desire for a slightly higher number of children (4.0 versus 3.9 according to females), but the desired breakdown by sex of the child was almost identical (2.3 males and 1.7 females). Unmarried young people expressed a desire for fewer children than their married counterparts. Unmarried males expressed a desire for more children (3.0) and had a stronger preference for males (2.1) than did females (who on the average cited 1.7 males). Desire for female children was slightly higher for unmarried females at 1.4 versus 1.3 for unmarried males. These comparisons are found in Figure 5.20. 
Figure 5.20 Mean desired number of male and female children, by sex and marital status, among $20-24$ year olds

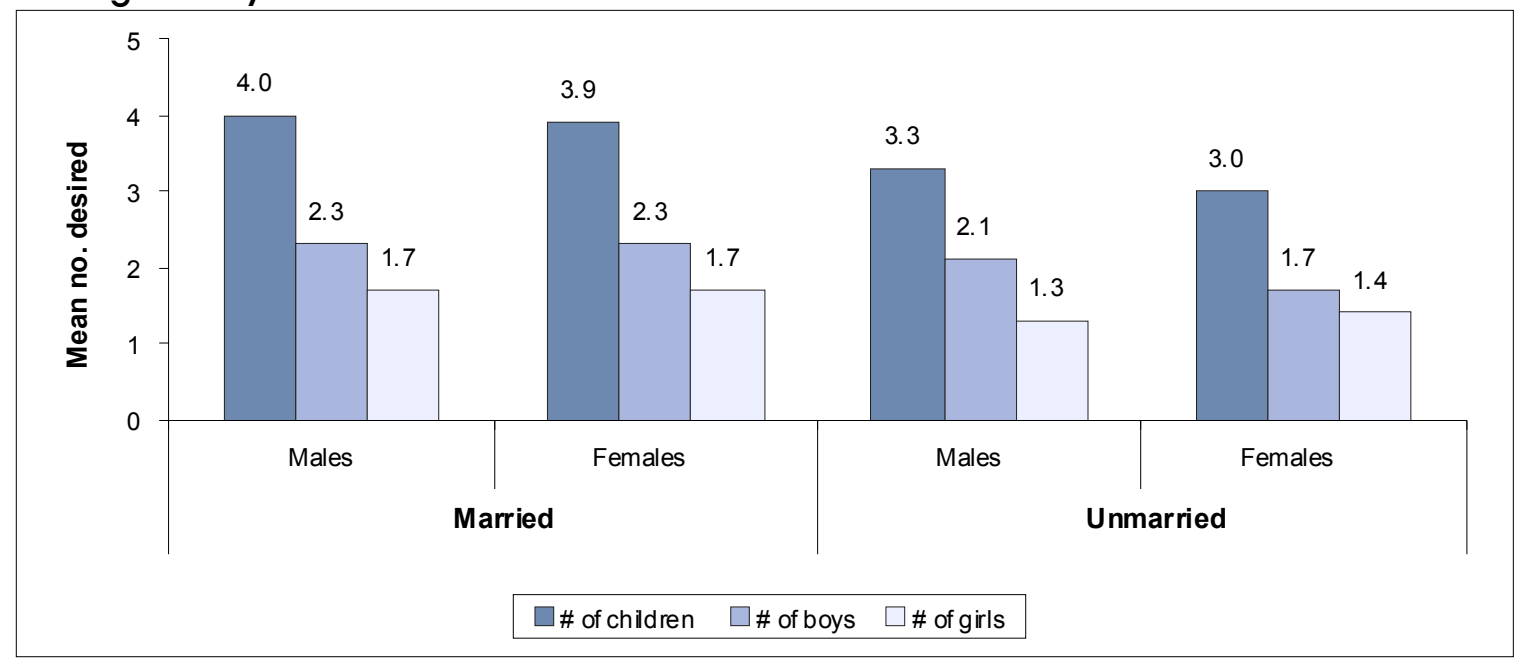

Among married respondents, Punjab residents cited the lowest number of desired children (3.6 for males and females aged 20-24), while those in Balochistan expressed the highest numbers (5.4 among males and 5.8 among females). The desire for children decreased with socioeconomic status as well as with education. Urban residents cited lower numbers than rural ones, although this was less of a distinction for males (Table 5.25).

\section{Contraceptive use}

Given the strong cultural norms in Pakistan to prove fertility soon after marriage, it is not surprising to see only a small proportion of young people using any contraceptive method. ${ }^{25}$ Among adolescent females, according to the AYP, five percent report currently using contraception, while five percent of male and 12 percent of female youth report current use (Table 5.26). These figures for females are similar to the 2000-01 Pakistan Reproductive Health and Family Planning Survey (Figure 5.21). Over the past decade, there has been an increase in use among females aged 20-24, but very little change among the younger age group.

Figure 5.21 Trends in current use of any family planning method (married females)

\begin{tabular}{lrrrrr}
\hline \multirow{2}{*}{ Age } & PDHS & PCPS & PFFPS & PRHFPS & AYP \\
\cline { 2 - 6 } 15-19 years & $\mathbf{1 9 9 0 - 9 1}$ & $\mathbf{1 9 9 4 - 9 5}$ & $\mathbf{1 9 9 6 - 9 7}$ & $\mathbf{2 0 0 0 - 0 1}$ & $\mathbf{2 0 0 1 - 0 2}$ \\
20-24 years & 2.6 & 3.4 & 6.2 & 4.8 & 5.0 \\
\hline
\end{tabular}

Source: Pakistan Reproductive Health and Family Planning Survey 2000-01, p. 66.

25 The question about contraception was asked only of currently married young people. 
The sample of married males aged 15-19 is too small to comment upon in this section. Twenty percent of the older cohort of females report having ever used contraception (Figure 5.22). Much higher percents anticipate using contraception in the future: 46 percent of the older cohort of males and over 50 percent of all females.

Figure 5.22 Percent of currently married young people who are current, ever, or future users of contraception, by age and sex

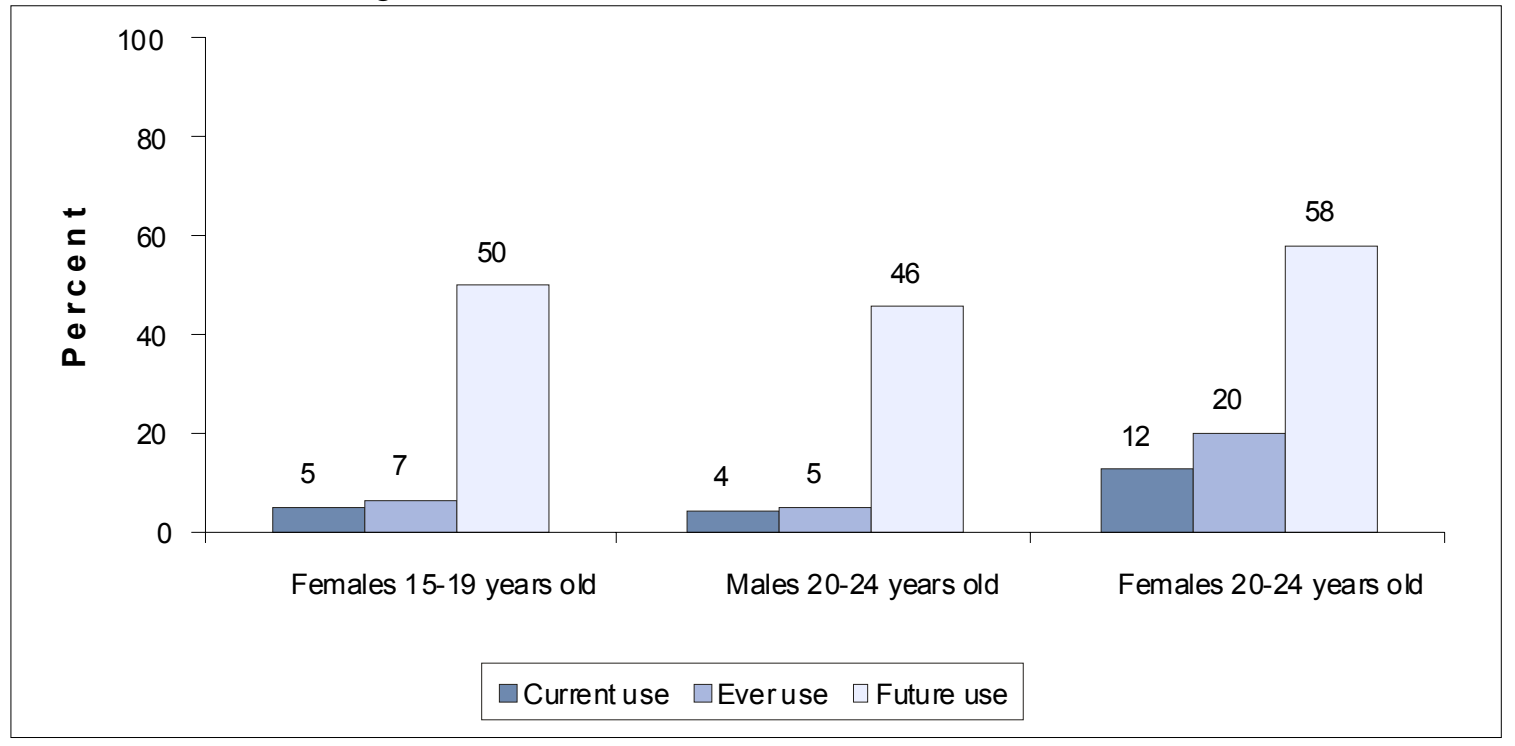

Current contraceptive use is highest among women in Punjab, men in NWFP, higher socioeconomic strata, and urban areas. While use does not have a clear relationship with level of schooling, having never attended school results in lower levels of contraception than having attended some for all ages and both sexes (Table 5.26).

As noted in Figure 5.22, a significant number of young people anticipate using contraception in the future. For females, future use is closely related to socioeconomic status, particularly in the older cohort, where 45 percent of those coming from the poorest homes anticipate use, compared to 74 percent of those from the richest homes (Table 5.27). Likewise, anticipated use of family planning is associated with educational attainment for males and females in the oldest cohort.

Among those who intend to use family planning in the future, the method varied considerably by sex (Table 5.28). Males of both age cohorts cited the pill as the method to be used, followed by injectables. In contrast, the most often stated reply among females of both groups was that the method to be used was "undecided." Additional qualitative work would be necessary to discern the roots of this indecision and to determine if it reflects a lack of information, agency, or other factors. 


\section{CONCLUSION}

As highlighted in the previous chapters on education and work, gender disparities define many of the attitudes, decisionmaking processes, timing, and interpretation of puberty, marriage, and childbearing among young people in Pakistan.

Although the onset of puberty occurs earlier for females than for males, females are less likely to be informed about the event in advance and are less likely to be among peers in school when it occurs. Thus among those who do gain some information, males obtain information from male peers, while females learn from their mothers.

Of particular interest is the gap between the onset of puberty and the time of marriage for young females. This gap is increasing, due to the increased age at marriage, but there is little evidence that there is substantive, skills-enhancing activity to fill this increasing gap. As seen in earlier chapters, males are much more likely to be in school and working during this period. But with limited mobility and acceptable activities in the public sphere, an unmarried post-pubescent female has few opportunities to enhance herself and define herself outside of her relationship to her family.

While age at marriage has increased for both males and females over the past fifty years, females continue to marry at a significantly younger age than their male counterparts, and rural residents tend to marry much earlier than those in urban areas. A rural adolescent female is more than twice as likely to be married before age 20 as her urban peer (58 percent versus 27, respectively). While the level of marriage is much lower for males, the relative rural effect is even stronger: 18 percent of rural versus 5 percent of urban males are married by age 20. Although provincial differences exist, these basic patterns are quite consistent within each province. Adolescent marriage is also strongly associated with school attendance for females, although it appears to have only a nominal effect on males.

Critical to any discussion of the transition to marriage are the economic aspects that are either implicit or explicit in the process. The most explicit economic component of marriage is the dowry, the combination of money and goods that are transferred from the bride's family to the groom's family at the time of marriage. The dowry is a common and almost universal practice throughout Pakistan. A major concern for a prospective bride is that she has a sufficient dowry. This was highlighted in the two issues identified by household respondents for the delay of marriage for females: lack of economic resources and trouble arranging dowry. 
Transfers in the other direction (from the groom's family to the bride and her family) are much less prevalent. However, the economic pressures of the groom-to-be are also significant as they include current as well as future/potential economic status. In citing reasons for later marriage among males, household respondents cited lack of economic resources and delayed by employment search. When asked why a certain age is appropriate for marriage, the large majority of young people and household respondents stated that males at that age would have financial means or a job, making make him ready for marriage. Thus the young woman is pressured to have sufficient means going into the marriage (dowry), while a young man needs to bring a respectable amount, but more importantly identify his potential to provide into the future.

Childbearing is closely linked to marriage in Pakistan and therefore questions concerning childbearing were only asked of the ever-married sample. Most characteristics of early childbearing thus mimic those associated with early marriage. The unique aspect of this survey was the focus on the experience of the youngest cohort, aged 15-19. Few of the youngest females, aged 15 and 16, were pregnant or already mothers (five percent of 15 year olds and eight percent of 16 year olds). However, of those currently aged 20-24, 42 percent were pregnant prior to the age of 20. Of those married before they were 20 years old, 85 percent had four or less years of education.

The first pregnancy is rarely associated with antenatal care with the exception of urban areas and it appears that the younger cohort is receiving less care for first births than the older cohort did for their first births. Home births of a first-born are common among all young women, but more so among the younger cohort than the older cohort. The younger cohort was also more likely to have a traditional attendant and less likely to have a medical person at her first birth, when compared to the older cohort. Thus adolescent childbearing appears to be taking place in a more risky environment than just five years earlier.

Young married women and men are not likely to use contraception until later in marriage. As a result, first birth intervals are very short. Although the majority of both males and females plan to use contraception in the future, females tend to answer that they are undecided regarding the method of choice, while males most frequently mention pill or injectables as the method to be used in the household. 



\section{The Communities in which Young People Live}

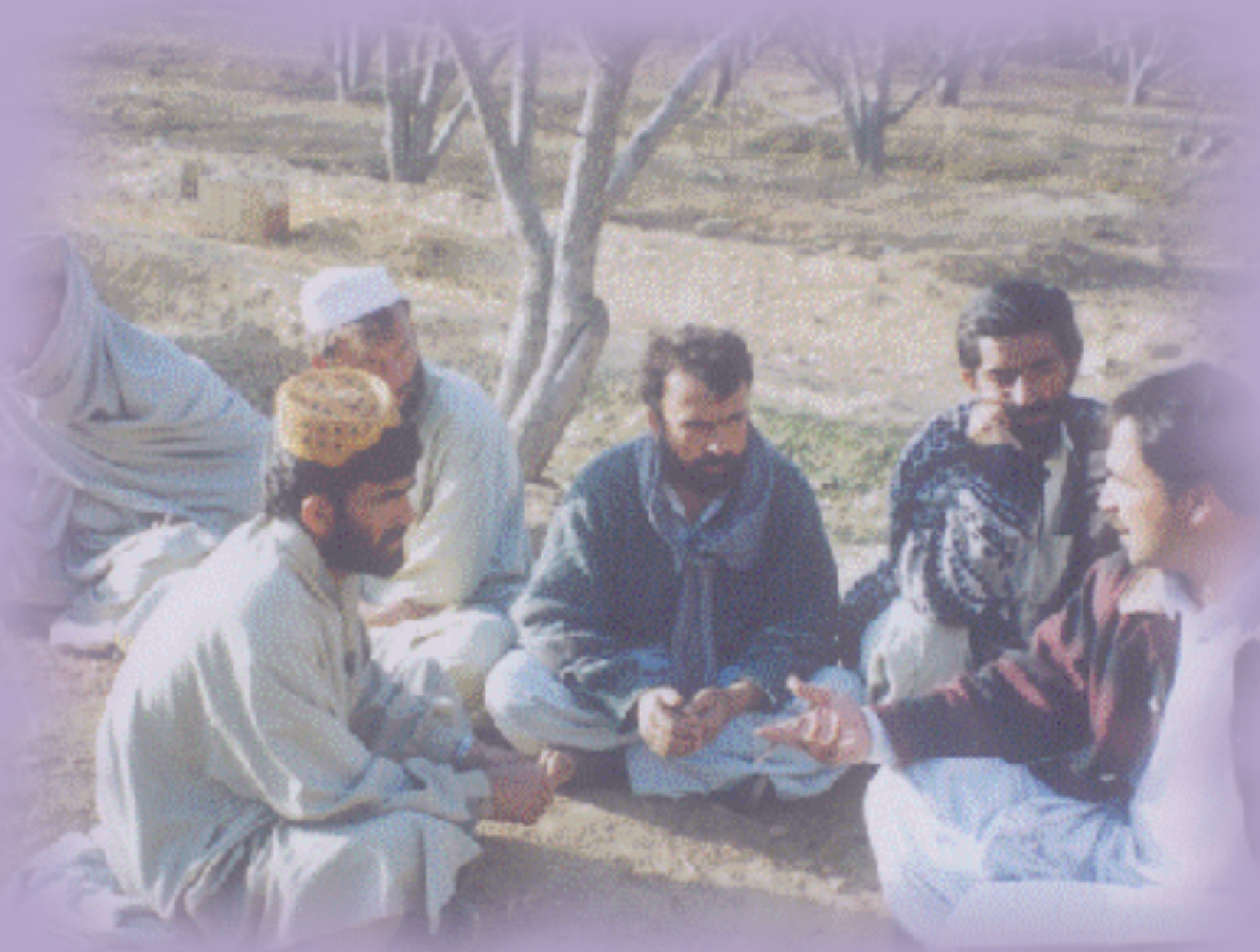

In this chapter:

- Introduction

- Topography and Irrigation

- Access to Roads and Transport

- Access to Other Infrastructure

- Health Services

- School Availability

- NGO Activities

- Conclusion

- References 


\section{The Communities in Which Young People Live}

\section{INTRODUCTION}

As noted throughout the previous chapters, there are social dimensions at the individual and household levels that critically shape and define the life course of a young person. Likewise, the broader context of the community plays an instrumental role in either opening or closing doors in a young person's development. This chapter looks at the constraints and opportunities afforded to young people by virtue of the community in which they reside.

Community may be defined in various ways. A community may refer to persons "sharing a defined physical space or geographical area such as a neighborhood, city, village, or hamlet." Alternatively a community or group might be defined as "sharing common traits, a sense of belongingness, and/or maintaining social ties and interactions which shape it into a distinctive social entity, such as an ethnic, religious, academic, or professional community" (Kuper and Kuper 1989). However, when communities are defined in territorial terms only, there are problems relating to the definition of boundaries (Hillery 1968, in Kuper and Kuper 1989:135). In Pakistan, challenges in defining community relate largely to its diversity in terms of geographical and provincial boundaries, culture, language, and ethnicity. However, from the perspective of research and programs, there is a need to measure certain common characteristics that people living in a geographical vicinity share, such as access to services, communications, and other social networks.

For practical purposes, this survey used a block of 200-250 households, the definition of a Primary Sample Unit used by the Federal Bureau of Statistics to delineate a community. While this definition was adequate for rural areas where a PSU was likely to coincide with a village or hamlet, it was more problematic in urban areas. For example, PSUs in rural areas yielded a realistic assessment about the proximity and availability of various services such as schools, whereas in urban PSUs, which are usually more densely populated and located over a few streets or a mohallah (a cluster of households), there was more ambiguity. Several urban PSUs reported no primary schools in their immediate vicinity; while they had access to schools, they were located outside the survey's definition of their community or neighborhood. Care has been 
taken in the analysis of data to reflect a more realistic sense of a community's access to services; throughout this chapter, any reference to a facility that is "inside" a community also includes those that are within two kilometers of the community's border.

The community section of the AYP used a different interview methodology, employing structured guided group discussions and attempts were made to reach a consensus. In each of the 254 communities, five to seven reliable key informants were asked to discuss a range of issues related to opportunities for young people in their community. Key informants included teachers, village leaders or elders, headmen, shopkeepers, Moulvi (religious leaders), social workers, and guards. In a neutral setting, a consensus was reached among group members on the profile of the community. While these profiles provide a useful insight into the environment where young people live, it must be noted that given the limited sample of communities, the results are not appropriate for generalizations at the national level.

This chapter provides insight into the characteristics of the communities where young people live, including the topography and irrigation, access to roads and transport, the level of infrastructure (e.g., safe water and electricity), the availability of health services, and schooling. The chapter also highlights the presence of NGOs in these communities and indicates the focus of their work.

\section{TOPOGRAPHY AND IRRIGATION}

Pakistan is composed of distinctly different topographical territories. Out of the 254 communities visited, the majority were located in the plains; 39 were in mountainous areas; 9 in river flooded plains; and 7 were located in desert areas.

Overall, 152 communities were rural and 102 were urban. Interviews were carried out in 113 communities in Punjab, 69 in Sindh, 44 in NWFP and 28 in Balochistan. In Punjab and Sindh, most communities were situated in the plains although 3 communities were situated in the desert in Sindh. In NWFP the majority of communities are located in mountainous areas but 4 were situated in desert areas where there were no roads or motorized transport and survey teams had to travel by camel. In Balochistan, the majority of communities are also in mountainous areas but 3 communities were located in river flood areas despite the eight-year drought (Table 6.1). Taking into account the vast area of Balochistan and the scattered setting of households, the field teams navigated massive deserts to reach communities that often had no access to a road. Furthermore, reaching the selected households in such communities required ample time, travel, and effort. 
As noted earlier, Pakistan's economy is largely agrarian and over 65 percent of its population resides in rural areas. The country has one of the most extensive canal irrigation systems in the world. Over half of all agricultural communities rely on canal water and tube wells while about a quarter depend on natural rainfall. Sindh and Punjab mainly depend on artificial means of irrigation, while a major proportion of communities in Balochistan rely on rainfall (Figure 6.1).

Figure 6.1 Distribution of communities by source of irrigation, of those communities that are agrarian, by province

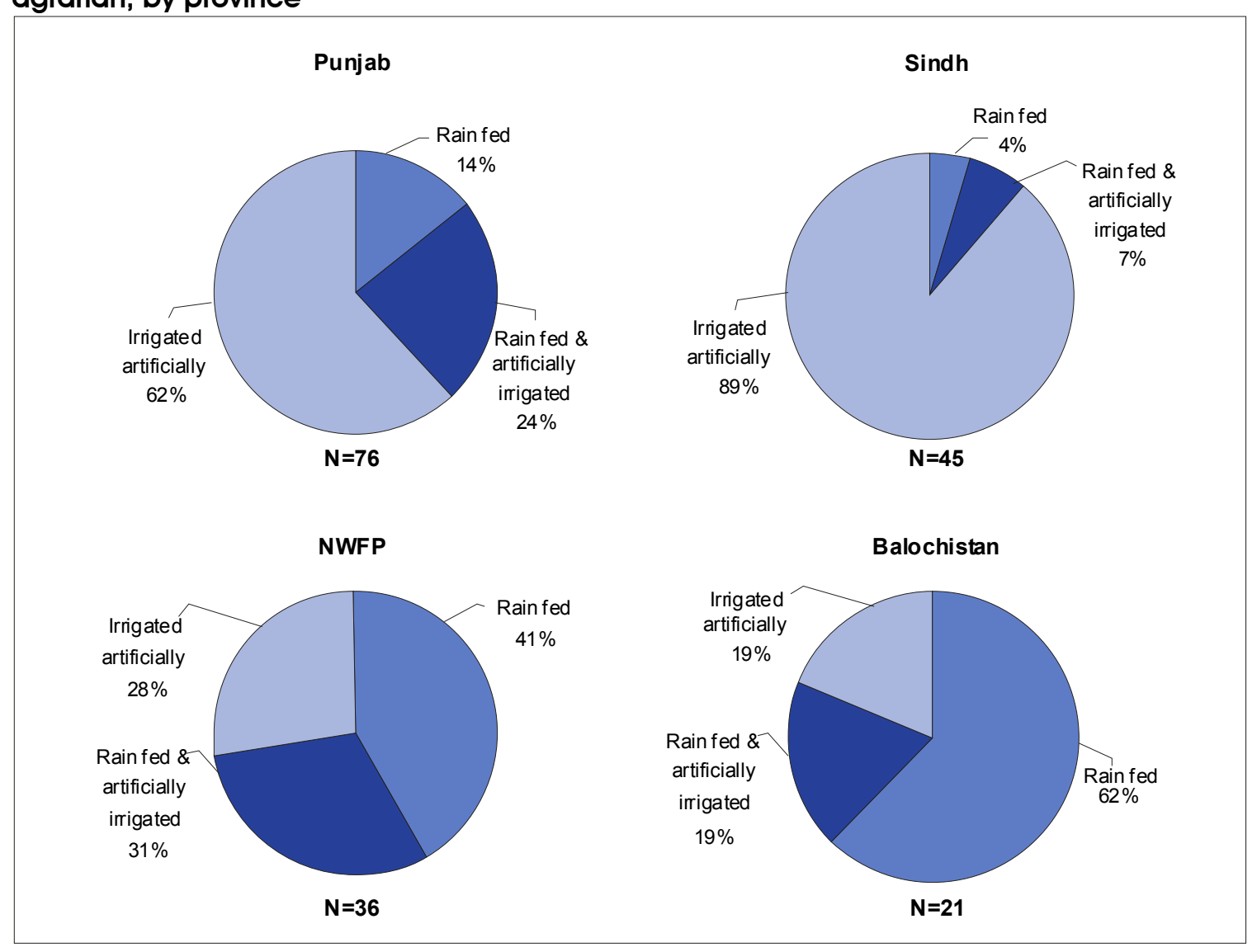

\section{ACCESS TO ROADS AND TRANSPORT}

The degrees of access communities have to roads and transport is an important reflection of their development status. For young people, road and transport access is an important marker of mobility, education, and employment opportunities. It also indicates connections to the outside world. In those communities where access to roads and transportation is poor or non-existent, young people grow up with limited opportunities for quality schooling and vocational training, as teachers and trainers are 
often less attracted to isolated rural communities. Young males seeking waged work have few choices: agricultural work, waged labor, if it is available, or migration out of the community. Females living in this situation will be even more disadvantaged, given cultural restrictions on their mobility and the burden of domestic chores, which leave less time for travel.

The overall picture of community access to roads and transport is dramatically different between rural and urban areas (Figure 6.2). Urban communities visited during the survey have much better road access and transport whereas rural communities have markedly less access.

\section{Figure 6.2 Distribution of communities by access to roads, by residence}

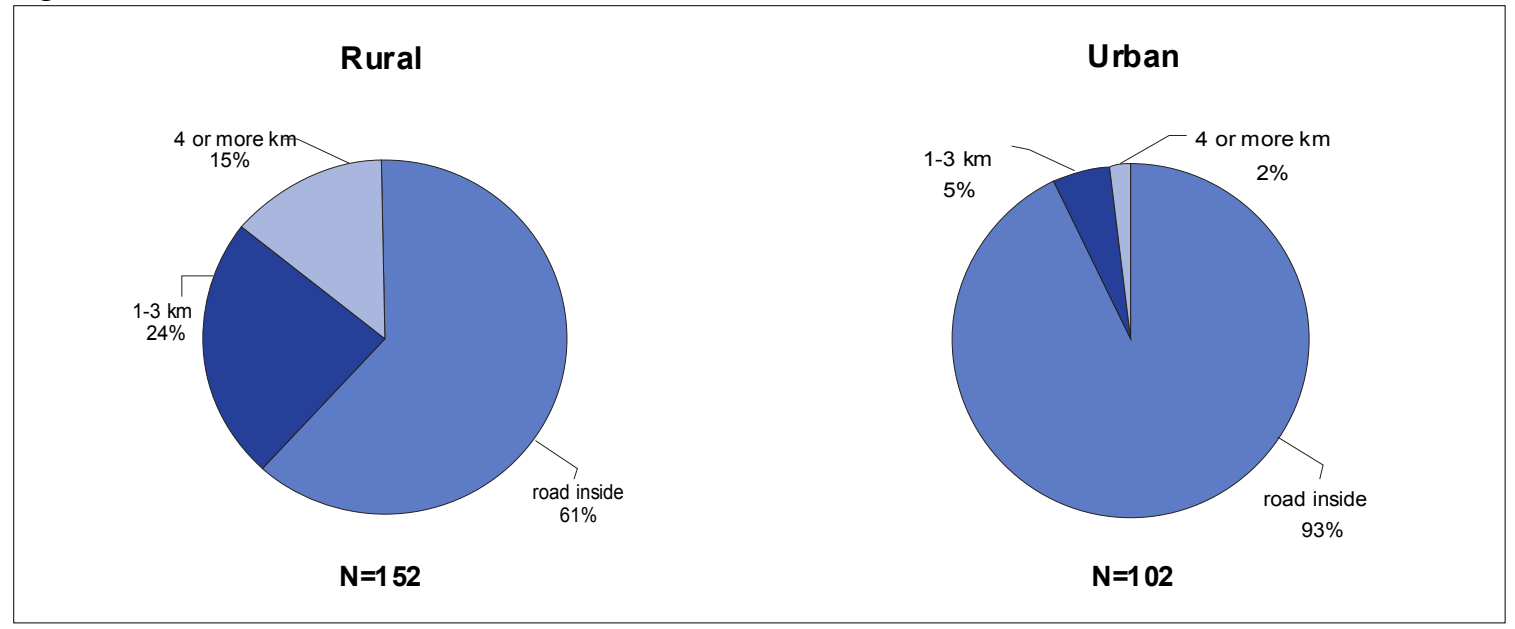

A comparison across provinces shows that Punjab has the best access to transport and roads. More than three-quarters of Punjabi communities have direct access to metal roads, while Sindhi and NWFP communities have less direct access, and Balochistan communities have the least direct access of all (Table 6.2).

There is a distinct provincial pattern to the various forms of public transportation used. Almost three-quarters of communities in NWFP use pickups while the majority of communities in Sindh rely on a bus or a wagon. A considerable proportion of Punjabi communities use the tonga (a horse-drawn buggy) but motorbike rickshaws also appear to be growing in popularity and are considered a cost-effective way of traveling. Indeed, half of Punjabi and a little less than half of Sindhi communities use rickshaws as a major means of transportation (Table 6.2). 
Out of 254 communities visited, 40 communities reported having no form of public transport readily available. An overwhelming majority of the population of Balochistan is scattered over a larger area that may hamper access to roads and transportation. In addition, only 43 percent of surveyed communities in Balochistan have two or more forms of transport available while 60 percent of the communities in other provinces report the same (Figure 6.3).

Figure 6.3 Distribution of availability of multiple forms of public transportation, of all communities, by province

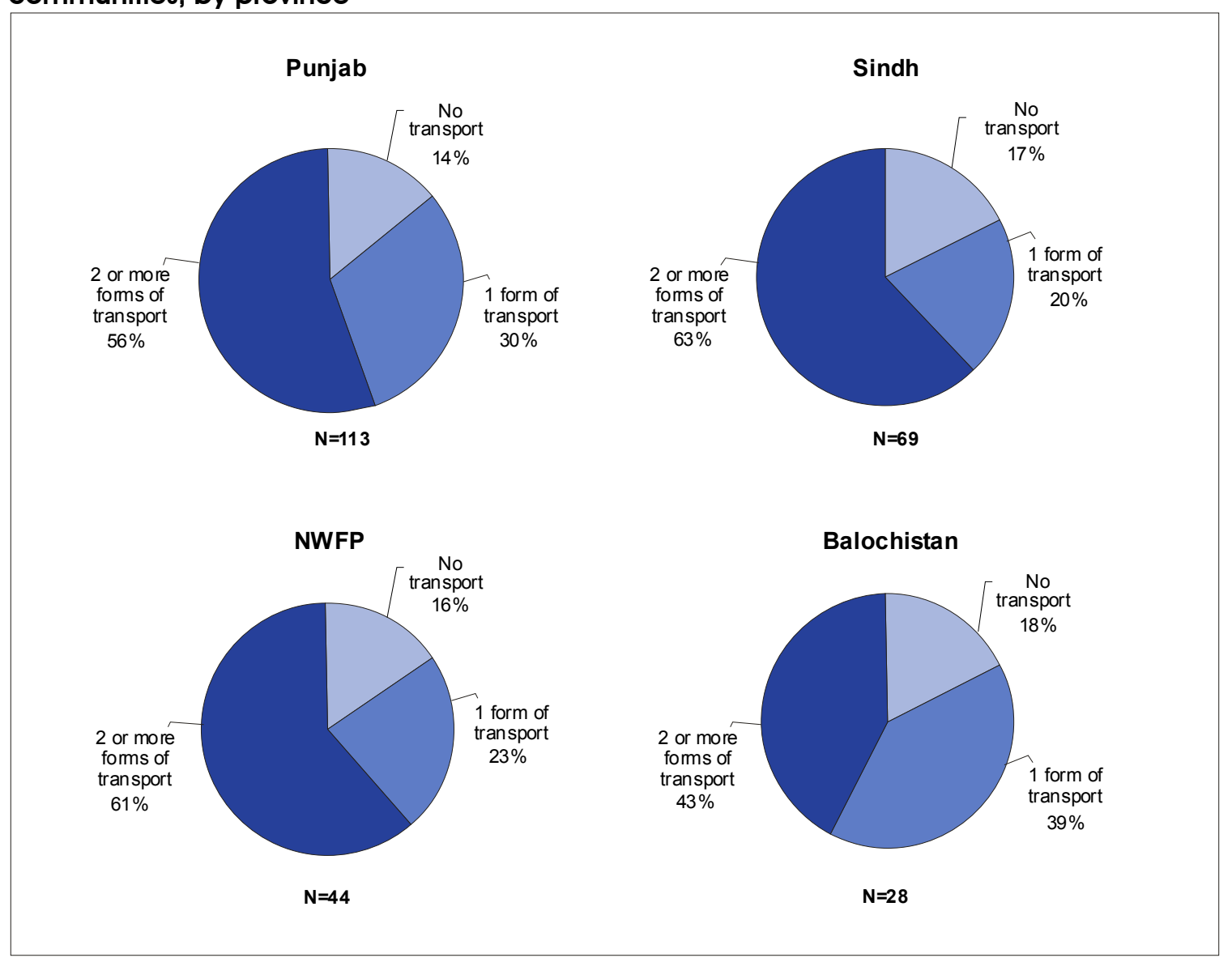

\section{ACCESS TO OTHER INFRASTRUCTURE}

For young people growing up in Pakistan access to key facilities such as piped water, sewage, electricity, and gas, is very dependent on residence. In urban areas there are much greater levels of access to essential facilities than rural areas, and yet the rural population is more significant in number. The community profile provides details on access to key facilities, which reflects the development status of the environment where young people are living. 
The availability of piped water and sewage systems indicates communities where young people may be better protected from waterborne communicable diseases. ${ }^{26}$ Public call offices (PCOs), home telephones, and post offices reveal to what extent communities have connections to the outside world and to greater social networks than those offered by the neighborhood or community alone. Banks indicate the potential to save earnings and receive loans, while factories provide employment opportunities outside the agricultural sector, particularly in urban and peri-urban areas.

Most communities have access to one or more of the facilities described. The majority have access to electricity; less than half have piped water; and less than onethird have sewage and natural gas (Table 6.3). In terms of communication facilities, most communities have some households with telephones, while half have a PCO, and almost one-third have a post-office. However, only a handful of communities report a bank or a factory.

As expected, urban communities are better served than rural communities. For example, three-quarters of urban communities report the availability of piped water whereas in rural areas less than one-fifth of all communities have such access. The figures are much worse for sanitation. Although rural areas are more disadvantaged than urban areas, for telephone connections they are better than expected with half reporting household connections. Only one-fifth of rural communities have a PCO and one-third a post office.

There are provincial variations in access to basic facilities. The survey found that the majority of communities in NWFP report access to three or more of the facilities. In contrast, communities in Balochistan, the least densely populated of the four provinces, stand out as the most underdeveloped (Table 6.3).

26 Piped water supply is considered to be a safer source of water in Pakistan than other sources such as well water, river, and streams 
Figure 6.4 Distribution of communities by basic facilities available, by residence

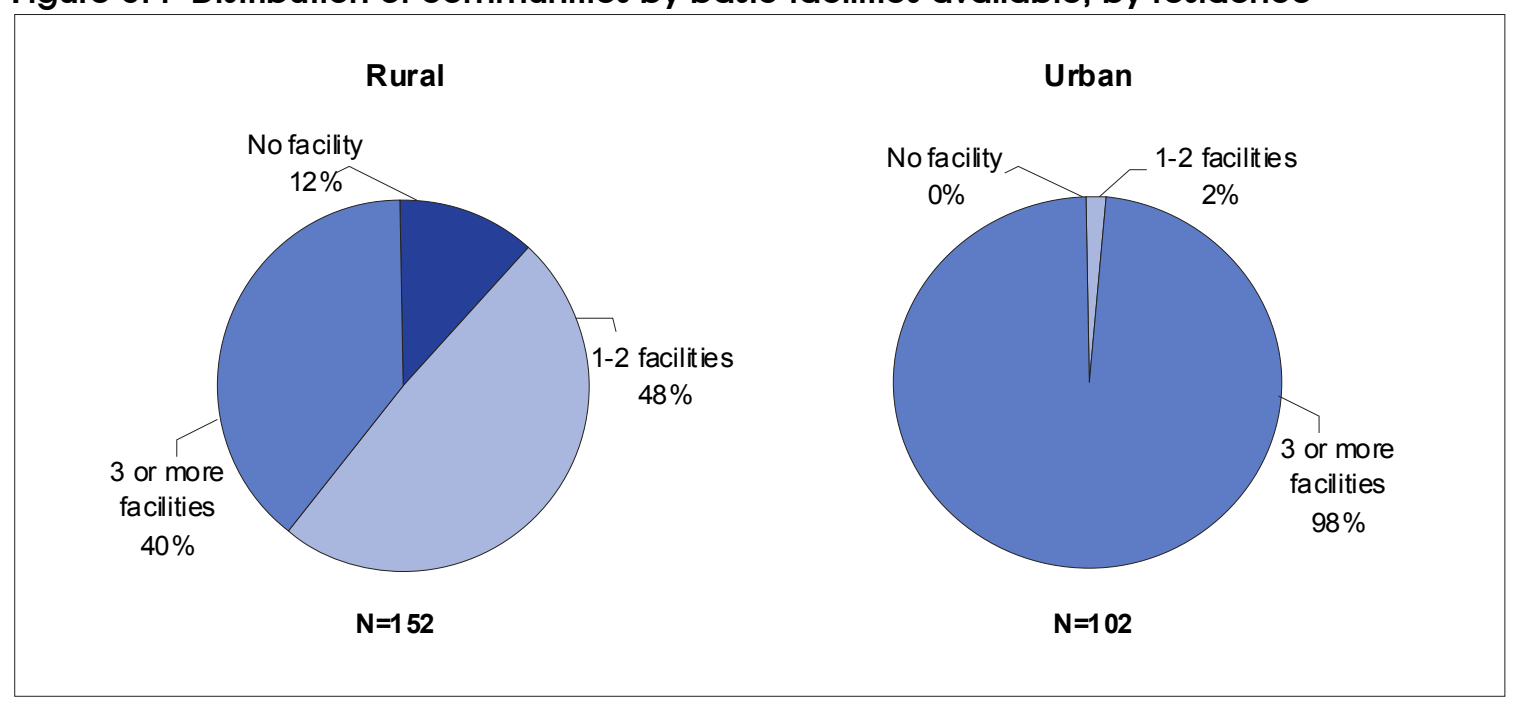

Figure 6.4 shows rural and urban variations with respect to the number of basic facilities available within communities. Eighteen rural communities reported no basic facility in their vicinity. That indicates a significant number of young people growing up in isolated, disadvantaged, and underdeveloped communities. The majority of urban communities report access to three or more basic facilities, whereas less than half of rural communities report the same access.

\section{HEALTH SERVICES}

Community key informants were asked about available health services and facilities. Where there were no immediate facilities, key informants estimated the distance to the nearest available facility. The chemist or medical store appeared to be available in most of the communities, followed by private doctors. As expected, more urban communities report the availability of private doctors than rural communities. Most communities report hakims ${ }^{27}$ and homeopaths as the third most available health service. However, there are differences by residence. The majority of urban communities report the availability of a hakim, whereas only a handful of rural communities report the same (Table 6.4).

The availability of primary health outlets within communities is very low. Less than one-third of communities report a Basic Health Unit (BHU) (a government facility providing primary care) and more than one-third say they have to travel five kilometers or more to reach such a facility. Less than one-fifth of all communities report the

27 A hakim is a traditional healer using herbs for treatment. 
presence of Rural Health Centers (which are better equipped with paramedical staff and medical equipment), but the majority of rural community members have to travel five kilometers or more to reach one. Mother and Child Health Clinics are barely available in rural communities (Table 6.4).

Figure 6.5 illustrates how communities are served in terms of the number of health facilities available inside the community or within two kilometers. As expected, more rural communities lack access to health care facilities than urban communities. Over 43 percent of the rural communities reported no health service available in their vicinity, compared with only 14 percent of urban communities reporting the same. Likewise, the urban communities are three times more likely to have two or more health care facilities than their rural counterparts (76 percent and 21 percent, respectively). This picture highlights the poor access of rural residents to health care outlets and draws attention to the need to improve the access to health care facilities in rural areas.

Figure 6.5 Percent of communities according to the number of health facilities available, by residence

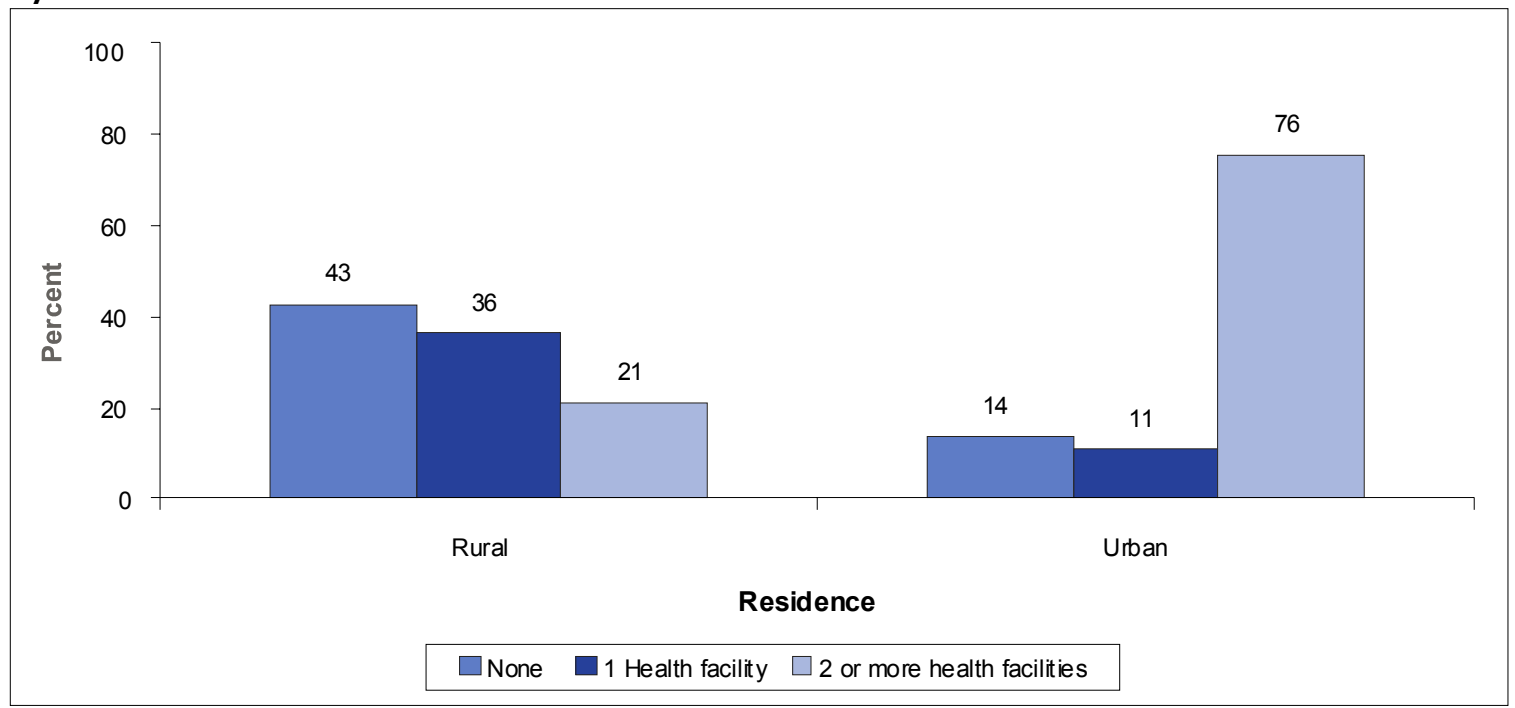

In addition to questions regarding the availability of health services, the key informants were also asked about the health care facilities that are most frequently utilized by members of the community. The majority of the communities reported that residents seek advice from more than one source (Table 6.5). A comparison across provinces shows that the majority of communities tend to seek treatment through private doctors, with many also utilizing public health facilities. Communities in NWFP appear to have almost equal utilization of public and private health facilities (Figure 6.6). 
Balochistan, on the other hand, has the lowest percentage of communities seeking treatment from private doctors. A modest percent of community members also seek medical services through hakims, homeopaths, chemists/paramedic staff (e.g., dispensers, lady health visitors, and lady health workers). It is important to note that even though these services are just as available as private doctors and BHUs, only a minority of residents of communities prefer to use these facilities as their primary source of treatment.

Figure 6.6 Distribution of preferred sources of health treatment of all communities, by province

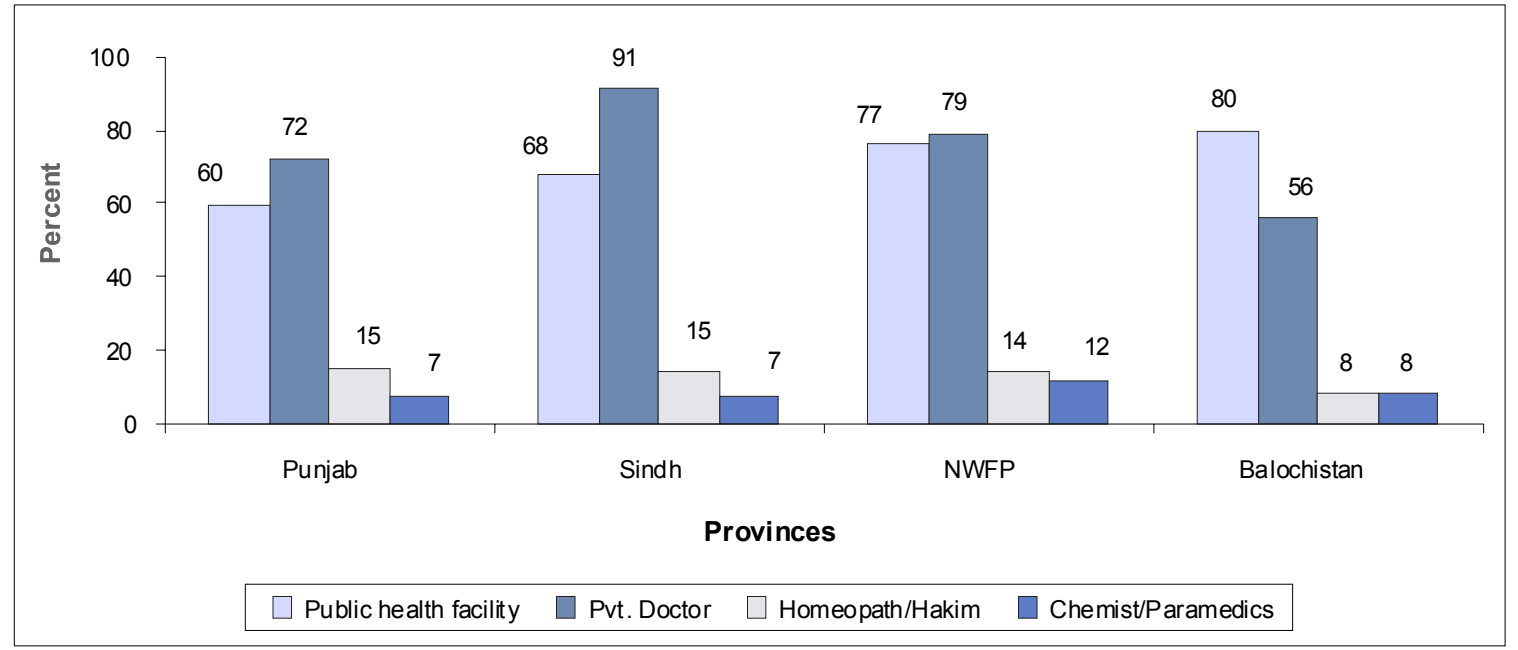

Note: Generated through multiple responses.

\section{SCHOOL AVAILABILITY}

In the 254 communities surveyed, key informants provided a range of details on the schools attended by the majority of children in their area.

A striking majority of communities in all provinces have one or more primary schools within a distance of two kilometers. Provincial comparisons of school availability reveal that NWFP has the largest percentage of communities with schools available at each level (Figure 6.7). Data show that Sindh has the lowest percentage of communities reporting a primary school within two kilometers. The picture for middle and secondary schools is different to that of primary schools. Overall, the majority of communities do not report the availability of middle and secondary schools with some 
variation across provinces. ${ }^{28}$ NWFP appears distinctly better off than other provinces for middle, secondary and higher secondary schooling. School availability drops sharply for higher secondary and above level institutions in communities across all provinces.

Figure 6.7 Percent of communities with at least one school available inside the community or within two kilometers, by province

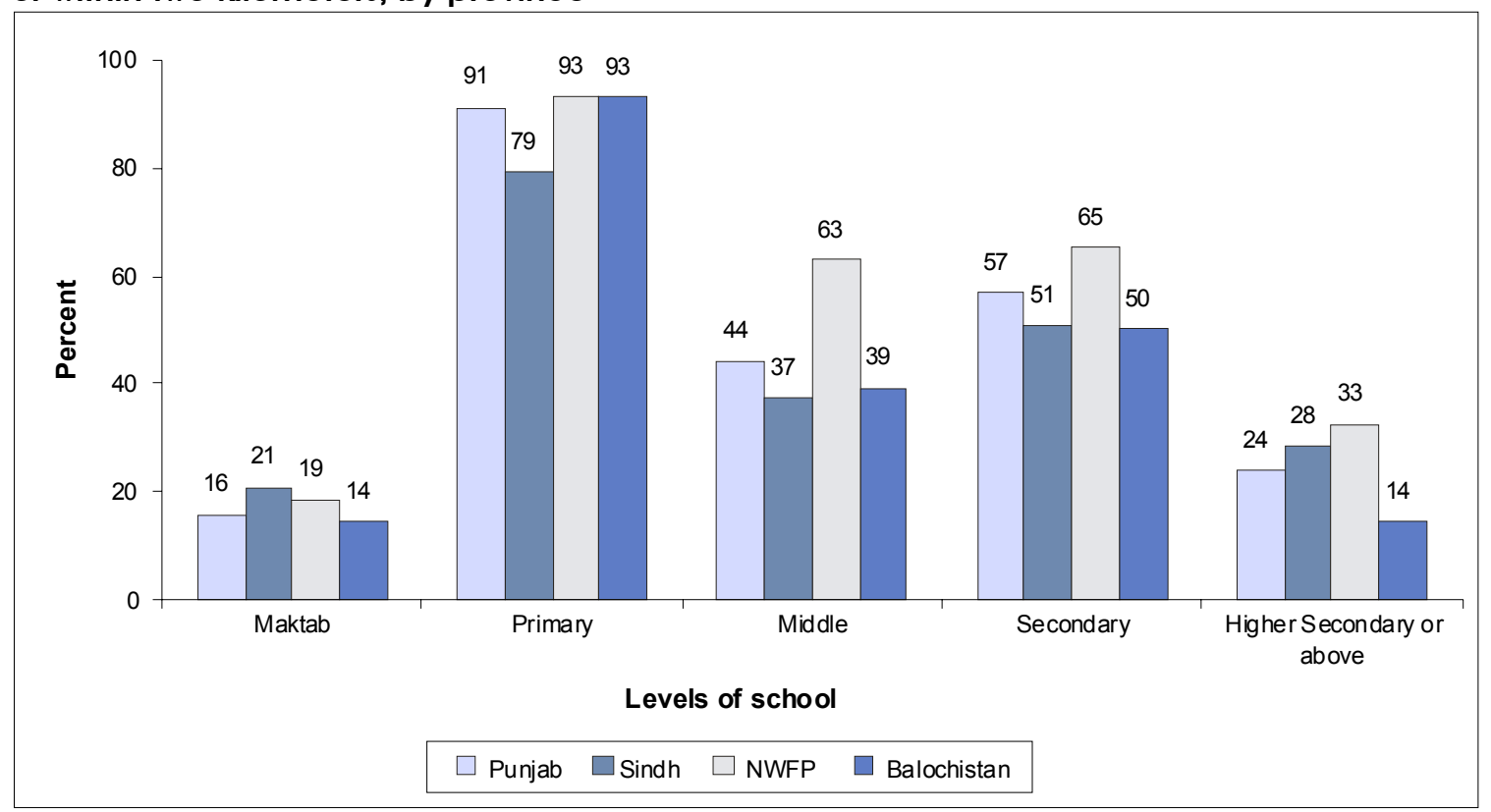

One key to understanding the disparity in school attendance between males and females is school availability. Since only a little more than half of all females reported having ever attended school, it is important to consider whether a shortage of schools for females accounts for a gender imbalance in enrollment. The community data contain information on the number and type of schools open to males and females. Thus, community data yield important information about gender differences in school availability.

The majority of communities reported primary schools available either inside the community or within two kilometers for both males and females (Table 6.6). However, access to education in Pakistan differs dramatically by sex, with young females at a greater disadvantage than young males. Even though almost all communities have access to at least one primary school within two kilometers, not all schools are open to both sexes. Although a modest number of communities have access to mixed schools,

${ }^{28}$ A small proportion of schools in Pakistan contain multiple levels. In instances where a middle or secondary school also included the primary classes, the school was classified by the highest level available. 
166 communities have access to single-sex primary schools for males and 130 communities have access to single-sex primary schools for females (Table 6.6). Furthermore, it is clear that females are particularly disadvantaged in rural areas.

The situation deteriorates for middle schools, since 49 communities have a school for males within two kilometers, whereas 53 communities report the same for females. Of all communities, 40 report access to a mixed middle school, although most of these communities are found in urban areas. The availability of higher secondary schools is even more alarming, since only 38 communities report at least one higher secondary school for males and only 22 communities report the same for females (Table 6.6).

There are significant provincial disparities. Overall, communities in NWFP have the greatest degree of access to single-sex schools for both males and females at every level. Although there are relatively fewer communities in Balochistan with access to single-sex schools for males at the primary level, Balochistan almost matches Punjab with the percent of single-sex primary schools for females (65 percent in Balochistan and 64 percent in Punjab. Sindhi communities report the lowest proportion of communities with educational opportunities for females at almost every level, relative to the other provinces (Table 6.6).

Of the communities that report access to schools, most report access to schools that are government run, while a substantial minority also reports the presence of private and NGO schools (Table 6.7). NWFP has the highest proportion of communities reporting government-run primary schools, while the highest percent of communities with private schools are in Punjab. Furthermore, while the majority of communities report access to government-run middle schools, a higher proportion of communities at this level of school report access to private institutions, particularly in urban areas. Although, a modest proportion of communities have access to secondary schools run by the government, a substantial number of communities also report private secondary schools inside or within two kilometers of their vicinity.

Most of the higher secondary schools appear to be government run; most communities reporting access to a private higher secondary school are in urban areas. Since access to middle, secondary, and higher secondary schools is less common than access to primary schools, the presence of private schools probably reflects the high demand for higher education. 


\section{NGO ACTIVITIES}

According to Social Policy and Development Centre (2002), there are about 56,219 registered NGOs in Pakistan. Most of these NGOs have mandates aimed at bringing about social change or community development. During the community survey, key informants indicated whether their area had any NGO, and if so, the nature of their work. Relatively little NGO activity was reported and out of 254 communities. Only 86 reported at least one NGO in their vicinity affiliated with any other organization. Punjab appears to have the most communities with NGOs, followed by Sindh (Table 6.8). Interestingly, half of the urban communities report an NGO compared to only a quarter of rural communities.

The majority of the communities report that NGOs in their area are working independently, whereas 10 communities report NGO affiliation with an international NGO. Affiliation with a national NGO was reported by only 9 communities (Table 6.8).

Key informants were further asked about the beneficiaries of the activities undertaken by these NGOs. It is evident from the data that most of the NGOs focus on activities that benefit the whole community (Table 6.9). It is important to note that NGOs working for young people are confined to 21 communities largely concentrated in urban areas. A rather negligible number of rural communities mentioned NGO work that is addressed toward young people.

Most communities that report the presence of NGOs say they are working on community development (Table 6.10). Slightly less than half as many communities report NGOs working on formal education or health and family planning. Along other lines, four communities have NGOs working to improve access to microcredit and seven have NGOs addressing sports and games. These low levels of activity suggest that as social sector service providers in the four provinces, NGOs play a small and limited role and one largely confined to urban areas. As a potential means of delivering services that benefit significant numbers of adolescents and youth in Pakistan, NGOs may not represent the most viable option at the present time.

\section{CONCLUSION}

This chapter has highlighted some of the methodological problems associated with defining community as a block of households, particularly in rural areas where boundaries are more fluid and difficult to demarcate. It has also provided insight into

the characteristics of communities where young people live, highlighting the wide 
diversity in terms of topography, accessibility, infrastructure, and opportunities in the area of school and work.

The chapter points out that young people in rural areas of Pakistan are less advantaged in terms of access to essential facilities (roads, transport, networks of communication, piped water supply, sewage systems, post offices, and banks) than their urban counterparts. Lack of facilities exposes young people in rural areas to more health risks and impedes the delivery of quality schooling. One-tenth of rural communities have no facilities at all, which indicates a significant number of young people growing up in disadvantaged and underdeveloped areas. Rural areas that have no facilities are unlikely to attract quality teachers or trainers, which hampers their young people's development, skills, and chances in life. Of all provinces, communities in Balochistan appear to be the most underserved.

The availability of health facilities in communities is also dependent on residence. Urban areas have more public and private heath outlets whereas a considerable proportion of communities in rural areas travel five kilometers or more to reach a BHU. The majority of communities use a combination of public and private doctors, but a significant proportion also rely on local healers.

Most communities appear to have some schooling facilities available. However, schools for females at each level (primary, middle, secondary, and higher) are less available than schools for males. This gender gap in the delivery of schooling is most pronounced in rural areas. Privately funded maktabs affiliated with religious parties appear to be a negligible part of the education delivery system in Pakistan. On the other hand, private-sector primary schools are now a significant part of the urban landscape. At the higher levels of education, there are more schools available in urban areas than rural areas. In this respect, NWFP appears to be better served than other provinces while Sindh and Balochistan are the least served.

Finally, the chapter ends by highlighting the limited role NGOs appear to play as service providers or facilitators of development in the communities visited for this survey. It appears that when NGOs are available they are largely located in urban areas where their focus is on community development rather than education or health. The limited outreach of NGOs indicates they do not currently have the potential to reach significant numbers of young people, especially those living in underdeveloped areas. 
ADOLESCENTS AND YOUTH IN PAKISTAN 2001-2002: A NATIONALLY REPRESENTATIVE SURVEY

\section{REFERENCES}

Pasha, Aisha, Jamal Haroon and Iqbal Asif. 2002. Dimensions of the nonprofit sector in Pakistan. Working paper No. 1. Social Policy and Development Centre.

Kuper, Adam and Jessica Kuper. (eds.) 1989. The Social Science Encyclopedia. Lahore: Services Book Club. Survey of Pakistan, 1997. Atlas of Pakistan.

Survey of Pakistan, 1997. Atlas of Pakistan. Surveyor General of Pakistan. 


\section{Conclusion}

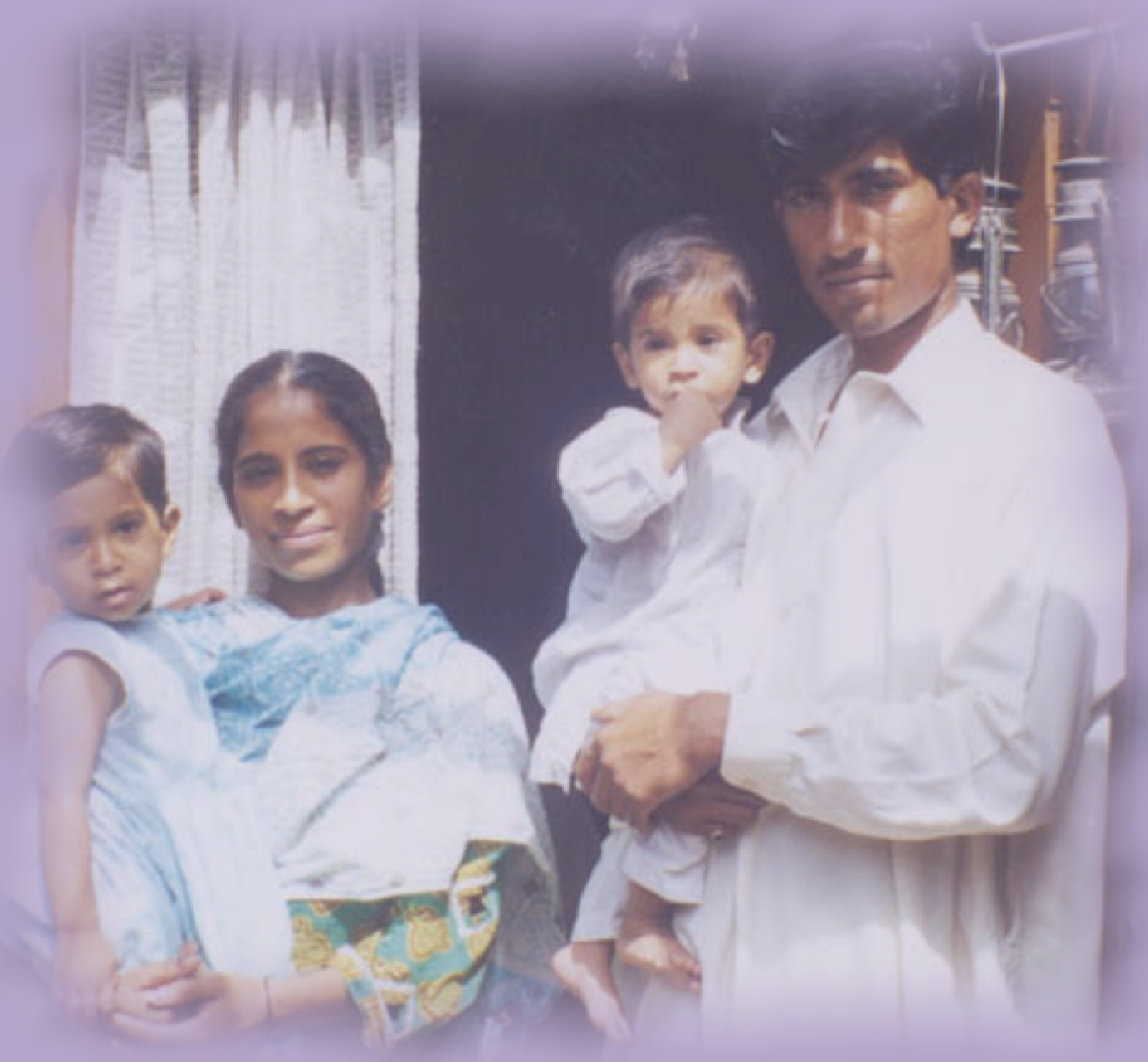




\section{CONCLUSION}

Young people are arguably the most important resource for a country's future. They represent Pakistan's prospects for economic and social development and the potential for change. In order to realize the full potential of its adolescents and youth, Pakistan ultimately needs to grapple with the challenging national issues of economic development and resource allocation. The economy has to grow in order to create new opportunities such as jobs, schools, universities, and recreational facilities. In the meantime, it is imperative that the country tackle immediately achievable issues, such as the under availability of basic education for young persons, particularly females, in each community in Pakistan.

The aspirations of Pakistan's young people are well expressed and defined by them in terms of what they want to achieve and the lives they want to live. Unfortunately, the reality of their lives does not correspond with their aspirations. This gap between aspirations and what is on offer in terms of opportunities combined with severe constraints and where all efforts at policies and programs for youth and adolescents have to be addressed. It is not simply the obligation of one generation to another to respond to their aspirations and translate them into reality, but indeed it is incumbent for the very survival of the country to do so. An investment for the future generation of citizens is an urgent priority in all regards. Without it, the untenable outcome will be a whole cohort, one of the largest in the country's history, facing a future with little or no capability of meeting the challenges of a rapidly changing world.

All young people express aspirations for education well beyond the primary school level. Indeed, almost all males and females feel they should be educated either to the secondary or university level, although there is a slight difference between rural and urban areas. Young females in rural areas feel that acquiring a secondary education is sufficient, whereas in urban areas there was more of a tendency for females to opt for going to university. There appears to be a positive generational change in the attitude toward education. Young people have higher aspirations for their education than their parents. This is indeed a positive trend that augurs well for the future. 
The dilemma confronting Pakistani youth today relates to their inability to see their aspirations for education being translated into reality. The situation on the ground is that young females in Pakistan continue to be at a disadvantage in the pursuit of education when compared to young males. The survey demonstrates that fewer than half of all young females aged 15-24 have ever enrolled in school. Even among those who are fortunate enough to gain some education, females are more likely to drop out of school at an earlier class than their male counterparts. This pattern of low enrollment for females is magnified at the lowest socioeconomic stratum. Only 20 percent of females from the lowest income group remain in school by the end of class five, as compared to 80 percent of females in the highest income group among those who ever enrolled. While there is evidence that the school enrollment of females has increased in the last five years, the gains are small and the gender gap remains huge. Nonetheless, it is now true that for the first time in Pakistan, over half of adolescent females aged 15-19 have been enrolled in school (54 percent).

There is enormous variation in educational attainment across provinces, between income groups, and by rural and urban residence. Female ever enrollment is highest in Punjab, while, of all young people who were able to attend school, those in NWFP had the greatest mean number of completed classes. Socioeconomic status played a very important role in all aspects of educational attainment examined in this survey. Young people from the lowest group, especially females, were the least likely to ever attend school. Those females who did enroll are more likely to drop out of school at an earlier class, begin school at a later age, and complete fewer classes. These differences have to be acknowledged and addressed in a way that ultimately raises achievements for females on par with those of males.

While there is evidence that cultural barriers to the education of females persist, the community sample of the survey highlights that there are fewer schools open to females and hence a gender bias in public expenditure on education. It is also clear from the statements from young people that reasons for not going to school or for dropping out are quite different by gender. Furthermore, rising private school enrollment suggests that many parents perceive the quality of government schools to be inadequate. As males' enrollment in private schooling is rising faster than for females, it appears that parents are willing to incur greater educational costs for their sons than for their daughters. As a result, young females from the poorest families are particularly disadvantaged. 
Undoubtedly, education is the major transition in young people's lives. Given that a large proportion of young females and a substantial number of young males never make that transition, prioritizing educational opportunities appears to be the most unequivocal way of altering young people's lives. It changes their worlds of information and exposure and influences their subsequent transitions to work, marriage, and childbearing. The need to set up quality, functioning schools for children of both sexes, but particularly for females in rural areas, is the foremost recommendation of this report. The lack of gender-equitable access to schools is a major obstacle to achieving universal primary education. The issue of access to schooling is further compounded by the poverty experienced by many young people. The primary reasons that young people give for dropping out of school are related to family poverty. Direct measures to redress this situation would include the provision of free textbooks, uniforms, and meals. School retention rates require as urgent attention as enrollments.

While private schools may meet the demand for schooling among those who can afford to pay higher costs, it is the Government that bears the responsibility for providing primary and middle level schooling for all Pakistanis. It can build partnerships with the private sector wherever possible but in the end, the Government has to ensure adequate funding for education and cannot relinquish its responsibility.

Precious funds that are available for education could best be used by mapping out and targeting those communities (and there are a sufficiently large number) where there is no school specifically for girls. Local government can certainly play a huge and critical role in this exercise. One of the direct and immediate effects of devolution of responsibility and financial expenditures could be to encourage greater targeting of communities with no access to primary schools. In fact a major drive as part of the devolution process can be for local and provincial governments to conduct a cost analysis of providing primary schools where they do not exist and lobby for greater expenditure. District administration in particular needs to be encouraged to provide schools and teachers in areas where they do not exist. Furthermore, there should be incentives for public/private collaboration in rural areas in order to utilize opportunities for higher enrolments.

While clearly the availability, improved quality, and uniform standards of schools are an absolute priority, there is still a need for advocacy for expounding the benefits of education for both males and females. The media can be utilized, particularly television and radio, to encourage parents, communities, and the government at all levels to support primary and secondary education for children. The attitudinal change 
which has begun needs to be reinforced by working with existing sources of advocacy such as dramas and soap operas in order to change attitudes and behavior. The benefits of schooling have to be driven home through the demonstration of positive role models, reinforcement of innovative schemes, and provision of scholarships.

The second significant transition for most young people is to work. This report highlights and documents the huge differences between males and females in the levels of formal and informal work, types of work, and hours spent in work. Currently, the transition to work plays out very differently for young males and females in Pakistan. While most young males eventually enter the paid labor force, less than 40 percent of young females have entered the workforce by the age of 24 . Indeed, throughout their childhood and adolescent years, the majority of young females remain invisible in that they are neither attending school nor engaging in formal economic work. Female domestic work, which is largely ignored and unrecorded, was measured through time use data, which confirms the heavy domestic burden carried by young females.

Among young people who work, the most common type of employment is in the agricultural sector. Other employment domains are segregated by gender, with many young females engaged in stitching, embroidery, and knitting while young males work in factories, are self-employed, or are engaged in skilled labor. Young females are also much more likely to work at home and to engage in seasonal work than young males. On average, young males work longer hours than young females. Furthermore, young females are slightly less likely to receive their pay directly, but if they do, they are more likely to be able to keep it.

For young people growing up in Pakistan there are limited opportunities for developing their skills or capabilities through work. In urban areas most vocational training opportunities for males are in computer centers or apprenticeships in mechanical or electrical workshops. Fewer avenues are open to females and are often limited to handicrafts, or, for the literate, computer centers. In rural areas, opportunities for vocational training are uncommon for both sexes, but those that exist consist of mechanical workshops for males and handicrafts for females. In urban areas, waged labor, employment in industry, and some private-service work are available for males, while for females, jobs in industry, private service, and the government are limited. In rural areas, agricultural work and waged labor are almost the only options available to both males and females. 
Work starts early for children with the least education and from the poorest households. Child labor, work before age 15, involves at least a third of all girls and half of all boys in the poorest quartile of the population. The prevalence of child labor is higher in rural areas than in urban areas, particularly for females. The highest rates for both males and females are to be found in Sindh. In rural Balochistan and NWFP, slightly more young males in the younger cohort have engaged in child labor than have males in the older cohort. Although adolescents are less likely than youth to have worked before age 15 in rural Punjab, in urban areas adolescents are slightly more likely than youth to have worked at younger ages. To a large extent these differences between the two cohorts may reflect rising poverty in some of these areas; hopefully, the poverty reduction strategy will address the incidence of child labor more directly. It is also likely that an increase in the number of children who complete primary school will lead to a decline in child labor, as this survey shows that very few young people combine work with schooling.

One of the most striking findings of the survey is that most young people express the desire to work in the near future if opportunities are available. This is particularly surprising in the case of females, 80 percent of whom would like to work. Clearly young people see work as a positive attribute, such that the constraints of mobility and the fear of leaving the home would be overridden if suitable opportunities were available. In most instances, work is seen as a way to enhance household income or to increase one's capabilities to cope and interact with the world outside the home.

Undoubtedly, the most effective and desirable solution would be for the economy to grow at a rapid rate, and to diversify markets and employment, so that young people are easily absorbed in jobs and have choices in terms of the work that they do. The growth of the private sector would be particularly important as an alternative source of employment. However, this would depend almost entirely on the financial policies that the government follows. The growth of the private sector would be particularly important as an alternative source of employment. However, this would depend heavily on the attractiveness of drawing in investment in a climate of relative instability and uncertainty. In any scenario, an educated youth would provide the necessary inputs to ensure a thriving industrial and skilled labor force. Here once more the need to prioritize the education of young people has infinite importance for the immediate future.

Employment generation needs to accompany investment in jobs for those who complete education at different levels. It would be shortsighted not to create job 
opportunities commensurate with a moderate level of education, given the low education base Pakistan is likely to have in the short and medium run. But skill enhancement has to accompany such job creation. Internships and reinforcement of the apprenticeship system in existing industries and sectors for those who complete a primary and middle level education has to be put in place and encouraged. Self employment may be a more promising way to enhance job opportunities. But for this there have to be schemes in place that promote entrepreneurial skills training for young females and males completing primary and higher levels of education.

Just as the acceptability of the education of young women must be expanded, the accompanying social values and milieu must change to promote the greater acceptance of young women working in the public sphere. The media can project positive images of working women and the contributions they can make to society, promoting greater autonomy and scope for development for young women.

Both the adult respondents and the young people divided responsibilities in and outside the home along clearly gendered lines, indicating that there is very little digression from stereotyped divisions of responsibilities within the home. Rarely are equal domestic responsibilities ascribed to both females and males. Furthermore, the work that young females currently do remains unrecorded and therefore unappreciated in formal employment and national accounts. This report provides clear evidence of the excessive number of hours young females aged 15-24 spend on domestic responsibilities that are essential for household survival. The greater recognition and appreciation of the roles and contributions of females in the realm of non-economic work could be a theme for bringing about social change.

As highlighted in all other aspects of young people's lives, gender disparities define many of the attitudes, decision-making processes, timing, and interpretation of puberty, marriage, and childbearing among young people in Pakistan. The onset of puberty occurs earlier for young females than for young males. However, females are also less likely to be informed about the event in advance and are less likely to be around anyone other than their own nuclear family when it occurs. Thus females have limited means to obtain information about puberty, as compared to males, some of whom do gain some information from male peers. Not surprisingly, the small proportion of females who were informed in advance about puberty learned about it from their mothers. Given the low levels of education reported for the mothers of the adolescent and youth respondents, it is questionable how adequately mothers are able to pass along this information indeed how well informed they are themselves. Since so few 
females were enrolled in school at the time of puberty, school may not be the ideal place to gain information about this transition as compared to the home. In addition to schoolbased life-skills training, parents should be encouraged to speak with their children about puberty and receive guidance as to how to broach this subject appropriately. Early marriage and childbearing have been major concerns in Pakistan over the years. This survey confirmed that age at marriage has increased for both males and especially females over the past fifty years. Females continue to marry at a significantly younger age than their male counterparts, and rural residents tend to marry much earlier than young people in urban areas. As a result of the increased age at marriage, the gap between the onset of puberty and the time of marriage for young women has been increasing. This can be regarded as a positive achievement, as young women have more of an opportunity to mature physically and mentally before entering a major change in their lives and responsibilities. However, a large proportion of these young women are not able to use this period of time for any substantive, skills-enhancing activity. Young men, on the other hand, are much more likely to be in school and working during this period between puberty and marriage. Their chances of acquiring skills and some exposure to the outside world are much better. In contrast, with limited mobility and acceptable activities in the public sphere, an unmarried post pubescent female has few opportunities to enhance herself and define herself outside of her relationship to her family. Interventions are desperately needed to fill this void with activities that both enhance skills and opportunities while protecting young women's reputation and honor. There needs to be simultaneous work in changing gender attitudes across the community to ensure that such opportunities are actualized and respected.

The most explicit economic component of marriage is dowry, the combination of money and goods that are transferred from the bride's family to the groom's family at the time of marriage. The dowry is a common and almost universal practice throughout Pakistan. However, the pervasiveness of dowry exchange does not make it less of a burden on the families of young women; the two issues identified by household respondents for the delay of marriage for young women were "lack of economic resources" and "trouble arranging dowry." The economic and social pressure to produce a substantive dowry leaves young women vulnerable and perceived as a burden on their families. Women's groups have taken up the dowry issue and the media has increasingly portrayed its negative impact, but these efforts need to be amplified. Transfers in the other direction (from the groom's family to the bride and her family) are much less prevalent, except in NWFP and Balochistan. 
Childbearing closely follows marriage in Pakistan, and therefore most characteristics of early childbearing are parallel to those associated with early marriage. When married, young females and males have very short birth intervals and are not likely to use contraception until later in marriage. The policy recommendations here center on the need to delay the first pregnancy. Both young husbands and wives need counseling on the advantages of delaying their first birth. Such instruction needs to be done in a sensitive way, perhaps following the model used in Iran to counsel betrothed couples.

While a substantial proportion of married adolescents and youth do intend to use contraception in the future, not many of them are currently using any method of family planning. This intention ought to be firmly linked with a more concrete, thought out, and well-informed decision to use a particular method in a finite time frame. Health and family planning providers, particularly community-based workers, will need training on how to approach younger couples, many of whom they tend to bypass when counseling for family planning. This is due to their own preconceived notion that such couples are unlikely to adopt contraception. The need for counseling young newlyweds regarding the importance of delaying conception stems from the level of risk surrounding early pregnancies. Forty-two percent of females aged 20-24 became mothers before the age of 20 . Antenatal care is rarely sought during the first pregnancy, except in urban areas, and few births are attended by a trained professional. Clearly the importance of early antenatal care and the dangers of the first birth warrant special attention and immediate actions.

The report highlights the largely restricted life of young females as compared to young males and the limited possibilities for school and work that are available to females. Regardless of socioeconomic status, females tend to be restricted to a life that largely centers on home and domestic chores, while males have much greater exposure to the outside world. Whereas mobility is severely constrained for females, it is not entirely unconstrained for males. There are, however, important gender dimensions in the degree of constraints on young people. Once young males gain permission from parents they are able to move outside the home unaccompanied, whereas females need to be accompanied almost anywhere outside the home, apart from visiting their neighbors. This has direct implications for the attainment of education, access to health facilities, opportunities for work, and recreation and social networks for young females. The manifestation of these gendered restrictions is seen in all aspects of young people's lives. Indeed, as evidence from this survey shows, social restrictions implemented by the family on women clearly affect access to resources and services (physical, social, and 
psychological). Once more, social mores and attitudes need to reinforce the positive aspects of girls and women leaving the home, and the negatives associated with fears of harassment have to be addressed through increased security on the streets and in other public places.

Those places considered 'unsafe' by parents differ for young females and males, as do the reasons justifying restrictions on mobility. In the case of males, parents' fears are related to concern about their son's personal safety and his integrity (i.e., whether they could have an accident that results in physical harm or fall into bad company). However, for females there appears to be more at stake than personal physical safety; concerns tend to center on family honor and reputation. The other dramatic difference in the lives of young people is in how they spend their time. For adolescent males, school, waged work, and recreation are likely to take up most of the day, while females are most likely to be involved in household chores with less time for going to school and little potential for recreation. Clearly, young females in Pakistan lack the opportunities of schooling, work and recreation afforded to males. While males in urban and rural areas across socioeconomic groups have uneven opportunities as well, it is the gender differences that are most striking.

In terms of broad programs for young people, priority must be given to all young females and to young males from poorer homes and underserved areas. Sports facilities, places for group activities (i.e., sports and savings clubs), and facilities that provide use of computers and the internet are all important interventions to take up for these groups who would otherwise be totally excluded from these opportunities to form peer relationships, develop social capital, gain economic skills, and other life-enhancing building-blocks. Although many children leave school before they become teenagers, most communities have schools that could be used to reach adolescents after school hours.

Agency in decision making varies between males and females and by the topic under discussion. Overall young persons in Pakistan have limited agency to shape important decisions affecting their lives. Generally, young people defer to parents regarding important decisions about their lives. While parents report conferring some authority to young persons, there is a notable gap between their perceptions and reality. Given this gap, there may be an opportunity for communication campaigns that endorse basic rights for young people and reinforce the critical role played by adults in enabling young people to exercise these rights. Efforts to reach young people are unlikely to be successful unless they involve parents and other gatekeepers. 
Finally, there are some factors that directly affect the lives of young persons because they affect household conditions. These include overcrowded households, lack of kitchen space, inadequate safe water, and lack of sanitation, which vary significantly by economic class and by residence. In some cases, lack of these facilities impacts on males and females differentially, as is the case with water and sanitation where girls and young women bear the burden of collection and inconvenience. In the case of home versus community access to telephones, television, and internet, more young males with their expanded mobility are likely to benefit from community-level facilities than young females.

The data on communities have provided insights into the characteristics of communities where young people live, highlighting the wide diversity in terms of topography, accessibility, infrastructure, and opportunities in the area of school and work. These data clearly point out the residential and provincial differences in access to communications, opportunities, and services. Young people in rural areas of Pakistan are less advantaged in terms of access to essential facilities (i.e., roads, transport, networks of communication, piped water supply, sewage systems, post offices, and banks) than their urban counterparts. Lack of facilities exposes young people in rural areas to more health risks and impedes the delivery of quality schooling. The availability of health facilities in communities is also dependent on residence. Urban areas have more public and private heath outlets whereas in a considerable proportion of communities in rural areas people must travel 5 kilometers or more to reach a Basic Health Unit. The majority of communities use a combination of public and private doctors but a significant proportion also rely on local healers.

One-tenth of rural communities have no facilities at all, which indicates that a significant number of young people are growing up in disadvantaged and underdeveloped conditions. Rural areas that have no facilities are unlikely to attract quality teachers or trainers; this reduces the access of rural youth to developmental opportunities, including acquiring skills and improving their chances in life. Of all provinces, communities in Balochistan appear to be the most underserved. Clearly any adolescent or youth initiative should target the rural areas and Balochistan as a whole.

In the end, the report points to the limited role NGOs appear to play as service providers or facilitators of development in the communities visited for this survey. It appears that when NGOs are available they are largely located in urban areas where their focus is on community development rather than education or health. The limited 
outreach of NGOs indicates they do not currently have the potential to reach significant numbers of young people or those who live in underdeveloped areas. It appears that NGOs, despite considerable donor investment in Pakistan, are currently playing a minimum role in the four provinces as service providers in capacity-development initiatives aimed at young people in Pakistan. However, a more in-depth assessment of their current capacity to reach young people is recommended along with a mapping exercise to understand more fully where NGOs are located and the scope of their outreach.

The most important findings of the report relate to the asymmetry between young women and men's experience of growing up in Pakistan. In most instances, gender disparities are further exacerbated by socioeconomic status and rural residence, leaving girls from the poorest families living in rural areas at the worst disadvantage in all aspects of their lives. Throughout the report, we are reminded of the need to plan and program very differently for young people belonging to various strata. No uniform policy or programs can be developed in Pakistan. The very basis of assessing needs and providing services and opportunities of young people will have to be their age, their gender, the economic status of the household, and the profile of the community where they live. This is the most important contribution of the report toward programs and policies, especially the national policy on youth, which are being developed to address the needs of young people. 

TABLes 


\section{Tables Chapter 2}

Table 2.1 Percent living with both biological parents in the same household, of all young people, by age and sex

\begin{tabular}{|c|c|c|c|c|c|c|c|c|}
\hline \multirow[b]{2}{*}{ Category } & \multicolumn{2}{|c|}{$15-19$ year olds } & $\vdots$ & \multicolumn{2}{|c|}{ 20-24 year olds } & \multicolumn{2}{|c|}{ Total } & \multirow[b]{2}{*}{$\mathbf{N}$} \\
\hline & Male & Female & : & Male & Female & : Male & Female & \\
\hline Total & 79.7 & 62.6 & $i$ & 71.5 & 29.7 & 76.6 & 48.5 & $\vdots$ \\
\hline$N$ & 2,052 & 2,743 & ! & 1,272 & 1,989 & : 3,324 & 4,732 & 8,056 \\
\hline \multicolumn{9}{|l|}{ Province } \\
\hline Punjab & 81.2 & 65.2 & i & 72.9 & 34.7 & 78.1 & 51.8 & 4,476 \\
\hline Sindh & 80.0 & 61.3 & 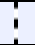 & 70.2 & 22.0 & 76.2 & 45.1 & 2,172 \\
\hline NWFP & 72.6 & 56.3 & : & 68.9 & 22.6 & 71.3 & 41.4 & 980 \\
\hline Balochistan & 79.0 & 57.0 & $i$ & 69.5 & 26.6 & 75.3 & 46.1 & 432 \\
\hline$N$ & 2,052 & 2,743 & 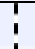 & 1,272 & 1,989 & 3,324 & 4,732 & 8,056 \\
\hline \multicolumn{9}{|l|}{ Residence } \\
\hline Rural & 80 & 59 & i & 72.2 & 25.2 & 77.1 & 44.4 & 5,755 \\
\hline Urban & 79.2 & 71.8 & 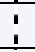 & 69.7 & 41.8 & 75.5 & 59.3 & 2,303 \\
\hline$N$ & 2,052 & 2,743 & i & 1,272 & 1,989 & 3,324 & 4,732 & 8,056 \\
\hline \multicolumn{9}{|l|}{ SES } \\
\hline Low & 80.9 & 50.5 & i & 71.3 & 18.2 & 77.3 & 36.8 & 1,726 \\
\hline Low-mid & 77.4 & 59.1 & 1 & 66.2 & 24.5 & 73.4 & 45.1 & 1,856 \\
\hline High-mid & 77.5 & 66.8 & i & 73.2 & 30.5 & 76.0 & 51.2 & 2,029 \\
\hline High & 83.9 & 73.0 & $i$ & 73.8 & 43.5 & 79.8 & 59.6 & 2,111 \\
\hline$N$ & 1,971 & 2,624 & ! & 1,202 & 1,909 & 3,173 & 4,533 & 7,706 \\
\hline \multicolumn{3}{|l|}{ Educational attainment } & ! & & & ! & & i \\
\hline Never attended & 75.6 & 51.8 & $i$ & 62.1 & 17.8 & 70.1 & 35.9 & 2,885 \\
\hline Less than primary & 77.7 & 64.0 & 1 & 68.9 & 28.5 & 74.6 & 51.7 & 1,046 \\
\hline Completed primary & 81.2 & 73.9 & : & 75.2 & 39.8 & 79.4 & 62.9 & 2,709 \\
\hline Completed secondary & 80.5 & 75.0 & $i$ & 73.4 & 55.5 & 76.7 & 64.3 & 1,418 \\
\hline$N$ & 2,051 & 2,743 & $i$ & 1,272 & 1,989 & 3,323 & 4,732 & 8,055 \\
\hline \multicolumn{9}{|l|}{ Ever married } \\
\hline Yes & 75.8 & 4.4 & : & 65.2 & 4.5 & 67.8 & 4.5 & : 2,371 \\
\hline No & 79.9 & 79.7 & $i$ & 73.9 & 73.1 & 78.0 & 78.0 & : 5,686 \\
\hline$N$ & 2,052 & 2,743 & 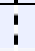 & 1,271 & 1,988 & 3,323 & 4,731 & 8,054 \\
\hline \multicolumn{9}{|l|}{ Ever worked } \\
\hline Yes & 79.2 & 58.6 & $!$ & 70.8 & 28.7 & 75.2 & 44.4 & 3,788 \\
\hline No & 80.4 & 64.4 & $!$ & 74.2 & 30.3 & 79.3 & 50.6 & 4,228 \\
\hline$N$ & 2,038 & 2,729 & i & 1,269 & 1,978 & 3,307 & 4,707 & 8,014 \\
\hline
\end{tabular}


Table 2.2 Percent of all households that are nuclear, of all households interviewed and all households containing young people

\begin{tabular}{|c|c|c|c|c|c|c|c|c|}
\hline \multirow[b]{2}{*}{ Province } & \multicolumn{2}{|c|}{ Rural } & \multicolumn{2}{|c|}{ Urban } & \multicolumn{2}{|c|}{ All HHs } & \multicolumn{2}{|c|}{ Youth HHs } \\
\hline & All HHs & Youth HHs', & All HHs & Youth HHs ' & Total & $N_{1}^{\prime}$ & Total & $\mathbf{N}$ \\
\hline Total & 48.7 & 41.5 & 53.4 & 48.5 & 50.1 & : & 43.4 & \\
\hline$N$ & 3,925 & 2,743 & 2,646 & 1,781 & 6,571 & 6,571 & 4,524 & $\overline{4,524}$ \\
\hline \multicolumn{9}{|l|}{ Province } \\
\hline Punjab & 52.3 & $45.9 !$ & 55.4 & $50.3 !$ & 53.2 & 3,249 & 47.1 & 2,049 \\
\hline Sindh & 39.8 & $32.8 !$ & 49.6 & $45.7 !$ & 43.8 & 1,643 & 37.5 & 1,212 \\
\hline NWFP & 50.5 & $41.9 !$ & 58.1 & $52.2 !$ & 51.6 & 1,060 & 43.5 & 744 \\
\hline Balochistan & 32.9 & 29.3 & 42.8 & $35.9 !$ & 34.2 & 619 & 30.1 & 519 \\
\hline$N$ & 3,925 & 2,743 & 2,646 & $1,781 !$ & 6,571 & 6,571 & 4,524 & 4,524 \\
\hline
\end{tabular}

Table 2.3 Mean size of all households, and those households where young people were interviewed

\begin{tabular}{|c|c|c|c|c|c|c|c|c|}
\hline \multirow[b]{2}{*}{ Province } & \multicolumn{2}{|c|}{ Rural } & \multicolumn{2}{|c|}{ Urban } & \multicolumn{2}{|c|}{ All $\mathrm{HH}$} & \multicolumn{2}{|c|}{ HH w/YP } \\
\hline & All HH & HH w/YP & All HH & HH w/YP & Total & $\mathbf{N}$ & Total & $\mathbf{N}$ \\
\hline Total & 7.7 & 8.5 & 7.4 & 8.1 & 7.6 & 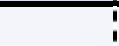 & 8.4 & \\
\hline$N$ & 3,926 & 2,744 & 2,652 & 1,786 & 6,578 & 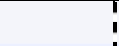 & 4,530 & \\
\hline \multicolumn{9}{|l|}{ Province } \\
\hline Punjab & 7.2 & 8.0 & 7.0 & 7.8 & 7.2 & 3,250 & 7.9 & 2,050 \\
\hline Sindh & 8.7 & 9.4 & 7.8 & 8.4 & 8.3 & 1,643 & 9.0 & 1,212 \\
\hline NWFP & 7.9 & 8.5 & 7.8 & 8.6 & 7.9 & 1,066 & 8.5 & 749 \\
\hline Balochistan & 9.8 & 10.4 & 8.8 & 9.7 & 9.7 & 619 & 10.3 & 519 \\
\hline$N$ & 3,926 & 2,744 & 2,652 & 1,786 & & 6,578 & & 4,530 \\
\hline
\end{tabular}

$\mathrm{HH}$ w/ YP = Households where young people were interviewed.

Table 2.4 Mean number of rooms in households and mean number of persons per living rooms, of all households containing young people

\begin{tabular}{|c|c|c|c|c|c|c|c|c|}
\hline \multirow[b]{2}{*}{ Province } & \multicolumn{4}{|c|}{ Mean number of rooms } & \multicolumn{4}{|c|}{ Mean number of persons per room } \\
\hline & Rural & Urban & Total & $N$ & Rural & Urban & Total & $\mathbf{N}$ \\
\hline Total & 2.5 & 2.7 & 2.5 & & 4.1 & 3.8 & 4.0 & \\
\hline$N$ & 2,727 & 1,777 & 4,504 & & 2,727 & 1,777 & 4,504 & \\
\hline \multicolumn{9}{|l|}{ Province } \\
\hline Punjab & 2.5 & 2.6 & 2.5 & 2,045 & 3.8 & 3.7 & 3.8 & 2,045 \\
\hline Sindh & 2.2 & 2.8 & 2.4 & 1,210 & 5.1 & 3.8 & 4.6 & 1,210 \\
\hline NWFP & 2.8 & 2.8 & 2.8 & 731 & 3.5 & 3.8 & 3.5 & 731 \\
\hline Balochistan & 2.9 & * & 2.9 & 518 & 4.6 & * & 4.5 & 518 \\
\hline$N$ & 2,727 & 1,777 & 4,504 & 4,504 & 2,727 & 1,777 & 4,504 & 4,504 \\
\hline
\end{tabular}

Note: "Living rooms" is defined as any room used by the residents of the households, including bedrooms and sitting rooms.

${ }^{*}$ Denominator $<30$. 


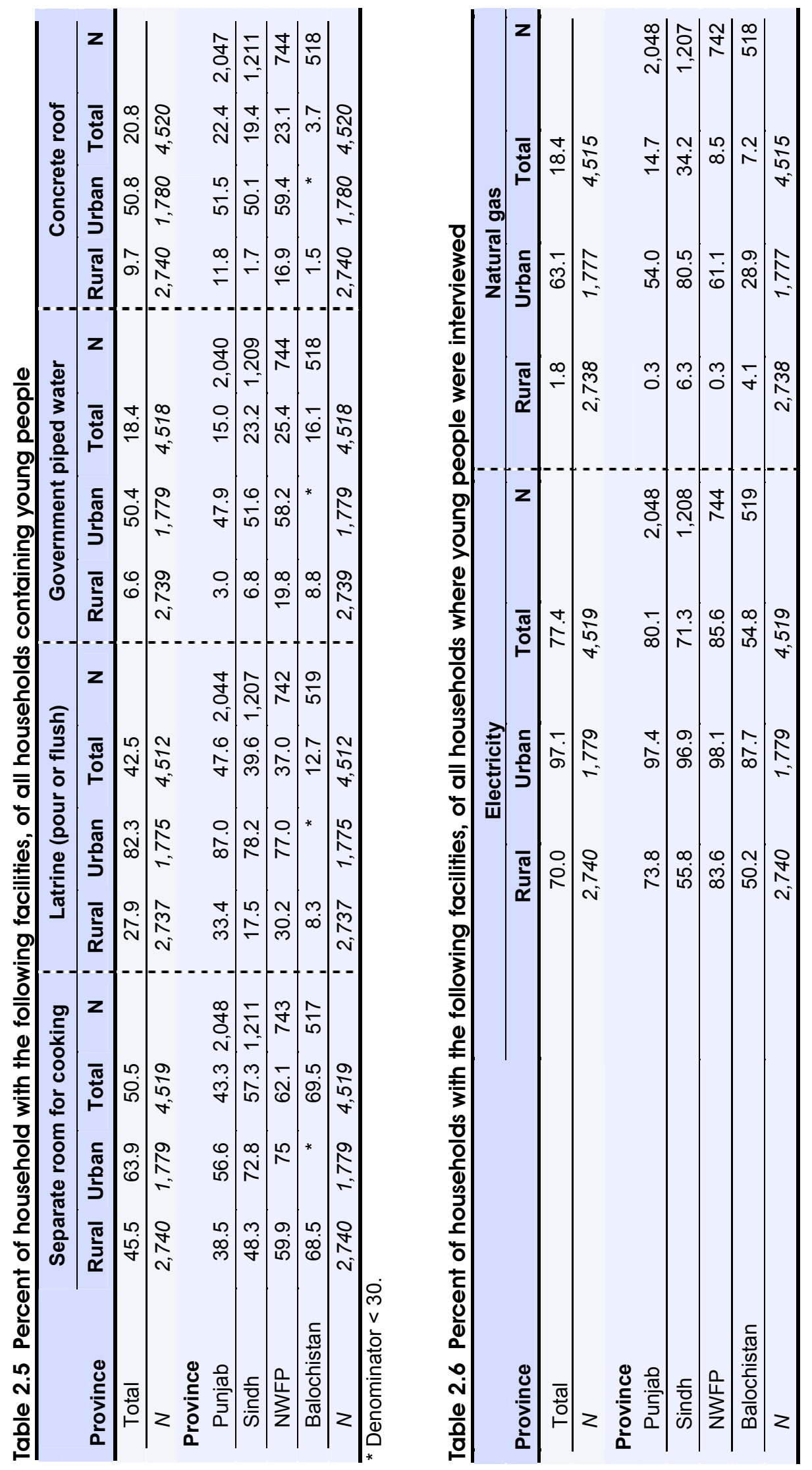



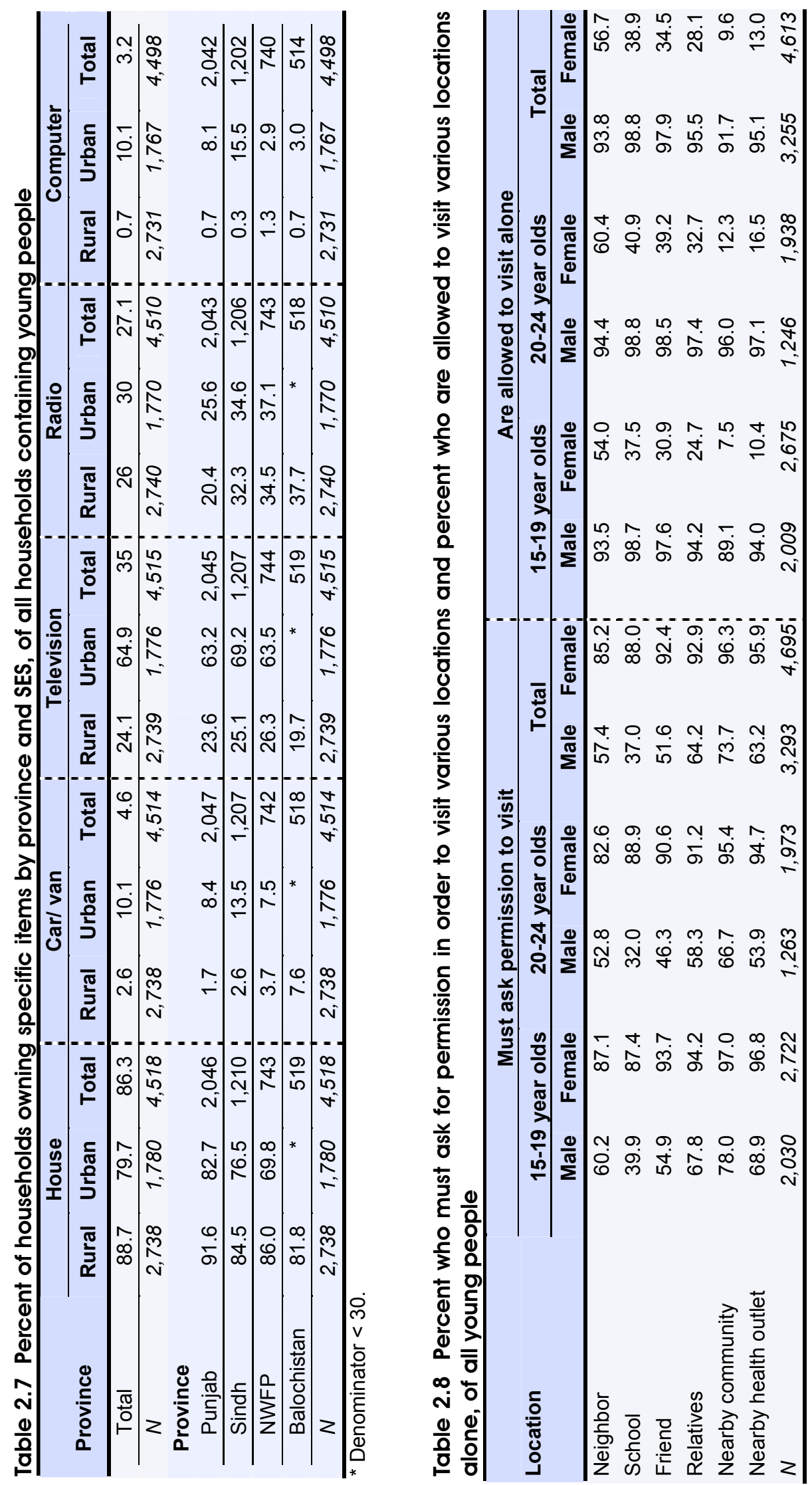
Table 2.9 Percent of adults who reported places in the community where young people are not allowed to go, by type of such places

\begin{tabular}{|c|c|c|c|c|c|c|}
\hline \multirow[b]{2}{*}{ Places } & \multicolumn{2}{|c|}{ Rural } & \multicolumn{2}{|c|}{ Urban } & \multicolumn{2}{|c|}{ Total } \\
\hline & Male & Female & Male & Female & Male & Female \\
\hline Market/shop & 13.7 & 33.3 & 10.5 & 46.0 & 12.4 & 37.4 \\
\hline Park & 3.1 & 3.5 & 9.5 & 15.8 & 5.7 & 7.5 \\
\hline $\begin{array}{l}\text { Graveyard } \\
\text { Snooker/table football }\end{array}$ & 9.1 & 0.4 & 5.1 & 6.8 & 7.5 & 2.5 \\
\hline game & 9.2 & 9.0 & 21.9 & 13.4 & 14.3 & 10.4 \\
\hline Video games shops & 9.9 & 1.1 & 39.9 & 9.7 & 22.0 & 3.9 \\
\hline Cinema/minicinema & 17.7 & 3.8 & 36.0 & 18.7 & 25.1 & 8.7 \\
\hline Hotel/restaurants & 14.1 & 6.2 & 12.5 & 8.6 & 13.5 & 7.0 \\
\hline Others & 58.3 & 70.2 & 31.6 & 34.4 & 47.5 & 58.5 \\
\hline$N$ & 566 & 830 & 668 & 734 & 1,234 & 1,564 \\
\hline
\end{tabular}

Table 2.10 Percent of young people reporting places in their area where they are not allowed to go, by type of place, of all young people who reported such places

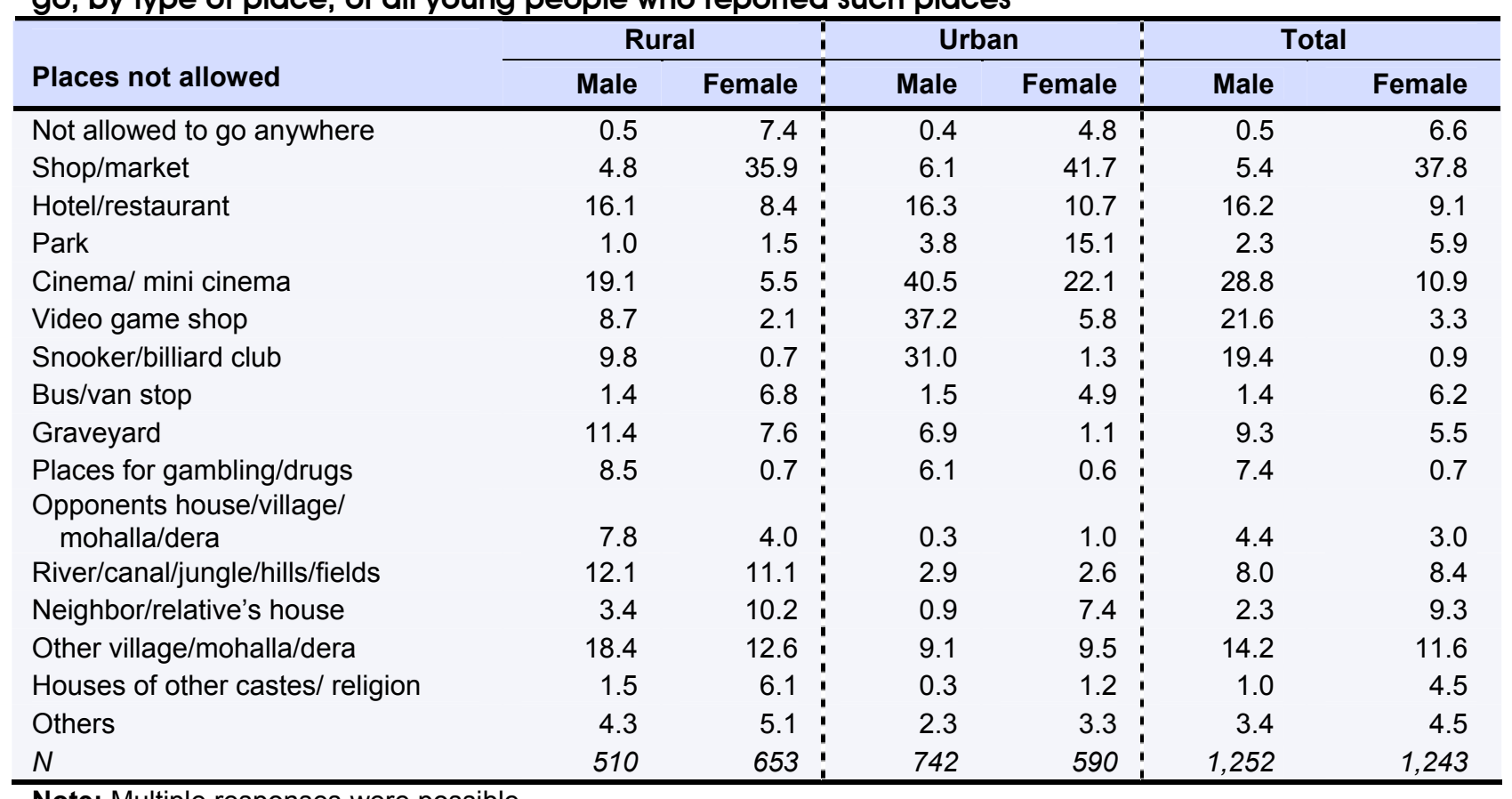

Note: Multiple responses were possible. 
Table 2.11 Percent of young people and responsible adults citing specific reasons for not being allowed to go to "unsafe" places, of all who reported such places

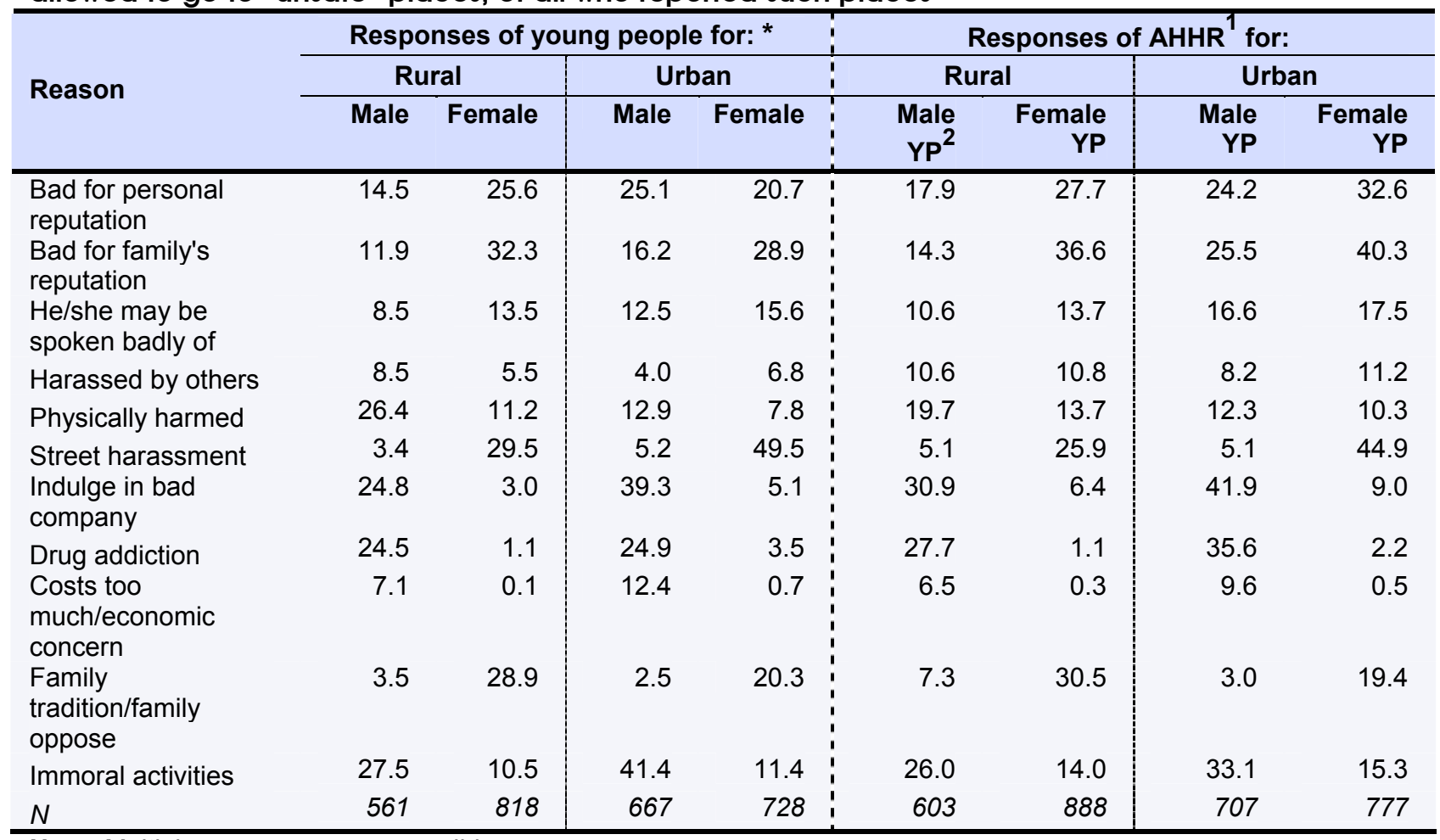

Note: Multiple responses were possible.

${ }^{*}$ These questions were asked only for 15-year-old unmarried adolescents.

1. AHHR=Adult Household Respondents

2. YP=Young People (15-24)

Table 2.12 Percent distribution of reasons for visit in the last six months, by marital status and sex, of those young people who have visited a place outside their own city or village

\begin{tabular}{lrrrrrrr} 
& \multicolumn{2}{c}{ Married } & \multicolumn{2}{c}{ Not married } & \multicolumn{2}{c}{ Total } \\
\cline { 2 - 7 } Reason & Male & Female & Male & Female & Male & Female \\
\hline For work & 47.0 & 1.5 & 27.0 & 1.4 & 30.0 & 1.5 \\
For education & 2.3 & 0.1 & 7.6 & 4.3 & 6.8 & 2.4 \\
For general recreation & 16.4 & 3.7 & 21.5 & 5.5 & 20.7 & 4.7 \\
To attend marriage/ funeral & & & & & \\
family event & 5.7 & 18.1 & 11.2 & 24.2 & 10.4 & 21.5 \\
To visit relatives & 23.3 & 51.7 & 36.0 & 49.4 & 34.1 & 50.4 \\
For medical care & 8.7 & 28.8 & 6.2 & 14.4 & 6.6 & 20.9 \\
For shopping/household needs & 29.7 & 15.3 & 19.7 & 16.1 & 21.2 & 15.7 \\
Other & 10.1 & 4.3 & 11.1 & 5.1 & 11.0 & 4.7 \\
$N$ & 330 & 770 & 1,959 & 1,033 & 2,290 \\
\hline
\end{tabular}


Table 2.13 Percent who have ever migrated, of all young people

\begin{tabular}{|c|c|c|c|c|c|c|c|}
\hline \multirow{2}{*}{ Characteristic } & \multicolumn{2}{|c|}{ 15-19 year olds } & \multicolumn{2}{|c|}{$20-24$ year olds } & \multicolumn{2}{|c|}{ Total } & \multirow{2}{*}{$\mathbf{N}$} \\
\hline & Male & Female & Male & Female & Male & Female & \\
\hline Total & 22.5 & 25.2 & 26.0 & 43.0 & 23.8 & 32.8 & \\
\hline$N$ & 2,021 & 2,694 & 1,256 & 1,953 & 3,277 & 4,647 & 7,924 \\
\hline \multicolumn{8}{|l|}{ Province } \\
\hline Punjab & 18.2 & 24.2 & 19.0 & 42.4 & 18.5 & 32.2 & 3,450 \\
\hline Sindh & 31.9 & 28.7 & 36.1 & 46.9 & 33.5 & 36.1 & 2,211 \\
\hline NWFP & 19.3 & 22.1 & 29.2 & 42.9 & 22.6 & 31.3 & 1,309 \\
\hline Balochistan & 23.2 & 25.6 & 34.5 & 31.4 & 27.6 & 27.7 & 954 \\
\hline$N$ & 2,021 & 2,694 & 1,256 & 1,953 & 3,277 & 4,647 & \\
\hline \multicolumn{8}{|l|}{ SES } \\
\hline Low SES & 27.2 & 27.3 & 34.1 & 46.1 & 29.8 & 35.3 & 1,477 \\
\hline Low-mid SES & 18.1 & 27.0 & 23.4 & 45.4 & 20.0 & 34.4 & 1,574 \\
\hline High-mid SES & 20.4 & 23.3 & 23.2 & 45.6 & 21.4 & 32.9 & 1,999 \\
\hline High SES & 24.1 & 24.7 & 24.3 & 35.5 & 24.2 & 29.6 & 2,529 \\
\hline$N$ & 1,942 & 2,577 & 1,187 & 1,873 & 3,129 & 4,450 & \\
\hline \multicolumn{8}{|l|}{ Educational attainment } \\
\hline Never attended & 27.9 & 27.4 & 30.5 & 46.3 & 29.0 & 36.3 & 2,582 \\
\hline Less than primary & 19.1 & 25.1 & 30.0 & 44.5 & 22.9 & 31.9 & 990 \\
\hline Completed primary & 21.7 & 22.4 & 24.6 & 42.9 & 22.6 & 29.1 & 2,765 \\
\hline Completed secondary & 22.7 & 23.8 & 23.6 & 32.6 & 23.1 & 28.6 & 1,587 \\
\hline$N$ & 2,021 & 2,694 & 1,256 & 1,953 & 3,277 & 4,647 & \\
\hline \multicolumn{8}{|l|}{ Marital status } \\
\hline Ever married & 28.9 & 55.5 & 27.6 & 57.2 & 27.9 & 56.7 & 2,188 \\
\hline Never married & 22.1 & 16.3 & 25.4 & 18.7 & 23.1 & 16.9 & 5,735 \\
\hline$N$ & 2,021 & 2,694 & 1,255 & 1,953 & 3,276 & 4,647 & \\
\hline \multicolumn{8}{|l|}{ Residence } \\
\hline Rural & 20.5 & 24.5 & 25.4 & 44.0 & 22.3 & 33.0 & 4,654 \\
\hline Urban & 27.2 & 27.0 & 27.4 & 40.4 & 27.3 & 32.5 & 3,270 \\
\hline$N$ & 2,021 & 2,694 & 1,256 & 1,953 & 3,277 & 4,647 & \\
\hline
\end{tabular}




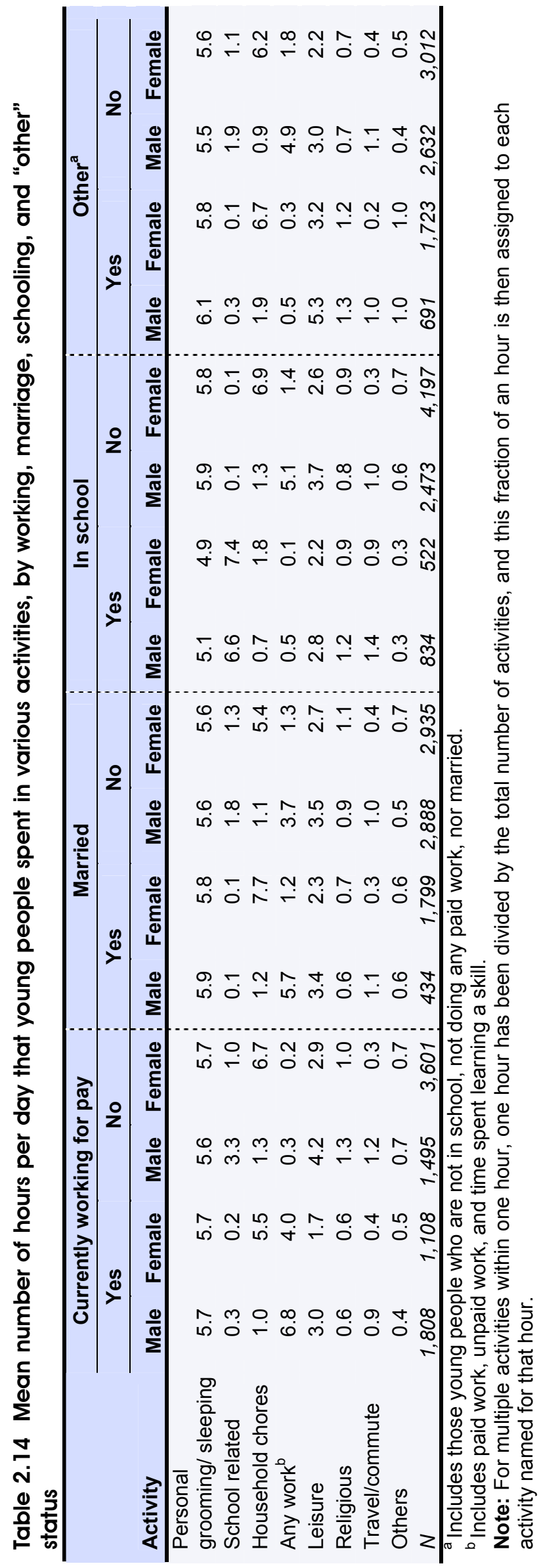




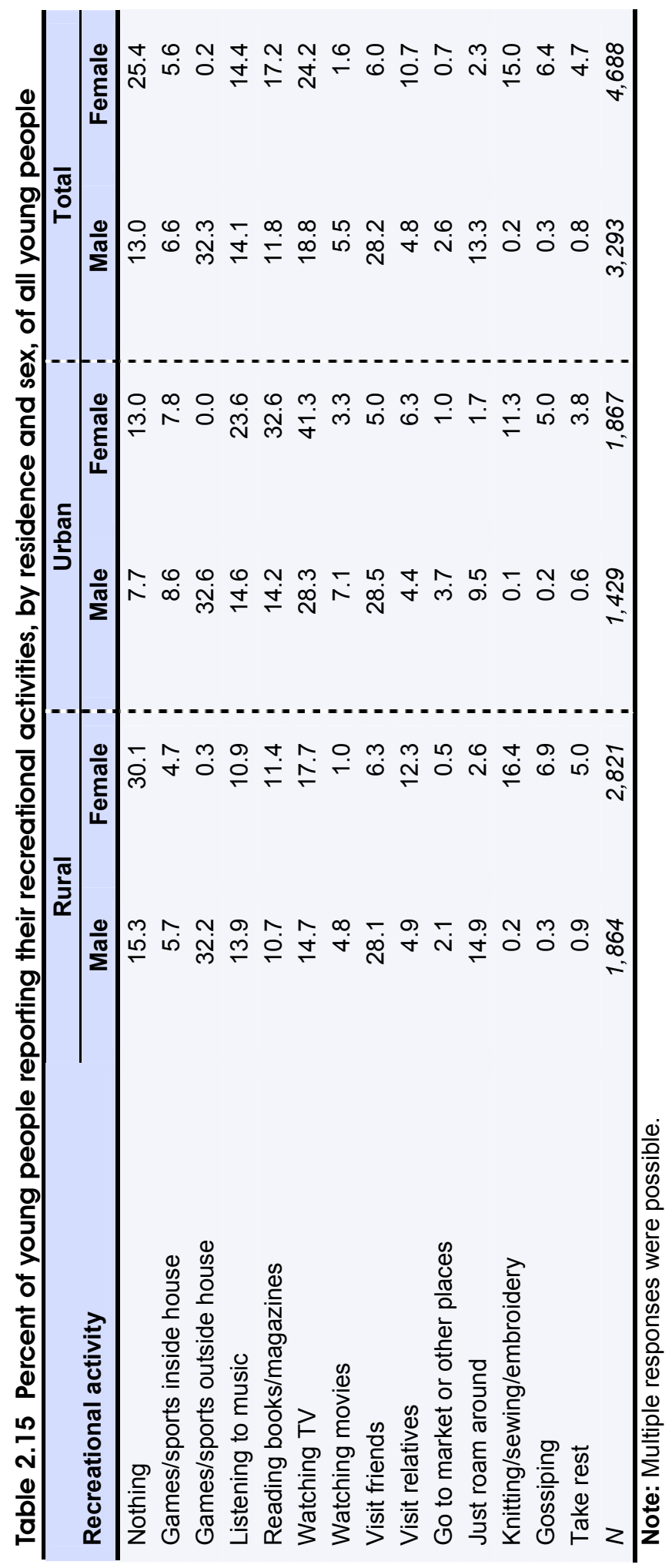




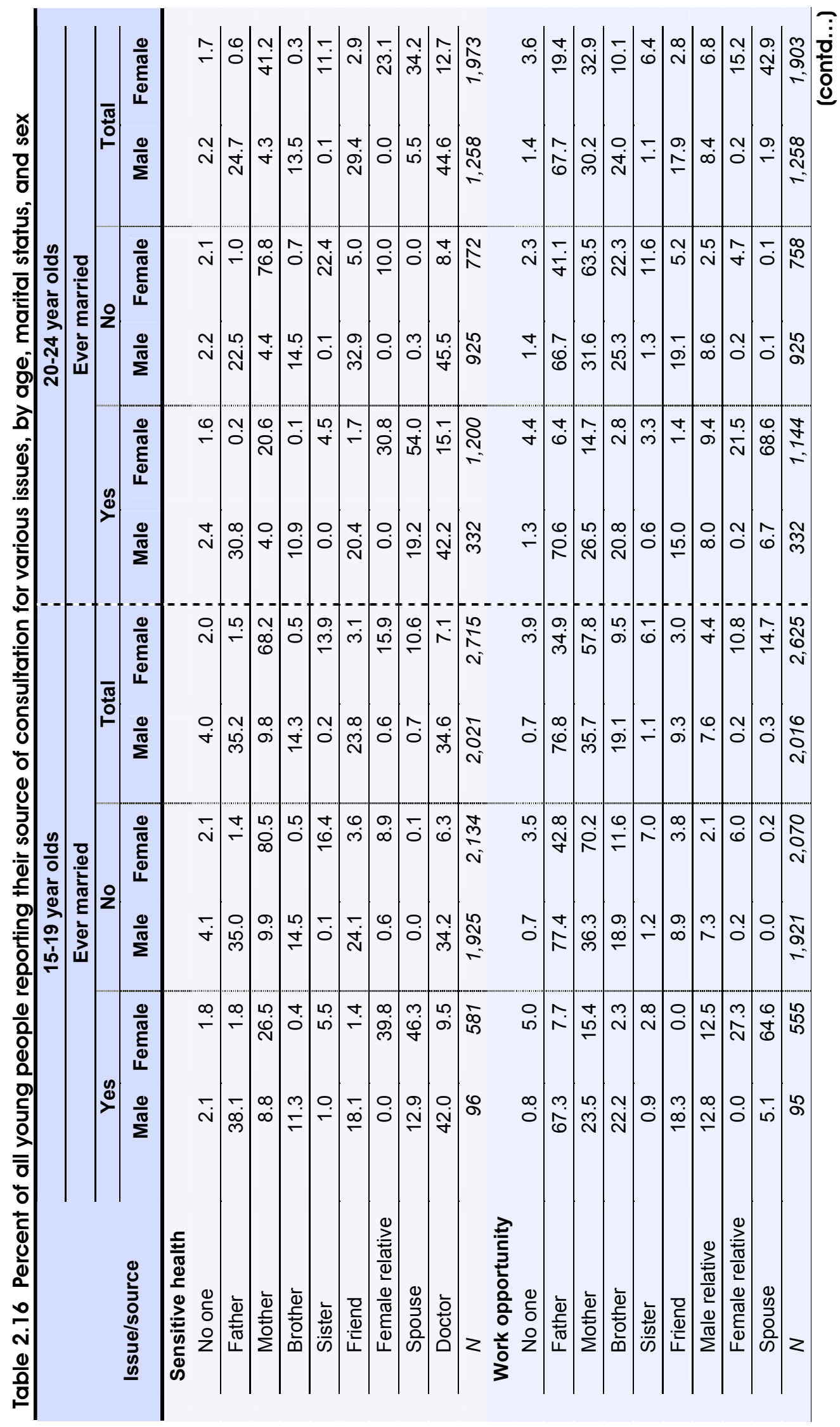




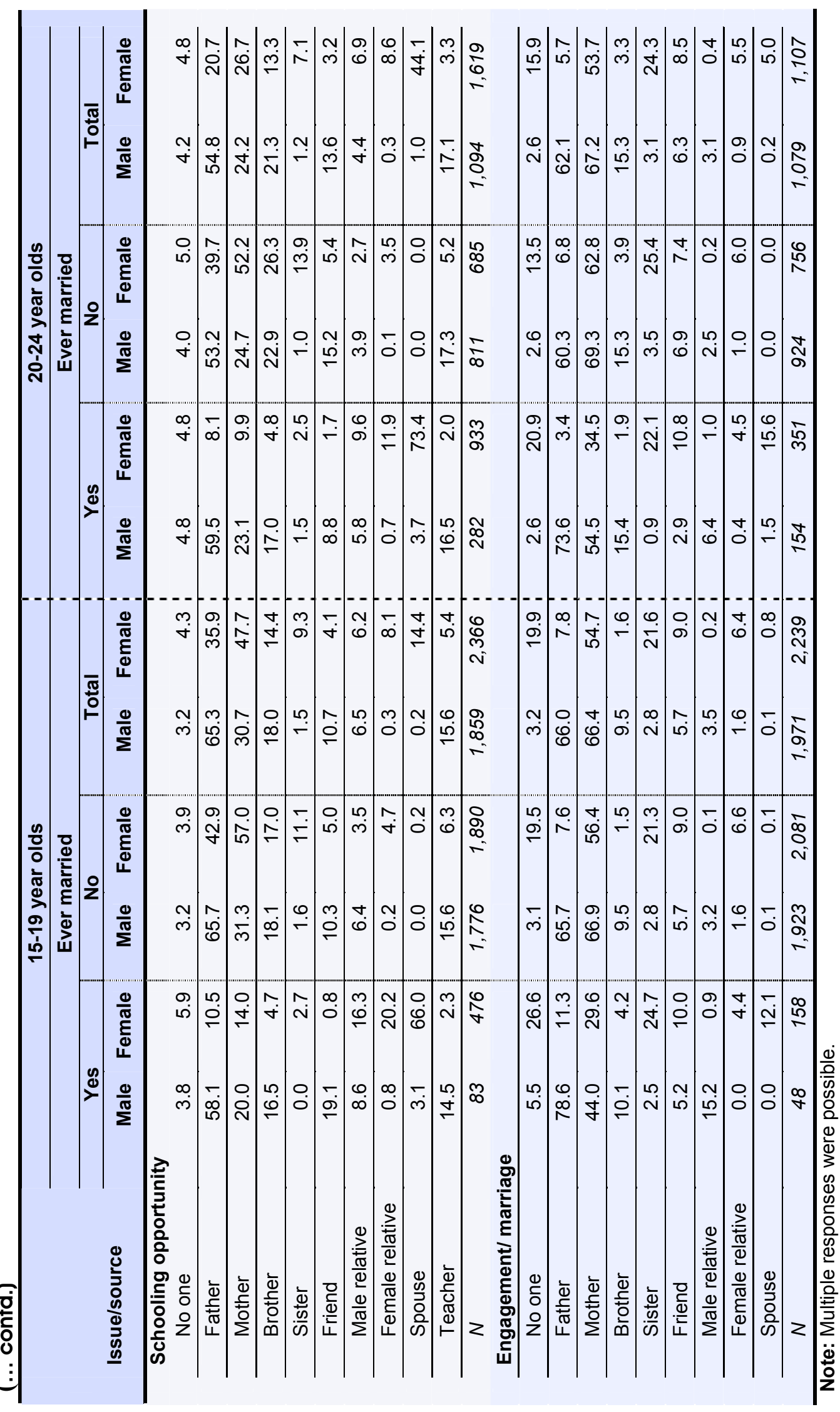



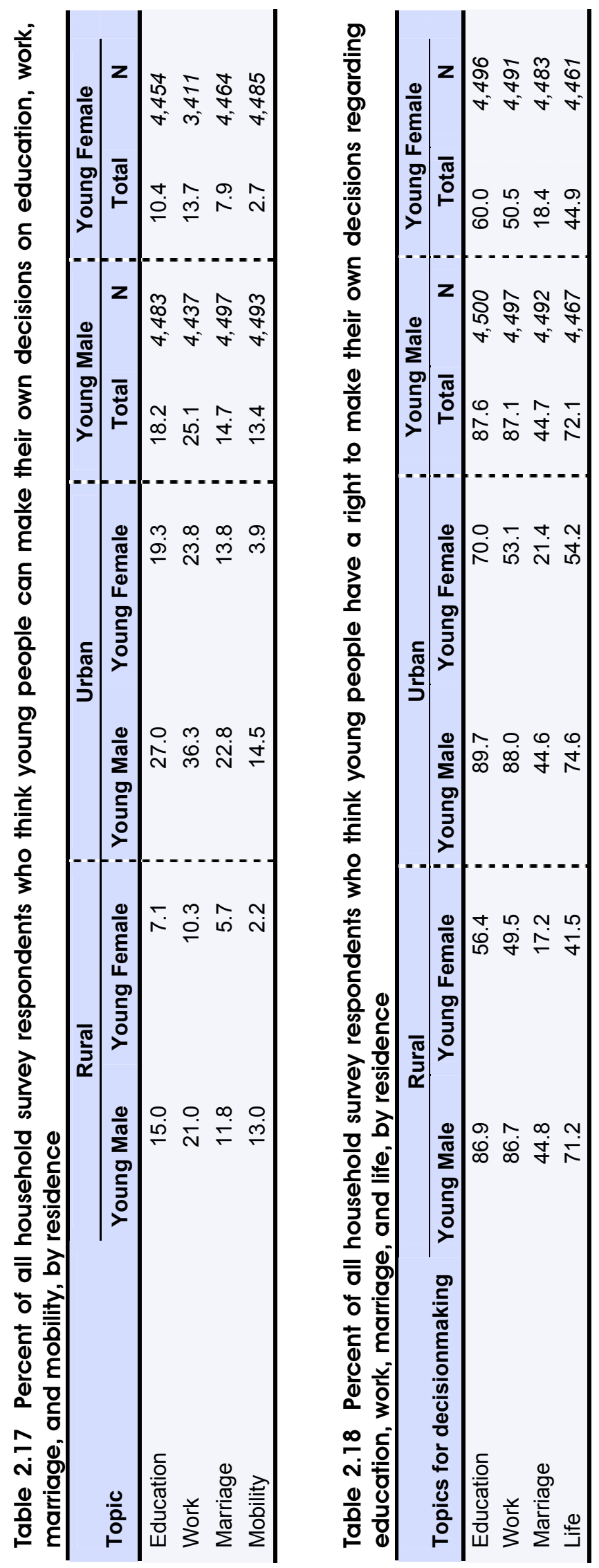


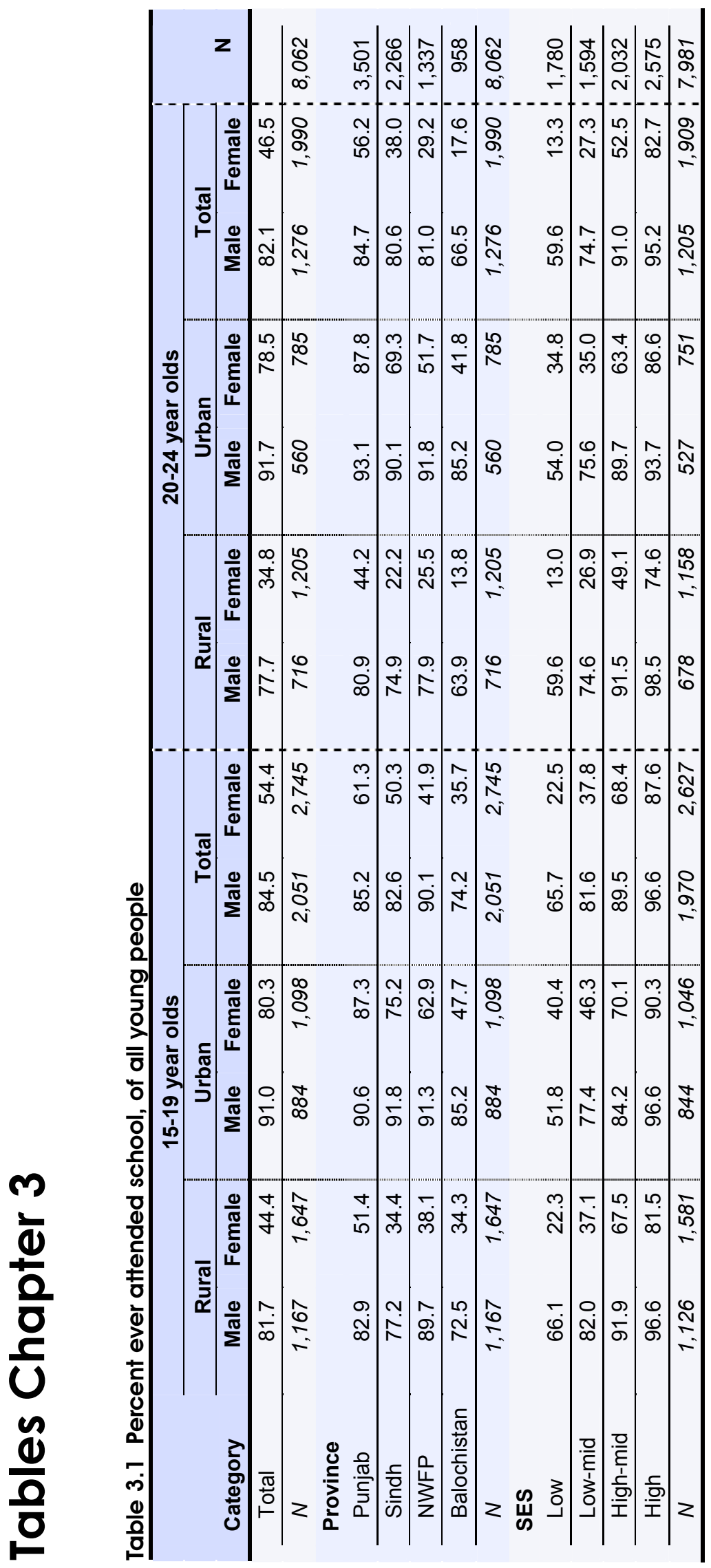




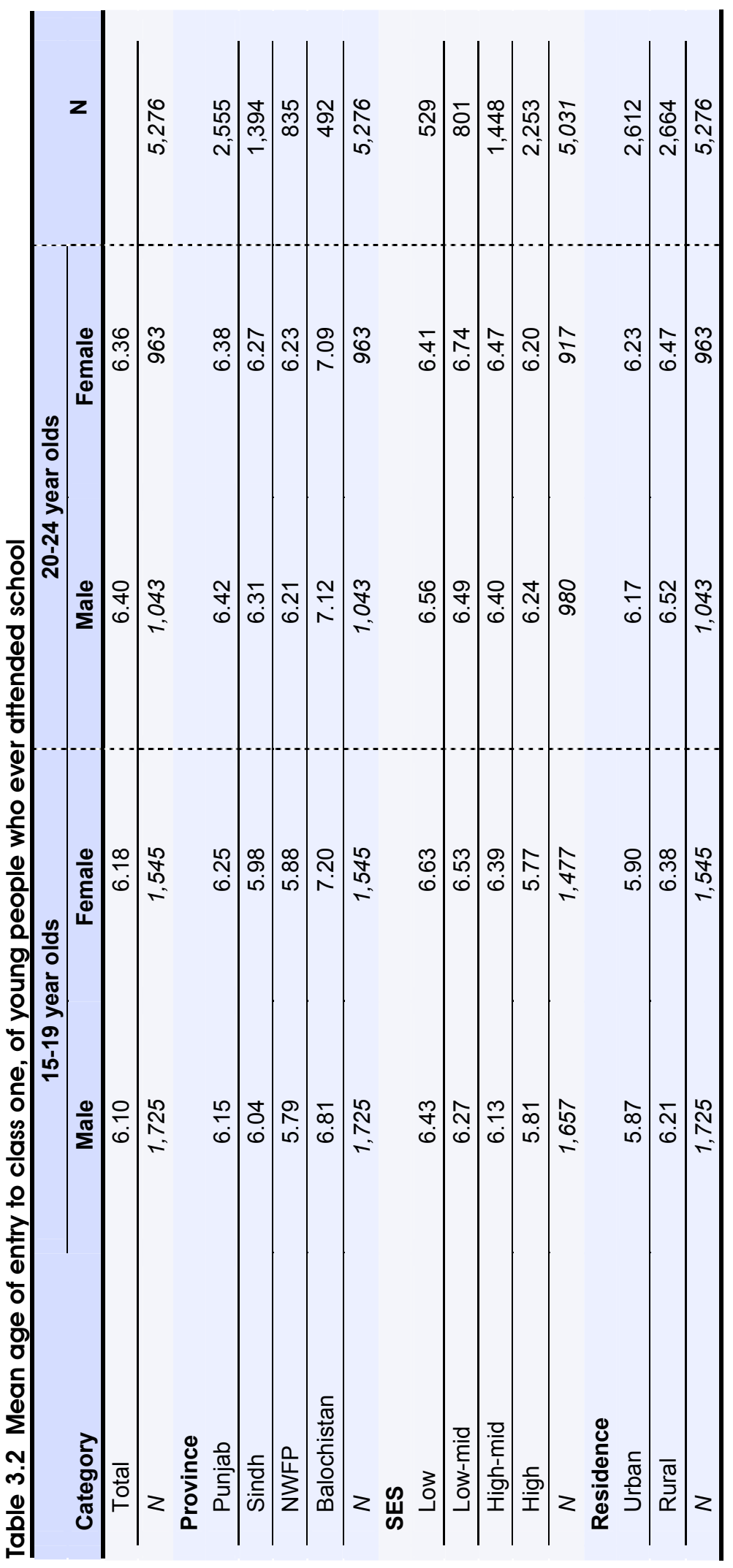




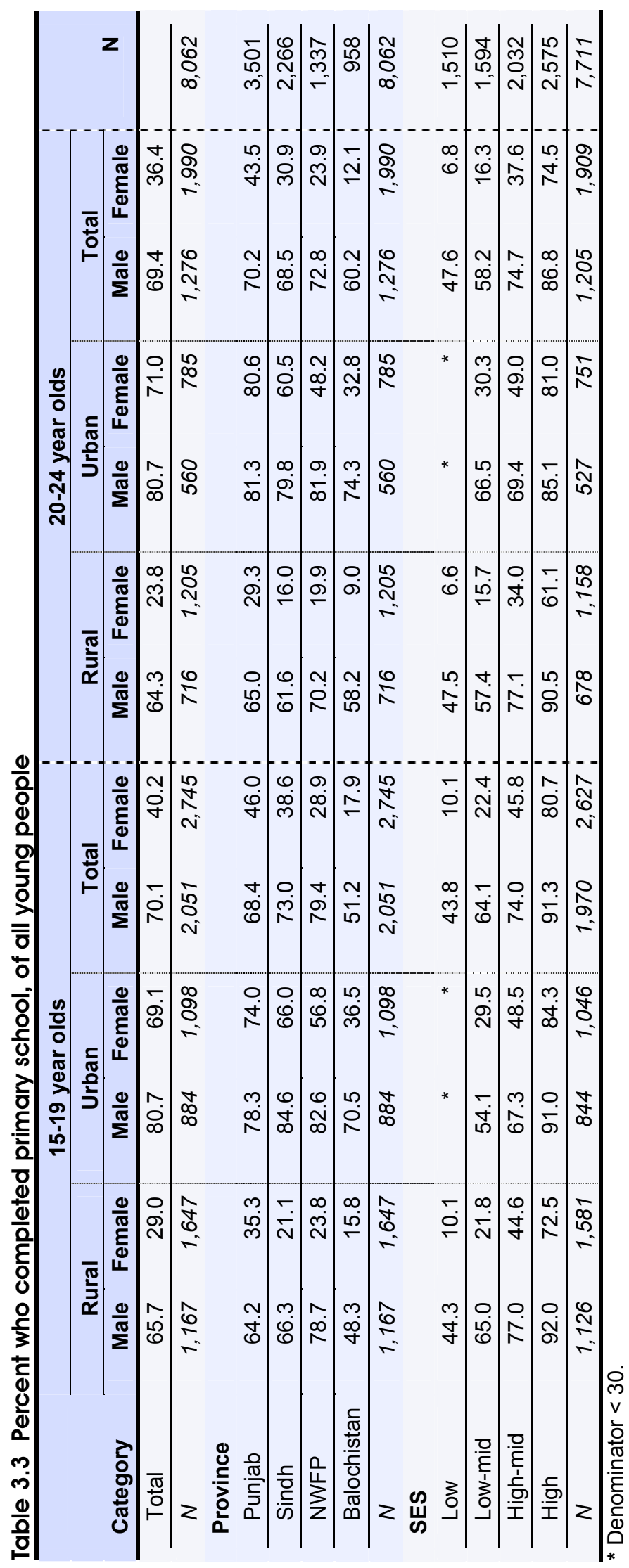


Table 3.4 Percent of young people (aged 20-24) who completed middle school

\begin{tabular}{|c|c|c|}
\hline \multirow[b]{2}{*}{ Category } & \multicolumn{2}{|c|}{ Completed middle school } \\
\hline & Male & Female \\
\hline Total & 52.0 & 24.4 \\
\hline$N$ & 1,228 & 2,055 \\
\hline \multicolumn{3}{|l|}{ Province } \\
\hline Punjab & 47.9 & 29.3 \\
\hline Sindh & 57.7 & 20.3 \\
\hline NWFP & 61.8 & 16.7 \\
\hline Balochistan & 41.3 & 7.3 \\
\hline$N$ & 1,229 & 2,056 \\
\hline \multicolumn{3}{|l|}{ Residence } \\
\hline Rural & 45.7 & 12.8 \\
\hline Urban & 65.6 & 56.5 \\
\hline$N$ & 1,228 & 2,055 \\
\hline \multicolumn{3}{|l|}{ SES } \\
\hline Low & 33.2 & 1.6 \\
\hline Low-mid & 35.4 & 8.9 \\
\hline High-mid & 53.7 & 20.6 \\
\hline High & 74.5 & 59.1 \\
\hline$N$ & 1,158 & 1,976 \\
\hline
\end{tabular}

Table 3.5 Percent of young people (aged 20-24) who completed secondary school

\begin{tabular}{l|rr}
\hline Category & \multicolumn{2}{c}{ Completed secondary school } \\
\hline Total & Male & Female \\
\hline$N$ & 32.7 & 17.7 \\
Province & 1,228 & 2,055 \\
Punjab & & 20.6 \\
\hline Sindh & 24.8 & 16.0 \\
\hline NWFP & 44.4 & 12.3 \\
\hline Balochistan & 41.0 & 4.6 \\
\hline$N$ & 29.6 & 2,055 \\
Residence & 1,227 & 8.0 \\
\hline Rural & & 55.7 \\
\hline Urban & 27.5 & 2,056 \\
\hline$N$ & 55.9 & 1,228 \\
SES & & 1.1 \\
\hline Low & 14.9 & 3.7 \\
\hline Low-mid & 18.7 & 11.1 \\
\hline High-mid & 29.2 & 47.8 \\
\hline High & 56.8 & 1,976 \\
\hline$N$ & 1,157 & \\
\hline
\end{tabular}


Table 3.6 Mean highest class completed, of young people aged 20-24 who ever attended school

\begin{tabular}{|c|c|c|c|}
\hline \multirow[b]{2}{*}{ Category } & \multicolumn{2}{|c|}{ 20-24 year olds } & \multirow[b]{2}{*}{$\mathbf{N}$} \\
\hline & Male & Female & \\
\hline Total & 6.7 & 3.5 & \\
\hline$N$ & 1,276 & 1,990 & 3,266 \\
\hline \multicolumn{4}{|l|}{ Province } \\
\hline Punjab & 6.5 & 4.2 & 1457 \\
\hline Sindh & 7.1 & 3.0 & 922 \\
\hline NWFP & 7.4 & 2.4 & 528 \\
\hline Balochistan & 5.5 & 1.1 & 359 \\
\hline$N$ & 1276 & 1990 & 3,266 \\
\hline \multicolumn{4}{|l|}{ SES } \\
\hline Low & 4.2 & 0.6 & 608 \\
\hline Low-mid & 5.2 & 1.4 & 606 \\
\hline High-mid & 6.9 & 3.3 & 783 \\
\hline High & 9.3 & 7.6 & 1117 \\
\hline$N$ & 1205 & 1909 & 3,114 \\
\hline \multicolumn{4}{|l|}{ Residence } \\
\hline Urban & 6.0 & 2.1 & 1,921 \\
\hline Rural & 8.3 & 7.3 & 1345 \\
\hline$N$ & 1276 & 1990 & 3,266 \\
\hline
\end{tabular}




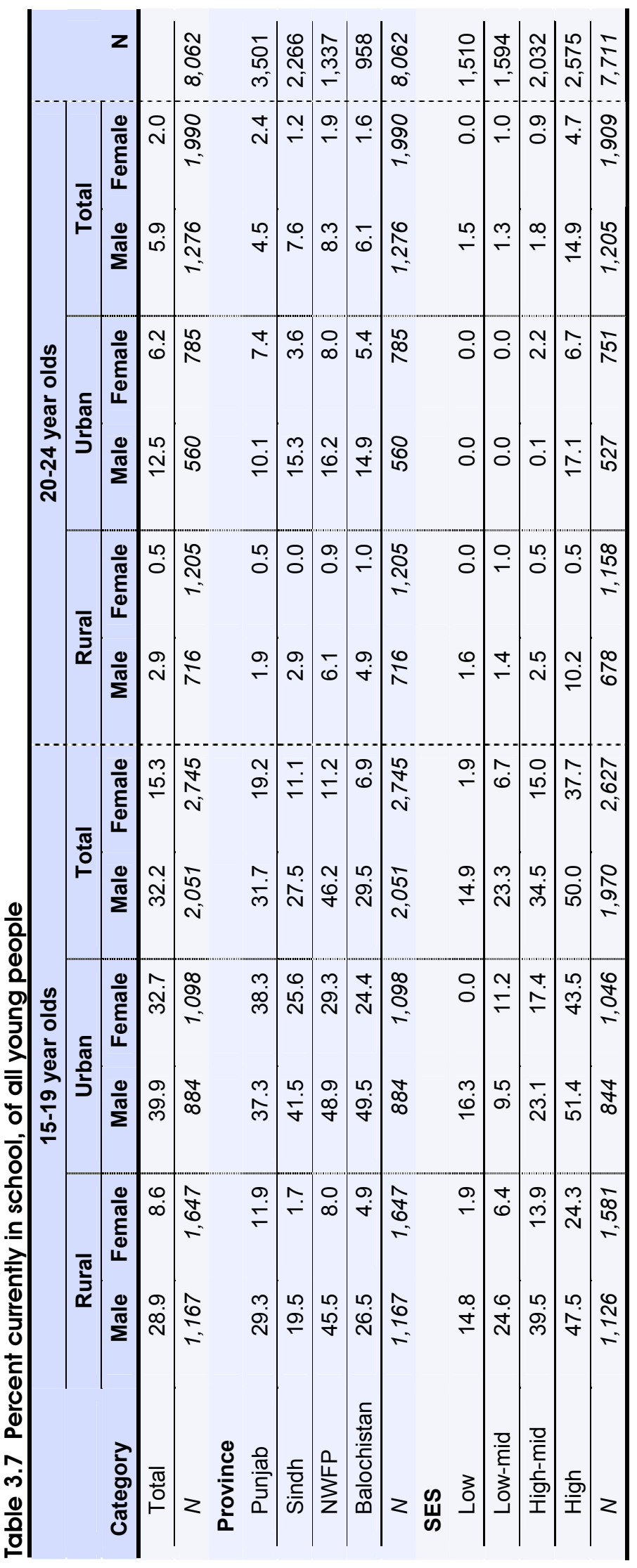




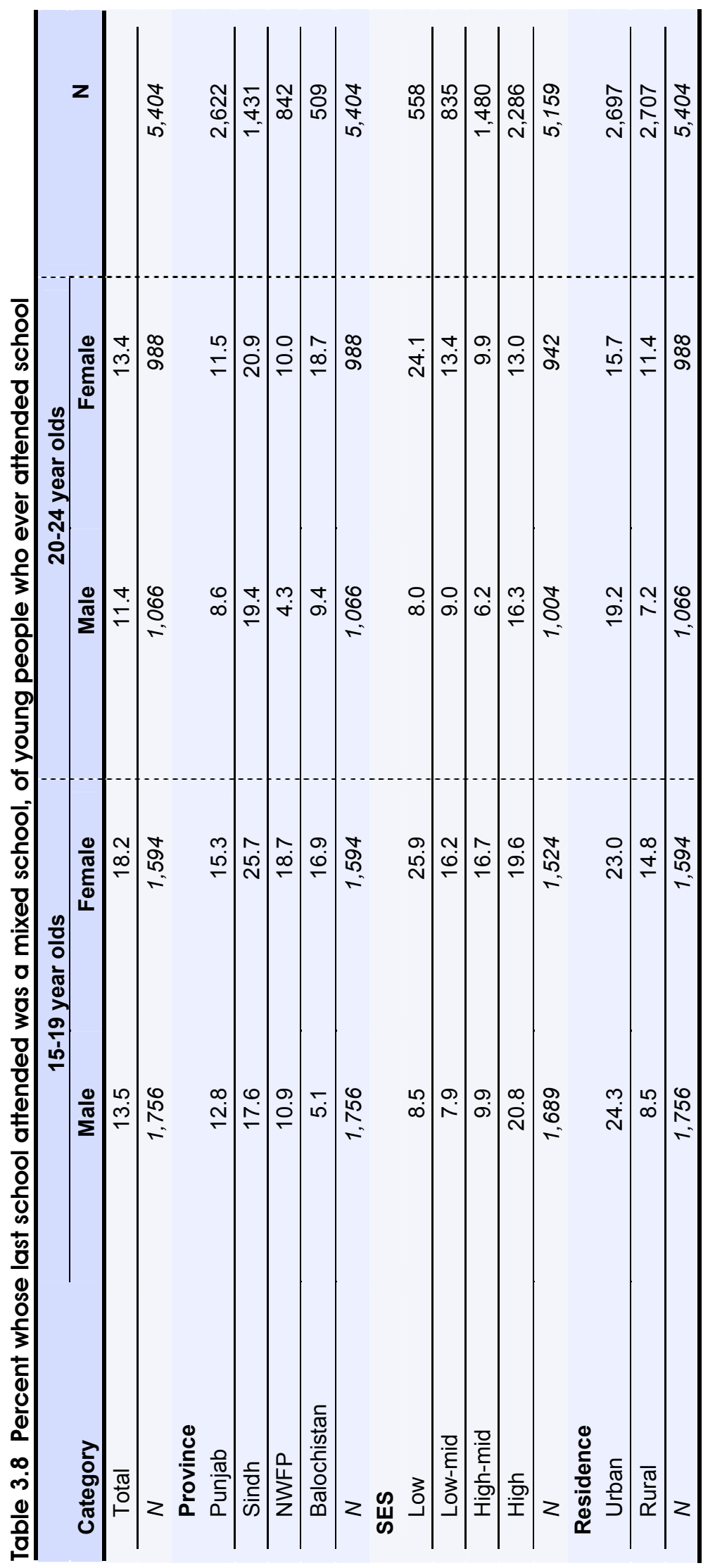




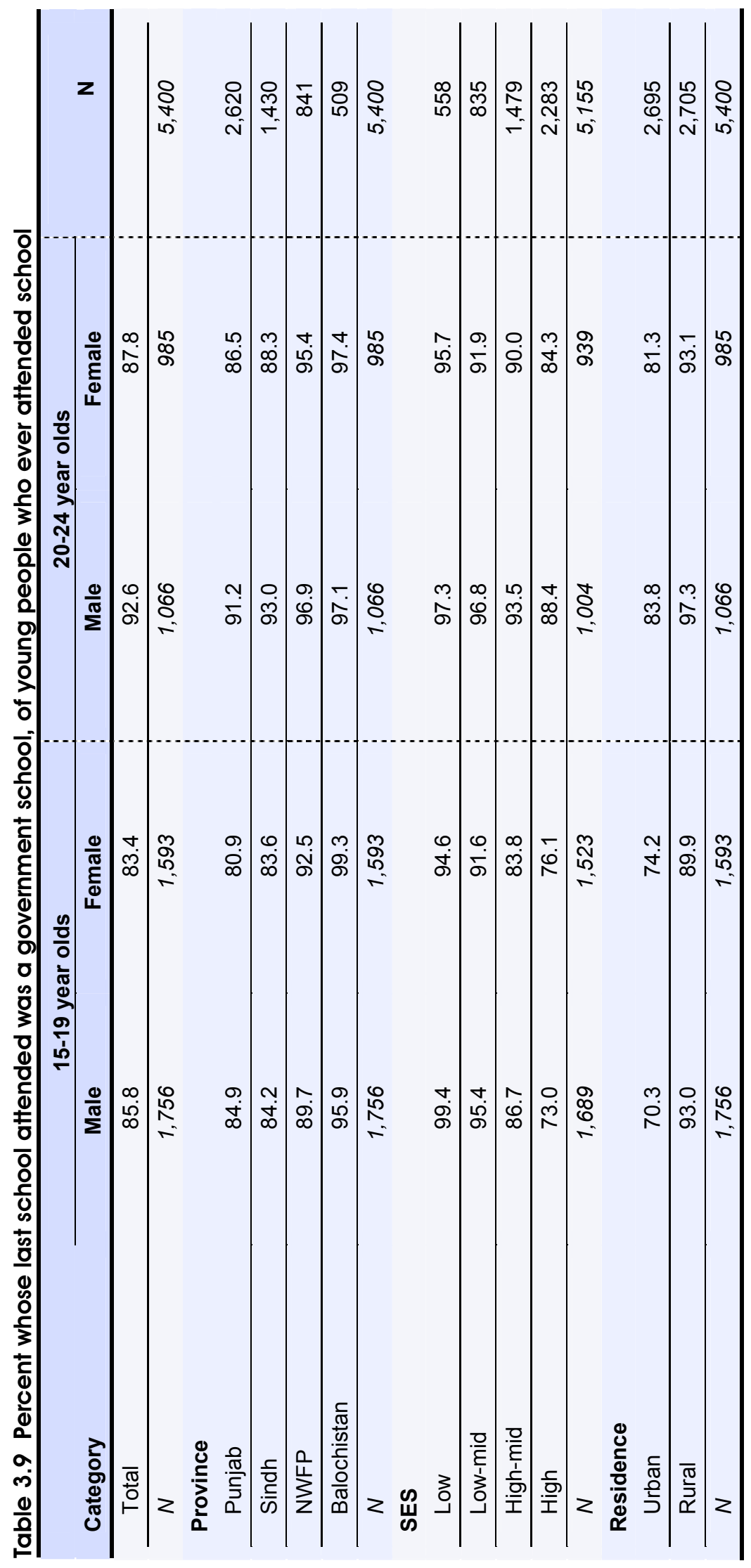




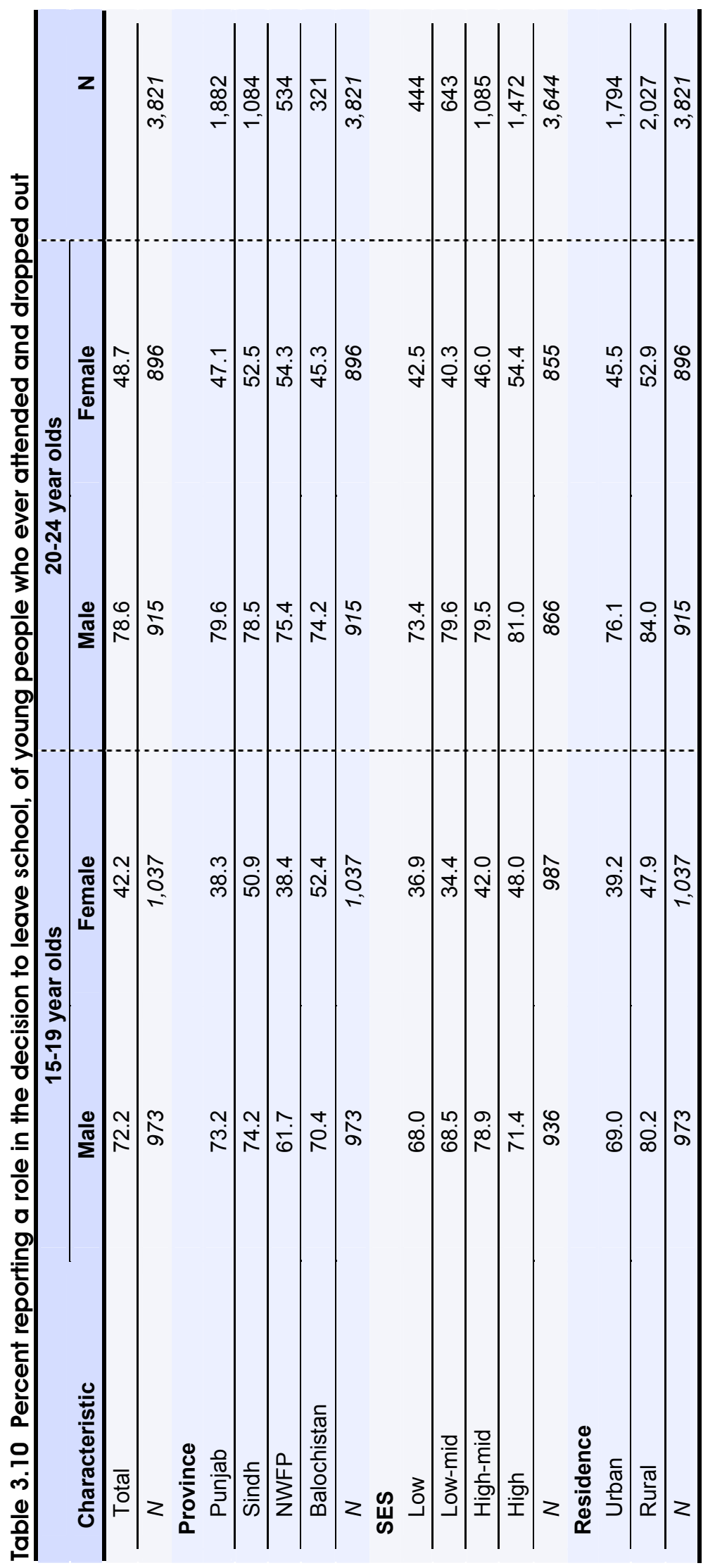




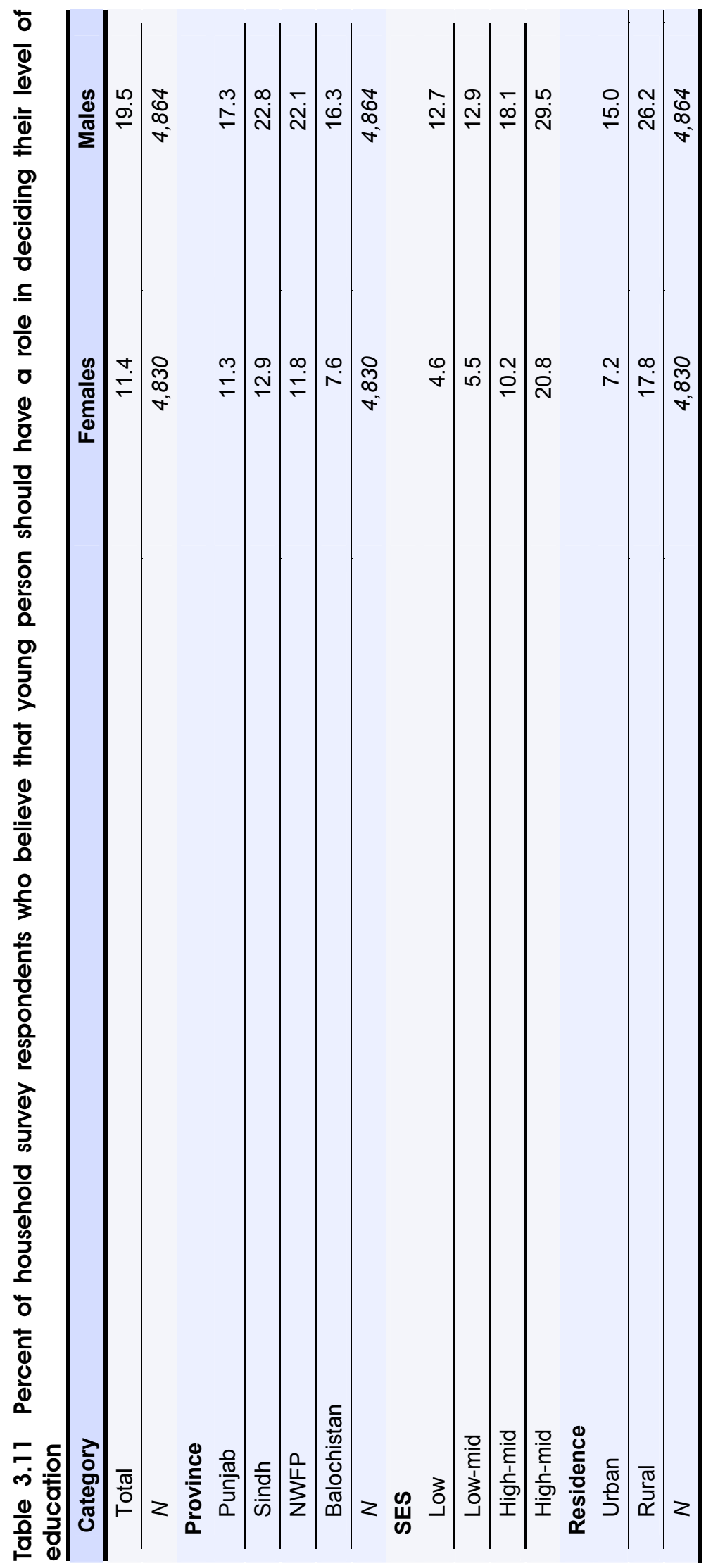




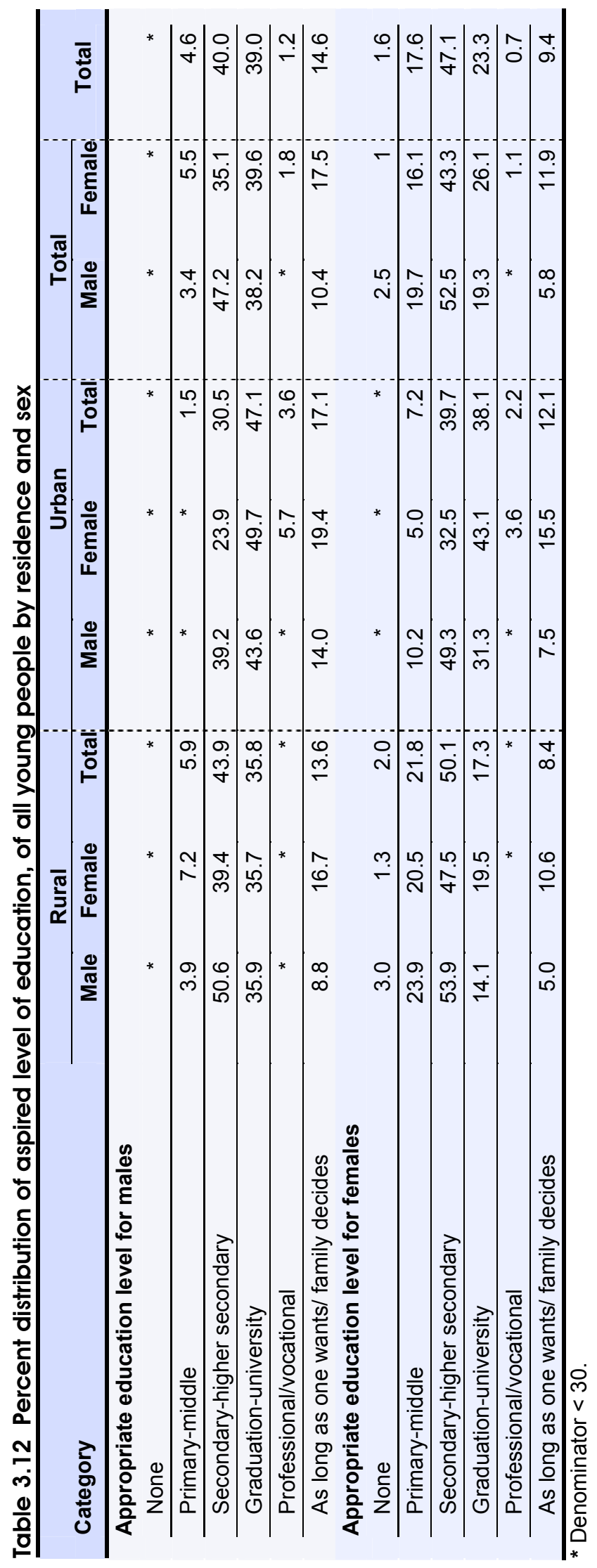




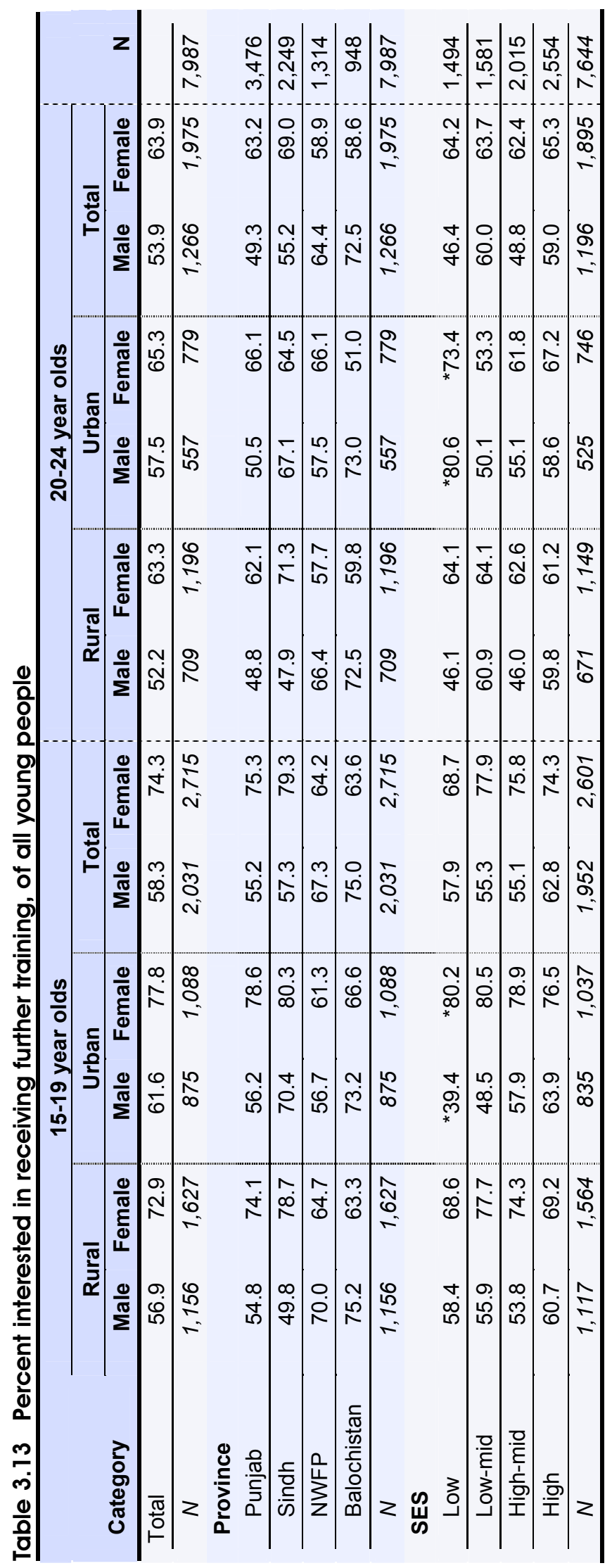




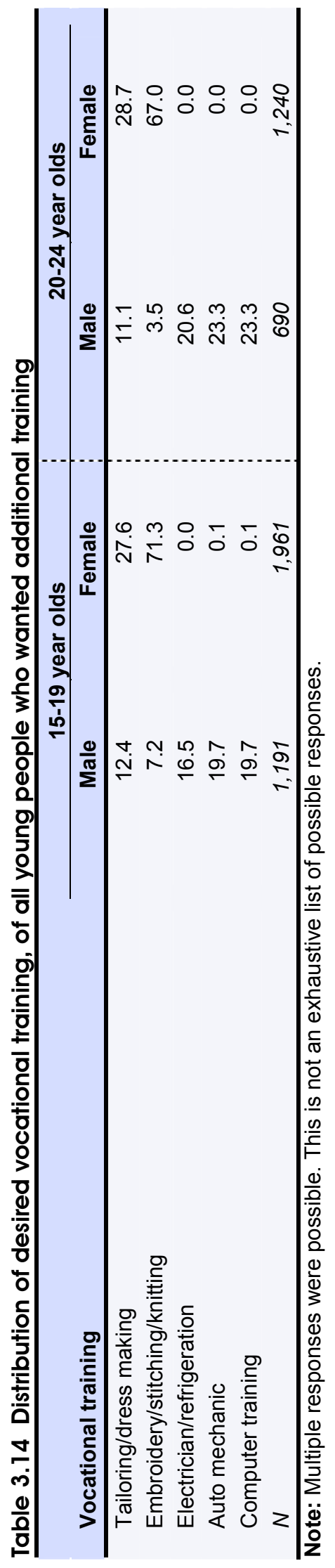




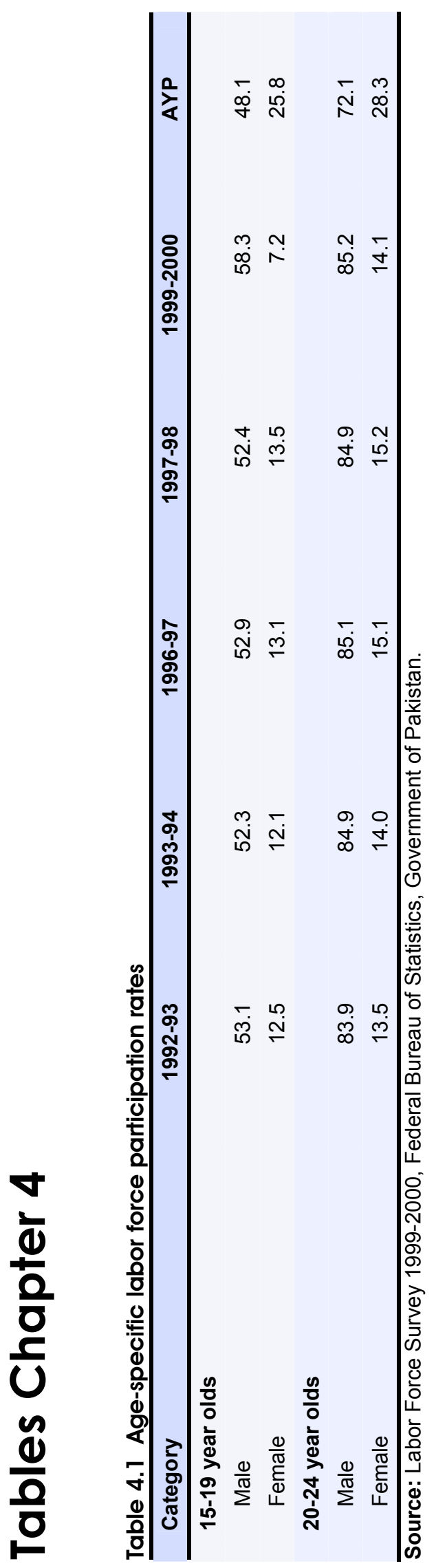




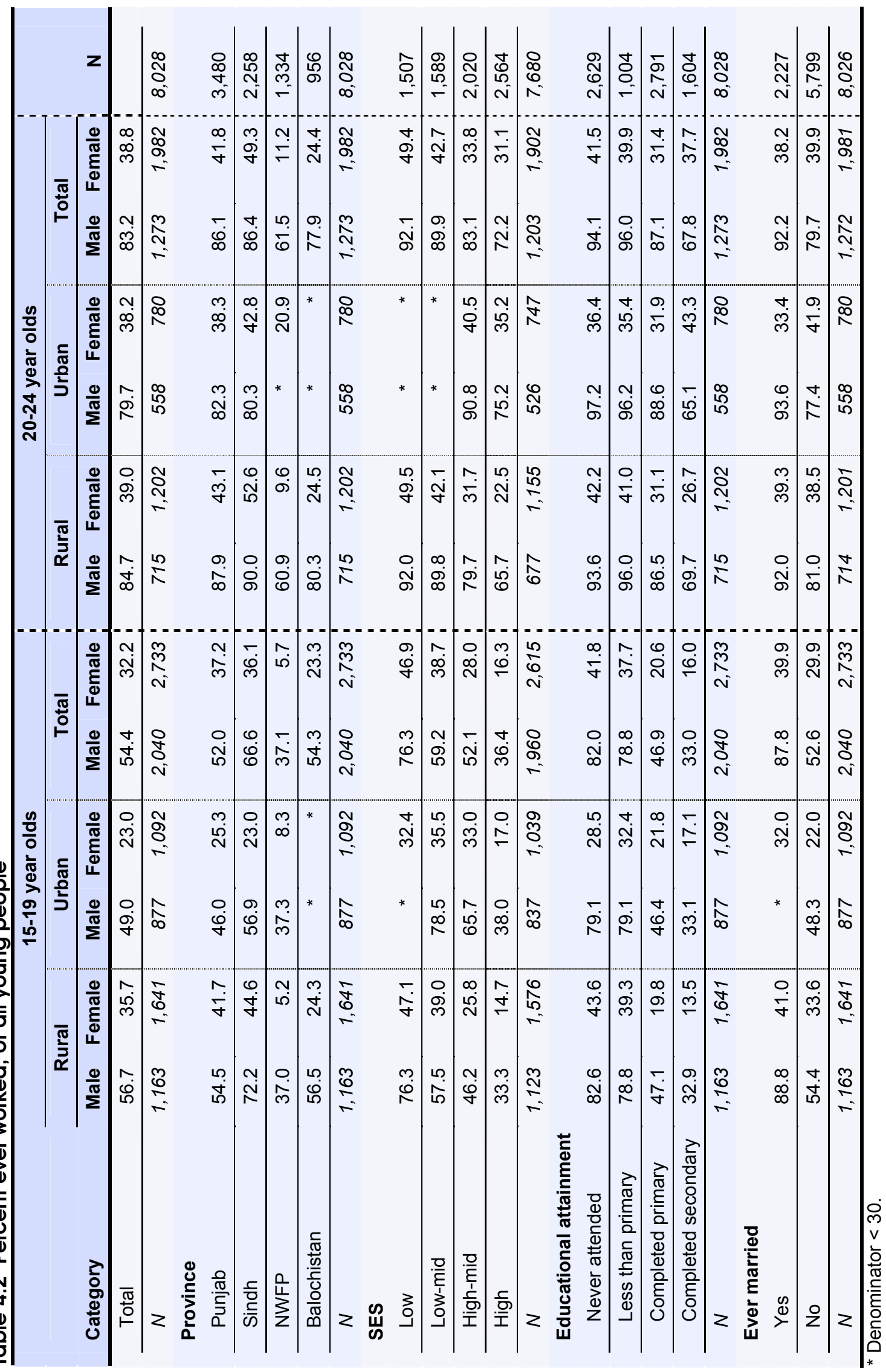




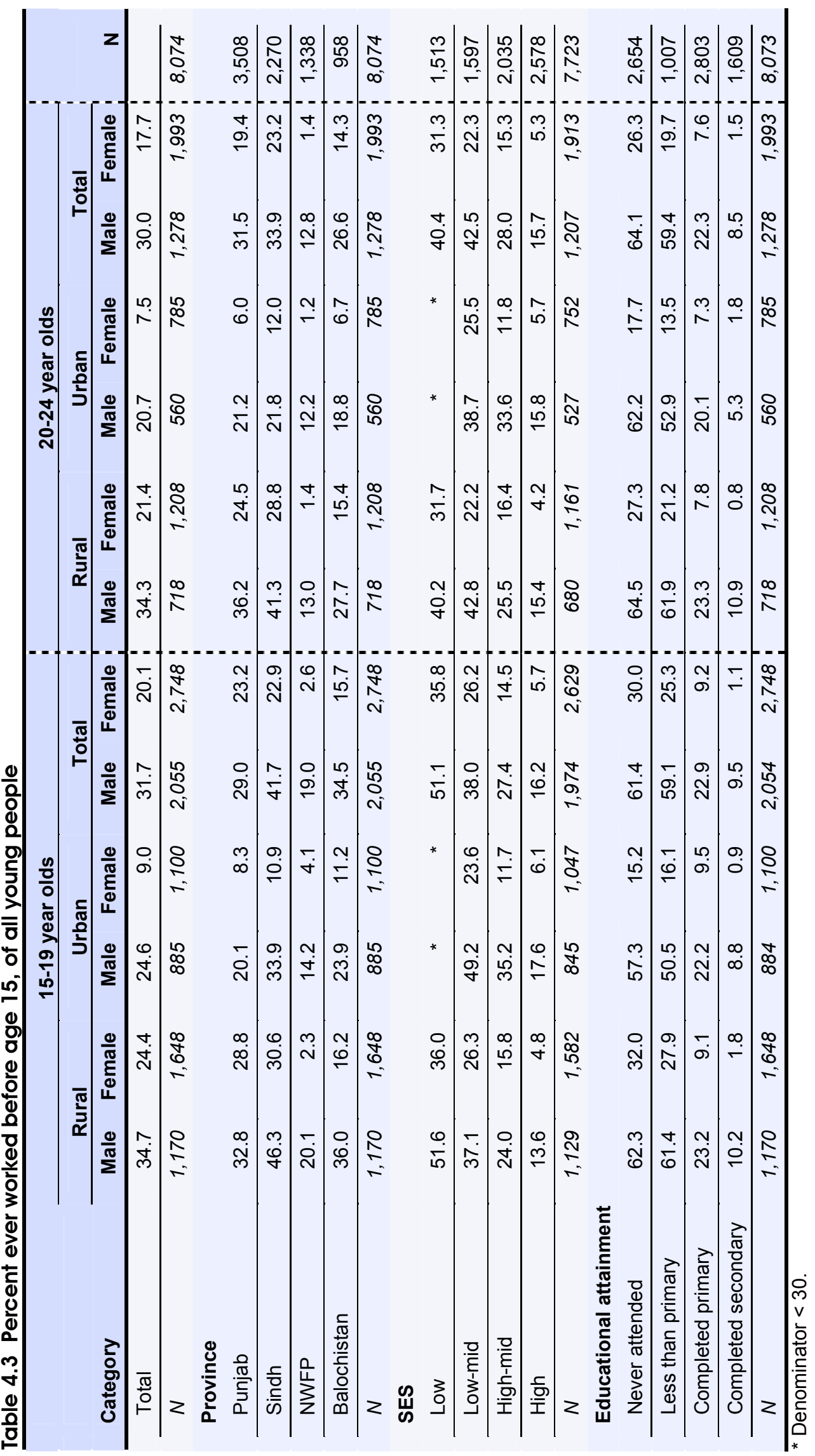




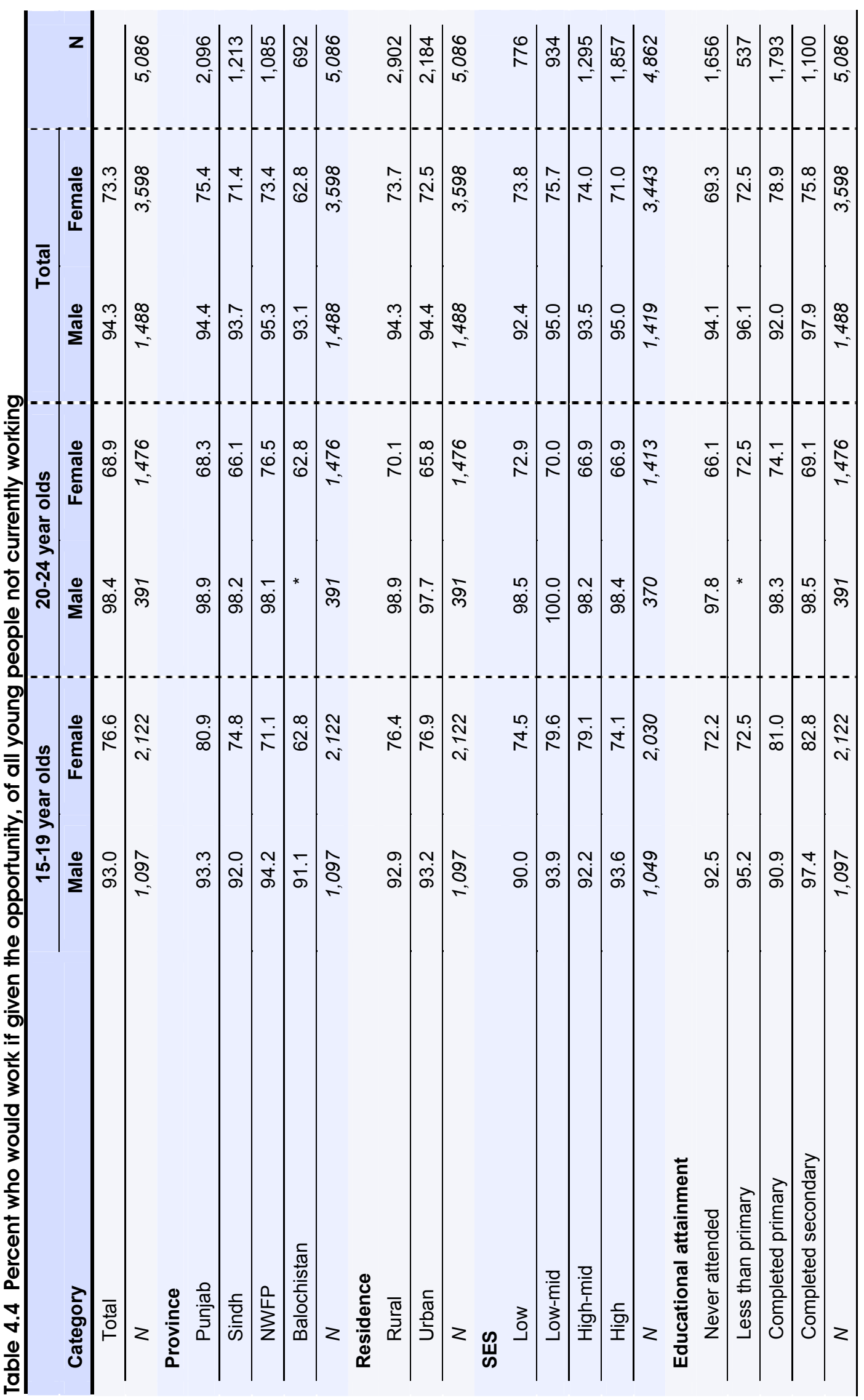




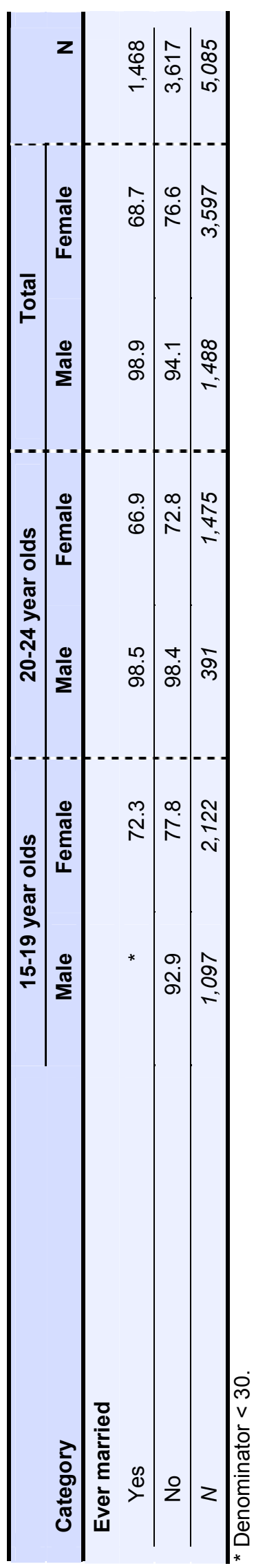




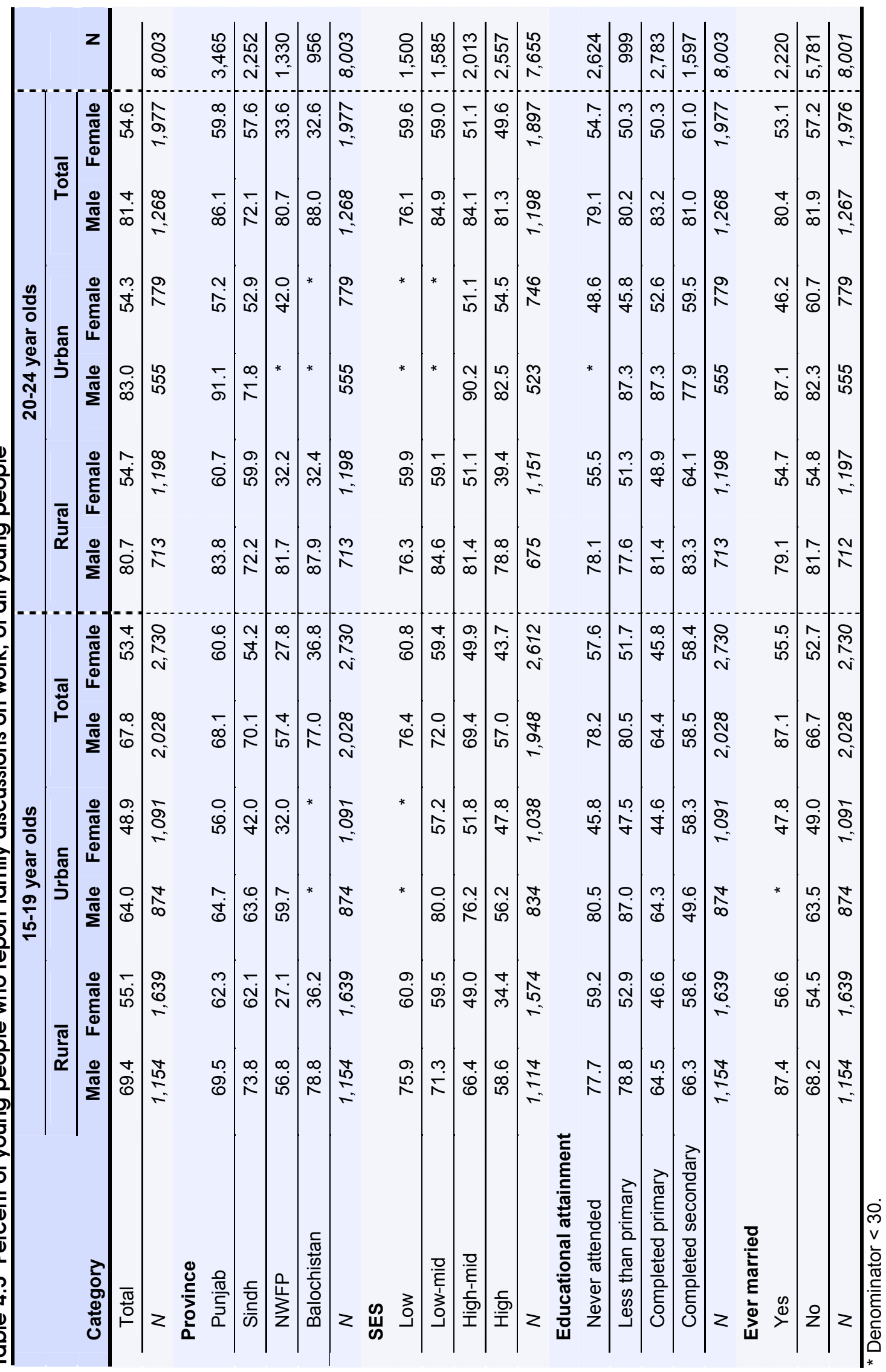




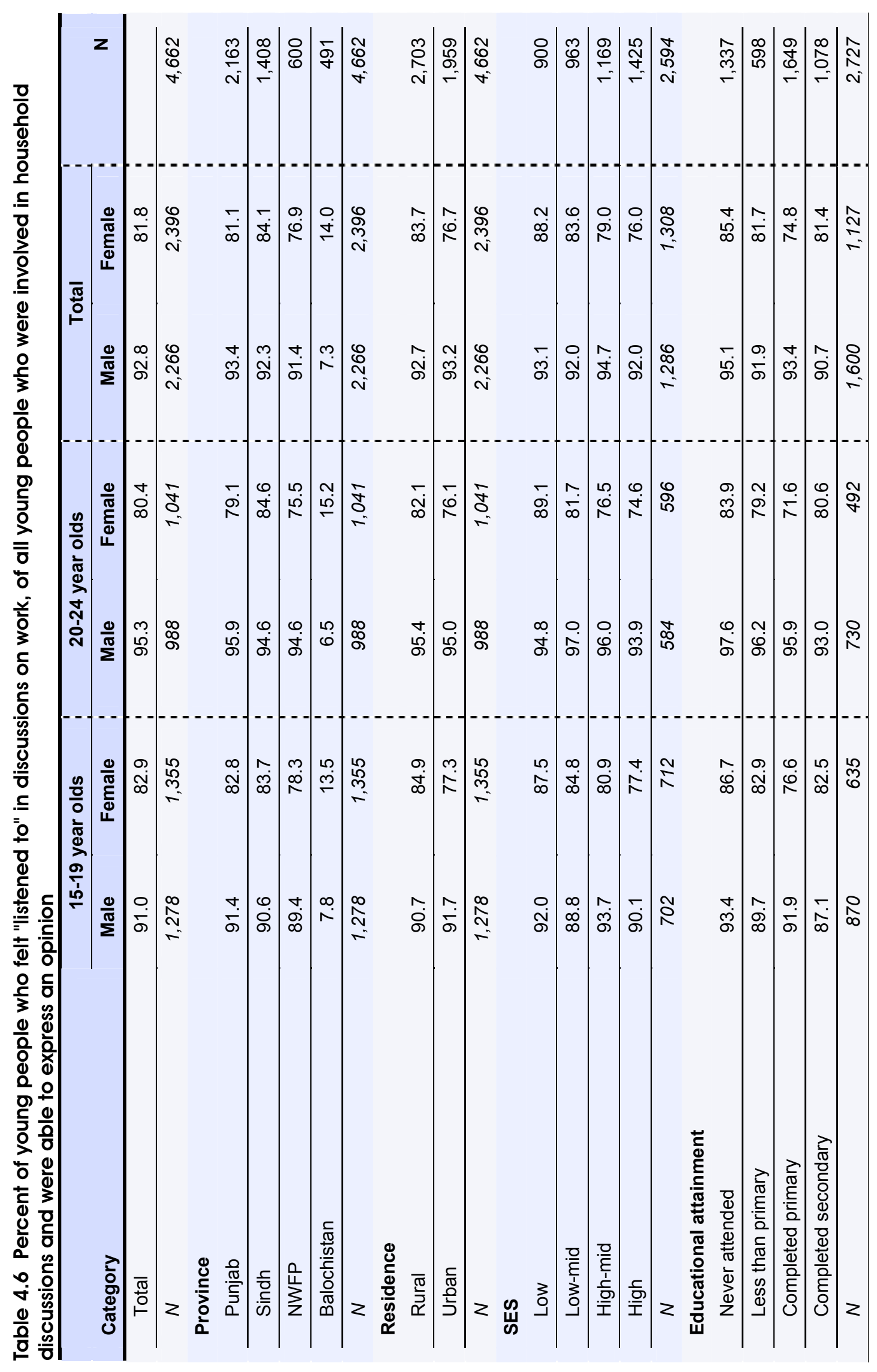




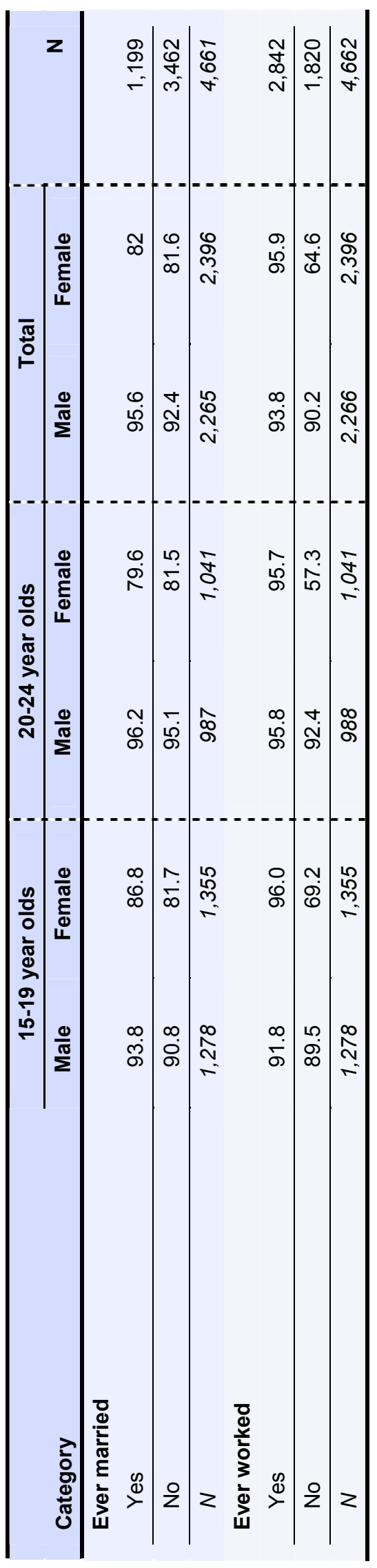




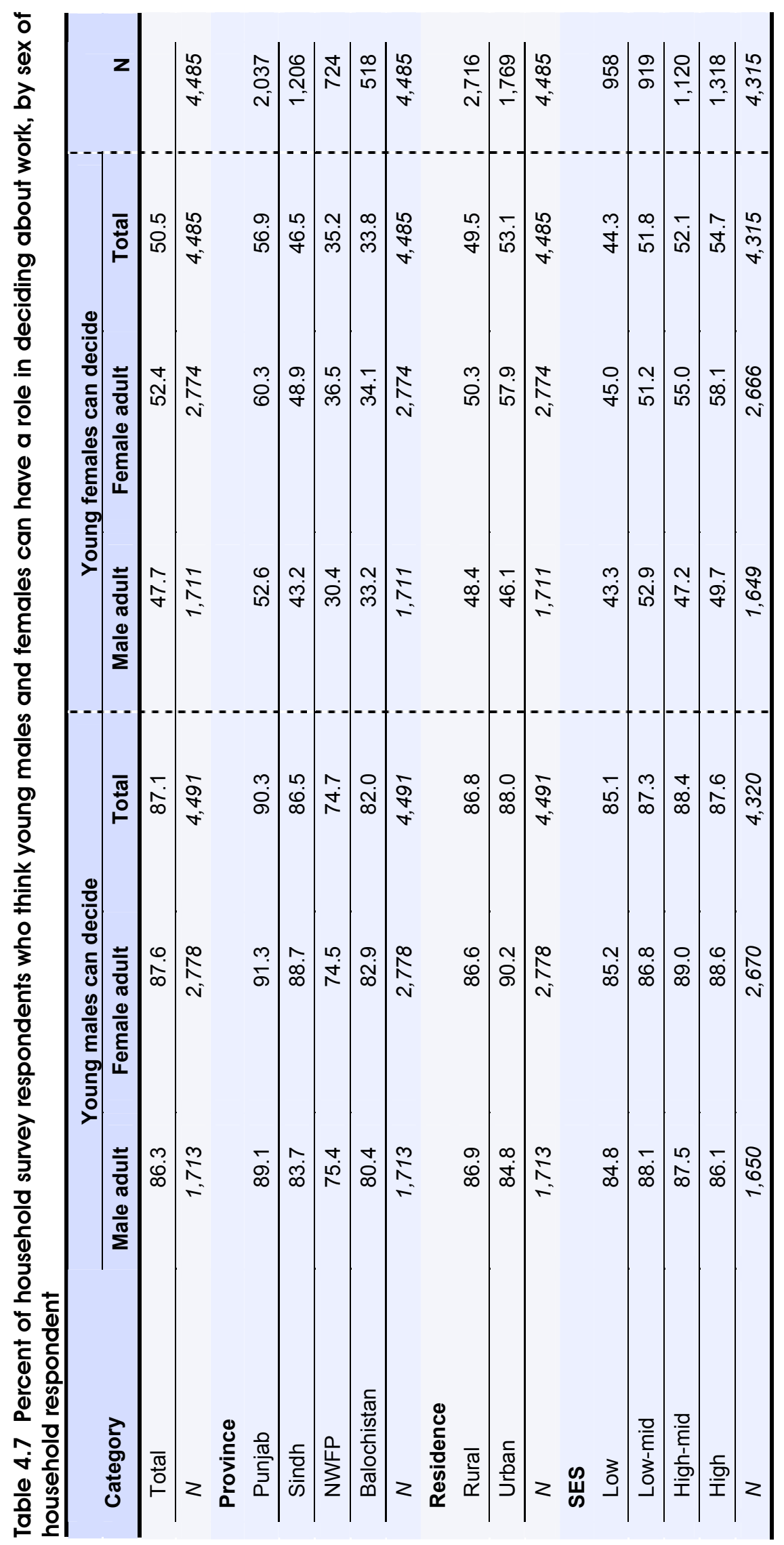




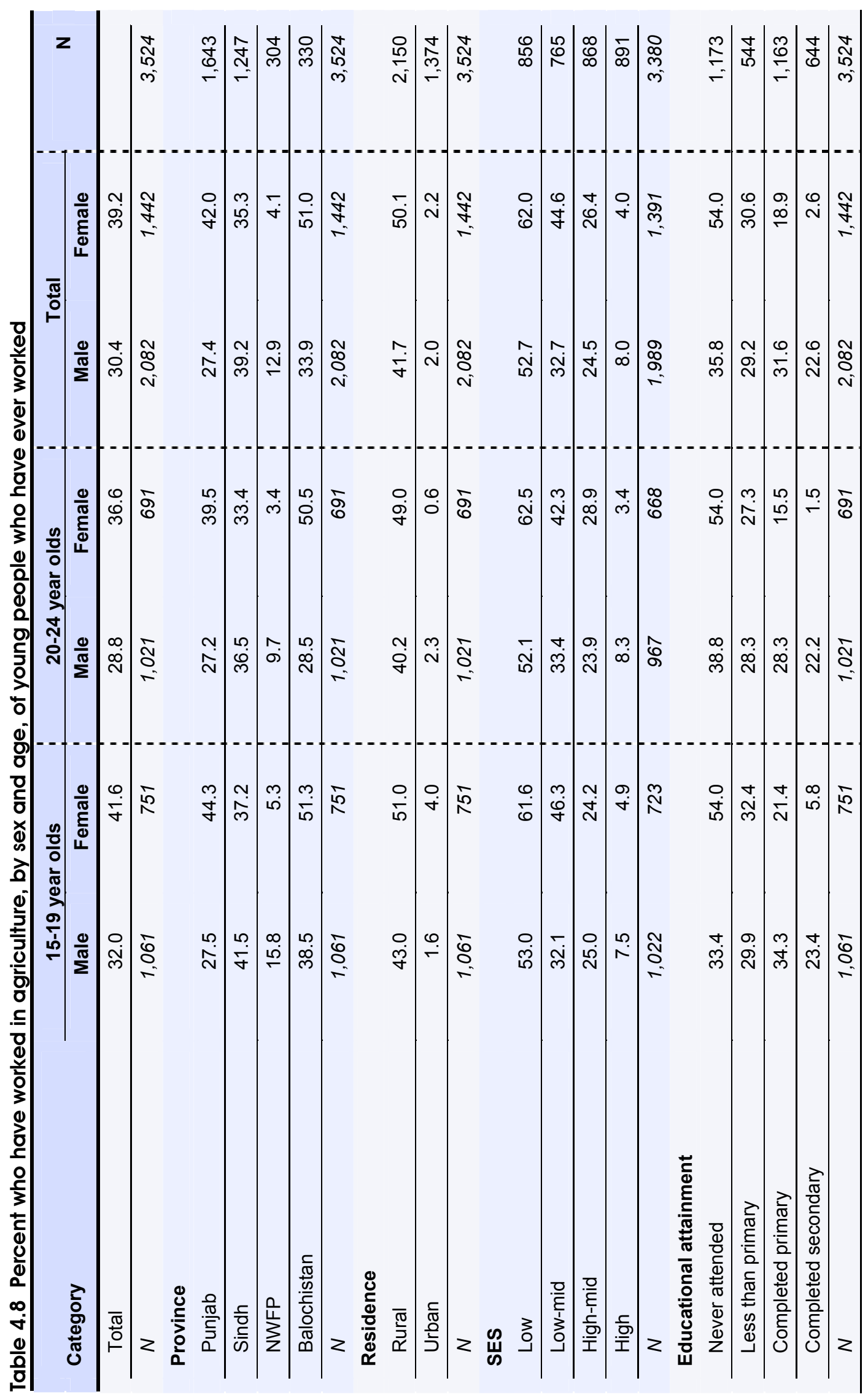




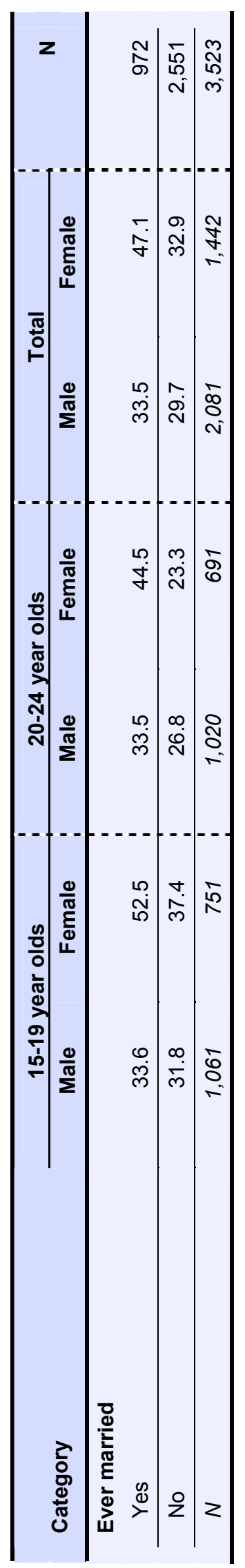




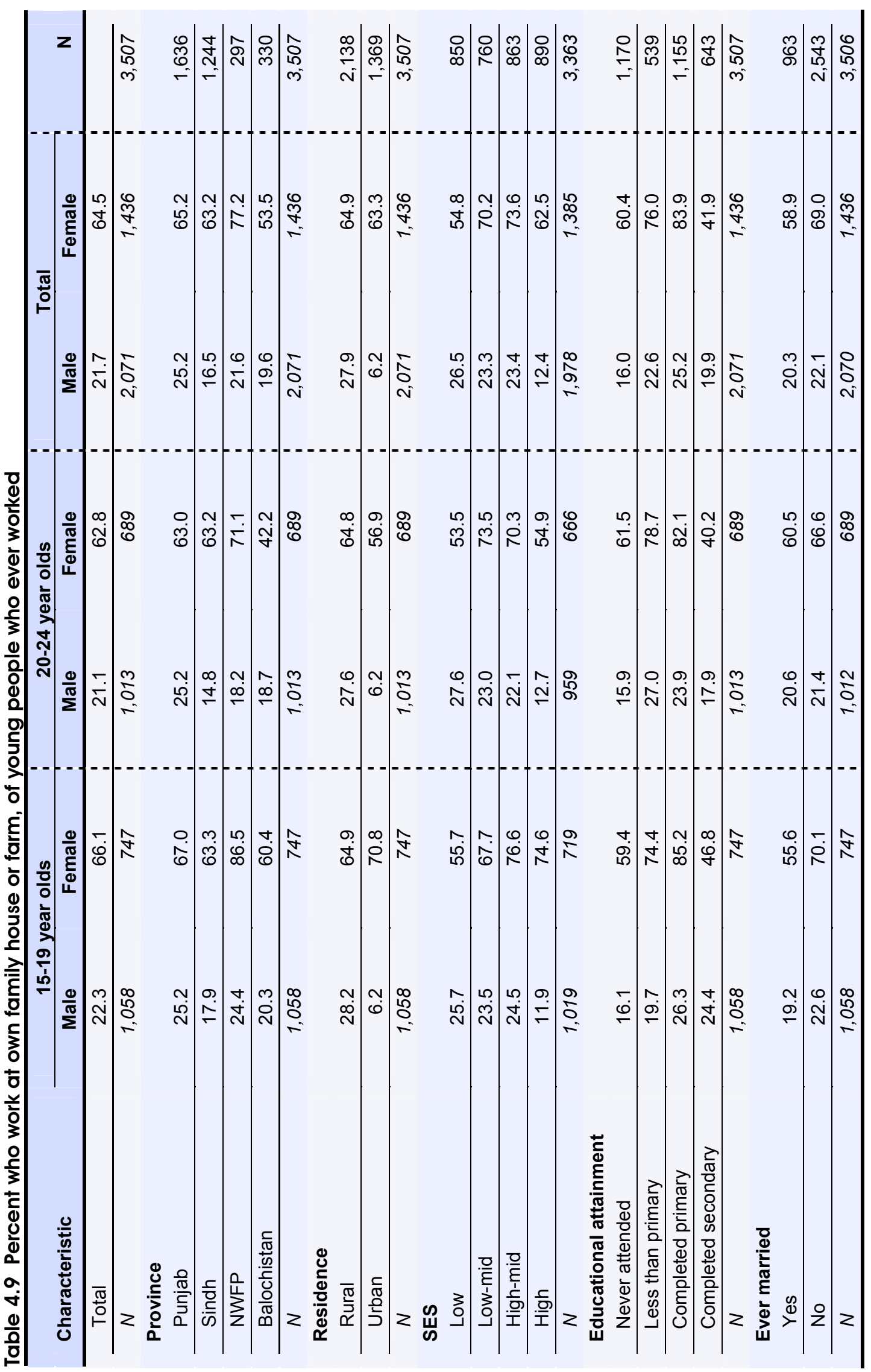




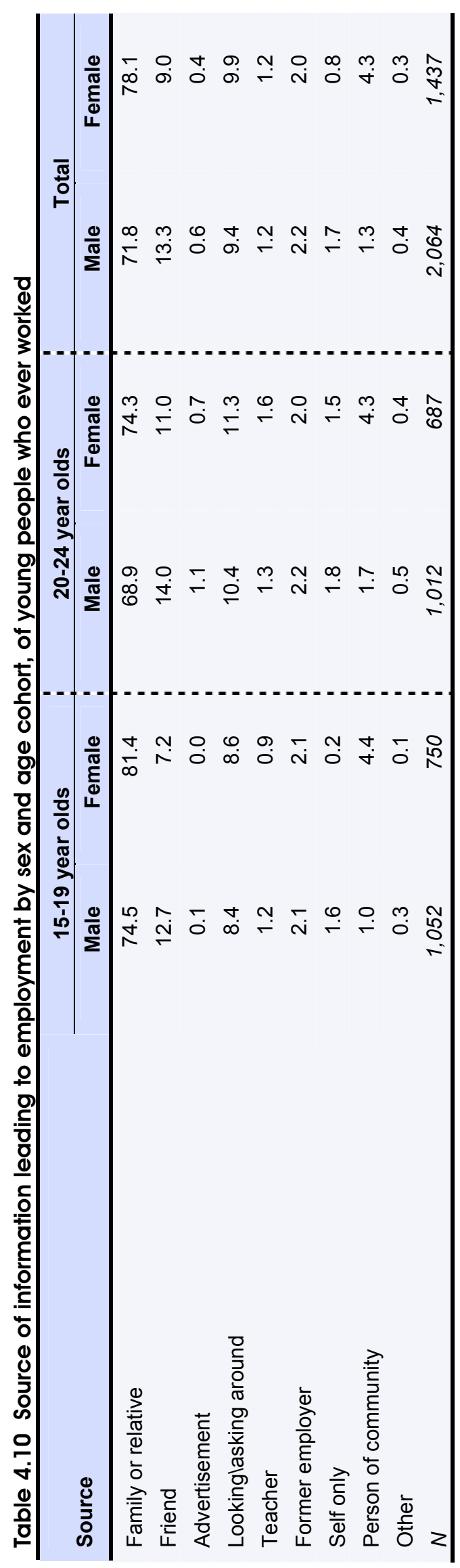




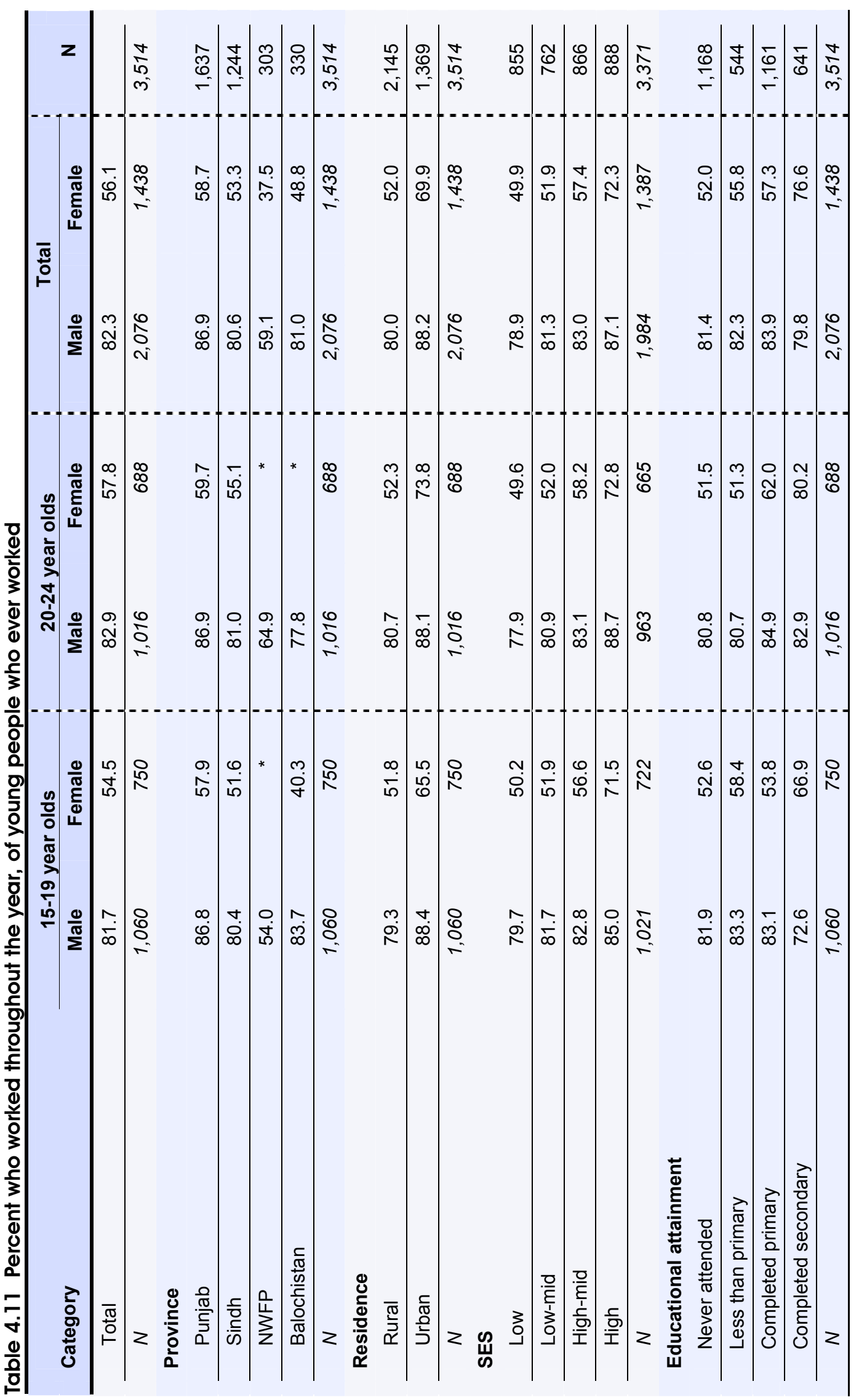




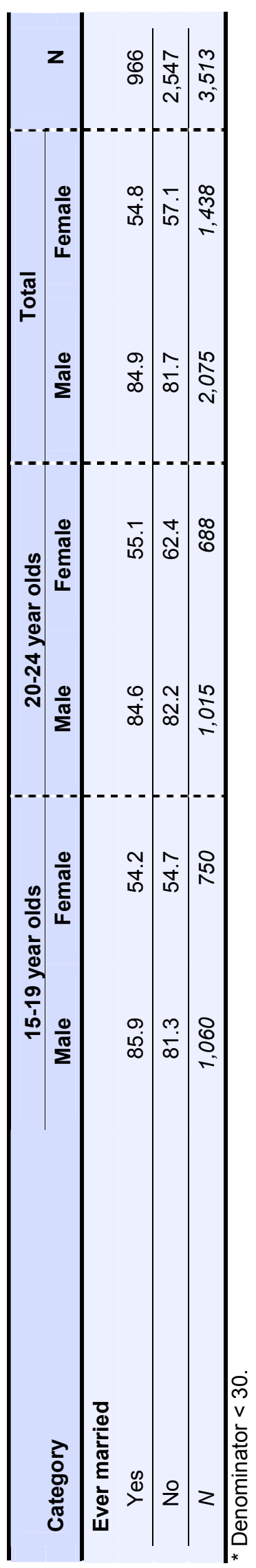




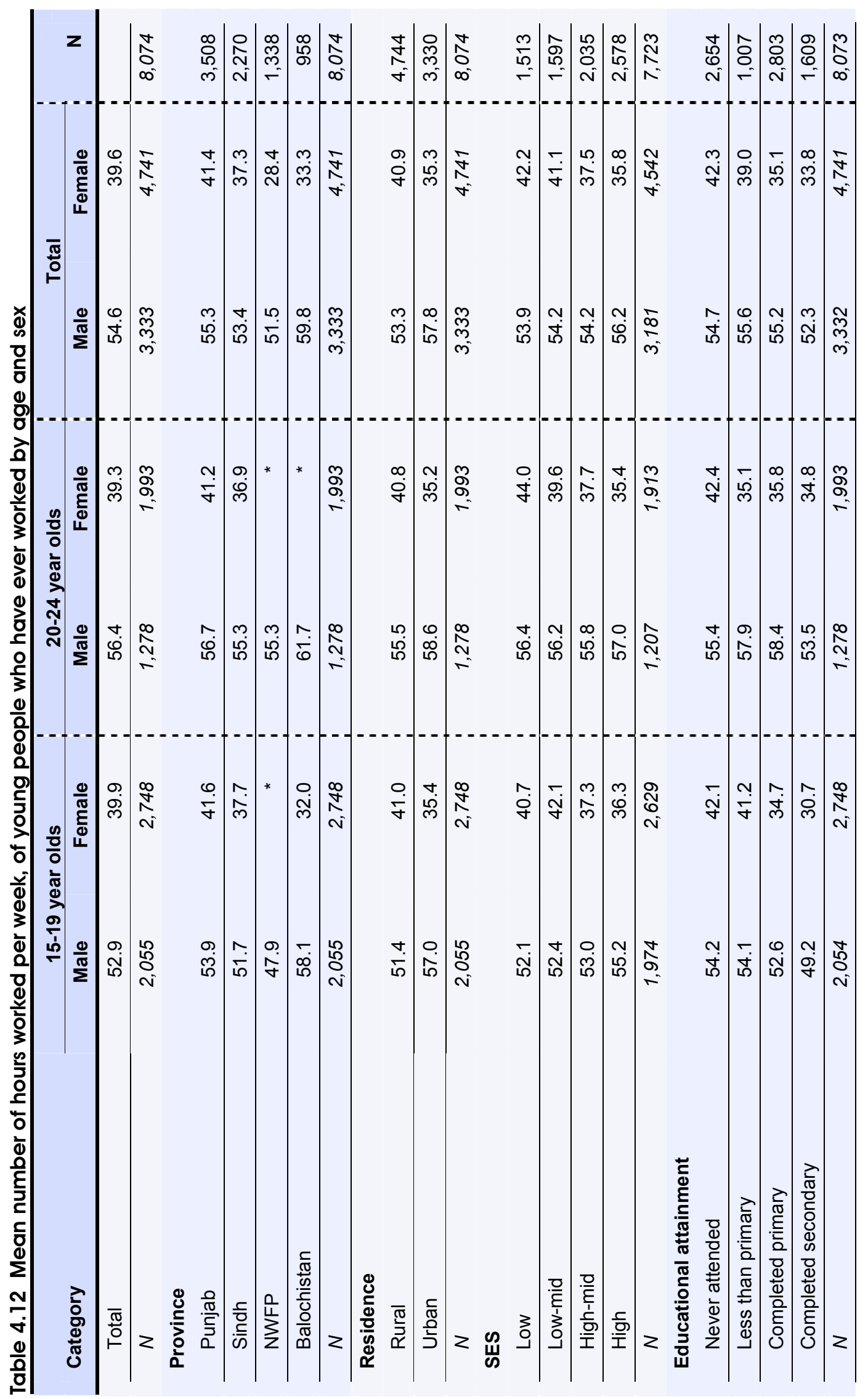




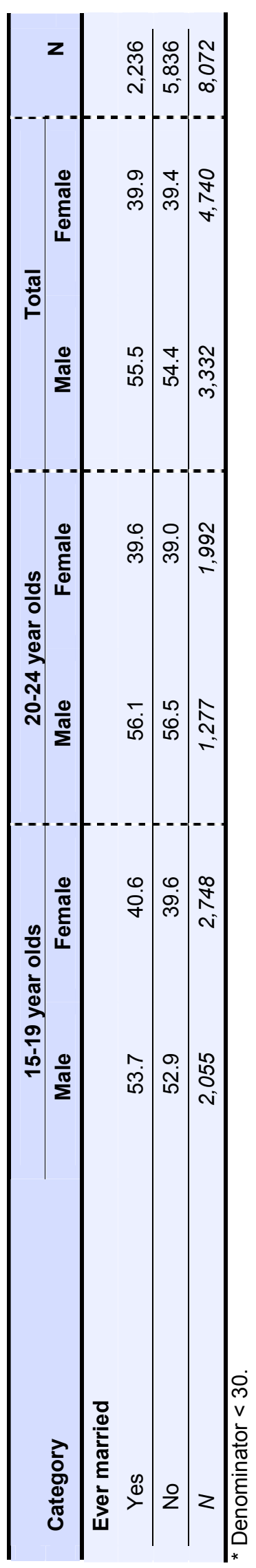




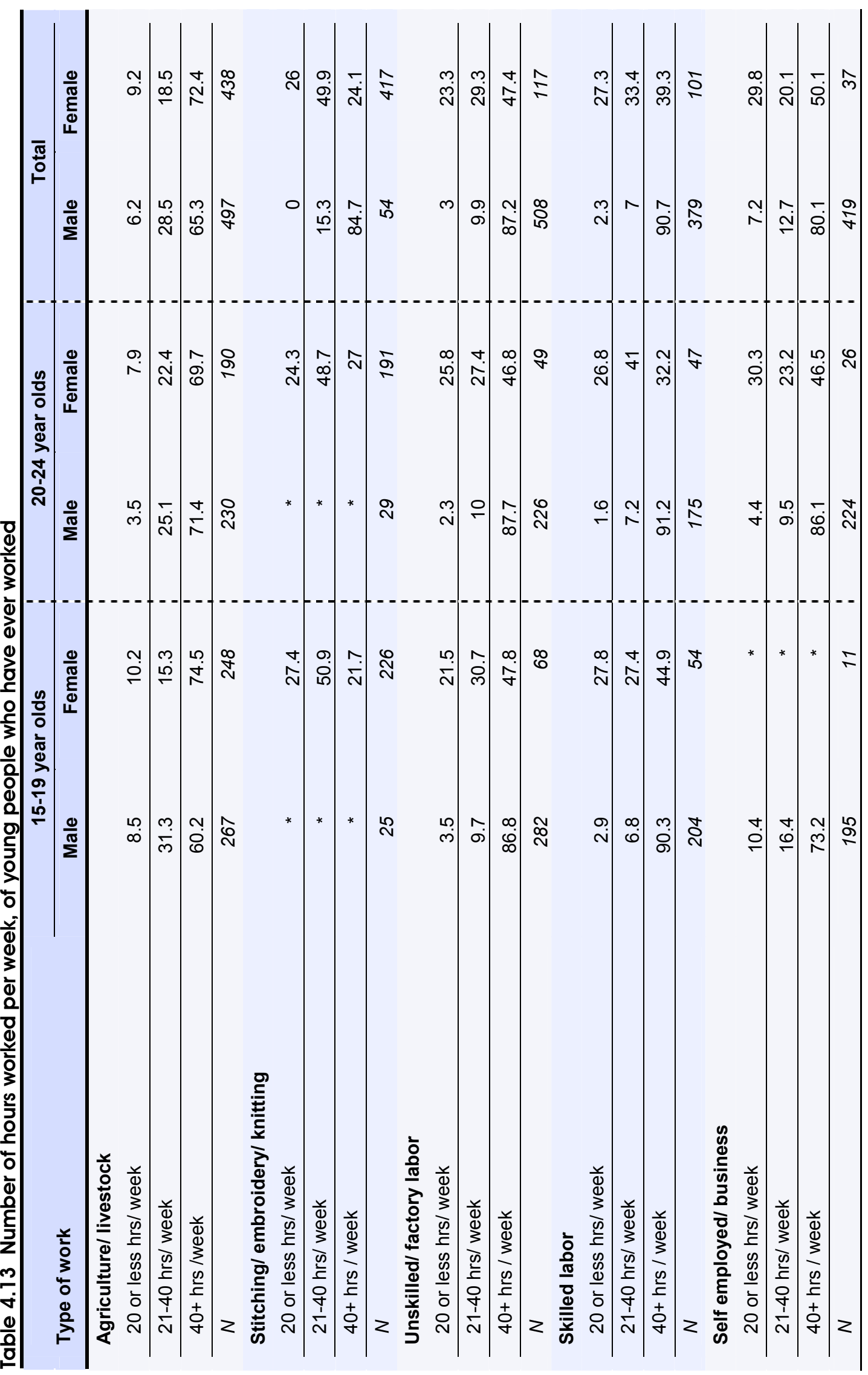




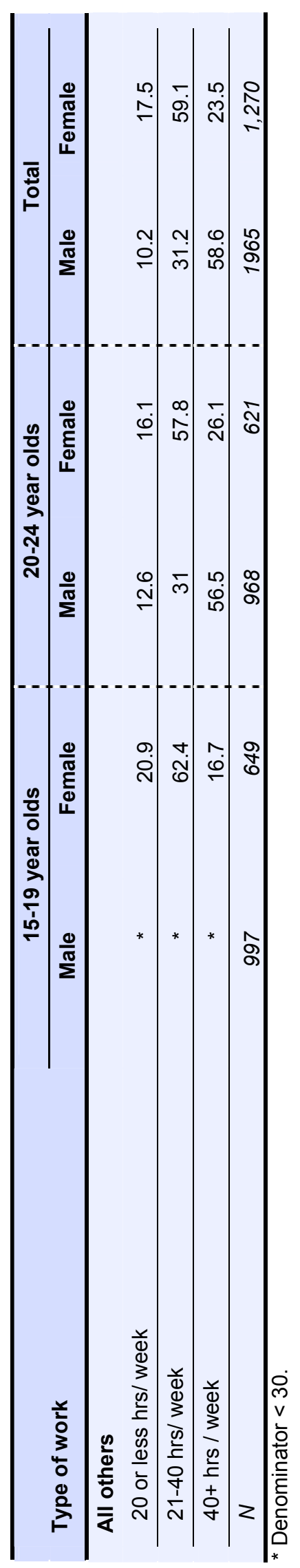




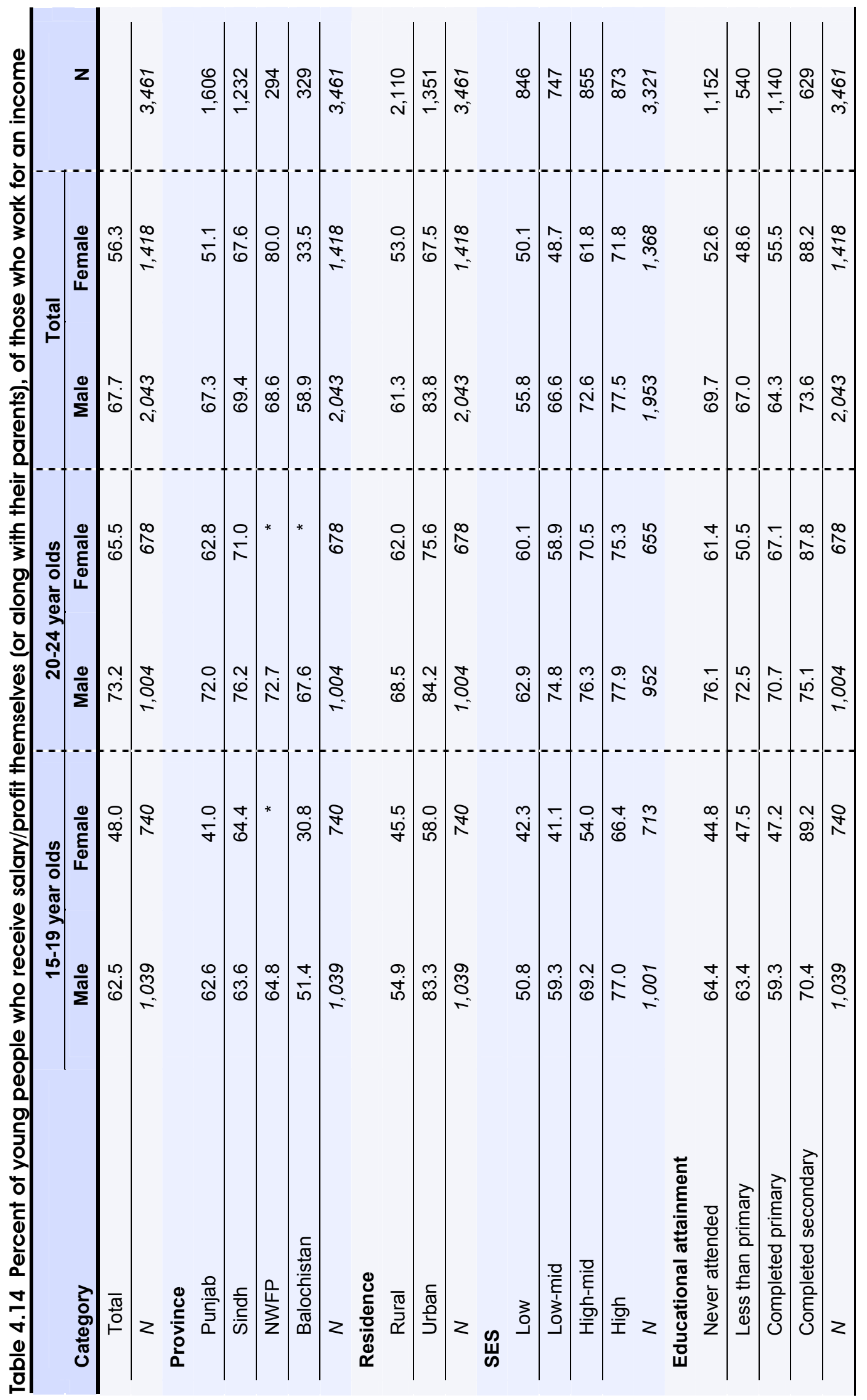




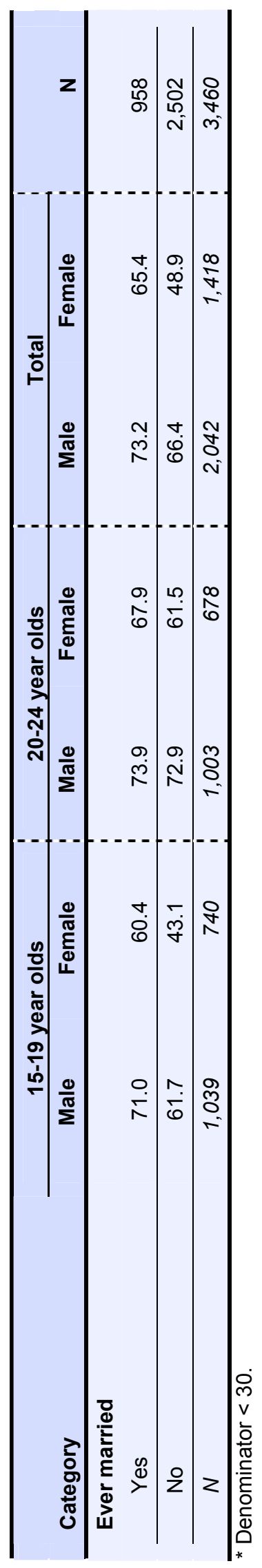




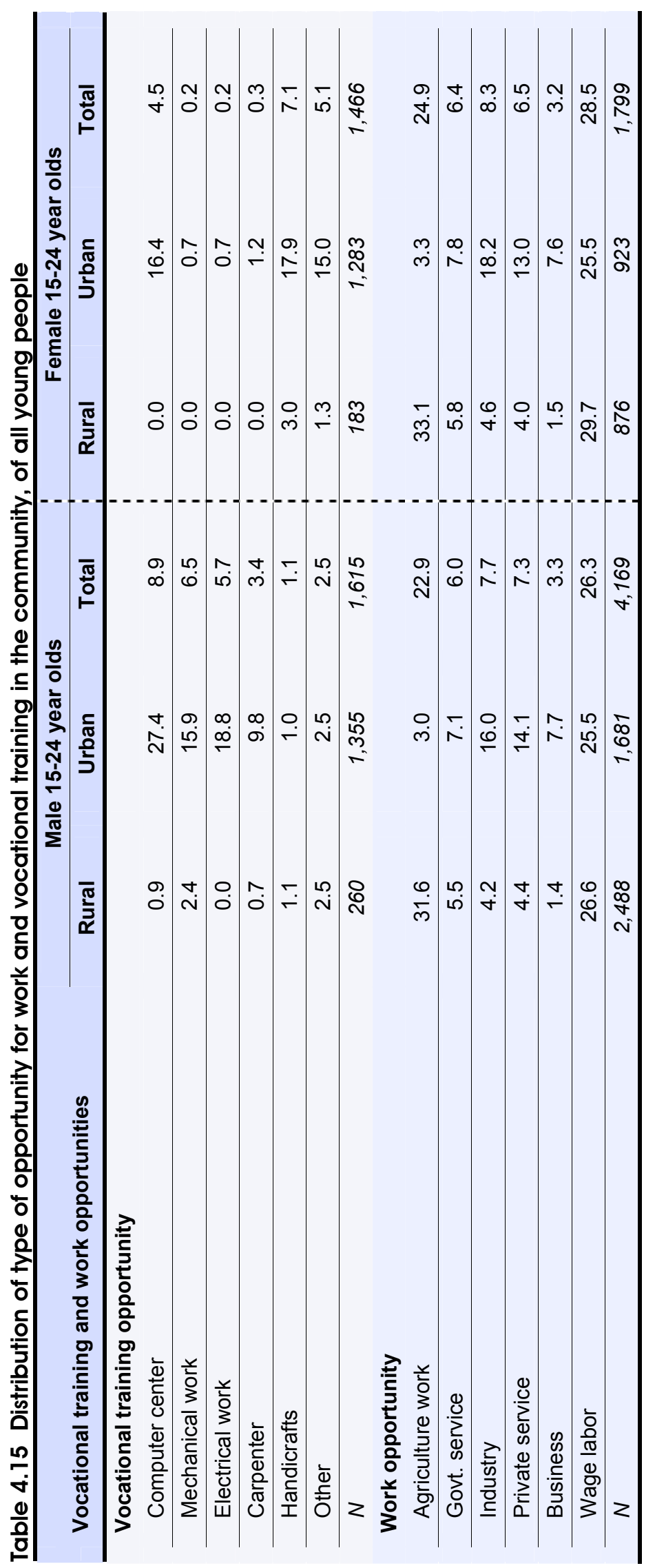




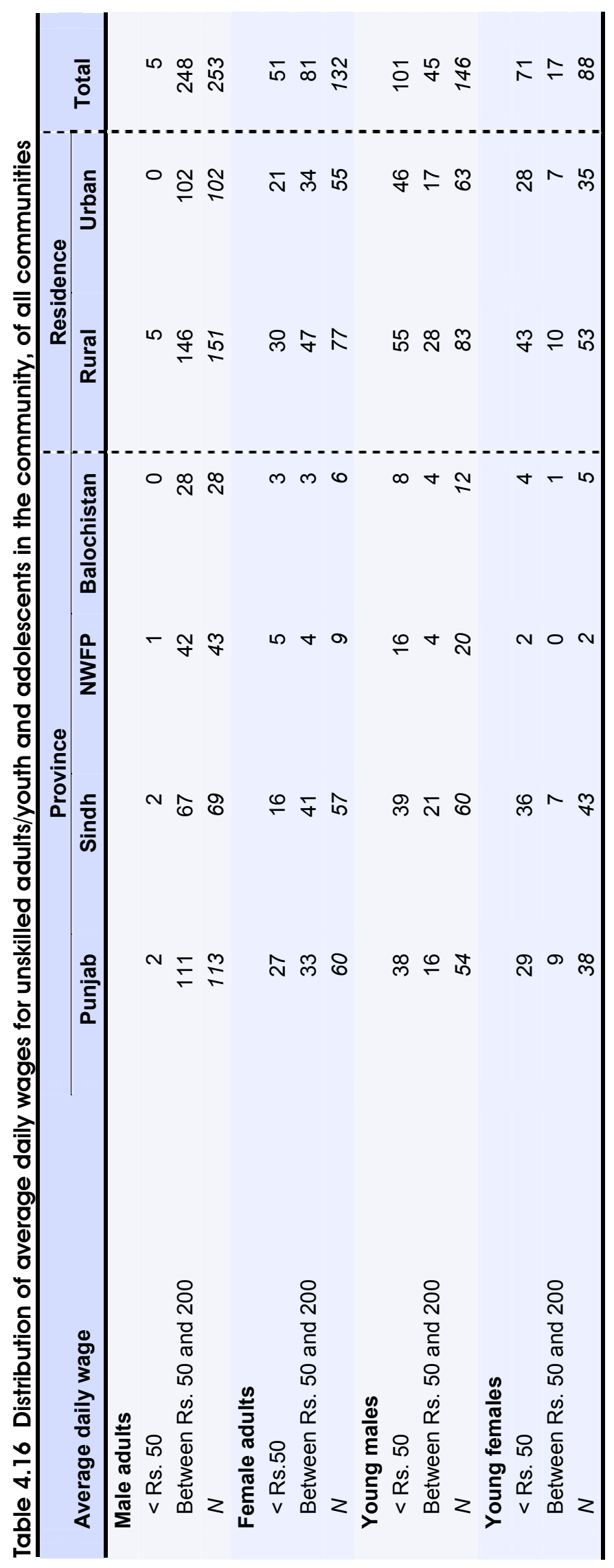




\section{Tables Chapter 5}

Table 5.1 Mean age of puberty among those currently 20-24 years old

\begin{tabular}{|c|c|c|c|}
\hline \multirow[b]{2}{*}{ Category } & \multicolumn{2}{|c|}{ 20-24 year olds } & \multirow[b]{2}{*}{$\mathbf{N}$} \\
\hline & Male & Female & \\
\hline Total & 15.0 & 13.5 & \\
\hline$N$ & 1,205 & 1,834 & 7,394 \\
\hline \multicolumn{4}{|l|}{ Province } \\
\hline Punjab & 15.0 & 13.6 & 3,283 \\
\hline Sindh & 15.2 & 13.2 & 2,026 \\
\hline NWFP & 14.6 & 13.6 & 1,223 \\
\hline Balochistan & 14.9 & 13.4 & 862 \\
\hline$N$ & 1,205 & 1,834 & 7,394 \\
\hline \multicolumn{4}{|l|}{ SES } \\
\hline Low & 14.9 & 13.4 & 1,354 \\
\hline Low-mid & 14.8 & 13.5 & 1,478 \\
\hline High-mid & 15.1 & 13.6 & 1,865 \\
\hline High & 15.2 & 13.5 & 2,381 \\
\hline$N$ & 1,141 & 1,759 & 7,078 \\
\hline \multicolumn{4}{|l|}{ Educational attainment } \\
\hline Never attended & 14.7 & 13.4 & 2,380 \\
\hline Less than primary & 15.1 & 13.4 & 921 \\
\hline Completed primary & 15.1 & 13.6 & 2,585 \\
\hline Completed secondary & 15.1 & 13.8 & 1,508 \\
\hline$N$ & 1,205 & 1,834 & 7,394 \\
\hline \multicolumn{4}{|l|}{ Residence } \\
\hline Urban & 15.3 & 13.6 & 3,038 \\
\hline Rural & 14.9 & 13.5 & 4,356 \\
\hline$N$ & 1,205 & 1,834 & 7,394 \\
\hline
\end{tabular}

Note: Those 15-19 years old were excluded since not all have entered puberty. 
Table 5.2 Percent who were informed about puberty before it began, among those who had undergone puberty

\begin{tabular}{|c|c|c|c|c|c|}
\hline \multirow[b]{2}{*}{ Category } & \multicolumn{2}{|c|}{$15-19$ year olds } & \multicolumn{2}{|c|}{ 20-24 year olds } & \multirow[b]{2}{*}{$\mathbf{N}$} \\
\hline & Male & Female & Male & Female & \\
\hline Total & 41.3 & 32.8 & 41.4 & 28.6 & \\
\hline$N$ & 1,842 & 2,513 & 1,205 & 1,834 & 7,394 \\
\hline \multicolumn{6}{|l|}{ Province } \\
\hline Punjab & 40.1 & 30.6 & 38.2 & 28.2 & 3,283 \\
\hline Sindh & 45.7 & 33.7 & 45.0 & 28.3 & 2,026 \\
\hline NWFP & 36.1 & 37.0 & 45.2 & 29.9 & 1,223 \\
\hline Balochistan & 42.2 & 42.2 & 46.0 & 31.7 & 862 \\
\hline$N$ & 1,842 & 2,513 & 1,205 & 1,834 & 7,394 \\
\hline \multicolumn{6}{|l|}{ SES } \\
\hline Low & 40.0 & 39.9 & 41.2 & 32.8 & 1,354 \\
\hline Low-mid & 42.1 & 32.7 & 42.9 & 27.1 & 1,478 \\
\hline High-mid & 41.4 & 30.9 & 42.0 & 28.8 & 1,865 \\
\hline High & 40.4 & 28.9 & 41.5 & 26.0 & 2,381 \\
\hline$N$ & 1,770 & 2,408 & 1,141 & 1,759 & 7,078 \\
\hline \multicolumn{6}{|l|}{ Educational attainment } \\
\hline Never attended & 42.5 & 35.5 & 24.3 & 31.1 & 2,380 \\
\hline Less than primary & 32.3 & 31.5 & 45.7 & 30.7 & 921 \\
\hline Completed primary & 41.9 & 31.4 & 39.9 & 23.1 & 2,585 \\
\hline Completed secondary & 40.4 & 27.3 & 50.6 & 25.6 & 1,508 \\
\hline$N$ & 1,842 & 2,513 & 1,205 & 1,834 & 7,394 \\
\hline \multicolumn{6}{|l|}{ Residence } \\
\hline Urban & 39.2 & 25.0 & 36.5 & 21.8 & 4,356 \\
\hline Rural & 42.2 & 35.8 & 43.6 & 31.0 & 3,038 \\
\hline$N$ & 1,842 & 2,513 & 1,205 & 1,834 & 7,394 \\
\hline
\end{tabular}


Table 5.3 Percent of young people who think information about puberty should be provided in advance

\begin{tabular}{|c|c|c|c|c|c|}
\hline \multirow[b]{2}{*}{ Category } & \multicolumn{2}{|c|}{$15-19$ year olds } & \multicolumn{2}{|c|}{ 20-24 year olds } & \multirow[b]{2}{*}{$\mathbf{N}$} \\
\hline & Male & Female : & Male & Female : & \\
\hline Total & 63.2 & $72.4 !$ & 69.8 & 75.8 & \\
\hline$N$ & 2,024 & 2,702 & 1,256 & 1,966 & 7,948 \\
\hline \multicolumn{6}{|l|}{ Province } \\
\hline Punjab & 62.0 & 74.5 & 67.1 & 78.2 & 3,452 \\
\hline Sindh & 68.8 & $66.3 !$ & 77.5 & 68.8 & 2,234 \\
\hline NWFP & 58.4 & 76.5 & 66.2 & 81.5 & 1,311 \\
\hline Balochistan & 57.5 & 71.2 & 60.7 & 66.7 & 951 \\
\hline$N$ & 2,024 & 2,702 & 1,256 & 1,966 & 7,948 \\
\hline \multicolumn{6}{|l|}{ SES } \\
\hline Low & 65.0 & 66.0 & 64.3 & 70.0 & 1,483 \\
\hline Low-mid & 64.1 & 68.4 & 71.9 & 70.9 & 1,570 \\
\hline High-mid & 63.1 & $77.6 !$ & 67.3 & 79.4 & 2,001 \\
\hline High & 60.4 & $76.1:$ & 73.9 & 80.4 & 2,548 \\
\hline$N$ & 1,945 & 2,585 & 1,187 & 1,885 & 7,602 \\
\hline \multicolumn{6}{|l|}{ Educational attainment } \\
\hline Never attended & 59.2 & $64.8 i$ & 59.9 & 71.2 & 2,592 \\
\hline Less than primary & 60.3 & 72.8 & 64.3 & 75.7 & 991 \\
\hline Completed primary & 63.3 & 80.2 & 68.3 & 82.5 & 2,774 \\
\hline Completed secondary & 68.7 & 81.7 & 78.9 & 82.4 & 1,591 \\
\hline$N$ & 2,024 & 2,702 & 1,256 & 1,966 & 7,948 \\
\hline \multicolumn{6}{|l|}{ Residence } \\
\hline Urban & 61.4 & 73.6 & 74.0 & 79.6 & 3,286 \\
\hline Rural & 64.0 & 71.9 & 67.9 & 74.4 & 4,662 \\
\hline$N$ & 2,024 & 2,702 & 1,256 & 1,966 & 7,948 \\
\hline
\end{tabular}

Table 5.4 Person who should provide information about puberty, according to those who think information should be provided

\begin{tabular}{lcr:rc}
\hline \multirow{2}{*}{ Person } & \multicolumn{2}{c}{$\mathbf{1 5 - 1 9}$ year olds } & \multicolumn{2}{c}{$\mathbf{2 0 - 2 4}$ year olds } \\
\cline { 2 - 5 } & Male & Female & Male & Female \\
\hline Father/mother $^{\mathrm{a}}$ & 29.2 & 81.0 & 28.0 & 83.8 \\
Brother/sister & 23.6 & 53.4 & 20.9 & 57.9 \\
Friend & 66.6 & 19.4 & 71.5 & 20.4 \\
Another adult relative & 6.7 & 9.8 & 6.4 & 11.3 \\
$N$ & 1,273 & 1,977 & 876 & 1,501 \\
\hline
\end{tabular}

\footnotetext{
${ }^{a}$ Male respondents were offered choice of male relatives and friends; females were offered choice of female
} relatives or friends. 
Table 5.5 Percent of all females enrolled in a school at the time of puberty

\begin{tabular}{|c|c|c|c|}
\hline Category & $15-19$ year olds & 20-24 year olds & $\mathbf{N}$ \\
\hline Total & 31.8 & 28.0 & \\
\hline$N$ & 2,659 & 1,936 & 4,595 \\
\hline \multicolumn{4}{|l|}{ Province } \\
\hline Punjab & 38.0 & 34.3 & 2,023 \\
\hline Sindh & 26.8 & 21.4 & 1,265 \\
\hline NWFP & 21.0 & 19.1 & 744 \\
\hline Balochistan & 17.3 & 9.2 & 563 \\
\hline$N$ & 2,659 & 1,936 & 4,595 \\
\hline \multicolumn{4}{|l|}{ SES } \\
\hline Low & 5.8 & 2.6 & 873 \\
\hline Low-mid & 13.9 & 13.2 & 931 \\
\hline High-mid & 34.7 & 24.0 & 1,167 \\
\hline High & 69.0 & 63.4 & 1,429 \\
\hline$N$ & 2,543 & 1,857 & 4,400 \\
\hline \multicolumn{4}{|l|}{ Residence } \\
\hline Urban & 60.3 & 59.5 & 2,746 \\
\hline Rural & 20.4 & 16.3 & 1,849 \\
\hline$N$ & 2,659 & 1,936 & 4,595 \\
\hline
\end{tabular}




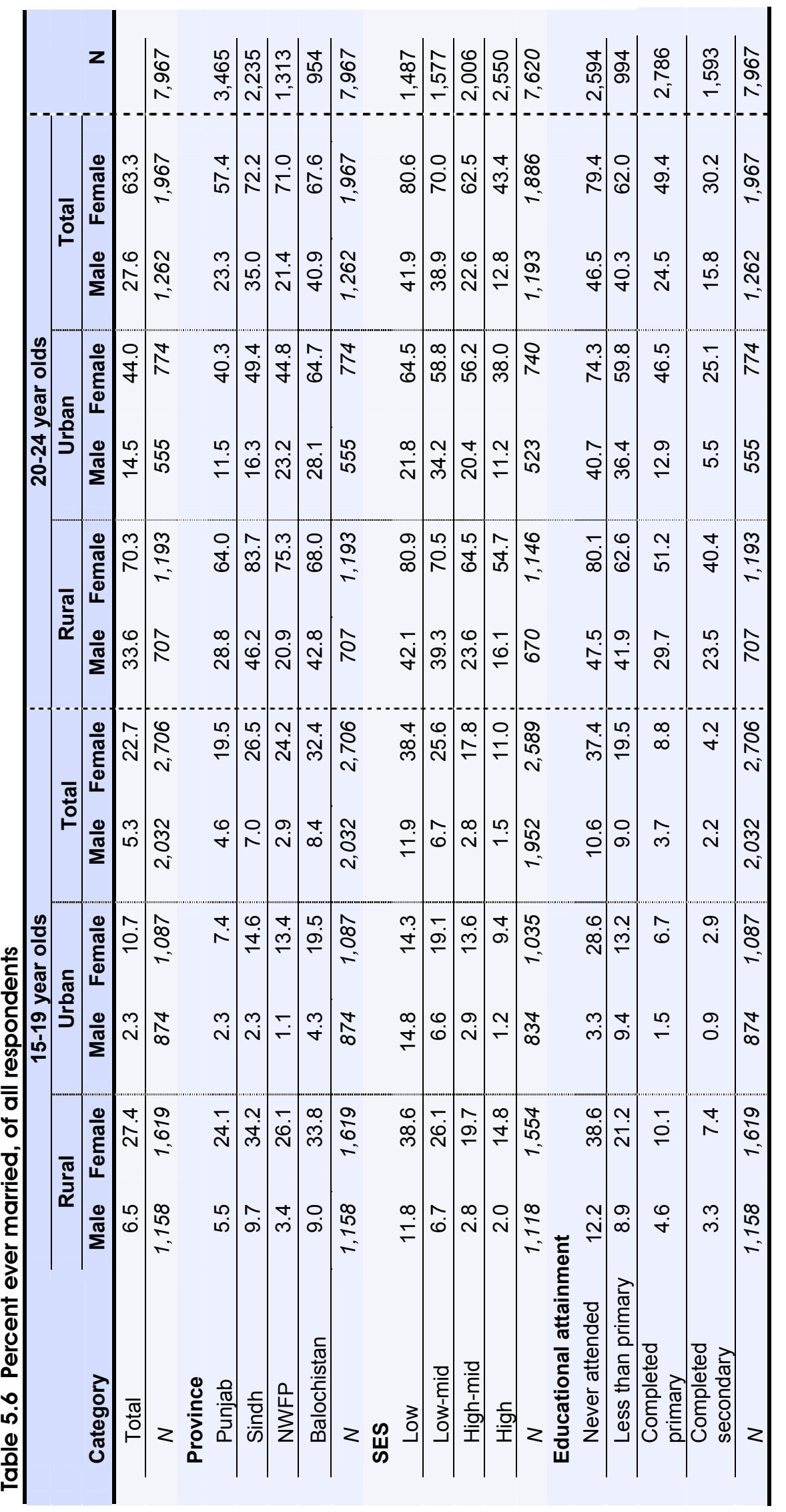




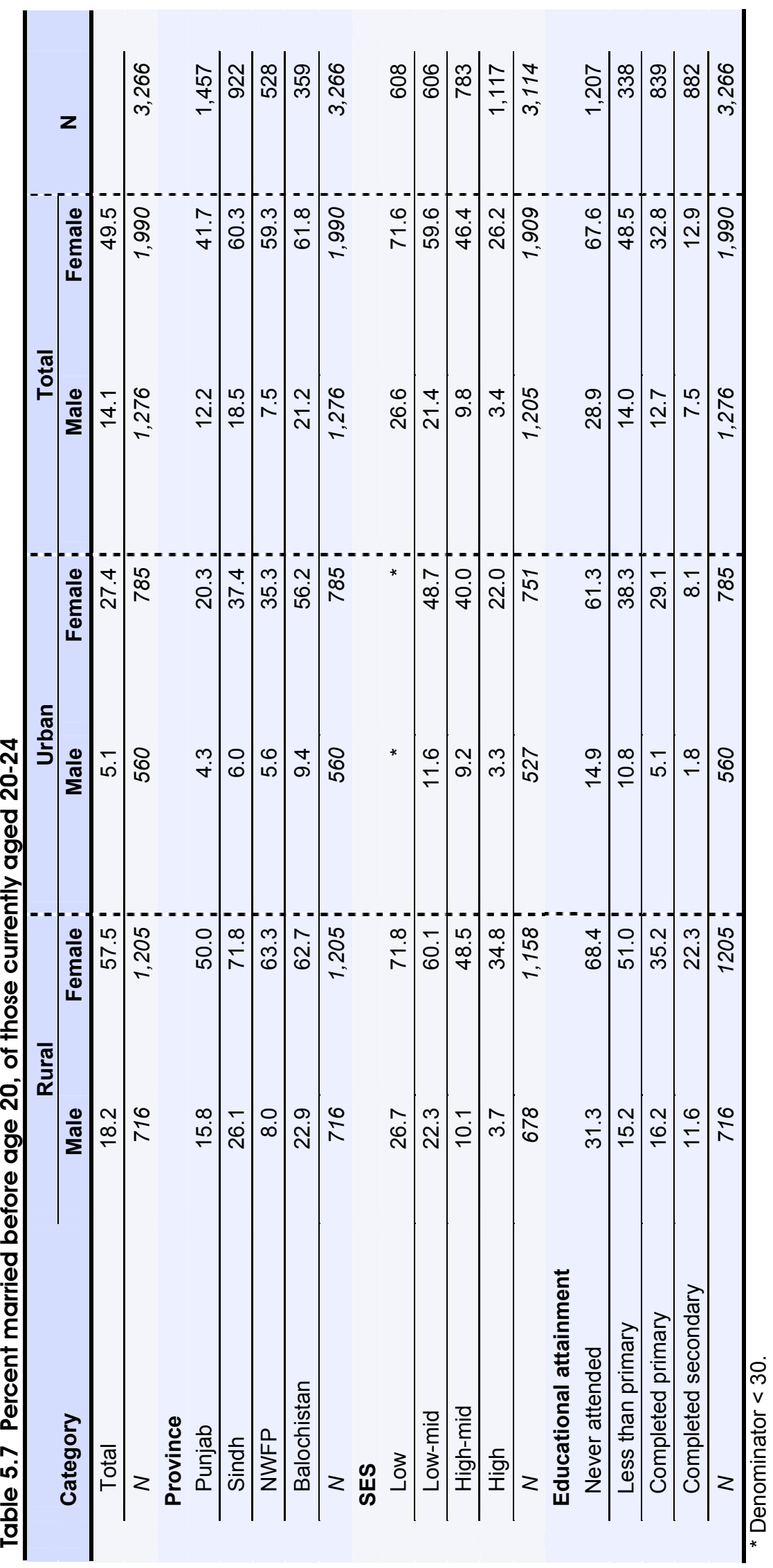




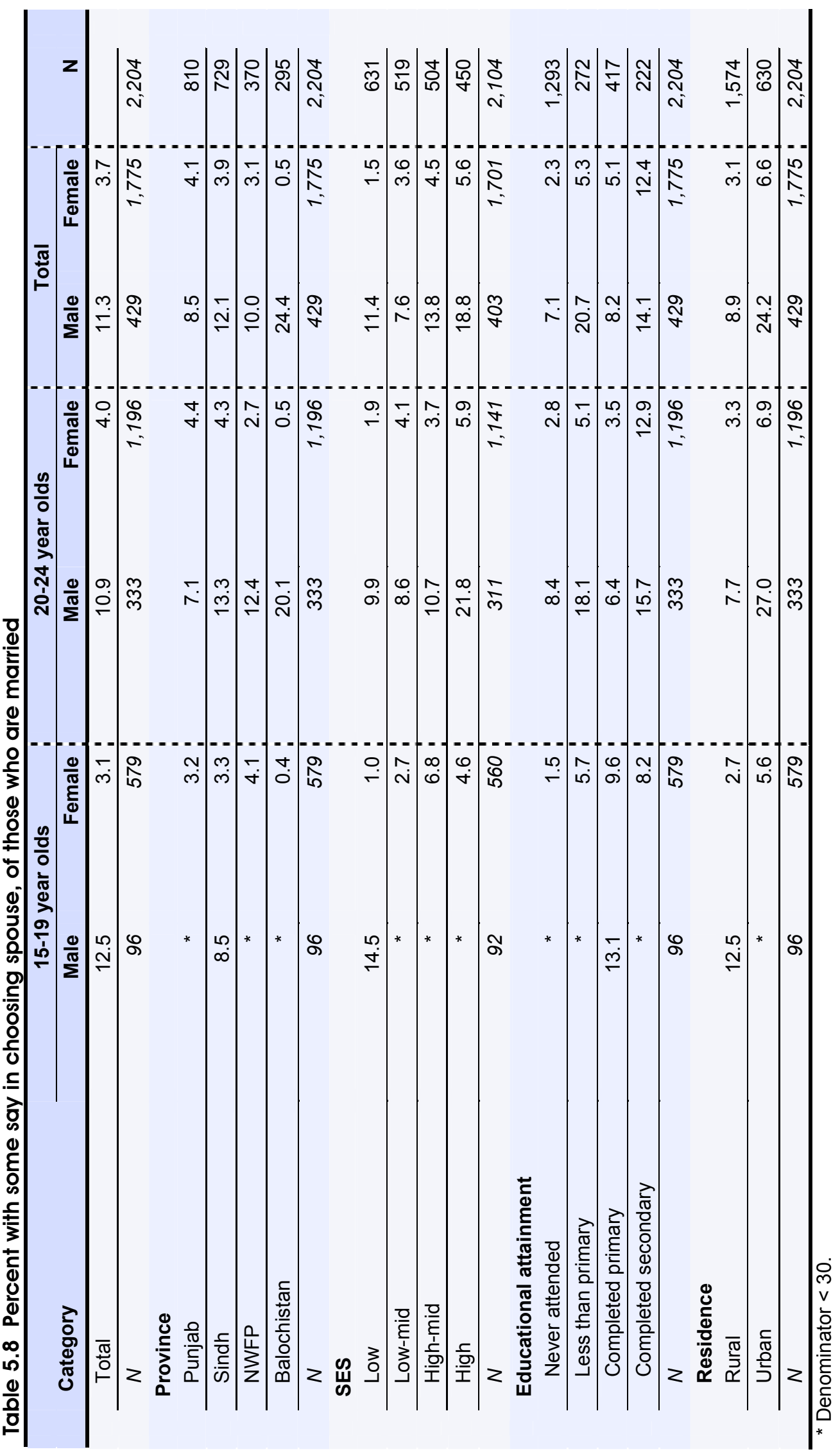




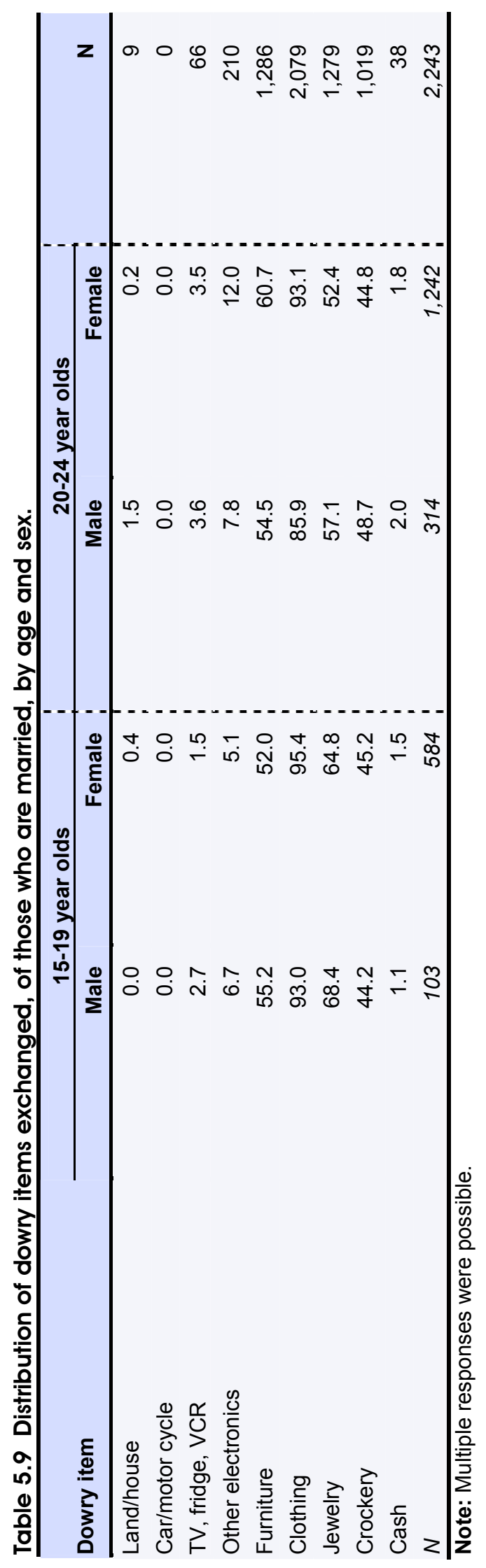




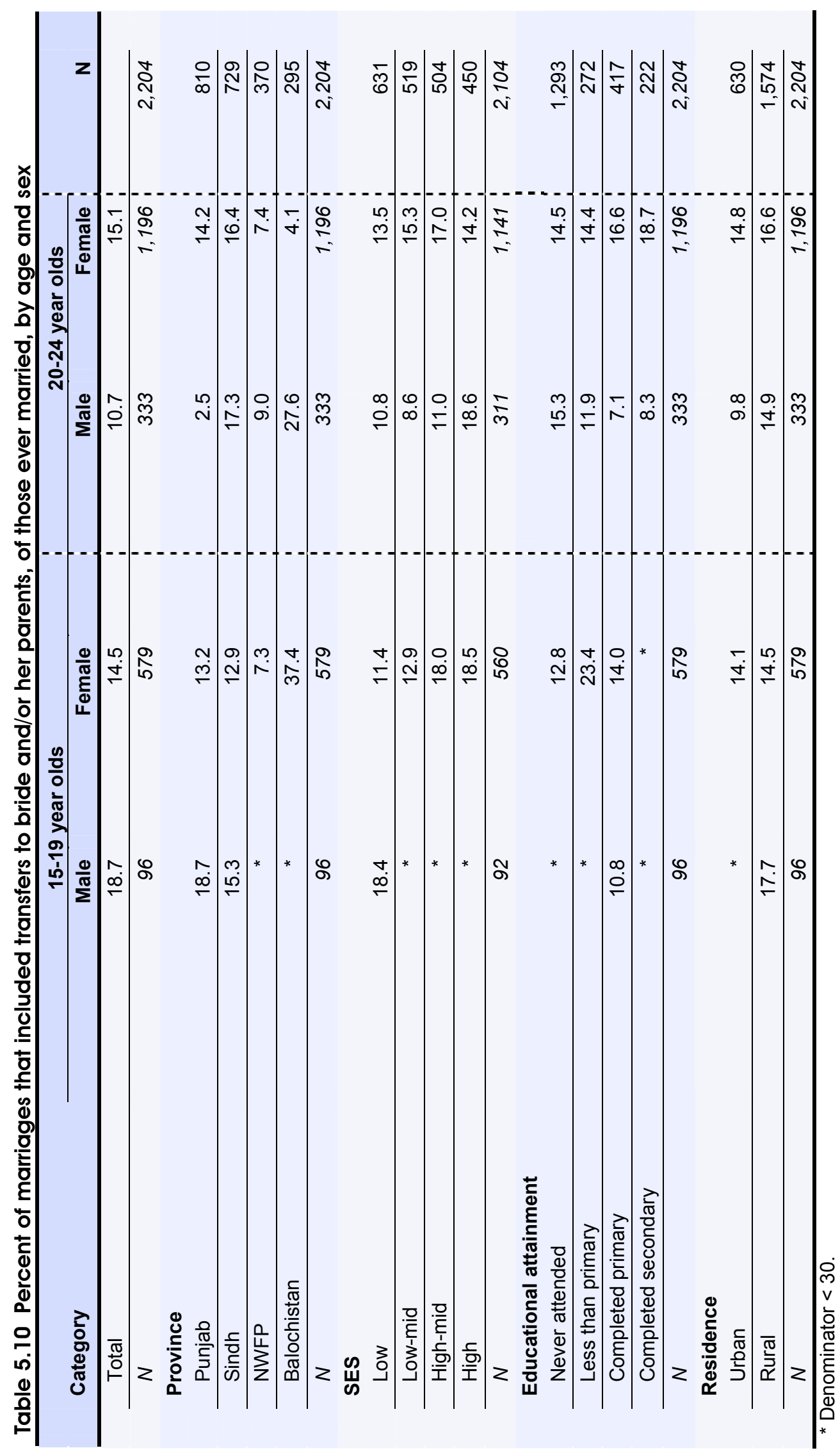




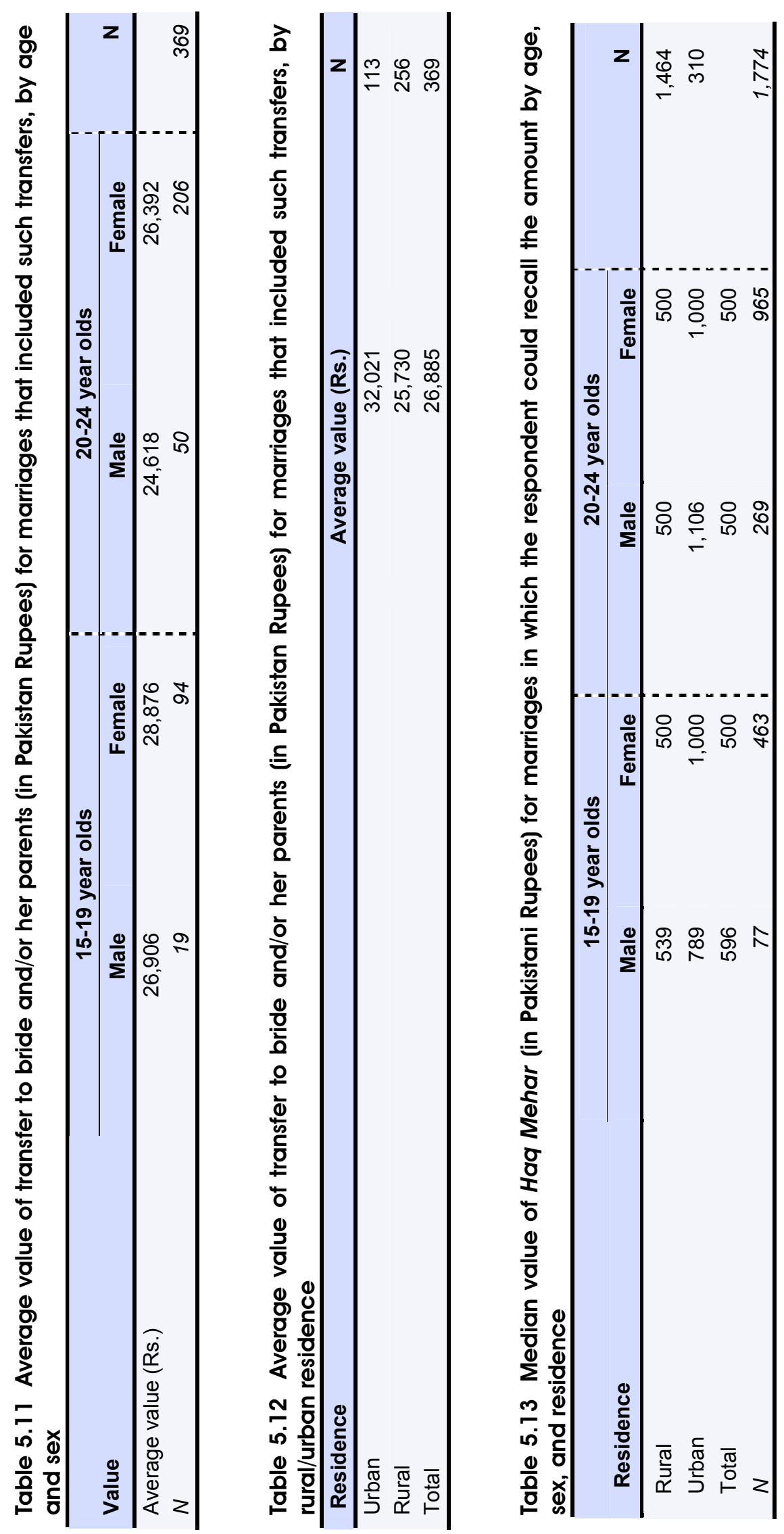




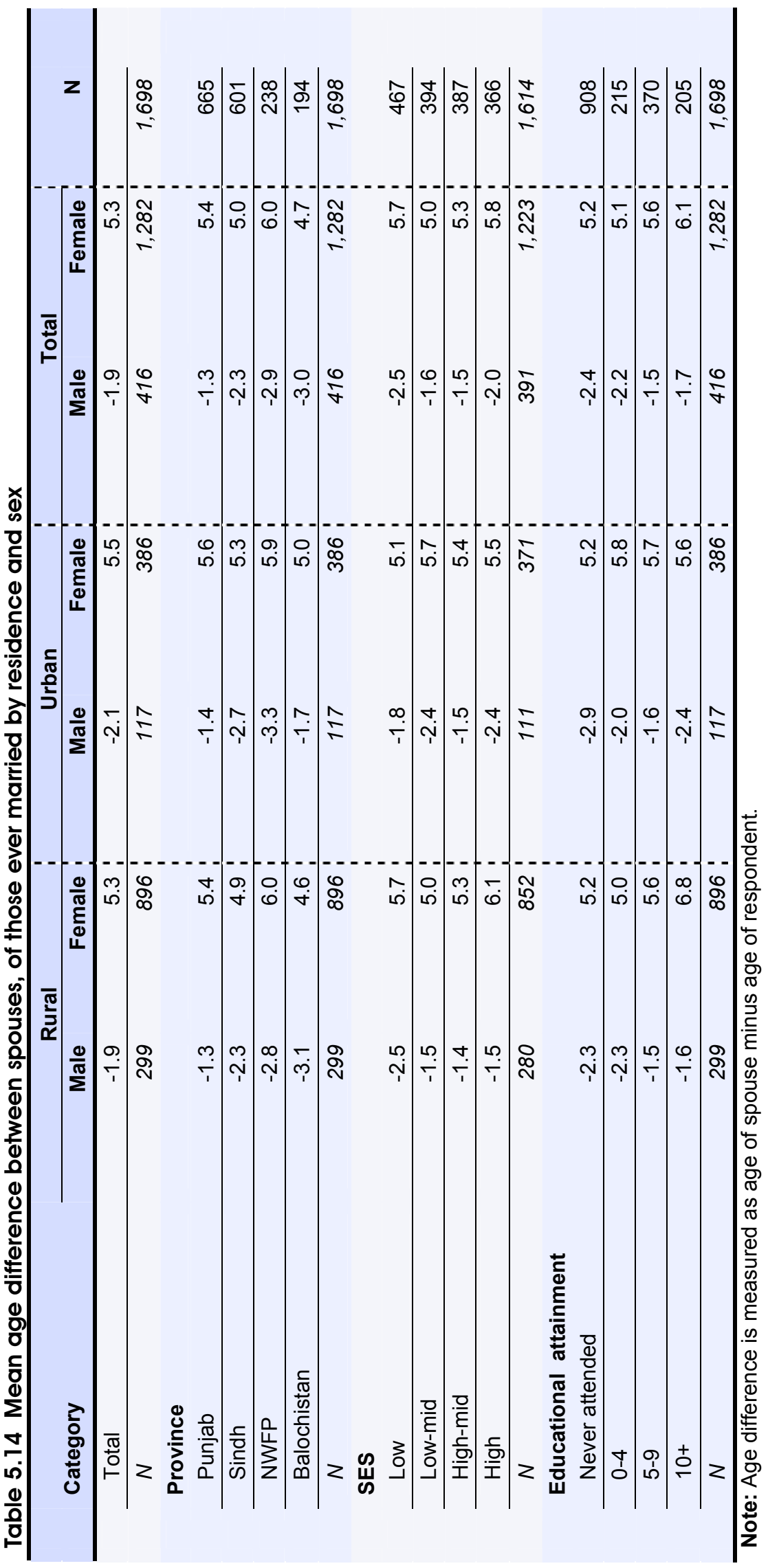




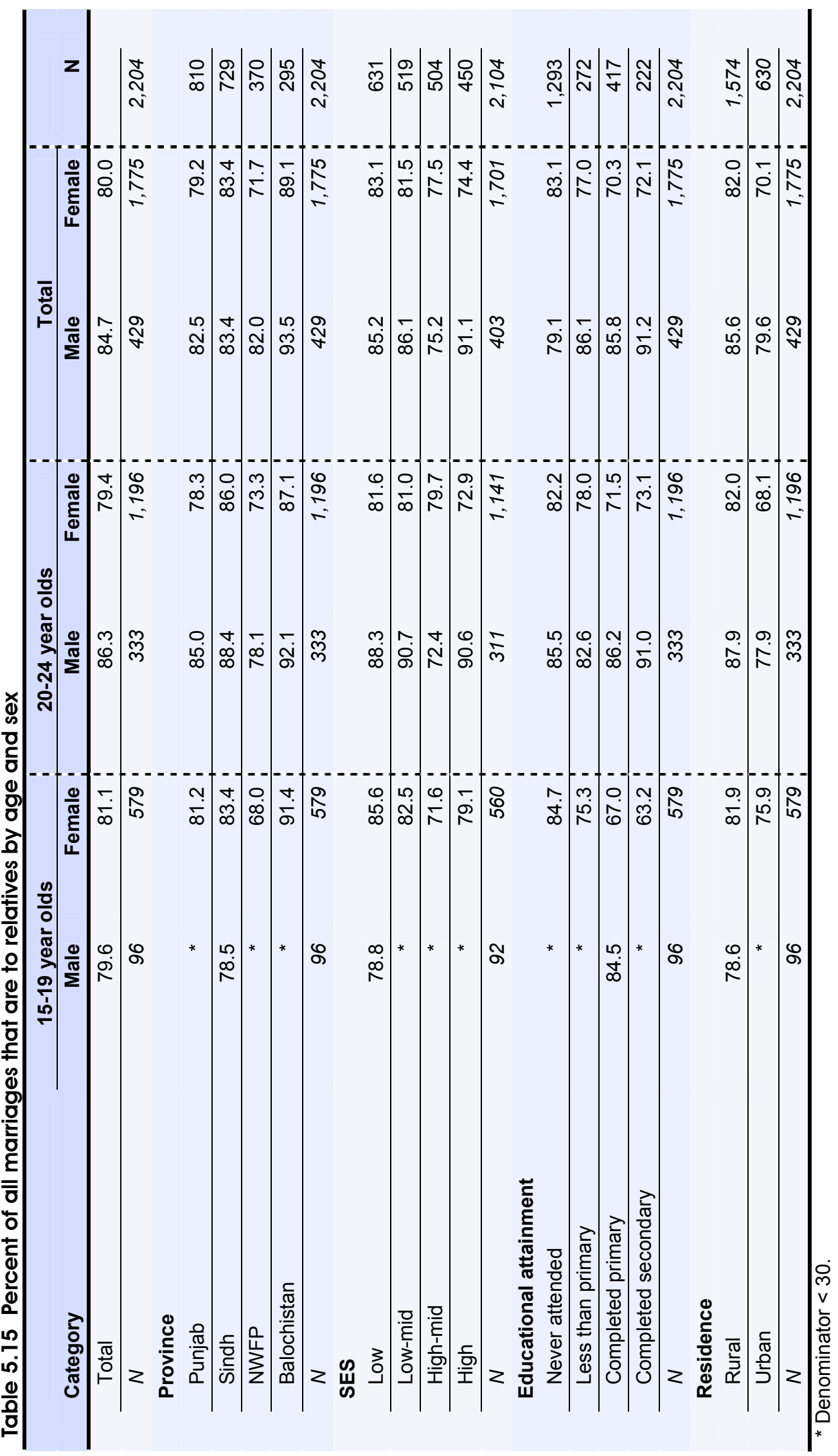




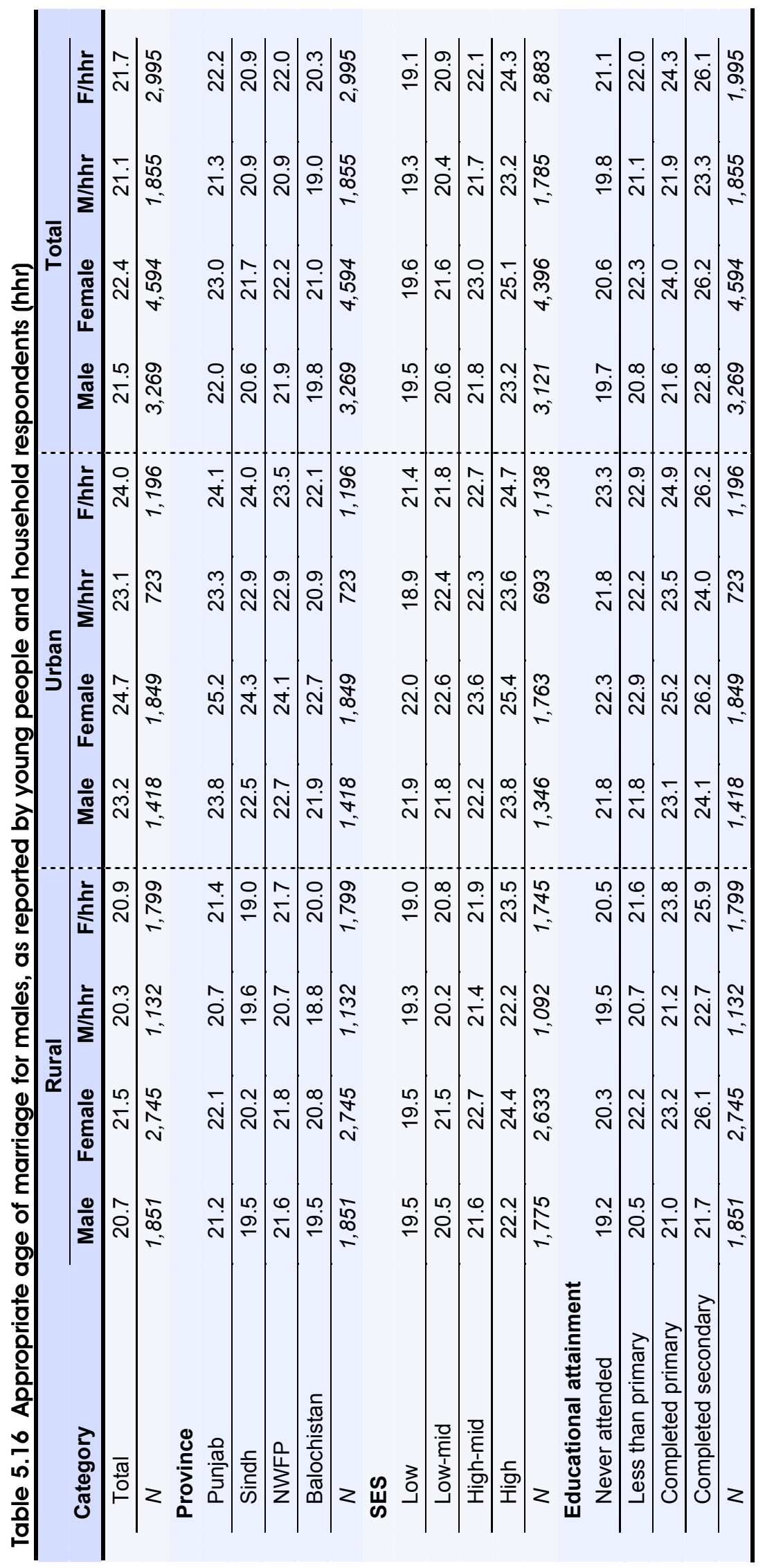




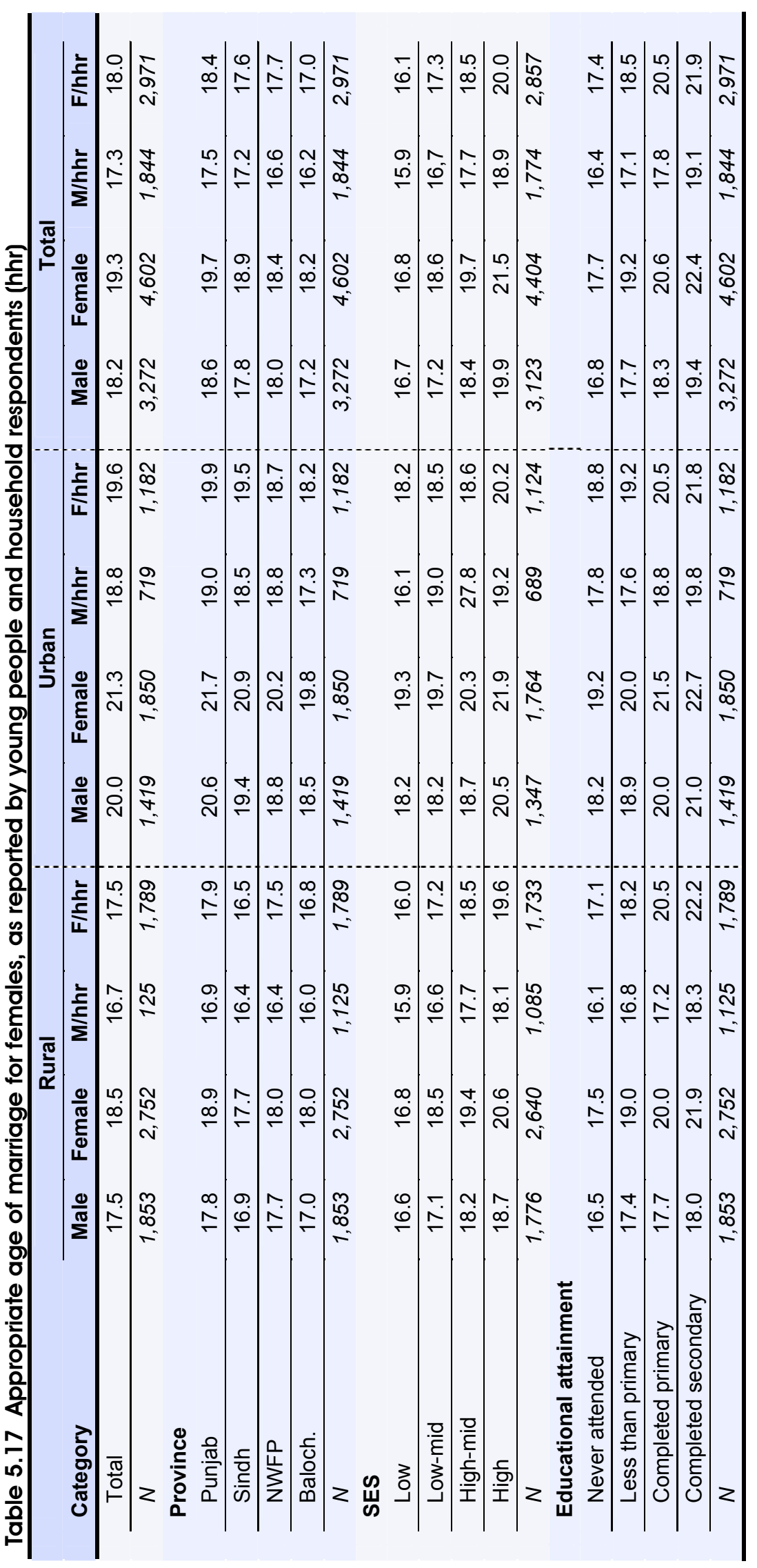


Table 5.18 Minimum appropriate age of marriage for males, as reported by young people, by age and sex and marital status

\begin{tabular}{|c|c|c|c|c|c|c|c|c|}
\hline \multirow{3}{*}{$\begin{array}{l}\text { Marital } \\
\text { status }\end{array}$} & \multicolumn{4}{|c|}{$15-19$ year olds } & \multicolumn{4}{|c|}{$20-24$ year olds } \\
\hline & \multicolumn{2}{|c|}{ Rural } & \multicolumn{2}{|c|}{ Urban } & \multicolumn{2}{|c|}{ Rural } & \multicolumn{2}{|c|}{ Urban } \\
\hline & Male & Female & Male & Female ! & Male & Female & Male & Female \\
\hline Married & 18.8 & 19.9 & 20.1 & $21.9 !$ & 19.7 & 20.9 & 21.3 & 24.3 \\
\hline$N$ & 72 & 420 & 24 & $144 !$ & 238 & 819 & 95 & 363 \\
\hline Unmarried & 20.7 & 22.0 & 23.2 & $24.6 !$ & 21.5 & 23.6 & 23.6 & 26.1 \\
\hline$N$ & 1,075 & 1,147 & 842 & $932 \vdots$ & 466 & 358 & 457 & 407 \\
\hline
\end{tabular}

Table 5.19 Minimum appropriate age of marriage for females, as reported by young people, by age, sex and marital status

\begin{tabular}{|c|c|c|c|c|c|c|c|c|}
\hline \multirow{3}{*}{$\begin{array}{l}\text { Marital } \\
\text { status }\end{array}$} & \multicolumn{4}{|c|}{$15-19$ year olds } & \multicolumn{4}{|c|}{ 20-24 year olds } \\
\hline & \multicolumn{2}{|c|}{ Rural } & \multicolumn{2}{|c|}{ Urban } & \multicolumn{2}{|c|}{ Rural } & \multicolumn{2}{|c|}{ Urban } \\
\hline & Male & Female & Male & Female : & Male & Female & Male & Female \\
\hline Married & 16.3 & 16.9 & 18.4 & 18.7 & 16.6 & 17.8 & 17.8 & 20.3 \\
\hline$N$ & 71 & 425 & 24 & 145 & 236 & 823 & 95 & 362 \\
\hline Unmarried & 17.8 & 19.1 & 19.8 & 21.3 & 17.5 & 20.2 & 20.6 & 22.6 \\
\hline$N$ & 1,079 & 1,144 & 843 & 932 & 467 & 358 & 457 & 408 \\
\hline
\end{tabular}

Table 5.20 Mean children ever born, of those ever married by age and sex

\begin{tabular}{|c|c|c|c|c|c|}
\hline \multirow[b]{2}{*}{ Category } & \multicolumn{2}{|c|}{$15-19$ year olds } & \multicolumn{2}{|c|}{ 20-24 year olds } & \multirow[b]{2}{*}{$\mathbf{N}$} \\
\hline & Male & Female & Male & Female : & \\
\hline Total & 0.5 & 0.7 & 1.1 & $1.9 !$ & \\
\hline$N$ & 96 & 579 & 332 & 1,196 & 2,203 \\
\hline \multicolumn{6}{|l|}{ Province } \\
\hline Punjab & * & $0.7 i$ & 1.0 & $1.8 i$ & 809 \\
\hline Sindh & 0.6 & 0.7 & 1.2 & $2.0 !$ & 729 \\
\hline NWFP & * & 0.5 & 1.1 & 1.8 & 370 \\
\hline Balochistan & * & $0.6 !$ & 1.2 & $2.1 !$ & 295 \\
\hline$N$ & 96 & 579 & 333 & 1,196 & 2,203 \\
\hline \multicolumn{6}{|l|}{ SES } \\
\hline Low & 0.6 & $0.8:$ & 1.2 & $2.1 !$ & 631 \\
\hline Low-mid & * & 0.7 & 1.0 & $2.1 !$ & 519 \\
\hline High-mid & * & 0.7 & 1.1 & $1.7 !$ & 503 \\
\hline High & * & $0.6 !$ & 0.7 & $1.5 !$ & 450 \\
\hline$N$ & 92 & 560 & 311 & 1,141 & 2,103 \\
\hline \multicolumn{6}{|l|}{ Educational attainment } \\
\hline Never attended & * & $0.7 \vdots$ & 1.3 & $2.1 !$ & 1,292 \\
\hline Less than primary & * & 0.8 & 0.7 & $1.8 !$ & 272 \\
\hline Completed primary & 0.4 & 0.5 & 1.1 & $1.5 !$ & 417 \\
\hline Completed secondary & * & * & 1.1 & $1.2 !$ & 222 \\
\hline$N$ & 96 & 579 & 333 & 1,196 & 2,203 \\
\hline
\end{tabular}




\begin{tabular}{|c|c|c|c|c|c|}
\hline \multirow[b]{2}{*}{ Category } & \multicolumn{2}{|c|}{$15-19$ year olds } & \multicolumn{2}{|c|}{ 20-24 year olds } & \multirow[b]{2}{*}{$\mathbf{N}$} \\
\hline & Male & Female : & Male & Female & \\
\hline Residence & & & & 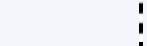 & \\
\hline Urban & * & 0.7 & 0.8 & 1.6 & 629 \\
\hline Rural & 0.5 & $0.7 !$ & 1.2 & $2.0 !$ & 1,574 \\
\hline$N$ & 96 & $579 !$ & 333 & 1,196 & 2,203 \\
\hline
\end{tabular}

* Denominator < 30 .

Table 5.21 Of those ever married, percent who have ever been pregnant (or whose spouse has ever been pregnant)

\begin{tabular}{|c|c|c|c|c|c|}
\hline \multirow[b]{2}{*}{ Category } & \multicolumn{2}{|c|}{$15-19$ year olds } & \multicolumn{2}{|c|}{$20-24$ year olds } & \multirow[b]{2}{*}{$\mathbf{N}$} \\
\hline & Male & Female & Male & Female & \\
\hline Total & 63.8 & 67.7 & 73.6 & 89.4 & 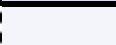 \\
\hline$N$ & 96 & 579 & 333 & 1,196 & 2,204 \\
\hline \multicolumn{6}{|l|}{ Province } \\
\hline Punjab & * & 74.9 & 74.1 & 88.6 & 810 \\
\hline Sindh & 65.8 & 65.9 & 75.5 & 91.1 & 729 \\
\hline NWFP & * & 51.1 & 70.4 & 88.8 & 370 \\
\hline Balochistan & * & 59.2 & 64.4 & 90.9 & 295 \\
\hline$N$ & 96 & 579 & 333 & 1,196 & 2,204 \\
\hline \multicolumn{6}{|l|}{ SES } \\
\hline Low & 65.5 & 68.2 & 70.0 & 90.1 & 631 \\
\hline Low-mid & * & 73.1 & 78.7 & 93.9 & 519 \\
\hline High-mid & * & 59.4 & 70.0 & 85.4 & 504 \\
\hline High & * & 65.4 & 64.9 & 88.9 & 450 \\
\hline$N$ & 92 & 560 & 311 & 1,141 & 2,104 \\
\hline \multicolumn{6}{|l|}{ Educational attainment } \\
\hline Never attended & * & 68.2 & 78.3 & 89.8 & 1,293 \\
\hline Less than primary & * & 68.5 & 61.1 & 92.6 & 272 \\
\hline Completed primary & 63.4 & 60.7 & 78.9 & 84.4 & 417 \\
\hline Completed secondary & * & * & 68.8 & 91.3 & 222 \\
\hline$N$ & 96 & 579 & 333 & 1,196 & 2,204 \\
\hline \multicolumn{6}{|l|}{ Residence } \\
\hline Urban & 53.2 & 66.8 & 67.1 & 87.6 & 630 \\
\hline Rural & 65.4 & 67.8 & 74.8 & 89.9 & 1,574 \\
\hline$N$ & 96 & 579 & 333 & 1,196 & 2,204 \\
\hline
\end{tabular}

\footnotetext{
* Denominator $<30$
} 
Table 5.22 Percent pregnant before age 20, of those aged 20-24 who were ever married

\begin{tabular}{|c|c|c|c|c|c|c|c|}
\hline \multirow[b]{2}{*}{ Category } & \multicolumn{2}{|c|}{ Rural } & \multicolumn{2}{|c|}{ Urban } & \multicolumn{2}{|c|}{ Total } & \multirow[b]{2}{*}{$\mathbf{N}$} \\
\hline & Male & Female : & Male & Female : & Male & Female : & \\
\hline Total & 13.0 & 48.5 & 3.3 & $23.2 !$ & 9.9 & $41.7 !$ & \\
\hline$N$ & 715 & $1,200 !$ & 559 & $784 !$ & 1,274 & 1,984 ! & 3,258 \\
\hline \multicolumn{8}{|l|}{ Province } \\
\hline Punjab & 12.0 & $43.0 !$ & 2.2 & $17.1 !$ & 8.8 & $35.8 !$ & 1,453 \\
\hline Sindh & 17.4 & $60.4 !$ & 4.6 & $30.8 !$ & 12.5 & 50.4 ! & 914 \\
\hline NWFP & 7.2 & 50.2 & 3.4 & $32.7 !$ & 6.3 & $47.7 !$ & 527 \\
\hline Balochistan & 14.0 & $53.9 !$ & 11.5 & $51.5 !$ & 13.6 & 53.6 & 359 \\
\hline$N$ & 715 & 1,200 & 559 & $784 i$ & 1,274 & 1,984 i & 3,258 \\
\hline \multicolumn{8}{|l|}{ SES } \\
\hline Low & 19.3 & $60.4 i$ & * & * & 19.2 & $60.0 !$ & 605 \\
\hline Low-mid & 15.5 & $53.6 !$ & 5.9 & $42.3 !$ & 14.7 & $53.2 !$ & 604 \\
\hline High-mid & 7.1 & $38.6 !$ & 4.9 & $35.0 !$ & 6.5 & $37.8 !$ & 782 \\
\hline High & 2.4 & $27.8 !$ & 2.8 & $18.2 !$ & 2.6 & 37.8 & 1,115 \\
\hline$N$ & 677 & 1,153 & 526 & $750 !$ & 1,203 & $21.3 !$ & 3,106 \\
\hline \multicolumn{8}{|l|}{ Educational attainment } \\
\hline Never attended & 23.6 & $58.5 !$ & 9.2 & $54.2 !$ & 21.5 & $58.1 '$ & 1,201 \\
\hline Less than primary & 14.1 & $45.0 !$ & 6.7 & $31.4 !$ & 12.0 & 42.3 & 336 \\
\hline Completed primary & 11.1 & $25.4 !$ & 4.2 & $23.9 !$ & 8.9 & $24.8 !$ & 839 \\
\hline Completed secondary & 6.3 & $17.8 !$ & 0.7 & 6.4 & 4.0 & 10.2 & 882 \\
\hline$N$ & 715 & $1,200 !$ & 559 & $784 !$ & 1,274 & $1,984 !$ & 3,258 \\
\hline
\end{tabular}

* Denominator $<30$ 
Table 5.23 Percent who received any antenatal care for their first birth, of those ever married who had a child

\begin{tabular}{|c|c|c|c|c|c|}
\hline \multirow[b]{2}{*}{ Category } & \multicolumn{2}{|c|}{$15-19$ year olds } & \multicolumn{2}{|c|}{$20-24$ year olds } & \multirow[b]{2}{*}{$\mathbf{N}$} \\
\hline & Male & Female : & Male & Female : & \\
\hline Total & 31.3 & $44.3 !$ & 49.9 & $50.6 !$ & \\
\hline$N$ & 35 & 293 & 194 & 986 & 1,507 \\
\hline \multicolumn{6}{|l|}{ Province } \\
\hline Punjab & * & 38.4 & 55.3 & $46.6 !$ & 566 \\
\hline Sindh & * & 54.8 & 49.9 & 55.0 & 504 \\
\hline NWFP & * & $42.8 ！$ & 31.1 & $56.0 !$ & 242 \\
\hline Balochistan & * & $43.4 !$ & 34.3 & 50.5 & 195 \\
\hline$N$ & 35 & 293 & 194 & $986 \vdots$ & 1,507 \\
\hline \multicolumn{6}{|l|}{ SES } \\
\hline Low & * & $34.1 !$ & 30.1 & $30.7 !$ & 421 \\
\hline Low-mid & * & 40.9 & 54.4 & 36.0 & 361 \\
\hline High-mid & * & 53.1 ! & 70.0 & $60.8 !$ & 348 \\
\hline High & * & $78.5 !$ & 70.3 & $86.7 !$ & 308 \\
\hline$N$ & 34 & $285 !$ & 176 & $944 \vdots$ & 1,438 \\
\hline \multicolumn{6}{|l|}{ Educational attainment } \\
\hline Never attended & * & 37.2 & 38.1 & $38.6 !$ & 925 \\
\hline Less than primary & * & 50.2 & 58.9 & 60.5 & 174 \\
\hline Completed primary & * & 79.1 & 47.1 & 77.6 & 255 \\
\hline Completed secondary & * & $90.0 !$ & 74.0 & $92.4:$ & 153 \\
\hline$N$ & 35 & $293 !$ & 194 & $986 !$ & 1,507 \\
\hline \multicolumn{6}{|l|}{ Residence } \\
\hline Urban & * & 70.9 & 66.4 & $77.9 !$ & 432 \\
\hline Rural & * & 40.3 ! & 47.6 & 44.6 & 1,075 \\
\hline$N$ & 35 & $293 !$ & 194 & $986 !$ & 1,507 \\
\hline
\end{tabular}

* Denominator $<30$. 
Table 5.24 Percent of first births at home, among those ever married who had a child

\begin{tabular}{|c|c|c|c|c|c|}
\hline \multirow[b]{2}{*}{ Category } & \multicolumn{2}{|c|}{ 15-19 year olds } & \multicolumn{2}{|c|}{ 20-24 year olds } & \multirow[b]{2}{*}{$\mathbf{N}$} \\
\hline & Male & Female : & Male & Female : & \\
\hline Total & 88.4 & $78.4 !$ & 72.7 & $70.0 !$ & \\
\hline$N$ & 35 & $292 \vdots$ & 194 & $986:$ & 1,507 \\
\hline \multicolumn{6}{|l|}{ Province } \\
\hline Punjab & * & $81.7 !$ & 75.4 & $72.6 !$ & 566 \\
\hline Sindh & * & 73.2 & 65.2 & $62.9 !$ & 504 \\
\hline NWFP & * & 71.2 & * & $68.7 !$ & 242 \\
\hline Balochistan & * & $86.9 !$ & * & $86.3 !$ & 195 \\
\hline$N$ & 35 & $292 ：$ & 194 & $986:$ & 1,507 \\
\hline \multicolumn{6}{|l|}{ SES } \\
\hline Low & * & $93.0 !$ & 81.7 & $85.2 !$ & 421 \\
\hline Low-mid & * & 70.8 & 70.6 & $80.5 !$ & 361 \\
\hline High-mid & * & $75.2 !$ & 66.3 & $67.7 !$ & 348 \\
\hline High & * & $49.9 !$ & 50.9 & $34.7 !$ & 308 \\
\hline$N$ & 34 & $284 !$ & 176 & $944:$ & 1,438 \\
\hline \multicolumn{6}{|l|}{ Educational attainment } \\
\hline Never attended & * & $80.6 !$ & 80.3 & $80.3 !$ & 925 \\
\hline Less than primary & * & 84.2 & * & $64.3 !$ & 174 \\
\hline Completed primary & * & $62.4 !$ & 72.6 & $48.5 !$ & 255 \\
\hline Completed secondary & * & *! & 72.2 & $27.6 !$ & 153 \\
\hline$N$ & 35 & $292 !$ & 194 & $986 !$ & 1,507 \\
\hline \multicolumn{6}{|l|}{ Residence } \\
\hline Urban & * & $64.7 !$ & 58.4 & $50.6 !$ & 432 \\
\hline Rural & * & 80.5 : & 74.7 & $74.2 !$ & 1,075 \\
\hline$N$ & 35 & $292 !$ & 194 & $986 !$ & 1,507 \\
\hline
\end{tabular}

* Denominator $<30$. 
Table 5.25 Mean desired number of children, among ever-married (who expressed gender preference)

\begin{tabular}{|c|c|c|c|c|c|}
\hline \multirow[b]{2}{*}{ Category } & \multicolumn{2}{|c|}{$15-19$ year olds } & \multicolumn{2}{|c|}{ 20-24 year olds } & \multirow[b]{2}{*}{$\mathbf{N}$} \\
\hline & Male & Female : & Male & Female : & \\
\hline Total & 4.2 & $4.0 !$ & 4.0 & $3.9 !$ & \\
\hline$N$ & 65 & $435 !$ & 274 & $972 \vdots$ & 1,746 \\
\hline \multicolumn{6}{|l|}{ Province } \\
\hline Punjab & * & $3.7 !$ & 3.6 & $3.6 i$ & 722 \\
\hline Sindh & * & 4.2 & 4.3 & 4.3 & 546 \\
\hline NWFP & * & $4.3 !$ & 4.2 & $3.6 !$ & 288 \\
\hline Balochistan & * & $4.9 !$ & 5.4 & $5.8 !$ & 190 \\
\hline$N$ & 65 & $435 !$ & 274 & $972 \vdots$ & 1,746 \\
\hline \multicolumn{6}{|l|}{ SES } \\
\hline Low & * & $4.4 !$ & 4.6 & $4.5 !$ & 457 \\
\hline Low-mid & * & $4.0 !$ & 4.2 & $4.0 !$ & 391 \\
\hline High-mid & * & $3.5 i$ & 3.5 & $3.5 i$ & 422 \\
\hline High & * & $3.5 i$ & 3.5 & $3.4 i$ & 400 \\
\hline$N$ & 63 & $422 !$ & 255 & $930 \vdots$ & 1,670 \\
\hline \multicolumn{6}{|l|}{ Educational attainment } \\
\hline Never attended & * & $4.3 i$ & 4.5 & $4.2 i$ & 965 \\
\hline Less than primary & * & 3.2 & 4.0 & $3.5:$ & 227 \\
\hline Completed primary & * & $3.3 !$ & 3.9 & $3.3 !$ & 350 \\
\hline Completed secondary & * & *! & 3.6 & $3.1 !$ & 204 \\
\hline$N$ & 65 & $435 !$ & 274 & $972 \vdots$ & 1,746 \\
\hline \multicolumn{6}{|l|}{ Residence } \\
\hline Urban & * & $3.6 !$ & 3.9 & $3.5 i$ & 540 \\
\hline Rural & 4.3 & $4.0 !$ & 4.0 & $4.0 !$ & 1,206 \\
\hline$N$ & 65 & $435 i$ & 274 & $972 !$ & 1,746 \\
\hline
\end{tabular}

* Denominator $<30$. 
Table 5.26 Percent currently using family planning, of those currently married

\begin{tabular}{|c|c|c|c|c|c|}
\hline \multirow[b]{2}{*}{ Category } & \multicolumn{2}{|c|}{$15-19$ year olds } & \multicolumn{2}{|c|}{$20-24$ year olds } & \multirow[b]{2}{*}{$\mathbf{N}$} \\
\hline & Male & Female : & Male & Female : & \\
\hline Total & 3.9 & $5.0 !$ & 4.5 & $12.4 !$ & \\
\hline$N$ & 96 & $567 \vdots$ & 331 & 1,181 & 2,175 \\
\hline \multicolumn{6}{|l|}{ Province } \\
\hline Punjab & * & $6.6 i$ & 3.9 & $14.7 !$ & 803 \\
\hline Sindh & 1.6 & $3.7 !$ & 5.4 & $11.6 !$ & 720 \\
\hline NWFP & * & $3.5:$ & 6.6 & $7.5 !$ & 361 \\
\hline Balochistan & * & $3.0:$ & 1.2 & $6.0 !$ & 291 \\
\hline$N$ & 96 & 567 & 331 & 1,181 & 2,175 \\
\hline \multicolumn{6}{|l|}{ SES } \\
\hline Low & 0 & $3.2 i$ & 2.3 & $6.1 i$ & 626 \\
\hline Low-mid & * & $2.2:$ & 4.0 & 11.2 & 509 \\
\hline High-mid & * & $5.6:$ & 3.8 & $15.1 !$ & 499 \\
\hline High & * & $16.2 !$ & 12.8 & $18.0 !$ & 443 \\
\hline$N$ & 92 & $549 !$ & 309 & 1,127 & 2,077 \\
\hline \multicolumn{6}{|l|}{ Educational attainment } \\
\hline Never attended & * & $2.6 !$ & 3.2 & $9.9 !$ & 1,280 \\
\hline Less than primary & * & 10.8 & 1.5 & 18.7 & 264 \\
\hline Completed primary & 9.0 & 9.5 & 5.0 & $19.1 !$ & 410 \\
\hline Completed secondary & * & * & 8.3 & $12.8 !$ & 221 \\
\hline$N$ & 96 & $567 !$ & 331 & 1,181 & 2,175 \\
\hline \multicolumn{6}{|l|}{ Residence } \\
\hline Urban & * & $14.8 '$ & 10.6 & $19.7 !$ & 621 \\
\hline Rural & 3.8 & $3.5:$ & 3.2 & $10.7 !$ & 1,554 \\
\hline$N$ & 96 & $567 i$ & 331 & 1,181 & 2,175 \\
\hline
\end{tabular}

* Denominator $<30$. 
Table 5.27 Percent who plan to use family planning in the future, of those currently married

\begin{tabular}{|c|c|c|c|c|c|}
\hline \multirow[b]{2}{*}{ Category } & \multicolumn{2}{|c|}{$15-19$ year olds } & \multicolumn{2}{|c|}{ 20-24 year olds } & \multirow[b]{2}{*}{$\mathbf{N}$} \\
\hline & Male & Female : & Male & Female : & \\
\hline Total & 42.4 & $49.8 !$ & 45.6 & $58.3 !$ & \\
\hline$N$ & 96 & 565 & 329 & 1,173 & 2,163 \\
\hline \multicolumn{6}{|l|}{ Province } \\
\hline Punjab & * & $64.5 !$ & 57.0 & $66.3 !$ & 801 \\
\hline Sindh & 38.9 & 38.4 & 39.7 & 45.2 & 715 \\
\hline NWFP & * & $41.0 !$ & 41.8 & $67.5 !$ & 356 \\
\hline Balochistan & * & $21.7 !$ & 13.5 & $22.1 !$ & 291 \\
\hline$N$ & 96 & 565 & 329 & 1,173 & 2,163 \\
\hline \multicolumn{6}{|l|}{ SES } \\
\hline Low & 33.6 & $45.0 !$ & 29.4 & $45.1 !$ & 623 \\
\hline Low-mid & * & 51.3 & 50.9 & 57.0 & 505 \\
\hline High-mid & * & $52.7 !$ & 57.8 & $64.0 !$ & 498 \\
\hline High & * & 55.2 & 50.5 & $73.6 !$ & 439 \\
\hline$N$ & 92 & $547 !$ & 307 & 1,119 & 2,065 \\
\hline \multicolumn{6}{|l|}{ Educational attainment } \\
\hline Never attended & * & $48.2 !$ & 31.8 & $52.9 !$ & 1,273 \\
\hline Less than primary & * & $57.5 !$ & 46.7 & $66.7 !$ & 266 \\
\hline Completed primary & 57.4 & 50.8 & 52.8 & $67.1 !$ & 406 \\
\hline Completed secondary & * & *! & 53.5 & $76.0 !$ & 218 \\
\hline$N$ & 96 & $565 !$ & 329 & $1,173 !$ & 2,163 \\
\hline \multicolumn{6}{|l|}{ Residence } \\
\hline Urban & * & $53.4 !$ & 52.5 & $65.4 !$ & 614 \\
\hline Rural & 38.1 & $49.2 !$ & 44.2 & $56.7 !$ & 1,549 \\
\hline$N$ & 96 & $565 !$ & 329 & $1,173 !$ & 2,163 \\
\hline
\end{tabular}

* Denominator $<30$.

Table 5.28 Method to be used, of currently married young people who intend to use family planning in the future

\begin{tabular}{|c|c|c|c|c|}
\hline \multirow[b]{2}{*}{ Family planning method } & \multicolumn{2}{|c|}{$15-19$ year olds } & \multicolumn{2}{|c|}{ 20-24 year olds } \\
\hline & Male & Female ! & Male & Female \\
\hline Pill & 55.2 & 19.7 & 34.1 & 22.6 \\
\hline Injectable & 30.7 & $24.5 i$ & 25.7 & 18.9 \\
\hline Female sterilization & 17.3 & $17.2 \vdots$ & 14.0 & 20.3 \\
\hline Condom & 15.5 & $4.3 !$ & 20.1 & 9.8 \\
\hline IUD & 9.1 & $8.4 i$ & 1.8 & 9.9 \\
\hline Undecided & 9.5 & $36.0 !$ & 24.1 & 28.0 \\
\hline$N$ & 45 & $253 !$ & 140 & 656 \\
\hline
\end{tabular}

Note: Multiple responses possible. 


\section{Tables Chapter 6}

Table 6.1 Number of communities by topography and irrigation, by province and residence

\begin{tabular}{|c|c|c|c|c|c|c|c|}
\hline \multirow[b]{2}{*}{ Category } & \multicolumn{4}{|c|}{ Province } & \multicolumn{2}{|c|}{ Residence } & \multirow[b]{2}{*}{ Total } \\
\hline & Punjab & Sindh & NWFP & $\begin{array}{l}\text { Baloch- } \\
\text { istan }\end{array}$ & Rural & Urban & \\
\hline \multicolumn{8}{|l|}{ Topography $^{a}$} \\
\hline Mountainous & 5 & 0 & 19 & 15 & 30 & 9 & 39 \\
\hline Plain & 106 & 67 & 22 & 15 & 119 & 91 & 210 \\
\hline River flooded plain & 5 & 1 & 0 & 3 & 5 & 4 & 9 \\
\hline Desert/drought -prone & 0 & 3 & 4 & 0 & 5 & 2 & 7 \\
\hline$N$ & 113 & 67 & 42 & 28 & 149 & 102 & 251 \\
\hline \multicolumn{8}{|c|}{ Source of irrigation in community } \\
\hline No agriculture & 36 & 22 & 7 & 7 & 2 & 70 & 72 \\
\hline Rain fed alone & 11 & 2 & 15 & 13 & 32 & 9 & 41 \\
\hline $\begin{array}{l}\text { Both, rain fed and irrigated } \\
\text { through artificial means }\end{array}$ & 18 & 3 & 11 & 4 & 31 & 5 & 36 \\
\hline $\begin{array}{l}\text { Irrigated through artificial } \\
\text { means alone }\end{array}$ & 47 & 40 & 10 & 4 & 85 & 16 & 101 \\
\hline$N$ & 112 & 67 & 43 & 28 & 150 & 100 & 250 \\
\hline
\end{tabular}

${ }^{a}$ Figures on topography have been generated through multiple responses.

Table 6.2 Community access to road and public transportation, by province and residence

\begin{tabular}{|c|c|c|c|c|c|c|c|}
\hline \multirow[b]{2}{*}{ Transportation issues } & \multicolumn{4}{|c|}{ Province } & \multicolumn{2}{|c|}{ Residence } & \multirow[b]{2}{*}{ Total } \\
\hline & Punjab & Sindh & NWFP & $\begin{array}{c}\text { Baloch- } \\
\text { istan }\end{array}$ & Rural & Urban & \\
\hline \multicolumn{8}{|l|}{ Distance to metal road } \\
\hline Road inside & 93 & 50 & 30 & 15 & 93 & 95 & 188 \\
\hline $1-3 \mathrm{~km}$ & 16 & 11 & 10 & 4 & 36 & 5 & 41 \\
\hline 4 or more km & 4 & 8 & 3 & 9 & 22 & 2 & 24 \\
\hline$N$ & 113 & 69 & 43 & 28 & 151 & 102 & 253 \\
\hline \multicolumn{8}{|c|}{ Availability of public transportation within community ${ }^{a}$} \\
\hline No transportation & 17 & 9 & 2 & 1 & 25 & 4 & 29 \\
\hline Bus/wagon & 55 & 45 & 20 & 13 & 67 & 66 & 133 \\
\hline Tonga & 60 & 25 & 13 & 5 & 58 & 45 & 103 \\
\hline Motorbike rickshaw & 57 & 30 & 12 & 8 & 41 & 66 & 107 \\
\hline Pickup & 32 & 33 & 30 & 11 & 48 & 58 & 106 \\
\hline Other & 19 & 23 & 7 & 1 & 27 & 23 & 50 \\
\hline$N$ & 113 & 69 & 44 & 28 & 152 & 102 & 254 \\
\hline
\end{tabular}

${ }^{a}$ Figures on public transport have been generated through multiple responses. Public transport is restricted to access that is within the village or community itself and does not include those within two kilometers. 
Table 6.3 Number of communities with access to various facilities and amenities, by province and residence

\begin{tabular}{|c|c|c|c|c|c|c|c|}
\hline \multirow[b]{2}{*}{ Facilities/amenities } & \multicolumn{4}{|c|}{ Province } & \multicolumn{2}{|c|}{ Residence } & \multirow[b]{2}{*}{ Tota } \\
\hline & Punjab & Sindh & NWFP & $\begin{array}{r}\text { Baloch- } \\
\text { istan }\end{array}$ & Rural & Urban & \\
\hline \multicolumn{8}{|l|}{ Access to facilities } \\
\hline Road & 93 & 50 & 30 & 15 & 93 & 95 & 188 \\
\hline Piped water supply & 34 & 31 & 29 & 13 & 30 & 77 & 107 \\
\hline Electricity & 106 & 62 & 41 & 22 & 130 & 102 & 231 \\
\hline Natural gas & 30 & 33 & 8 & 6 & 8 & 69 & 77 \\
\hline Sewerage system & 30 & 34 & 8 & 4 & 18 & 58 & 76 \\
\hline Telephone at home & 78 & 45 & 35 & 16 & 77 & 97 & 174 \\
\hline $\mathrm{PCO}$ & 56 & 34 & 14 & 11 & 31 & 84 & 115 \\
\hline Bank & 15 & 17 & 6 & 7 & 6 & 39 & 45 \\
\hline Post office & 38 & 21 & 16 & 6 & 45 & 36 & 81 \\
\hline Factory & 15 & 17 & 3 & 4 & 12 & 27 & 39 \\
\hline$N$ & 113 & 69 & 43 & 28 & 151 & 102 & 253 \\
\hline \multicolumn{8}{|c|}{ Number of facilities available } \\
\hline None & 5 & 7 & 3 & 3 & 18 & 0 & 18 \\
\hline One to two facilities & 38 & 16 & 11 & 11 & 74 & 2 & 76 \\
\hline $\begin{array}{l}\text { Three or more } \\
\text { facilities }\end{array}$ & 70 & 46 & 30 & 14 & 60 & 100 & 160 \\
\hline$N$ & 113 & 69 & 44 & 28 & 152 & 102 & 254 \\
\hline
\end{tabular}


Table 6.4 Number of communities by access to health facilities, by province and residence

\begin{tabular}{|c|c|c|c|c|c|c|c|}
\hline \multirow[b]{2}{*}{ Health facilities } & \multicolumn{4}{|c|}{ Province } & \multicolumn{2}{|c|}{ Residence } & \multirow[b]{2}{*}{ Total } \\
\hline & Punjab & Sindh & NWFP & $\begin{array}{r}\text { Baloch- } \\
\text { istan }\end{array}$ & Rural & Urban & \\
\hline \multicolumn{8}{|l|}{ Basic Health Unit } \\
\hline Inside & 23 & 16 & 8 & 14 & 37 & 24 & 61 \\
\hline $1-4 \mathrm{~km}$ & 44 & 13 & 14 & 2 & 47 & 26 & 73 \\
\hline $5 \mathrm{~km} \mathrm{\&} \mathrm{more}$ & 34 & 15 & 14 & 7 & 59 & 11 & $\overline{70}$ \\
\hline$N$ & 101 & 44 & 36 & 23 & 143 & 102 & 204 \\
\hline \multicolumn{8}{|c|}{ Rural Health Center } \\
\hline Inside & 14 & 12 & 4 & 8 & 12 & 26 & 38 \\
\hline $1-4 \mathrm{~km}$ & 32 & 6 & 4 & 3 & 27 & 18 & 45 \\
\hline $5 \mathrm{~km} \mathrm{\&} \mathrm{more}$ & 41 & 23 & 23 & 10 & 86 & 11 & 97 \\
\hline$N$ & 87 & 41 & 31 & 21 & 125 & 55 & 180 \\
\hline \multicolumn{8}{|c|}{ Mother and Child Health Clinic } \\
\hline Inside & 21 & 18 & 7 & 9 & 12 & 43 & 55 \\
\hline $1-4 \mathrm{~km}$ & 41 & 10 & 9 & 3 & 23 & 40 & 63 \\
\hline $5 \mathrm{~km} \mathrm{\&} \mathrm{more}$ & 46 & 31 & 23 & 11 & 100 & 11 & 111 \\
\hline$N$ & 108 & 59 & 39 & 23 & 135 & 94 & 229 \\
\hline \multicolumn{8}{|l|}{ Private doctor } \\
\hline Inside & 45 & 41 & 9 & 10 & 27 & 78 & 105 \\
\hline $1-4 \mathrm{~km}$ & 29 & 12 & 13 & 5 & 39 & 20 & 59 \\
\hline $5 \mathrm{~km} \&$ more & 39 & 16 & 21 & 11 & 84 & 3 & 87 \\
\hline$N$ & 113 & 69 & 43 & 26 & 150 & 101 & 251 \\
\hline \multicolumn{8}{|c|}{ Homeopathic doctor } \\
\hline Inside & 48 & 23 & 14 & 8 & 24 & 69 & 93 \\
\hline $1-4 \mathrm{~km}$ & 26 & 15 & 8 & 2 & 24 & 27 & 51 \\
\hline $5 \mathrm{~km} \&$ more & 39 & 25 & 21 & 14 & 96 & 3 & 99 \\
\hline$N$ & 113 & 63 & 43 & 24 & 144 & 99 & 243 \\
\hline \multicolumn{8}{|l|}{ Hakim } \\
\hline Inside & 55 & 20 & 7 & 8 & 28 & 62 & 90 \\
\hline $1-4 \mathrm{~km}$ & 29 & 12 & 11 & 4 & 32 & 24 & 56 \\
\hline $5 \mathrm{~km} \&$ more & 26 & 26 & 24 & 13 & 81 & 8 & 89 \\
\hline$N$ & 110 & 58 & 42 & 25 & 141 & 94 & 235 \\
\hline \multicolumn{8}{|c|}{ Chemist/ medical store } \\
\hline Inside & 44 & 41 & 26 & 14 & 40 & 85 & 125 \\
\hline $1-4 \mathrm{~km}$ & 37 & 14 & 6 & 3 & 43 & 17 & 60 \\
\hline $5 \mathrm{~km} \&$ more & 31 & 14 & 12 & 10 & 67 & & 67 \\
\hline$N$ & 101 & 44 & 36 & 23 & 143 & 102 & 204 \\
\hline
\end{tabular}


Table 6.5 Number of communities that seek medical treatment primarily from various health service providers, by province and residence

\begin{tabular}{|c|c|c|c|c|c|c|c|}
\hline \multirow[b]{2}{*}{ Health provider } & \multicolumn{4}{|c|}{ Province } & \multicolumn{2}{|c|}{ Residence } & \multirow[b]{2}{*}{ Total } \\
\hline & Punjab & Sindh & NWFP & Balochistan ! & Rural & Urban : & \\
\hline Public health facility & 67 & 47 & 33 & $20 !$ & 100 & $67 !$ & 167 \\
\hline Private doctor & 81 & 63 & 34 & $14 \vdots$ & 106 & 86 & 192 \\
\hline Homeopath or hakim & 15 & 10 & 6 & $2 !$ & 15 & $18 !$ & 33 \\
\hline Chemist & 5 & 4 & 4 & $0 \vdots$ & 9 & 4 & 13 \\
\hline Total & 113 & 69 & 44 & $28 !$ & 152 & $102 !$ & 254 \\
\hline
\end{tabular}

Multiple responses were possible.

Table 6.6 Number of communities with single sex and mixed schools inside/ within two kilometers by province and residence

\begin{tabular}{|c|c|c|c|c|c|c|c|}
\hline \multirow{2}{*}{ Level of schools } & \multicolumn{4}{|c|}{ Province } & \multicolumn{2}{|c|}{ Residence } & \multirow{2}{*}{ Total } \\
\hline & Punjab & Sindh & NWFP & Balochistani & Rural & Urban' & \\
\hline \multicolumn{8}{|l|}{ Maktab } \\
\hline Boys & 15 & 8 & 4 & $4:$ & 22 & $9 !$ & 31 \\
\hline Girls & 2 & 1 & 2 & 0 & 1 & $4:$ & 5 \\
\hline Mixed & 2 & 7 & 2 & $0:$ & 6 & $5 !$ & 11 \\
\hline \multicolumn{8}{|l|}{ Primary only } \\
\hline Boys & 70 & 44 & 36 & 16 & 114 & 52 & 166 \\
\hline Girls & 67 & 21 & 26 & 16 & 82 & $48:$ & 130 \\
\hline Mixed & 43 & 9 & 10 & 7 & 31 & $38 !$ & 69 \\
\hline \multicolumn{8}{|l|}{ Middle } \\
\hline Boys & 21 & 10 & 13 & $5:$ & 29 & 20 & 49 \\
\hline Girls & 20 & 7 & 22 & $4:$ & 31 & $22 !$ & 53 \\
\hline Mixed & 19 & 10 & 7 & 4 & 13 & 27 & 40 \\
\hline \multicolumn{8}{|l|}{ Secondary } \\
\hline Boys & 43 & 22 & 24 & 13 & 36 & $66 !$ & 102 \\
\hline Girls & 30 & 13 & 13 & 10 & 14 & 52 & 66 \\
\hline Mixed & 26 & 18 & 6 & 4 & 10 & 44 ! & 54 \\
\hline \multicolumn{8}{|c|}{ Higher secondary or above } \\
\hline Boys & 18 & 11 & 9 & 0 & 15 & $23 !$ & 38 \\
\hline Girls & 13 & 4 & 3 & 2 & 8 & 14 & 22 \\
\hline Mixed & 6 & 8 & 3 & $2:$ & 3 & $16 !$ & 19 \\
\hline Total Communities & 113 & 67 & 43 & 28 & : 149 & 102 & 251 \\
\hline
\end{tabular}

Multiple responses were possible. 
Table 6.7 Number of communities with government, private and NGO schools inside/ within two kilometers by province and residence

\begin{tabular}{|c|c|c|c|c|c|c|c|}
\hline \multirow[b]{2}{*}{ Level of schools } & \multicolumn{4}{|c|}{ Province } & \multicolumn{2}{|c|}{ Residence } & \multirow[t]{2}{*}{ Total } \\
\hline & Punjab & Sindh & NWFP & Balochista & Rural & Urban & \\
\hline \multicolumn{8}{|l|}{ Maktab } \\
\hline Govt & 11 & 8 & 6 & 4 & 19 & $10 !$ & 29 \\
\hline Pvt & 6 & 7 & 3 & 0 & 9 & $7 !$ & 16 \\
\hline NGO & 1 & 1 & 1 & 0 & 2 & $1 !$ & 3 \\
\hline \multicolumn{8}{|l|}{ Primary only } \\
\hline Govt & 93 & 48 & 37 & $24 !$ & 134 & $68 !$ & 202 \\
\hline Pvt & 37 & 7 & 8 & $3:$ & 19 & $36 !$ & 55 \\
\hline NGO & 5 & 3 & 1 & 4 & 4 & $9 !$ & 13 \\
\hline \multicolumn{8}{|l|}{ Middle } \\
\hline Govt & 33 & 17 & 26 & 6 & 50 & $32 !$ & 82 \\
\hline Pvt & 20 & 10 & 7 & $6:$ & 14 & $29 !$ & 43 \\
\hline NGO & 0 & 1 & 0 & 0 & 0 & $1 i$ & 1 \\
\hline \multicolumn{8}{|l|}{ Secondary } \\
\hline Govt & 52 & 29 & 27 & 14 & 42 & $80 \vdots$ & 122 \\
\hline Pvt & 27 & 17 & 7 & $4 !$ & 11 & $44 !$ & 55 \\
\hline NGO & 2 & 1 & 0 & 0 & 1 & $2 !$ & 3 \\
\hline Higher secondary or above & & & & 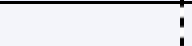 & & 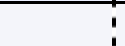 & \\
\hline Govt & 23 & 15 & 9 & 4 & 18 & $33 !$ & 51 \\
\hline Pvt & 7 & 5 & 4 & $0:$ & 4 & $12:$ & 16 \\
\hline NGO & 2 & 1 & 0 & $0:$ & 1 & $2 !$ & 3 \\
\hline Total Communities & 113 & 67 & 43 & 28 & 149 & $102 !$ & 251 \\
\hline
\end{tabular}

Multiple responses were possible.

Table 6.8 Distribution of communities by affiliation with other NGOs, by province and residence

\begin{tabular}{|c|c|c|c|c|c|c|c|}
\hline & \multicolumn{3}{|c|}{ Province } & \multicolumn{3}{|c|}{ Residence } & \multirow[b]{2}{*}{ Total } \\
\hline & Punjab & Sindh & NWFP & $\begin{array}{r}\text { Baloch- } \\
\text { istan }\end{array}$ & Rural & Urban : & \\
\hline Affiliation with any NGO & 32 & 23 & 21 & $10 \vdots$ & 40 & $46 !$ & 86 \\
\hline$N$ & 113 & 69 & 44 & $28 \vdots$ & 152 & $\begin{array}{r}102 \\
\vdots \\
\end{array}$ & 254 \\
\hline \multicolumn{8}{|l|}{ Types of NGOs affiliated with: } \\
\hline Independent & 29 & 19 & 16 & $5 ;$ & 27 & $42 i$ & 69 \\
\hline $\begin{array}{l}\text { Local/ district/ provincial NGO } \\
\text { (including those affiliated with } \\
\text { local government departments } \\
\text { and not other NGOs) }\end{array}$ & 1 & 2 & 0 & 3 & 4 & $2 \vdots$ & 6 \\
\hline National NGO & 0 & 3 & 3 & 3 & 7 & $2 !$ & 9 \\
\hline International NGO & 5 & 1 & 1 & $3 i$ & 6 & $4 i$ & 10 \\
\hline$N$ & 31 & 22 & 20 & $10 !$ & 38 & $45 !$ & 83 \\
\hline
\end{tabular}


Table 6.9 Distribution of communities by who benefits from the work of NGOs, by province and residence

\begin{tabular}{|c|c|c|c|c|c|c|c|}
\hline \multirow[b]{2}{*}{ Beneficiary } & \multicolumn{4}{|c|}{ Province } & \multicolumn{2}{|c|}{ Residence } & \multirow[b]{2}{*}{ Tota } \\
\hline & Punjab & Sindh & NWFP & $\begin{array}{r}\text { Baloch- } \\
\text { istan }\end{array}$ & Rural & Urban & \\
\hline Whole community & 25 & 18 & 20 & 7 & 32 & 38 & 70 \\
\hline Community men & 2 & 2 & 2 & 0 & 5 & 1 & 6 \\
\hline Community women & 0 & 0 & 0 & 1 & 0 & 1 & 1 \\
\hline Young males (<25 years) & 4 & 1 & 1 & 5 & 2 & 9 & 11 \\
\hline Young females ( $<25$ year) & 3 & 2 & 1 & 4 & 2 & 8 & 10 \\
\hline Others & 6 & 5 & 0 & 2 & 6 & 7 & 13 \\
\hline$N$ & 31 & 22 & 20 & 10 & 38 & 45 & 83 \\
\hline
\end{tabular}

Table 6.10 NGO activities in communities, by province and residence

\begin{tabular}{|c|c|c|c|c|c|c|c|}
\hline \multirow[b]{2}{*}{ Activities of NGOs } & \multicolumn{3}{|c|}{ Province } & 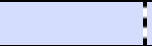 & \multicolumn{2}{|c|}{ Residence } & \multirow[b]{2}{*}{ Total } \\
\hline & Punjab & Sindh & NWFP & $\begin{array}{r}\text { Baloch- : } \\
\text { istan : }\end{array}$ & Rural & Urban : & \\
\hline Community development & 21 & 16 & 15 & $6 !$ & 32 & $26 !$ & 58 \\
\hline Religious activities & 6 & 3 & 3 & 0 & 3 & $9:$ & 12 \\
\hline $\begin{array}{l}\text { Games/sports } \\
\text { Informal education/ vocational }\end{array}$ & 2 & 0 & 2 & $3 !$ & 4 & $3 !$ & 7 \\
\hline education & 7 & 3 & 1 & $2 !$ & 5 & $8:$ & 13 \\
\hline Formal education & 9 & 4 & 6 & $7 !$ & 12 & $14 !$ & 26 \\
\hline Health/family planning & 10 & 6 & 4 & 5 & 8 & 17 & 25 \\
\hline Provision of micro credit & 4 & 0 & 0 & 0 & 2 & 2 & 4 \\
\hline Others & 8 & 8 & 5 & $3 !$ & 8 & $16 "$ & 24 \\
\hline$N$ & 32 & 22 & 20 & $10 !$ & 39 & 45 & 84 \\
\hline
\end{tabular}

Note: Generated through multiple responses. 

APPENDICES 


\section{Appendix I SAMPLING DESIGN}

\section{Universe}

The universe of the AYP consists of all urban and rural areas in the four provinces, as defined by the 1998 population census, and changes made thereafter by provincial governments. Military restricted areas and protected areas have been excluded from the scope of the survey. The population of the excluded areas constitutes about two percent of the total population of Pakistan.

\section{Sample frame}

The Federal Bureau of Statistics (FBS) uses different sampling frames for urban and rural areas. For urban areas, the FBS has developed its own urban area frame, using Quick Count Record Survey techniques. Following this frame, all cities and towns in the urban domain have been divided into small compact enumeration blocks (EBs). Each EB is comprised of 200-250 households, and has been classified into low, middle, and high income groups, keeping in view the standard of the majority of households. This frame was updated in 1995. It has been used for drawing samples from the urban areas of the universe. With regard to the rural areas, the list of villages, mouzas, and dehs outlined in the 1998 population census was used as the sampling frame. There are 22,800 EBs in the urban frame and 50,588 villages in the rural frame.

\section{Sample design}

A two-staged stratified random sample design was adopted for the survey.

\section{Stratification plan}

In the urban domain of this survey each of the large units (Karachi, Lahore, Gujranwala, Faisalabad, Rawalpindi, Multan, Sialkot, Sargodha, Hyderabad, Peshawar, Quetta, and Islamabad) are treated as independent strata. Each of these cities is further stratified according to low, middle, and high income groups in respect to each enumeration block. After excluding the population of large cities, the remaining urban population in each defunct administrative division in all provinces is treated as an independent stratum.

With respect to the rural areas, the population of each defunct administrative division in Punjab, Sindh, NWFP, and Balochistan provinces is grouped together to form a stratum. Thus each division in rural areas is treated as a separate stratum. 


\section{Selection of primary sampling units}

The EBs demarcated as part of the urban sampling frame and the list of villages, mouzas, and dehs prepared by the Population Census Organization at the time of the 1998 census have been taken as PSUs. Sample PSUs from each stratum/sub-stratum have been selected with probability proportionate to size. The number of households and the size of the population have been considered as a measure of size pertaining to urban and rural domains respectively.

\section{Selection of secondary sampling snits}

Households have been considered as secondary sampling units (SSUs) in urban and rural areas. Based on an actual listing of households undertaken in each sample PSU, specified number of households were selected from each rural and urban sample area, adopting systematic sampling techniques with a random start.

\section{Sample size and its allocation}

Keeping in mind the level of estimates required, the range of the study variables, and cost constraints, a sample of 254 PSUs was considered sufficient for this survey. The breakdown of primary and secondary sampling units follows:

\begin{tabular}{lrrrrrr}
\hline & \multicolumn{3}{c}{ Sample PSUs } & \multicolumn{3}{c}{ Sample SSUs } \\
\cline { 2 - 7 } Province & Urban & Rural & Total & Urban & Rural & Total \\
\hline Punjab & 45 & 68 & 113 & 862 & 1,366 & 2,228 \\
Sindh & 32 & 37 & 69 & 580 & 694 & 1,274 \\
NWFP & 15 & 29 & 44 & 272 & 531 & 803 \\
Balochistan & 10 & 18 & 28 & 190 & 344 & 534 \\
Total & 102 & 152 & 254 & 1,904 & 2,935 & 4,839 \\
\hline
\end{tabular}




\section{Appendix II CONSTRUCTION OF THE SOCIOECONOMIC StATUS INDEX}

Following recent arguments that an asset index can serve as reliable proxy for a household's socioeconomic status, ${ }^{29}$ the AYP used 29 questions from the household survey that pertained to household possessions and amenities. These variables served as the inputs to a principal components analysis. ${ }^{30}$ Twenty-eight components were generated; of these, the first component explained 20.29 percent of the variance. The first eigen value was 5.9 and the second was 2.2. Since there are two eigen values greater than one, there is an indication that the "co-movement" of the assets is explained by more than one factor. However, following the lead of Filmer and Pritchett, 31 we assume that the first component can reasonably be interpreted as a household's socioeconomic status. Therefore, the first component was scored and the weighted households were divided into quartiles of approximately equal size. The household socioeconomic status was then matched to the adolescent survey; since this variable was created at the household level, the adolescent respondents are not evenly distributed across the quartiles.

Responses to the following 29 questions contributed to the construction of the socioeconomic variable:

- Does household own dwelling?

- Is there a separate room for cooking?

- Is there a latrine-pour or flush?

- Is the main entrance to dwelling a gate?

- Is the roof constructed from cement, mixed concrete, T-iron girder, or tin/metal?

- Is the floor constructed from cement, mixed concrete, or bricks?

- Are the walls constructed from cement, mixed concrete, or stone?

${ }^{29}$ Filmer, Deon and Lant Pritchett. "The Effect of Household Wealth on Educational Attainment: Evidence from 35 Countries." Population and Development Review, 25(1): 85-120, March 1999; Kenneth A. Bollen, Jennifer L. Glanville, and Guy Stecklov. "Economic status proxies in studies of fertility in developing countries: Does the measure matter?" Population Studies, 56(1): 81-96, March 2002.

${ }^{30}$ Stata 7 User's Guide, Volume 1. "Principal component and factor analysis." College Station, TX: Stata Press. Pp. 505-526.

31 Filmer and Pritchett. 2002. p.89. 
- Does the household drinking water come from a government supply inside house or from a hand pump inside house?

- Are there more than 0.25 rooms per resident?

- Does the household have electricity?

- Does the household have a telephone?

- Does the household have natural gas that is piped or from an LPG gas cylinder?

- Does the household have a bicycle?

- Does the household have a motorcycle?

- Does the household have a car or van?

- Does the household have a radio?

- Does the household have a television?

- Does the household have a satellite dish/cable?

- Does the household have a VCR?

- Does the household have a refrigerator?

- Does the household have a computer?

- Does the household own any agricultural land?

- Does the household own any poultry?

- Does the household own any goats or sheep?

- Does the household own any cattle?

- Does the household own any buffalo?

- Does the household own any oxen?

- Does the household own any camels?

- Does the household own any other livestock? 


\section{Appendix III RESPONSE RATES}

A response rate of 75 percent was achieved for individual interviews with young people, but it differed by sex and educational attainment, as shown in the table. Responses by females outnumber males across all provinces and urban/rural residence. Those males who were interviewed did not differ substantively, except that they were slightly younger and better educated than those who were not interviewed.

Response rates by characteristics of respondents

\begin{tabular}{|c|c|c|c|c|c|c|c|}
\hline \multirow[b]{2}{*}{ Category } & \multicolumn{2}{|c|}{$15-19$ year olds } & \multicolumn{2}{|c|}{$20-24$ year olds } & \multicolumn{2}{|c|}{ Total } & \multirow[b]{2}{*}{$\mathbf{N}$} \\
\hline & Male & Female : & Male & Female : & Male & Female & \\
\hline Total & 69.1 & 83.4 & 62.7 & $81.6 !$ & 66.4 & 82.6 & \\
\hline$N$ & 2,871 & 3,186 & 2,151 & 2,552 & 5,022 & 5,738 & 10,760 \\
\hline \multicolumn{8}{|l|}{ Province } \\
\hline Punjab & 68.3 & 81.7 & 59.5 & 79.6 & 64.5 & 80.7 & 4,794 \\
\hline Sindh & 69.9 & $82.1 !$ & 67.9 & $81.8 !$ & 69.0 & 81.9 & 2,995 \\
\hline NWFP & 71.8 & $84.7 !$ & 63.2 & $84.1 !$ & 68.6 & 84.4 & 1,729 \\
\hline Balochistan & 66.8 & $90.8:$ & 61.0 & $86.8 !$ & 64.3 & 89.2 & 1,242 \\
\hline$N$ & 2,871 & $3,186 !$ & 2,151 & $2,552 ：$ & 5,022 & 5,738 & 10,760 \\
\hline \multicolumn{8}{|l|}{ SES } \\
\hline Low & 66.9 & $83.8 !$ & 63.5 & $82.8 !$ & 65.4 & 83.4 & 1,850 \\
\hline Low-mid & 70.9 & 81.9 & 61.5 & 79.0 & 67.0 & 80.6 & 2,051 \\
\hline High-mid & 71.1 & 83.1 ' & 63.3 & $83.7 !$ & 67.8 & 83.3 & 2,696 \\
\hline High & 69.1 & $84.3 !$ & 62.6 & 81.1 ; & 66.4 & 82.8 & 3,703 \\
\hline$N$ & 2,765 & 3,046 & 2,055 & 2,434 & 4,820 & 5,480 & 10,300 \\
\hline \multicolumn{8}{|l|}{ Educational attainment } \\
\hline Never attended & 60.7 & 81.8 & 55.7 & 81.4 & 58.4 & 81.6 & 3,844 \\
\hline Less than primary & 60.6 & $88.0 !$ & 60.0 & $85.4 !$ & 60.3 & 87.1 & 1,045 \\
\hline Completed primary & 71.4 & $83.7 !$ & 62.3 & 82.6 & 68.4 & 83.3 & 3,660 \\
\hline Completed secondary & 76.9 & $84.7 !$ & 68.4 & 80.0 & 72.1 & 82.0 & 2,211 \\
\hline$N$ & 2,871 & $3,186 !$ & 2,151 & $2,552 ；$ & 5,022 & 5,738 & 10,760 \\
\hline \multicolumn{8}{|l|}{ Marital status } \\
\hline Never married & 69.4 & $83.6 !$ & 62.1 & $82.0 ；$ & 66.7 & 83.2 & 7,812 \\
\hline Ever married & 64.4 & $82.9 !$ & 64.1 & $81.6 !$ & 64.1 & 82.0 & 2,810 \\
\hline$N$ & 2,866 & $3,172 !$ & 2,137 & $2,547 !$ & 5,003 & 5,719 & 10,722 \\
\hline \multicolumn{8}{|l|}{ Residence } \\
\hline Rural & 68.3 & $84.4 i$ & 62.4 & $82.6 !$ & 65.7 & 83.6 & 6,287 \\
\hline Urban & 70.2 & 81.9 & 63.1 & $80.1 ；$ & 67.2 & 81.1 & 4,473 \\
\hline$N$ & 2,871 & 3,186 & 2,151 & 2,552 & 5,022 & 5,738 & 10,760 \\
\hline
\end{tabular}




\section{Appendix IV \\ LIST OF STAFF INVOLVED IN THE SURVEY}

\author{
Main Trainers \\ Minhaj ul Haque \\ Mumraiz Khan \\ Munawar Sultana \\ Tahira Perveen \\ Wajahat Raza Khan \\ Data Processing \\ Irfan Masood \\ In-charge data entry \\ Muhammad Rehan Niazi \\ Quality data editor \\ Danish Hasan Khan \\ Data entry operator
}

\section{Field Staff in Balochistan}

Abdul Ghafoor Orakzai

Interviewer

Abdul Rehman

Interviewer

Agha Hassan

Interviewer

Gul Noor Bugti

Interviewer

Haji Akhtar Muhammad

Interviewer

Hameed Khan

Logistic In-charge

\author{
Training Logistics \\ Ashfa Hashmi \\ Nayyer Farooq \\ Mohammad Khalil \\ Wajahat Raza Khan
}

\author{
Saadia Habib \\ Data entry operator \\ Wisal Khan \\ Data entry operator \\ Waheed Altaf Abbasi \\ Data entry operator
}

Khair-un-Nissa

Interviewer

Muhammad Ayub Akhter

Provincial Coordinator

Muhammad Imran Khan

Logistic In-charge

Nasira Gul

Interviewer

Naveeda Hayat

Interviewer

Nazia Balouch

Interviewer
Editing and Quality Check

Ashfa Hashmi

Nayyer Farooq

Nadia Mumtaz

Shagufta Naheed

Rukhsana Kausar

Data entry operator

Shahid Mehmood Abassi

Data entry operator

Khurram Shehzad

Data entry operator

Sadia Haider

Interviewer

Samina Saeed

Supervisor

Syed Muhammad Jaffer

Interviewer

Tahira Shahwani

Supervisor

Zubaida Mangel

Interviewer 
ADOLESCENTS AND YOUTH IN PAKISTAN 2001-2002: A NATIONALLY REPRESENTATIVE SURVEY

\section{Field Staff in Punjab}

\begin{tabular}{|c|c|c|}
\hline Ambreen Gull & Khizar Hayat & Rukhasna Kausar \\
\hline Supervisor & Interviewer & Interviewer \\
\hline Aneela Khan & Khurram Shehzad & Safi Haider \\
\hline Interviewer & Interviewer & Logistic In charge \\
\hline Aneela Sardar & Mohammad Aashiq & Saira Jehangiri \\
\hline Interviewer & Logistic In-charge & Interviewer \\
\hline Anjum Seemab & Mohammad Haseeb & Sajeda Naheed \\
\hline Supervisor & Interviewer & Supervisor \\
\hline Arshad Iqbal & Muhammad Jahanzeb & Saqib Shehzad Akhter \\
\hline Interviewer & Interviewer & Logistic In-charge \\
\hline Azra Jabeen & Muhammad Zaheer & Shaheen Islam \\
\hline Interviewer & Logistic In-charge & Supervisor \\
\hline Azra Naureen & Nageena Shaheen & Shahid Bashir \\
\hline Interviewer & Interviewer & Interviewer \\
\hline Farhana Leghari & Naseem Raza & Shazia Rafaq \\
\hline Supervisor & Interviewer & Logistic In-charge \\
\hline Farhana Qadir & Nilofer Ali & Shehzad Ahmed \\
\hline Interviewer & Interviewer & Interviewer \\
\hline Farida Naeem & Noshaba Manzoor & Sultan Muhammad \\
\hline Interviewer & Interviewer & Logistic In-charge \\
\hline Ghazala Bibi & Rafeeq Ahemd & Tanveer Akhter \\
\hline Interviewer & Interviewer & Interviewer \\
\hline Imrana Jabeen & Raja Nasir Aziz & Tanzeela Shah \\
\hline Interviewer & Interviewer & Interviewer \\
\hline Irum Baloch & Rizwan Baig & Tariq Mehmood \\
\hline Interviewer & Logistic In-charge & Interviewer \\
\hline $\begin{array}{l}\text { Khadija Yasmeen } \\
\text { Interviewer }\end{array}$ & $\begin{array}{l}\text { Rubina Hassan } \\
\text { Interviewer }\end{array}$ & $\begin{array}{l}\text { Yousuf Jamal } \\
\text { Interviewer }\end{array}$ \\
\hline
\end{tabular}




\section{Field Staff in NWFP}

\begin{tabular}{|c|c|}
\hline $\begin{array}{l}\text { Abdul Wadood } \\
\text { Interviewer }\end{array}$ & $\begin{array}{l}\text { Rehmat-Ullah Jaan } \\
\text { Interviewer }\end{array}$ \\
\hline $\begin{array}{l}\text { Ameer Khan } \\
\text { Provincial Coordinator }\end{array}$ & $\begin{array}{l}\text { Roshi Javed } \\
\text { Interviewer }\end{array}$ \\
\hline $\begin{array}{l}\text { Bakht Muhammad } \\
\text { Interviewer }\end{array}$ & $\begin{array}{l}\text { Sabeena Gul } \\
\text { Interviewer }\end{array}$ \\
\hline $\begin{array}{l}\text { Fazli Wadood } \\
\text { Logistic In-charge }\end{array}$ & $\begin{array}{l}\text { Sabeena Shaheen } \\
\text { Supervisor }\end{array}$ \\
\hline $\begin{array}{l}\text { Huma Naz Khan } \\
\text { Interviewer }\end{array}$ & $\begin{array}{l}\text { Sadia Gul } \\
\text { Interviewer }\end{array}$ \\
\hline $\begin{array}{l}\text { Humaira Iqbal } \\
\text { Interviewer }\end{array}$ & $\begin{array}{l}\text { Said Shah } \\
\text { Interviewer }\end{array}$ \\
\hline $\begin{array}{l}\text { Khalil ur Rehman } \\
\text { Interviewer }\end{array}$ & $\begin{array}{l}\text { Salma Mumtaz } \\
\text { Supervisor }\end{array}$ \\
\hline $\begin{array}{l}\text { Mohammad Ejaz } \\
\text { Interviewer }\end{array}$ & $\begin{array}{l}\text { Shahid Hussain } \\
\text { Logistic In-charge }\end{array}$ \\
\hline $\begin{array}{l}\text { Mohammad Hayat } \\
\text { Logistic In-charge }\end{array}$ & $\begin{array}{l}\text { Shakila Begum } \\
\text { Interviewer }\end{array}$ \\
\hline $\begin{array}{l}\text { Nabeela Sahrai } \\
\text { Interviewer }\end{array}$ & $\begin{array}{l}\text { Zahida Rafique } \\
\text { Interviewer }\end{array}$ \\
\hline $\begin{array}{l}\text { Najma Shoukat } \\
\text { Supervisor }\end{array}$ & $\begin{array}{l}\text { Zainab Shah } \\
\text { Interviewer }\end{array}$ \\
\hline
\end{tabular}


ADOLESCENTS AND YOUTH IN PAKISTAN 2001-2002: A NATIONALLY REPRESENTATIVE SURVEY

\section{Field Staff in Sindh}

\begin{tabular}{|c|c|}
\hline $\begin{array}{l}\text { Almas Chaudhary } \\
\text { Interviewer }\end{array}$ & $\begin{array}{l}\text { Rozeena Narejo } \\
\text { Interviewer }\end{array}$ \\
\hline $\begin{array}{l}\text { Dr Abdul Majeed Memon } \\
\text { Interviewer }\end{array}$ & $\begin{array}{l}\text { Rukhsana Talpur } \\
\text { Interviewer }\end{array}$ \\
\hline $\begin{array}{l}\text { Dr. Muhammad Abdullah } \\
\text { Interviewer }\end{array}$ & $\begin{array}{l}\text { Saira Memon } \\
\text { Supervisor }\end{array}$ \\
\hline $\begin{array}{l}\text { Faisal Abdullah } \\
\text { Logistic In-charge }\end{array}$ & $\begin{array}{l}\text { Sajid Ahmed Channa } \\
\text { Provincial Coordinator }\end{array}$ \\
\hline $\begin{array}{l}\text { Humaira Khanum Somro } \\
\text { Supervisor }\end{array}$ & $\begin{array}{l}\text { Sarwat Soomro } \\
\text { Interviewer }\end{array}$ \\
\hline $\begin{array}{l}\text { Hussain Bux Mallah } \\
\text { Logistic In-charge }\end{array}$ & $\begin{array}{l}\text { Shagufta Shamas } \\
\text { Supervisor }\end{array}$ \\
\hline $\begin{array}{l}\text { Kashif Ahmed Memon } \\
\text { Interviewer }\end{array}$ & $\begin{array}{l}\text { Shahzadi Aaliya Sheikh } \\
\text { Interviewer }\end{array}$ \\
\hline $\begin{array}{l}\text { Kashif Bajeer } \\
\text { Logistic In-charge }\end{array}$ & $\begin{array}{l}\text { Shamima Khoso } \\
\text { Supervisor }\end{array}$ \\
\hline $\begin{array}{l}\text { Muhammad Jameel Munawar } \\
\text { Interviewer }\end{array}$ & $\begin{array}{l}\text { Shazia Shah } \\
\text { Interviewer }\end{array}$ \\
\hline $\begin{array}{l}\text { Muhammad Khan Jamali } \\
\text { Logistic In-charge }\end{array}$ & $\begin{array}{l}\text { Shireen Khan Zonur } \\
\text { Interviewer }\end{array}$ \\
\hline $\begin{array}{l}\text { Mumtaz Begum } \\
\text { Interviewer }\end{array}$ & $\begin{array}{l}\text { Suhail Faisal Abro } \\
\text { Interviewer }\end{array}$ \\
\hline $\begin{array}{l}\text { Noor Nabi Memon } \\
\text { Interviewer }\end{array}$ & $\begin{array}{l}\text { Tahmina Baloch } \\
\text { Interviewer }\end{array}$ \\
\hline $\begin{array}{l}\text { Nusrat Panhwar } \\
\text { Interviewer }\end{array}$ & $\begin{array}{l}\text { Zulfiqar Halepoto } \\
\text { Logistic In-charge }\end{array}$ \\
\hline $\begin{array}{l}\text { Paras Memon } \\
\text { Interviewer }\end{array}$ & \\
\hline $\begin{array}{l}\text { Riaz Ahmed } \\
\text { Interviewer }\end{array}$ & \\
\hline $\begin{array}{l}\text { Riaz Ahmed Rajar } \\
\text { Interviewer }\end{array}$ & \\
\hline
\end{tabular}

Rozeena Narejo

Rukhsana Talpur

Interviewer

Saira Memon

Sajid Ahmed Channa

Sarwat Soomro

Shagufta Shamas

Shahzadi Aaliya Sheikh

Interviewer

Shamima Khoso

Shazia Shah

Shireen Khan Zonu

Suhail Faisal Abro

Tahmina Baloch

Interviewer

Zulfiqar Halepoto

Logistic In-charge 


\section{Appendix V}

\section{STANDARD ERRORS OF ESTIMATES}

\begin{tabular}{|c|c|c|c|c|c|c|}
\hline \multirow{2}{*}{ Province } & \multirow{2}{*}{$\begin{array}{l}\text { Estimate } \\
\text { description }\end{array}$} & \multirow[b]{2}{*}{ Age in years } & \multicolumn{2}{|l|}{ Male } & \multicolumn{2}{|c|}{ Female } \\
\hline & & & Estimate & SE & Estimate & SE \\
\hline \multirow[t]{6}{*}{ Punjab } & \multirow[t]{2}{*}{ Ever attended school } & $15-19$ & 85.03 & 2.16 & 61.41 & 2.07 \\
\hline & & $20-24$ & 84.33 & 2.04 & 56.32 & 2.51 \\
\hline & \multirow[t]{2}{*}{ Ever worked } & $15-19$ & 51.73 & 2.51 & 37.19 & 2.16 \\
\hline & & $20-24$ & 85.72 & 1.64 & 41.79 & 2.03 \\
\hline & \multirow[t]{2}{*}{ Ever married } & $15-19$ & 4.54 & 0.85 & 19.79 & 1.62 \\
\hline & & $20-24$ & 23.33 & 2.16 & 57.54 & 2.15 \\
\hline \multirow[t]{6}{*}{ Sindh } & \multirow[t]{2}{*}{ Ever attended school } & $15-19$ & 82.44 & 3.03 & 50.37 & 2.99 \\
\hline & & $20-24$ & 80.63 & 2.61 & 38.10 & 3.19 \\
\hline & \multirow[t]{2}{*}{ Ever worked } & $15-19$ & 66.62 & 2.67 & 36.10 & 2.29 \\
\hline & & $20-24$ & 86.37 & 2.20 & 49.32 & 2.67 \\
\hline & \multirow[t]{2}{*}{ Ever married } & $15-19$ & 7.13 & 1.14 & 26.36 & 1.86 \\
\hline & & $20-24$ & 35.04 & 3.32 & 71.92 & 3.25 \\
\hline \multirow[t]{6}{*}{ NWFP } & \multirow[t]{2}{*}{ Ever attended school } & $15-19$ & 88.05 & 3.33 & 41.80 & 4.28 \\
\hline & & $20-24$ & 76.88 & 5.02 & 29.79 & 3.47 \\
\hline & \multirow[t]{2}{*}{ Ever worked } & $15-19$ & 36.23 & 3.44 & 5.60 & 1.67 \\
\hline & & $20-24$ & 58.39 & 5.26 & 11.16 & 2.44 \\
\hline & \multirow[t]{2}{*}{ Ever married } & $15-19$ & 2.87 & 1.14 & 24.09 & 2.72 \\
\hline & & $20-24$ & 20.21 & 3.43 & 71.00 & 2.41 \\
\hline \multirow[t]{6}{*}{ Balochistan } & \multirow[t]{2}{*}{ Ever attended school } & $15-19$ & 74.16 & 5.61 & 35.87 & 7.15 \\
\hline & & $20-24$ & 66.54 & 6.91 & 17.55 & 3.78 \\
\hline & \multirow[t]{2}{*}{ Ever worked } & $15-19$ & 54.32 & 6.10 & 23.29 & 3.31 \\
\hline & & $20-24$ & 77.94 & 3.44 & 24.40 & 3.92 \\
\hline & \multirow[t]{2}{*}{ Ever married } & $15-19$ & 8.28 & 1.03 & 32.41 & 4.29 \\
\hline & & $20-24$ & 40.95 & 5.91 & 67.58 & 4.34 \\
\hline
\end{tabular}

$\overline{\mathrm{SE}}=$ Standard errors of estimates, are calculated by using PC CARP software, developed by lowa State University, USA.

Estimates and standard errors are expressed in percentages.

Confidence interval at 95 percent confidence level can be calculated by following formula: $\mathrm{Cl}=$ estimate \pm $1.96(\mathrm{SE})$. 

Questionnaires 
Transition to Adulthood:

Education, Work and Marriage among Adolescents and Youth

in Pakistan

\section{Adolescent Questionnaire (For girls aged 15-24)}




\section{Greet: (Assalam-o-Alaikam)}

My name is. I belong to Population Council Islamabad. A national survey is being carried out in four provinces of Pakistan. We are collecting information regarding Education, Work, Health and Marriage from young boys and girls age 15-24. We need your co-operation in this regard.

Please be assured that your responses are confidential. Your participation is voluntary and if there is any question, which you do not like, you are not bound to answer that. If you permit, may I start the interview?

\section{List of contents}

$\begin{array}{ll}\text { S. \# } & \text { Sections } \\ 1 & \text { A } \\ 2 & \text { B } \\ 3 & \text { C } \\ 4 & \text { D } \\ 5 & \text { E } \\ 6 & \text { F } \\ 7 & \text { G } \\ 8 & \text { H } \\ 9 & \text { I } \\ 10 & \text { J }\end{array}$

\section{Descriptions}

Identification

Background Information

Life Event Calendar

Educational Attainment

Work/ livelihood

Time Use Profile

Empowerment and Gender

Fertility and Marriage

Home Conditions at Age 15

Migration

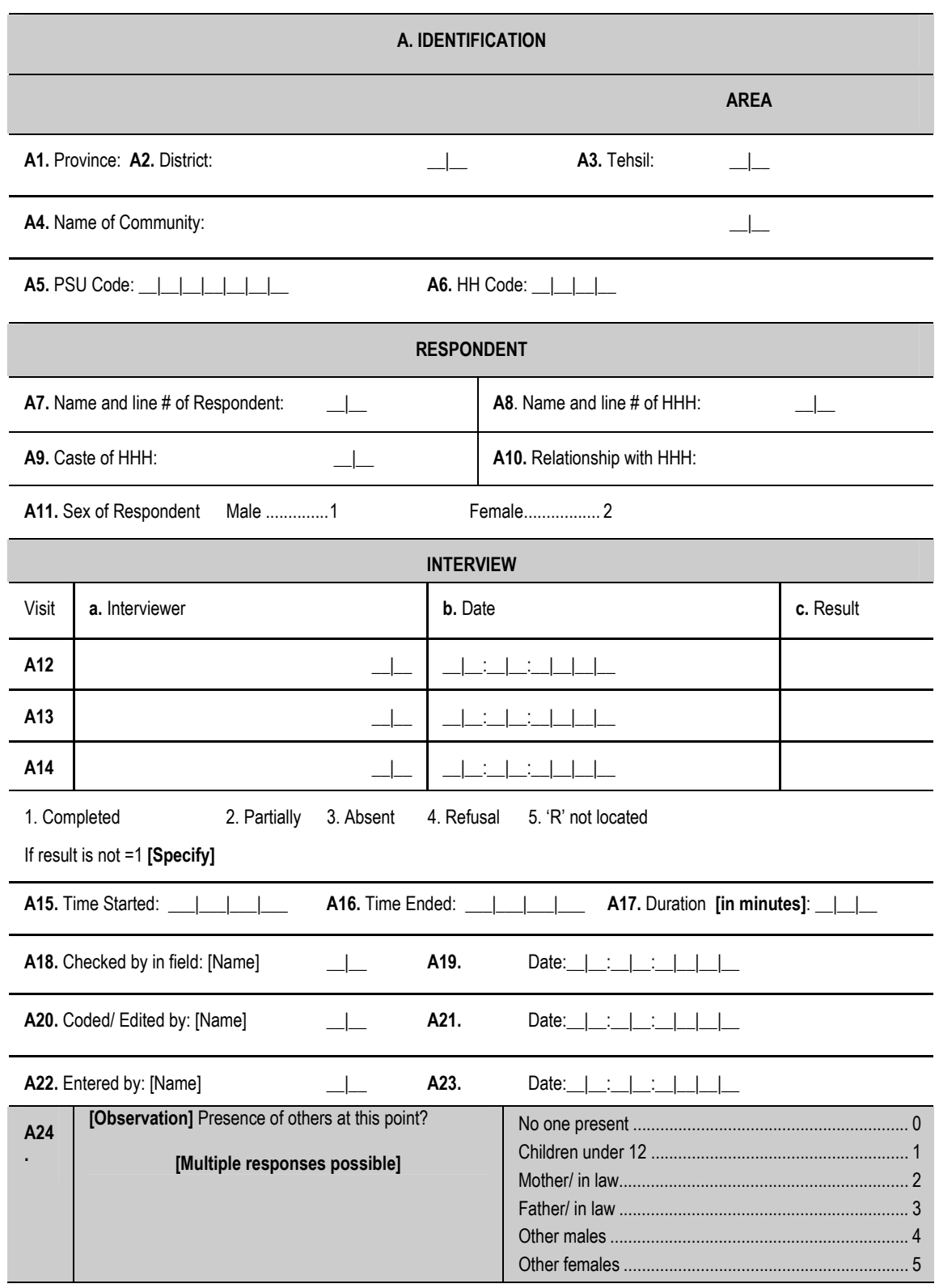


B. BACKGROUND INFORMATION

\begin{tabular}{|c|c|c|}
\hline \multicolumn{3}{|c|}{ B. BACKGROUND INFORMATION } \\
\hline S.\# & Questions and Filters & Responses and Codes \\
\hline B1 & $\begin{array}{l}\text { How old are you? } \\
\text { [Probe for the most accurate answer } \\
\text { possible] }\end{array}$ & Age in completed years \\
\hline B2 & What is your date of birth? & 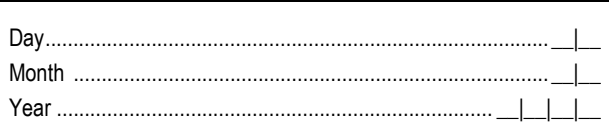 \\
\hline B3 & What is your marital status? & 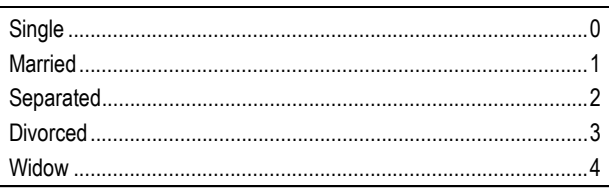 \\
\hline \multicolumn{3}{|c|}{$\begin{array}{l}\text { If married line \# of husband from } \mathrm{HH} \text { profile } \\
\text { (Filled by supervisor) }\end{array}$} \\
\hline B4 & $\begin{array}{l}\text { How many living brothers and sisters do you } \\
\text { have?(excluding yourself) }\end{array}$ & 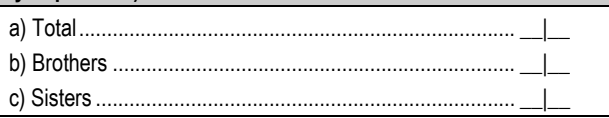 \\
\hline B5 & Does your father live in the same $\mathrm{HH}$ with you? & 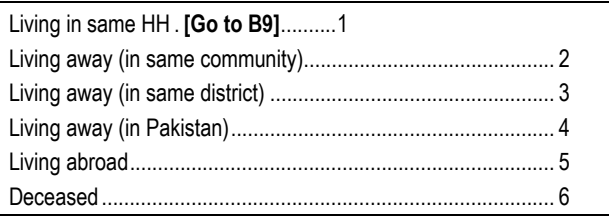 \\
\hline \multicolumn{3}{|c|}{ If deceased ask B6. Otherwise Go to B7 } \\
\hline B6 & $\begin{array}{l}\text { How old were you when your father died? } \\
\text { [Probe for the most accurate answer } \\
\text { possible] }\end{array}$ & 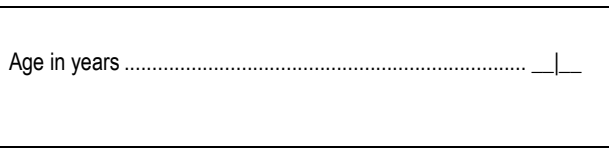 \\
\hline B7 & Can/ could your father read and/or write? & $\begin{array}{l}\text { Yes, both } \\
\text { Can read only } \\
\text { Can write only } \\
\text { Can neither read nor write }\end{array}$ \\
\hline B8 & $\begin{array}{l}\text { What was the highest grade of schooling your } \\
\text { father ever completed? }\end{array}$ & $\begin{array}{l}\text { Grade completed } \\
\text { DK }\end{array}$ \\
\hline
\end{tabular}




\begin{tabular}{|c|c|c|}
\hline S.\# & Questions and Filters & Responses and Codes \\
\hline B9 & $\begin{array}{c}\text { What is/ was your father's main occupation? } \\
\text { [Multiple responses possible] }\end{array}$ & 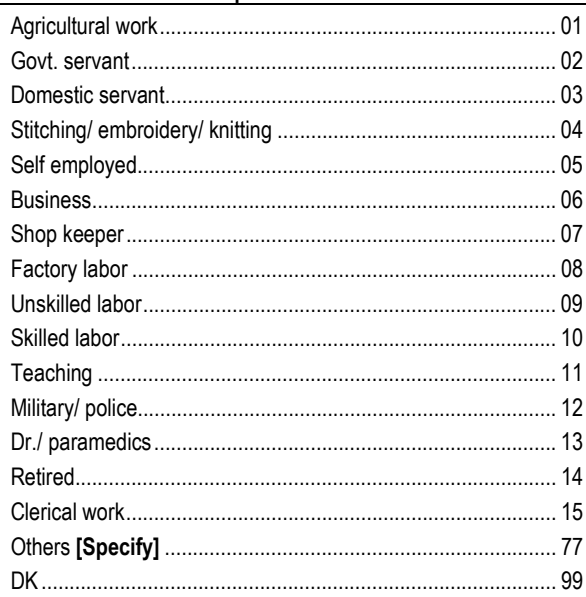 \\
\hline B10 & $\begin{array}{l}\text { Does your mother live in the same } \mathrm{HH} \text { with } \\
\text { you? }\end{array}$ & 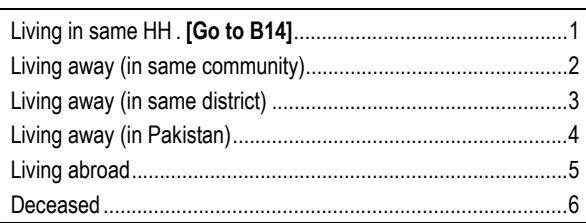 \\
\hline \multicolumn{3}{|c|}{ If deceased ask B11. Otherwise Go to B12 } \\
\hline B11 & $\begin{array}{l}\text { How old were you when your mother died? } \\
\text { [Probe for the most accurate answer } \\
\text { possible] }\end{array}$ & 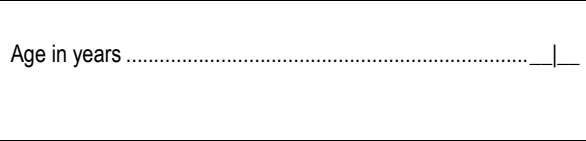 \\
\hline B12 & Can/could your mother read and/ or write? & 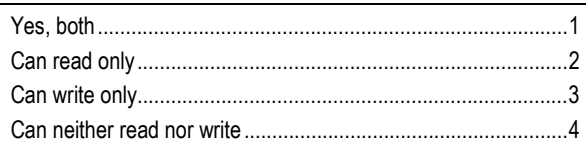 \\
\hline B13 & $\begin{array}{l}\text { What was the highest grade of schooling your } \\
\text { mother ever completed? }\end{array}$ & $\begin{array}{l}\text { Grade completed } \\
\text { DK }\end{array}$ \\
\hline
\end{tabular}

\begin{tabular}{|c|c|c|}
\hline S.\# & Questions and Filters & Responses and Codes \\
\hline \multirow[t]{19}{*}{ B14 } & \multirow[t]{3}{*}{ What is/ was your mother's main occupation? } & Agricultural work \\
\hline & & Govt. Service \\
\hline & & Domestic servant \\
\hline & \multirow[t]{16}{*}{ [Multiple responses possible] } & 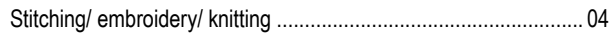 \\
\hline & & 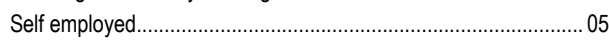 \\
\hline & & $\ldots \ldots \ldots-1.06$ \\
\hline & & Shop keeper \\
\hline & & 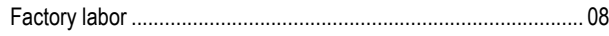 \\
\hline & & Unskilled labor \\
\hline & & Skilled labor \\
\hline & & 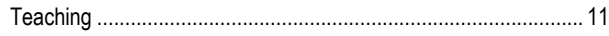 \\
\hline & & Military/ police........ \\
\hline & & Dr./paramedics....... \\
\hline & & Retired....................... \\
\hline & & Clerical work........................ \\
\hline & & House wife .............................. \\
\hline & & Dai \\
\hline & & Others [Specify] \\
\hline & & 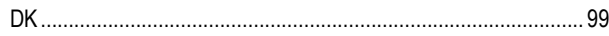 \\
\hline \multirow[t]{4}{*}{ B15 } & \multirow[t]{4}{*}{ What is your religion? } & Islam …………………………………………………. \\
\hline & & $\ldots$ \\
\hline & & Hinduism \\
\hline & & Others [Specify] \\
\hline \multirow{6}{*}{ B16 } & \multirow[t]{2}{*}{ [Observation] Presence of others at this point? } & No one present \\
\hline & & Children under 12 \\
\hline & \multirow[t]{4}{*}{ [Multiple responses possible] } & Mother/ in law \\
\hline & & $\ldots$ \\
\hline & & 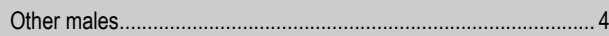 \\
\hline & & 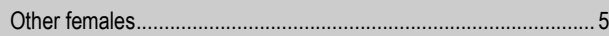 \\
\hline
\end{tabular}




\section{LIFE EVENT CALANDER}

The year of puberty is the start of transition from childhood to adulthood. After reaching puberty many of important changes start to take place in terms of education, work, marriage and migration. We want year wise information on these events.

\section{Column 1}

Calendar years are written in reverse chronological order starting from the year 2001. The year 2001, like all other years, is divided into two cells. The first cell represents events that occur later in the year and the second cell represents event that occur early in the year.

\section{Column 2}

This column is for recoding age in years. Start by current age (in completed year) for the calendar year 2001 and proceed in reverse order till the age of five.

Column 3

This column is for schooling status. Start from calendar year 2001 and proceed in reverse order. Code status by each year

\section{Column 4}

Grade attending during different years of life. Mention the class passed in front of the calendar year.

Column 5

This column is for work/ employment. [Learn definition of work from manual]

\section{Column 6}

This column is for nature of work, code accordingly.

Column 7

We want to know year-wise where the respondent has lived. First ask about for how long respondent has been living at this place, how many time respondent has migrated and which places he has lived. Has he lived in the same village or not.

\section{Column 8}

This column is related to migration (column 7). We want to know with whom the respondent has lived. Before filling any cell ask if the respondent has lived throughout with his parents. Sometime fathers live separately due to the nature of employment

Column 9

We want to know about respondents' marital status. Also ask about any engagements and code accordingly.

\section{Column 10}

Only for married respondents. Ask for how long the respondent has been married, then ask about the live births respondent ever had.

\section{Column 11}

Only for married respondents. Ask about family planning status first, then as about duration of use. If there is a long gap in birth ask what method was used during that period.

Note: The ideal way to proceed is to go backward in life history, however to facilitate the respondent for some columns you can start form the bottom and go upwards. The Most Important point is to follow the order of events.

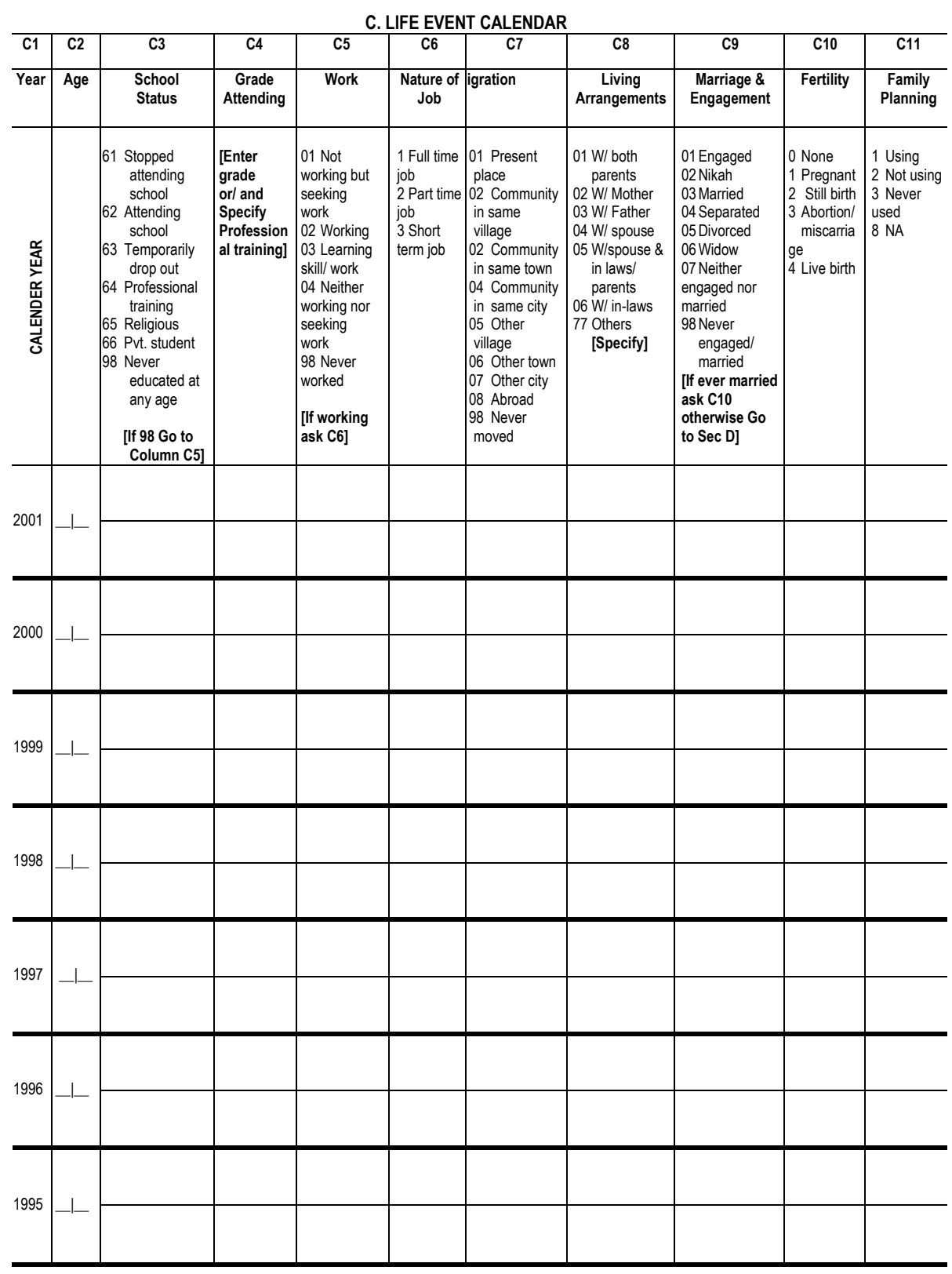




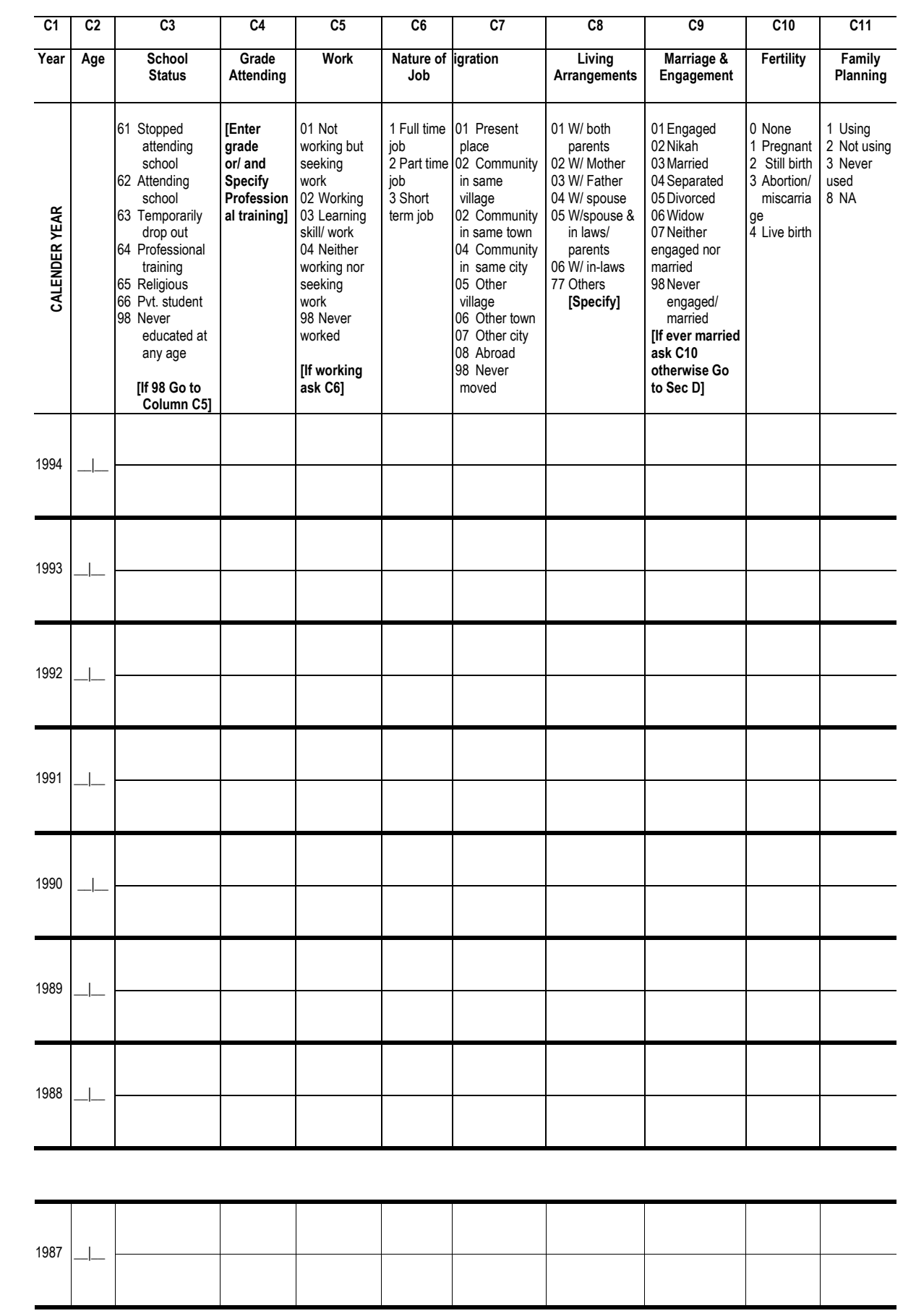

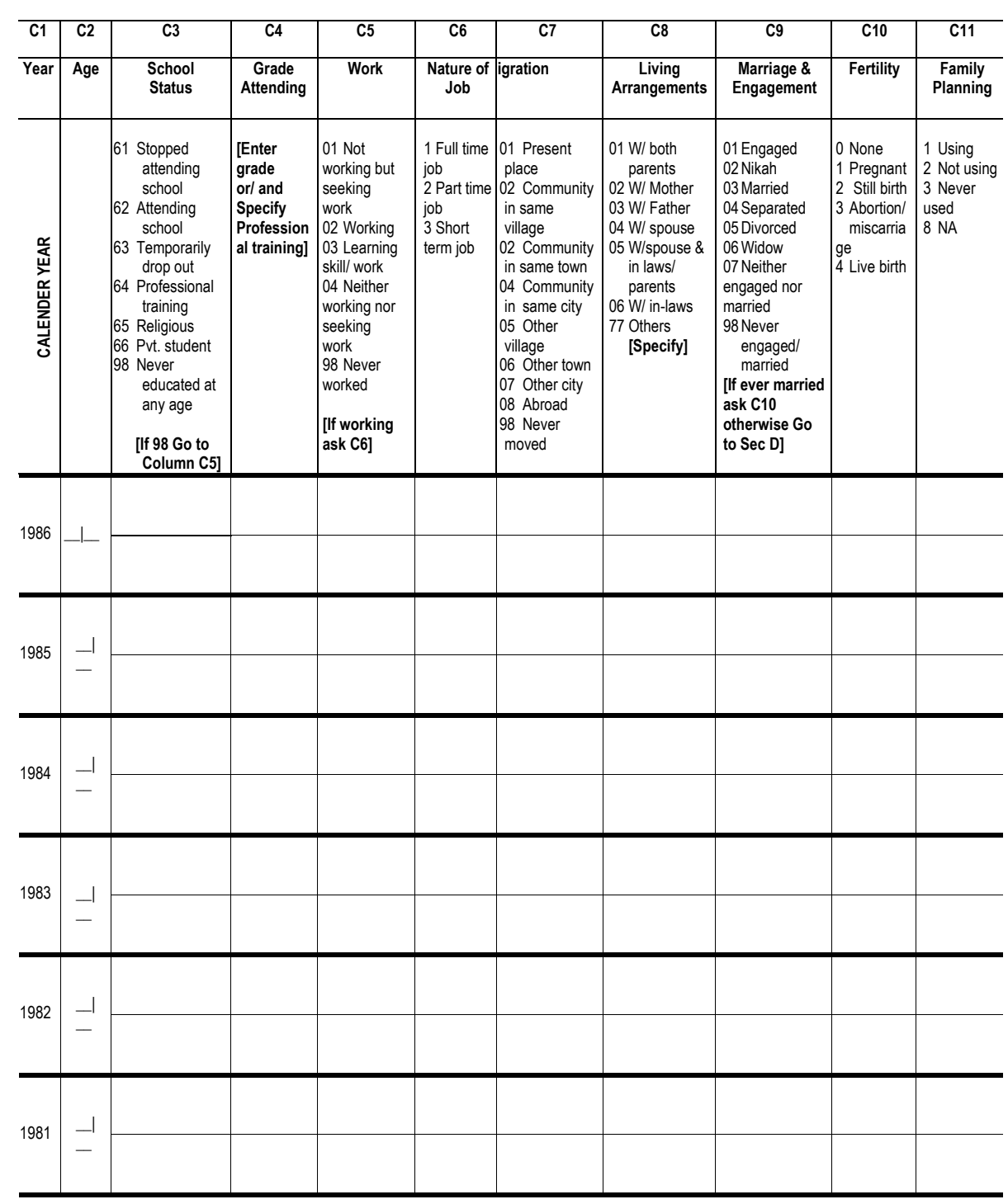




\section{EDUCATIONAL ATTAINMENT}

\begin{tabular}{|c|c|c|}
\hline \multirow[t]{3}{*}{ Do } & \multicolumn{2}{|r|}{ [Go to D2] $\ldots \ldots \ldots \ldots \ldots \ldots \ldots \ldots \ldots \ldots \ldots$} \\
\hline & Left school & [Go to D2] \\
\hline & Never been to school & [Go to D1] $\ldots \ldots \ldots$ \\
\hline
\end{tabular}

\begin{tabular}{|c|c|c|}
\hline S.\# & Questions and Filters & Responses and Codes \\
\hline D1 & $\begin{array}{l}\text { What are the major reasons that } \\
\text { you never attended school } \\
\text { (Class } 1 \text { onwards)? } \\
\text { [Multiple responses possible] }\end{array}$ & $\begin{array}{l}\text { School related concerns } \\
\text { No school available } \\
\text { School too far } \\
\text { No vacancies available in school } \\
\text { Poor quality of education } \\
\text { Could not pay school fees } \\
\text { Social concerns } \\
\text { Physically/ mentally disabled } \\
\text { Too sickly } \\
\text { Co aptitude/ not interested } \\
\text { Too many domestic responsibilities } \\
\text { Needed on family farm/ business } \\
\text { Family sees no benefit of schooling. } \\
\text { Parents disapprove of schooling } \\
\text { Others [Specify] } \\
\text { DK }\end{array}$ \\
\hline
\end{tabular}

\section{[Go to D15]}

\begin{tabular}{|c|c|c|}
\hline $\bar{D} 2$ & $\begin{array}{l}\text { What is the highest grade of } \\
\text { school that you have } \\
\text { completed? }\end{array}$ & Grade completed............ \\
\hline D3 & $\begin{array}{l}\text { How old were you when you first } \\
\text { enrolled in Class } 1 \text { ? } \\
\text { [Probe for the most accurate } \\
\text { answer possible] }\end{array}$ & .............___ \\
\hline D4 & $\begin{array}{l}\text { Have you ever attended Katchil } \\
\text { pre-primary? }\end{array}$ & 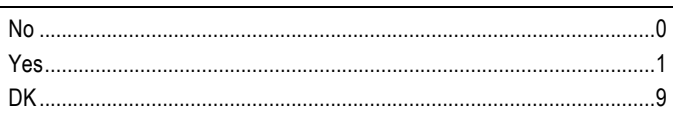 \\
\hline D5 & Are you currently in school? & 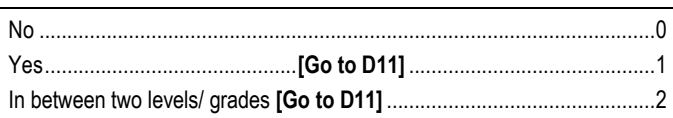 \\
\hline
\end{tabular}

\begin{tabular}{|c|c|c|}
\hline S. \# & Questions and Filters & Responses and Codes \\
\hline D6 & [Multiple responses possible] & 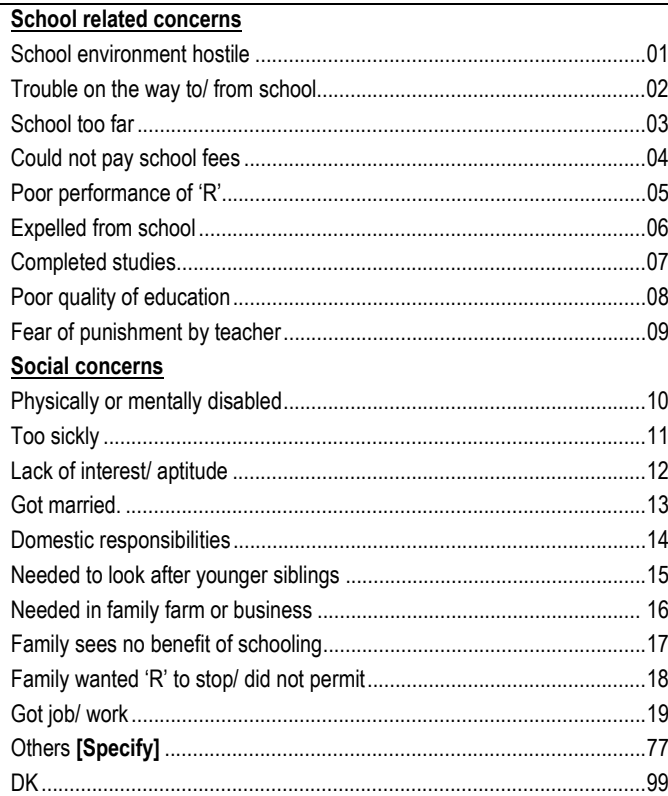 \\
\hline D7 & $\begin{array}{l}\text { Who made the decision that you } \\
\text { should leave school? }\end{array}$ & Father Mother r.t. \\
\hline D8 & $\begin{array}{l}\text { How old were you when you left } \\
\text { school? } \\
\text { [Probe for the most accurate }\end{array}$ & Age in years ...... \\
\hline $\mathrm{Dg}$ & $\begin{array}{l}\text { Did you try to re-enroll in } \\
\text { school? }\end{array}$ & 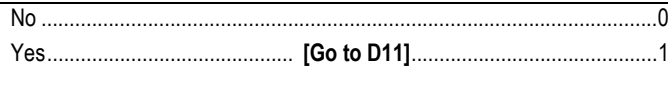 \\
\hline
\end{tabular}




\begin{tabular}{|c|c|c|}
\hline S.\# & Questions and Filters & Responses and Codes \\
\hline D10 & $\begin{array}{l}\text { What were the main reasons for } \\
\text { not trying to get re-enrolled in } \\
\text { school? } \\
\text { [Multiple responses possible] }\end{array}$ & 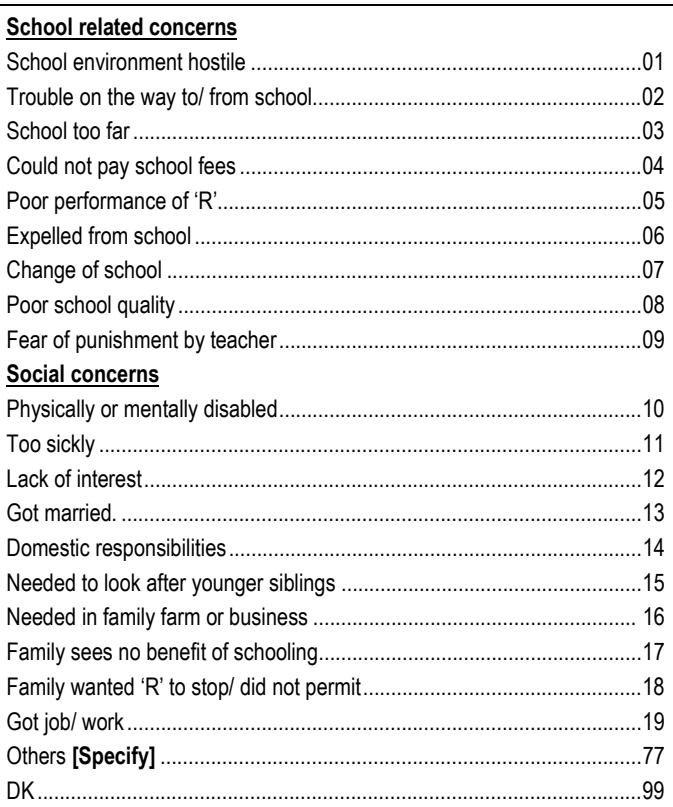 \\
\hline D11 & $\begin{array}{l}\text { Have you ever withdrawn from } \\
\text { school temporarily?( At least one } \\
\text { month) }\end{array}$ & 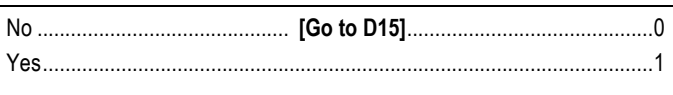 \\
\hline D12 & $\begin{array}{l}\text { Considering all the times this } \\
\text { happened together, how many } \\
\text { months in, total, did you } \\
\text { temporarily withdraw from } \\
\text { school? }\end{array}$ & 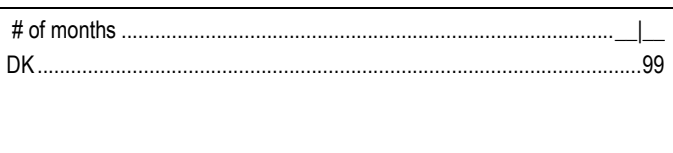 \\
\hline D13 & $\begin{array}{l}\text { Have you missed any class due } \\
\text { to this gap? }\end{array}$ & 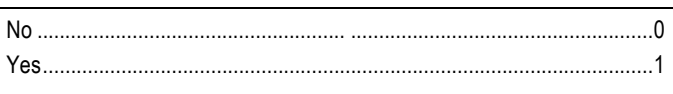 \\
\hline
\end{tabular}

\begin{tabular}{|c|c|c|}
\hline S. \# & Questions and Filters & Responses and Codes \\
\hline D14 & [Multiple responses possible] & 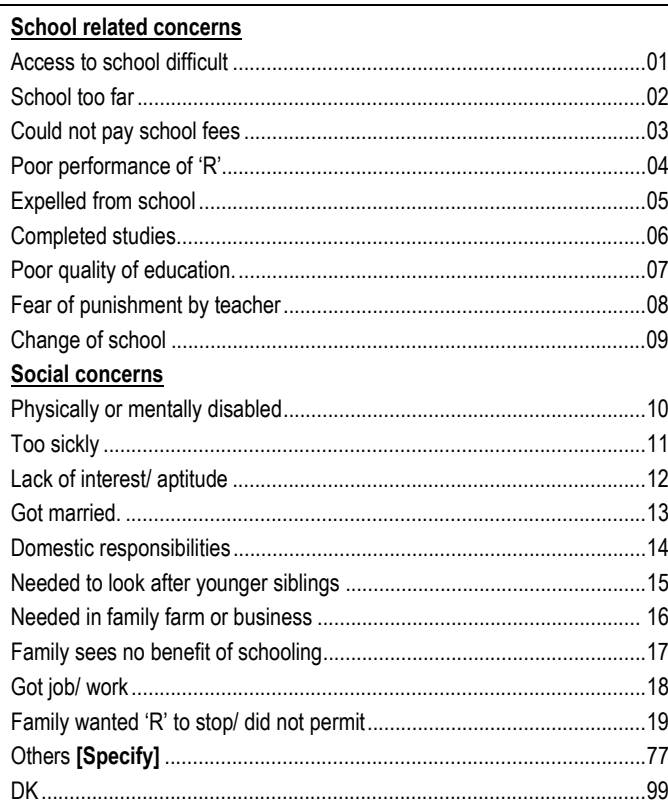 \\
\hline D15 & $\begin{array}{l}\text { What level of education do you } \\
\text { think boys in your community } \\
\text { should attain? }\end{array}$ & $\begin{array}{l}\text { None } \\
\text { Primary } \\
\text { Middle } \\
\text { Secondary . } \\
\text { H. Secondary } \\
\text { Graduation } \\
\text { University } \\
\text { Professional/ vocational training } \\
\text { As long as he wants } \\
\text { Whatever the family decides } \\
\text { Others [Specify] }\end{array}$ \\
\hline D16 & $\begin{array}{l}\text { What level of education do you } \\
\text { think girls in your community } \\
\text { should attain? }\end{array}$ & $\begin{array}{l}\text { None } \\
\text { Primary } \\
\text { Middle } \\
\text { Secondary } \\
\text { H. Secondary } \\
\text { Graduation } \\
\text { University } \\
\text { Professional/ vocational training } \\
\text { As long as she wants } \\
\text { Whatever the family decides } \\
\text { Others [Specify] }\end{array}$ \\
\hline D17 & $\begin{array}{l}\text { Have you ever received any } \\
\text { vocational/ skill training? }\end{array}$ & $\begin{array}{l}\text { No } \\
\text { Yes. }\end{array}$ \\
\hline
\end{tabular}




\begin{tabular}{|c|c|c|}
\hline S. \# & Questions and Filters & Responses and Codes \\
\hline D18 & $\begin{array}{l}\text { What type of vocational training } \\
\text { have you received? } \\
\text { [Multiple responses possible] }\end{array}$ & 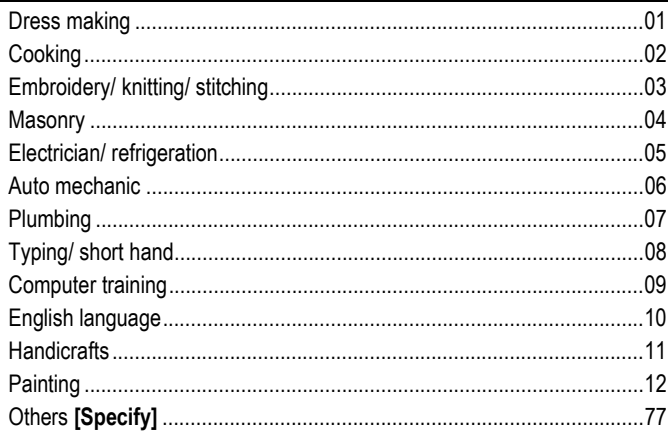 \\
\hline D19 & $\begin{array}{l}\text { Are there any skills in which you } \\
\text { would like training? }\end{array}$ & $\begin{array}{l}\text { No } \\
\text { Yes } \\
\text { DK }\end{array}$ \\
\hline D20 & $\begin{array}{l}\text { Which skills would you like to } \\
\text { have training in? } \\
\text { [Multiple responses possible] }\end{array}$ & 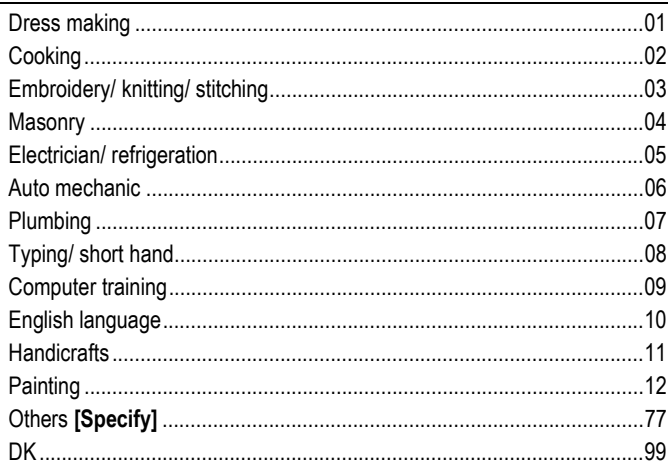 \\
\hline $\mathrm{D} 21$ & $\begin{array}{l}\text { Was the question of how much } \\
\text { education you should/ should } \\
\text { not receive ever discussed in } \\
\text { your household? }\end{array}$ & 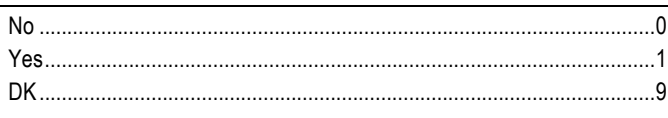 \\
\hline D22 & $\begin{array}{l}\text { Were you able to express an } \\
\text { opinion on this issue in your } \\
\text { household? }\end{array}$ & $\begin{array}{l}\text { No } \\
\text { Yes } \\
\text { DK }\end{array}$ \\
\hline D23 & $\begin{array}{l}\text { Do you feel your opinion was } \\
\text { listened to? }\end{array}$ & $\begin{array}{l}\text { No } \\
\text { Yes. } \\
\text { DK }\end{array}$ \\
\hline
\end{tabular}

\section{SCHOOL HISTORY}

\begin{tabular}{|c|c|c|c|}
\hline D24 & \multirow{2}{*}{22} & Respondent never been to school & [Go to D34].. \\
\hline & & Respondent ever been to school & [Continue with D25]......... \\
\hline
\end{tabular}

I would like to know a little something about each of these schools you attended, last or currently attending [Start from primary school and continue up to highest grade attended].

\begin{tabular}{|c|c|c|c|c|c|}
\hline $\begin{array}{l}\text { D25. Grades } \\
\text { of school. }\end{array}$ & \begin{tabular}{|l|} 
D26. Level of \\
School.
\end{tabular} & \begin{tabular}{|l|} 
D27. Is/ was it \\
a [Type] \\
school.
\end{tabular} & $\begin{array}{l}\text { D28. Type of } \\
\text { school boys, } \\
\text { girls or } \\
\text { mixed. }\end{array}$ & $\begin{array}{l}\text { D29. Medium of } \\
\text { instruction in class. }\end{array}$ & $\begin{array}{l}\text { D30. Why were you enrolled } \\
\text { in this particular school? } \\
\text { [Multiple Responses } \\
\text { possible] }\end{array}$ \\
\hline From Grade & $\begin{array}{l}01 . . \text { Prim. } \\
02 . . \text { Mid. } \\
03 \text {..Sec. } \\
04 \text {.. H.Sec. } \\
05 \text {.. Grad. } \\
06 \text {..Univ. } \\
77 \text {.. Others } \\
\text { [Specify] }\end{array}$ & \begin{tabular}{|l|}
$1 \ldots \ldots \ldots \ldots . . . G o v t$ \\
$2 \ldots \ldots \ldots \ldots . . . P v t$ \\
$3 \ldots \ldots \ldots \ldots . . . \mathrm{NGO}$ \\
$9 \ldots \ldots \ldots \ldots . . \mathrm{DK}$
\end{tabular} & $\begin{array}{l}1 \ldots \ldots \ldots . . . \text { Boys } \\
2 \ldots \ldots \ldots \ldots \text { Girls } \\
3 \ldots \ldots \ldots . . . \text { Mixed }\end{array}$ & 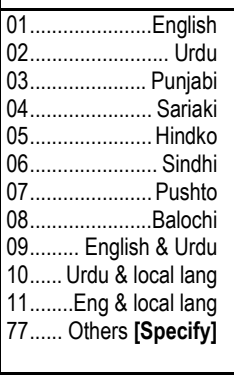 & 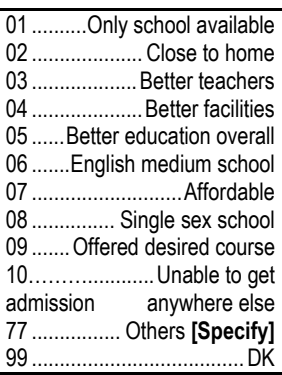 \\
\hline a.__ to & & & & & 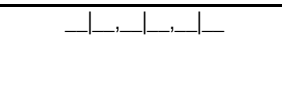 \\
\hline $\begin{array}{c}\text { b.___to } \\
\text { __ }\end{array}$ & & & & & 一_,_L,_L \\
\hline $\begin{array}{c}\text { c. ___to } \\
\text { _L }\end{array}$ & & & & & _-_,_-_,_l \\
\hline $\begin{array}{c}\text { d. } \_ \text {_ to } \\
\text { - }\end{array}$ & & & & & 一_,_L,_L \\
\hline $\begin{array}{l}\text { e._L_to } \\
\text { _L }\end{array}$ & & & & & 一_,_L,_L \\
\hline f. ___to & & & & & _-—,__,_- \\
\hline g.___ to & & & & & 一_,_L,_上 \\
\hline $\begin{array}{c}\text { h. _L_to } \\
-1 \text { t }\end{array}$ & & & & & 一__,_L,_L \\
\hline i. __ to & & & & & 一_,_L,_L \\
\hline
\end{tabular}




\begin{tabular}{|c|c|c|}
\hline S\# & Questions and Filters & Responses and Codes \\
\hline D31 & $\begin{array}{l}\text { In the grade you are currently attending/ last } \\
\text { attended, would you say that on average your } \\
\text { teachers are/ were absent frequently, absent } \\
\text { sometimes or never/ rarely absent? }\end{array}$ & 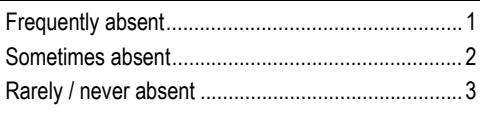 \\
\hline D32 & $\begin{array}{l}\text { In the grade you are currently attending/ last } \\
\text { attended, did you feel your teachers persuaded you to } \\
\text { take private tutions with them? }\end{array}$ & 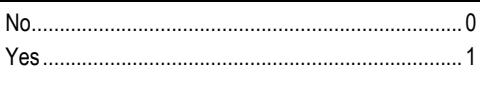 \\
\hline D33 & $\begin{array}{l}\text { In the grade you are currently attending/ last } \\
\text { attended, do/ did you take any private tutions? }\end{array}$ & 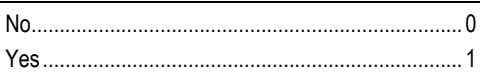 \\
\hline D34 & $\begin{array}{l}\text { [Observation] Presence of others at this point? } \\
\text { [Multiple responses possible] }\end{array}$ & $\begin{array}{l}\text { No one present } \\
\text { Children under } 12 \\
\text { Mother/ in law } \\
\text { Father/ in law }\end{array}$ \\
\hline
\end{tabular}

\section{E. WORK/ LIVELIHOOD}

As you know some people are involved in sowing, harvesting or picking crops, raising and selling livestock, selling dairy products, stitching/ embroidery or piece rate work etc to help their family (for livelihood). Some time this work is paid in cash or in kind or not paid at all.

\begin{tabular}{|c|c|c|}
\hline S. \# & Questions and Filters & Responses and Codes \\
\hline E1 & $\begin{array}{l}\text { Have you ever done or currently doing any such } \\
\text { activity for pay, profit or family gain? }\end{array}$ & 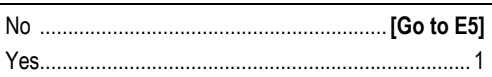 \\
\hline E2 & $\begin{array}{l}\text { How old were you when you first did such work? } \\
\text { [Probe for the most accurate answer possible] }\end{array}$ & Age in years \\
\hline E3 & How long ago did you last work? & 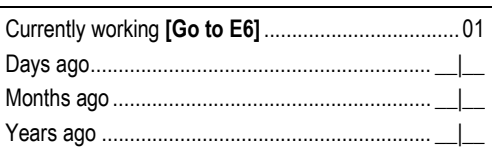 \\
\hline E4 & $\begin{array}{l}\text { What are the main reasons that you are no longer } \\
\text { doing work? } \\
\text { [Multiple responses possible] }\end{array}$ & 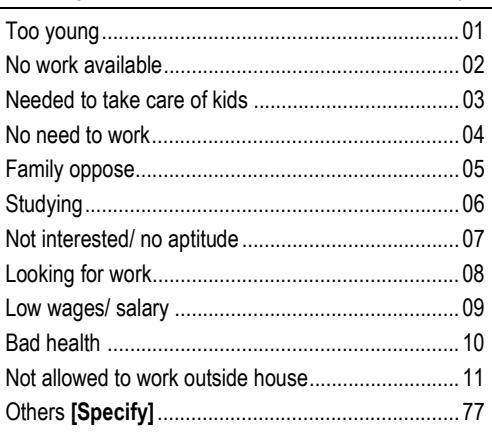 \\
\hline E5 & $\begin{array}{l}\text { If work opportunities were available, would you like to } \\
\text { work in the near future? }\end{array}$ & 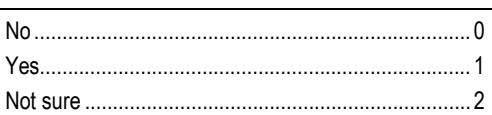 \\
\hline
\end{tabular}




\begin{tabular}{|c|c|c|}
\hline S.\# & Questions and Filters & Responses and Codes \\
\hline E6 & $\begin{array}{l}\text { What is the main type of work you are/ were doing? } \\
\text { [lf not currently working, then ask for most recent } \\
\text { work, if more than one job] }\end{array}$ & 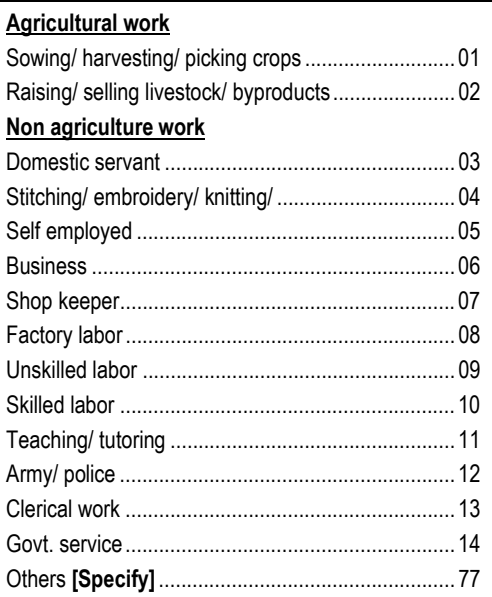 \\
\hline E7 & Where did you do/ are doing this work? & $\begin{array}{l}\text { In own/ family's house } \\
\text { In own/ family's fields } \\
\text { In other house } \\
\text { In other fields } \\
\text { Factory } \\
\text { Market } \\
\text { Shop } \\
\text { Office }\end{array}$ \\
\hline E8 & $\begin{array}{l}\text { Is/ was this your own work, is/ was HH/ family work, } \\
\text { are/ were you employed somewhere, OR are/ were } \\
\text { you the employer? }\end{array}$ & 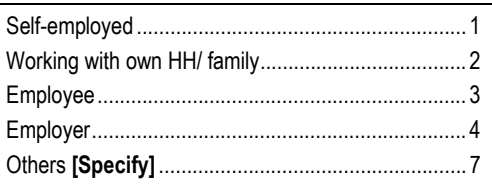 \\
\hline E9 & How or by whom did you find this work? & 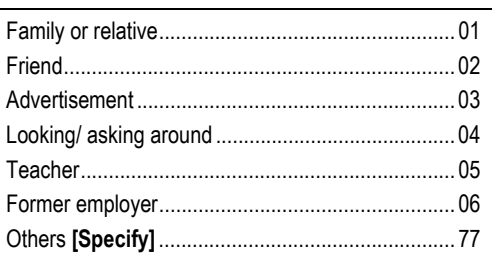 \\
\hline
\end{tabular}

\begin{tabular}{|c|c|c|}
\hline S.\# & Questions and Filters & Responses and Codes \\
\hline E10 & $\begin{array}{l}\text { Who made the decision that you should take up this } \\
\text { work? } \\
\text { [Ask with reference to current/ most recent job/ } \\
\text { work] } \\
\text { [Multiple responses possible] }\end{array}$ & $\begin{array}{l}\text { Father } \\
\text { Mother } \\
\text { Parents } \\
\text { Parents and self } \\
\text { Family } \\
\text { Family and self } \\
\text { Self only } \\
\text { Spouse } \\
\text { In laws } \\
\text { Others } \\
\text { DK }\end{array}$ \\
\hline E11 & $\begin{array}{l}\text { Approximately how many hours a week do/did you do } \\
\text { this work? } \\
\text { [Probe for the most accurate answer possible] }\end{array}$ & 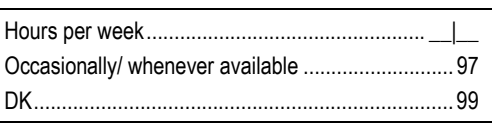 \\
\hline E12 & $\begin{array}{l}\text { Do/did you do this work throughout the year or for } \\
\text { some specific months or some specific time? }\end{array}$ & 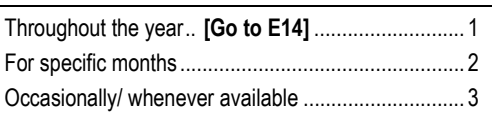 \\
\hline E13 & $\begin{array}{l}\text { Approximately how many months do/ did you usually } \\
\text { spend doing this work? }\end{array}$ & 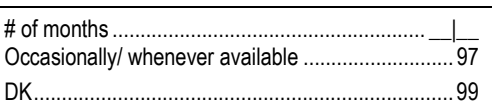 \\
\hline E14 & $\begin{array}{l}\text { Are/were you or any of your family paid for this work, } \\
\text { either in cash or kind? }\end{array}$ & 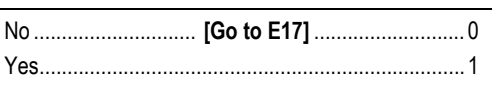 \\
\hline E15 & Who receives/ received your pay, cash or kind? & 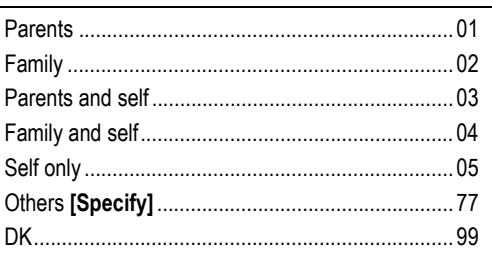 \\
\hline \multicolumn{3}{|c|}{ If other than $05 \mathrm{Go}$ to $\mathrm{E} 17$, continue otherwise } \\
\hline E16 & $\begin{array}{l}\text { Do/did you keep all your pay with you, do/ did you } \\
\text { give all to HH, do / did you keep some with you and } \\
\text { give some to HH? }\end{array}$ & 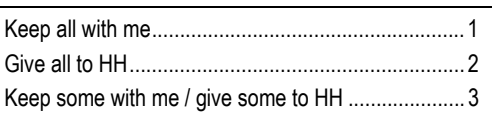 \\
\hline E17 & $\begin{array}{l}\text { Was the question of whether or not you should work } \\
\text { ever discussed in your household? }\end{array}$ & 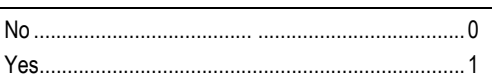 \\
\hline
\end{tabular}




\begin{tabular}{|c|c|c|}
\hline S.\# & Questions and Filters & Responses and Codes \\
\hline E18 & $\begin{array}{l}\text { Were you able to express an opinion on this issue in } \\
\text { your household? }\end{array}$ & 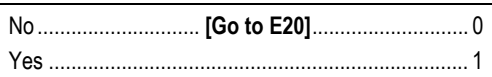 \\
\hline E19 & Do you feel your opinion was listened to? & 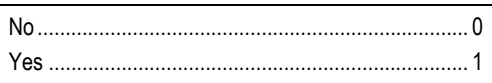 \\
\hline E20 & $\begin{array}{l}\text { [Observation] Presence of others at this point? } \\
\text { [Multiple responses possible] }\end{array}$ & $\begin{array}{l}\text { No one present } \\
\text { Children under } 12 \\
\text { Mother/ in law } \\
\text { Fatherl in law } \\
\text { Other males } \\
\text { Other females }\end{array}$ \\
\hline
\end{tabular}

Instructions: The grid on the following page is to be used to record the activities pursued by the respondent yesterday. The one exception is that, if the respondent is still in school, the day recorded should be the most recent school day, ven if that day was not yesterday.

The grid divides up the day between 6:00 am and 12:00 midnight into hour-long segments. For each segment, work with the respondent to remember what she did during that period of time. Do not read activities to the respondent; rather, allow her to tell you what she did, and then determine, yourself, the line on the grid that most closely matches this

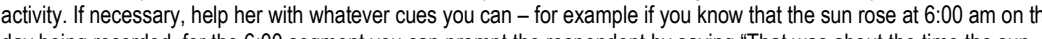
came up" If

For each segment, Code1 beside all activities listed by respondent.

\begin{tabular}{|c|c|c|c|}
\hline S. \# & Questions and Filters & \multicolumn{2}{|c|}{ Responses and Codes } \\
\hline FO & Check D24: the Respondent & currently going to school ..............1 & $\begin{array}{l}\text { All others .............................. } 2 \\
\text { [Always yesterday] }\end{array}$ \\
\hline F1 & $\begin{array}{l}\text { Was yesterday a usual/ routine } \\
\text { day for you? }\end{array}$ & $\begin{array}{ll}\text { No } & \text { [Go to F3] } \\
\text { Yes } & \ldots . . .1 .1\end{array}$ & 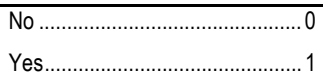 \\
\hline F2 & $\begin{array}{l}\text { If yesterday was not a usual day, } \\
\text { enter how many days ago it was? }\end{array}$ & No. of days ago....................___ & \\
\hline F3 & What day of the week was it? & 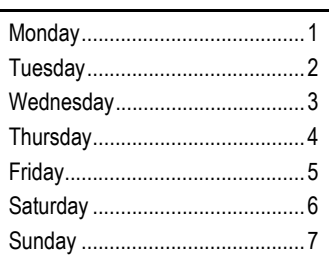 & 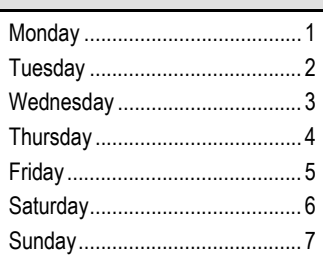 \\
\hline
\end{tabular}




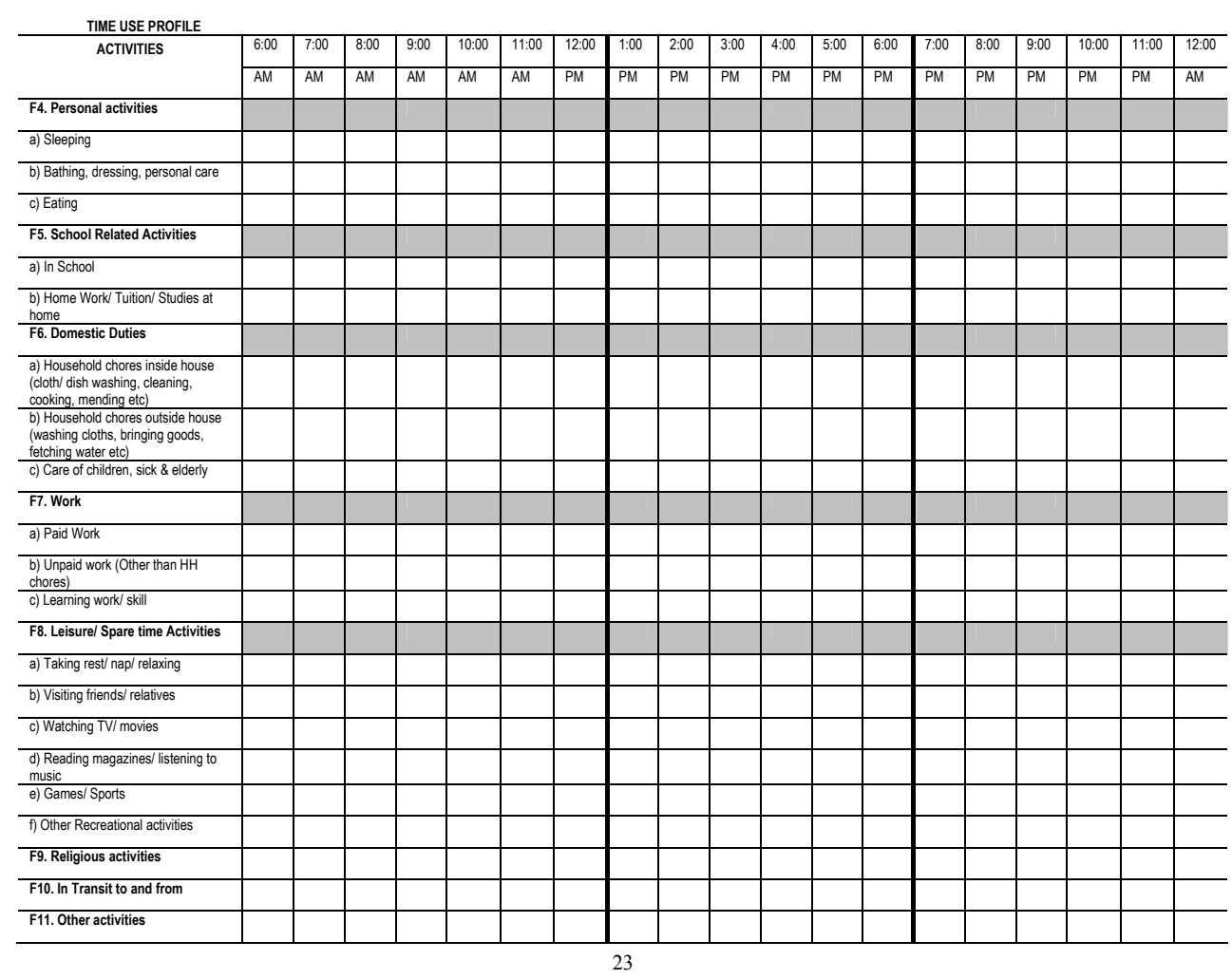

G. EMPOWERMENT AND GENDER

Now I would like to ask about some responsibilities within a HH.

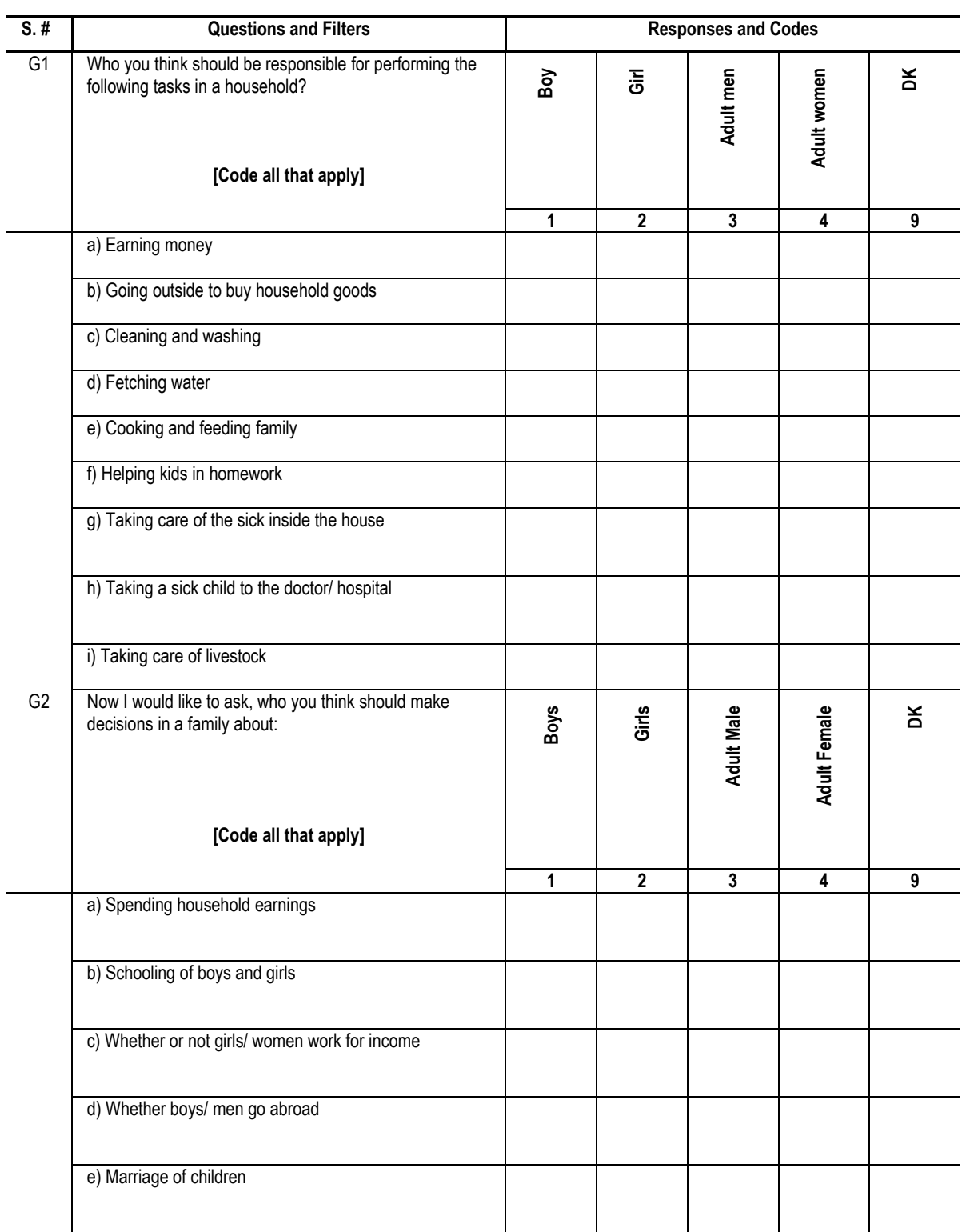




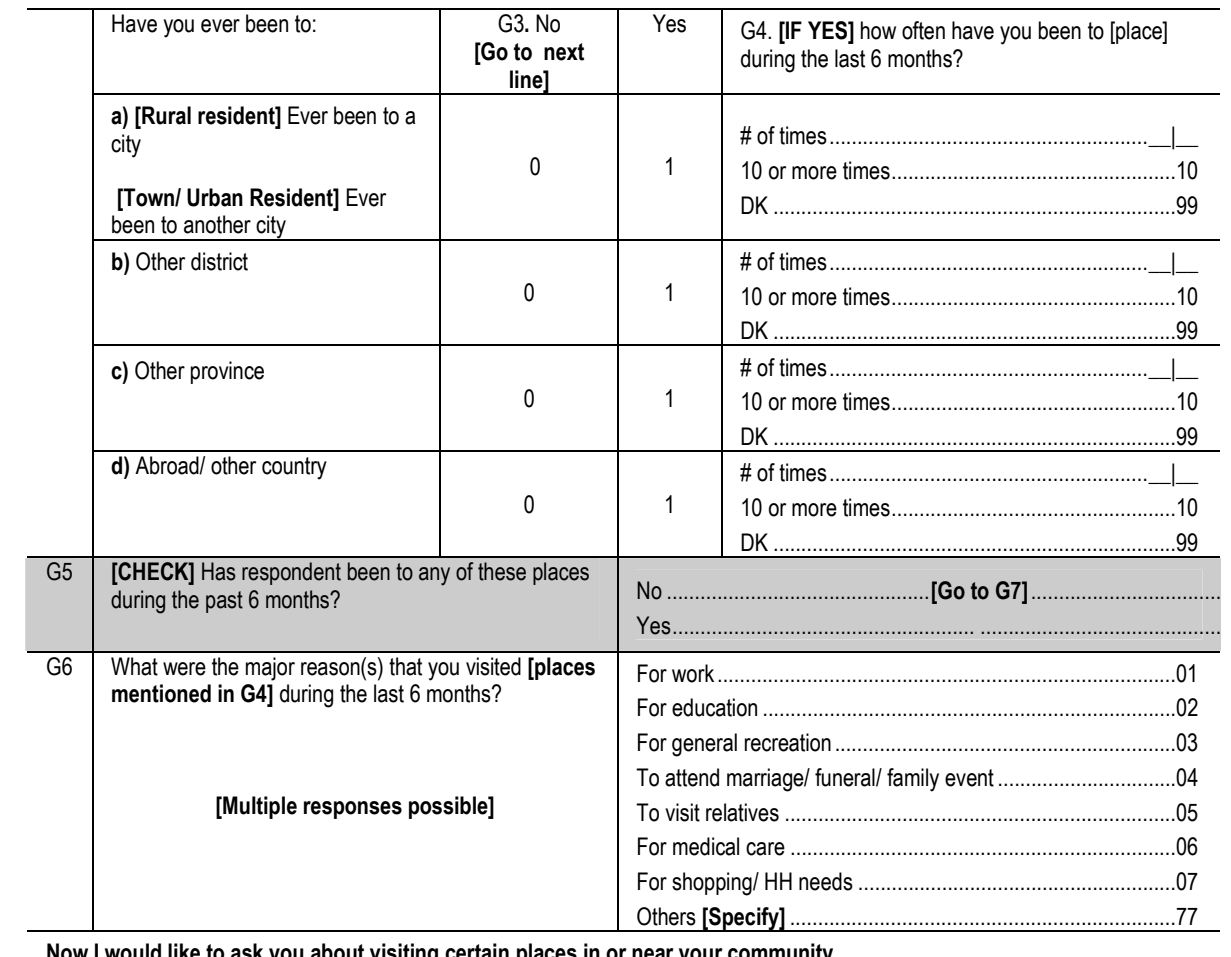

Now I would like to ask you about visiting certain places in or near your community.

\begin{tabular}{|c|c|c|c|c|c|}
\hline \multirow[t]{2}{*}{ Places } & \multicolumn{3}{|c|}{$\begin{array}{l}\text { G7. Do you need PERMISSION if you } \\
\text { want to go there [place] alone? } \\
\text { [lf NA go to next line] }\end{array}$} & \multicolumn{2}{|c|}{ G8. Can you go there ALONE? } \\
\hline & No & Yes & NA & No & Yes \\
\hline a) Neighbor & 0 & 1 & 8 & 0 & 1 \\
\hline b) Nearby shop & 0 & 1 & 8 & 0 & 1 \\
\hline c) School & 0 & 1 & 8 & 0 & 1 \\
\hline d) Sports Ground & 0 & 1 & 8 & 0 & 1 \\
\hline e) Friends & 0 & 1 & 8 & 0 & 1 \\
\hline f) Relatives & 0 & 1 & 8 & 0 & 1 \\
\hline $\begin{array}{l}\text { g) Fields inside } \\
\text { village }\end{array}$ & 0 & 1 & 8 & 0 & 1 \\
\hline $\begin{array}{l}\text { h) Fields outside } \\
\text { village }\end{array}$ & 0 & 1 & 8 & 0 & 1 \\
\hline $\begin{array}{l}\text { i) Other nearby } \\
\text { community }\end{array}$ & 0 & 1 & 8 & 0 & 1 \\
\hline $\begin{array}{l}\text { j) Nearby health } \\
\text { outlet }\end{array}$ & 0 & 1 & 8 & 0 & 1 \\
\hline
\end{tabular}

\begin{tabular}{|c|c|c|}
\hline S.\# & Questions and Filters & Responses and Codes \\
\hline G9 & $\begin{array}{l}\text { Are there places in or near your community that you are not } \\
\text { allowed to go to at all? }\end{array}$ & 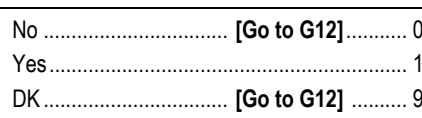 \\
\hline G10 & What places are you not allowed to go to at all? & 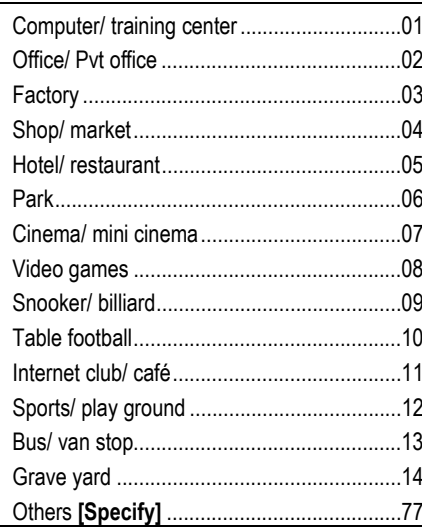 \\
\hline G11 & $\begin{array}{l}\text { What is/ are the main reasons that you are not allowed to go to } \\
\text { these places? } \\
\text { [Multiple responses possible] }\end{array}$ & $\begin{array}{l}\text { Bad for personal reputation } \\
\text { Bad for family's reputation } \\
\text { She may be spoken badly of } \\
\text { Harassed by others } \\
\text { Physically harmed } \\
\text { Eve teasing } \\
\text { Indulge in bad company } \\
\text { Drug addiction } \\
\text { Place too far/ no transport } \\
\text { Costs too much/ economic concern } \\
\text { Family tradition/ family oppose } \\
\text { Immoral activities } \\
\text { Others [Specify] } \\
\text { DK }\end{array}$ \\
\hline $\mathrm{G} 12$ & $\begin{array}{l}\text { What are some things you do for recreation/ fun when you have } \\
\text { spare time? } \\
\text { [Multiple responses possible] }\end{array}$ & 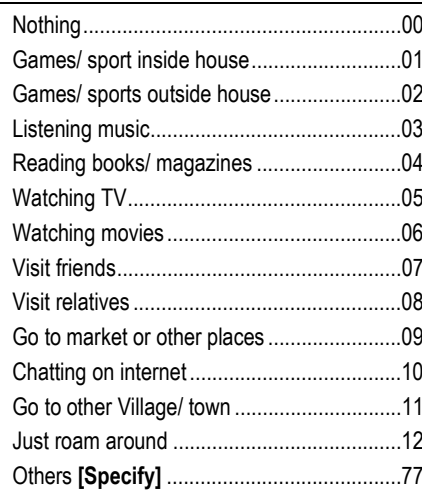 \\
\hline
\end{tabular}




\begin{tabular}{|c|c|c|}
\hline S.\# & Questions and Filters & Responses and Codes \\
\hline G13 & $\begin{array}{l}\text { Other than these, what sort of recreational activities would you like } \\
\text { to be able to do? } \\
\text { [Multiple responses possible] }\end{array}$ & 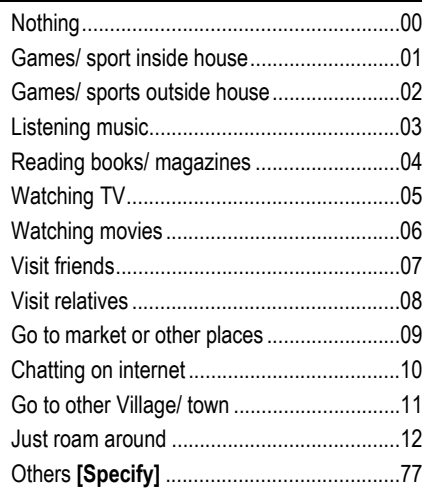 \\
\hline
\end{tabular}

\begin{tabular}{|c|c|c|c|c|c|c|c|c|c|c|c|c|c|c|c|}
\hline \multirow[t]{8}{*}{ G14 } & $\begin{array}{l}\text { Who would } \\
\text { you ask if } \\
\text { you had a } \\
\text { question } \\
\text { about }\end{array}$ & $\begin{array}{l}\text { ò } \\
\text { ○े }\end{array}$ & 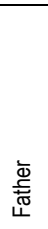 & 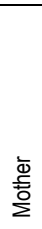 & 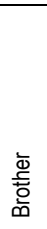 & $\begin{array}{l}\frac{\bar{s}}{\mathrm{~m}} \\
\frac{\mathrm{m}}{\omega}\end{array}$ & 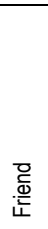 & $\begin{array}{l}\frac{c}{w} \\
\overline{0} \\
\text { o }\end{array}$ & 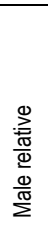 & 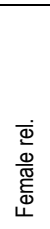 & $\begin{array}{l}\text { \% } \\
\text { పे } \\
\text { के }\end{array}$ & 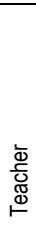 & 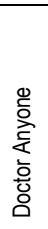 & 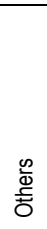 & $\Sigma$ \\
\hline & $\begin{array}{l}\text { [Code all } \\
\text { that apply] }\end{array}$ & 01 & 02 & 03 & 04 & 05 & 06 & 07 & 08 & 09 & 10 & 11 & 12 & 77 & 88 \\
\hline & $\begin{array}{l}\text { a) General } \\
\text { health }\end{array}$ & & & & & & & & & & & & & & \\
\hline & $\begin{array}{l}\text { b) Sensitive } \\
\text { health }\end{array}$ & & & & & & & & & & & & & & \\
\hline & $\begin{array}{l}\text { c) Work } \\
\text { opportunities }\end{array}$ & & & & & & & & & & & & & & \\
\hline & $\begin{array}{l}\text { d) Schooling } \\
\text { opportunities }\end{array}$ & & & & & & & & & & & & & & \\
\hline & $\begin{array}{l}\text { e) } \\
\text { Engagement, } \\
\text { marriage }\end{array}$ & & & & & & & & & & & & & & \\
\hline & $\begin{array}{l}\text { f) How to } \\
\text { settle a } \\
\text { conflict you } \\
\text { were havil }\end{array}$ & & & & & & & & & & & & & & \\
\hline
\end{tabular}

\begin{tabular}{|c|c|c|}
\hline S.\# & Questions and Filters & Responses and Codes \\
\hline G15 & $\begin{array}{l}\text { Who would you go to talk to if someone did something that upset } \\
\text { you? } \\
\text { [Multiple responses possible] }\end{array}$ & 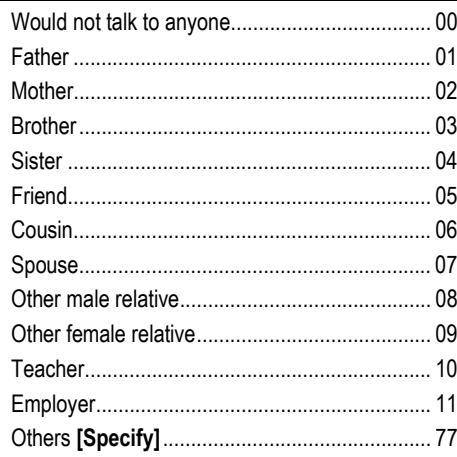 \\
\hline G16 & $\begin{array}{l}\text { In the past week, how many times did you spend an hour or more } \\
\text { visiting with friends, not including time spent at workplace or in } \\
\text { school? }\end{array}$ & \# of times \\
\hline G17 & $\begin{array}{l}\text { [Observation] Presence of others at this point? } \\
\text { [Multiple responses possible] }\end{array}$ & $\begin{array}{l}\text { No one person } \\
\text { Children under } 12 \\
\text { Mother/ in law } \\
\text { Father/ in law } \\
\text { Other males } \\
\text { Other female }\end{array}$ \\
\hline
\end{tabular}




\section{H. FERTILITY AND MARRIAGE}

\begin{tabular}{|c|c|c|}
\hline S.\# & Questions and Filters & Responses and Codes \\
\hline $\mathrm{H} 1$ & Have you begun to have monthly menstrual periods? & 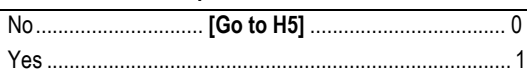 \\
\hline $\mathrm{H} 2$ & $\begin{array}{l}\text { How old were you when you first got a menstrual period? } \\
\text { [Probe for the most accurate answer possible] }\end{array}$ & Age in years. \\
\hline $\mathrm{H} 3$ & $\begin{array}{l}\text { Were you informed about monthly menstrual cycles before } \\
\text { they started? }\end{array}$ & 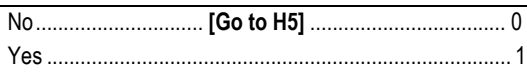 \\
\hline $\mathrm{H} 4$ & $\begin{array}{l}\text { From where/ by whom did you get information regarding } \\
\text { menstrual cycles before they started? } \\
\text { [Multiple responses possible] }\end{array}$ & 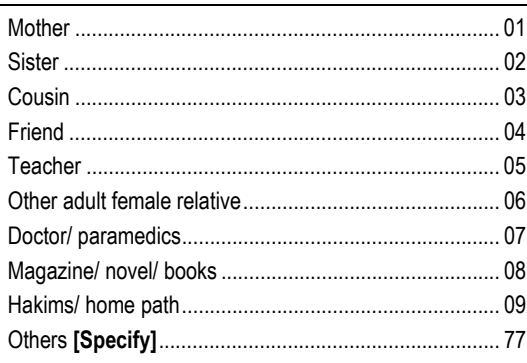 \\
\hline $\mathrm{H} 5$ & $\begin{array}{l}\text { Do you think young girls should be informed about the } \\
\text { menstrual cycles before they begun? }\end{array}$ & 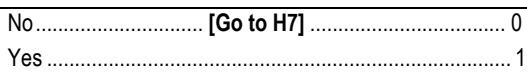 \\
\hline $\mathrm{H} 6$ & $\begin{array}{l}\text { Who do you think should inform girls about menstural } \\
\text { cycle? } \\
\text { [Multiple responses possible] }\end{array}$ & 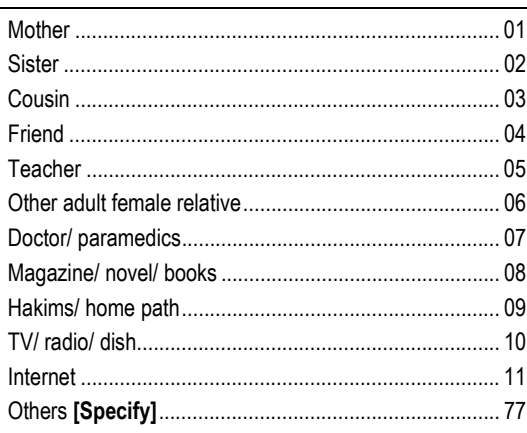 \\
\hline
\end{tabular}

READ OUT FOR MALE RESPONDENT

For boys: As boys begin to mature into men, certain changes occur in their bodies - for example, their voices become deeper, For boys: As boys begin to mature into men, certain changes occur in their bodies - for example, their voices become deeper, on

\begin{tabular}{|c|c|c|}
\hline S.\# & Questions and Filters & Responses and Codes \\
\hline $\mathrm{HO}$ & [Observation] Is boy visibly past puberty? & 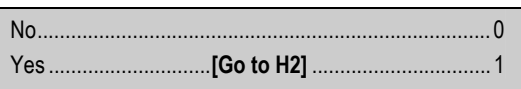 \\
\hline $\mathrm{H} 1$ & Have any of these changes begun to happen to you? & 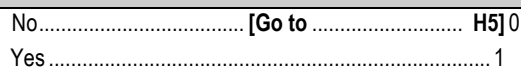 \\
\hline $\mathrm{H} 2$ & $\begin{array}{l}\text { At what age did you first notice such changes } \\
\text { happening in your body? } \\
\text { [Probe for the most accurate answer possible] }\end{array}$ & 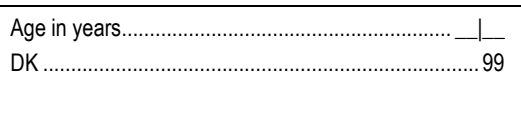 \\
\hline $\mathrm{H} 3$ & $\begin{array}{l}\text { Were you informed about such changes before any of } \\
\text { them happening in your body? }\end{array}$ & 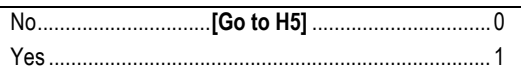 \\
\hline $\mathrm{H} 4$ & $\begin{array}{l}\text { From where/ by whom did you get information } \\
\text { regarding such changes before any of them happening } \\
\text { in your body? } \\
\text { [Multiple responses possible] }\end{array}$ & 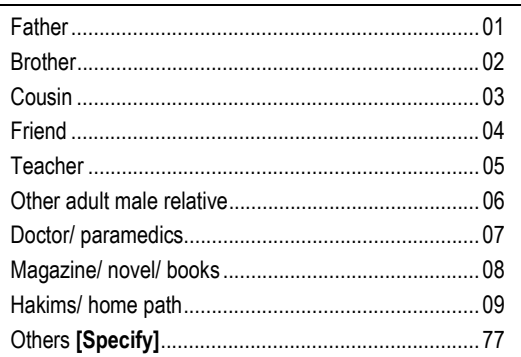 \\
\hline $\mathrm{H} 5$ & $\begin{array}{l}\text { Do you think young boys should be informed about } \\
\text { these changes before happening? }\end{array}$ & 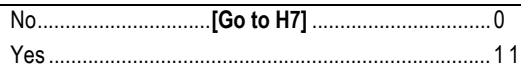 \\
\hline $\mathrm{H} 6$ & $\begin{array}{l}\text { Who do you think should imform such information to } \\
\text { young boys? } \\
\text { [Multiple responses posible] }\end{array}$ & 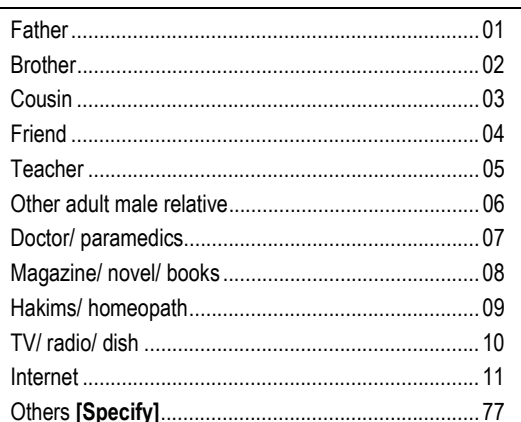 \\
\hline
\end{tabular}




\begin{tabular}{|c|c|c|}
\hline S.\# & Questions and Filters & Responses and Codes \\
\hline $\mathrm{H} 21 \mathrm{~b}$ & Who selected your husband? & $\begin{array}{l}\text { Parents } \\
\text { Family } \\
\text { Parents and self } \\
\text { Family and self } \\
\text { Self only } \\
\text { Others [Specify }\end{array}$ \\
\hline $\mathrm{H} 21 \mathrm{c}$ & $\begin{array}{l}\text { Why was your husband selected? } \\
\text { [Multiple responses possible] }\end{array}$ & 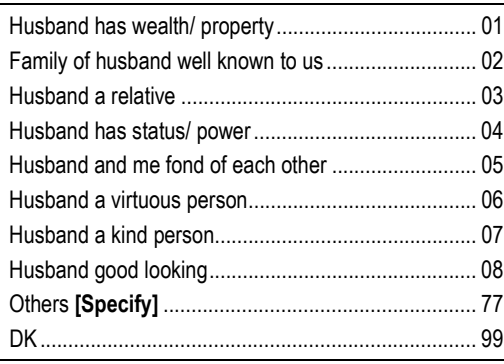 \\
\hline $\mathrm{H} 22$ & $\begin{array}{l}\text { What were the items of the dowry? } \\
\text { [Multiple responses posible] }\end{array}$ & $\begin{array}{l}\text { Land/ house } \\
\text { Carl motor cycle } \\
\text { TV, Fridge, VCR } \\
\text { Other electronics } \\
\text { Furniture } \\
\text { Clothing } \\
\text { Jewelry } \\
\text { Crockery } \\
\text { Oash }\end{array}$ \\
\hline $\mathrm{H} 23$ & $\begin{array}{l}\text { What was the value of [NAME]. } \\
\text { ( Convert into Rs.) } \\
\text { [Probe for the most accurate answer } \\
\text { possible] } \\
\text { [Code } 88 \text { if NA, code } 99 \text { if DK] }\end{array}$ & $\begin{array}{l}\text { a) Haq Mehar } \\
\text { b) Bride price } \\
\text { (Paid to bride's parents by in laws) } \\
\text { c) Other items } \\
\text { (Paid to bride by in laws) }\end{array}$ \\
\hline \multicolumn{3}{|r|}{ Go to $H 30$} \\
\hline H24 & $\begin{array}{l}\text { How old would you like to be when you get } \\
\text { married? }\end{array}$ & 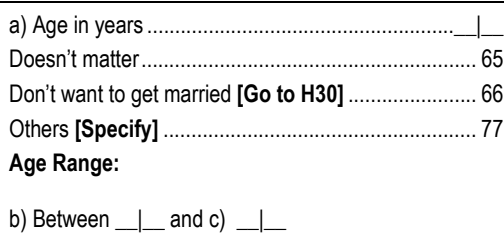 \\
\hline
\end{tabular}

\begin{tabular}{|c|c|c|}
\hline S.\# & Questions and Filters & Responses and Codes \\
\hline H25 & $\begin{array}{l}\text { What do you think are the main reasons that you } \\
\text { should get married at this age? } \\
\text { [Multiple responses posible] }\end{array}$ & Able to complete education \\
\hline H26 & Who would you want to choose your husband? & $\begin{array}{l}\text { Parents } \\
\text { Family } \\
\text { Parents and self } \\
\text { Family and self } \\
\text { Self only } \\
\text { Others [Specify] }\end{array}$ \\
\hline H27 & $\begin{array}{l}\text { Have you thought about how many children you } \\
\text { would like to have? }\end{array}$ & $\begin{array}{l}\text { No } \\
\text { Yes }\end{array}$ \\
\hline H28 & How many boys and girls? & 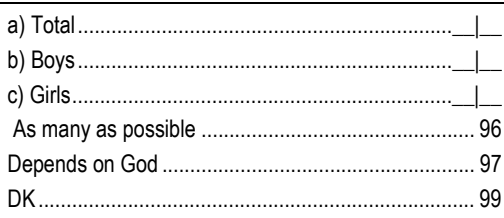 \\
\hline $\mathrm{H} 2 \mathrm{~g}$ & $\begin{array}{l}\text { How soon after getting married do you think a } \\
\text { couple should have their first child? }\end{array}$ & 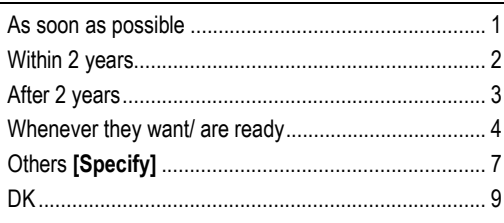 \\
\hline $\mathrm{H} 30$ & $\begin{array}{l}\text { Was the question of who you should be } \\
\text { engaged to or marry ever discussed in your } \\
\text { household? }\end{array}$ & 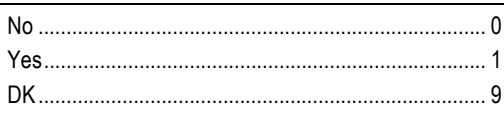 \\
\hline
\end{tabular}




\begin{tabular}{|c|c|c|}
\hline S. \# & Questions and Filters & Responses and Codes \\
\hline $\mathrm{H} 31$ & $\begin{array}{l}\text { Were you able to express an opinion on this } \\
\text { issue in your household? }\end{array}$ & 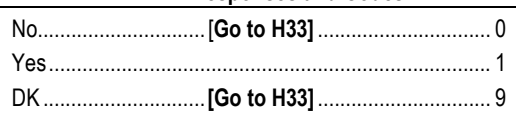 \\
\hline $\mathrm{H} 32$ & Do you feel your opinion was listened to? & $\begin{array}{l}\text { No } \\
\text { Yes } \\
\text { DK } 1-1\end{array}$ \\
\hline $\mathrm{H} 33$ & $\begin{array}{l}\text { [Observation] Presence of others at this point? } \\
\text { [Multiple responses possible] }\end{array}$ & 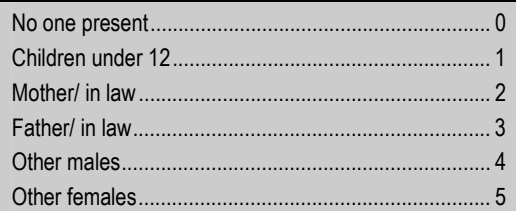 \\
\hline
\end{tabular}

REPRODUCTIVE HISTORY [Only for married respondents]

Now I would like to ask about your reproductive history.

\begin{tabular}{|c|c|c|}
\hline S.\# & Questions and Filters & Responses and Codes \\
\hline $\mathrm{H} 34$ & Have you ever been pregnant? & $\begin{array}{l}\text { No } \\
\text { Yes } \\
\text { Unsure }\end{array}$ \\
\hline H35 & $\begin{array}{l}\text { How old were you the first time you became } \\
\text { pregnant? } \\
\text { [Probe for the most accurate answer possible] }\end{array}$ & 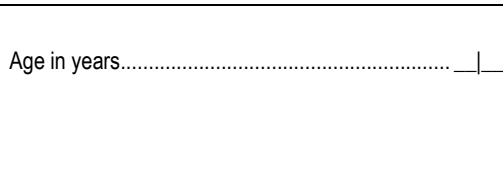 \\
\hline H36 & Are you currently pregnant? & $\begin{array}{l}\text { No } \\
\text { Yes } \\
\text { Unsure }\end{array}$ \\
\hline H37 & $\begin{array}{l}\text { How many times have you been pregnant, total } \\
\text { [including current pregnancy]? }\end{array}$ & $\begin{array}{l}\text { \# of pregnancies } \\
\text { DK }\end{array}$ \\
\hline $\mathrm{H} 38$ & $\begin{array}{l}\text { How many live births have you ever had in your } \\
\text { lifetime? } \\
\text { Please include those babies who cried or showed } \\
\text { any signs of life; do not include any babies that were } \\
\text { stillborn [no longer alive when born]. }\end{array}$ & 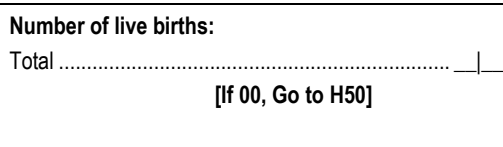 \\
\hline
\end{tabular}


Now I would like to ask you a few questions about all your live births, starting with the first one you had. [lf more than 3 , ask about 3 earliest.]

\begin{tabular}{|c|c|c|c|c|c|}
\hline & QUESTION & BIRTH \#1 (first) & BIRTH \#2 (next earliest) & $\begin{array}{l}\text { BIRTH \#3 (third } \\
\text { earliest) }\end{array}$ & BIRTH (for Twin) \\
\hline H39 & $\begin{array}{l}\text { Name and line \# of child? } \\
\text { [Code } 00 \text { if not listed in } \\
\text { Roster] }\end{array}$ & -1 & $-\_$ & -1 & 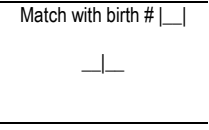 \\
\hline $\mathrm{H} 40$ & Is [Name] boy or a girl? & 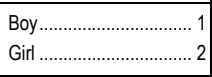 & 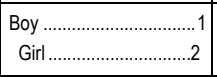 & 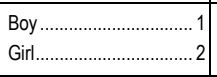 & 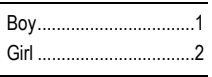 \\
\hline H41 & $\begin{array}{l}\text { Was [Name] single birth, or a } \\
\text { multiple birth (wwins, triplets, } \\
\text { etc.)? }\end{array}$ & 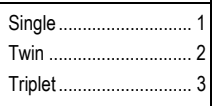 & 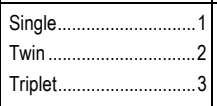 & 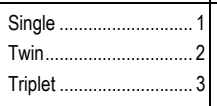 & 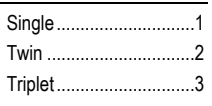 \\
\hline H42 & $\begin{array}{l}\text { In what month and year was } \\
\text { [Name] born? } \\
\text { PROBE: What is [Name] } \\
\text { birthday? OR In what season } \\
\text { was he/she born? } \\
\text { [Record season only if month } \\
\text { not known] }\end{array}$ & 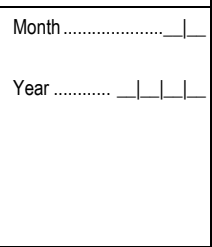 & 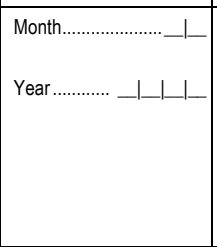 & 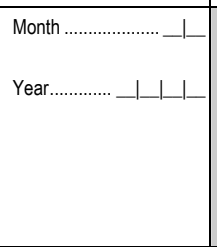 & \\
\hline H42a & $\begin{array}{l}\text { Age of (name) } \\
\text { [ln completed yers] }\end{array}$ & Years......................- & Years .....................-1- & Years.....................-1- & \\
\hline H43 & Is [Name] still alive? & \begin{tabular}{|l|} 
No $\ldots . . . \ldots \ldots \ldots \ldots \ldots \ldots \ldots \ldots . . . .$. \\
Yes. [Go to H45]......... 1
\end{tabular} & \begin{tabular}{|l|} 
No $. . . \ldots \ldots \ldots \ldots \ldots \ldots \ldots \ldots \ldots . .$. \\
Yes[Go to H45] .......... 1
\end{tabular} & $\begin{array}{l}\text { No........................ } \\
\text { Yes [Go to H45] ......... } 11\end{array}$ & $\begin{array}{l}\text { No ......................... } \\
\text { Yes.............. [Go to H45]. }\end{array}$ \\
\hline H44 & $\begin{array}{l}\text { IF DEAD: How old was [Name] } \\
\text { when died? } \\
\text { IF "1 YEAR," PROBE: How } \\
\text { many months/days old was } \\
\text { [Name]? } \\
\text { [Record days if under } 1 \text { month, } \\
\text { months if under } 1 \text { year] }\end{array}$ & 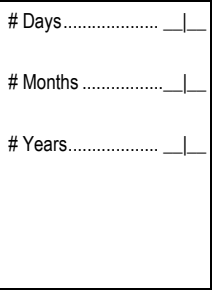 & 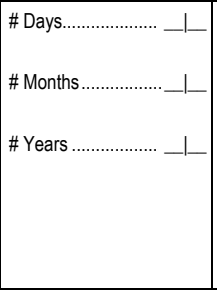 & $\begin{array}{l}\text { \# Days................... } \_-1 \\
\text { \# Months................... } \_-1 \\
\text { \# Years .................... } \_-1\end{array}$ & 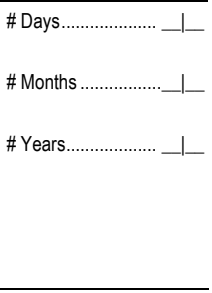 \\
\hline
\end{tabular}

\begin{tabular}{|c|c|c|c|c|}
\hline $\mathrm{H} 45$ & $\begin{array}{l}\text { When you were pregnant } \\
\text { with [Name], did you go for } \\
\text { any antenatal care? }\end{array}$ & 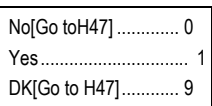 & $\mid$\begin{tabular}{|l|} 
No[Go toH47] $\ldots \ldots \ldots \ldots . . . .0$ \\
Yes ....................... \\
DK[Go to H47] .......... 9
\end{tabular} & $\begin{array}{l}\text { No[Go toH47] ............ } 0 \\
\text { Yes....................... } 1 \\
\text { DK[Go to H47] .......... } 9\end{array}$ \\
\hline $\mathrm{H} 46$ & $\begin{array}{l}\text { How many times did you go } \\
\text { for and receive antenatal } \\
\text { care? } \\
\text { [Probe for most accurate } \\
\text { answer possible] }\end{array}$ & $\begin{array}{l}\text { \# of times................ }-1 \\
\text { DK } \ldots . \ldots \ldots \ldots \ldots . . . . . . . . . . . .99\end{array}$ & \begin{tabular}{|l|} 
\# of times .................. -1 \\
DK.............................
\end{tabular} & 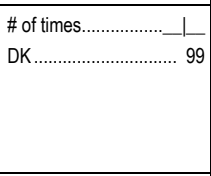 \\
\hline $\mathrm{H} 47$ & $\begin{array}{l}\text { Where were you living } \\
\text { before the time [Name] was } \\
\text { born, at Natal home or in } \\
\text { laws? }\end{array}$ & 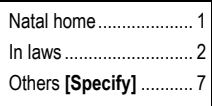 & 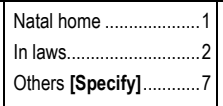 & $\begin{array}{l}\text { Natal home.................... } \\
\text { In laws..................... } \\
\text { Others [Specify] ........... }\end{array}$ \\
\hline $\mathrm{H} 48$ & $\begin{array}{l}\text { Where was [Name] born? } \\
\text { At home, or at a medical } \\
\text { institution? }\end{array}$ & \begin{tabular}{|l|} 
At home ....................... \\
At medical facility .......... \\
Others [Specify] ...........7
\end{tabular} & \begin{tabular}{|l|} 
At home ......................... \\
At medical facility ..........2 \\
Others [Specify] ............
\end{tabular} & 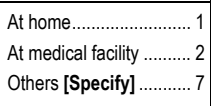 \\
\hline H49 & $\begin{array}{l}\text { Who assisted at the birth of } \\
\text { [Name]? } \\
\text { [Multiple responses } \\
\text { possible] }\end{array}$ & $\begin{array}{l}\text { No one..................... } 0 \\
\text { Relative/ Friend .......... } 1 \\
\text { Traditional Practitioner...2 } \\
\text { Medical person ............. } \\
\text { Others [Specify]........... }\end{array}$ & \begin{tabular}{|c|} 
No one ....................... \\
Relative/ Friend.......... \\
Tradititional Practitioner...2 \\
Medical person ............. \\
Others [Specify] ...........
\end{tabular} & $\begin{array}{l}\text { No one........................ } 0 \\
\text { Relative/ Friend ............. } 1 \\
\text { Traditional Practitioner ...2 } \\
\text { Medical person ............. } \\
\text { Others [Specify] ........... }\end{array}$ \\
\hline
\end{tabular}




\begin{tabular}{|c|c|c|}
\hline S. \# & Questions and Filter & Responses and Codes \\
\hline $\mathrm{H} 5 \mathrm{O}$ & Is there any special care a woman needs when she is pregnant? & $\begin{array}{l}\text { No } \\
\text { Yes } \\
\text { DK } \\
\text {. } \\
\text { [Go to H5o toH52] } 0\end{array}$ \\
\hline H51 & $\begin{array}{l}\text { What kind of special care does a pregnant woman need? } \\
\text { [Multiple responses possible] }\end{array}$ & 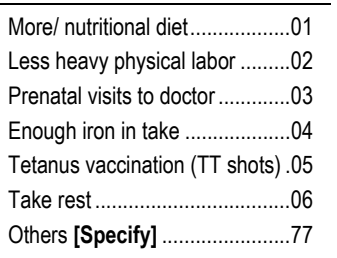 \\
\hline H52 & $\begin{array}{l}\text { How soon after a couple gets married do you think they should have their } \\
\text { first child? }\end{array}$ & 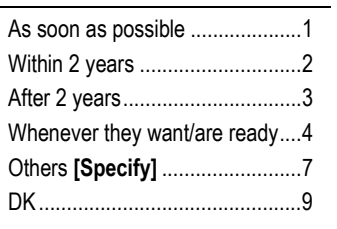 \\
\hline H53 & $\begin{array}{l}\text { How many children in total, would you like to have in your lifetime? How } \\
\text { many boys and girls }\end{array}$ & 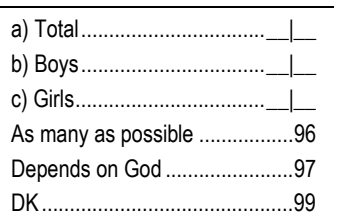 \\
\hline H54 & Have you ever discussed how many children to have with your husband? & 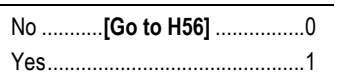 \\
\hline H55 & Do you agree with your husband on the number of children to have? & 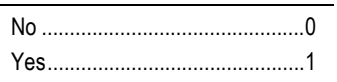 \\
\hline H56 & $\begin{array}{l}\text { Have you or your husband ever used any ways or methods to space or limit } \\
\text { births? }\end{array}$ & 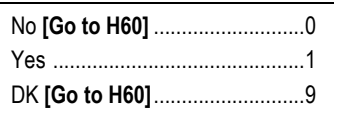 \\
\hline H57 & $\begin{array}{l}\text { Are you or your husband currently using any methods to space or limit } \\
\text { births? }\end{array}$ & 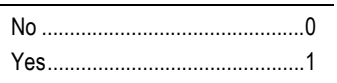 \\
\hline
\end{tabular}

\begin{tabular}{|c|c|c|}
\hline S.\# & Questions and Filter & Response and Codes \\
\hline H58 & $\begin{array}{l}\text { Which methods have you or your husband ever used to space or limit } \\
\text { births? } \\
\text { [Multiple responses possible] } \\
\text { [For the method currently in use also tick () after circling] }\end{array}$ & 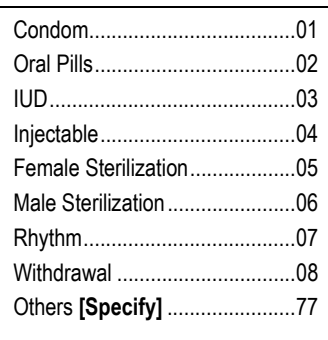 \\
\hline H59 & $\begin{array}{l}\text { How old were you the first time you or your husband used any method to } \\
\text { space or limit births? } \\
\text { [Probe for the most accurate answer possible] }\end{array}$ & Age in years .........................._- \\
\hline $\mathrm{H} 60$ & Will you or your husband use FP method in future? & $\begin{array}{l}\text { No [Go to H62] } \ldots \ldots \ldots \ldots \ldots \ldots \ldots \ldots . . .1 \\
\text { Yes }\end{array}$ \\
\hline H61 & [Multiple responses possible] & 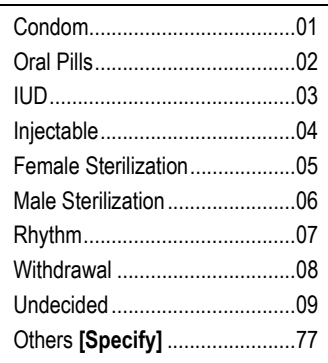 \\
\hline $\mathrm{H} 62$ & $\begin{array}{l}\text { [Observation] Presence of others at this point? } \\
\text { [Multiple responses possible] }\end{array}$ & 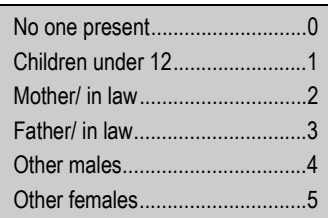 \\
\hline
\end{tabular}




\section{HOME CONDITIONS AT AGE 15}

[Check]. From Life Event Calendar and enter year when Respondent was 15

Now I would like to ask you some questions about conditions in your household when you turned 15 years old - that s, in [year entered above]. [Please do your best to accurately remember conditions in your household at that time, and to answer the following questions accordingly].

\begin{tabular}{|c|c|c|}
\hline S.\# & Questions and Filters & Responses and Codes \\
\hline i1 & $\begin{array}{l}\text { Is respondent less than } 16 \text { years old? } \\
\text { [Check from B1] }\end{array}$ & 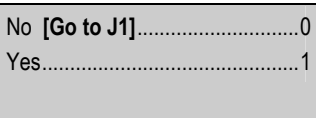 \\
\hline i2 & $\begin{array}{l}\text { What was the status of the dwelling you lived in when you were } 15 \text {, did you } \\
\text { own it, did you rent it, or did the government allot it? }\end{array}$ & 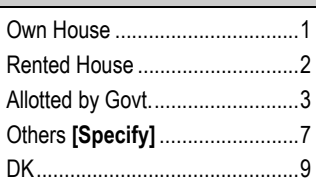 \\
\hline i3 & $\begin{array}{l}\text { Are you still living in the same dwelling in which you were living when you } \\
\text { were } 15 \text { ? }\end{array}$ & 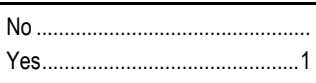 \\
\hline i4 & $\begin{array}{l}\text { Have there been any important structural changes in your dwelling since } \\
\text { you were } 15 \text { ? }\end{array}$ & $\begin{array}{l}\text { No [Go to i11] } \\
\text { Yes..... } \\
\text { DK } \\
\end{array}$ \\
\hline i5 & How many (living) rooms were there in your dwelling, at that time? & 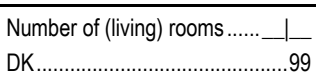 \\
\hline i6 & What kind of kitchen did you have in your dwelling? & $\begin{array}{l}\text { Separate room for cooking ..........1 } \\
\text { Cook in living room of house .......2 } \\
\text { Use open space for cooking ........ } \\
\text { Others [Specify] } \ldots \ldots \ldots \ldots \ldots \ldots . . .7\end{array}$ \\
\hline i7 & What type of latrine/ toilet facility did your dwelling have? & 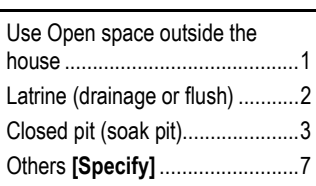 \\
\hline
\end{tabular}

\begin{tabular}{|c|c|c|}
\hline i8 & What type of main entrance does your dwelling had? & 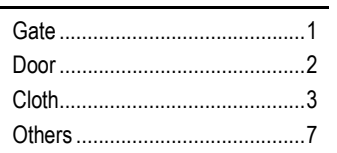 \\
\hline i9 & Did your dwelling have a boundry wall? & 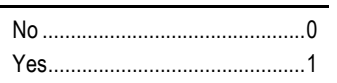 \\
\hline
\end{tabular}




\begin{tabular}{|c|c|c|}
\hline S. \# & Questions and Filters & Respondents and Codes \\
\hline \multirow[t]{4}{*}{$\mathrm{i10}$} & What were the following parts of your dwelling primarily made of? & \\
\hline & a) Roof & 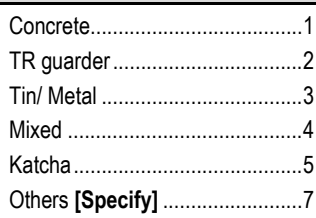 \\
\hline & b) Floor & 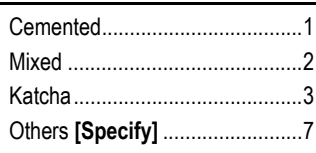 \\
\hline & c) Walls & 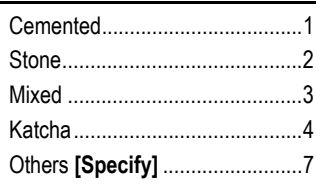 \\
\hline i11 & Who was the main earner in your household when you were $15 ?$ & 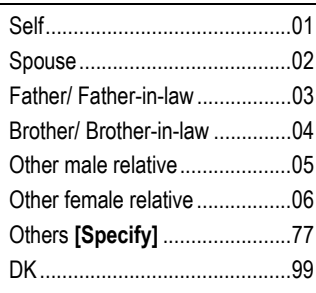 \\
\hline$i 12$ & $\begin{array}{l}\text { What was/ were the main sources of income in your household? } \\
\text { [Multiple responses possible] }\end{array}$ & 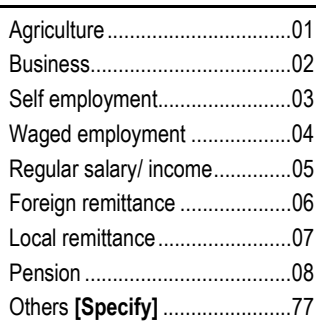 \\
\hline
\end{tabular}

\begin{tabular}{|c|c|c|c|}
\hline S. \# & Questions and Filters & \multicolumn{2}{|c|}{ Responses and Codes } \\
\hline \multirow[t]{6}{*}{ i13 } & Was your dwelling equipped with any of these amenities when you were $15 ?$ & No & Yes \\
\hline & a) Electricity & 0 & 1 \\
\hline & b) Piped natural gas & 0 & 1 \\
\hline & c) LPG gas cylinder & 0 & 1 \\
\hline & d) Piped water [Govt. supply] & 0 & 1 \\
\hline & e) Telephone & 0 & 1 \\
\hline \multirow[t]{10}{*}{ i14 } & $\begin{array}{l}\text { Which of the following items did your household have at home, when you } \\
\text { were } 15 \text { ? }\end{array}$ & No & Yes \\
\hline & a) Cycle & 0 & 1 \\
\hline & b) Motor Cycle & 0 & 1 \\
\hline & c) Car/ Van & 0 & 1 \\
\hline & d) Radio & 0 & 1 \\
\hline & e) TV & 0 & 1 \\
\hline & f) Dish/ Cable & 0 & 1 \\
\hline & g) VCR & 0 & 1 \\
\hline & h) Refrigerator & 0 & 1 \\
\hline & i) Computer & 0 & 1 \\
\hline i15 & From where did you get your drinking water? & \multicolumn{2}{|c|}{ 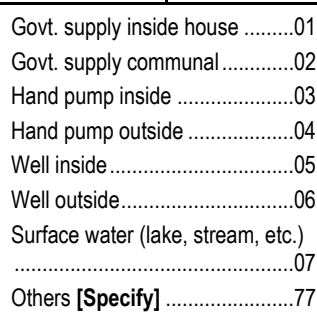 } \\
\hline i16 & Did your household own plot or agriculture land at that time? & \multicolumn{2}{|c|}{$\begin{array}{l}\text { No [Go to i18] } \\
\text { Yes } \ldots \ldots \ldots \ldots \ldots \\
\end{array}$} \\
\hline$i 17$ & What was the size of land/ plot your household owned at that time? & \multicolumn{2}{|c|}{$\begin{array}{l}\text { Non-Agriculture } \\
\text { a) Land/ plot in Marla.......____ } \\
\text { b) Land/ plot in Kanal......____ } \\
\text { Agriculture } \\
\text { c) Agricultural land in Kanal } \\
\text { d) Agricultural land in Acres }\end{array}$} \\
\hline i18 & Did your household own livestock? & \multicolumn{2}{|c|}{$\begin{array}{l}\text { No [Go to i20] } \\
\text { Yes }\end{array}$} \\
\hline
\end{tabular}




\begin{tabular}{|c|c|c|}
\hline S. \# & Questions and Filters & Responses and Codes \\
\hline$i 19$ & $\begin{array}{l}\text { Which livestock did your } \mathrm{HH} \text { have at that time? Write the number } \\
\text { of each livestock. } \\
\text { [Code } 00 \text { for none] }\end{array}$ & 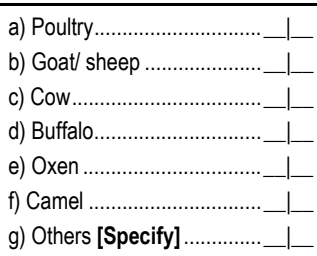 \\
\hline
\end{tabular}

Now I want to get a sense of how free you were to move around in your community when you were 15 years old. I am going to read you a list of places.

\begin{tabular}{|c|c|c|c|}
\hline \multicolumn{4}{|c|}{ When you were 15, would your parents have allowed you to go to [place] alone? } \\
\hline & Place & 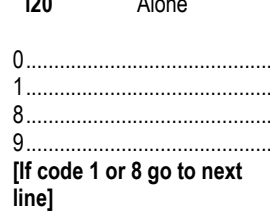 & $\begin{array}{l}\text { 121. Accompanied } \\
0 . \\
1 \\
8 \\
9\end{array}$ \\
\hline \multicolumn{4}{|c|}{ a) Neighbor } \\
\hline \multicolumn{4}{|c|}{ b) Nearby shop } \\
\hline \multicolumn{4}{|c|}{ c) School } \\
\hline \multicolumn{4}{|c|}{ d) Sports ground } \\
\hline \multicolumn{4}{|c|}{ e) Friends } \\
\hline \multicolumn{4}{|c|}{ f) Relatives } \\
\hline \multicolumn{4}{|c|}{ g) Field inside village } \\
\hline \multicolumn{4}{|c|}{ h) Field outside village } \\
\hline \multicolumn{4}{|c|}{ i) Other nearby community } \\
\hline \multicolumn{4}{|c|}{ j) Nearby health outlet } \\
\hline 122 & [Observation] $\mathrm{F}$ & $\begin{array}{l}\text { at this point. } \\
\text { es possible] }\end{array}$ & 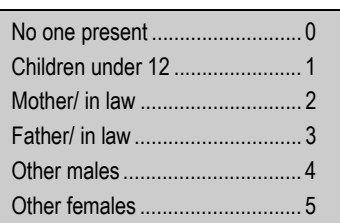 \\
\hline
\end{tabular}

\section{J. MIGRATION}

\begin{tabular}{|c|c|c|}
\hline S.\# & Questions and Filters & Responses and Codes \\
\hline $\mathrm{J} 1$ & $\begin{array}{l}\text { Which (village/ town/ city) have you lived in your lifetime? Write \# of places. } \\
\text { [Code } 00 \text { if none] }\end{array}$ & 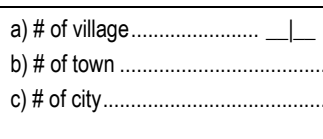 \\
\hline $\mathrm{J} 2$ & $\begin{array}{l}\text { How old were you when moved to this (village/ town/ city)? } \\
\text { [Probe for the most accurate answer possible] }\end{array}$ & Age in years ......................_- \\
\hline $\mathrm{J} 3$ & $\begin{array}{l}\text { How long ago did you move to this (village/ town/ city)? } \\
\text { [Code in years, if less than a year code in months] }\end{array}$ & $\begin{array}{l}\text { Months ago } \ldots . . . . . . . . . . . . . . . . . . .1-1-1 \\
\text { Years ago........................_- }\end{array}$ \\
\hline $\mathrm{J} 4$ & $\begin{array}{l}\text { What were the reasons for your move to this (village /town/ city)? } \\
\text { [Multiple responses possible] }\end{array}$ & 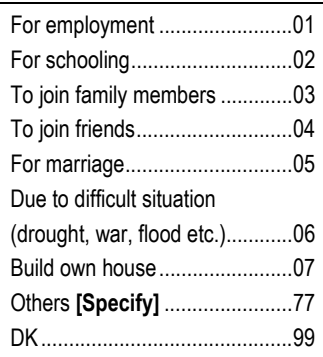 \\
\hline $\mathrm{J} 5$ & $\begin{array}{l}\text { Who made the decision to move here, when you moved to this (village/ town/ } \\
\text { city)? } \\
\text { [Multiple responses possible] }\end{array}$ & 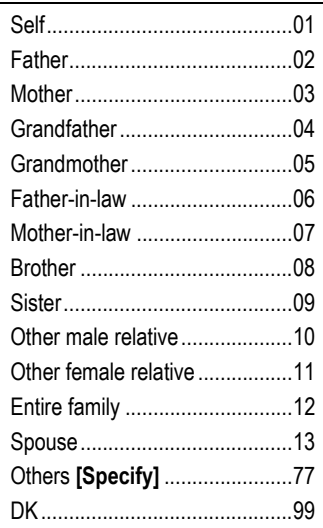 \\
\hline
\end{tabular}




\begin{tabular}{|c|c|c|}
\hline S.\# & Questions and Filters & Responses and Codes \\
\hline J6 & $\begin{array}{l}\text { Who came with you when you moved to this (village/ town/ city)? } \\
\text { [Multiple responses possible] }\end{array}$ & 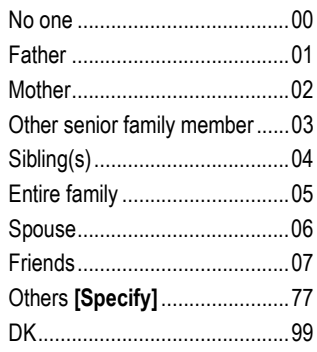 \\
\hline J7 & $\begin{array}{l}\text { [Observation] Presence of others at this point. } \\
\text { [Multiple responses possible] }\end{array}$ & $\begin{array}{l}\text { No one present } \\
\text { Children under } 12 \\
\text { Mother/ in law } \\
\text { Father/ in law } \\
\text { Other males }\end{array}$ \\
\hline
\end{tabular}

[Go to Identification page and complete it. Continue with other Adolescents (if more

respondents are available) otherwise thank the respondent, say goodbye and leave the house]. 


\section{Transition to Adulthood:}

Education, Work and Marriage among Adolescents and Youth in Pakistan

\section{Household Profile}


Greet: (Assalam-o-Alaikam)

My name is__ . I belong to Population Council Islamabad. A national survey is being carried out in four provinces of Pakistan. We are collecting information regarding Education, Work, Health and Marriage throug young boys and girls age 15-24. We need your co-operation in this regard. We need information about al

household members in a sampled household, so we can identify boys and girls of age 15-24, and can get

information regarding the facilities available in this household as well.

Please be assured that your responses are confidential. Your participation is voluntary and if there is any question that you don't like, you are not bound to answer that. If you permit, may I start the interview?

\section{List of contents}

Introduction

Identification

Household roster

Household structure

Attitudes towards adolescents (15-24)
IDENTIFICATION

\begin{tabular}{|c|c|c|c|c|c|c|c|}
\hline \multicolumn{8}{|c|}{ AREA } \\
\hline \multicolumn{2}{|c|}{ 2. District: } & $\_-$ & 3. Tehsil: & ـ & \multicolumn{3}{|c|}{ 4. PSU Code:_|_|_|_|_|_ } \\
\hline \multicolumn{2}{|c|}{ 5. Name of Community: } & - & & & \multicolumn{3}{|c|}{ 6. HH Code:_L__ } \\
\hline \multicolumn{8}{|c|}{ RESPONDENT } \\
\hline \multicolumn{2}{|c|}{ 7. Name and line \# of Respondent: } & - & & \multicolumn{3}{|c|}{ 8. Name and line \# of $\mathrm{HHH}$ : } & - - \\
\hline \multicolumn{4}{|c|}{ 9. Caste of $\mathrm{HHH}$ : } & \multicolumn{4}{|c|}{ 10. Relationship with $\mathrm{HHH}$ : } \\
\hline \multicolumn{8}{|c|}{ INTERVIEW } \\
\hline Visits & \multicolumn{2}{|l|}{ a. Interviewer } & \multicolumn{2}{|c|}{ b. Date } & \multicolumn{2}{|c|}{$\begin{array}{l}\text { c. Result [lf not }=1 \\
\text { Specify] }\end{array}$} & Result Codes \\
\hline 11 & \multicolumn{2}{|c|}{-1 } & \multicolumn{2}{|c|}{ 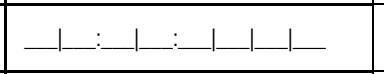 } & & & $\begin{array}{ll}1 & \text { Completed } \\
2 & \text { Partially }\end{array}$ \\
\hline 12 & -1 & \multicolumn{3}{|c|}{-1 : - L : - _ L } & & & $\begin{array}{ll}3 & \text { Absent } \\
4 & \text { Refusal }\end{array}$ \\
\hline 13 & -1 & \multicolumn{3}{|c|}{$-1-1-1-1-1-$} & & & $\mid \begin{array}{ll}5 & \text { HH Not } \\
& \text { Located } \\
7 & \text { Others }\end{array}$ \\
\hline \multicolumn{2}{|c|}{ 14. Time Started: ___ } & \multicolumn{3}{|c|}{ 15. Time Ended: _ـ_ : _ـ } & \multicolumn{3}{|c|}{ 16. Duration (in minutes): _____ } \\
\hline \multicolumn{8}{|c|}{ To be filled by interviewer after completing $\mathrm{HH}$ Roster and before leaving $\mathrm{HH}$} \\
\hline & & \multicolumn{2}{|c|}{ a. Total } & \multicolumn{2}{|c|}{ b. Male } & \multicolumn{2}{|c|}{ c. Female } \\
\hline 17. $\mathrm{HH} \mathrm{I}$ & iembers & & & & & & \\
\hline 18. Adol & scent (age 13-26) & & & & & & \\
\hline 19. Eligi & le adolescents (age 15-24) & & & & & & \\
\hline To be & lled by supervisor after con & pleting $\mathrm{H}$ & before lea & ving for next PSU. & & & \\
\hline 20. Date & 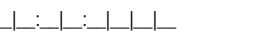 & & & b. Male & & c. Female & \\
\hline 21. Adol & scents interviewed & & & & & & \\
\hline 22. Tota & Adolescents not interviewed & & & b. Line\# & c. Reason & d. Line\# & e. Reason \\
\hline $\begin{array}{l}\text { Reason } \\
01 \\
02 \\
03 \\
04 \\
05 \\
06 \\
77\end{array}$ & $\begin{array}{l}\text { for not interviewed } \\
\text { Absent } \\
\text { Refused } \\
\text { Not eligible } \\
\text { Not allowed } \\
\text { Not located } \\
\text { Partially } \\
\text { Others [Specify] }\end{array}$ & $\begin{array}{l}\text { Total } \\
\text { Male } \\
\text { Female }\end{array}$ & $\begin{array}{l}-\llcorner \\
-\leftarrow \\
-1\end{array}$ & $\begin{array}{ll}1 . & -1- \\
2 . & -\mid- \\
3 . & -\mid\end{array}$ & $\begin{array}{l}-1 \\
-1 \\
-1\end{array}$ & $\begin{array}{ll}\text { 1. } & -1- \\
2 . & -1- \\
\text { 3. } & -1-\end{array}$ & $\begin{array}{l}-1- \\
-1- \\
-1\end{array}$ \\
\hline 23. Che & ked by in field: [Name] & & & -1 & 24. Date & — |:-_L:-|_|_| & \\
\hline 25. Edite & by/ Coded by: [Name] & & & -1 & 26. Date: & 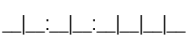 & \\
\hline 27. Ente & ed by: [Name] & & & -1 & 28. Date: & 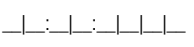 & \\
\hline
\end{tabular}


List all members of $\mathrm{HH}$ including non-relatives. Start with Household head, and list all couples with their biological children in a sequence, including children who are currently living with or away from their parents

\begin{tabular}{|c|c|c|c|c|c|c|c|c|c|}
\hline \multicolumn{10}{|c|}{ HOUSEHOLD ROSTER } \\
\hline 誊 & R01. Name & \begin{tabular}{|l|} 
Ro2. \\
Sex \\
\\
1. Male \\
2. Female
\end{tabular} & $\begin{array}{l}\text { R03. } \\
\text { Relationship } \\
\text { with HHH } \\
\text { [See codes } \\
\text { at the } \\
\text { bottom of } \\
\text { pg] }\end{array}$ & $\begin{array}{l}\text { R04.Relationship } \\
\text { with Respondent } \\
\text { [See codes at } \\
\text { the bottom of } \\
\text { pg] }\end{array}$ & $\begin{array}{l}\text { R05. Father } \\
\text { line \# } \\
\text { [If non- } \\
\text { resident } \\
\text { give code] } \\
\text { 70. Live in } \\
\text { the same } \\
\text { community } \\
\text { 71. Live } \\
\text { away } \\
\text { 90. Dead } \\
\text { 99. Nl }\end{array}$ & $\begin{array}{l}\begin{array}{l}\text { R06. Mother } \\
\text { Line \# } \\
\text { [If non- } \\
\text { resident } \\
\text { give code] }\end{array} \\
\text { 70. Live in } \\
\text { the same } \\
\text { community } \\
\text { 71. Live } \\
\text { away } \\
\text { 90. Dead } \\
\text { 99. NI }\end{array}$ & $\begin{array}{l}\text { Ro7. } \\
\text { Family/ Unit } \\
\text { Code } \\
\text { [Give } \\
\text { unique } \\
\text { code in } \\
\text { sequence] }\end{array}$ & $\begin{array}{l}\begin{array}{l}\text { R08. Date of } \\
\text { Birth }\end{array} \\
\text { [Code } 99 \text { if } \\
\text { DK] }\end{array}$ & $\begin{array}{l}\text { R09. Age in } \\
\text { Years }\end{array}$ \\
\hline 01 & & & & & -1 & -1 & -1 & $\begin{array}{l}\text { D. _L } \\
\text { M._L_ } \\
\text { Y._L__L }\end{array}$ & $\begin{array}{c}\qquad \perp \\
\text { In years } \\
{[\text { [lf }<5 \text { go to }} \\
\text { Next] }\end{array}$ \\
\hline 02 & & & & & $\_-$ & $\_-$ & -1 & $\begin{array}{l}\text { D. _L } \\
\text { M._L_ } \\
\text { Y._L__L }\end{array}$ & $\begin{array}{c}-1- \\
\text { In years } \\
{[\text { [lf }<5 \text { go to }} \\
\text { Next] }\end{array}$ \\
\hline 03 & & & & & $\_-$ & $\_-$ & -1 & $\begin{array}{l}\text { D. _L } \\
\text { M._L_ } \\
\text { Y._L_LL }\end{array}$ & $\begin{array}{c}-1- \\
\text { In years } \\
\text { Iff }<5 \text { go to } \\
\text { Next] }\end{array}$ \\
\hline 04 & & & & & -1 & - & - & $\begin{array}{l}\text { D. _L } \\
\text { M._L } \\
\text { Y._L_LL }\end{array}$ & $\begin{array}{l}\perp- \\
\text { In years } \\
\text { IIf }<5 \text { go to } \\
\text { Next] }\end{array}$ \\
\hline 05 & & & & & - & - & - & $\begin{array}{l}\text { D. _L } \\
\text { M._L_ } \\
\text { Y._L_L__ }\end{array}$ & $\begin{array}{l}\qquad \perp- \\
\text { In years } \\
\text { IIf }<5 \text { go to } \\
\text { Next] }\end{array}$ \\
\hline 06 & & & & & - & - & - & $\begin{array}{l}\text { D. _L } \\
\text { M._L } \\
\text { Y._L_L_L }\end{array}$ & $\begin{array}{l}\qquad \perp- \\
\text { In years } \\
\text { [lf }<5 \text { go to } \\
\text { Next] }\end{array}$ \\
\hline 07 & & & & & - & - & - & $\begin{array}{l}\text { D. - L_ } \\
\text { M._L } \\
\text { Y._L_L_L }\end{array}$ & $\begin{array}{c}\qquad-1 \\
\text { In years } \\
\text { [lf < } 5 \text { go to } \\
\text { Next] }\end{array}$ \\
\hline 08 & & & & & $\_$ & -1 & -1 & $\begin{array}{l}\text { D._-_ } \\
\text { M. _L_ } \\
\text { Y._L__L_ }\end{array}$ & $\begin{array}{c}-1 \\
\text { In years } \\
\text { [lf < } 5 \text { go to } \\
\text { Next] }\end{array}$ \\
\hline
\end{tabular}

Relationship Codes

01 Self

04 Grand child 05 Father/ Mothe 06 Brother/ Sister
07 Nephew/ Niece

09 Father/ Mother in law
10 Brotherl Sister in law 77 Others [Specify] $99 \mathrm{DK}$

\begin{tabular}{|c|c|c|c|c|c|c|c|c|c|c|}
\hline 年 & \begin{tabular}{|l|}
$\begin{array}{l}\text { R10. Can } \\
\text { [Name] read } \\
\text { and write? }\end{array}$ \\
1. Yes, both \\
2. Can read \\
only \\
3. Can write \\
only \\
4. Can neither \\
read nor write
\end{tabular} & \begin{tabular}{|l} 
R11. Schooling \\
StatuS \\
1. Currently in \\
school \\
2. Left school \\
3. Never been to \\
school \\
[If 3 Go to R13]
\end{tabular} & $\begin{array}{l}\text { R12. Highest } \\
\text { grade } \\
\text { completed }\end{array}$ & \begin{tabular}{|l}
$\begin{array}{l}\text { R13. Marital } \\
\text { Status }\end{array}$ \\
1. Currently \\
Married \\
2. Separated \\
3. Divorced \\
4. Widowed/ \\
widower \\
5. Never \\
Married \\
[lf 1 , ask R14, \\
otherwise Go \\
to R15]
\end{tabular} & $\begin{array}{l}\begin{array}{l}\text { R14. Line \# } \\
\text { of Spouse }\end{array} \\
\text { [Give line } \\
\text { number of } \\
\text { spoose. If } \\
\text { spouse not } \\
\text { listed in } \\
\text { roster } \\
\text { code 00] }\end{array}$ & 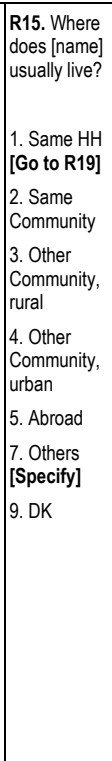 & $\begin{array}{l}\begin{array}{l}\text { R16. Why } \\
\text { has [Name] } \\
\text { moved away } \\
\text { from the } \\
\text { house? }\end{array} \\
\text { 1. Marriage } \\
\text { 2. Studies } \\
\text { 3. Work/Job } \\
\begin{array}{l}\text { 4. Moved } \\
\text { w/family } \\
\text { 7. Others } \\
\text { [Specify] }\end{array}\end{array}$ & \begin{tabular}{|l} 
R17. \\
For \\
how \\
long \\
has \\
[Name] \\
been \\
away \\
from \\
the \\
house?
\end{tabular} & $\begin{array}{l}\text { R18. How } \\
\text { often } \\
\text { does } \\
\text { [Name] } \\
\text { usually } \\
\text { return to } \\
\text { visit the } \\
\text { house? } \\
\\
\text { O0. Not at } \\
\text { all } \\
\text { 01. Within } \\
6 \text { days } \\
\text { 02. Once } \\
\text { a week } \\
\text { 03. Twice } \\
\text { a month } \\
\text { 04. } \\
\text { Monthly } \\
\text { 05. } \\
\text { Quarterly } \\
\text { O6. } \\
\text { Annually } \\
77 . \\
\text { Others } \\
\text { [Specify] } \\
\text { 99. DK }\end{array}$ & 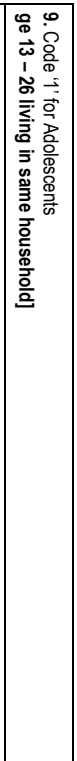 \\
\hline 01 & & & $\frac{1}{\ln \text { years }}$ & & -1 & & & $\begin{array}{l}\#-1-M \\
\# \_-1<Y\end{array}$ & & \\
\hline 02 & & & $\frac{1}{\ln \text { years }}$ & & -1 & & & 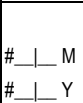 & & \\
\hline 03 & & & $\frac{1}{\ln \text { years }}$ & & $\_$ & & & 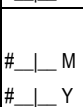 & & \\
\hline 04 & & & $\frac{1}{\ln \text { years }}$ & & ${ }_{-}$ & & & $\begin{array}{l}\#-1-M \\
\# \_-1 \_Y\end{array}$ & & \\
\hline 05 & & & $\frac{1}{\ln \text { years }}$ & & ${ }_{-}$ & & & $\begin{array}{l}\#-1 \sim M \\
\# \_-1<Y\end{array}$ & & \\
\hline 06 & & & $\frac{1}{\ln \text { years }}$ & & 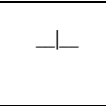 & & & $\begin{array}{l}\#-1 \sim \mathrm{M} \\
\# \_-1 \sim \mathrm{Y}\end{array}$ & & \\
\hline 07 & & & $\frac{1}{\ln \text { years }}$ & & - & & & $\begin{array}{l}\#-1 \sim \mathrm{M} \\
\text { \#_L_ }\end{array}$ & & \\
\hline 08 & & & $\frac{1}{\ln \text { years }}$ & & -1 & & & \begin{tabular}{|ll}
$\#-\perp$ & $M$ \\
$\#$ & $Y$
\end{tabular} & & \\
\hline
\end{tabular}




\begin{tabular}{|c|c|c|c|c|c|c|c|c|c|}
\hline 7 & $\begin{array}{l}\text { R01. } \\
\text { Name }\end{array}$ & $\begin{array}{l}\text { R02. } \\
\text { Sex } \\
1 . \\
\text { Male } \\
2 . \\
\text { Femal } \\
\text { e }\end{array}$ & $\begin{array}{l}\text { R03. } \\
\text { Relationship } \\
\text { with HHH } \\
\text { [See codes } \\
\text { at the } \\
\text { bottom of } \\
\text { pg] }\end{array}$ & $\begin{array}{l}\text { R04.Relationship } \\
\text { with Respondent } \\
\text { [See codes at the } \\
\text { bottom of pg] }\end{array}$ & $\begin{array}{l}\text { R05. } \\
\text { Father line } \\
\# \\
\text { [lf non- } \\
\text { resident } \\
\text { give code] } \\
\text { 70. Live in } \\
\text { the same } \\
\text { community } \\
\text { 71. Live } \\
\text { away } \\
\text { 90. Dead } \\
\text { 99. NI }\end{array}$ & $\begin{array}{l}\text { R06. } \\
\text { Mother } \\
\text { Line\# } \\
\text { [If non- } \\
\text { resident } \\
\text { give } \\
\text { code] } \\
\text { 70. Live in } \\
\text { the same } \\
\text { community } \\
\text { 71. Live } \\
\text { away } \\
\text { 90. Dead } \\
\text { 99. NI }\end{array}$ & $\begin{array}{l}\text { R07. } \\
\text { Familyl } \\
\text { Unit } \\
\text { Code } \\
\text { [Give } \\
\text { unique } \\
\text { code in } \\
\text { sequenc } \\
\text { e] }\end{array}$ & $\begin{array}{l}\text { R08. Date of } \\
\text { Birth } \\
\text { [Code } 99 \text { if } \\
\text { DK] }\end{array}$ & $\begin{array}{l}\text { R09. Age in } \\
\text { Years }\end{array}$ \\
\hline$\overline{p 9}$ & & & & & -1 & -1 & ${ }_{-}$ & $\begin{array}{l}\text { D. - L_ } \\
\text { M._L_ } \\
\text { Y._L_L_L }\end{array}$ & $\begin{array}{c}\quad-1 \\
\begin{array}{c}\text { In years } \\
\text { Iff }<5 \text { go to } \\
\text { Next] }\end{array}\end{array}$ \\
\hline 10 & & & & & -1 & -1 & - & $\begin{array}{l}\text { D. _L } \\
\text { M._L_ } \\
\text { Y._L_L__ }\end{array}$ & $\begin{array}{c}-1 \\
\text { In years } \\
\text { IIf }<5 \text { go to } \\
\text { Next] }\end{array}$ \\
\hline 11 & & & & & -1 & -1 & $-1-$ & $\begin{array}{l}\text { D. - L_ } \\
\text { M. _L_ } \\
\text { Y._L_L_L_ }\end{array}$ & $\begin{array}{c}\quad-1 \\
\begin{array}{c}\text { In years } \\
\text { [lf }<5 \text { go to } \\
\text { Next] }\end{array}\end{array}$ \\
\hline 12 & & & & & - & $-1-$ & -1 & $\begin{array}{l}\text { D. _L_ } \\
\text { M._L_ } \\
\text { Y._L_L_L_ }\end{array}$ & $\begin{array}{c}\quad-1 \\
\begin{array}{c}\text { In years } \\
\text { [lf }<5 \text { go to } \\
\text { Next] }\end{array} \\
\end{array}$ \\
\hline 13 & & & & & - & -1 & $-1-$ & $\begin{array}{l}\text { D. _L_ } \\
\text { M. _L_ } \\
\text { Y._L_L_L }\end{array}$ & $\begin{array}{c}\quad-1 \\
\begin{array}{c}\text { In years } \\
\text { [lf }<5 \text { go to } \\
\text { Next] }\end{array} \\
\end{array}$ \\
\hline 14 & & & & & -1 & $-1-$ & -1 & $\begin{array}{l}\text { D. _L_ } \\
\text { M. _L_ } \\
\text { Y._L_L_L_ }\end{array}$ & $\begin{array}{c}\quad-1 \\
\begin{array}{c}\text { In years } \\
\text { [lf }<5 \text { go to } \\
\text { Next] }\end{array}\end{array}$ \\
\hline 15 & & & & & -1 & $-1-$ & 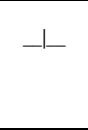 & $\begin{array}{l}\text { D. _L_ } \\
\text { M._L_ } \\
\text { Y._L__L_ }\end{array}$ & 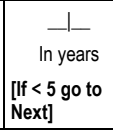 \\
\hline 16 & & & & & -1 & -1 & $-1-$ & $\begin{array}{l}\text { D. _L } \\
\text { M. _। } \\
\text { Y._L_I_। }\end{array}$ & 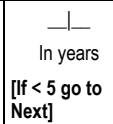 \\
\hline
\end{tabular}

\begin{tabular}{|c|c|c|c|c|c|c|c|c|c|}
\hline$\stackrel{\circ}{\Xi}$ & 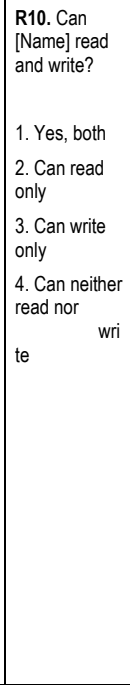 & $\begin{array}{l}\text { R11. Schooling } \\
\text { Status } \\
\text { 1. Currently in } \\
\text { school } \\
\text { 2. Left school } \\
\text { 3. Never been to } \\
\text { school } \\
\text { [If } 3 \text { Go to R13] }\end{array}$ & \begin{tabular}{|l} 
R12. \\
Highest \\
grade \\
completed
\end{tabular} & \begin{tabular}{|l} 
R13. Marital \\
Status \\
1. Currently \\
Married \\
2. Separated \\
3. Divorced \\
4. Widowed/ \\
\multicolumn{1}{c}{ widower } \\
5. Never \\
Married \\
[lf 1 , ask \\
R14, \\
otherwise \\
Go to R15]
\end{tabular} & \begin{tabular}{|l} 
R14. Line \\
\# of \\
Spouse \\
[Give line \\
number of \\
spouse. If \\
spouse \\
not \\
listed in \\
roster \\
code 00]
\end{tabular} & $\begin{array}{l}\text { R15. Where } \\
\text { does [name] } \\
\text { usually live? } \\
\\
\text { 1. Same HH } \\
\text { [Go to R19] } \\
\text { 2. Same } \\
\text { Community } \\
\text { 3. Other } \\
\text { Community, } \\
\text { rural } \\
\text { 4. Other } \\
\text { Community, } \\
\text { urban } \\
\text { 5. Abroad } \\
\text { 7. Others } \\
\text { [Specify] } \\
\text { 9. DK }\end{array}$ & $\begin{array}{l}\begin{array}{l}\text { R16. Why } \\
\text { has [Name] } \\
\text { moved away } \\
\text { from the } \\
\text { house? }\end{array} \\
\text { 1. Marriage } \\
\text { 2. Studies } \\
\text { 3. Work/Job } \\
\text { 4. Moved } \\
\text { w/family } \\
\text { 7. Others } \\
\text { [Specify] }\end{array}$ & $\begin{array}{l}\text { R17. For how } \\
\text { long has } \\
\text { [Name] been } \\
\text { away from the } \\
\text { house? }\end{array}$ & \begin{tabular}{|l} 
R18. How \\
often does \\
[Name] \\
usually \\
return to \\
visit the \\
house? \\
\\
00. Not at \\
all \\
01. Within 6 \\
days \\
02. Once a \\
week \\
03. Twice a \\
month \\
04. Monthly \\
05. \\
Quarterly \\
06. \\
Annually \\
77. Others \\
[Specify] \\
99. DK
\end{tabular} \\
\hline 09 & & & $\frac{1}{\ln \text { years }}$ & & -1 & & & $\begin{array}{l}\# \_-M \\
\# \_-Y\end{array}$ & \\
\hline 100 & & & $\stackrel{\perp}{\frac{1}{\ln \text { years }}}$ & & -1 & & & $\begin{array}{l}\# \_-M M \\
\# \_-Y Y\end{array}$ & \\
\hline 111 & & & $\frac{1}{\ln \text { years }}$ & & -1 & & & $\begin{array}{l}\# \text { \#-LM } \\
\#-C Y\end{array}$ & \\
\hline 12 & & & $\frac{1}{\ln \text { years }}$ & & - & & & 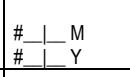 & \\
\hline 10 & & & $\frac{1}{\ln \text { years }}$ & & -1 & & & $\begin{array}{l}\# \_-M \\
\# \_-Y Y\end{array}$ & \\
\hline 14 & & & $\frac{1}{\ln \text { years }}$ & & - & & & $\begin{array}{l}\# \_-1 \mathrm{M} \\
\# \_-Y^{\prime}\end{array}$ & \\
\hline 15 & & & $\frac{1}{\ln \text { years }}$ & & -1- & & & $\begin{array}{l}\#-\_-M \\
\# \_-Y\end{array}$ & \\
\hline 16 & & & $\frac{1}{\ln \text { years }}$ & & -1 & & & $\begin{array}{l}\# \_-1 \mathrm{M} \\
\# \_-\mathrm{Y}\end{array}$ & \\
\hline
\end{tabular}

Note 1: Continue with next page if required.

\begin{tabular}{llll}
\hline & & & \\
01 Self & 04 Grand child & 07 Nephew/ Niece & 10 Brother/ Sister in law \\
02 Spouse & 05 Father/ Mother & 08 Son/ Daughter in law & 77 Others [Specify] \\
03 Son/ Daughter & 06 Brother/ Sister & 09 Father/ Mother in law & 99 DK
\end{tabular}


Now I would like to ask you some general questions about the household in which you live.

\begin{tabular}{|c|c|}
\hline \multicolumn{2}{|c|}{ HOUSEHOLD STRUCTURE } \\
\hline $\begin{array}{l}\text { 1. What is the status of the dwelling you live in - do } \\
\text { you own it, do you rent it, or does the government allot } \\
\text { or requisition? }\end{array}$ & 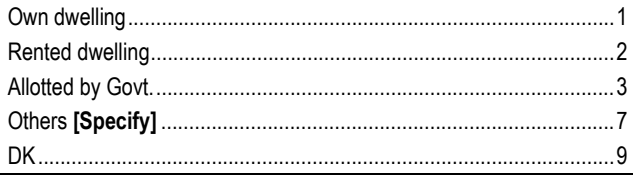 \\
\hline S2. How many households are in this $\mathrm{HH}$ structure? & \# of HHs. \\
\hline $\begin{array}{l}\text { S3. How many (living) rooms are there in your } \\
\text { dwelling? (Apart from bathroom, kitchen and rooms for } \\
\text { livestock) }\end{array}$ & 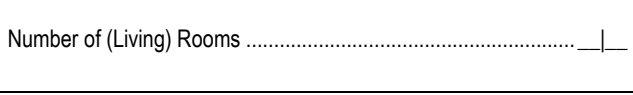 \\
\hline $\begin{array}{l}\text { S4. What kind of kitchen do you have in your } \\
\text { dwelling? }\end{array}$ & 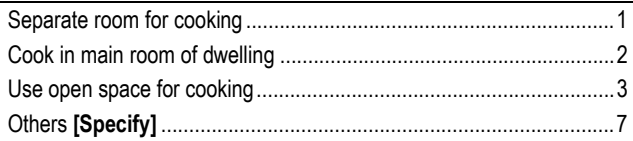 \\
\hline $\begin{array}{l}\text { S5. What type of latrine/ toilet facility does your } \\
\text { dwelling have? }\end{array}$ & 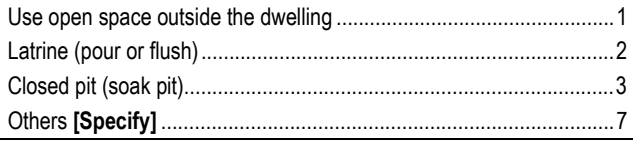 \\
\hline $\begin{array}{l}\text { S6. What type of main entrance does your dwelling } \\
\text { have? }\end{array}$ & 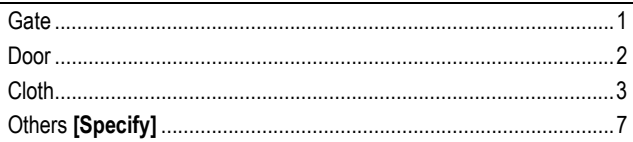 \\
\hline S7. Does your dwelling have a boundary wall? & 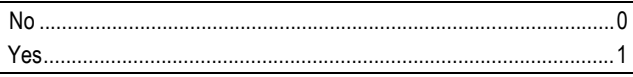 \\
\hline \multicolumn{2}{|c|}{ S8. What are the following parts of (living) rooms of your d2welling primarily made of? } \\
\hline a. Roof & 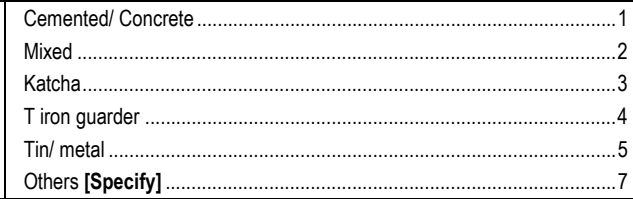 \\
\hline b. Floor & Cemented \\
\hline c. Walls & Cemented \\
\hline S9. What is the main language spoken in your dwelling? & 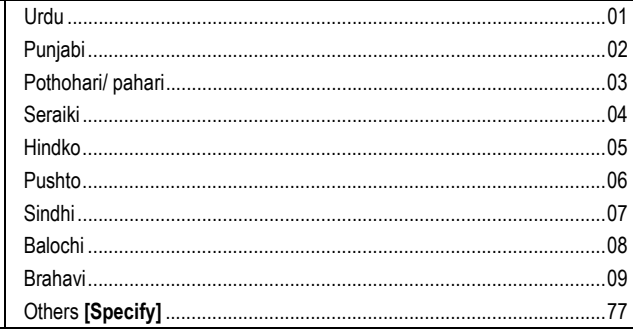 \\
\hline
\end{tabular}

$\ldots \ldots \ldots \ldots \ldots \ldots .1$

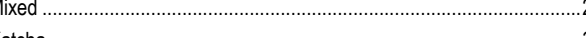

Others [Specify]

Cemented ...................................................................................

Others [Specify] .

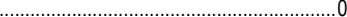

Pothohari/ pahari....

Seraiki.

Pento

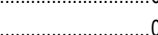

7

\section{[Multiple responses possible]}

S11. What is/ are the main sources of income in this household?

\section{[Multiple responses possible]}

\section{S12. Is your house equipped with any of these}

a) Electricity

b) Piped natural gas

c) LPG gas cylinder

d) Piped water (Govt. Supply)

e) Telephone

S13. From where do you get drinking water for

household use?

\begin{tabular}{|c|c|c|}
\hline & \multicolumn{2}{|c|}{ Others [Specify] } \\
\hline S14. Does your household have these items? & No & Yes \\
\hline a) Cycle & 0 & 1 \\
\hline b) Motor Cycle & 0 & 1 \\
\hline c) Car/ van & 0 & 1 \\
\hline d) Radio & 0 & 1 \\
\hline e) TV & 0 & 1 \\
\hline f) Dish/ Cable & 0 & 1 \\
\hline g) VCR & 0 & 1 \\
\hline h) Refrigerator & 0 & 1 \\
\hline i) Computer & 0 & 1 \\
\hline $\begin{array}{l}\text { S15. Does your household own any agricultural land/ } \\
\text { Plot? }\end{array}$ & \multicolumn{2}{|c|}{ 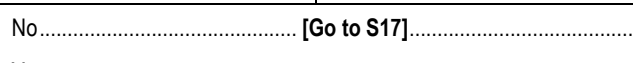 } \\
\hline
\end{tabular}

Line No. of member .................................................................__

Line No. of member ..............................................................- -

Line No. of member .........................................................-_

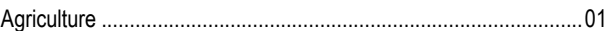

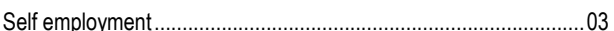

Waged employment........................................................................

Regular Salary ............................................................................

Local remittance ................................... 06

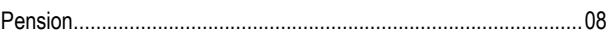

Others [Specify] ……………………………………......

\begin{tabular}{|l|l|} 
No & Yes \\
\hline 0 & 1 \\
\hline 0 & 1 \\
\hline 0 & 1 \\
\hline 0 & 1 \\
\hline 0 & 1 \\
\hline
\end{tabular}

Govt. supply inside house .............................................................. 01

Govt. supply communal ............................................................. 02

Hand pump inside ..................................................................... 03

Hand pump outside................................................................... 04

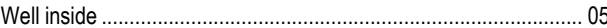

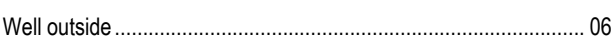

Surface water (lake, stream, etc.) .................................................. 07
Business .............................................................................

Foreign remittance ................................................................ 07

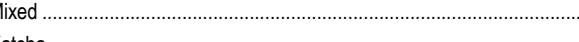




\begin{tabular}{|c|c|}
\hline S16. What size of land does your household own? & 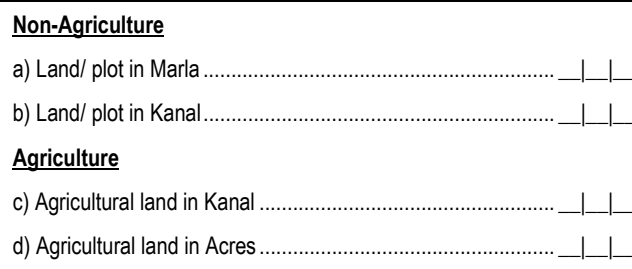 \\
\hline S17. Does your household own livestock? & No $\begin{array}{l}\text { Nes } \\
\text { Yes }\end{array}$ \\
\hline $\begin{array}{l}\text { S18. Which livestock does your HH have? Write the } \\
\text { number of each livestock. } \\
\text { [Code } 00 \text { If None] }\end{array}$ & $\begin{array}{l}\text { a) Poultry } \\
\text { b) Goat/ sheep } \\
\text { c) Cow } \\
\text { d) Buffalo } \\
\text { e) Oxen } \\
\text { f) Camel } \\
\text { g) Others [Specify] }\end{array}$ \\
\hline
\end{tabular}

Now I would like to know your opinion / attitude towards boys \& girls of age 15 - 24 regarding their education, work, marriage, mobility etc.

[Ask for boys first and then for girls]

\begin{tabular}{|c|c|c|}
\hline \multicolumn{3}{|c|}{ ATTITUDES TOWARDS ADOLESCENTS (15-24) } \\
\hline \multicolumn{3}{|c|}{ EDUCATION } \\
\hline Questions & Boys & Girls \\
\hline $\begin{array}{l}\text { A1. What do you think is the highest } \\
\text { level of schooling boys/ girls should } \\
\text { attain these days? }\end{array}$ & 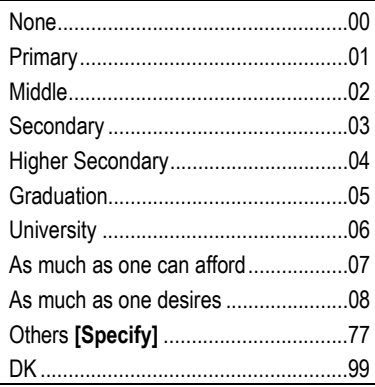 & $\begin{array}{l}\text { None } \\
\text { Primary } \\
\text { Middle } \\
\text { Secondary } \\
\text { Higher Secondary } \\
\text { Graduation } \\
\text { University } \\
\text { As much as one can afford } \\
\text { As much as one desires } \\
\text { Others } \\
\text { DK }\end{array}$ \\
\hline $\begin{array}{l}\text { A2. What do you think are the } \\
\text { advantages if boys/ girls attain this level } \\
\text { of schooling? }\end{array}$ & 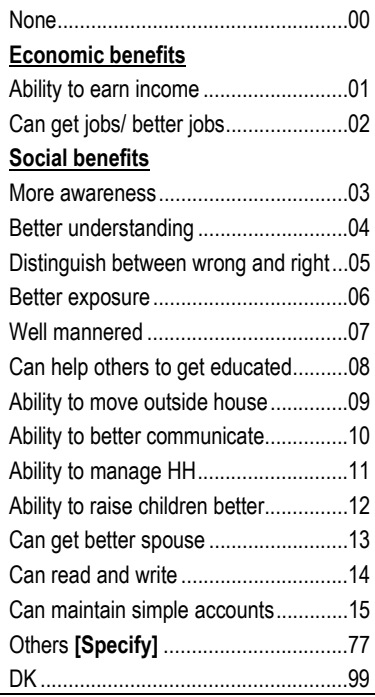 & 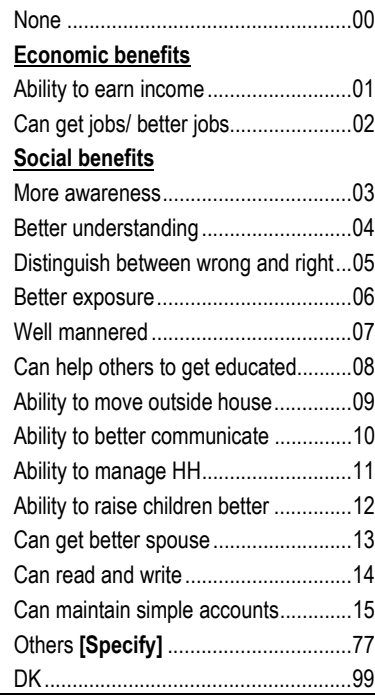 \\
\hline $\begin{array}{l}\text { A3. Who do you think should decide } \\
\text { what level of schooling boys/ girls } \\
\text { should attain? }\end{array}$ & $\begin{array}{l}\text { Father } \\
\text { Mother } \\
\text { Parents } \\
\text { Boy and parents } \\
\text { Family } \\
\text { Boy and family } \\
\text { Boy alone } \\
\text { [NOT A CATEGORY FOR BOYS] } \\
\text { [NOT A CATEGORY FOR BOYS] } \\
\text { Others [Specify] } \\
\text { DK }\end{array}$ & $\begin{array}{l}\text { Father } \\
\text { Mother } \\
\text { Parents } \\
\text { Girl and parents } \\
\text { Family } \\
\text { Girl and family } \\
\text { Girl alone } \\
\text { Spouse }\end{array}$ \\
\hline
\end{tabular}




\begin{tabular}{|c|c|c|}
\hline \multicolumn{3}{|c|}{ WORK } \\
\hline $\begin{array}{l}\text { A4. Do you approve of young boys/ girls } \\
\text { (15-24) should work, besides housework } \\
\text { for pay, profit or family gain? }\end{array}$ & $\begin{array}{l}\text { No } \\
\text { Yes } \\
\text { DK } \ldots \ldots \ldots \ldots \ldots \ldots \ldots \ldots \ldots \ldots \ldots \ldots \ldots \ldots \ldots \ldots \ldots \ldots \ldots \ldots \ldots \ldots \ldots \ldots \ldots \ldots \ldots \ldots \ldots \ldots \ldots \ldots \ldots \ldots \ldots \ldots \ldots \ldots \\
\text { [Go to } A 8]\end{array}$ & $\begin{array}{l}\text { No } \\
\text { Yes } \\
\text { DK } \ldots \ldots \ldots \ldots \ldots \ldots \ldots \ldots \ldots \ldots \ldots \ldots \ldots \ldots \ldots \ldots \ldots \ldots \\
\text { [Go to } A 8]\end{array}$ \\
\hline $\begin{array}{l}\text { A5. Who do you think should decide } \\
\text { whether or not the young boys/ girls (15- } \\
\text { 24) should work? }\end{array}$ & $\begin{array}{l}\text { Father } \\
\text { Mother } \\
\text { Parents........ } \\
\text { Boy and parents } \\
\text { Family } \\
\text { Boy and family } \\
\text { Boy alone } \\
\text { [NOT A CATEGORY } \\
\text { [NOT A CATEGORY } \\
\text { Others [Specify] } \\
\text { DK }\end{array}$ & 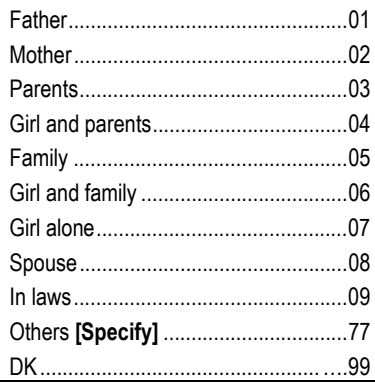 \\
\hline $\begin{array}{l}\text { A6. What type of work do you think boys/ } \\
\text { girls should do for pay, profit or family } \\
\text { gain? }\end{array}$ & 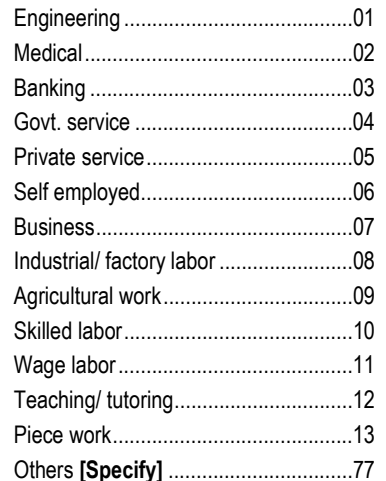 & $\begin{array}{l}\text { Engineering } \\
\text { Medical } \\
\text { Banking } \\
\text { Govt. service } \\
\text { Private service } \\
\text { Self employed } \\
\text { Business } \\
\text { Industrial/ factory labor } \\
\text { Agricultural work } \\
\text { Skilled labor } \\
\text { Wage labor } \\
\text { Teaching/ tutoring } \\
\text { Piece work } \\
\text { Others [Specify] }\end{array}$ \\
\hline $\begin{array}{l}\text { A7. At what age do you think it is } \\
\text { appropriate for boys/ girls to start doing } \\
\text { work for pay, profit or family gain? }\end{array}$ & $\begin{array}{l}\text { a) Age in years } \\
\text { Age range: } \\
\text { b) Between } \_ \text {__ and c) _L } \\
\text { DK }\end{array}$ & 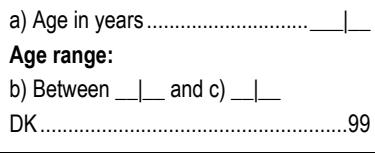 \\
\hline \multicolumn{3}{|c|}{ MARRIAGE } \\
\hline $\begin{array}{l}\text { A8. What do you think is the appropriate } \\
\text { age for boys/ girls to get married? }\end{array}$ & $\begin{array}{l}\text { a) Age in years } \\
\text { Age range: } \\
\text { b) Between _ _ and c) ___ } \\
\text { DK }\end{array}$ & $\begin{array}{l}\text { a) Age in years } \\
\text { Age range: } \\
\text { b) Between _ _ and c) ___ } \\
\text { DK }\end{array}$ \\
\hline
\end{tabular}

\begin{tabular}{|c|c|c|}
\hline $\begin{array}{l}\text { A9. What do you think are the reasons } \\
\text { that boys/ girls should get married at this } \\
\text { age? }\end{array}$ & 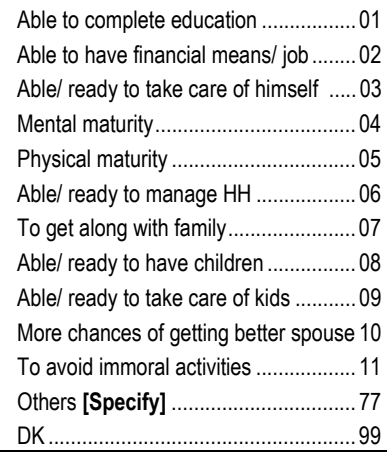 & 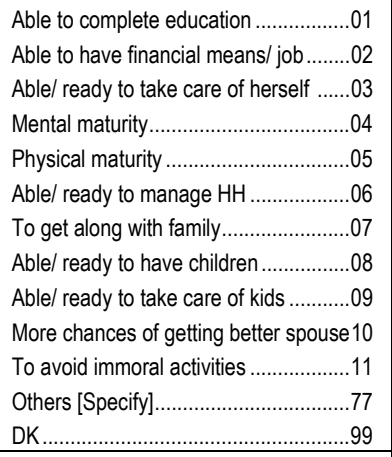 \\
\hline $\begin{array}{l}\text { A10. Who do you think should choose a } \\
\text { spouse for boys/ girls? }\end{array}$ & 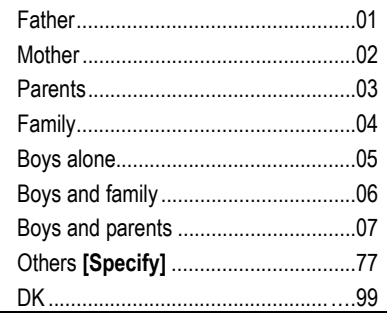 & 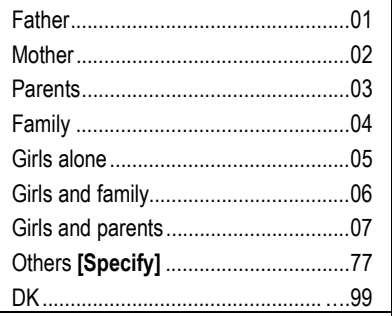 \\
\hline $\begin{array}{l}\text { A11. Do you feel that now days boys/ } \\
\text { girls are getting married at later age? }\end{array}$ & 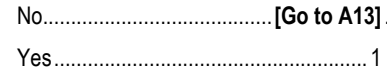 & $\begin{array}{l}\text { No ........ } \\
\text { Yes. }\end{array}$ \\
\hline $\begin{array}{l}\text { A12. Some boys/ girls are getting } \\
\text { married at later ages, what do think are } \\
\text { the main reasons for this? }\end{array}$ & 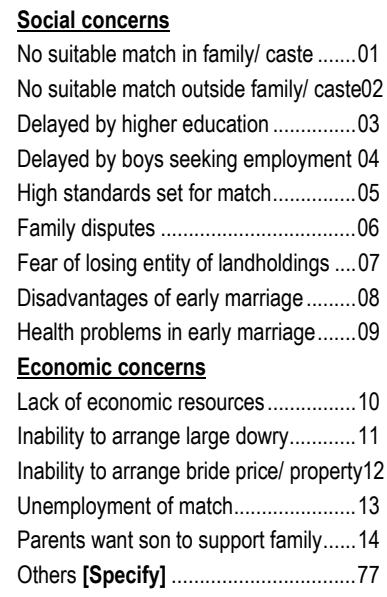 & 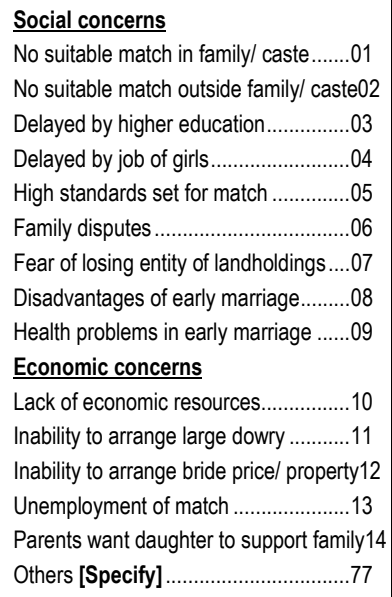 \\
\hline
\end{tabular}




\begin{tabular}{|c|c|c|}
\hline $\begin{array}{l}\text { A13. What considerations are taken in } \\
\text { your family while taking decision about } \\
\text { match for boys/ girls? }\end{array}$ & 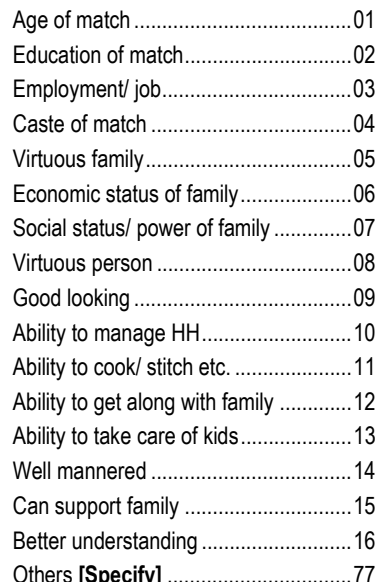 & 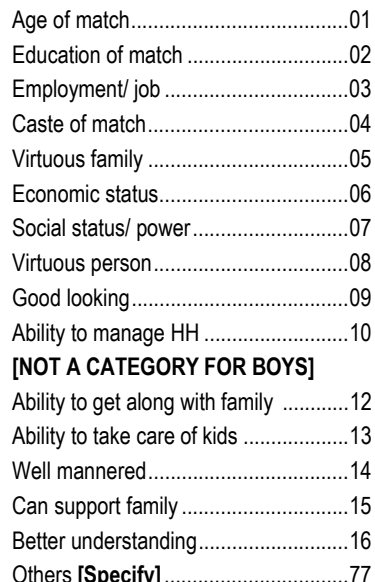 \\
\hline
\end{tabular}

Now I would like to ask your opinion about something. I will read you a list of places, and I would like to know whether you feel it would be permissible for a 15- year-old unmarried boy/ girl to go to this place alone. If you do not feel that this would be permissible, I would like to know if you feel it would be allowable for him/ her to go there if appropriately accompanied.

\begin{tabular}{|c|c|c|c|c|}
\hline \multicolumn{5}{|c|}{ MOBILITYI AUTONOMY } \\
\hline \multicolumn{2}{|c|}{ Questions } & \multirow{2}{*}{\begin{tabular}{l}
\multicolumn{1}{c}{ Boys } \\
A15. If No, Would it be \\
allowable for a 15 -year-old boy \\
to go to [Place] if appropriately \\
accompanied?
\end{tabular}} & \multicolumn{2}{|r|}{ Girls } \\
\hline \multicolumn{2}{|c|}{$\begin{array}{l}\text { A14. Would it be allowable for } \\
\text { a 15-year-old unmarried boy to } \\
\text { go to [Place] alone? }\end{array}$} & & $\begin{array}{l}\text { A16. Would it be } \\
\text { allowable for a 15- } \\
\text { year-old unmarried girl } \\
\text { to go to [Place] alone? }\end{array}$ & $\begin{array}{l}\text { A17. If No, Would it be } \\
\text { allowable for a 15-year-old girl } \\
\text { to go to [Place] if appropriately } \\
\text { accompanied? }\end{array}$ \\
\hline PLACES & 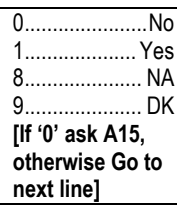 & 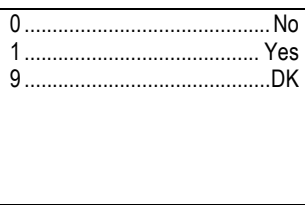 & 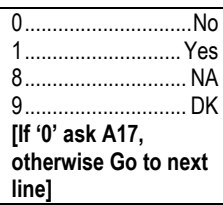 & 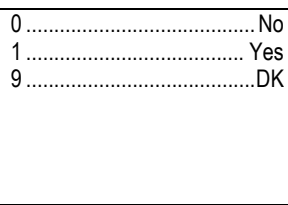 \\
\hline \multicolumn{5}{|l|}{ a) Neighbor } \\
\hline \multicolumn{5}{|l|}{$\begin{array}{l}\text { b) Nearby } \\
\text { shop }\end{array}$} \\
\hline \multicolumn{5}{|l|}{ c) School } \\
\hline \multicolumn{5}{|l|}{\begin{tabular}{|l|} 
d) Sports/ \\
Play ground
\end{tabular}} \\
\hline \multicolumn{5}{|l|}{ e) Friend } \\
\hline \multicolumn{5}{|l|}{ f) Relative } \\
\hline \multicolumn{5}{|l|}{\begin{tabular}{|l|} 
g) Fields \\
inside \\
village
\end{tabular}} \\
\hline \multicolumn{5}{|l|}{\begin{tabular}{|l|} 
h) Fields \\
outside \\
village
\end{tabular}} \\
\hline \multicolumn{5}{|l|}{$\begin{array}{l}\text { i) Other } \\
\text { nearby } \\
\text { community }\end{array}$} \\
\hline $\begin{array}{l}\text { j) Nearby } \\
\text { health outle }\end{array}$ & & & & \\
\hline
\end{tabular}




\begin{tabular}{|c|c|c|c|c|}
\hline Questions & \multicolumn{2}{|c|}{ Boys } & \multicolumn{2}{|c|}{ Girls } \\
\hline $\begin{array}{l}\text { A18. Is there any place in or near your } \\
\text { community that you feel a } 15 \text {-year- old } \\
\text { unmarried boy/ girl should not go alone } \\
\text { at all? }\end{array}$ & \multicolumn{2}{|c|}{$\begin{array}{l}\text { No [Go to A21] } \\
\text { Yes } \\
\text { DK [Go to A21] }\end{array}$} & \multicolumn{2}{|c|}{$\begin{array}{l}\text { No [Go to A21] } \\
\text { Yes } \\
\text { DK [Go to A21] }\end{array}$} \\
\hline $\begin{array}{l}\text { A19. What places should a15- years- old } \\
\text { unmarried boy/ girl not go alone to at all? }\end{array}$ & \multicolumn{2}{|c|}{ 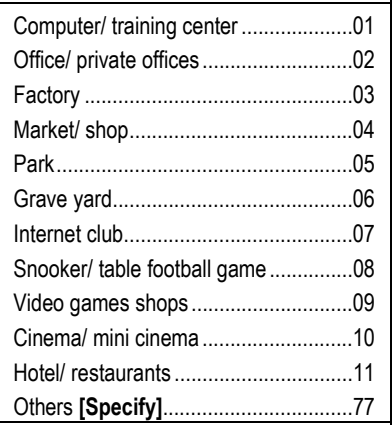 } & \multicolumn{2}{|c|}{ 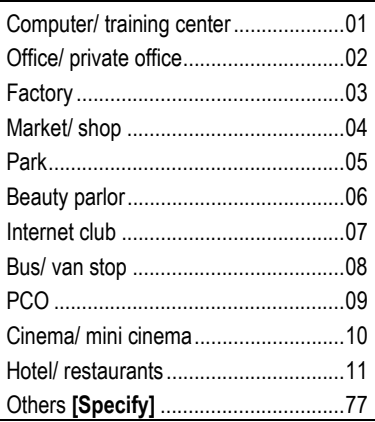 } \\
\hline $\begin{array}{l}\text { A20. What are the reasons that } 15- \\
\text { year- old unmarried boys/ girls should } \\
\text { not go to this/ these places? }\end{array}$ & \multicolumn{2}{|c|}{ 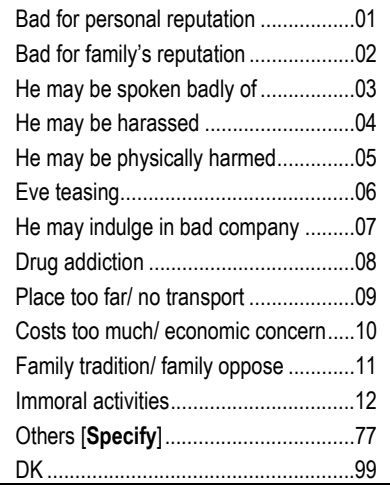 } & \multicolumn{2}{|c|}{ 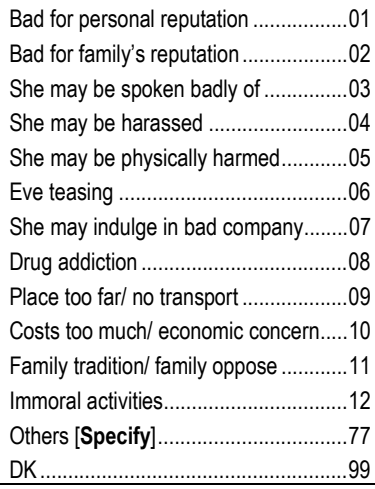 } \\
\hline $\begin{array}{l}\text { A21. Who do you think should decide } \\
\text { whether or not boys/ girls of age } 15 \text { can } \\
\text { go out side their houses? }\end{array}$ & \multicolumn{2}{|c|}{ 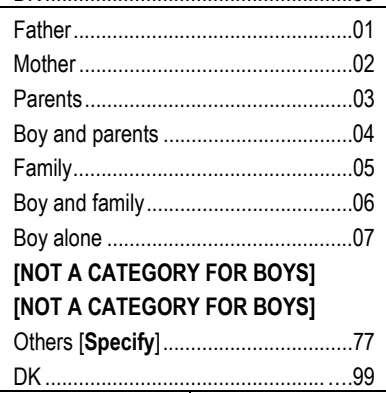 } & \multicolumn{2}{|c|}{ 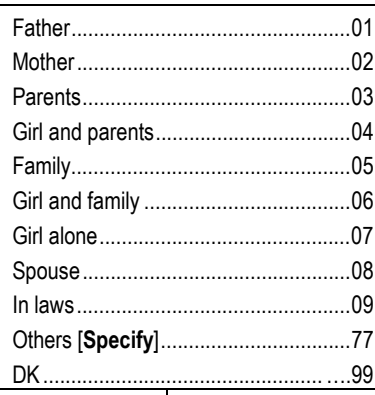 } \\
\hline \multirow{3}{*}{$\begin{array}{l}\text { A22. Do you think that young boys/ girls } \\
\text { (age15-24) can make decisions about } \\
\text { their education, work and marriage? }\end{array}$} & a) Education & $\begin{array}{l}\text { No } \ldots \ldots \ldots \ldots \ldots \ldots \ldots . . .1 \\
\text { Yes } \ldots \ldots \ldots \ldots \ldots \ldots \ldots \ldots \ldots\end{array}$ & a) Education & $\begin{array}{l}\text { No ....................... } 0 \\
\text { Yes............... } 1\end{array}$ \\
\hline & b) Work & 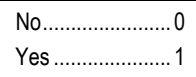 & b) Work & $\begin{array}{l}\text { No } \ldots \ldots \ldots \ldots \ldots \ldots \ldots . . . . . . . . . .1 \\
\text { Yes.................. } 1\end{array}$ \\
\hline & c) Marriage & 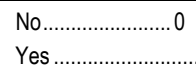 & c) Marriage & $\begin{array}{l}\text { No ....................... } 0 \\
\text { Yes................ } 1\end{array}$ \\
\hline
\end{tabular}

\begin{tabular}{|c|c|c|}
\hline Questions & Boys & Girls \\
\hline $\begin{array}{l}\text { A23. Do you think that young boys/ girls } \\
\text { (15-24) have the "right" to make } \\
\text { decisions about their life on their own? }\end{array}$ & 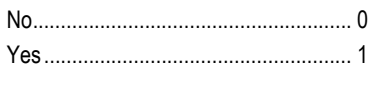 & $\begin{array}{l}\text { No } \\
\text { Yes }\end{array}$ \\
\hline $\begin{array}{l}\text { A24. Do I have permission to interview } \\
\text { all eligible } \\
\text { boys and girls age (15-24 ) resident of } \\
\text { this household? }\end{array}$ & 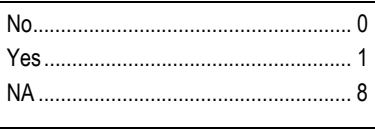 & 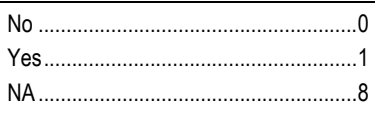 \\
\hline
\end{tabular}

